\title{
Small Molecule Activation with Dinuclear Cobalt Complexes based on the Two-In-One Pincer Ligands
}

\author{
Dissertation \\ For the Award of the Degree \\ "Ph.D. Division of Mathematics and Natural Sciences" \\ of the Georg-August-Universität Göttingen \\ Within the Doctoral Program Chemistry of the Georg-August University School of \\ Science (GAUSS)
}

Submitted by

Ming Li

From Henan, P. R. China

Göttingen 2020 


\section{Thesis Committee}

Prof. Dr. Franc Meyer

Institute of Inorganic Chemistry, Georg-August University Göttingen

Prof. Dr. Sven Schneider

Institute of Inorganic Chemistry, Georg-August University Göttingen

\section{Members of the Examination Board}

Reviewer: Prof. Dr. Franc Meyer

Institute of Inorganic Chemistry, Georg-August University Göttingen

Second Reviewer: Prof. Dr. Sven Schneider

Institute of Inorganic Chemistry, Georg-August University Göttingen

\section{Further members of the Examination Board}

Prof. Dr. Inke Siewert

Institute of Inorganic Chemistry, Georg-August University Göttingen

Prof. Dr. Dietmar Stalke

Institute of Inorganic Chemistry, Georg-August University Göttingen

Prof. Dr. Manuel Alcarazo

Institute of Organic and Biomolecular Chemistry, Georg-August University Göttingen

Dr. Michael John

Institute of Organic and Biomolecular Chemistry, Georg-August University Göttingen

Date of the oral examination: 26.10 .2020 


\section{Contents}

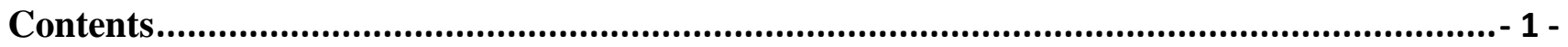

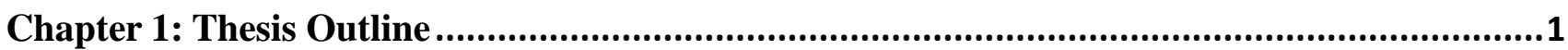

Chapter 2: Oligonuclear Cobalt Dinitrogen Complexes Based on A Two-In-One Pincer Ligand and Their Application for Catalytic Silylation of Dinitrogen to Silylamine ...............................3

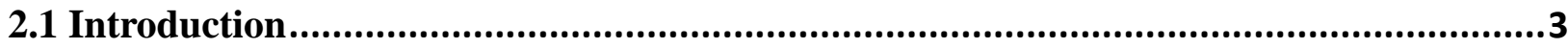

2.1.1 Nitrogen Fixation by Nitrogenase or through the Haber-Bosch Process...................... 3

2.1.2 $\mathrm{N}_{2}$ Coordination to Transition Metal Complexes...........................................................

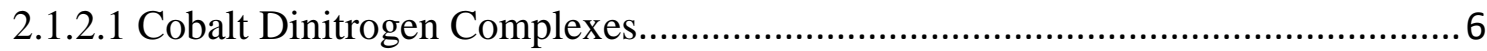

2.1.3 Catalytic Conversion of Dinitrogen into Ammonia Using Transition Metal Complexes8

2.1.4 Catalytic Conversion of Dinitrogen into Silylamine Using Transition Metal Complexes8

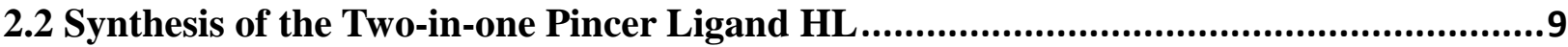

2.3 Synthesis of Dicobalt Chloride Complex 1 ............................................................... 10

2.4 Direct Synthesis of Dicobalt Dinitrogen Complex 2 .............................................. 14

2.5 Stepwise Synthesis of Dicobalt Dinitrogen Complexes ............................................20

2.5.1 Deprotonation of the Side Arms of 1 to Form a Dearomatized Complex 3 ................20

2.5.2 Conversion of 3 to Dicobalt Dinitrogen Complexes................................................22

2.5.3 Synthesis of Dicobalt Dinitrogen Complex with Sodium Cation..............................26

2.6 Tetracobalt Dinitrogen Complex Formation via Protonation of 2 or 4 ......................... 27

2.7 Reduction of Dicobalt Dinitrogen Complexes ...........................................................41

2.8 Catalytic Silylation of $\mathrm{N}_{2}$ by Using the Cobalt Complexes as Catalysts .......................44

2.9 Conclusion ..............................................................................................................47

Chapter 3: Backbone Modification of the Two-In-One Pincer Ligand and Cobalt/Dinitrogen

Coordination Chemistry ..........................................................................................49

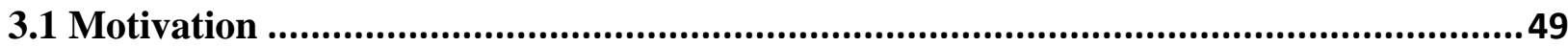

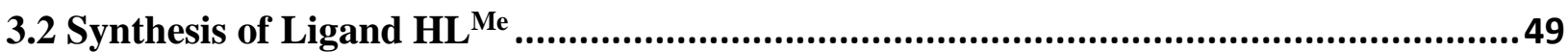

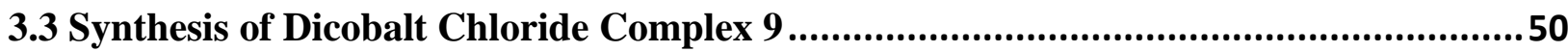

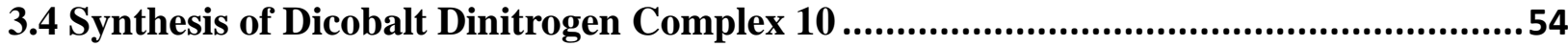

3.4.1 An Alternative Way to Synthesize Dicobalt Dinitrogen Complex 11 .........................59

3.5 Reduction of Complex 11 to Give Complex 12 ..........................................................63

3.6 Catalytic Silylation of $\mathrm{N}_{2}$ by Using Complexes 9-12 as Catalysts .............................65

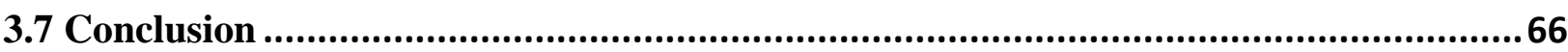

Chapter 4: New Model Complexes as Possible Intermediates in Dinitrogen Reduction using a Bimetallic Cobalt Dinitrogen Complex as Platform ......................................................69

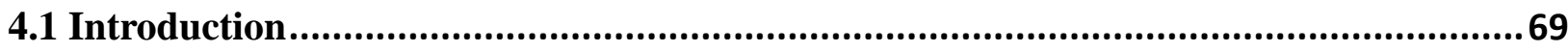

4.2 Synthesis of An End-on Bridged Diazene Complex.....................................................71

4.3 Synthesis of An End-on Bridged Methyldiazene Complex ........................................ 76

4.4 Synthesis of An End-on Bridged 1,2-Dimethyldiazene Complex............................... 80

4.5 Synthesis of An End-on Bridged Hydrazido Complex ............................................83

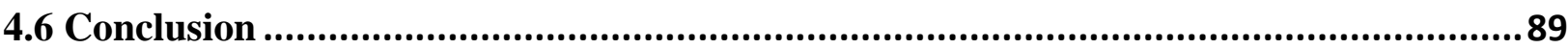

Chapter 5: $\mathrm{CO}_{2}$ Reductive Disproportionation and CO Reactions Mediated by the Dicobalt

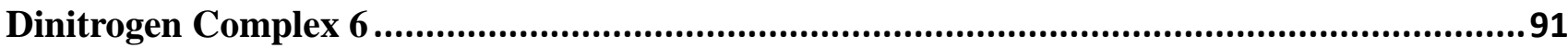




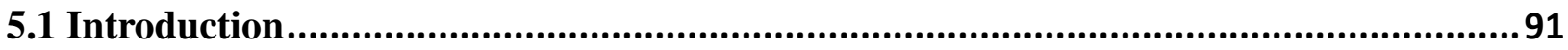

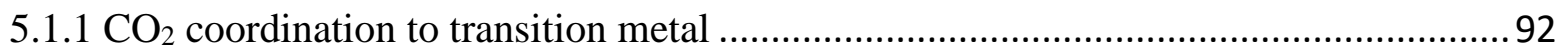

5.1.2 $\mathrm{CO}_{2}$ Reductive Disproportionation and Oxalate Formation .....................................93

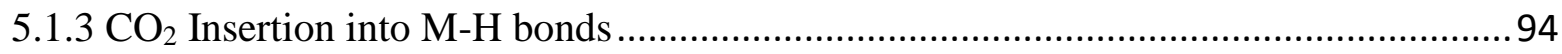

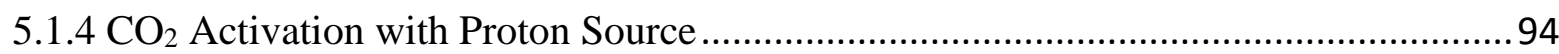

$5.2 \mathrm{CO}_{2}$ Reductive Disproportionation Mediated by Complex 6 ...................................95

5.3 CO Reactions of Complex 6 ............................................................................... 102

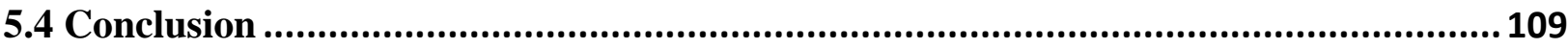

Chapter 6: Hydrosilane Reactions of Tetracobalt Dinitrogen Complex 6 ............................. 111

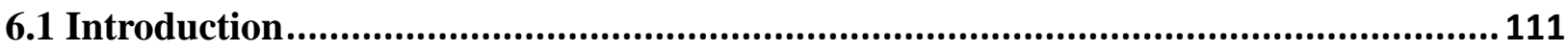

6.1.1 Redistribution in Transition Metal Silyl Complexes .............................................113

6.1.2 Disilyne and Multiply Bonded Silylanionic Chemistry .......................................... 114

6.2 Reaction of Complex 6 with Diphenylsilane.........................................................115

6.3 Oxidation and $\sigma$-Complex Formation of Complex 6 with Methylphenylsilane ...........119

6.4 Reaction of Complex 6 with Phenylsilane ............................................................... 121

6.4.1 The Synthesis of Tetracobalt Disilyl Complex 22 ................................................121

6.4.2 The Synthesis of Tetracobalt Tetrasilyl Complex 23 .............................................. 129

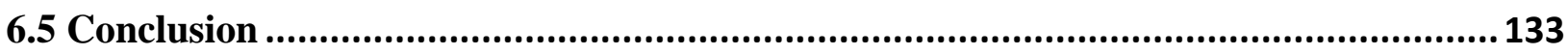

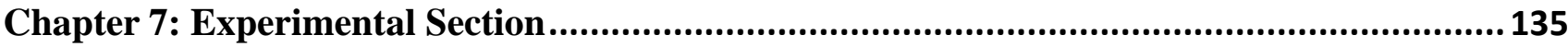

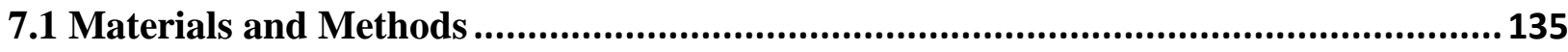

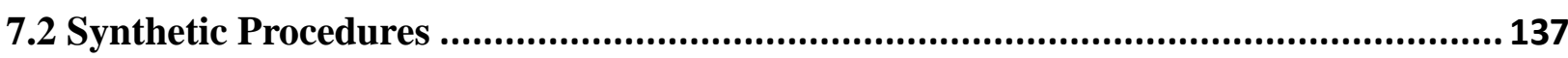

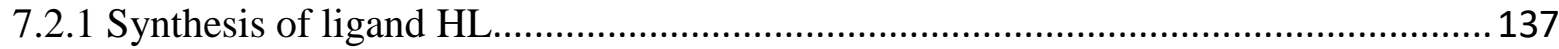

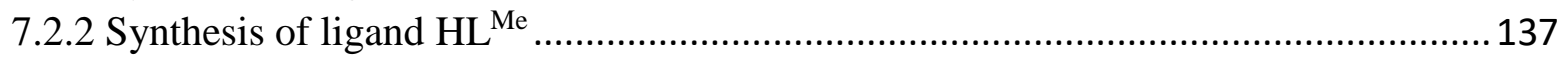

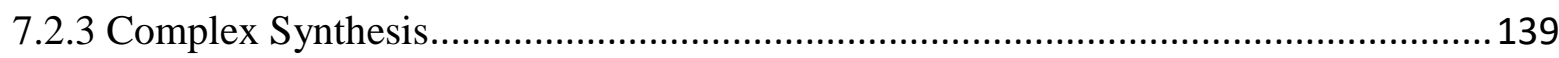

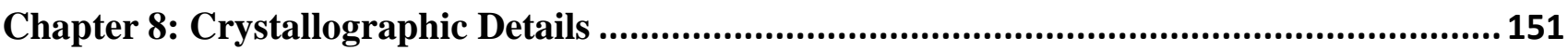

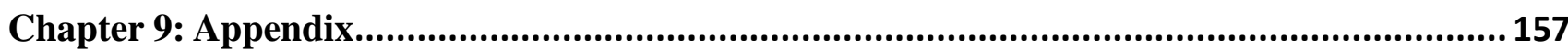

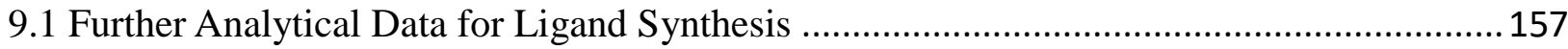

9.2 Further Analytical Data for Complexes .......................................................................... 159

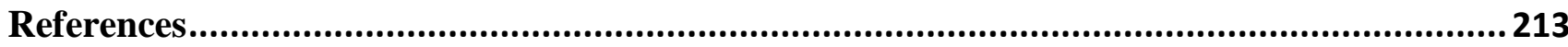

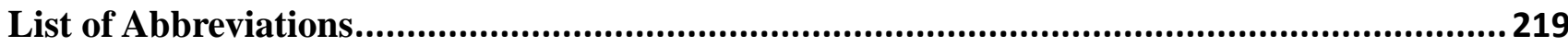

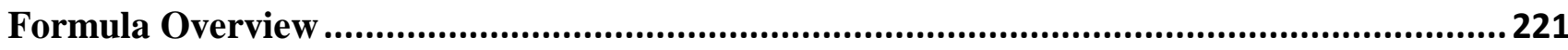

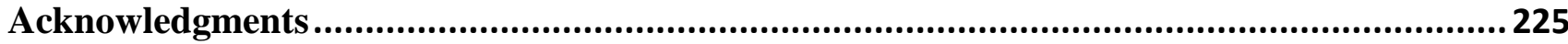




\section{Chapter 1: Thesis Outline}

Tridentate, meriodinally coordinating pincer ligands have been extensively exploited in the field of inorganic chemistry. Generally, pincer-type ligands consist of a central anionic or neutral aryl or alkyl moiety flanked by two neighboring donors, which can result in a chelating, rigid binding mode when coordinating with transition metals. ${ }^{1}$ Pincer complexes may exhibit metal-ligand cooperativity (MLC) via the (de)protonation of the back bone and concomitant (de)aromatization of the central aromatic moiety. ${ }^{2}$ The MLC in pincer complexes has furnished unprecedented opportunities for homogeneous catalysis and small molecule activation. ${ }^{3}$ On the other hand, two proximate metal ions may exhibit metal-metal cooperativity (MMC), which is well known from the active sites of some metalloenzymes, are capable of mediating the transformation of challenging substrates. ${ }^{4}$

To combine MLC and MMC, as shown in Figure 1.1, previous work by S. Samanta established the synthesis of a new two-in-one pincer ligand scaffold, composed of two PNN pincer-type subunits and a 3,5-substituted pyrazole as a bridging unit. ${ }^{5}$ Moreover, S. Samanta synthesized a diiron(II) complex $\mathrm{LFe}_{2}(\mathrm{OTf})_{3}\left(\mathrm{CH}_{3} \mathrm{CN}\right)$, which underwent a reversible and complete spin transition to the low-spin state with decreasing temperature based on a triflate/MeCN ligand exchange equilibrium and the cooperativity of two metal centers. A. Gers-Barlag synthesized a series of zinc, cobalt and rhodium complexes bearing this two-in-one pincer ligand and their reactivity in catalysis and electrochemical properties were also investigated. ${ }^{6}$ Additionally, P. Goursot isolated an asymmetric hydrido/hydroxo dinickel complex through the addition of one equivalent of water into the dihydride dinickel complex and a correlation between the two hydrogen atoms of the $\mathrm{Ni}-\mathrm{OH}$ and $\mathrm{Ni}-\mathrm{H}$ was observed by NMR spectroscopy. ${ }^{7}$

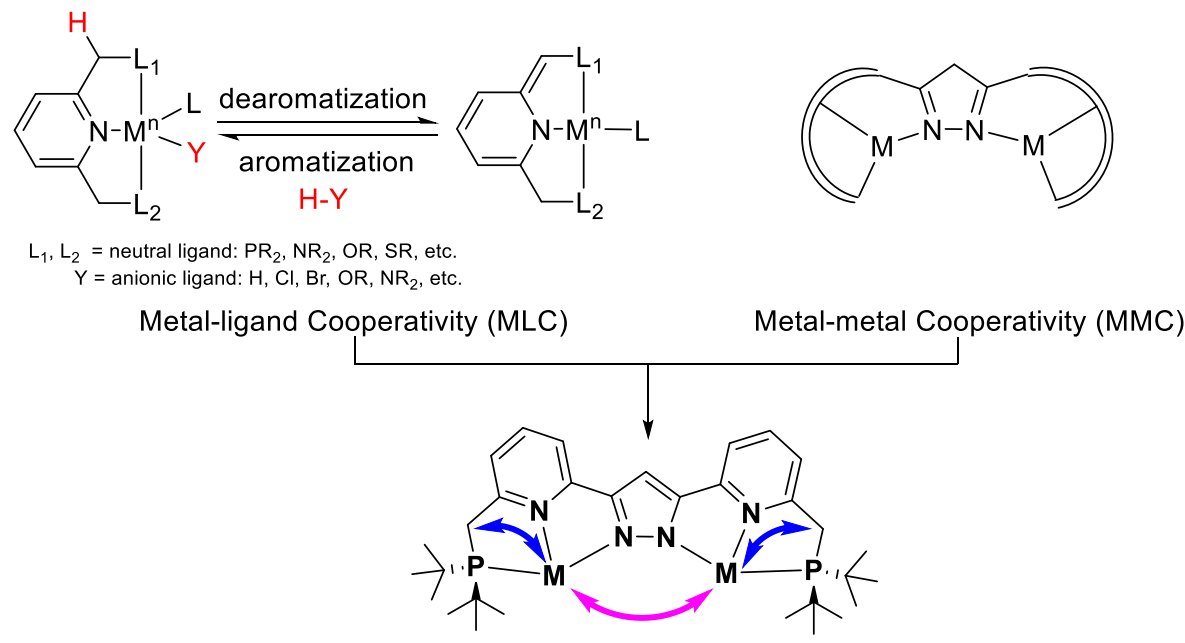

Figure 1.1: The dinucleating Two-in-one pincer systems combining MLC and MMC.

As mentioned above, dinuclear complexes based on this two-in-one pincer ligand scaffold have exhibited fascinating magnetic properties and promise high reactivity in catalysis and small molecule activation. In this thesis, the main objective is to accomplish small molecule activation using dinuclear cobalt complexes as precursors and isolate important intermediate complexes for better 
understanding the possible mechanisms of small molecule activation. More specifically, this thesis work can be divided into five parts: $\mathrm{N}_{2}$ fixation and catalytic conversion of $\mathrm{N}_{2}$ (Chapters 2 and 3), the formation of diazene complexes and reduction of azobenzene (Chapter 4), $\mathrm{CO}_{2}$ reduction and $\mathrm{CO}$ reactions (Chapter 5) and hydrosilane reactions (Chapter 6).

Chapter 2 describes the synthesis and characterization of a series of cobalt complexes bearing the two-in-one pincer ligand, including dicobalt and tetracobalt dinitrogen complexes. Moreover, a novel reversible conversion between the tetracobalt dinitrogen complex 6 and the triflate-bridged complex 7 was investigated. By employing these cobalt complexes as catalysts, the catalytic silylation of dinitrogen into $\mathrm{N}\left(\mathrm{SiMe}_{3}\right)_{3}$ has been explored.

To avoid the $\mathrm{C}-\mathrm{H}$ activation on the ligand, a new methyl-modified ligand $\mathrm{HL}^{\mathrm{Me}}$ has been exploited in Chapter 3. However, the reduction of dicobalt dinitrogen complex 10 with strong reductant did not lead to $\mathrm{N}_{2}$ activation but the dissociation of one cobalt $(0)$ atom.

To synthesize a series of $\mathrm{M}\left(\mathrm{N}_{2} \mathrm{H}_{\mathrm{x}} \mathrm{R}\right)$ complexes as potential intermediates in the $\mathrm{N}_{2}$ fixation process, in Chapter 4, hydrazine, methylhydrazine and 1,2-dimethylhydrazine have been employed to react with dicobalt dinitrogen complex $\mathbf{2}$ and after the disproportionation of hydrazine, methylhydrazine or 1,2-dimethylhydrazine, the reactions form diazene-, methyldiazene- or 1,2-dimethyldiazene-bridged complexes. It is worth noting that the employment of azobenzene with complex 2 leads to two electron transfer from the metal centers to azobenzene.

In Chapter 5, $\mathrm{CO}_{2}$ reduction mediated by the tetracobalt(I) dinitrogen complex $\mathbf{6}$ was investigated and the formation of a cobalt(II) carbonate complex and a dicobalt(I) dicarbonyl complex indicate $\mathrm{CO}_{2}$ reductive disproportionation. In addition, direct $\mathrm{CO}$ reactions gave rise to the dicarbonyl complex and a tetracarbonyl complex.

Chapter 6 presents the reactions of silanes with the tetracobalt dinitrogen complex 6 . The addition of diphenylsilane or methylphenylsilane into THF solution of complex 6 results in the formation of a mixed-valent $\mathrm{Co}^{\mathrm{I} / \mathrm{II}}$ diphenylsilyl $\sigma$-complex $\mathbf{2 0}$ or a mixed-valent $\mathrm{Co}^{\mathrm{I} / \mathrm{II}}$ methylphenylsilyl $\sigma$-complex 21. Interestingly, phenylsilane (4.0 eq.) reacts with complex 6 and generates a mixed-valent $\mathrm{Co}^{\mathrm{I} / \mathrm{II}}$ disilyl complex $\left[\mathrm{L}_{2} \mathrm{Co}_{4}\left(\mu-\mathrm{SiH}_{2} \mathrm{SiH}_{2}\right)\right](\mathrm{OTf})_{2} 22$ by redistribution. Moreover, the reaction of phenylsilane (6.0 eq.) and complex $\mathbf{6}$ formed a tetracobalt tetrasilyl complex $\left[\mathrm{L}_{2} \mathrm{Co}_{4}\left(\mu-\mathrm{PhSi}_{4} \mathrm{H}_{3}\right](\mathrm{OTf})_{2} 23\right.$. 


\section{Chapter 2: Oligonuclear Cobalt Dinitrogen Complexes Based on A Two-In-One Pincer Ligand and Their Application for Catalytic Silylation of Dinitrogen to Silylamine}

\subsection{Introduction}

\subsubsection{Nitrogen Fixation by Nitrogenase or through the Haber-Bosch Process}

Nitrogen, the most abundant element in the atmosphere on Earth, is an essential ingredient in cellular biomass. ${ }^{8}$ Nitrogen exists mainly in the form of chemically inert gaseous diatomic molecular dinitrogen $\left(\mathrm{N}_{2}\right)$. However, most organisms are only capable of metabolizing nitrogenous substances, such as ammonia $\left(\mathrm{NH}_{3}\right)$ or nitrate $\left(\mathrm{NO}_{3}{ }^{-}\right)$, rather than the inert $\mathrm{N}_{2} .{ }^{9}$ Thus, the conversion of molecular $\mathrm{N}_{2}$ through nitrogen fixation to ammonia is a most fundamental and crucial step in the biogeochemical nitrogen cycle.

In nature, nitrogen fixation is performed by some specific bacterial and archaeal organisms which contain a nitrogen-fixing enzyme called nitrogenase. ${ }^{10}$ In general, nitrogenase consists of dinitrogenase reductase (the electron-transfer $\mathrm{Fe}$ protein) and dinitrogenase (P-cluster and iron-molybdenum cofactor (FeMo-co), iron-vanadium cofactor (FeV-co), or iron-iron cofactor $(\mathrm{FeFe}-\mathrm{co})){ }^{10 a} \mathrm{FeMo}-\mathrm{co}$ was structurally characterized and it shows that FeMo-co possesses $\mathrm{Fe}_{4} \mathrm{~S}_{3}$ and $\mathrm{Fe}_{3} \mathrm{MoS}_{3}$ units bridged by a carbon atom and three sulfur atoms between each other. ${ }^{11}$ The molybdenum atom is coordinatively saturated, whereas the iron atoms surrounding the carbon atom have vacant sites, suggesting that nitrogen fixation occurs on the coordinatively unsaturated iron atoms. For molybdenum nitrogenase-catalyzed nitrogen fixation, 8 equivalents of electrons and protons and 16 equivalents of ATP (ATP = adenosine triphosphate) are consumed under ambient conditions for reducing 1 equivalent of dinitrogen to form 2 equivalents of ammonia together with the formation of an equimolar amount of dihydrogen gas. ${ }^{10 a}$ The structures of FeV-co and FeFe-co are quite similar to FeMo-co, however, vanadium and iron-only nitrogenases are less effective in nitrogen fixation, requiring more protons, electrons and ATP consumptions. ${ }^{10 \mathrm{c}}$

However, the exact mechanism of nitrogen fixation by nitrogenase remains unclear. There are two possible pathways proposed for $\mathrm{N}_{2}$ reduction invoking distinct intermediates (Figure 2.1). ${ }^{10 \mathrm{a}, \mathrm{c}}$ In the distal pathway, the distal $\mathrm{N}$ atom is hydrogenated in the first three steps until the first $\mathrm{NH}_{3}$ is liberated and the remaining nitrido- $\mathrm{N}$ is hydrogenated again to produce the second $\mathrm{NH}_{3}$. $\mathrm{This}$ distal pathway has been demonstrated in molybdenum, tungsten or iron model complexes. The alternating pathway, where both distal and proximal nitrogen atoms are protonated stepwise with the formation of diazenido $\left(\mathrm{N}_{2} \mathrm{H}^{-}\right)$, diazene $\left(\mathrm{N}_{2} \mathrm{H}_{2}\right)$, hydrazido $\left(\mathrm{N}_{2} \mathrm{H}_{3}{ }^{-}\right)$, hydrazine $\left(\mathrm{N}_{2} \mathrm{H}_{4}\right)$ and amido $\left(\mathrm{NH}_{2}{ }^{-}\right)$ complexes as intermediary products, is highly likely to apply to FeMo-co of the nitrogenase, because hydrazine is also detected as a minor product in dinitrogen reduction reactions under appropriate reaction conditions. ${ }^{12}$ 

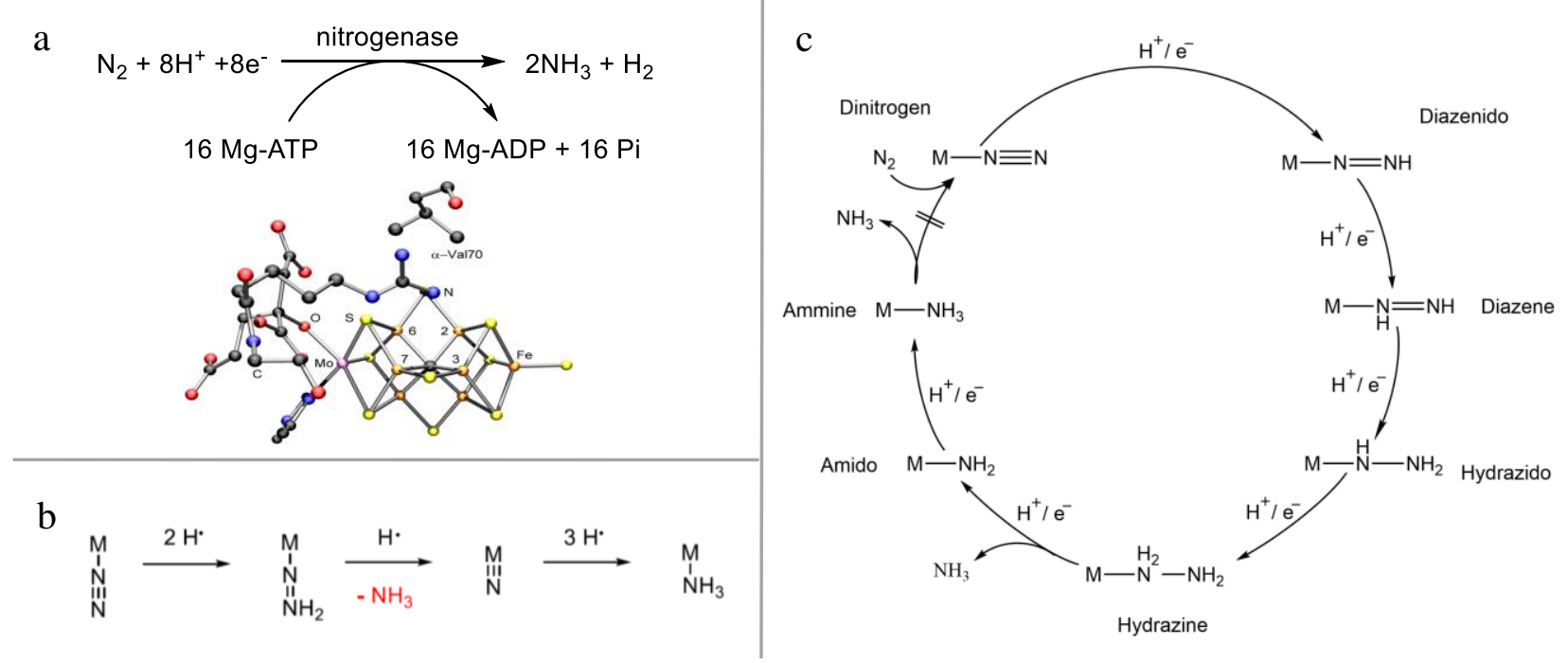

Figure 2.1: (a) Proposed stoichiometry of biological nitrogen fixation by nitrogenase and structure of nitrogenase. (b): Proposed distal pathway for $\mathrm{N}_{2}$ reduction. (c): Proposed alternating pathway for $\mathrm{N}_{2}$ reduction.

In industry, as shown in Figure 2.2, $\mathrm{N}_{2}$ can be reduced to ammonia $\left(\mathrm{NH}_{3}\right)$ with dihydrogen $\left(\mathrm{H}_{2}\right)$ in the presence of heterogeneous Fe-based catalysts through the Haber-Bosch process under high pressure and temperature $\left(100-200 \mathrm{~atm}, 300-500{ }^{\circ} \mathrm{C}\right) .{ }^{10 \mathrm{c}}$ The development of the Haber-Bosch process in the beginning of the 20th century is one of the most important technical achievement and continues to provide important fertilizers for the agriculture with significant economic benefits. ${ }^{13}$ The Haber-Bosch process is based on the initial homolytic splitting of dinitrogen molecules on the surface of the catalyst to form metal nitride species, which further react with chemisorbed dihydrogen to generate ammonia. Although the synthesis of ammonia is exothermic and thermodynamically favored $\left(\Delta_{\mathrm{r}} H^{\circ}=-45.90 \mathrm{~kJ} \mathrm{~mol}^{-1}, \Delta_{\mathrm{r}} G^{\circ}=-16.37 \mathrm{~kJ} \mathrm{~mol}^{-1}\right)$, this reaction can hardly occur at ambient conditions because of the high dissociation energy of the dinitrogen triple bond $\left(D_{0}{ }^{\circ}=945.37 \mathrm{~kJ} \mathrm{~mol}^{-1}\right){ }^{14}$ So the Haber-Bosch process consumes fossil fuels, $1-2 \%$ of the world's annual primary energy supply, to produce the required $\mathrm{H}_{2}$ and to obtain the high pressure and temperature necessary for $\mathrm{N}_{2}$ activation and ammonia production, but it also leads to the emission of more than 450 million metric tons of greenhouse gas $\mathrm{CO}_{2}$ and brings serious environmental issues. ${ }^{10 \mathrm{c}}$

$\mathrm{N}_{2}+3 \mathrm{H}_{2} \frac{\text { cat. } \mathrm{Fe}_{3} \mathrm{O}_{4} / \mathrm{K}_{2} \mathrm{O} / \mathrm{Al}_{2} \mathrm{O}_{3}}{100-200 \mathrm{~atm}, 300-500{ }^{\circ} \mathrm{C}} 2 \mathrm{NH}_{3}$

a

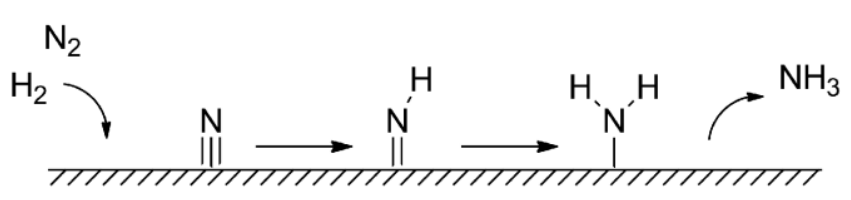

$\mathrm{b}$

Figure 2.2: (a): Proposed stoichiometry of nitrogen fixation through Haber-Bosch process. (b): The mechanism of nitrogen fixation by the surface of the catalyst in the Haber-Bosch process. 


\subsection{2 $\mathrm{N}_{2}$ Coordination to Transition Metal Complexes}

As mentioned above, molecular $\mathrm{N}_{2}$ fixation plays a crucial role in both the biosphere and the chemical industry. However, $\mathrm{N}_{2}$ fixation and conversion to ammonia is still extremely challenging and consumes a large amount of energy, which is reflected by the minimum requirement of 16 ATPs per $\mathrm{N}_{2}$ molecule in nitrogenase and by the reaction conditions of high pressure and temperature through the Haber-Bosch process. ${ }^{10 a, c}$ This is primarily attributed to the intrinsic inertness of $\mathrm{N}_{2}$. A depicted in Figure 2.3, in molecular dinitrogen, two nitrogen atoms are bound via a triple bond formed by one $\sigma$ bond and two $\pi$ bonds and the high bond dissociation enthalpy of $\mathrm{N} \equiv \mathrm{N}$ triple bond is $941 \mathrm{~kJ} \mathrm{~mol}^{-1}$, which reveals the high thermodynamic stability of $\mathrm{N}_{2} \cdot{ }^{10 \mathrm{c}, 15} \mathrm{In}$ addition, the first-bond cleavage energy from $\mathrm{N} \equiv \mathrm{N}$ triple bond to $\mathrm{N}=\mathrm{N}$ double bond is $410 \mathrm{~kJ} \mathrm{~mol}^{-1}$, almost half of the full dissociation enthalpy, highlighting the difficulty of $\mathrm{N}_{2}$ reduction. Moreover, the large energy gap of $10.82 \mathrm{eV}$ between the HOMO and LUMO means the $\mathrm{N}_{2}$ molecule is reluctant to accept or lose electrons, disfavoring redox reactions of dinitrogen. The $\mathrm{N}_{2}$ molecule's non-polarity, low proton affinity, high ionization potential and negative electron affinity determine the kinetic and thermodynamic stability of $\mathrm{N}_{2}$. All of these intrinsic properties together make $\mathrm{N}_{2}$ unreactive. However, it has been shown that the coordination of transition metals with $\mathrm{N}_{2}$ molecules facilitates the cleavage of the $\mathrm{N}_{2}$ bond. ${ }^{10 \mathrm{c}}$

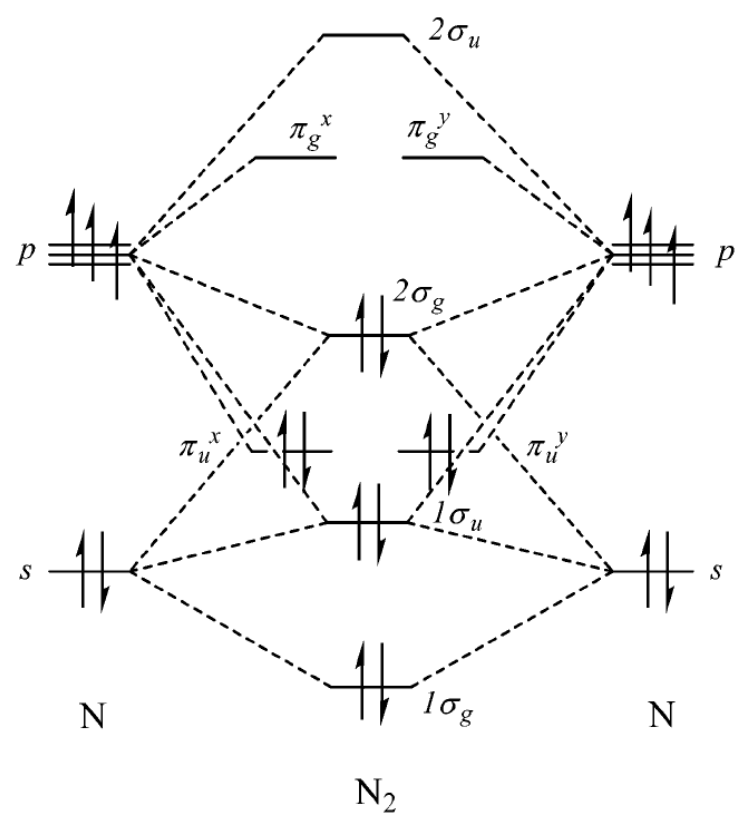

Figure 2.3: Simplified $\mathrm{N}_{2}$ molecular orbital diagram.

In 1965, Allen and Senoff obtained the first dinitrogen complex $\left[\mathrm{Ru}\left(\mathrm{NH}_{3}\right)_{5}\left(\mathrm{~N}_{2}\right)\right]^{2+}$ by reduction of $\left[\mathrm{RuCl}_{3}\left(\mathrm{H}_{2} \mathrm{O}\right)_{3}\right]$ with hydrazine hydrate in water at room temperature. ${ }^{16}$ In 1967 , Yamamoto reported a cobalt-dinitrogen complex $\left[\mathrm{CoH}\left(\mathrm{N}_{2}\right)\left(\mathrm{PPh}_{3}\right)_{3}\right]$ from the reduction of $\left[\mathrm{Co}(\mathrm{acac})_{3}\right]$ with $\mathrm{AlEt}_{2} \mathrm{OEt}$ under nitrogen atmosphere, which is the first transition metal-dinitrogen complex derived from the direct fixation of gaseous molecular dinitrogen. ${ }^{17}$ Since then, a wide range of mononuclear dinitrogen or multinuclear dinitrogen-bridged complexes have been prepared, typically exhibiting the general 
bonding modes illustrated in Figure $2.4 .{ }^{18,10 \mathrm{c}} \mathrm{N}_{2}$ is typically coordinated to the transition metal center in an end-on manner, where $\sigma$ donation is from the HOMO orbital of dinitrogen to a suitable empty $d$ orbital of the transition metal, and the backbonding is from a suitably filled $\mathrm{d}$ orbital of the transition metal to the LUMO orbital of dinitrogen. Moreover, both experimental and theoretical studies confirm that side-on coordination is higher in energy than end-on coordination. ${ }^{19}$ The mode of $\mathrm{M}_{n}-\mathrm{N}_{2}$ bonding is related to different metal centers, the oxidation states of the metal and ligand properties. As the energy of HOMO and LUMO orbitals of dinitrogen does not match very well with the energy of the metal's d-orbitals, it leads to the instability of dinitrogen complexes or even dissociation of the dinitrogen complexes. ${ }^{10 \mathrm{c}}$ Furthermore, in dinuclear or multinuclear complexes, the bridging coordination of $\mathrm{N}_{2}$ to metal centers in low oxidation states is contributed to higher nitrogen activation because of stronger $\pi$-back donation from the metals to $\mathrm{N}_{2} \cdot{ }^{20}$ The extent of $\mathrm{N}_{2}$ activation, corresponding to the degree of elongation of $\mathrm{N}-\mathrm{N}$ bond, can be estimated by the N-N stretching frequency in IR spectroscopy in contrast to free $\mathrm{N}_{2}\left(v=2331 \mathrm{~cm}^{-1}\right) .{ }^{15}$

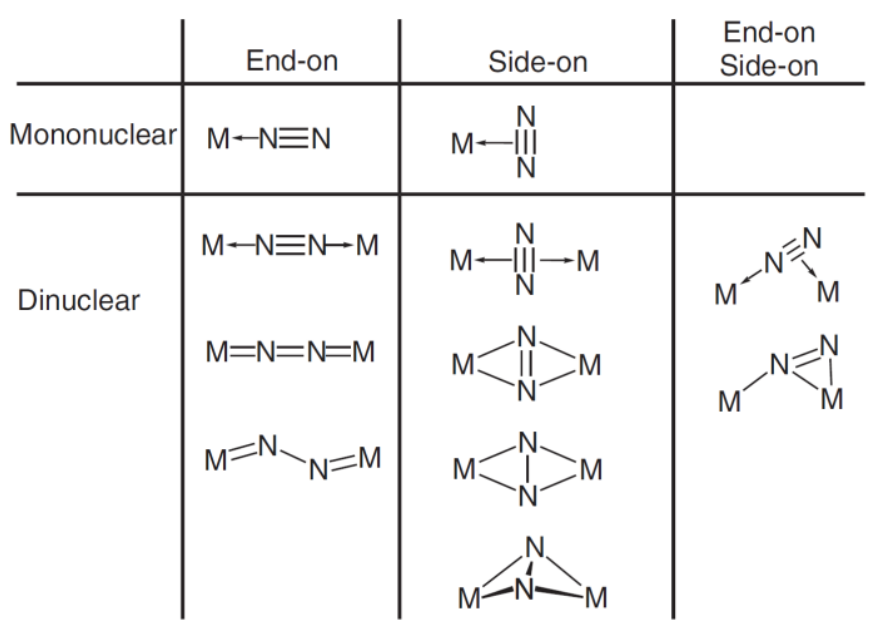

Figure 2.4: General bonding modes of dinitrogen in mononuclear and mutinuclear transition metal-dinitrogen complexes

\subsubsection{Cobalt Dinitrogen Complexes}

Iron plays an important role in $\mathrm{N}_{2}$ reduction as a catalyst in biological nitrogenase or the industrial Haber-Bosch process. ${ }^{10 \mathrm{c}}$ Of the $3 \mathrm{~d}$ metals, cobalt has many properties in common with iron making cobalt in low oxidation state and low coordination number an attractive target for $\mathrm{N}_{2}$ activation. Recently, several cobalt dinitrogen complexes have been obtained (Figure 2.5 and Table 2.1), ${ }^{21,} 22$ especially based on pincer ligands (Figure 2.5i-m). ${ }^{22}$ For example, the Mindiola group reported a rare cobalt(-1) dinitrogen complex $\left[\left\{\mathrm{Na}_{2}(\text { thf })_{3}\right\}_{2}\left\{(\mathrm{PNP}) \mathrm{Co}\left(\mathrm{N}_{2}\right)\right\}_{2}\right]$ based on a PNP-type ligand $\left(\mathrm{PNP}=\left[\mathrm{N}\left\{2-\mathrm{P}\left(\mathrm{CHMe}_{2}\right)_{2}-4-\mathrm{MeC}_{6} \mathrm{H}_{3}\right\}_{2}\right]^{-}\right)$, which was very reactive and became oxidized over several hours with transformation into a cobalt(I) $\mathrm{N}_{2}$-bridged complex $\left[\{(\mathrm{PNP}) \mathrm{Co}\}_{2}\left(\mu_{2}-\mathrm{N}_{2}\right)\right] .{ }^{22 a}$ However, due to the lower-energy d orbital than iron, only a few examples of cobalt complexes in $\mathrm{N}_{2}$ activation and $\mathrm{N}_{2}$ functionalization succeeded. As depicted in Figure 2.5a and b, the Holland group reported three $\beta$-diketiminato dicobalt dinitrogen complexes $\left[\mathrm{L}^{\mathrm{tBu}} \mathrm{Co}\left(\mu-\eta^{1}: \eta^{1}-\mathrm{N}_{2}\right) \mathrm{CoL}^{\mathrm{tBu}}\right]$ showing a significantly weakened $\mathrm{N}-\mathrm{N}$ bond $(1.139 \AA)$ and $\mathrm{M}_{2}\left[\mathrm{~L}^{\mathrm{tBu}} \mathrm{Co}\left(\mu-\eta^{1}: \eta^{1}-\mathrm{N}_{2}\right) \mathrm{CoL}^{\mathrm{tBu}}\right](\mathrm{M}=\mathrm{Na}$ or $\mathrm{K})$ after 
reduction by sodium or by potassium/graphite $\left(\mathrm{KC}_{8}\right)$ showing further weakened $\mathrm{N}-\mathrm{N}$ bonds (1.211-1.220 ̊). ${ }^{21 \mathrm{a}}$ By employing a monodentate N-heterocyclic carbene (NHC) as a ligand, the Deng group synthesized a cobalt $(0)$ dinitrogen complex [(ICy) $\left.{ }_{3} \operatorname{Co}\left(\mathrm{N}_{2}\right)\right]$ and a series of novel cobalt(-1) dinitrogen complexes $\left[(\mathrm{ICy})_{2} \mathrm{Co}\left(\mathrm{N}_{2}\right)_{2} \mathrm{M}\right]_{\mathrm{n}}(\mathrm{M}=\mathrm{K}, \mathrm{Rb}$ or Cs $) .{ }^{21 \mathrm{~h}}$ Moreover, the reactions of bis(dinitrogen)cobalt(-1) complexes with $\mathrm{R}_{3} \mathrm{SiCl}(\mathrm{R}=\mathrm{Me}, \mathrm{Et})$ resulted in the formation of diazene complexes $\left[(\mathrm{ICy})_{2} \mathrm{Co}\left(\eta^{2}-\mathrm{R}_{3} \mathrm{SiNNSiR}_{3}\right)\right]$, the first diazene complexes of late transition metals prepared from $\mathrm{N}_{2}$-functionalization reactions beyond the iron group (Figure $2.5 \mathrm{~g}$ ).
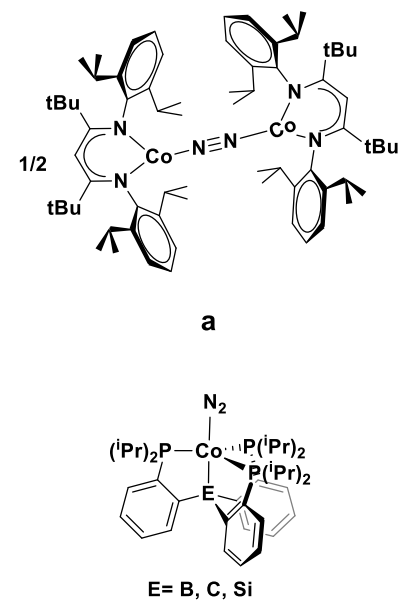

e

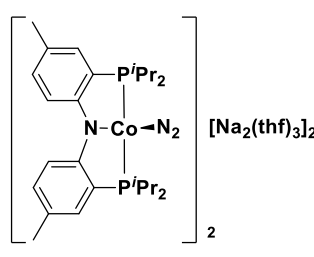

i

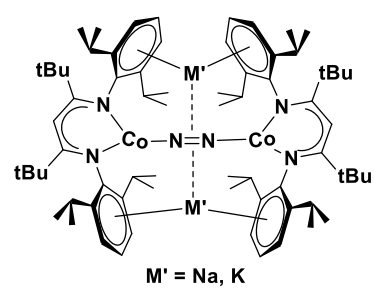

b

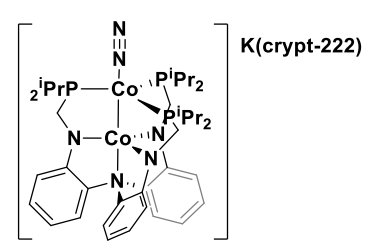

f
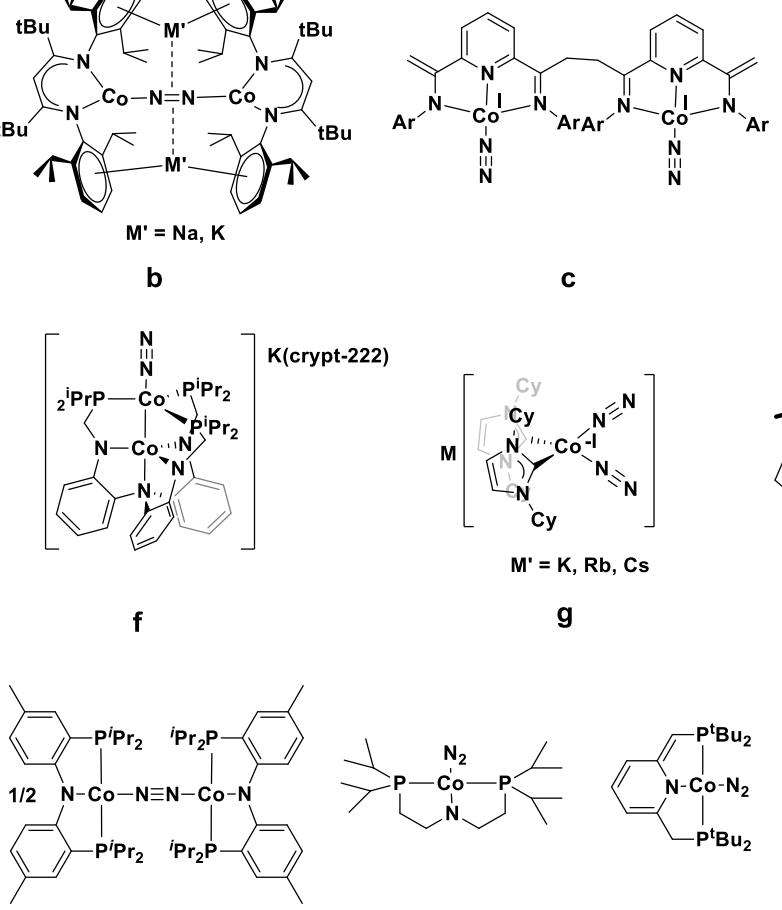

j c

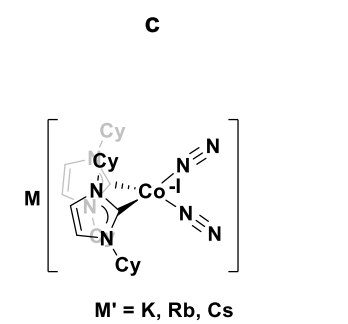

$M^{\prime}=K, R b, C s$

g

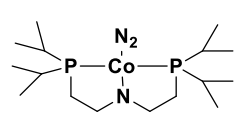

$\mathbf{k}$

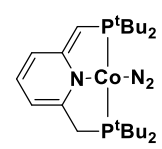

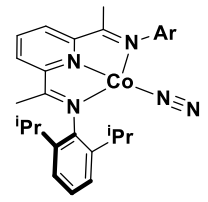

d

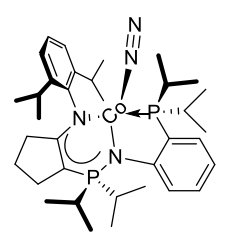

h

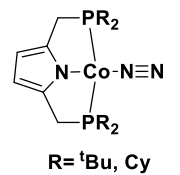

m

Figure 2.5: Selected examples of cobalt dinitrogen complexes reported.

Table 2.1: Comparison with bond lengths and $v_{\mathrm{N}-\mathrm{N}}$ stretching frequencies of cobalt dinitrogen complexes (in Figure 2.5) reported previously.

\begin{tabular}{cccccc}
\hline Complex & $\mathrm{Co}(\mathrm{n})$ & $\mathrm{M}-\mathrm{N}(\AA)$ & $\mathrm{N}-\mathrm{N}(\AA)$ & $v_{\mathrm{N}-\mathrm{N}}\left(\mathrm{cm}^{-1}\right)$ & Ref \\
\hline $\mathbf{a}$ & +1 & 1.8401 & 1.139 & - & $21 \mathrm{a}$ \\
\hline \multirow{2}{*}{$\mathbf{b}$} & & $\mathrm{Na}: 1.743,1.735$ & $\mathrm{Na}: 1.211$ & $\mathrm{Na}: 1598$ & $21 \mathrm{a}$ \\
& +1 & $\mathrm{~K}: 1.750$ & $\mathrm{~K}: 1.220$ & $\mathrm{~K}: 1599$ & \\
\hline c & +1 & 1.808 & 1.095 & 2153 & $21 \mathrm{~b}$ \\
\hline d & +1 & 1.7884 & 1.104 & $2093($ toluene $)$ & $21 \mathrm{c}$ \\
\hline & 0 & $\mathrm{~B}: 1.8653$ & $\mathrm{~B}: 1.057$ & $\mathrm{~B}: 2089$ & $21 \mathrm{~d}, 21 \mathrm{e}$, \\
$\mathbf{e}$ & +1 & $\mathrm{C}: 1.814$ & $\mathrm{C}: 1.024$ & $\mathrm{C}: 2057$ & $21 \mathrm{f}$ \\
& +1 & $\mathrm{Si}: 1.813$ & $\mathrm{Si}: 1.123$ & $\mathrm{Si}: 2063$ & \\
\hline
\end{tabular}




\begin{tabular}{cccccc}
\hline $\mathbf{f}$ & $+2,0$ & 1.770 & 1.114 & 1994 & $21 \mathrm{~g}$ \\
\hline & & $\mathrm{K}: 1.752 \sim 1.758$ & $\mathrm{~K}: 1.154 \sim 1.159$ & $\mathrm{~K}: 1807,1881$ & \\
$\mathbf{g}$ & -1 & $\mathrm{Rb}: 1.747 \sim 1.760$ & $\mathrm{Rb}: 1.151 \sim 1.162$ & $\mathrm{Rb}: 1804,1888$ & $21 \mathrm{~h}$ \\
& & $\mathrm{Cs}: 1.748 \sim 1.765$ & $\mathrm{Cs}: 1.145 \sim 1.159$ & $\mathrm{Cs}: 1811,1882$ & \\
\hline $\mathbf{h}$ & +1 & 1.99 & 1.126 & 2071 & $21 \mathrm{i}$ \\
\hline $\mathbf{i}$ & -1 & - & 1.185 & 1784 & $22 \mathrm{a}$ \\
\hline $\mathbf{j}$ & +1 & - & 1.144 & 2024 & $22 \mathrm{a}$ \\
\hline $\mathbf{k}$ & +1 & 1.740 & 1.124 & 1999 & $22 \mathrm{~b}$ \\
\hline $\mathbf{l}$ & +1 & 1.740 & 1.12 & 2021 & $22 \mathrm{c}$ \\
\hline & & ${ }^{\mathrm{t}} \mathrm{Bu}: 1.731$ & ${ }^{\mathrm{t}} \mathrm{Bu}: 1.117$ & ${ }^{\mathrm{t}} \mathrm{Bu}: 2016$ & $22 \mathrm{~d}$ \\
\hline $\mathbf{m}$ & +1 & $\mathrm{Cy}: 1.733$ & $\mathrm{Cy}: 1.090$ & $\mathrm{Cy}: 2020$ & \\
\hline
\end{tabular}

\subsubsection{Catalytic Conversion of Dinitrogen into Ammonia Using Transition Metal Complexes}

$$
\mathrm{N}_{2}+\mathrm{H}^{+}+\text {reductant } \underset{\text { solvent }}{\stackrel{\text { catalyst }}{\longrightarrow}} \mathrm{NH}_{3}
$$

Scheme 2.1: Catalytic conversion of $\mathrm{N}_{2}$ into ammonia.

Numerous cases of the catalytic conversions of $\mathrm{N}_{2}$ into ammonia have been reported previously using $\mathrm{Mo}, \mathrm{Fe}, \mathrm{Co}, \mathrm{Cr}$ and $\mathrm{Ti}$ complexes as catalysts (Scheme 2.1 ). ${ }^{23}$ In these, coordinated $\mathrm{N}_{2}$ can be possibly converted through a series of $\mathrm{H}^{+} / \mathrm{e}^{-}$delivery steps to ammonia. The Peters group described that $\mathrm{Fe}-\mathrm{N}_{2}$ complexes of tetradentate $\mathrm{P}_{3} \mathrm{E}$ ligands $(\mathrm{E}=\mathrm{B}, \mathrm{C}, \mathrm{Si})$ generate catalytic yields of $\mathrm{NH}_{3}$ up to 43 turnover number (TON) under an atmosphere of $\mathrm{N}_{2}$ with acid and reductant. ${ }^{24}$ Nishibayashi reported the catalytic reduction of dinitrogen into ammonia and hydrazine using $\mathrm{Fe}$ or Co complexes ligated by pyrrolide pincer ligands. ${ }^{12 \mathrm{a}, 2 \mathrm{~d}}$ However, until now, the yield of ammonia from catalytic $\mathrm{N}_{2}$ reduction remains extremely low in most cases.

\subsubsection{Catalytic Conversion of Dinitrogen into Silylamine Using Transition Metal Complexes}

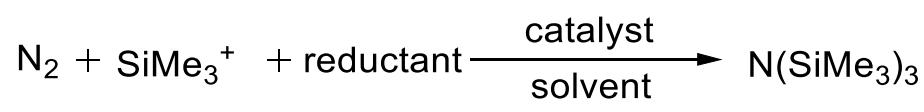

Scheme 2.2: Catalytic conversion of $\mathrm{N}_{2}$ into silylamine.

As silylamine can be readily hydrolyzed to ammonia with acid, catalytic formation of silylamine from dinitrogen is an alternative $\mathrm{N}_{2}$ fixation process and a complementary method of ammonia production (Scheme 2.2). The possible $\mathrm{N}_{2}$ silylation mechanism is that silyl radicals can be generated during the reactions of electrophilic $\mathrm{Me}_{3} \mathrm{Si}^{+}$(such as $\mathrm{Me}_{3} \mathrm{SiCl}, \mathrm{Me}_{3} \mathrm{SiOTf}$ ) and reductant (such as $\mathrm{Na}$, 
$\mathrm{K}, \mathrm{KC}_{8}$ ), which can react with the coordinated $\mathrm{N}_{2}$ by both the distal and alternating pathways and finally form silylamine $\mathrm{N}\left(\mathrm{SiMe}_{3}\right)_{3}{ }^{21 \mathrm{~g}}$ Several homogeneous catalytic silylation reactions of dinitrogen gas catalyzed by $\mathrm{Fe}, \mathrm{Co}, \mathrm{Cr}$, Mo and $\mathrm{W}-\mathrm{N}_{2}$ complexes have been reported. ${ }^{21 \mathrm{~g}, 21 \mathrm{i}, 25}$ The Fryzuk group showed an iminophosphorane-cobalt derivative, that could catalyze the conversion of $\mathrm{N}_{2}$ to $\mathrm{N}\left(\mathrm{SiMe}_{3}\right)_{3}\left(\sim 200\right.$ equivalents) at $233 \mathrm{~K} .^{21 \mathrm{i}}$

In addition, two proximate metal active sites of some metalloenzymes reveal the capability to mediate cooperativity in many enzymatic reactions. ${ }^{4}$ Inspired by that, well-designed bimetallic systems may show advantages over mononuclear systems such as lower redox potentials, performing multiple electron transfers and cooperativity between two metal centers to activate substrates or catalyze reactions. ${ }^{20,}{ }^{26}$ Our group synthesized a two-in-one pincer ligand, composed of two PNN pincer-type subunits. ${ }^{5,7}$ This binucleating scaffold is supposed to combine metal-ligand cooperativity (MLC) with metal-metal cooperativity (MMC) in small molecule activations and catalytic reactions. As part of the present work, the isolation of a series of novel dicobalt complexes based on this two-in-one pincer ligand scaffold has been achieved, including five cobalt dinitrogen complexes. By employing these cobalt complexes as catalysts, the catalytic silylation of dinitrogen into $\mathrm{N}\left(\mathrm{SiMe}_{3}\right)_{3}$ (using $\mathrm{KC}_{8}$ and $\mathrm{Me}_{3} \mathrm{SiCl}$ ) has been explored.

\subsection{Synthesis of the Two-in-one Pincer Ligand HL}
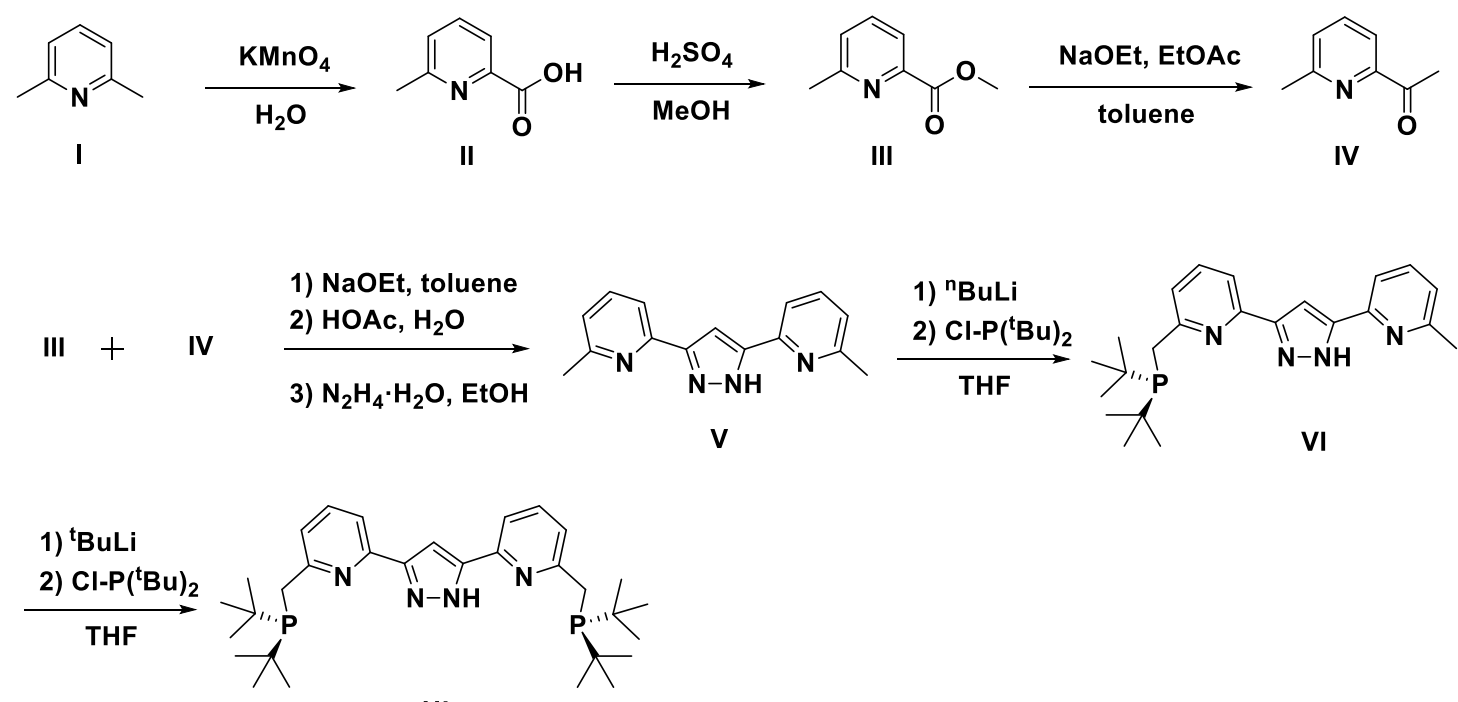

HL

Scheme 2.3: Synthetic pathway of the two-in-one pincer ligand HL. ${ }^{5,6,7}$

S. Samanta synthesized a new two-in-one pincer ligand scaffold, which consists of two PNN pincer-type subunits and a 3,5-substituted pyrazole as a bridging unit. ${ }^{5}$ Scheme 2.3 shows the synthetic pathway of ligand HL. In addition, compound IV can be synthesized by the reaction of 6-Methyl-2-pyridinecarbonitrile (VII) with Grignard reagent $\mathrm{MeMgBr}$ in THF to form imine and subsequent treatment with aqueous acid in $90 \%$ yield (Scheme 2.4). 


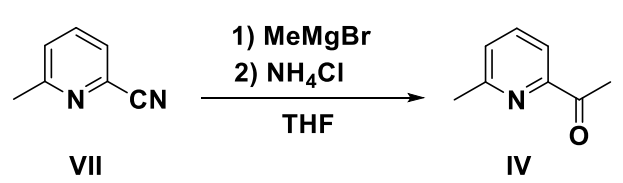

Scheme 2.4: An alternative pathway to synthesize compound IV.

\subsection{Synthesis of Dicobalt Chloride Complex 1}

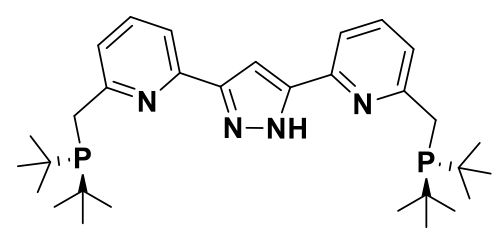

HL

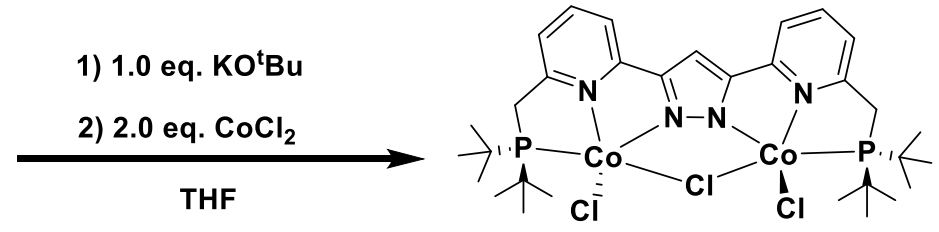

1

Scheme 2.5: Preparation of $\left[\mathrm{L}(\mathrm{CoCl})_{2}(\mu-\mathrm{Cl})\right]$ complex 1 .

To provide an entry into cobalt coordination chemistry of the ligand $\mathbf{L}^{-}$, a dinuclear $\left[\mathrm{L}(\mathrm{CoCl})_{2}(\mu-\mathrm{Cl})\right]$ complex 1 has been synthesized by the treatment of $\mathrm{HL}$ with $\mathrm{KO}^{t} \mathrm{Bu}$ in THF under inert atmosphere and subsequent addition of two equivalents of $\mathrm{CoCl}_{2}$ to generate a blue suspension (Scheme 2.5). After workup, blue rod-shaped crystals suitable for X-ray diffraction were obtained by slow diffusion of pentane into a $\mathrm{CH}_{2} \mathrm{Cl}_{2}$ solution in $90 \%$ yield.

The molecular structure is shown in Figure 2.6 and selected bond lengths and angles are listed in Table 2.2. Complex 1 crystallized in the monoclinic space group $P 2_{1} / \mathrm{n}$ with four molecules in the unit cell. Each of the cobalt atoms is coordinated in a distorted square-pyramidal geometry $\left(\tau_{5}=0.31\right.$ and 0.27$)$. The two cobalt(II) ions are hosted in two $\{\mathrm{PNN}\}$-tridentate binding sites of the anionic pincer ligand scaffold, bridged by the pyrazolate and an exogenous chloride in the equatorial position, coordinated with another chloride atom in the axial positions trans with respect to the pyrazolate-bared core, to furnish a dinuclear complex. The comparatively long Co-Cl2 (2.44/2.46 ̊) and Co1-N3/Co2-N4 bonds (2.24/2.26 $\AA$; compared to Co1-N1/Co2-N2 which are 2.00/2.01 $⿱$ ) indicate that the relatively wide Co $\cdots$ Co separation imposed by the binucleating scaffold $(3.81 \AA$ in 1) leads to some strain and significant deviation of the $\mathrm{N} 3 / 4-\mathrm{Co}-\mathrm{Cl} 2$ angles from linearity $\left(\angle \mathrm{N} 3-\mathrm{Co} 1-\mathrm{Cl} 2: 158.7^{\circ}, \angle \mathrm{N} 4-\mathrm{Co} 2-\mathrm{Cl} 2: 152.8^{\circ}\right)$. Positive ion electrospray ionization (ESI) mass spectrometry (Figure 2.7) shows one dominant peak at $\mathrm{m} / \mathrm{z}=725.1$ corresponding to the cation $\left[\mathrm{LCO}_{2} \mathrm{Cl}_{2}\right]^{+}$. 


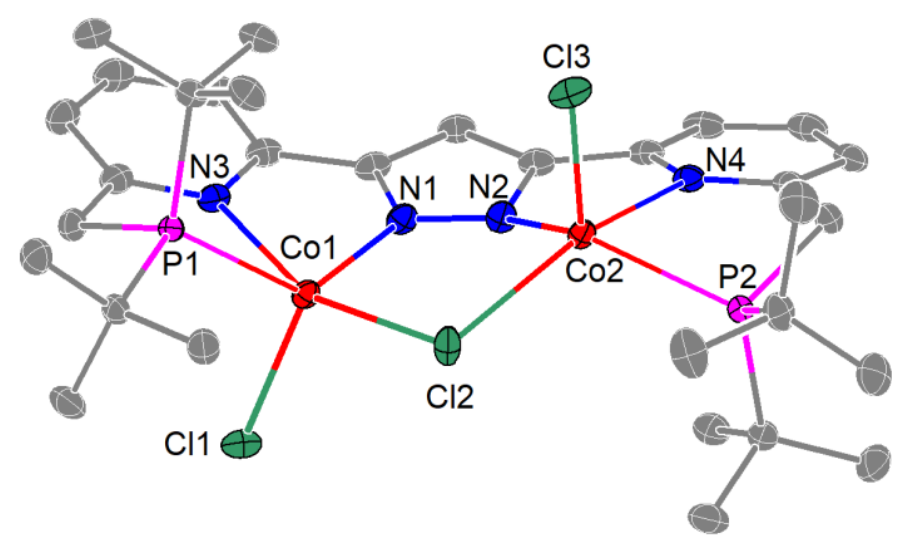

Figure 2.6: Molecular structure of complex 1 (30\% probability thermal ellipsoid); hydrogen atoms omitted for clarity.

Table 2.2: Selected bond lengths and angles for complex 1 .

\begin{tabular}{|c|c|c|c|}
\hline \multicolumn{2}{|c|}{ Bond lengths / } & \multicolumn{2}{|c|}{ Angles / ${ }^{\circ}$} \\
\hline $\mathrm{Co}(1)-\mathrm{N}(1)$ & $2.0030(18)$ & $\mathrm{N}(1)-\mathrm{Co}(1)-\mathrm{N}(3)$ & $72.85(7)$ \\
\hline $\mathrm{Co}(1)-\mathrm{N}(3)$ & $2.2434(18)$ & $\mathrm{N}(1)-\mathrm{Co}(1)-\mathrm{Cl}(1)$ & $116.79(6)$ \\
\hline $\mathrm{Co}(1)-\mathrm{Cl}(1)$ & $2.2915(7)$ & $\mathrm{N}(3)-\mathrm{Co}(1)-\mathrm{Cl}(1)$ & $93.32(5)$ \\
\hline $\operatorname{Co}(1)-\mathrm{P}(1)$ & $2.4142(6)$ & $\mathrm{N}(1)-\mathrm{Co}(1)-\mathrm{P}(1)$ & $129.11(6)$ \\
\hline $\mathrm{Co}(1)-\mathrm{Cl}(2)$ & $2.4433(6)$ & $\mathrm{N}(3)-\mathrm{Co}(1)-\mathrm{P}(1)$ & $75.02(5)$ \\
\hline $\mathrm{Co}(2)-\mathrm{N}(2)$ & $2.0136(19)$ & $\mathrm{Cl}(1)-\mathrm{Co}(1)-\mathrm{P}(1)$ & $103.37(2)$ \\
\hline $\mathrm{Co}(2)-\mathrm{N}(4)$ & $2.2604(17)$ & $\mathrm{N}(1)-\mathrm{Co}(1)-\mathrm{Cl}(2)$ & $88.84(6)$ \\
\hline $\mathrm{Co}(2)-\mathrm{Cl}(3)$ & $2.2721(7)$ & $\mathrm{N}(3)-\mathrm{Co}(1)-\mathrm{Cl}(2)$ & $158.67(5)$ \\
\hline $\mathrm{Co}(2)-\mathrm{P}(2)$ & $2.4143(6)$ & $\mathrm{Cl}(1)-\mathrm{Co}(1)-\mathrm{Cl}(2)$ & $104.90(2)$ \\
\hline $\mathrm{Co}(2)-\mathrm{Cl}(2)$ & $2.4575(6)$ & $\mathrm{P}(1)-\mathrm{Co}(1)-\mathrm{Cl}(2)$ & $110.47(2)$ \\
\hline \multirow[t]{11}{*}{$\mathrm{Co} 1 \cdots \mathrm{Co} 2$} & $3.8101(5)$ & $\mathrm{N}(2)-\mathrm{Co}(2)-\mathrm{N}(4)$ & $73.03(7)$ \\
\hline & & $\mathrm{N}(2)-\mathrm{Co}(2)-\mathrm{Cl}(3)$ & $110.48(6)$ \\
\hline & & $\mathrm{N}(4)-\mathrm{Co}(2)-\mathrm{Cl}(3)$ & $100.27(5)$ \\
\hline & & $\mathrm{N}(2)-\mathrm{Co}(2)-\mathrm{P}(2)$ & $136.79(6)$ \\
\hline & & $\mathrm{N}(4)-\mathrm{Co}(2)-\mathrm{P}(2)$ & $76.28(5)$ \\
\hline & & $\mathrm{Cl}(3)-\mathrm{Co}(2)-\mathrm{P}(2)$ & $104.29(3)$ \\
\hline & & $\mathrm{N}(2)-\mathrm{Co}(2)-\mathrm{Cl}(2)$ & $87.65(6)$ \\
\hline & & $\mathrm{N}(4)-\mathrm{Co}(2)-\mathrm{Cl}(2)$ & $152.83(6)$ \\
\hline & & $\mathrm{Cl}(3)-\mathrm{Co}(2)-\mathrm{Cl}(2)$ & $104.38(3)$ \\
\hline & & $\mathrm{P}(2)-\mathrm{Co}(2)-\mathrm{Cl}(2)$ & $107.97(2)$ \\
\hline & & $\mathrm{Co}(1)-\mathrm{Cl}(2)-\mathrm{Co}(2)$ & $102.05(2)$ \\
\hline
\end{tabular}




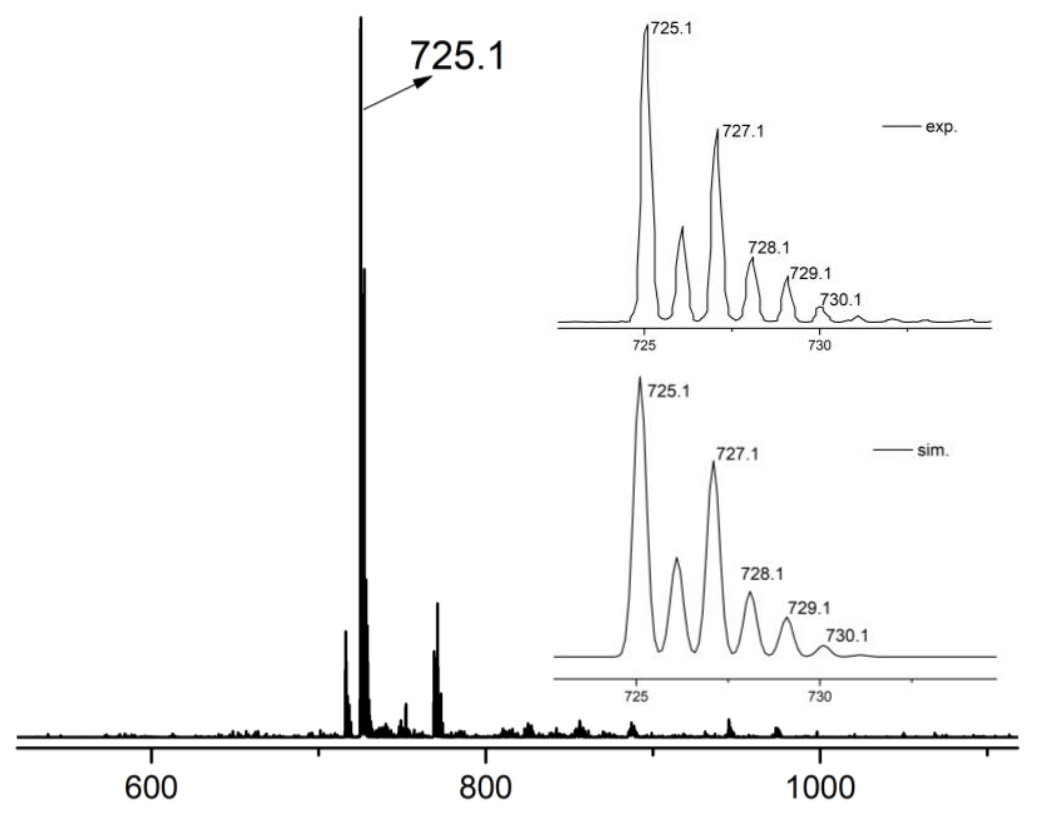

Figure 2.7: Positive ion ESI mass spectra of a solution of complex 1 in $\mathrm{MeCN}$. The inset shows the experimental and simulated isotopic distribution patterns for $\left[\mathrm{LCO}_{2} \mathrm{Cl}_{2}\right]^{+}$.

The ${ }^{1} \mathrm{H}-\mathrm{NMR}$ spectrum of complex $\mathbf{1}$ in $\mathrm{CDCl}_{3}$ (Figure 2.8) exhibits resonances outside the diamagnetic region, thereby indicating a paramagnetic species. Even though complex $\mathbf{1}$ shows paramagnetic properties, most resonances in the ${ }^{1} \mathrm{H}-\mathrm{NMR}$ spectrum could be assigned. To be specific, the single peak at $\delta=85.11 \mathrm{ppm}$ can be attributed to the $\mathrm{H}$-atom of the bridging pyrazole and two single peaks at $\delta=33.03$ and $-10.57 \mathrm{ppm}$ can be assigned to the $t \mathrm{Bu}$ groups on the basis of the integral. Three resonances at $\delta=52.34,44.75$ and $17.57 \mathrm{ppm}$ are assigned to pyridine protons based on the ${ }^{1} \mathrm{H}-{ }^{1} \mathrm{H}$ COSY spectrum (Figure 9.6). The remaining resonances attributed to the methylene spacers show one sharp peak at $\delta=55.08 \mathrm{ppm}$ and one broad peak at $\delta=44.14 \mathrm{ppm}$ due to the proximity to the paramagnetic $\mathrm{Co}$ (II) centers. As depicted in Figure 2.9, the ${ }^{13} \mathrm{C}$-NMR spectrum of complex 1 in $\mathrm{CD}_{2} \mathrm{Cl}_{2}$ shows a large range of paramagnetic chemical shifts. Based on the ${ }^{1} \mathrm{H}-{ }^{13} \mathrm{C}$ correlation experiment $\left({ }^{1} \mathrm{H}_{-}{ }^{13} \mathrm{C}\right.$ HSQC $)$ in Figure 9.7, two doublets $(\delta=783.39$ and $772.40 \mathrm{ppm})$ can be assigned to $\mathrm{C} 4$ or $\mathrm{C} 6$ of the pyridine and one weak peak ( $\delta=459.55 \mathrm{ppm})$ can be attributed to $\mathrm{C} 1$ of the bridging pyrazole. The signals of methyl carbon atoms from $t \mathrm{Bu}$ groups exhibit two doublets due to the ${ }^{13} \mathrm{C}-{ }^{31} \mathrm{P}$ coupling. The other carbon resonances are still unassignable or missing. No signals were observed in the ${ }^{31} \mathrm{P}$ NMR spectrum, presumably because of the vicinity of the nuclei to metal centers. 


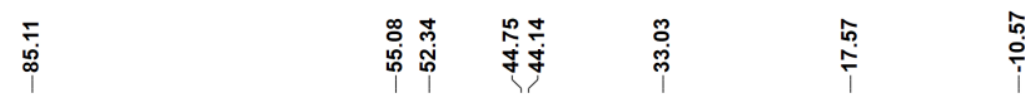
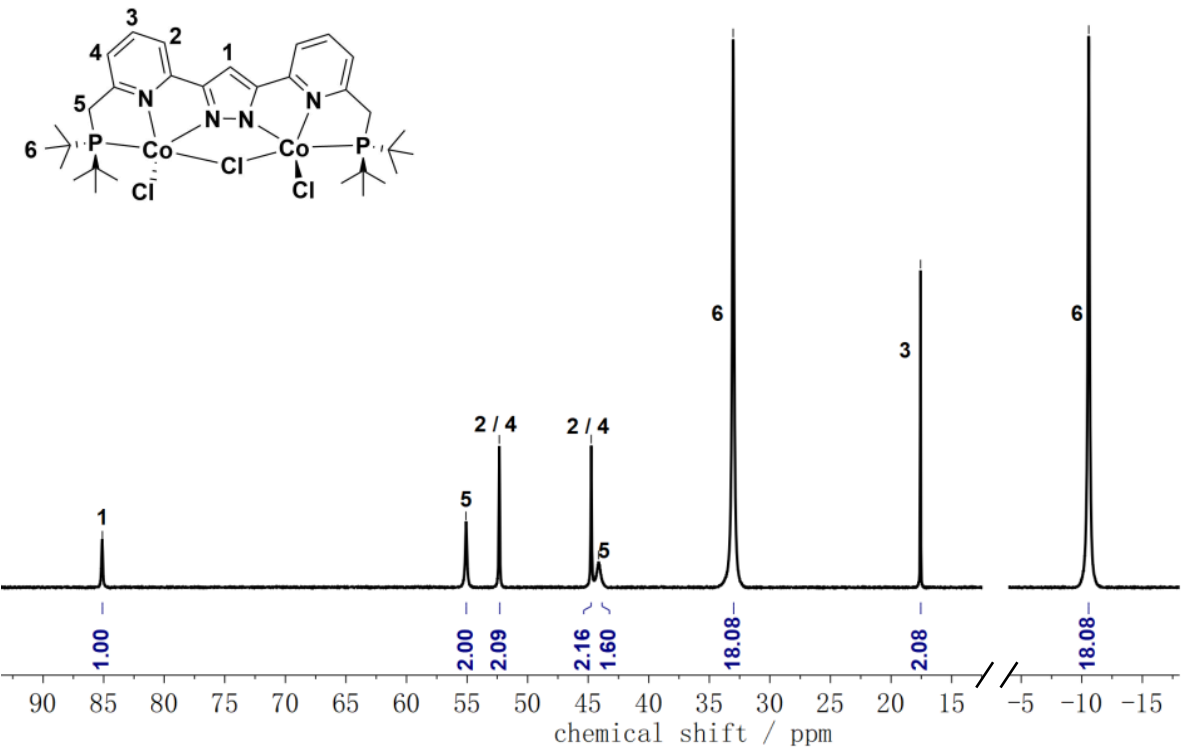

Figure 2.8: ${ }^{1} \mathrm{H}-\mathrm{NMR}$ spectrum $(500 \mathrm{MHz})$ of complex 1 in $\mathrm{CDCl}_{3}$.

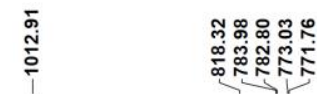

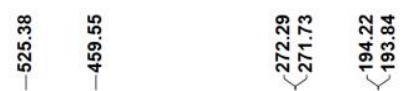
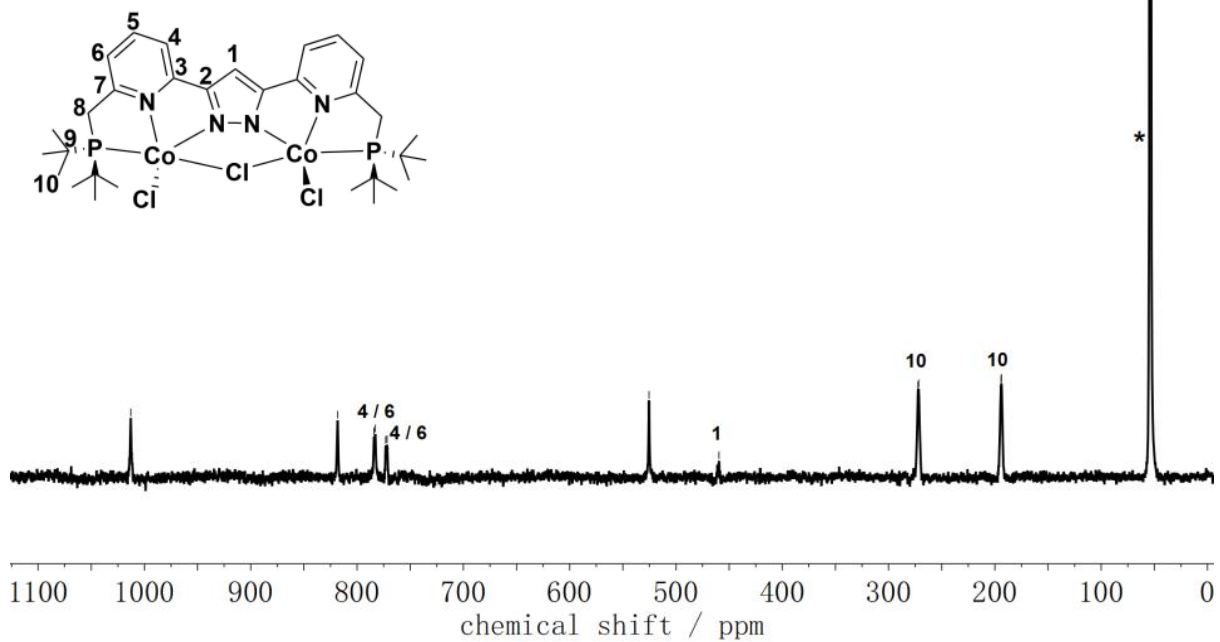

Figure 2.9: ${ }^{13} \mathrm{C}-\mathrm{NMR}$ spectrum $(500 \mathrm{MHz})$ of complex 1 in $\mathrm{CD}_{2} \mathrm{Cl}_{2}$. Solvent signals are marked with an asterisk $(*)$. 
Variable temperature magnetic susceptibility data recorded with a SQUID magnetometer in the range of $2-210 \mathrm{~K}$ (Figure 2.10) reveal that the $\chi_{\mathrm{M}} T$ product rises to $4.54 \mathrm{~cm}^{3} \mathrm{~mol}^{-1} \mathrm{~K}$ at $210 \mathrm{~K}$, showing that the cobalt(II) ions are in a high spin configuration with three unpaired electrons $(S=3 / 2)$. The data were fitted using the Heisenberg-Dirac-van-Vleck Hamiltonian $\hat{H}=-2 J \hat{S}_{1} \hat{S}_{2}+g \mu_{B} \vec{B}\left(\vec{S}_{1}+\vec{S}_{2}\right)$. The best fit leads to $g=2.4$. The decrease of the curve at low temperature indicates antiferromagnetic coupling $\left(J=-7.2 \mathrm{~cm}^{-1}\right)$. As $\mathrm{S}>1 / 2$ systems including cobalt complexes have low-lying excited states, spin-orbit coupling gives fast electronic relaxation, which corresponds to the relatively sharp signals in the NMR measurement of complex 1.

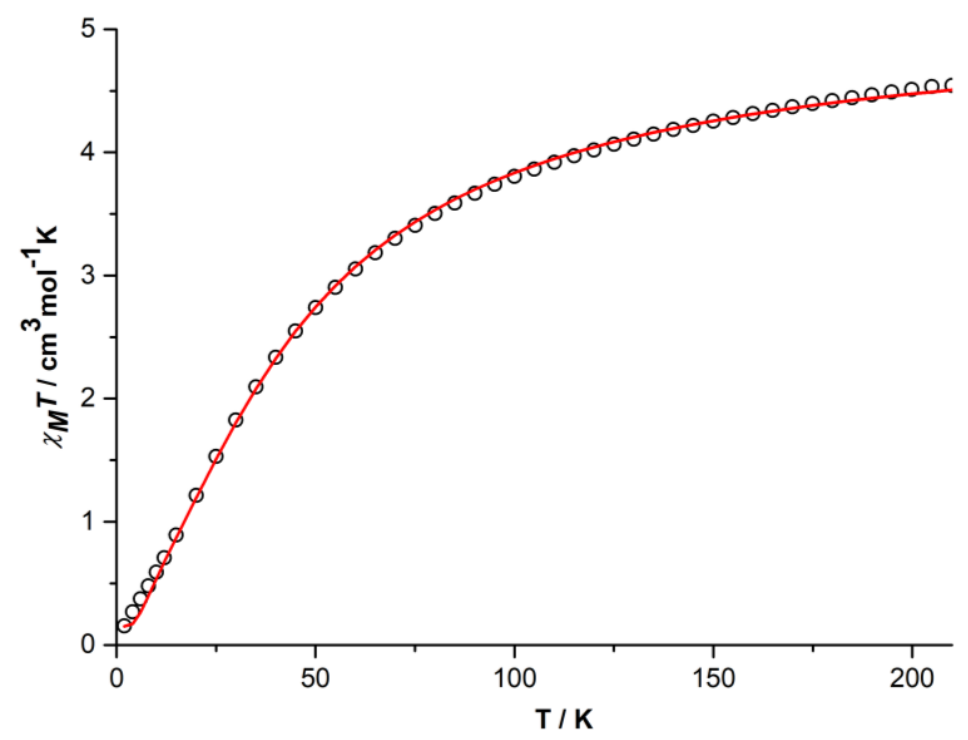

Figure 2.10: $\chi_{M} T$ vs. $T$ plot in the temperature range of $2-210 \mathrm{~K}$ at $0.5 \mathrm{~T}$ for a crystalline sample of complex 1. The red line corresponds to the best fit of the experimental magnetic results. The data were fitted using $\hat{H}=-2 J \hat{S}_{1} \hat{S}_{2}+g \mu_{B} \vec{B}\left(\vec{S}_{1}+\vec{S}_{2}\right)$ with $g=2.4, J=-7.2 \mathrm{~cm}^{-1}, T I P=170 \cdot 10^{-6} \mathrm{~cm}^{3} \mathrm{~mol}^{-1}$ and $P I=8 \%$ (with $S=3 / 2$ ).

\subsection{Direct Synthesis of Dicobalt Dinitrogen Complex 2}

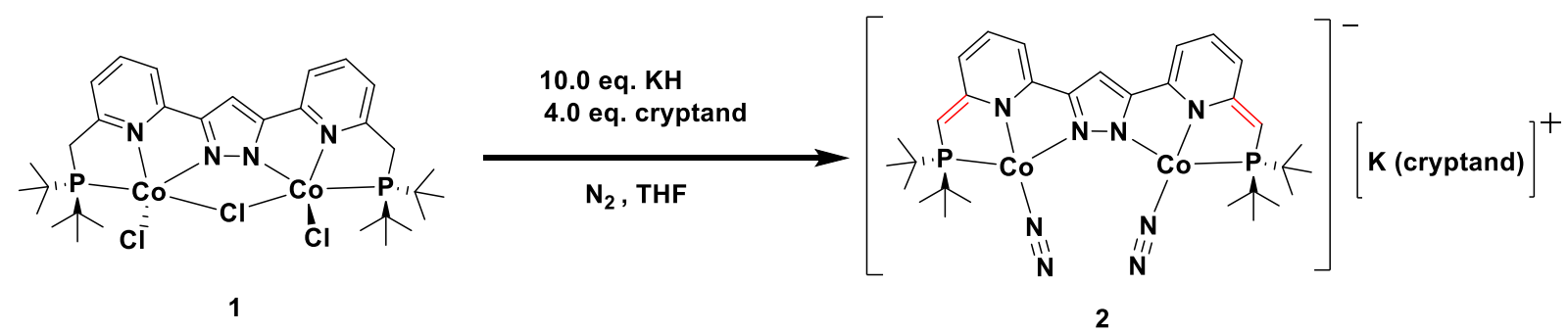

Scheme 2.6: Synthesis of the dicobalt dinitrogen complex 2 . 
Technically, the synthesis of $\mathrm{Co}\left(\mathrm{N}_{2}\right)$-type complexes can be achieved by the reduction of the halide precursors with addition of strong reductants, such as $\mathrm{Na} / \mathrm{Hg}, \mathrm{Na}\left(\mathrm{C}_{10} \mathrm{H}_{8}\right), \mathrm{MeMgCl}$ or $\mathrm{KC}_{8}$. However, in this dinuclear pincer system, neither stoichiometric reducing experiments nor excessive reducing reactions lead to the generation of dinitrogen complexes, presumably due to the instability of $\operatorname{Co}(0)$ complexes as final products. In addition, the formation of cobalt hydride species was attempted using $\mathrm{KHBEt}_{3}, \mathrm{KH}$ and $\mathrm{NaBH}_{4}$ but the results remained unclear. Then a novel one-pot reaction of complex 1 with $\mathrm{KH}$ and [2.2.2]cryptand has been exploited and finally gives rise to a cobalt dinitrogen complex. More specifically, the treatment of complex $\mathbf{1}$ with ten equivalents of $\mathrm{KH}$ and four equivalents of [2.2.2]cryptand in THF under a nitrogen atmosphere at room temperature afforded a dark blue solution (Scheme 2.6). After filtration, the filtrate was crystallized by layering with hexane/Et ${ }_{2} \mathrm{O}$ at $-40{ }^{\circ} \mathrm{C}$ and complex $\left[\left(\mathrm{L}^{* *}\left(\mathrm{CoN}_{2}\right)_{2}\right)(\mathrm{K}([2.2 .2]\right.$ cryptand $\left.))\right] 2$ was isolated in $55 \%$ yield.

Complex 2 crystallized in the monoclinic space group $P 2_{1} / \mathrm{n}$ with four molecules in the unit cell. The potassium cation is encapsulated by [2.2.2]cryptand. The molecular structure of the anionic complex 2 (Figure 2.11), established by X-ray analysis, exhibits the cobalt ions in a distorted square-planar coordination environment. Selected bond lengths and angels are listed in Table 2.3. The methylene groups of pyridine moieties are deprotonated with release of $\mathrm{H}_{2}$ gas, which lead to the dearomatization of the pyridine rings and a negative charge on the nitrogen atoms of the pyridine. Most pronounced is the change of the $\mathrm{C}-\mathrm{C}$ bond lengths in the side arms from 1.506(3) and 1.507(3) $\AA$ in complex 1 to $1.372(3)$ and 1.384(3) $\AA$ in complex 2 . The two cobalt(I) ions are hosted in two $\{\mathrm{PNN}\}$-tridentate binding pockets of the trianionic pincer ligand scaffold and coordinated with one terminal dinitrogen molecule. In the dearomatized species 2, the Co...Co separation of $4.30 \AA$ is distinctly longer by $0.49 \AA$ than in complex 1 and the Co-N-N-Co torsion angle is $34.2^{\circ}$. The $\mathrm{N} \equiv \mathrm{N}$ bond lengths of the coordinated dinitrogen molecules are 1.124(3) and 1.125(3) $\AA$, which are consistent with those in previously reported $\mathrm{Co}\left(\mathrm{N}_{2}\right)$ complexes and similar to the $\mathrm{N} \equiv \mathrm{N}$ bond lengths of cobalt complexes in Figure 2.5 (such as h, k, 1 and m). ${ }^{21,22}$ Possibly because of steric congestion, the two dinitrogen molecules are pointing below and above the equatorial plane defined by the pyrazolate heterocycle. The results in (non-crystallographic) $C_{2}$ symmetry of the anion of $\mathbf{2}$, with both enantiomers present in the crystal.
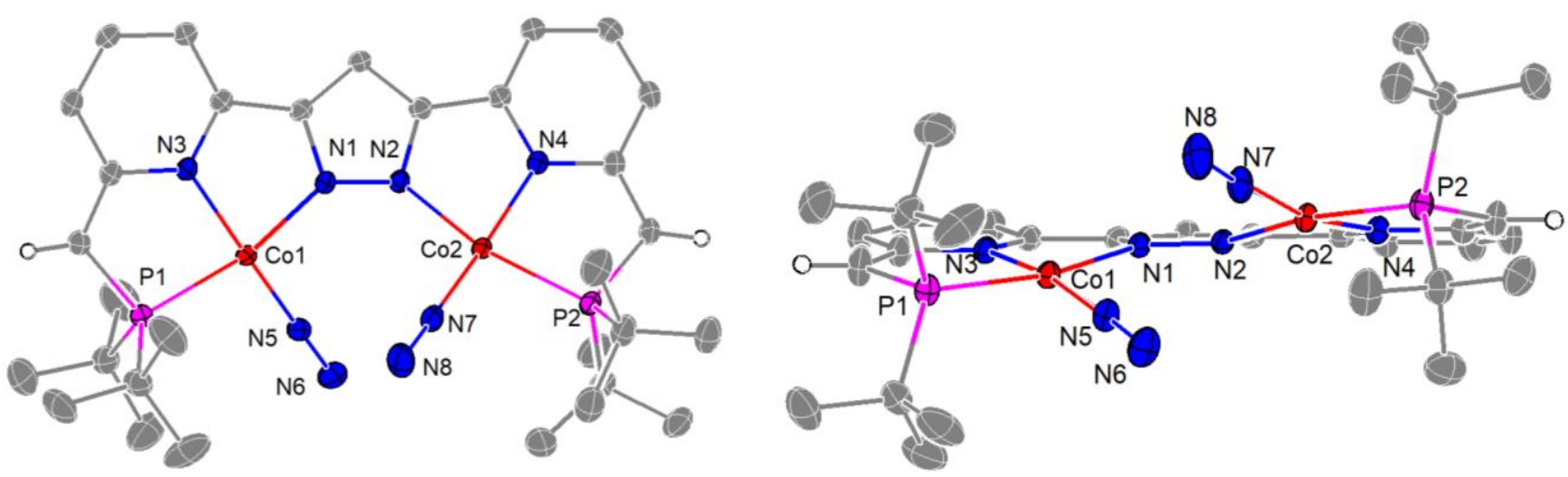

Figure 2.11: Top view (left) and front view (right) of the molecular structure of the anionic complex $2\left(30 \%\right.$ probability thermal ellipsoid); most hydrogen atoms, the cation $(\mathrm{K}([2.2 .2] \text { cryptand }))^{+}$and 
solvent molecules omitted for clarity.

Table 2.3: Selected bond lengths and angles for complex 2 .

\begin{tabular}{llll}
\hline \multicolumn{2}{c}{ Bond lengths / $\AA$} & \multicolumn{2}{c}{ Angles / } \\
\hline $\mathrm{Co}(1)-\mathrm{N}(5)$ & $1.7419(17)$ & $\mathrm{N}(5)-\mathrm{Co}(1)-\mathrm{N}(3)$ & $169.87(8)$ \\
$\mathrm{Co}(1)-\mathrm{N}(3)$ & $1.9135(16)$ & $\mathrm{N}(5)-\mathrm{Co}(1)-\mathrm{N}(1)$ & $97.99(7)$ \\
$\mathrm{Co}(1)-\mathrm{N}(1)$ & $1.9395(16)$ & $\mathrm{N}(3)-\mathrm{Co}(1)-\mathrm{N}(1)$ & $81.84(7)$ \\
$\mathrm{Co}(1)-\mathrm{P}(1)$ & $2.1889(6)$ & $\mathrm{N}(5)-\mathrm{Co}(1)-\mathrm{P}(1)$ & $96.57(6)$ \\
$\mathrm{Co}(2)-\mathrm{N}(7)$ & $1.7422(19)$ & $\mathrm{N}(3)-\mathrm{Co}(1)-\mathrm{P}(1)$ & $84.33(5)$ \\
$\mathrm{Co}(2)-\mathrm{N}(4)$ & $1.9076(17)$ & $\mathrm{N}(1)-\mathrm{Co}(1)-\mathrm{P}(1)$ & $165.18(5)$ \\
$\mathrm{Co}(2)-\mathrm{N}(2)$ & $1.9509(16)$ & $\mathrm{N}(7)-\mathrm{Co}(2)-\mathrm{N}(4)$ & $167.76(9)$ \\
$\mathrm{Co}(2)-\mathrm{P}(2)$ & $2.1970(6)$ & $\mathrm{N}(7)-\mathrm{Co}(2)-\mathrm{N}(2)$ & $97.87(7)$ \\
$\mathrm{Co} 1 \cdots \mathrm{Co} 2$ & $4.2987(7)$ & $\mathrm{N}(4)-\mathrm{Co}(2)-\mathrm{N}(2)$ & $81.77(7)$ \\
$\mathrm{N}(5)-\mathrm{N}(6)$ & $1.125(3)$ & $\mathrm{N}(7)-\mathrm{Co}(2)-\mathrm{P}(2)$ & $96.63(6)$ \\
$\mathrm{N}(7)-\mathrm{N}(8)$ & $1.124(3)$ & $\mathrm{N}(4)-\mathrm{Co}(2)-\mathrm{P}(2)$ & $84.40(5)$ \\
& & $\mathrm{N}(2)-\mathrm{Co}(2)-\mathrm{P}(2)$ & $165.41(5)$ \\
\hline
\end{tabular}

Complex 2 is extremely sensitive to air and moisture, and its characterization was carried out under rigorously dry $\mathrm{N}_{2}$ or Ar conditions. The ${ }^{1} \mathrm{H}-\mathrm{NMR}$ spectrum in THF-d $($ Figure 2.12) shows complex 2 is a diamagnetic $\mathrm{Co}^{\mathrm{I}}$ species. It demonstrates one triplet at $\delta=6.07 \mathrm{ppm}$ and two doublets at $\delta=$ 5.60 and $5.14 \mathrm{ppm}$ for pyridine protons, one singlet at $\delta=2.93 \mathrm{ppm}$ for $\mathrm{CH}$ groups in the side arms and one doublet at $\delta=1.43 \mathrm{ppm}$ for the $t \mathrm{Bu}$ groups based on ${ }^{1} \mathrm{H}-{ }^{1} \mathrm{H}$ COSY and ${ }^{1} \mathrm{H}-{ }^{1} \mathrm{H}$ NOESY spectra (Figure 9.10 and 9.11), which reveals apparent $C_{2 v}$ symmetry of complex 2 in solution on the NMR time scale at room temperature. The ${ }^{31} \mathrm{P}-\mathrm{NMR}$ spectrum (Figure 2.13) reveals a peak at 81.31 ppm. The ${ }^{15} \mathrm{~N}-\mathrm{NMR}$ spectrum (Figure 2.14) of complex 2, which was prepared under isotopically labeled ${ }^{15} \mathrm{~N}_{2}$ atmosphere, exhibits two peaks at $\delta=-28.62$ and $-58.11 \mathrm{ppm}$ corresponding to $\mathrm{N}_{\beta}$ and $\mathrm{N}_{\alpha}$ of the coordinated dinitrogen molecules, respectively ( $\mathrm{N}_{\alpha}$ for nitrogen bound to metal and $\mathrm{N}_{\beta}$ for terminal nitrogen). This assignment is based on the presence of a larger ${ }^{31} \mathrm{P}_{-}{ }^{15} \mathrm{~N}$ coupling of $\mathrm{N}_{\alpha}$ and its relatively high field chemical shift with respect to $\mathrm{N}_{\beta}$. 


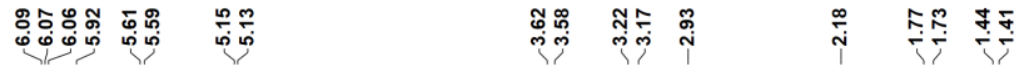

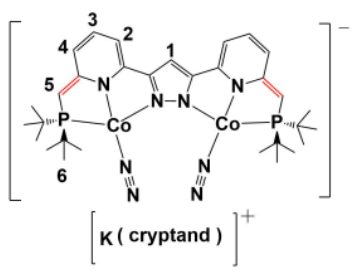

Figure 2.12: ${ }^{1} \mathrm{H}-\mathrm{NMR}$ spectrum of complex 2 in THF-d $\mathrm{d}_{8}$. Solvent signals are marked with an asterisk $(*)$.

$$
\text { 啇 }
$$

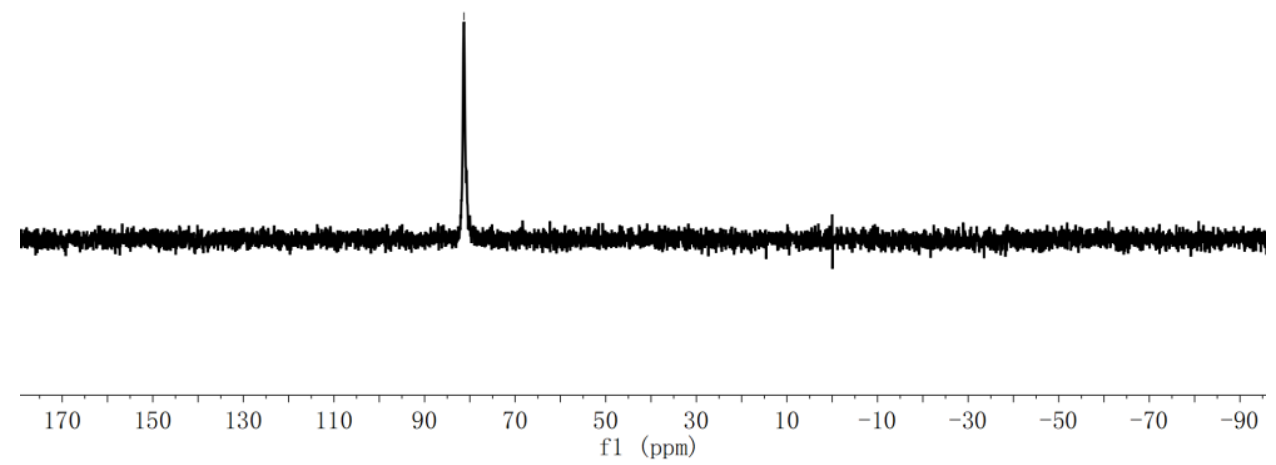

Figure 2.13: ${ }^{31} \mathrm{P}-\mathrm{NMR}$ spectrum of complex 2 in $\mathrm{THF}-\mathrm{d}_{8}$. 

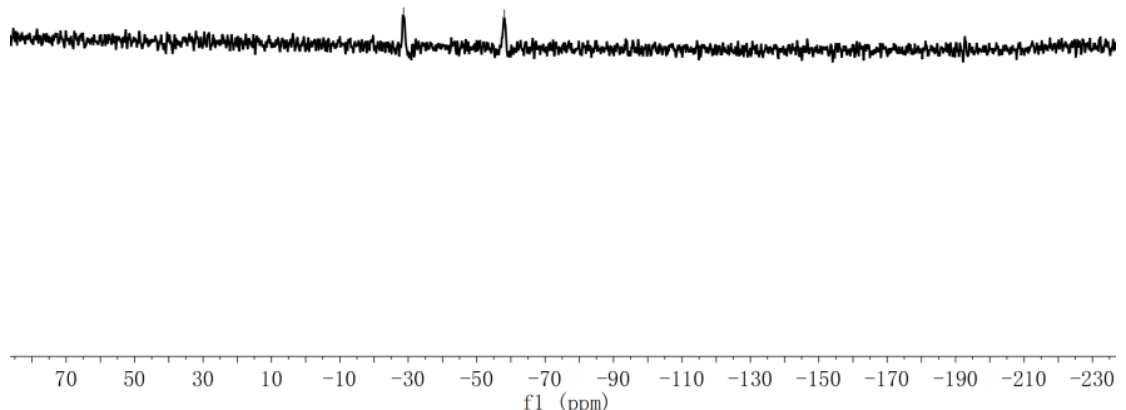

Figure 2.14: ${ }^{15} \mathrm{~N}-\mathrm{NMR}$ spectrum of complex $2-{ }^{15} \mathrm{~N}_{2}$ in THF-d8.

Additionally, the reaction of complex 1 with excess KH in THF without cryptand for two days generated a brown solution. According to NMR, the product may contain diamagnetic and paramagnetic species, which could not be identified. As complex 2, the final product after the deprotonation and reduction of complex 1 (reacting with $\mathrm{KH}$ and [2.2.2]cryptand), is diamagnetic, it reveals that the cryptand plays a crucial role in the reaction of $\mathrm{KH}$ with complex $\mathbf{1}$ to complex $\mathbf{2}$, which may not only improve the solubility of KH in THF, but also increase the reactivity of $\mathrm{KH}$ in this reaction.

As shown in Figure 2.15, two intense peaks at 2032 and $2009 \mathrm{~cm}^{-1}$ of the IR spectra of solid material correspond to the asymmetric and symmetric N-N stretching vibrations, respectively, which show significantly lower frequencies than that for free dinitrogen molecules $\left(2331 \mathrm{~cm}^{-1}\right)$. Complex 2 was also prepared under isotopically labeled ${ }^{15} \mathrm{~N}_{2}$ atmosphere and the two peaks for N-N stretching shift to 1973 and $1950 \mathrm{~cm}^{-1}$, which are very close to the expected values (1963 and $1941 \mathrm{~cm}^{-1}$; $\Delta\left({ }^{15} \mathrm{~N}_{2}-{ }^{14} \mathrm{~N}_{2}\right)=-59 \mathrm{~cm}^{-1}, \tilde{v}\left({ }^{14} \mathrm{~N}-{ }^{14} \mathrm{~N}\right) / \tilde{v}\left({ }^{15} \mathrm{~N}-{ }^{15} \mathrm{~N}\right)=1.030$, calculated 1.035 for an isolated harmonic

$\mathrm{N}-\mathrm{N}$ oscillator). DFT calculations on the optimized molecular structure of 2 predict $\mathrm{N}-\mathrm{N}$ stretching vibrations at 2079 and $2060 \mathrm{~cm}^{-1}$ (Figure 9.16 and 9.17). Based on the DFT calculated IR spectrum the two bands are assigned to the asymmetric and symmetric N-N stretches, respectively, indicating substantial vibrational coupling. As mentioned above, $\mathrm{N}_{2}$ activation is related to the overall negative charges, metal oxidation states or different donors. The extent of $\mathrm{N}_{2}$ activation is not only corresponding to the degree of elongation of $\mathrm{N}-\mathrm{N}$ bond, but can also be evaluated by the N-N stretching frequency in IR spectroscopy. In contrast to the cobalt dinitrogen complexes in Figure 2.5, complex 2 exhibits similar extent of $\mathrm{N}_{2}$ activation to complexes in Figure 2.5j, 2.51 and 2,5m, and shows more reduced $\mathrm{N}_{2}$ than complexes in Figure 2.5c, 2,5d, 2.5e and $2.5 \mathrm{~h}$ based on $\mathrm{N}-\mathrm{N}$ bond lengths in $\mathrm{N}_{2}$ and the $\mathrm{N}-\mathrm{N}$ stretching frequency in IR spectroscopy. $\mathrm{N}_{2}$ ligands of complexes in 
Figure 2.5b, 2.5g and 2.5i are more reduced than those in complex 2, not only because of negative charges of the ligands and stronger $\pi$-back bonding of Co in low oxidation states to $\mathrm{N}_{2}$, but also because of the interactions of sodium or potassium ions with $\mathrm{N}_{2}$.

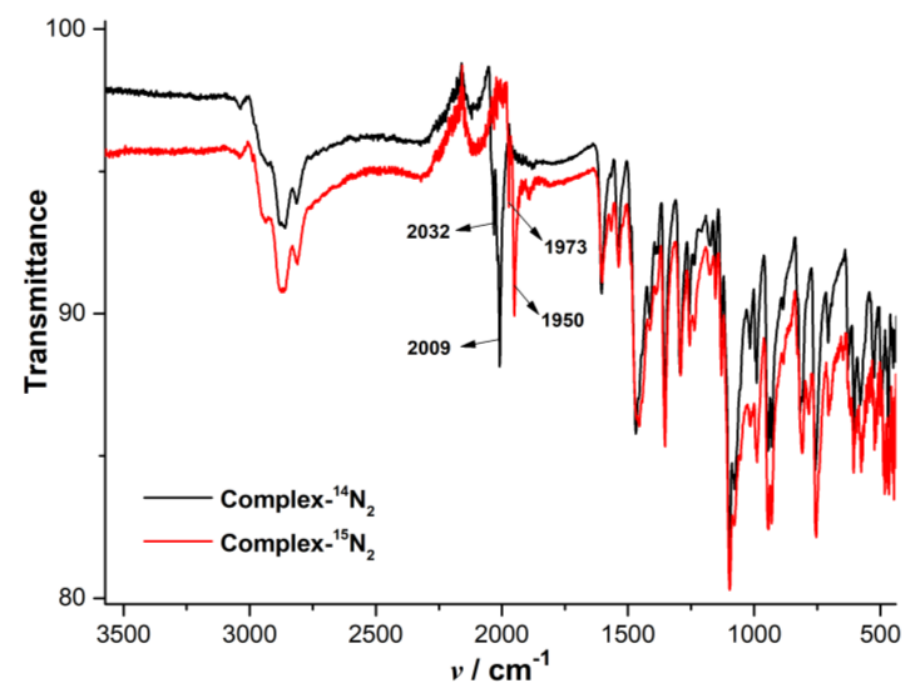

Figure 2.15: IR spectra of complex $2\left({ }^{14} \mathrm{~N}_{2}\right.$ and $\left.{ }^{15} \mathrm{~N}_{2}\right)$ in solid state.

UV-vis spectroscopy (Figure 2.16) shows that the absorbance of complex 2 increases slightly as the temperature drops from $293 \mathrm{~K}$ to $193 \mathrm{~K}$. The intense band on display in the high-energy range below $300 \mathrm{~nm}$ at $\lambda_{\max }=267 \mathrm{~nm}$ is assigned to $\pi \rightarrow \pi^{*}$ transitions on the ligand. The bands at $\lambda_{\max }=335,479$, 521 and $621 \mathrm{~nm}$ may be attributed to metal-to-ligand (including $\mathrm{N}_{2}$ ) charge transfer (MLCT) transitions.

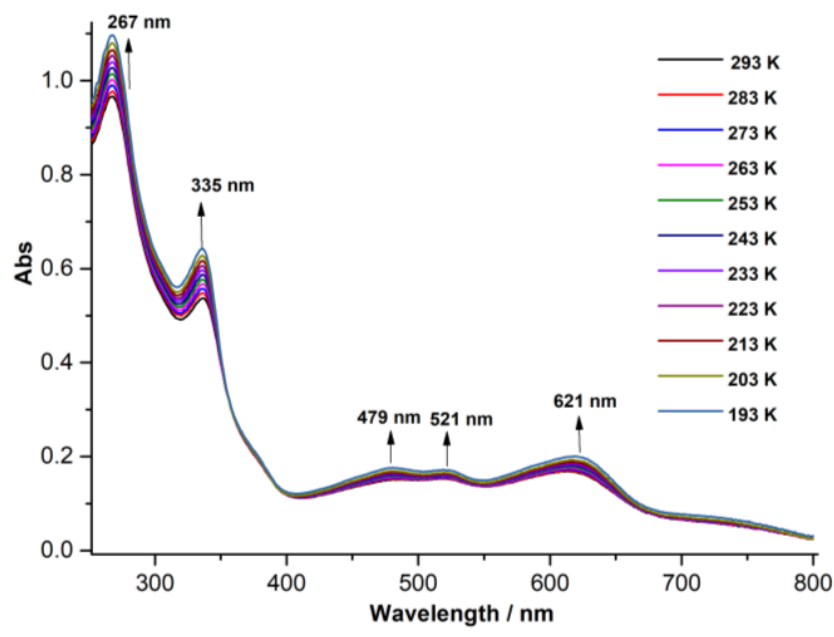

a

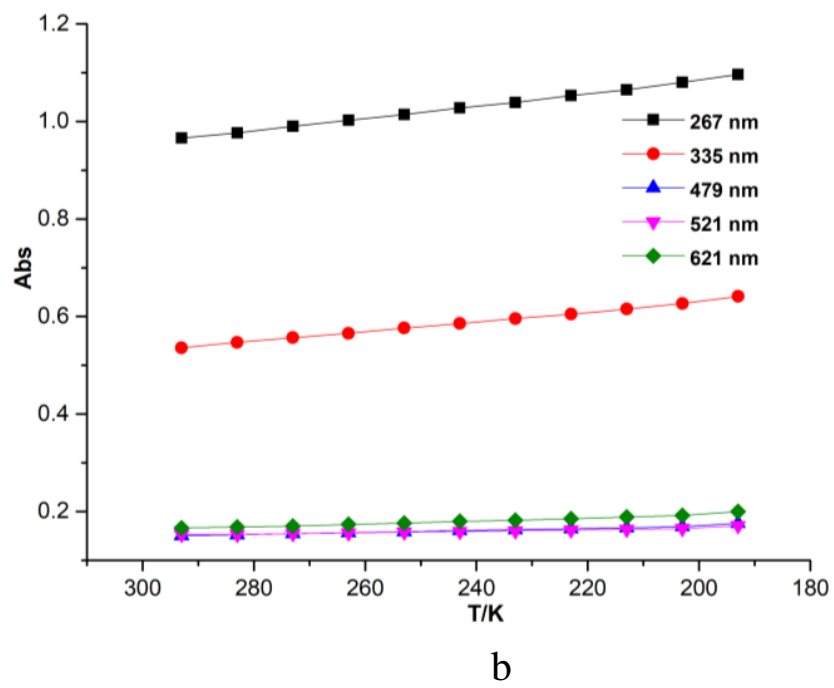

$\mathrm{b}$

Figure 2.16: (a): Variable temperature UV-vis spectra of complex 2 in THF solution in the temperature range of $293 \mathrm{~K}$ to $193 \mathrm{~K}$. (b): Plots of absorption features at different temperature. 


\subsection{Stepwise Synthesis of Dicobalt Dinitrogen Complexes}

In this one-pot reaction of complex $\mathbf{1}$ with $\mathrm{KH}$ and [2.2.2]cryptand to form complex 2, KH not only deprotonates the methylene groups of the side arms, but also leads to the abstraction of chlorine and the reduction of metal centers. Furthermore, four equivalents of [2.2.2]cryptand were employed in this one-pot reaction, which resulted in some impurities in the bulk product (mainly, $\mathrm{K}$ (cryptand)Cl). A multistep synthetic route was developed to afford mechanistic insight into such processes and obtain purer dicobalt dinitrogen product in high yield.

\subsubsection{Deprotonation of the Side Arms of 1 to Form a Dearomatized Complex 3}

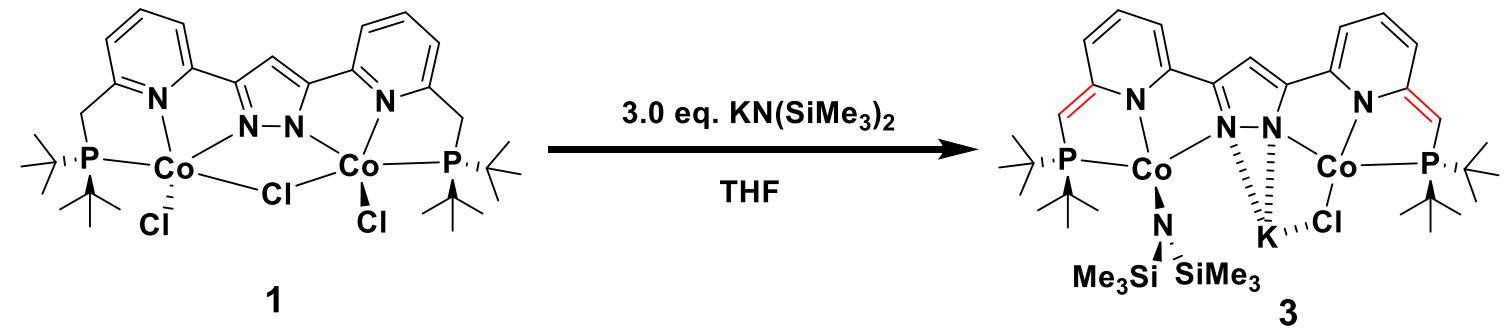

Scheme 2.7: Synthesis of the novel dearomatized complex 3.

In this new synthetic route, complex 1 firstly reacted with three equivalents of $\mathrm{KN}\left(\mathrm{SiMe}_{3}\right)_{2}$ in $\mathrm{THF}$ at room temperature, and the color changed to red immediately indicating the formation of the novel dearomatized complex $\left[\mathrm{L}^{* *}\left(\mathrm{CoN}\left(\mathrm{SiMe}_{3}\right)_{2}\right)(\mathrm{CoCl})\left(\mathrm{K}(\mathrm{THF})_{3}\right)\right] 3$ (Scheme 2.7). Crystals suitable for $\mathrm{X}$-ray diffraction analysis (Figure 2.17) were grown by layering a concentrated THF solution with hexane at $-40{ }^{\circ} \mathrm{C}$. Selected bond lengths and angels are listed in Table 2.4. Complex 3 crystallized in the orthorhombic space group Pbca with eight molecules in the unit cell. The dearomatized structure shows the replacement of chloride ions and the deprotonation of methylene groups of pyridine moieties with concomitant formation of $\mathrm{KCl}$. The $\mathrm{C}-\mathrm{C}$ bond lengths in the side arms are 1.366(3) and 1.381(3) $\AA$ in complex 3. $\operatorname{Co}(1)\left(\tau_{4}=0.71\right)$ is in a distorted tetrahedral geometry and coordinated with one $\mathrm{N}\left(\mathrm{SiMe}_{3}\right)_{2}$ anion above the equatorial plane. $\mathrm{Co}(2)\left(\tau_{4}=0.21\right)$ is in approximately square planar geometry and coordinated with a chloride anion, which is also connected with a potassium cation. There is an interaction between the potassium and the pyrazole of the ligand. The Co …Co separation of $4.54 \AA$ in complex 3 is distinctly longer by $0.24 \AA$ than in complex 2 and the Co-N-N-Co torsion angle is $62.0^{\circ}$. 


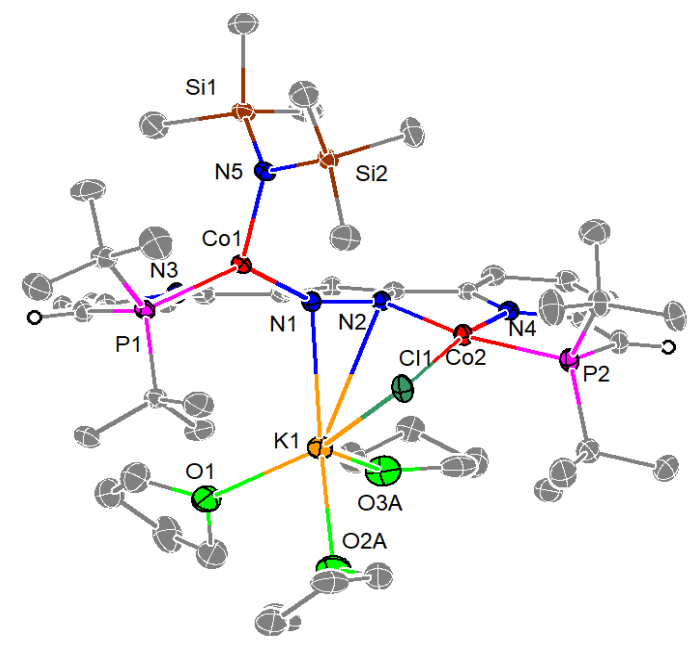

Figure 2.17: Molecular structure of complex 3 (30\% probability thermal ellipsoid). Hydrogen atoms omitted for clarity.

Table 2.4: Selected bond lengths and angles for complex 3 .

\begin{tabular}{llll}
\hline \multicolumn{2}{c}{ Bond lengths / $\AA$} & \multicolumn{2}{c}{ Angles / } \\
\hline $\mathrm{Co}(1)-\mathrm{N}(5)$ & $1.9396(15)$ & $\mathrm{N}(5)-\mathrm{Co}(1)-\mathrm{N}(3)$ & $123.60(6)$ \\
$\mathrm{Co}(1)-\mathrm{N}(3)$ & $2.0080(15)$ & $\mathrm{N}(5)-\mathrm{Co}(1)-\mathrm{N}(1)$ & $108.41(6)$ \\
$\mathrm{Co}(1)-\mathrm{N}(1)$ & $2.0988(15)$ & $\mathrm{N}(3)-\mathrm{Co}(1)-\mathrm{N}(1)$ & $78.14(6)$ \\
$\mathrm{Co}(1)-\mathrm{P}(1)$ & $2.4549(5)$ & $\mathrm{N}(5)-\mathrm{Co}(1)-\mathrm{P}(1)$ & $115.17(5)$ \\
$\mathrm{Co}(2)-\mathrm{N}(4)$ & $1.8863(14)$ & $\mathrm{N}(3)-\mathrm{Co}(1)-\mathrm{P}(1)$ & $80.34(4)$ \\
$\mathrm{Co}(2)-\mathrm{N}(2)$ & $1.9569(14)$ & $\mathrm{N}(1)-\mathrm{Co}(1)-\mathrm{P}(1)$ & $136.33(4)$ \\
$\mathrm{Co}(2)-\mathrm{Cl}(1)$ & $2.2017(5)$ & $\mathrm{N}(4)-\mathrm{Co}(2)-\mathrm{N}(2)$ & $82.48(6)$ \\
$\mathrm{Co}(2)-\mathrm{P}(2)$ & $2.2215(5)$ & $\mathrm{N}(4)-\mathrm{Co}(2)-\mathrm{Cl}(1)$ & $163.15(5)$ \\
$\mathrm{Co} 1 \cdots \mathrm{Co} 2$ & $4.5381(7)$ & $\mathrm{N}(2)-\mathrm{Co}(2)-\mathrm{Cl}(1)$ & $95.06(4)$ \\
& & $\mathrm{N}(4)-\mathrm{Co}(2)-\mathrm{P}(2)$ & $84.81(5)$ \\
& & $\mathrm{N}(2)-\mathrm{Co}(2)-\mathrm{P}(2)$ & $166.85(5)$ \\
& & $\mathrm{Cl}(1)-\mathrm{Co}(2)-\mathrm{P}(2)$ & $98.08(2)$ \\
\hline
\end{tabular}

The ${ }^{1} \mathrm{H}$ NMR spectrum of complex 3 in THF- $\mathrm{d}_{8}$ exhibits a paramagnetic behavior and its resonances could not be assigned (Figure 9.18). A magnetic susceptibility measurement with a SQUID magnetometer (Figure 2.18) shows that the $\chi_{M} T$ product rises to $2.96 \mathrm{~cm}^{3} \mathrm{~mol}^{-1} \mathrm{~K}$ at $295 \mathrm{~K}$, which then reveals that the $\mathrm{Co}(1)$ ion is in high spin configuration with three unpaired electrons $(\mathrm{S}=3 / 2)$ and $\operatorname{Co}(2)$ is in low spin state with one unpaired electron $(S=1 / 2)$. The data were fitted using the Heisenberg-Dirac-van Vleck Hamiltonian $\hat{H}=-2 J \hat{S}_{1} \cdot \hat{S}_{2}+D_{1}\left(\hat{S}_{z, 1}^{2}-1 / 3 \hat{S}_{1}\left(\hat{S}_{1}+1\right)\right)+g_{1} \beta \hat{S}_{1} \cdot \hat{B}+g_{2} \beta \hat{S}_{2} \cdot \hat{B}$. The best fit gives $\mathrm{D}=-65.7, g_{x}=g_{y}=2.51, g_{z}=2.17$ for $\operatorname{Co}(1)$, and $g=2.1$ for $\operatorname{Co}(2)$. The decrease of the 
curve at very low temperature indicates antiferromagnetic coupling $\left(J=-1.04 \mathrm{~cm}^{-1}\right)$.

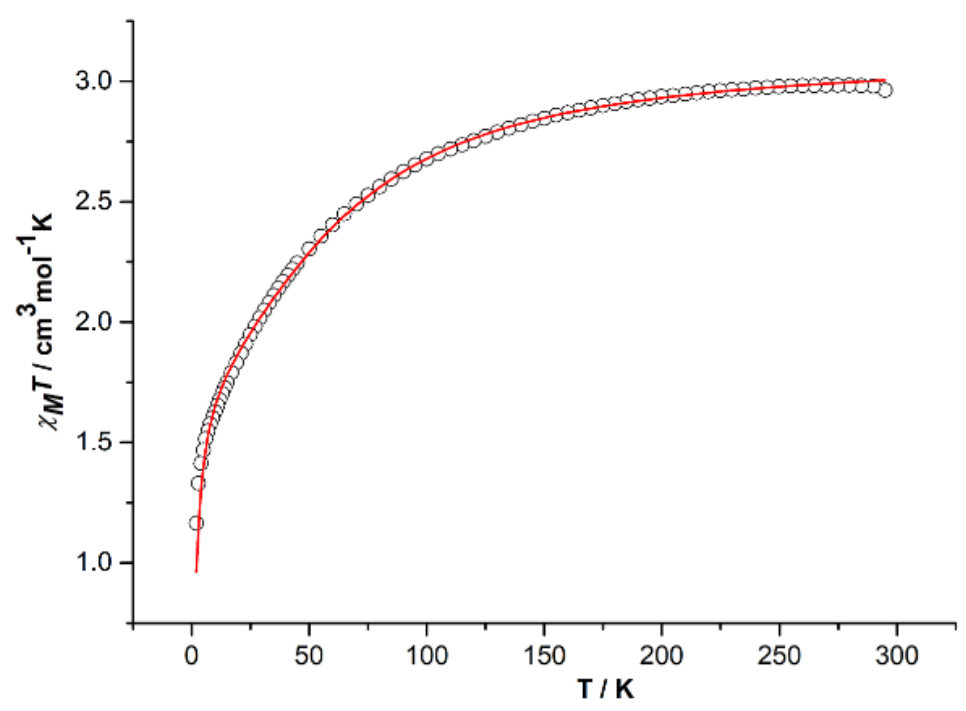

Figure 2.18: $\chi_{\mathrm{M}} T$ vs. $T$ plot in the temperature range of $2-295 \mathrm{~K}$ at $0.5 \mathrm{~T}$ of complex 3 . The red line corresponds to the best fit of the experimental magnetic results. The data were fitted using the Hamiltonian $\hat{H}=-2 J \hat{S}_{1} \cdot \hat{S}_{2}+D_{1}\left(\hat{S}_{z, 1}^{2}-1 / 3 \hat{S}_{1}\left(\hat{S}_{1}+1\right)\right)+g_{1} \beta \hat{S}_{1} \cdot \hat{B}+g_{2} \beta \hat{S}_{2} \cdot \hat{B}$ with $D=-66 \mathrm{~cm}^{-1}, g_{x}=g_{y}=2.51, g_{z}=$ 2.17 for $\operatorname{Co}(1), g=2.1$ for $\operatorname{Co}(2), J=-1.0 \mathrm{~cm}^{-1}$ and $T I P=2600 \cdot 10^{-6} \mathrm{~cm}^{3} \mathrm{~mol}^{-1}$.

\subsubsection{Conversion of 3 to Dicobalt Dinitrogen Complexes}

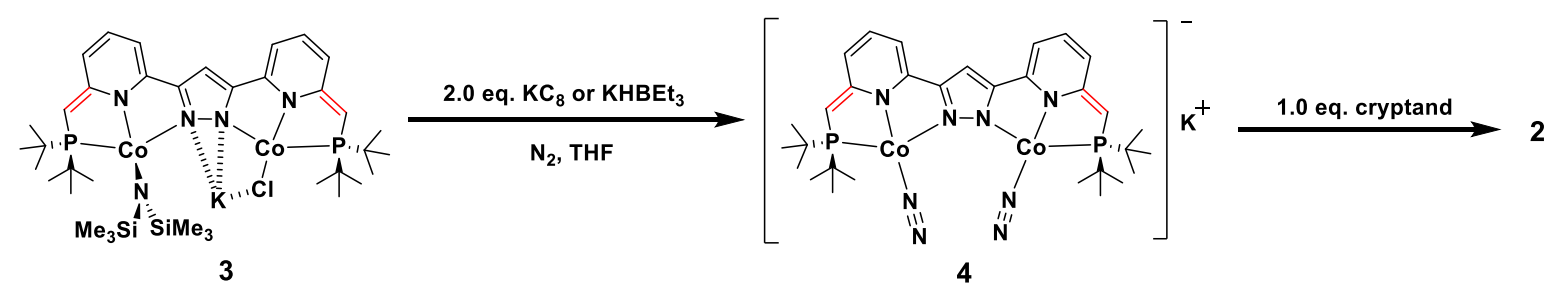

Scheme 2.8: An alternative way to synthesize the dicobalt dinitrogen complexes.

Complex 3 was reduced by $\mathrm{KHBEt}_{3}$ or $\mathrm{KC}_{8}$ (2 equiv.) in $\mathrm{THF}$ solution under a dinitrogen atmosphere and after filtration, hexane was incorporated into the final dark blue solution. Then the solution precipitated at $-40{ }^{\circ} \mathrm{C}$ overnight to generate complex 4. Crystallization of complex 4 failed. But N-N stretching vibrations at 2044 and $2004 \mathrm{~cm}^{-1}$ were observed in the IR spectrum, confirming that complex 4 is a dinitrogen species (Figure 2.19). Furthermore, the two N-N stretching vibrations of complex 4 after isotopical labelling with a ${ }^{15} \mathrm{~N}_{2}$ atmosphere shift to 1979 and $1953 \mathrm{~cm}^{-1}$. Moreover, the reaction of complex 4 and one equivalent of [2.2.2]cryptand was crystallized in $90 \%$ yield and structurally characterized to be complex 2 . This multistep synthetic route provides a more favorable route to complex 2 with less impurities. 


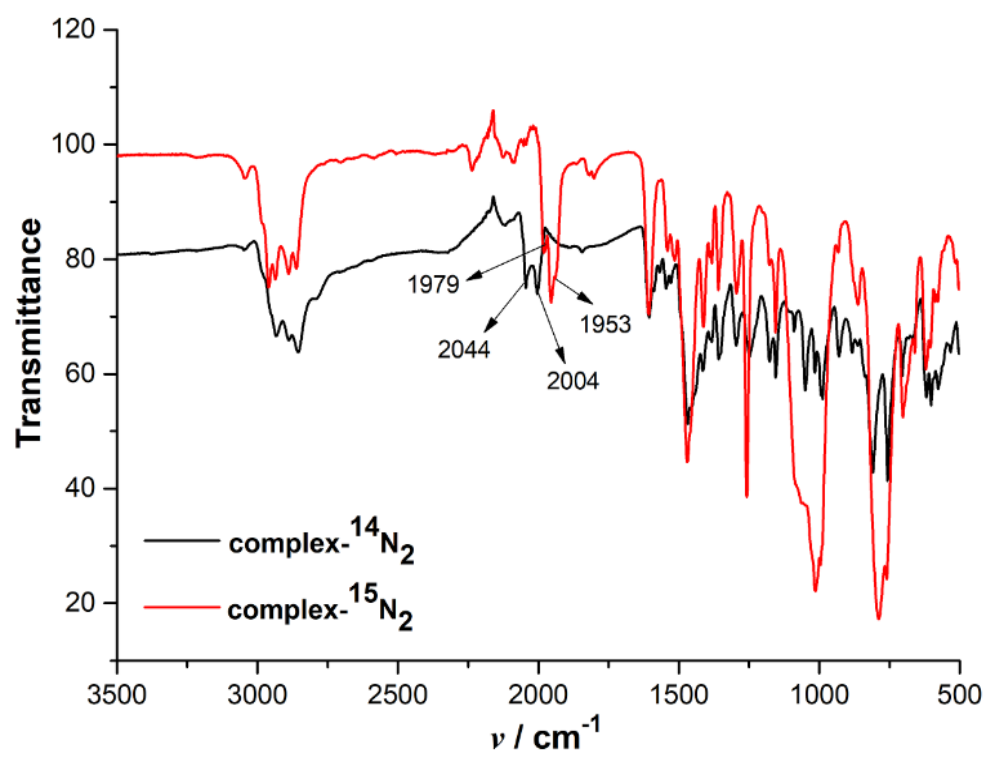

Figure 2.19: IR spectra of complex $4\left({ }^{14} \mathrm{~N}_{2}\right.$ and $\left.{ }^{15} \mathrm{~N}_{2}\right)$ in solid state.

The ${ }^{1} \mathrm{H}-\mathrm{NMR}$ spectrum of complex 4 in THF- $\mathrm{d}_{8}$ (Figure 2.20) is very similar to the spectrum of 2 (except for the missing cryptand signals and the presence of non-deuterated THF that likely serves as a ligand to $\mathrm{K}^{+}$in the isolated material of 4); the spectrum shows that it is a diamagnetic complex that exhibits an apparent $C_{2 v}$ symmetry on the NMR time scale at room temperature. The combined findings confirm that 4 is a $\left[\mathrm{K}(\mathrm{THF})_{\mathrm{x}}\right]^{+}$salt of $\left[\mathrm{L}^{* *}\left(\mathrm{CoN}_{2}\right)_{2}\right]^{-}$; the slight shift in IR bands for the N-N stretches compared to $\mathbf{2}$ suggests some interaction of $\mathrm{K}^{+}$with the anion, but details remain unclear as long as crystallographic insight is lacking. Variable temperature ${ }^{1} \mathrm{H}-\mathrm{NMR}$ spectra of complex 4 in THF- $\mathrm{d}_{8}$ were measured from $298 \mathrm{~K}$ to $183 \mathrm{~K}$ and show no obvious differences of the resonances except a small shift of the resonance corresponding to the $\mathrm{H}$-atom of the pyrazole (Figure 2.21). The ${ }^{31} \mathrm{P}-\mathrm{NMR}$ spectrum (Figure 2.22) reveals a peak at $81.42 \mathrm{ppm}$, which is approximately the same as that observed for complex 2. The ${ }^{15} \mathrm{~N}-\mathrm{NMR}$ spectrum of complex $4-{ }^{15} \mathrm{~N}_{2}$ (Figure 2.23) exhibits two signals at $-28.92 \mathrm{ppm}$ and $-57.87 \mathrm{ppm}$ assigned to $\mathrm{N}_{\beta}$ and $\mathrm{N}_{\alpha}$ of the coordinated dinitrogen molecules respectively. 


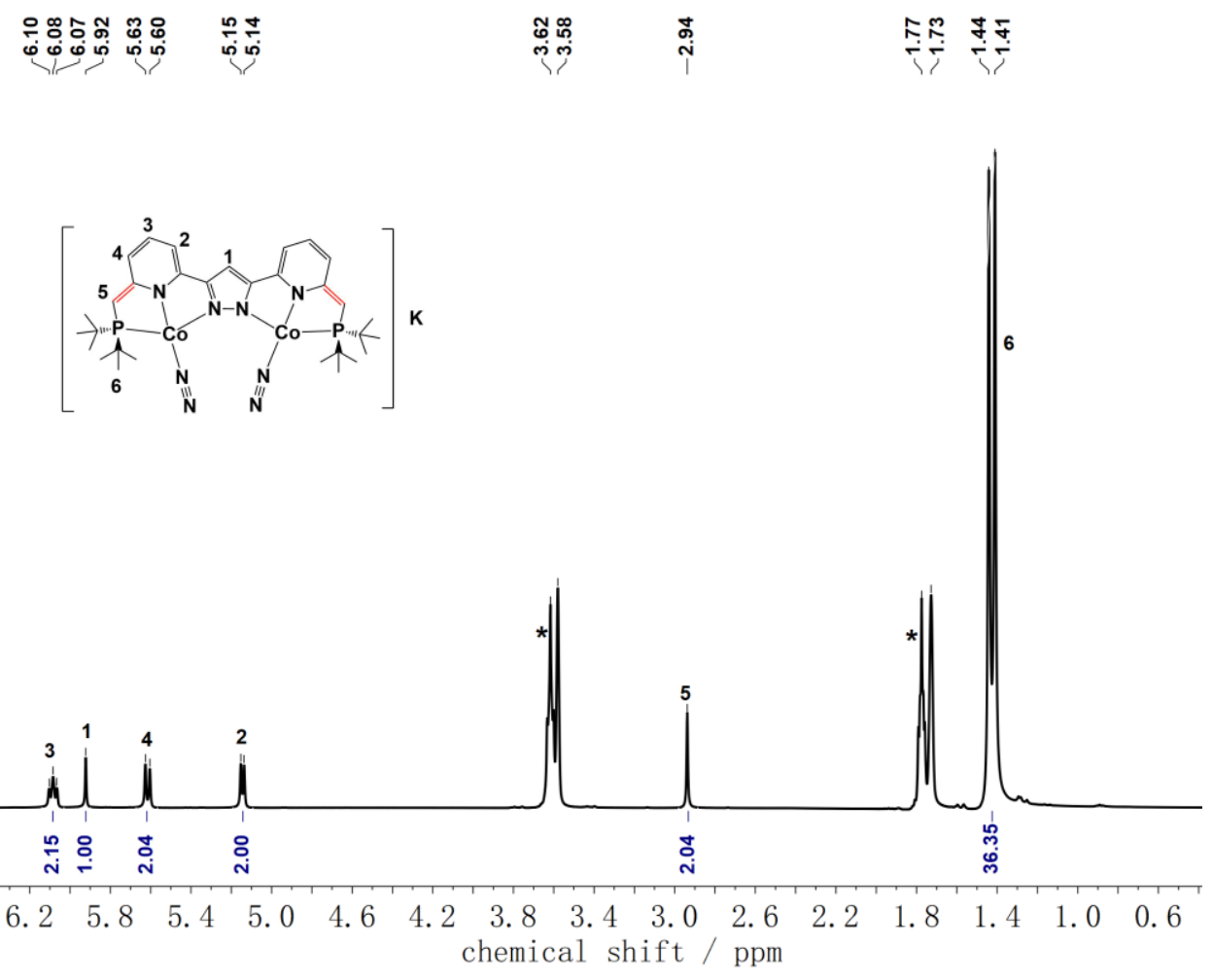

Figure 2.20: ${ }^{1} \mathrm{H}-\mathrm{NMR}$ spectrum of complex 4 in THF-d8. Solvent signals are marked with an asterisk $(*)$.

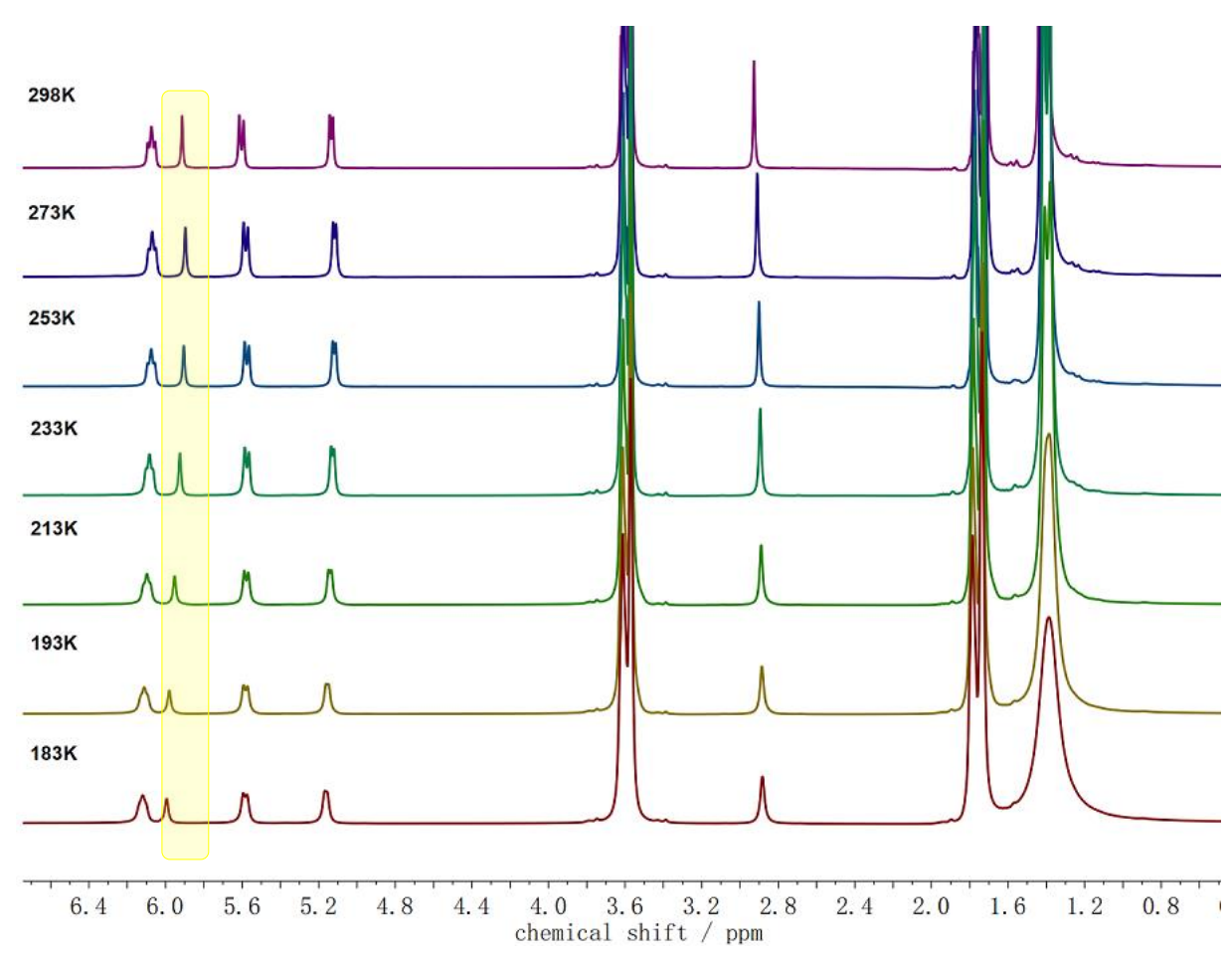

Figure 2.21: Variable temperature ${ }^{1} \mathrm{H}-\mathrm{NMR}$ spectra of complex 4 in $\mathrm{THF}-\mathrm{d}_{8}$, highlighting the resonance attributed to $\mathrm{H}$-atom of the pyrazole. 
$\underset{\substack{1 \\ \text { \& }}}{\mathfrak{2}}$

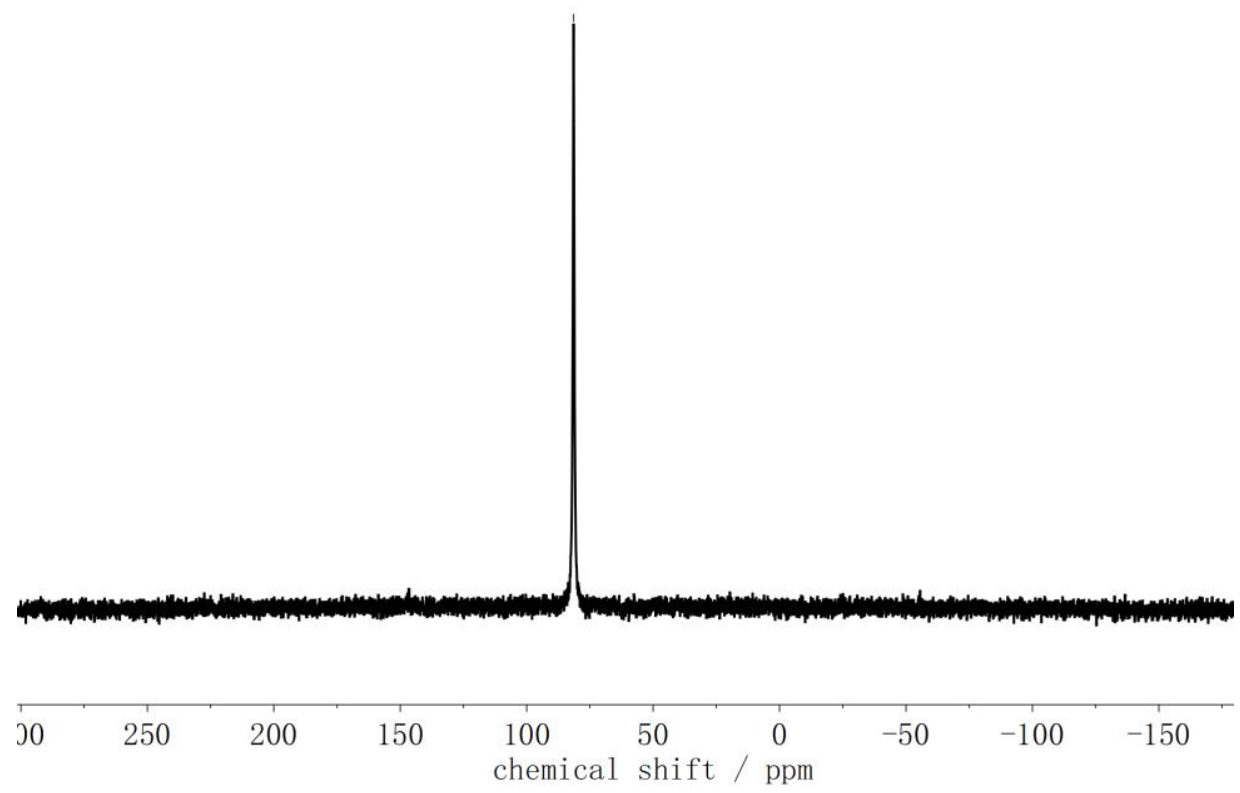

Figure 2.22: ${ }^{31} \mathrm{P}-\mathrm{NMR}$ spectrum of 4 in $\mathrm{THF}-\mathrm{d}_{8}$.

$$
\stackrel{\substack{\infty \\ i}}{\stackrel{\infty}{\infty}}
$$

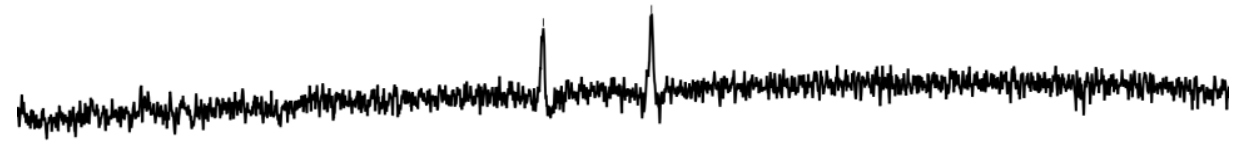

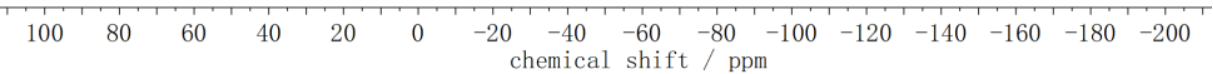

Figure 2.23: ${ }^{15} \mathrm{~N}-\mathrm{NMR}$ spectrum of complex $4-{ }^{15} \mathrm{~N}_{2}$ in THF- $\mathrm{d}_{8}$.

UV-vis spectra in THF were also collected to investigate the dynamic properties of the complex 4 
and it shows the bands at 337, $482 \mathrm{~nm}, 520 \mathrm{~nm}$ and $614 \mathrm{~nm}$ which may be attributed to MLCT transitions (Figure 2.24). The UV-vis spectra of complex $\mathbf{4}$ are a bit blue-shifted compared with those of complex 2. Overall the spectral data for complex $\mathbf{2}$ and $\mathbf{4}$ are very similar, suggesting that interaction of $\mathrm{K}^{+}$with the $\left[\mathrm{L}^{* * *} \mathrm{Co}_{2}\left(\mathrm{~N}_{2}\right)_{2}\right]$ is weak in THF.

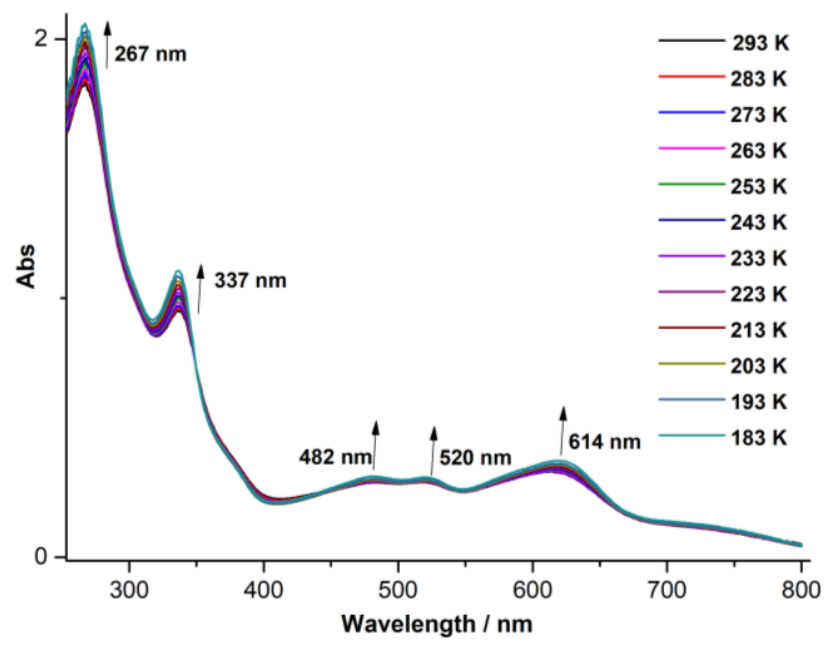

a

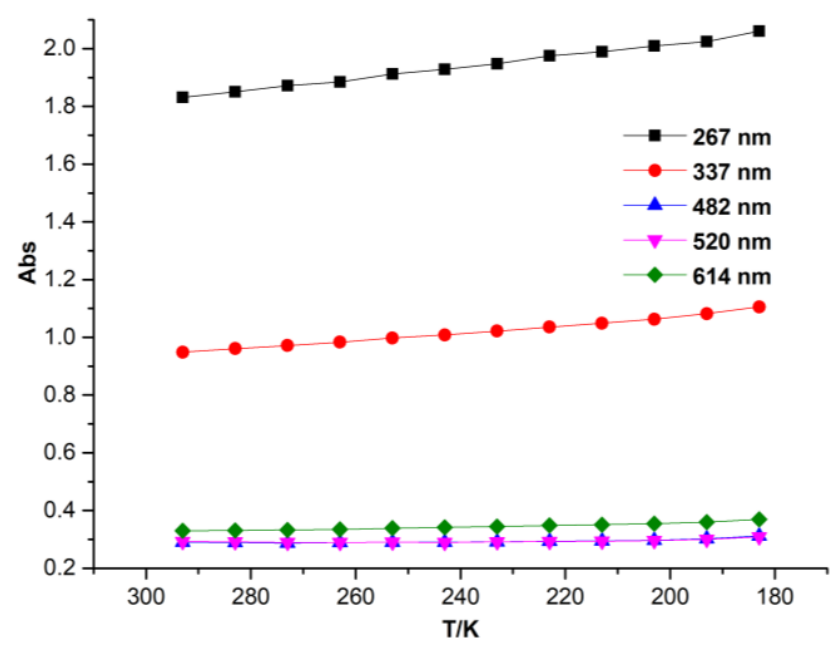

b

Figure 2.24: (a) Variable temperature UV-vis spectra of complex 4 in THF solution in the temperature range of $293 \mathrm{~K}$ to $183 \mathrm{~K}$. (b) Plots of absorption features at different temperature.

\subsubsection{Synthesis of Dicobalt Dinitrogen Complex with Sodium Cation}

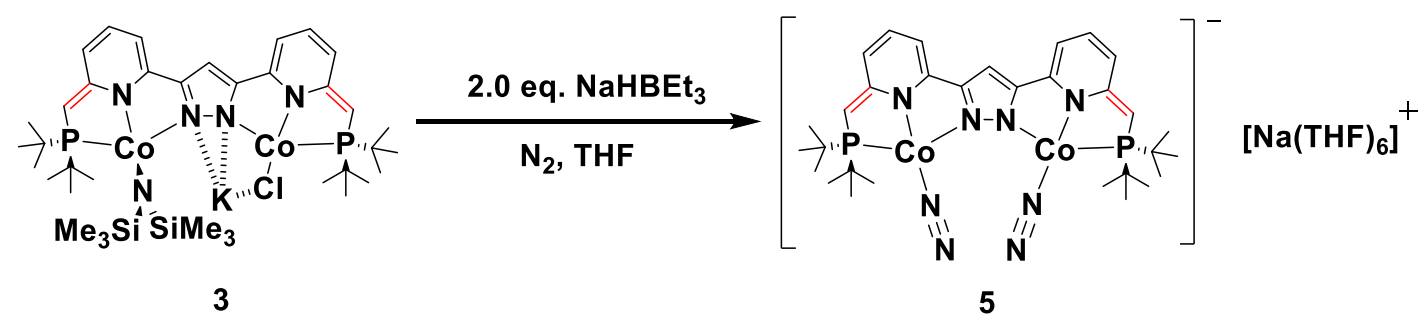

Scheme 2.9: The synthesis of dicobalt dinitrogen complex with sodium cation.

With the goal of synthesizing cobalt hydride complexes or crystallizing a dinitrogen complex suitable for X-ray analysis as well as exploring the possible interaction between the metal cation and the coordinated dinitrogen molecules, reduction of complex 3 by the less reactive sodium hydride reagent $\mathrm{NaHBEt}_{3}$ was performed (Scheme 2.9). Afterwards, blue block crystals of complex 5 were obtained. Unfortunately, the crystallographic data were of poor quality (Figure 2.25). In IR spectrum of complex 5 (Figure 2.26), the N-N stretching vibrations were observed at 2037, 2028 and 2014 $\mathrm{cm}^{-1}$. A peak at $1845 \mathrm{~cm}^{-1}$ was observed and it may belong to a Co-H stretching frequency, suggesting the existence of small amount of cobalt hydride species. The peaks displaying N-N stretching vibrations indicate that there are also some dinitrogen intermediate species due to the lower reactivity of sodium hydride reagent. 


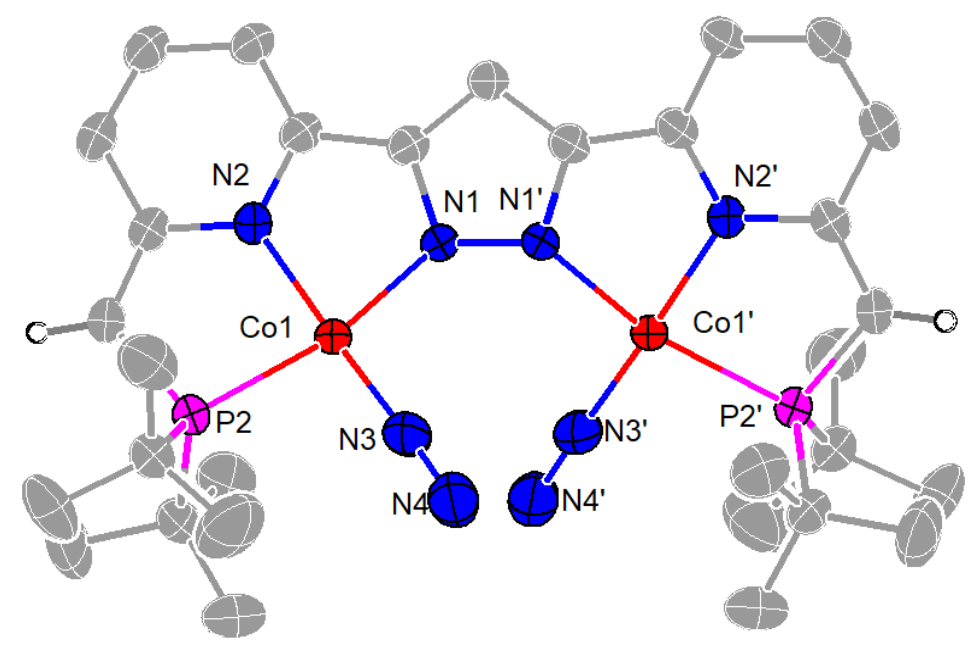

Figure 2.25: The molecular structure of the anionic complex 5. Thermal displacement ellipsoids shown at $30 \%$ probability; most hydrogen atoms, the cation $\left[\mathrm{Na}(\mathrm{THF})_{6}\right]^{+}$and solvent molecules omitted for clarity.

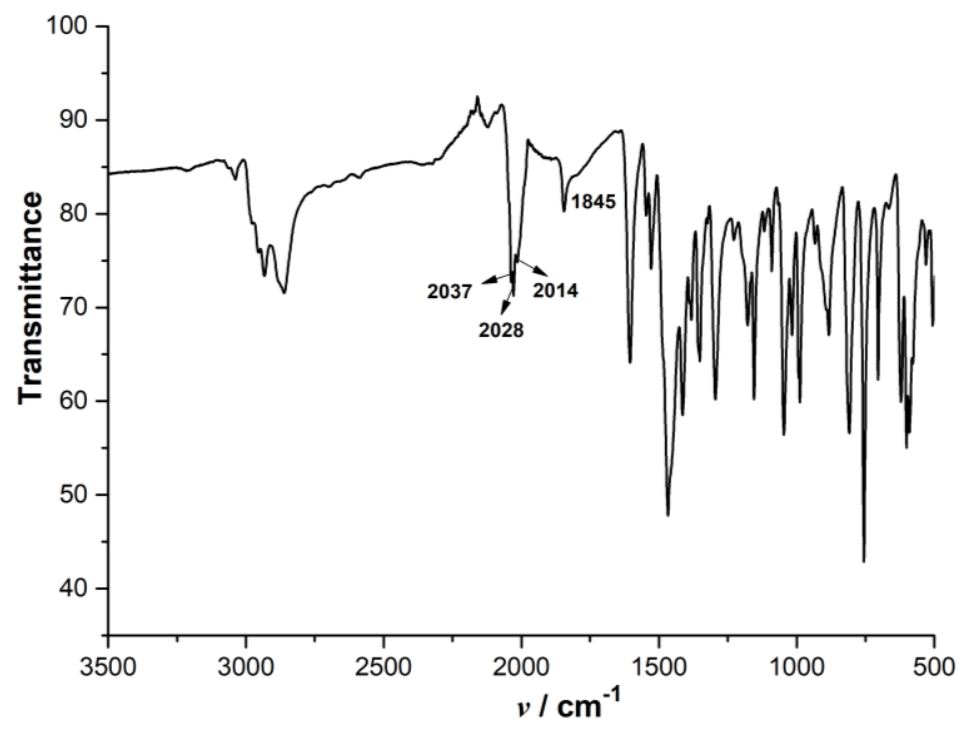

Figure 2.26: IR spectrum of complex 5 in solid state.

\subsection{Tetracobalt Dinitrogen Complex Formation via Protonation of 2 or 4}




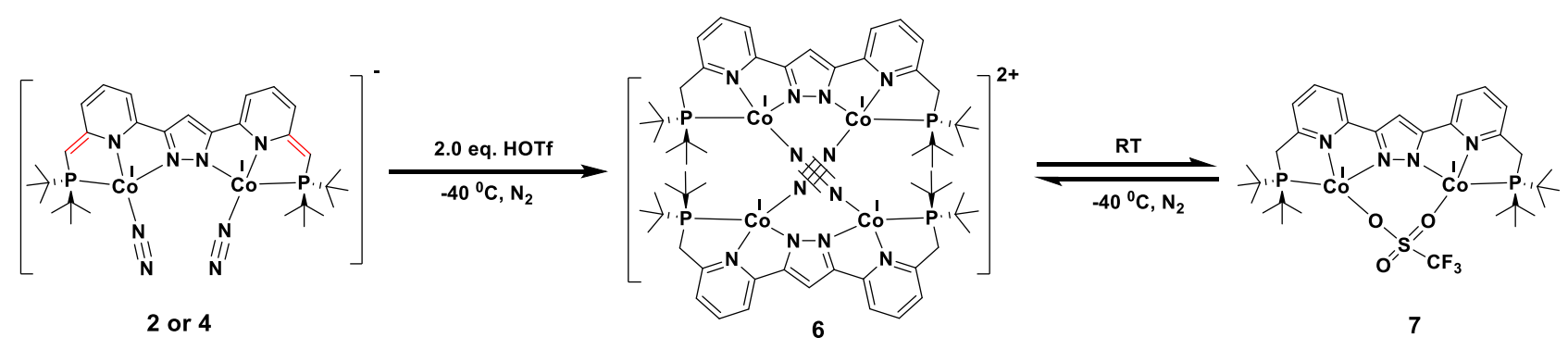

Scheme 2.10: Synthetic Route of complexes 6 and 7.

As $\mathrm{N}_{2}$ reduction is commonly assumed to proceed through coupled $\mathrm{H}^{+} / \mathrm{e}^{-}$transfer pathways, protonation of complex $\mathbf{2}$ or $\mathbf{4}$ was carried out individually to isolate possible intermediates during the $\mathrm{N}_{2}$ reduction process of this system. The protonation of complex $\mathbf{2}$ or $\mathbf{4}$ in THF (Scheme 2.10) with two equivalents of triflic acid (HOTf) under dinitrogen atmosphere at $-40{ }^{\circ} \mathrm{C}$ resulted in an immediate color change from dark blue to red brown. Block-shaped crystals suitable for X-ray diffraction analysis were grown in the concentrated red brown THF solution at $-40{ }^{\circ} \mathrm{C}$ and showed the formation of a tetracobalt dinitrogen-bridged complex $\left[\left(\mathrm{L}_{2} \mathrm{Co}_{4}\left(\mu-\mathrm{N}_{2}\right)_{2}\right)(\mathrm{OTf})_{2}\right] 6$.

The molecular structure of $\mathbf{6}$ is shown in Figure 2.27 and selected bond lengths and angles are listed in Table 2.5. Complex 6 crystallized in the triclinic space group $P-1$ with two molecules in the unit cell. The cobalt centers are coordinated in a distorted square-planar fashion with $\operatorname{Co}(1)-\operatorname{Co}(2)$ distance $4.35 \AA$ and $\mathrm{Co}(3)-\mathrm{Co}(4)$ distance $4.44 \AA$, which are longer by 0.05 and $0.14 \AA$ than in complex 2 (Table 2.6). Complex 6 features two $\left\{\mathrm{LCo}_{2}\right\}$ subunits, and metric parameters of the aromatic pyridine rings as well as the lengths of the exocyclic $\mathrm{C}-\mathrm{C}$ bonds $(1.490(8)-1.511(7) \AA)$ confirm that protonation has occurred at the ligand side arms. The ligand scaffold appears to be quite flexible and the backbones are twisted to minimize the deviation of the square plane leading to Co-N-N-Co torsion angles of $68.2^{\circ}$ and $70.0^{\circ}$. In the dicationic complex $\mathbf{6}$, two fragments are bound together by two bridging end-on dinitrogen ligands. Possibly, the $\mathrm{N}_{2}$ molecule is firstly coordinated with one Co center and then the terminal $\mathrm{N}$ shows nucleophilicity because of the donation of electron density from the Co center into the $\pi^{*}$-orbitals of dinitrogen, ultimately leading to the formation of the tetracobalt dinitrogen-bridged complex 6 . The N-N bond lengths (1.140(5) and 1.142(6) $\AA$ ) are in the range of typical Co- $\mu-\mathrm{N}_{2}-\mathrm{Co}$ species and quite similar to the $\mathrm{N}-\mathrm{N}$ bond lengths in dinitrogen-bridged complexes (Figure 2.5a and 2.5j), ${ }^{27}$ which are slightly longer than those in complex 2. Surprisingly, the Co-N $\left(\mathrm{N}_{2}\right)$ distances of complex 6 are in the range of 1.764(4)-1.783(4) $\AA$, which are also longer than those in complex 2 , reflecting diminished $\pi$-backdonation for the individual $\mathrm{Co} \rightarrow \mathrm{N}_{2}$ interactions and likely weakened Co- $\mathrm{N}_{2}$ bonding; the latter is evidenced in solution by facile temperature-dependent replacement of the $\mathrm{N}_{2}$ ligands by triflate (see below). Further, N-N $\left(\mathrm{N}_{2}\right)$ bond elongation in complex 6 may be related to two Co centers in the Co- $\mu-\mathrm{N}_{2}-\mathrm{Co}$ part, which may influence synergistically the $\mathrm{N}_{2}$ of the Co- $\mu-\mathrm{N}_{2}-\mathrm{Co}$ species. 

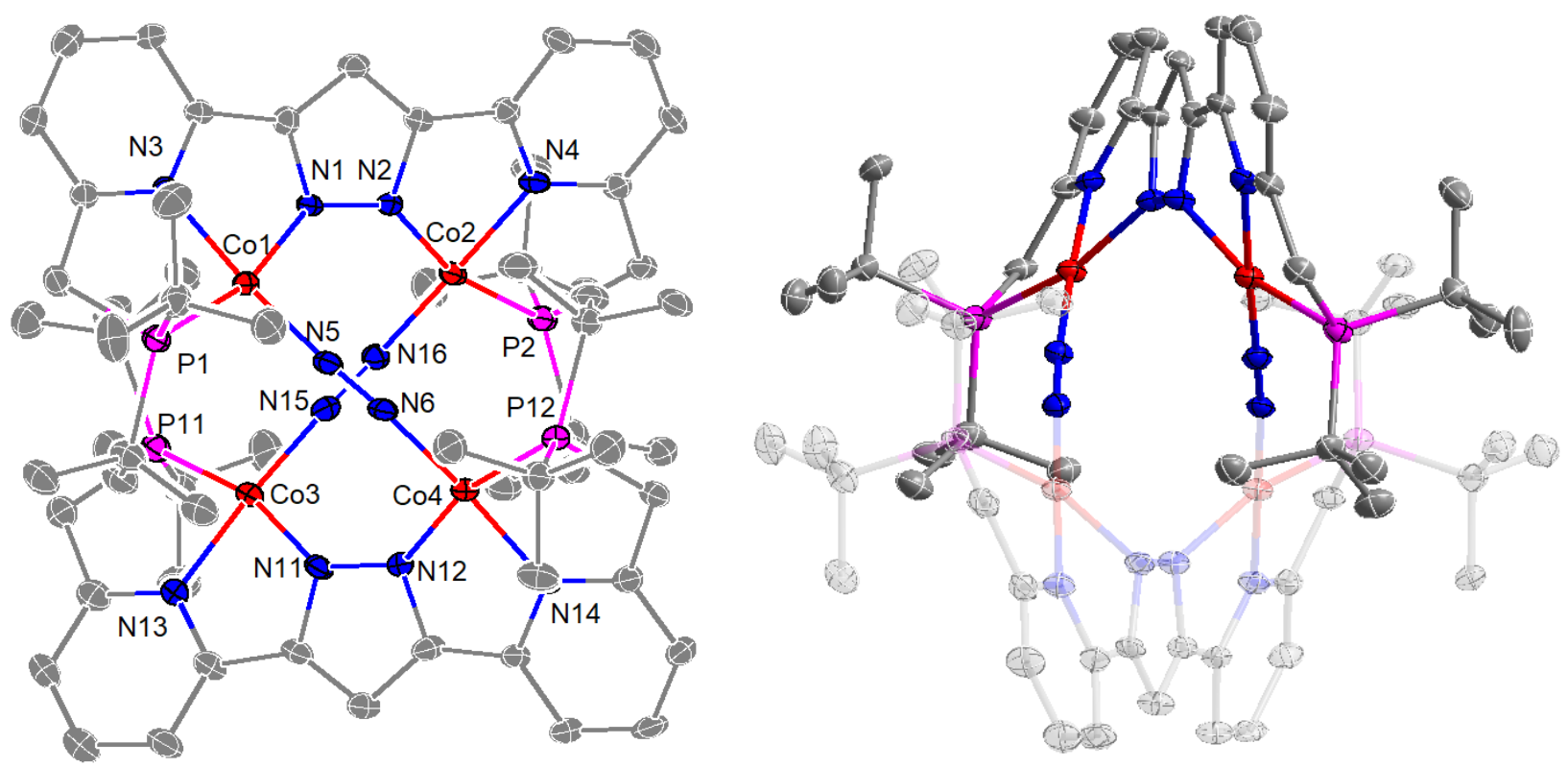

Figure 2.27: The views in different directions of the molecular structure of the cationic complex 6 . Thermal displacement ellipsoids shown at $30 \%$ probability; hydrogen atoms, two anions (OTf) ${ }^{-}$and solvent molecules omitted for clarity.

Table 2.5: Selected bond lengths and angles for complex 6 .

\begin{tabular}{llll}
\hline \multicolumn{2}{c}{ Bond lengths / $\AA$} & \multicolumn{2}{c}{ Angles $/{ }^{\circ}$} \\
\hline $\mathrm{Co}(1)-\mathrm{N}(5)$ & $1.770(5)$ & $\mathrm{N}(5)-\mathrm{Co}(1)-\mathrm{N}(3)$ & $174.38(18)$ \\
$\mathrm{Co}(1)-\mathrm{N}(3)$ & $1.906(4)$ & $\mathrm{N}(5)-\mathrm{Co}(1)-\mathrm{N}(1)$ & $94.83(18)$ \\
$\mathrm{Co}(1)-\mathrm{N}(1)$ & $1.928(4)$ & $\mathrm{N}(3)-\mathrm{Co}(1)-\mathrm{N}(1)$ & $81.65(18)$ \\
$\mathrm{Co}(1)-\mathrm{P}(1)$ & $2.1810(15)$ & $\mathrm{N}(5)-\mathrm{Co}(1)-\mathrm{P}(1)$ & $99.62(14)$ \\
$\mathrm{Co}(2)-\mathrm{N}(16)$ & $1.764(4)$ & $\mathrm{N}(3)-\mathrm{Co}(1)-\mathrm{P}(1)$ & $83.39(14)$ \\
$\mathrm{Co}(2)-\mathrm{N}(4)$ & $1.914(4)$ & $\mathrm{N}(1)-\mathrm{Co}(1)-\mathrm{P}(1)$ & $163.97(13)$ \\
$\mathrm{Co}(2)-\mathrm{N}(2)$ & $1.944(4)$ & $\mathrm{N}(16)-\mathrm{Co}(2)-\mathrm{N}(4)$ & $177.42(18)$ \\
$\mathrm{Co}(2)-\mathrm{P}(2)$ & $2.1810(15)$ & $\mathrm{N}(16)-\mathrm{Co}(2)-\mathrm{N}(2)$ & $96.09(18)$ \\
$\mathrm{Co}(3)-\mathrm{N}(15)$ & $1.778(5)$ & $\mathrm{N}(4)-\mathrm{Co}(2)-\mathrm{N}(2)$ & $81.54(17)$ \\
$\mathrm{Co}(3)-\mathrm{N}(13)$ & $1.905(4)$ & $\mathrm{N}(16)-\mathrm{Co}(2)-\mathrm{P}(2)$ & $98.75(13)$ \\
$\mathrm{Co}(3)-\mathrm{N}(11)$ & $1.965(4)$ & $\mathrm{N}(4)-\mathrm{Co}(2)-\mathrm{P}(2)$ & $83.71(13)$ \\
$\mathrm{Co}(3)-\mathrm{P}(11)$ & $2.1909(16)$ & $\mathrm{N}(2)-\mathrm{Co}(2)-\mathrm{P}(2)$ & $164.37(13)$ \\
$\mathrm{Co}(4)-\mathrm{N}(6)$ & $1.783(4)$ & $\mathrm{N}(15)-\mathrm{Co}(3)-\mathrm{N}(13)$ & $176.33(19)$ \\
$\mathrm{Co}(4)-\mathrm{N}(14)$ & $1.899(4)$ & $\mathrm{N}(15)-\mathrm{Co}(3)-\mathrm{N}(11)$ & $94.98(18)$ \\
$\mathrm{Co}(4)-\mathrm{N}(12)$ & $1.959(4)$ & $\mathrm{N}(13)-\mathrm{Co}(3)-\mathrm{N}(11)$ & $81.67(18)$ \\
$\mathrm{N}(5)-\mathrm{N}(6)$ & $1.140(5)$ & $\mathrm{N}(15)-\mathrm{Co}(3)-\mathrm{P}(11)$ & $99.77(14)$ \\
$\mathrm{N}(15)-\mathrm{N}(16)$ & $1.142(6)$ & $\mathrm{N}(13)-\mathrm{Co}(3)-\mathrm{P}(11)$ & $83.44(14)$ \\
$\mathrm{Co} 1 \cdots \mathrm{Co} 2$ & $4.3481(11)$ & $\mathrm{N}(11)-\mathrm{Co}(3)-\mathrm{P}(11)$ & $164.44(13)$ \\
$\mathrm{Co} 3 \cdots \mathrm{Co} 4$ & $4.4417(12)$ & $\mathrm{N}(6)-\mathrm{Co}(4)-\mathrm{N}(14)$ & $175.89(19)$ \\
& & $\mathrm{N}(6)-\mathrm{Co}(4)-\mathrm{N}(12)$ & $94.48(18)$ \\
\hline & & &
\end{tabular}




$\begin{array}{ll}\mathrm{N}(14)-\mathrm{Co}(4)-\mathrm{N}(12) & 82.09(17) \\ \mathrm{N}(6)-\mathrm{Co}(4)-\mathrm{P}(12) & 99.73(14) \\ \mathrm{N}(14)-\mathrm{Co}(4)-\mathrm{P}(12) & 83.51(13) \\ \mathrm{N}(12)-\mathrm{Co}(4)-\mathrm{P}(12) & 164.91(13)\end{array}$

Table 2.6: Selected interatomic distance and angles of complexes 2 and $\mathbf{6}$.

\begin{tabular}{ccc}
\hline & 2 & 6 \\
\hline $\mathrm{Co} . . . \mathrm{Co}(\AA)$ & 4.30 & $4.35,4.41,4.44,4.68,4.69$ \\
$\mathrm{~N}-\mathrm{N}(\AA)$ & $1.124(3) / 1.125(3)$ & $1.140(5) / 1.142(6)$ \\
$\mathrm{Co}-\mathrm{N}\left(\mathrm{N}_{2}\right)(\AA)$ & $1.742(2) / 1.742(2)$ & $1.764(4)-1.783(4)$ \\
& & \\
$\mathrm{Co}-\mathrm{N}-\mathrm{N}\left(\mathrm{N}_{2}\right)\left(^{\circ}\right)$ & $173.8(2) / 174.7(2)$ & $174.4(4)-176.9(4)$ \\
\hline
\end{tabular}

Variable temperature ${ }^{1} \mathrm{H}-\mathrm{NMR}$ spectra of complex 6 were measured in THF- $\mathrm{d}_{8}$ under a $\mathrm{N}_{2}$ atmosphere and show very broad features at $293 \mathrm{~K}$ (Figure 2.28), likely because of some paramagnetic impurities and a fast equilibrium arising from reversible displacement of $\mathrm{N}_{2}$ by solvent THF molecules and triflate anions. At $238 \mathrm{~K}$, the ${ }^{1} \mathrm{H}-\mathrm{NMR}$ spectrum of complex 6 in THF- $\mathrm{d}_{8}$ reveals a resonance pattern consistent with a diamagnetic species (Figure 2.29). The proton signals of the pyridine moieties in complex $\mathbf{6}$ are shifted downfield in comparison to the dearomatized species $\mathbf{2}$, suggesting a lower electron density of the complex after the protonation of the side arms and the aromatization of the pyridine moieties. At the lower temperature of $238 \mathrm{~K}$, slow dynamics for the hydrogen atoms in $\mathrm{CH}_{2}$ and $t \mathrm{Bu}$ groups leads to two inequivalent steric and electronic environments above and below the pyrazolate plane. Two doublets at $\delta=1.68$ and $1.25 \mathrm{ppm}$ can be assigned to $\mathrm{H}$-atoms of the $t \mathrm{Bu}$ groups, resulting from a coupling to the phosphorus nuclei. Only one doublet of doublets associated with the $\mathrm{CH}_{2}$ groups in the side arms was observed at $3.82 \mathrm{ppm}$ and the other one overlapped with the THF solvent signal at $3.58 \mathrm{ppm}$, based on the ${ }^{1} \mathrm{H}-{ }^{1} \mathrm{H}$ NOESY spectrum (Figure 9.32), resulting from the $\mathrm{H}-\mathrm{H}$ coupling and the coupling to the phosphorus nuclei. In order to elucidate the identity of complex 6 in solution, ${ }^{1} \mathrm{H}$-DOSY NMR spectra of complex $\mathbf{6}$ in THF-d $\mathrm{d}_{8}$ were collected at $238 \mathrm{~K}$ by using the residual protons of the solvent as an internal standard (Figure 2.30). ${ }^{28}$ It reveals that the diffusion coefficient of complex 6 at $238 \mathrm{~K}$ is $1.293 \times 10^{-10} \mathrm{~m}^{2} \mathrm{~s}^{-1}$ (Table 2.7). The hydrodynamic radius of complex 6, derived from the Stokes-Einstein equation (1), ${ }^{29}$ is determined to be $13.81 \AA$. On the assumption that all molecules in these complexes are spherical, according to equation (2), it suggests that $\mathbf{6}$ is a dimeric tetracobalt dinitrogen-bridged species by comparison with the diffusion coefficient of the HL ligand. 


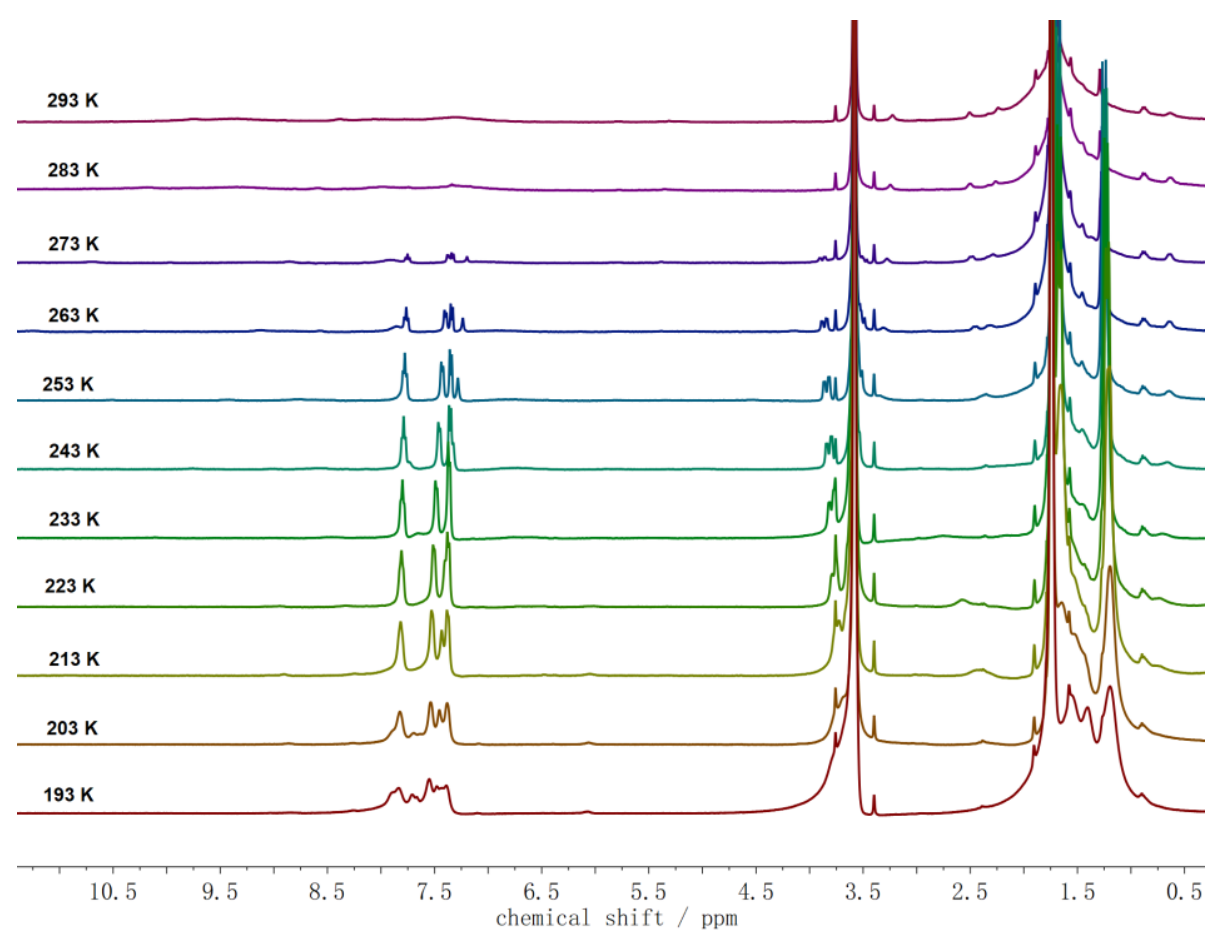

Figure 2.28: Variable temperature ${ }^{1} \mathrm{H}-\mathrm{NMR}$ spectra of complex 6 in $\mathrm{THF}-\mathrm{d}_{8}$ under $\mathrm{N}_{2}$ atmosphere.

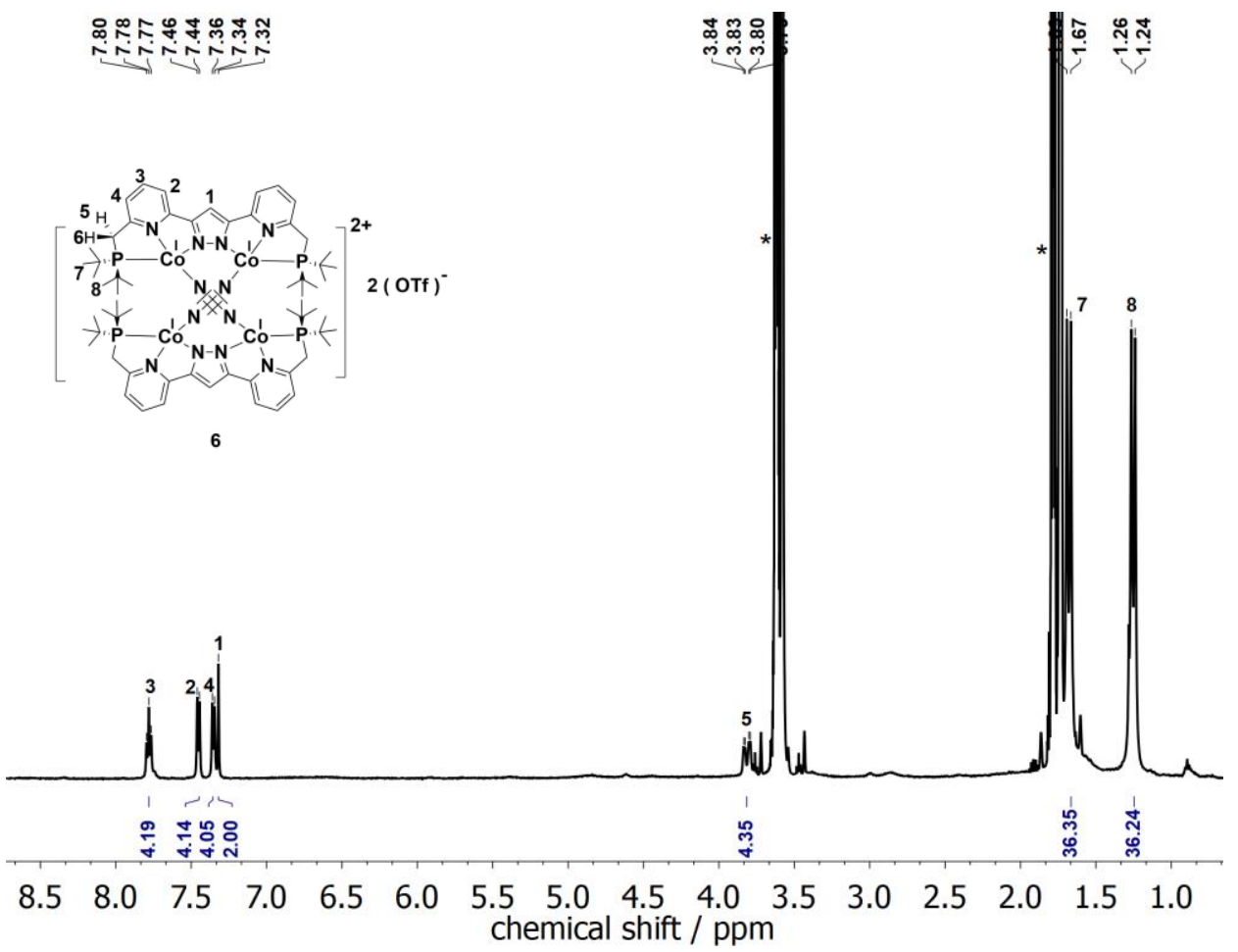

Figure 2.29: ${ }^{1} \mathrm{H}-\mathrm{NMR}$ spectrum of complex 6 in THF- $\mathrm{d}_{8}$ under $\mathrm{N}_{2}$ atmosphere at $238 \mathrm{~K}$. Solvent signals are marked with an asterisk $(*)$. 


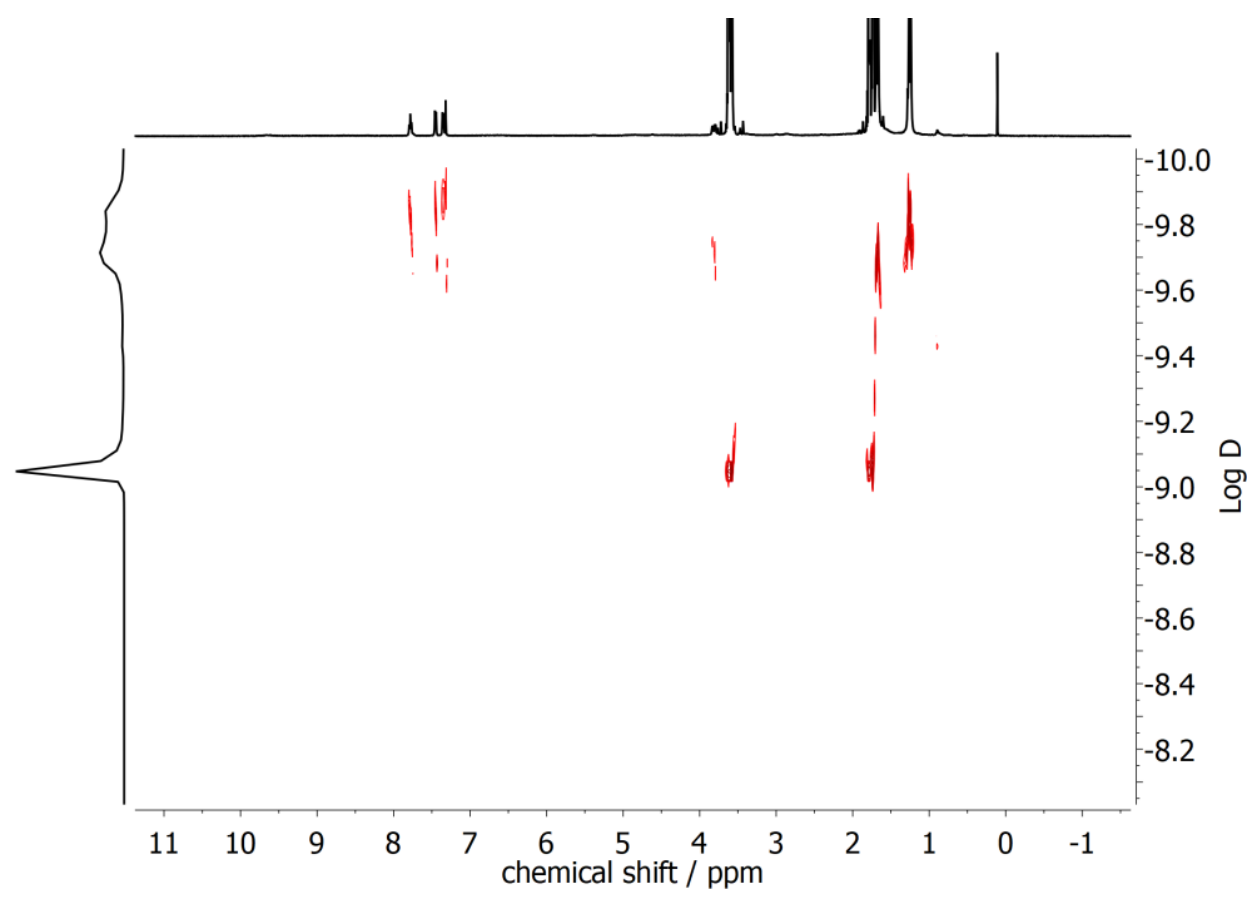

Figure 2.30: DOSY spectrum of complex 6 in THF-d $\mathrm{d}_{8}$ under $\mathrm{N}_{2}$ atmosphere at $238 \mathrm{~K}$.

Table 2.7: Diffusion constants and hydrodynamic radii for complexes 6 and 7 in THF solution at $238 \mathrm{~K}$.

\begin{tabular}{ccccc}
\hline Compound & $\begin{array}{c}\text { Diffusion Constant } \\
{\left[\mathrm{m}^{2} \mathrm{~s}^{-1}\right]}\end{array}$ & $\begin{array}{c}\text { Hydrodynamic Radius } \\
{[\AA]}\end{array}$ & $\begin{array}{c}\text { Ratio } \\
\mathrm{V}_{\text {complex }} / \mathrm{V}_{\mathrm{HL}}\end{array}$ & \\
\hline HL & $2.306 \times 10^{-10}$ & 7.74 & & \\
Complex 6 & $1.293 \times 10^{-10}$ & 13.81 & 5.68 & dimer \\
Complex 7 & $2.507 \times 10^{-10}$ & 7.12 & 0.778 & monomer \\
\hline
\end{tabular}

$$
D=\frac{k_{B} T}{6 \pi \eta r}
$$

$\mathrm{D}$ is the diffusion constant; $\mathrm{k}_{\mathrm{B}}$ is Boltzmann's constant;

$\mathrm{T}$ is the absolute temperature; $\eta$ is the dynamic viscosity; $\mathrm{r}$ is the radius of the spherical particle.

$$
\frac{v_{1}}{v_{2}}=\left(\frac{r_{1}}{r_{2}}\right)^{3}
$$

Variable temperature ${ }^{31} \mathrm{P}-\mathrm{NMR}$ spectra of complex 6 from $253 \mathrm{~K}$ to $213 \mathrm{~K}$ show a slight change of the chemical shift from 99.43 ppm to $99.77 \mathrm{ppm}$, which is a downfield shift compared with complex 2 (Figure 2.31). Variable temperature ${ }^{19} \mathrm{~F}-\mathrm{NMR}$ spectra reveal that the fluorine signal shifts upfield from $-75.44 \mathrm{ppm}$ at room temperature to $-78.82 \mathrm{ppm}$ at $213 \mathrm{~K}$ (Figure 2.32), which indicates that 
triflate anion is coordinated weakly with the metal centers at room temperature and is gradually dissociated with decreasing temperature. Therefore, low temperatures likely contribute to the dissociation of the triflate anion and the coordination of $\mathrm{N}_{2}$ with the metal centers.

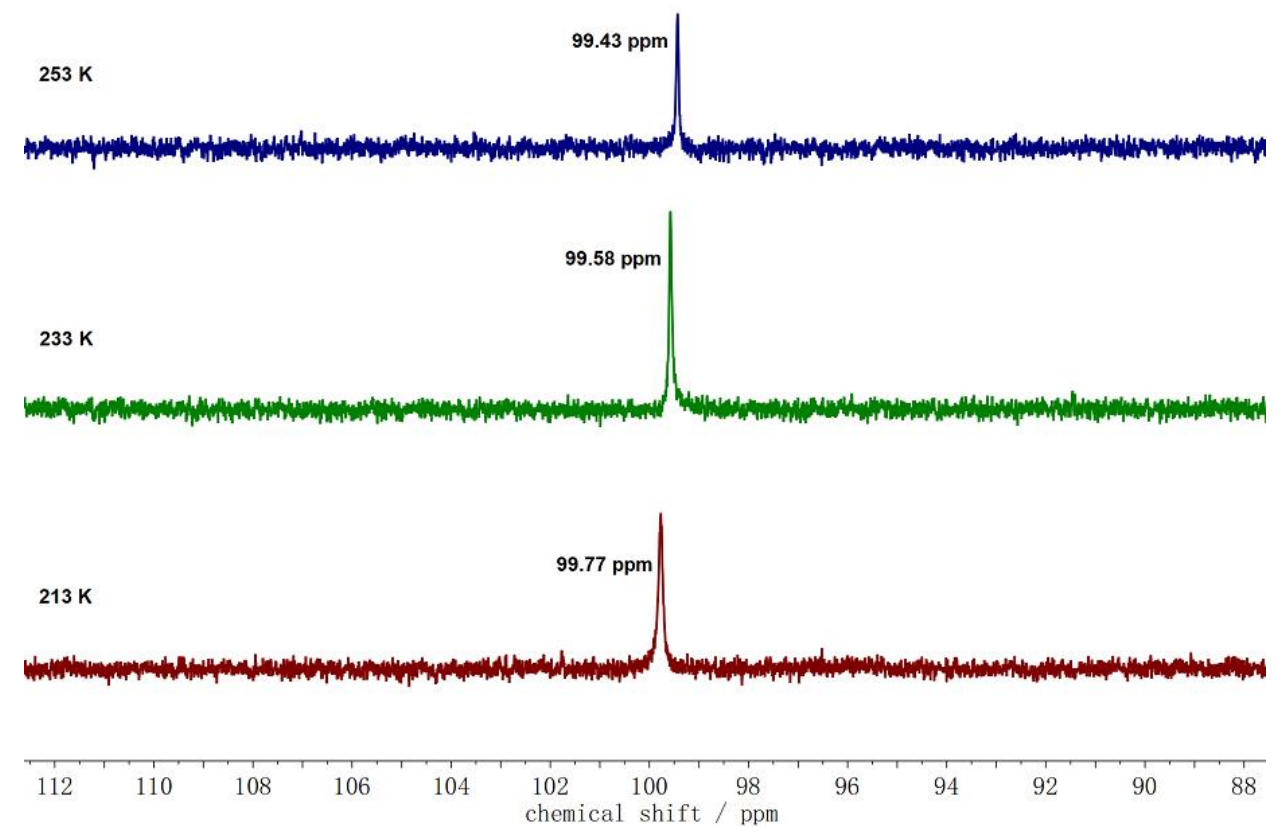

Figure 2.31: Variable temperature ${ }^{31} \mathrm{P}-\mathrm{NMR}$ spectra $(600 \mathrm{MHz})$ of complex 6 in THF-d $\mathrm{d}_{8}$ under $\mathrm{N}_{2}$ atmosphere.

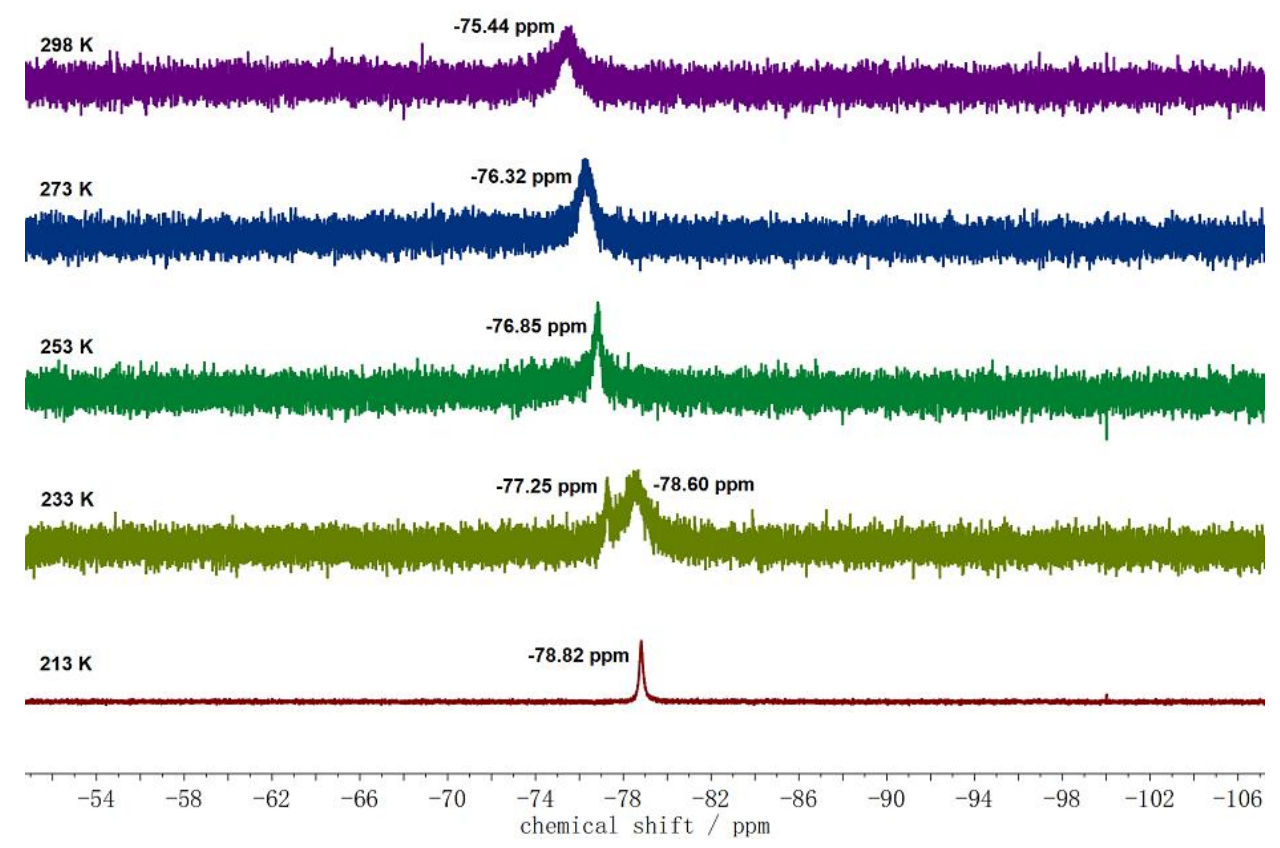

Figure 2.32: Variable temperature ${ }^{19} \mathrm{~F}-\mathrm{NMR}$ spectra $(600 \mathrm{MHz})$ of complex 6 in THF- $\mathrm{d}_{8}$ under $\mathrm{N}_{2}$ atmosphere. 
The N-N stretching vibrations of complex 6 were not observed in the IR spectrum (Figure 9.37), likely because the symmetric N-N stretch is not IR active. Thus, the Raman spectrum of complex 6 was measured and one absorption at $2000 \mathrm{~cm}^{-1}$ were found and assigned to the $\mathrm{N}-\mathrm{N}$ stretching vibrations (Figure 2.33). And for ${ }^{15} \mathrm{~N}_{2}$-labeled complex 6, the N-N stretching vibrations show the expected isotopic shifts at $1935 \mathrm{~cm}^{-1}$ to lower energies by $65 \mathrm{~cm}^{-1}$, which is close to the calculated value of $68 \mathrm{~cm}^{-1}\left(\tilde{v}\left({ }^{14} \mathrm{~N}-{ }^{14} \mathrm{~N}\right) / \tilde{v}\left({ }^{15} \mathrm{~N}^{15} \mathrm{~N}\right)=1.034\right.$, calculated 1.035 for an isolated harmonic $\mathrm{N}-\mathrm{N}$ oscillator). According to the N-N bond lengths and the N-N stretching frequency, $\mathrm{N}_{2}$ in complex 6 is more reduced than those in complex 2 and cobalt dinitrogen complexes (Figure 2.5c, 2.5d, 2.5e, 2.5h, $2.5 \mathrm{j} 2.51$ and $2.5 \mathrm{~m}$ ), but less reduced than those in complexes (Figure 2.5b, 2.5g and 2.5i) where Co centers are in low oxidation states and there are interactions between sodium or potassium ions and $\mathrm{N}_{2}$.

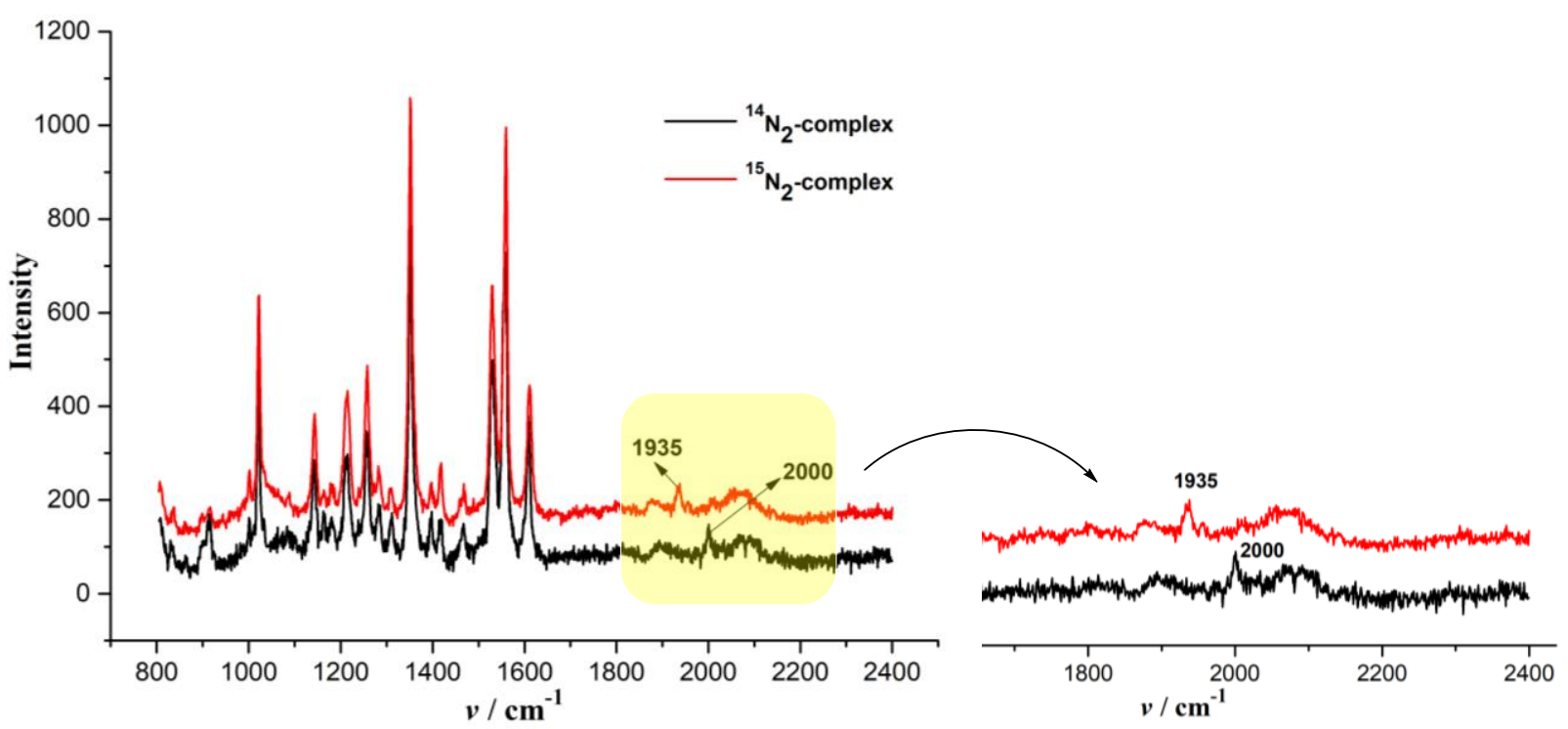

Figure 2.33: Raman spectra of complex 6 and ${ }^{15} \mathrm{~N}_{2}$-labeled 6 in solid state $\left(\lambda_{\mathrm{ex}}=633 \mathrm{~nm}\right)$.

A UV-vis spectrum of solid complex 6 was collected under $\mathrm{N}_{2}$ atmosphere and exhibits three absorption maximum at 323, 517 and $670 \mathrm{~nm}$ (Figure 2.34), which are tentatively assigned to metal to ligand charge transfer transitions. According to the ${ }^{1} \mathrm{H}-\mathrm{NMR}$ spectra, the THF solution of complex 6 at room temperature under $\mathrm{N}_{2}$ atmosphere shows a fast equilibrium arising from reversible displacement of $\mathrm{N}_{2}$ by solvent (THF) and OTf ${ }^{-}$anions, while cooling the solution to $238 \mathrm{~K}$ promotes the formation of complex $\mathbf{6}$. To explore and identify the temperature-dependent equilibria of complex 6 in solution, UV-vis spectroscopy was performed in the temperature range of $298 \mathrm{~K}$ to $233 \mathrm{~K}$ (Figure 2.35). At $298 \mathrm{~K}$, the UV-vis spectrum shows a prominent absorption at 313, 510 and $774 \mathrm{~nm}$, thereinto, two peaks of 313 and $510 \mathrm{~nm}$ are quite close to those in solid state but the peak at $774 \mathrm{~nm}$ has a large variation in comparison to the peak of $670 \mathrm{~nm}$ in solid state. Following the temperature down from $298 \mathrm{~K}$ to $233 \mathrm{~K}$, the absorptions at $510 \mathrm{~nm}$ and $774 \mathrm{~nm}$ continued to decrease in intensity and a new band at $656 \mathrm{~nm}$ increased, which is much close to the peak at $670 \mathrm{~nm}$ observed for solid 6 . Afterwards, the sample was maintained at $233 \mathrm{~K}$ and the spectra showed the intensities of bands at $510 \mathrm{~nm}$ and $774 \mathrm{~nm}$ kept decreasing and the intensity of the band at $656 \mathrm{~nm}$ kept increasing with 
isosbestic points at 481, 547 and $736 \mathrm{~nm}$, which confirmed the generation of complex 6 at $233 \mathrm{~K}$. The process is reversible upon warming and suggests binding of $\mathrm{N}_{2}$ to form $\mathbf{6}$ at lower temperatures; the characteristic electronic absorption at $656 \mathrm{~nm}$ is thus assigned to a $\mathrm{Co} \rightarrow \mathrm{N}_{2}$ MLCT transition in 6 .

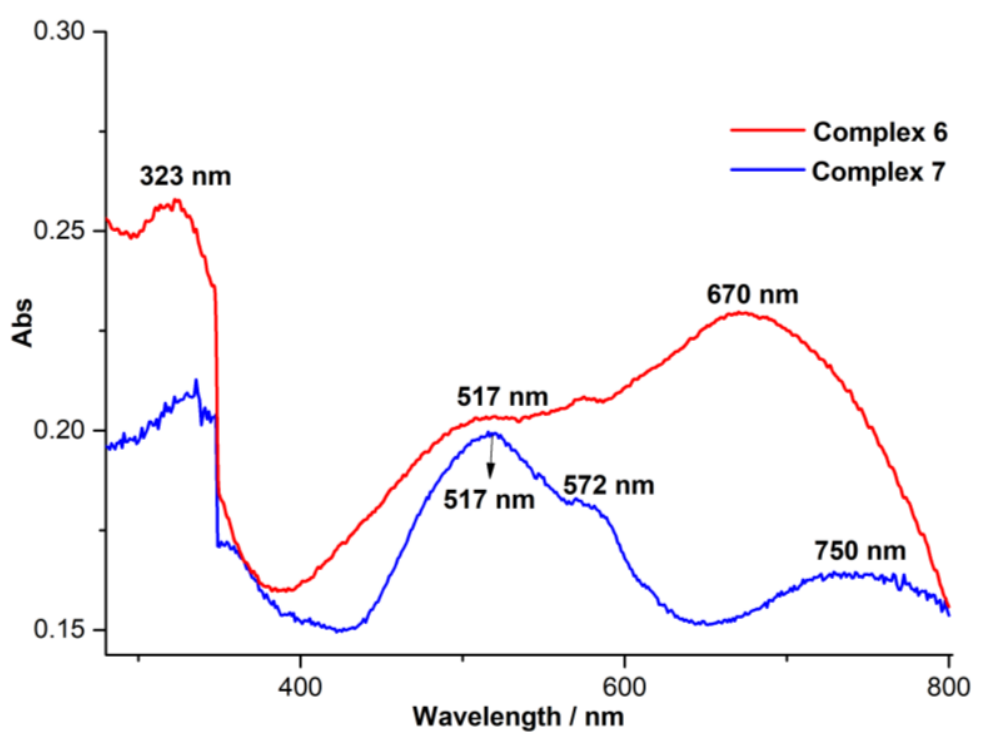

Figure 2.34: UV-vis spectra of complexes 6 and 7 in solid state under $\mathrm{N}_{2}$ atmosphere.

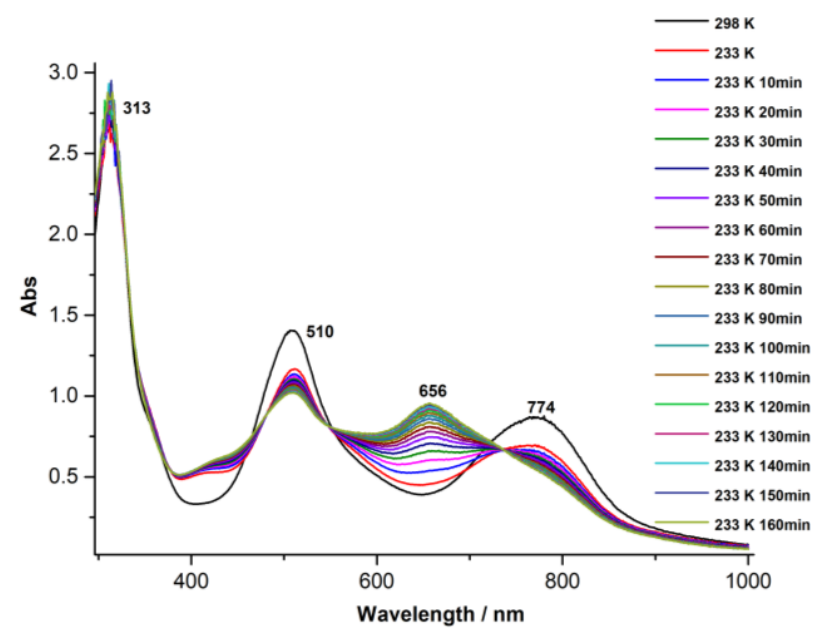

a

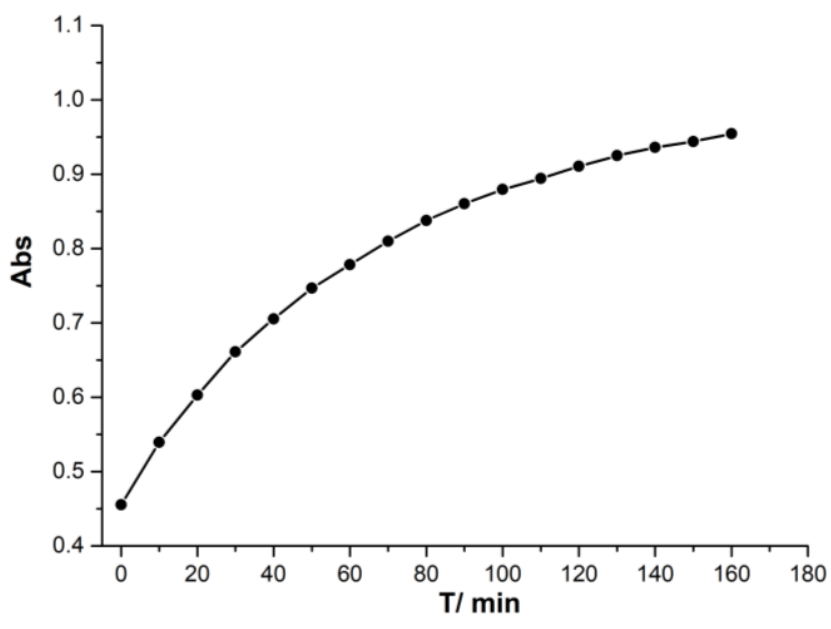

b

Figure 2.35: (a) Variable temperature UV-vis spectra of complex 6 in THF solution under $\mathrm{N}_{2}$ atmosphere in the temperature range from $298 \mathrm{~K}$ to $233 \mathrm{~K}$; (b) the increasing intensity of the band at $656 \mathrm{~nm}$ and the formation of 6 at $233 \mathrm{~K}$.

A magnetic susceptibility measurement using a SQUID magnetometer shows the solid powder complex 6 is diamagnetic (Figure 2.36). The solid powder was dissolved into THF again at room temperature and block-shaped crystals of complex $\left[\left(\mathrm{LCo}_{2}(\mu\right.\right.$-OTf $\left.)\right] 7$ were obtained by slow diffusion of pentane into the THF solution. 


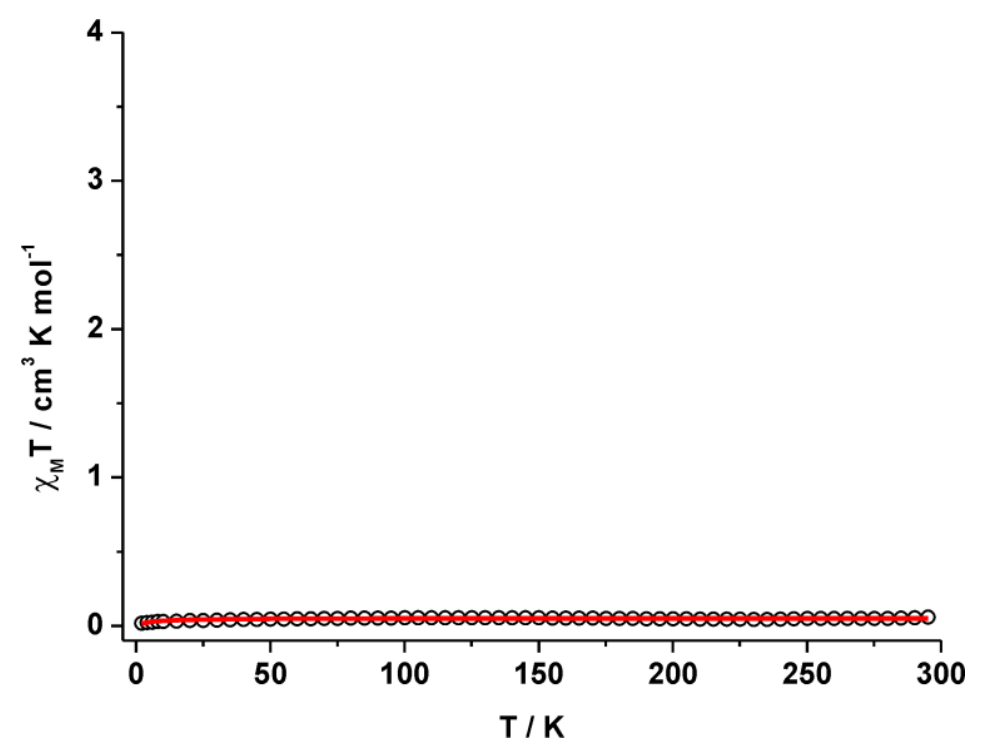

Figure 2.36: $\chi_{\mathrm{M}} T$ vs. $T$ plot in the temperature range of $2-295 \mathrm{~K}$ at $0.5 \mathrm{~T}$ of solid powder from complex 6. The red line corresponds to the best fits of the experimental magnetic results for $S=0$ spin state with $T I P=880 \cdot 10^{-6} \mathrm{~cm}^{3} \mathrm{~mol}^{-1}$ and $P I=2.7 \%$ (with $S=3 / 2$ ).

Complex 7 crystallized in the monoclinic space group $P 2_{1}$ with two molecules in the unit cell. The molecular structure is shown in Figure 2.37 and selected bond lengths and angels are listed in Table 2.8. Both cobalt centers are coordinated in an ideal square planar geometry, held with a $\{\mathrm{PNN}\}$-tridentate binding sites of the anionic pincer ligand scaffold and bridged with a $\mu-\eta^{l}: \eta^{l}$ triflate anion within the bimetallic pocket. The metal-metal distance is 4.419(8) $\AA$, which is in agreement with other dinuclear cobalt complexes, and the Co-N-N-Co torsion angle is $3.0^{\circ}$. Interestingly, when crystals were grown from a THF solution of complex 7 under $\mathrm{N}_{2}$ atmosphere at $-40{ }^{\circ} \mathrm{C}$, the dimeric dinitrogen complex 6 was crystallized, which indicates that the conversion between complex $\mathbf{6}$ and $\mathbf{7}$ is reversible.

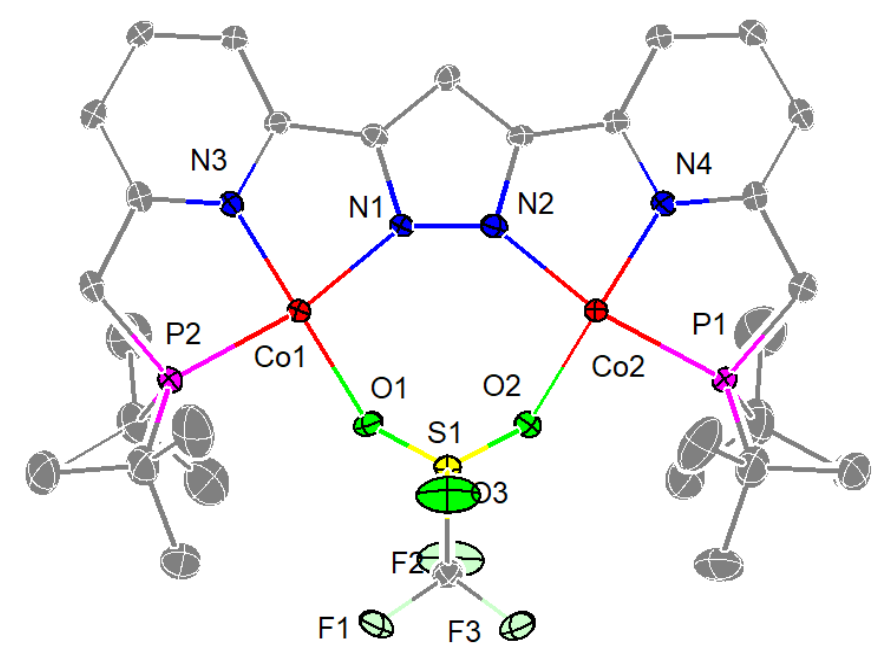

Figure 2.37: The molecular structure of complex 7. Thermal displacement ellipsoids shown at $30 \%$ 
probability; hydrogen atoms omitted for clarity.

Table 2.8: Selected bond lengths and angles for complex 7 .

\begin{tabular}{llll}
\hline \multicolumn{2}{c}{ Bond lengths / $\AA$} & \multicolumn{2}{c}{ Angles / } \\
\hline $\mathrm{Co}(1)-\mathrm{N}(3)$ & $1.843(9)$ & $\mathrm{N}(3)-\mathrm{Co}(1)-\mathrm{O}(1)$ & $176.9(5)$ \\
$\mathrm{Co}(1)-\mathrm{O}(1)$ & $1.953(8)$ & $\mathrm{N}(3)-\mathrm{Co}(1)-\mathrm{N}(1)$ & $83.8(4)$ \\
$\mathrm{Co}(1)-\mathrm{N}(1)$ & $1.963(9)$ & $\mathrm{O}(1)-\mathrm{Co}(1)-\mathrm{N}(1)$ & $97.1(4)$ \\
$\mathrm{Co}(1)-\mathrm{P}(2)$ & $2.160(3)$ & $\mathrm{N}(3)-\mathrm{Co}(1)-\mathrm{P}(2)$ & $85.3(3)$ \\
$\mathrm{Co}(2)-\mathrm{N}(4)$ & $1.847(9)$ & $\mathrm{O}(1)-\mathrm{Co}(1)-\mathrm{P}(2)$ & $93.7(3)$ \\
$\mathrm{Co}(2)-\mathrm{N}(2)$ & $1.946(9)$ & $\mathrm{N}(1)-\mathrm{Co}(1)-\mathrm{P}(2)$ & $169.0(3)$ \\
$\mathrm{Co}(2)-\mathrm{O}(2)$ & $1.951(8)$ & $\mathrm{N}(4)-\mathrm{Co}(2)-\mathrm{N}(2)$ & $83.8(4)$ \\
$\mathrm{Co}(2)-\mathrm{P}(1)$ & $2.157(3)$ & $\mathrm{N}(4)-\mathrm{Co}(2)-\mathrm{O}(2)$ & $177.6(5)$ \\
$\mathrm{Co} 1 \cdots \mathrm{Co} 2$ & $4.419(8)$ & $\mathrm{N}(2)-\mathrm{Co}(2)-\mathrm{O}(2)$ & $97.8(4)$ \\
& & $\mathrm{N}(4)-\mathrm{Co}(2)-\mathrm{P}(1)$ & $85.3(3)$ \\
& & $\mathrm{N}(2)-\mathrm{Co}(2)-\mathrm{P}(1)$ & $169.0(3)$ \\
& & $\mathrm{O}(2)-\mathrm{Co}(2)-\mathrm{P}(1)$ & $93.0(3)$ \\
\hline
\end{tabular}

Similar to the case of complex 6, the ${ }^{1} \mathrm{H}$-NMR spectrum of complex 7 in THF- $\mathrm{d}_{8}$ under an argon atmosphere at $293 \mathrm{~K}$ displays very broad resonances, suggesting paramagnetic contributions at higher temperatures caused by fast equilibria arising from triflate/THF ligand exchange. When the sample was cooled in THF- $\mathrm{d}_{8}$, it showed a diamagnetic species and exhibits the spectral pattern expected for a $C_{2 \mathrm{v}}$ symmetric complex (Figure 2.38). As depicted in Figure 2.39, the ${ }^{1} \mathrm{H}-\mathrm{NMR}$ spectrum of complex 7 at $238 \mathrm{~K}$ displays that the proton signals of pyridine moieties and the bridging pyrazole in complex $\mathbf{7}$ are shifted downfield compared with complex $\mathbf{6}$. Moreover, a singlet at $2.08 \mathrm{ppm}$ was assigned to $\mathrm{CH}_{2}$ groups in the side arms and another singlet corresponding to $t \mathrm{Bu}$ groups at $1.57 \mathrm{ppm}$ was observed. The ${ }^{1} \mathrm{H}$-DOSY spectrum of complex 7 at $238 \mathrm{~K}$ reveals that the diffusion coefficient of complex 7 at $238 \mathrm{~K}$ is $2.507 \times 10^{-10} \mathrm{~m}^{2} \mathrm{~s}^{-1}$ (Figure 2.40). The hydrodynamic radius of complex 7 was determined to be $7.12 \AA$ derived from the Stokes-Einstein equation and suggests that 7 is a dicobalt(I) species in comparison with HL ligand (Table 2.7). In addition, under $\mathrm{N}_{2}$ atmosphere the VT NMR spectra of $\mathbf{6}$ and $\mathbf{7}$ are identical, and at high temperatures they are essentially identical to the ones of $\mathbf{7}$ recorded under Ar atmosphere. 


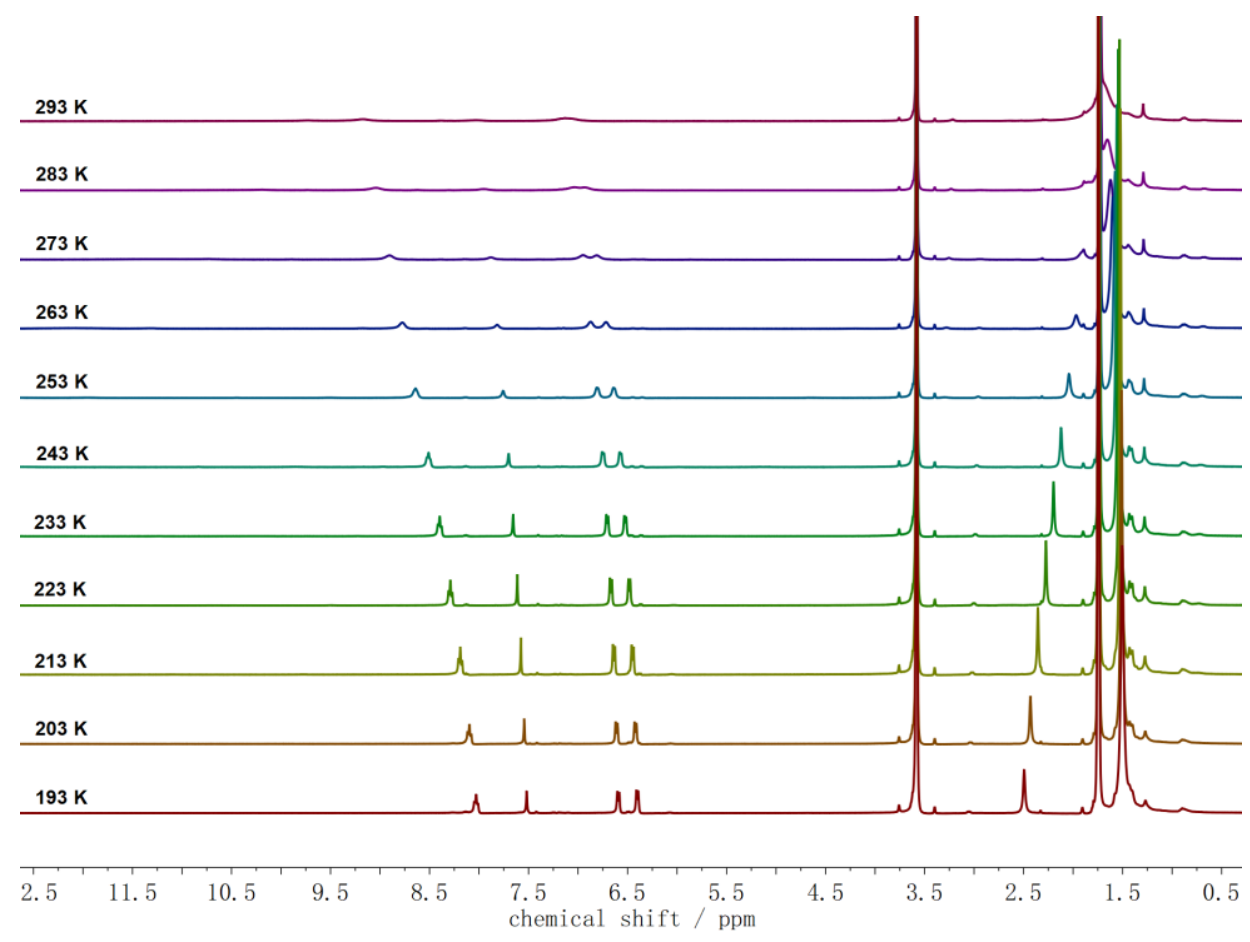

Figure 2.38: Variable temperature ${ }^{1} \mathrm{H}-\mathrm{NMR}$ spectra of complex 7 in $\mathrm{THF}-\mathrm{d}_{8}$ under an $\operatorname{argon}$ atmosphere.

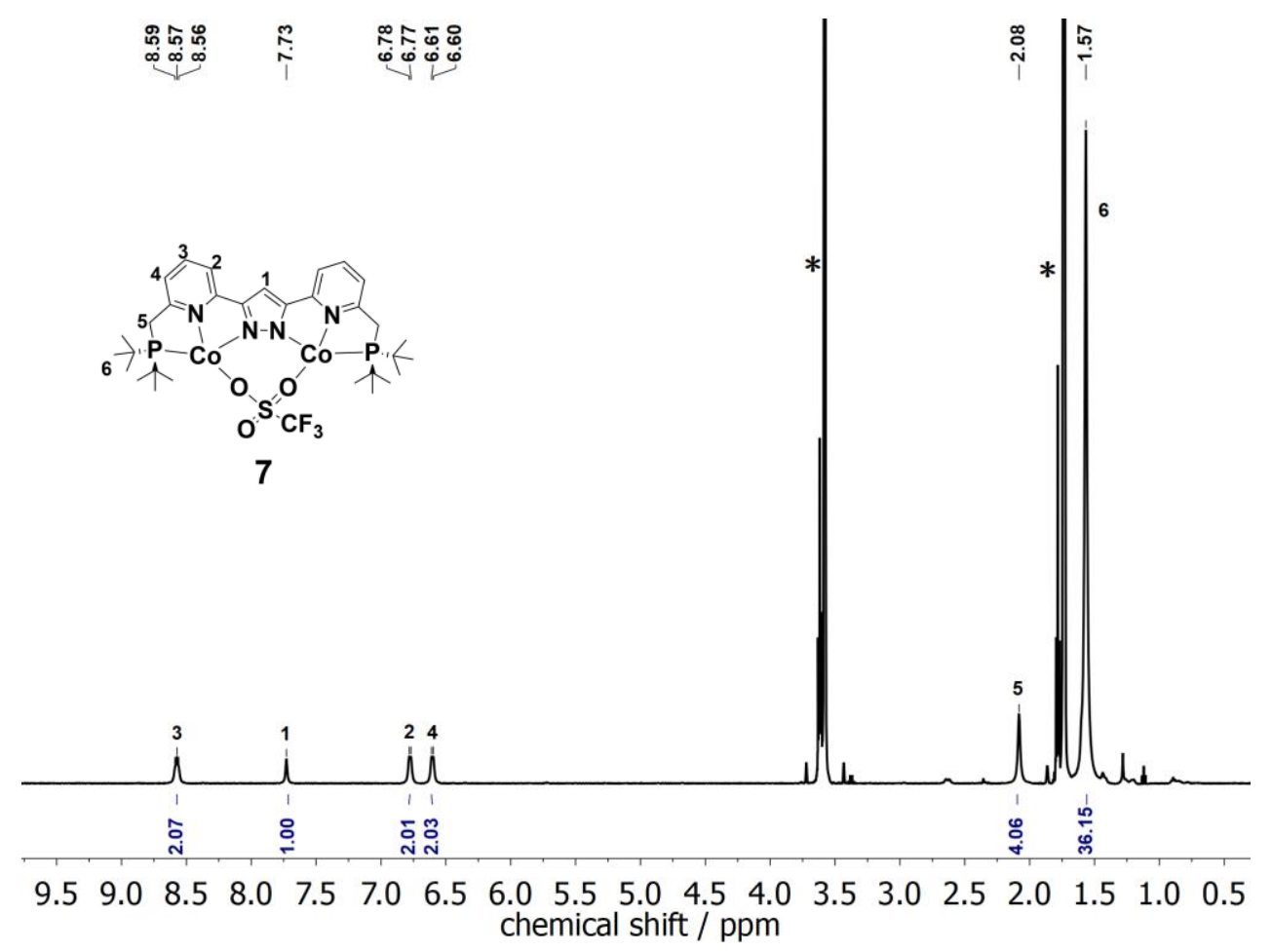

Figure 2.39: ${ }^{1} \mathrm{H}-\mathrm{NMR}$ spectrum of complex 7 in THF-d 8 under an argon atmosphere at $238 \mathrm{~K}$. Solvent signals are marked with an asterisk $(*)$. 


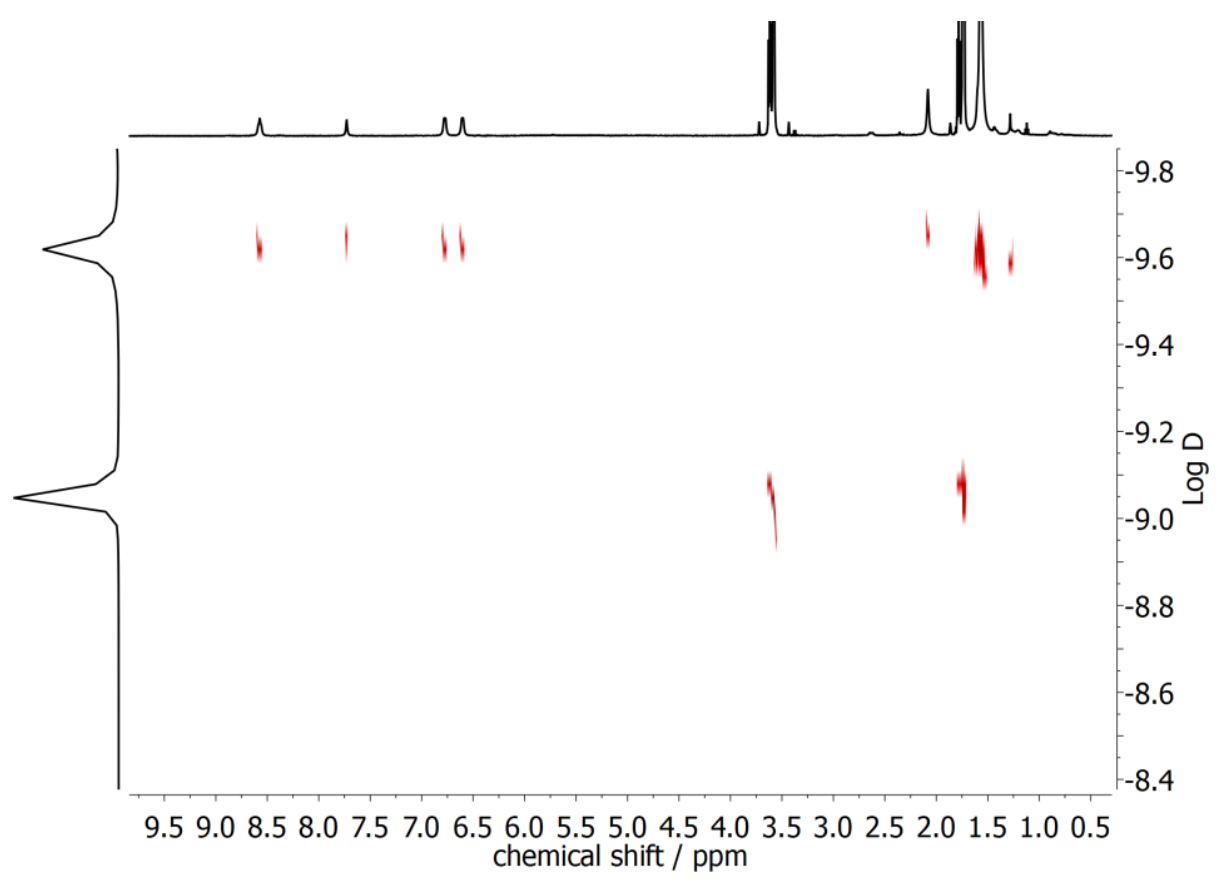

Figure 2.40: DOSY spectrum of complex 7 in THF- $\mathrm{d}_{8}$ under an argon atmosphere at $238 \mathrm{~K}$.

The ${ }^{31} \mathrm{P}$ spectrum of complex 7 in THF- $\mathrm{d}_{8}$ under an argon atmosphere at $238 \mathrm{~K}$ shows a broad peak at $219.0 \mathrm{ppm}$ (Figure 2.41) and no signal is observed at room temperature. Variable temperature ${ }^{19} \mathrm{~F}-\mathrm{NMR}$ spectra reveal that the fluorine resonance for bound triflate shifts upfield upon decreasing the temperature from $-75.65 \mathrm{ppm}$ at $293 \mathrm{~K}$ to $-77.75 \mathrm{ppm}$ at $213 \mathrm{~K}$ (Figure 2.42).

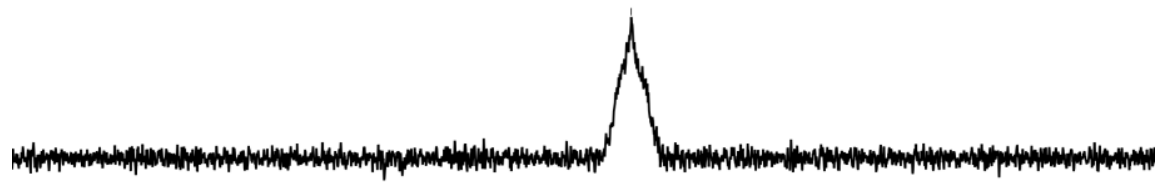

$\begin{array}{lllllllllllllllllllllll}460 & 440 & 420 & 400 & 380 & 360 & 340 & 320 & 300 & 280 & 260 & 240 & 220 & 200 & 180 & 160 & 140 & 120 & 100 & 80 & 60 & 40 & 20\end{array}$ chemical shift

Figure 2.41: ${ }^{31} \mathrm{P}$ spectrum of complex 7 in $\mathrm{THF}-\mathrm{d}_{8}$ under an argon atmosphere at $238 \mathrm{~K}$. 


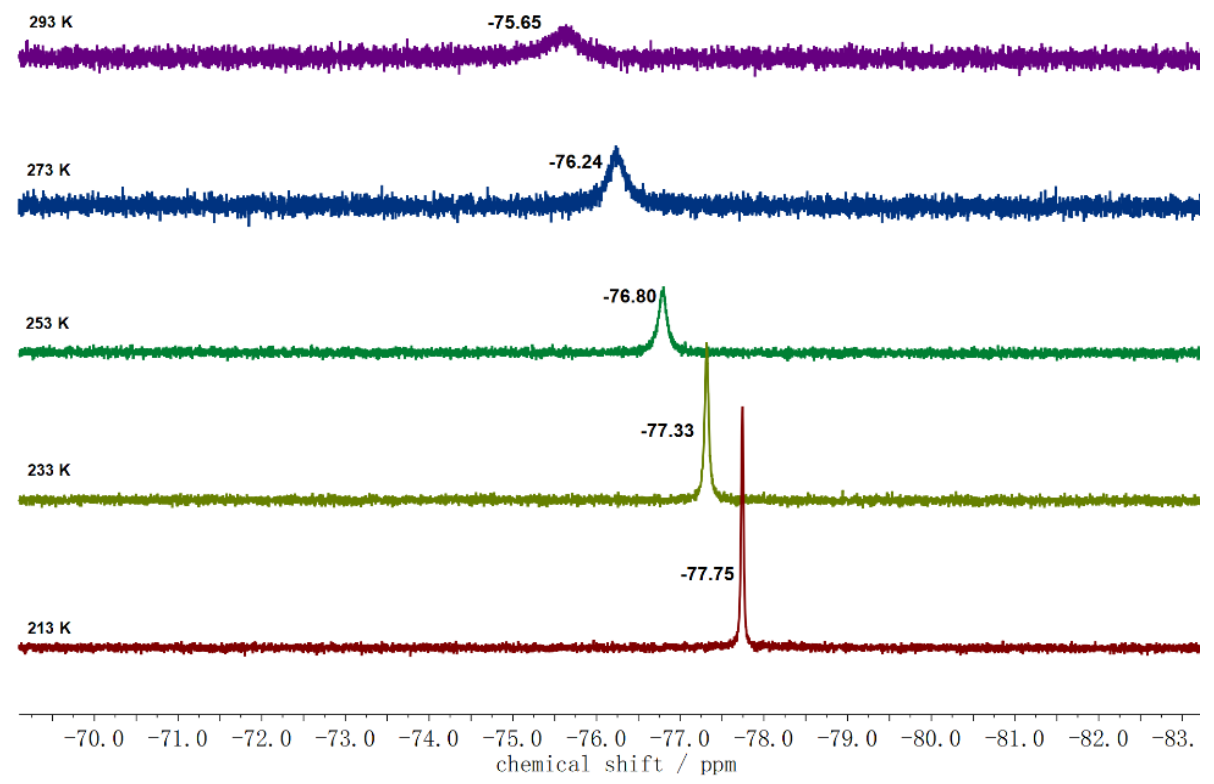

Figure 2.42: Variable temperature ${ }^{19} \mathrm{~F}-\mathrm{NMR}$ spectra of complex 7 in $\mathrm{THF}-\mathrm{d}_{8}$ under an argon atmosphere.

Variable temperature UV-vis spectra of complex 7 were recorded in THF from $298 \mathrm{~K}$ to $233 \mathrm{~K}$ (Figure 2.43). The spectrum at $298 \mathrm{~K}$ shows three prominent bands at 313, 509 and $774 \mathrm{~nm}$, which are quite similar to those of complex 6 in THF solution at $298 \mathrm{~K}$ and also close to the absorption at 517 and $750 \mathrm{~nm}$ of UV-vis spectrum of complex 7 in solid state (Figure 2.34). Differently, when the solution was cooled down from $298 \mathrm{~K}$ to $233 \mathrm{~K}$ in complex 7 , the bands were slightly shifted and the intensities of the bands increased a bit. No new bands appeared and the intensities of the bands remained stable at $233 \mathrm{~K}$.

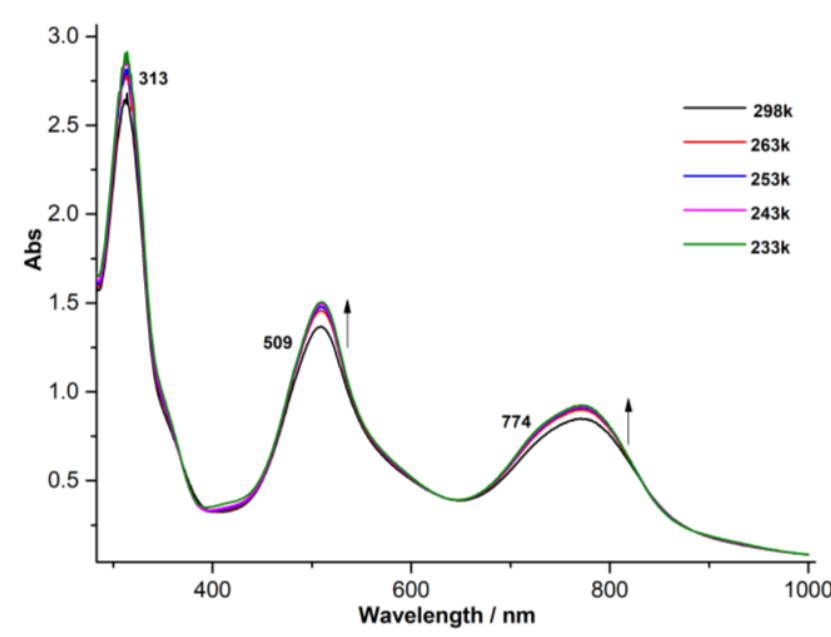

a

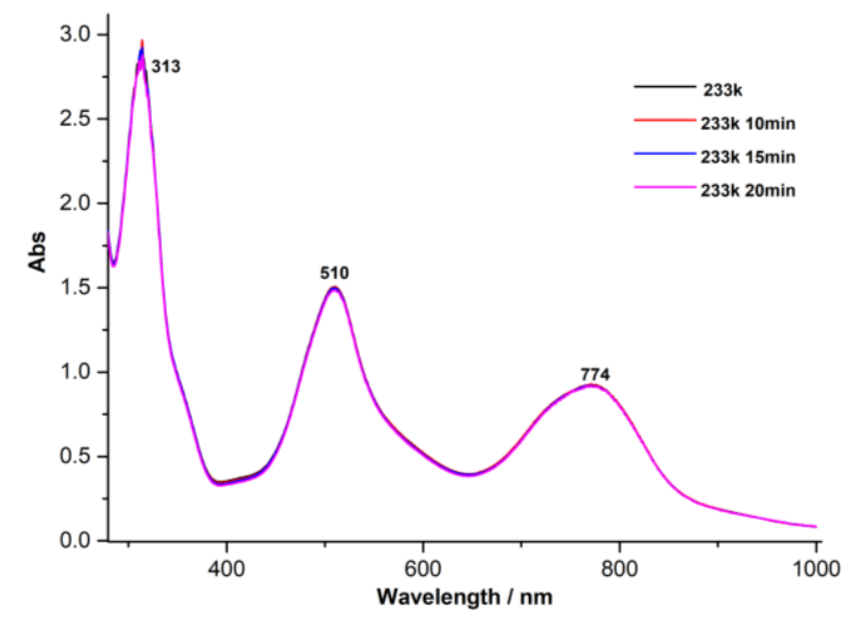

b

Figure 2.43: (a) Variable temperature UV/vis spectra of complex 7 in THF solution under an argon 
atmosphere in the temperature range from $298 \mathrm{~K}$ to $233 \mathrm{~K}$. (b) UV/vis spectra of complex 7 in THF solution being kept at $233 \mathrm{~K}$.

\subsection{Reduction of Dicobalt Dinitrogen Complexes}

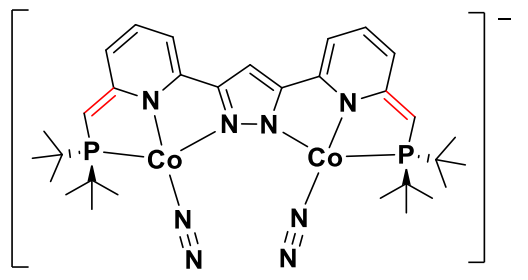

2 or 4

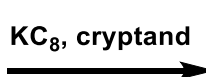

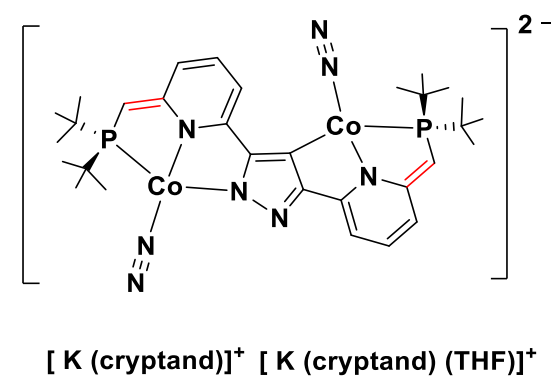

8

Scheme 2.11: Reduction of complex 2 or 4 to give complex 8 .

As low valent metal centers have stronger $\pi$-back donation to $\mathrm{N}_{2}$, the reduction of complex 2 or 4 was attempted. Two equivalents of $\mathrm{KC}_{8}$ were added to the THF solution of complex $\mathbf{2}$ or $\mathbf{4}$, which ultimately afforded a purple solution (Scheme 2.11). After filtration of the solution, two equivalents of cryptand were added and a dark blue solid of complex $\mathbf{8}$ precipitated from the solution immediately. Crystals for X-ray diffraction analysis were obtained from the filtrate after filtration again. Unfortunately, because of the low quality of the crystals, the crystallographic data were not optimal. As shown in Figure 2.44, complex 8 exhibits an unexpected pyrazolate $\mathrm{C}-\mathrm{H}$ bond activation at the 4-position and part of the ligand including the pyridine moieties and $t \mathrm{Bu}_{2} \mathrm{P}$ groups has rolled over to form a $\{\mathrm{PNC}\}$-tridentate binding site, which demonstrates that the reduction occurs on the ligand with consumption of only one equivalent of $\mathrm{KC}_{8}$. Therefore, $\mathrm{Co}(1)$ is hosted in one $\{\mathrm{PNN}\}$-tridentate binding pocket of the tetraanionic pincer ligand scaffold and coordinated with one terminal dinitrogen molecule, while $\mathrm{Co}(2)$ is hosted in one $\{\mathrm{PNC}\}$-tridentate binding site, connected with the pyrazolate and coordinated with one terminal dinitrogen molecule.

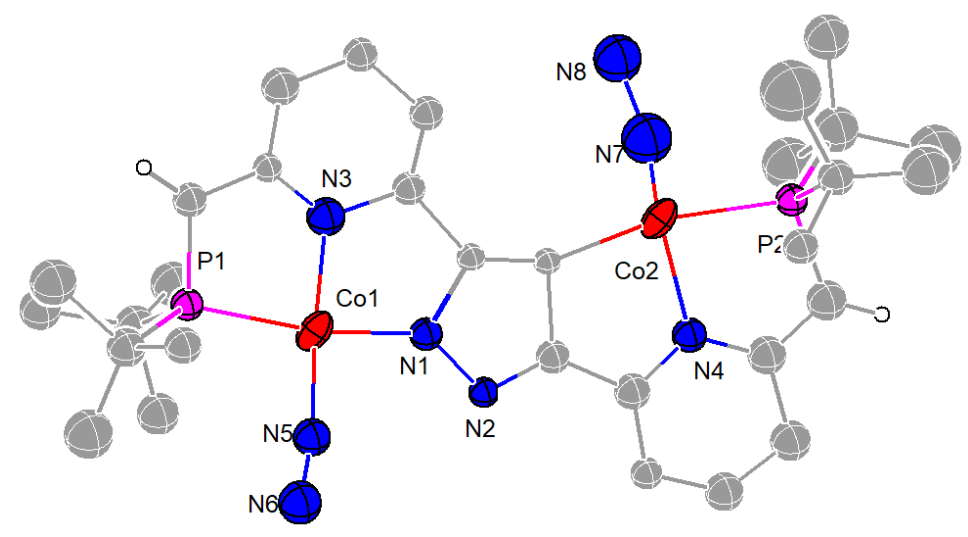

Figure 2.44: The molecular structure of the dianionic complex 8. Thermal displacement ellipsoids 
shown at $30 \%$ probability; most hydrogen atoms, the cation $(\mathrm{K}([2.2 .2] \text { cryptand }))^{+}$, the cation $(\mathrm{K}(\mathrm{THF})([2.2 .2] \text { cryptand }))^{+}$and solvent molecules omitted for clarity.

Due to the low solubility of complex 8 in THF, an ${ }^{1} \mathrm{H}-\mathrm{NMR}$ spectrum has not been obtained. As the ${ }^{31} \mathrm{P}-\mathrm{NMR}$ spectra of the reaction of complex 4 with $\mathrm{KC}_{8}$ and of isolated complex $\mathbf{8}$ exhibit similar resonances $\left(80.38 \mathrm{ppm}, 68.72 \mathrm{ppm}\right.$ for the reaction of complex 4 with $\mathrm{KC}_{8} ; 80.65 \mathrm{ppm}, 68.32 \mathrm{ppm}$ for complex $\mathbf{8}$; Figure 2.45), it is likely that complex $\mathbf{8}$ is formed in the reaction mixture and not only upon crystallization except without cryptand being coordinated with the potassium cation. The ${ }^{1} \mathrm{H}-\mathrm{NMR}$ spectrum of the reaction of complex 4 with $\mathrm{KC}_{8}$ is shown in Figure 2.46.
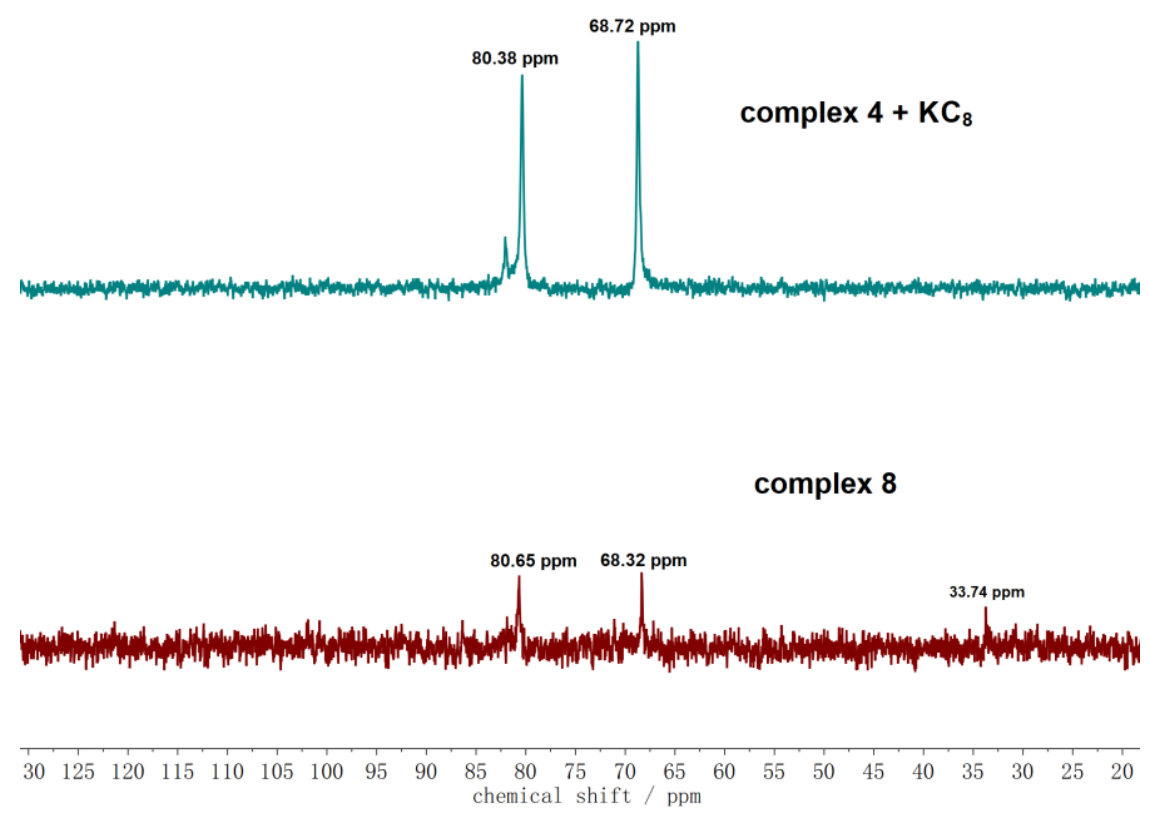

Figure 2.45: ${ }^{31} \mathrm{P}-\mathrm{NMR}$ spectra of complex 8 and the reaction of complex 4 with $\mathrm{KC}_{8}$ in $\mathrm{THF}-\mathrm{d}_{8}$ (The peak at $33.74 \mathrm{ppm}$ is from the ligand). 


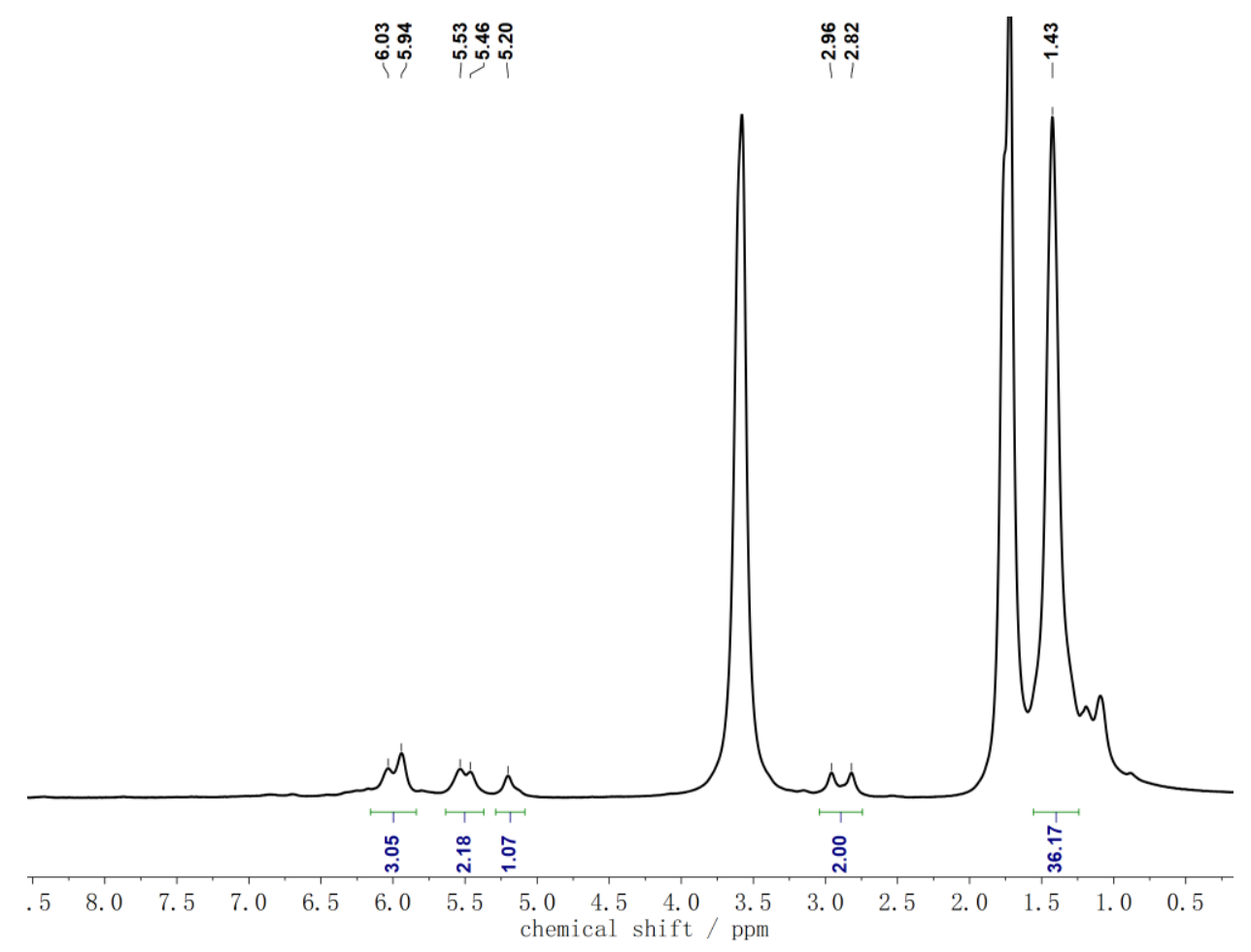

Figure 2.46: ${ }^{1} \mathrm{H}-\mathrm{NMR}$ spectrum of the reaction of complex 4 with $\mathrm{KC}_{8}$ in $\mathrm{THF}-\mathrm{d}_{8}$.

As shown in Figure 2.47, two intense peaks at 2017 and $1966 \mathrm{~cm}^{-1}$ are observed in the IR spectrum of solid $\mathbf{8}$, corresponding to the N-N stretching vibrations, which demonstrates that the $\mathrm{N}_{2}$ ligands in complex $\mathbf{8}$ are more reduced than those in complex $\mathbf{2}$. UV-vis spectroscopy of complex $\mathbf{8}$ was performed in the temperature range from $293 \mathrm{~K}$ to $193 \mathrm{~K}$ and as depicted in Figure 2.48, the spectrum shows a prominent absorption at $584 \mathrm{~nm}$, which is blue-shifted in comparison with that in complex $2(621 \mathrm{~nm})$ and is attributed to a $\mathrm{Co} \rightarrow \mathrm{N}_{2}$ MLCT transition.

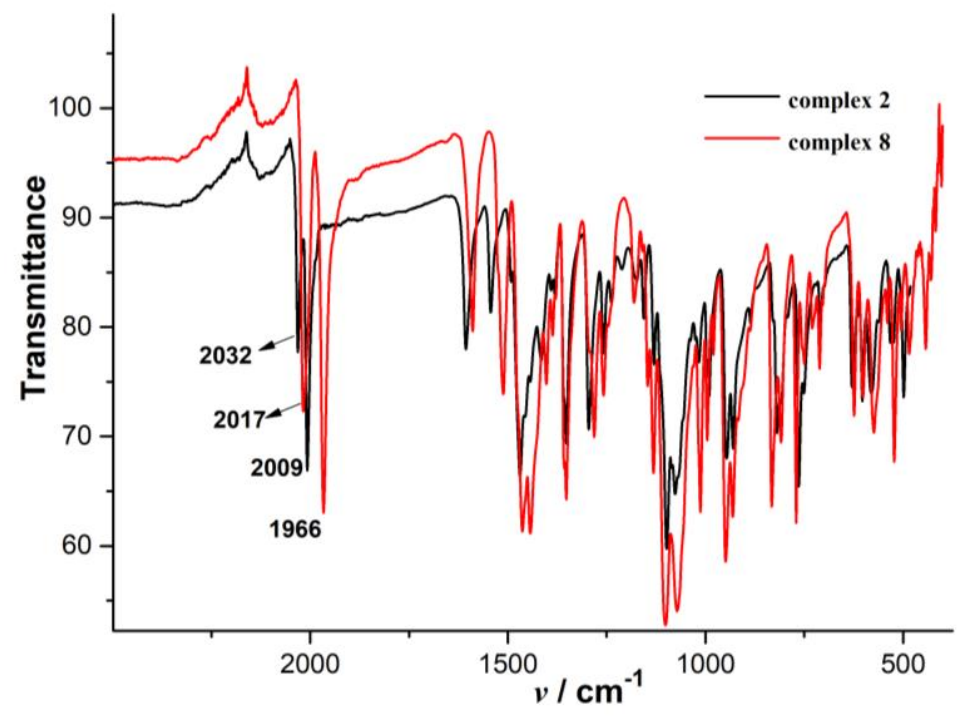

Figure 2.47: IR spectra of complex 8 comparing to complex 2 in solid state. 


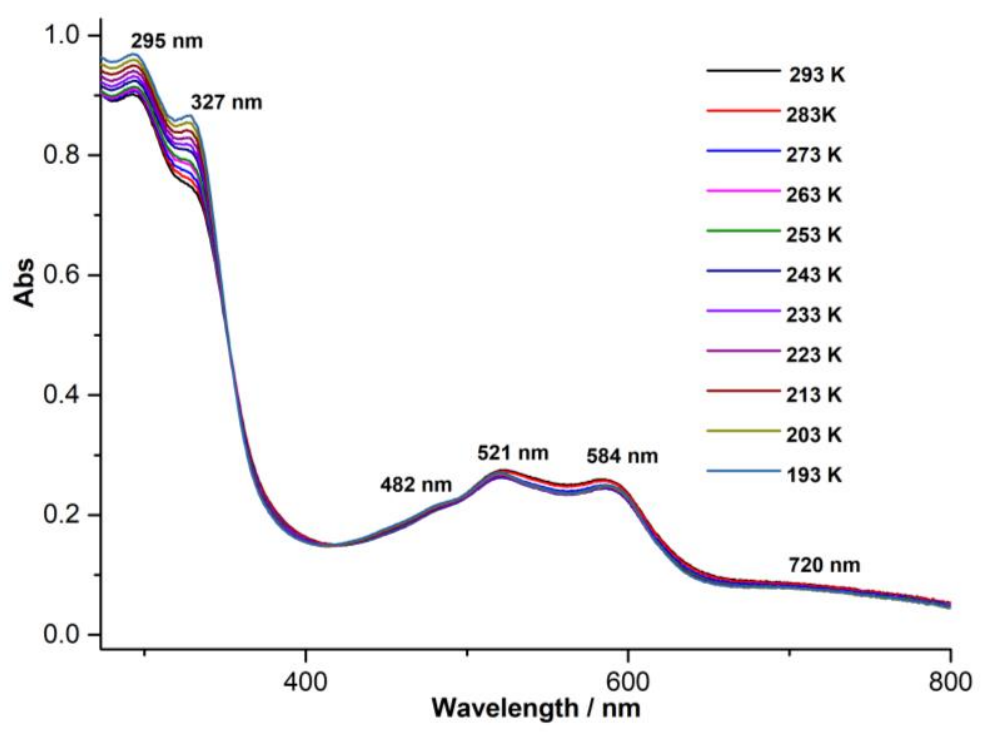

Figure 2.48: Variable temperature UV/vis spectra of complex 8 in THF solution under $\mathrm{N}_{2}$ atmosphere in the temperature range from $293 \mathrm{~K}$ to $193 \mathrm{~K}$.

\subsection{Catalytic Silylation of $\mathrm{N}_{2}$ by Using the Cobalt Complexes as Catalysts}

As previously mentioned, coordinated $\mathrm{N}_{2}$ can be converted through a series of $\mathrm{H}^{+} / \mathrm{e}^{-}$delivery to ammonia. Catalytic formation of silylamine from nitrogen gas is an alternative $\mathrm{N}_{2}$ fixation process and a complementary method of ammonia production. The possible $\mathrm{N}_{2}$ silylation mechanism in mononuclear systems is that silyl radicals can be generated during the reactions of electrophilic $\mathrm{Me}_{3} \mathrm{Si}^{+}$(such as $\mathrm{Me}_{3} \mathrm{SiCl}, \mathrm{Me}_{3} \mathrm{SiOTf}$ ) and reductants (such as $\mathrm{Na}, \mathrm{K}, \mathrm{KC}_{8}$ ), which can react with the coordinated $\mathrm{N}_{2}$ by the distal and alternating pathways and finally form silylamine $\mathrm{N}\left(\mathrm{SiMe}_{3}\right)_{3}$ (Scheme 2.12). ${ }^{21 \mathrm{~g}}$ Several homogeneous catalytic silylation reactions of $\mathrm{N}_{2}$ catalyzed by $\mathrm{Fe}, \mathrm{Co}, \mathrm{Cr}$, Mo and $\mathrm{W}-\mathrm{N}_{2}$ complexes have been reported. ${ }^{21 \mathrm{~g}, 21 \mathrm{i}, 25}$ The Nishibayashi group reported an efficient catalytic system, trans-[Mo( $\left.\left.\mathrm{N}_{2}\right)_{2}(\mathrm{depf})_{2}\right]$ (depf $=1,1^{\prime}$-bis(diethylphosphino)ferrocene), which could catalyze the conversion from $\mathrm{N}_{2}$ to $\mathrm{N}\left(\mathrm{SiMe}_{3}\right)_{3}$, and $\mathrm{TON}$ of 226 was observed. ${ }^{25 \mathrm{~b}}$ The Fryzuk group showed an iminophosphorane-cobalt derivative, that could catalyze the conversion of $\mathrm{N}_{2}$ to $\mathrm{N}\left(\mathrm{SiMe}_{3}\right)_{3}$ ( 200 equivalents) at $233 \mathrm{~K} .{ }^{21 \mathrm{i}}$ The Lu group synthesized an anionic dicobalt dinitrogen complex based on a trisphosphino-(triamido)amine ligand and with it as a catalyst, the TON of 195 was obtained and the highest TON of 316 was obtained in the second run of the catalytic reaction. ${ }^{21 g}$

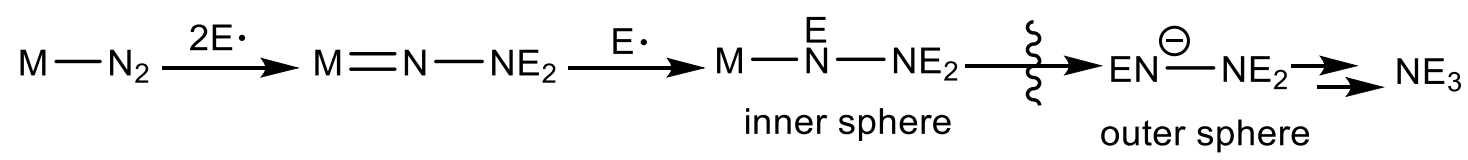

Scheme 2.12: Proposed mechanism in mononuclear system: $\mathrm{N}_{2}$ functionalization via $\mathrm{SiMe}_{3}$ reactions 
We investigate this process for the present cobalt complexes by using excess $\mathrm{KC}_{8}$ (2000 equiv) and $\mathrm{SiMe}_{3} \mathrm{Cl}$ (2000 equiv) in THF at different temperatures for $24 \mathrm{~h}$ (Table 2.9). From these experiments, it was found that the dicobalt complexes based on the two-in-one pincer ligand $(0.005 \mathrm{mmol}$, 1.0equiv) are quite productive in catalyzing silylation of $\mathrm{N}_{2}$ to $\mathrm{N}\left(\mathrm{SiMe}_{3}\right)_{3}$, which can be identified by GC MS and quantified by GC with cyclododecane as the internal standard. As can be seen from Entry 5-7, with complex 2 as catalyst, silylation of $\mathrm{N}_{2}$ can generate $\mathrm{N}\left(\mathrm{SiMe}_{3}\right)_{3}$ at room temperature in $22.4 \%$ yield (equals to turnover number (TON): 150). The yield rises to $36.0 \%$ (TON: 240) when the reaction is first conducted at $-40^{\circ} \mathrm{C}$ for $2 \mathrm{~h}$ before warming to r.t.; when carried out at $-90^{\circ} \mathrm{C}$ for $2 \mathrm{~h}$ the yield is $32.9 \%$ (TON: 219), which indicated that $-40{ }^{\circ} \mathrm{C}$ is the optimal temperature for the catalytic silylation reaction in high yield. Under the same condition $\left(-40^{\circ} \mathrm{C}\right.$ for $2 \mathrm{~h}$, then r.t.; Entry $1-5$, 8-9 and 11), complex 2 is the most effective in the silylation reaction among the dicobalt complexes studies (TON in complex 1: 190, TON in complex 2: 240, TON in complex 3: 228, TON in complex 4: 234, TON in complex 7: 208, TON in complex 8: 237). So it reveals that complexes 1-4, 7 and 8 based on the two-in-one pincer ligand are promising catalysts for catalytic reactions of $\mathrm{N}_{2}$. Other products generated in the challenging silylation reaction were identified and quantified by GC MS (experiments performed by Dr. Sandeep K. Gupta). These include hexamethyldisilane, $n$-butoxytrimethylsilane and trimethyl(4-(trimethylsilyl)butoxy)silane, the latter two resulting from ring cleavage and silylation of $\mathrm{THF}$ by $\mathrm{Me}_{3} \mathrm{Si}$. radicals under the harsh reaction conditions, as reported previously. ${ }^{[25 \mathrm{~d}]}$ Silyl ether formation, specifically the formation of significant amounts of trimethyl(4-(trimethylsilyl)butoxy)silane (Table 2.10), consumes substantial reducing equivalents and $\mathrm{SiMe}_{3} \mathrm{Cl}$, which may contribute to limiting the yield of $\mathrm{N}\left(\mathrm{SiMe}_{3}\right)_{3}$ to below $40 \%$ based on the reagent $\mathrm{SiMe}_{3} \mathrm{Cl}$. Considering the cooperativity between two metal centers in the dinuclear system, the possible mechanism in the catalytic silylation and potential intermediates are exceedingly complicated. The mechanism study and stoichiometric reactions are still in progress.

Table 2.9: Catalytic reactions of $\mathrm{N}_{2}$ to silylamine $\mathrm{N}\left(\mathrm{SiMe}_{3}\right)_{3}$ using complexes $\mathbf{1 - 4}, \mathbf{7}$ and 8 as catalysts.

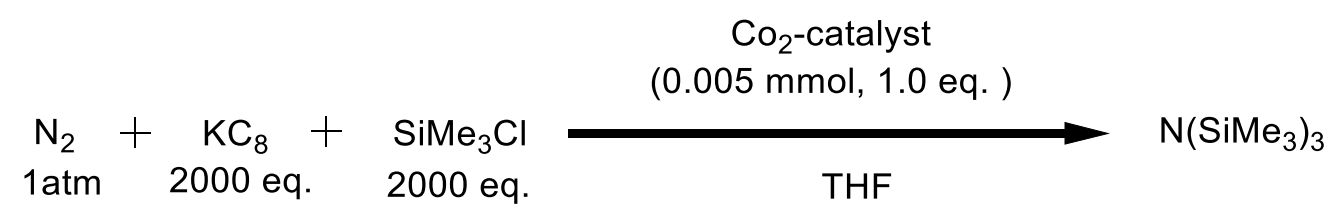

\begin{tabular}{|c|c|c|c|c|c|c|c|c|}
\hline \multirow{2}{*}{$\frac{\text { Entry }}{1}$} & \multirow{2}{*}{$\begin{array}{c}\text { Catalyst } \\
\text { Complex } 8\end{array}$} & \multicolumn{4}{|c|}{$\begin{array}{c}\text { Reaction Temperature } \\
\text { and Time }\end{array}$} & \multirow{2}{*}{$\begin{array}{c}\mathrm{N}(\mathrm{SiMe})^{3} \\
(\mathrm{mmol})^{a}\end{array}$} & \multirow{2}{*}{$\frac{\mathbf{T O N}^{b}}{237}$} & \multirow{2}{*}{$\begin{array}{c}\text { Yield } \\
(\%)^{c}\end{array}$} \\
\hline & & $-40^{\circ} \mathrm{C}$ & $2 \mathrm{~h}$ & R.T. & $22 \mathrm{~h}$ & & & \\
\hline 2 & Complex 7 & $-40^{\circ} \mathrm{C}$ & $2 \mathrm{~h}$ & R.T. & $22 \mathrm{~h}$ & 1.04 & 208 & 31.2 \\
\hline 3 & Complex 4 & $-40^{\circ} \mathrm{C}$ & $2 \mathrm{~h}$ & R.T. & $22 \mathrm{~h}$ & 1.17 & 234 & 35.1 \\
\hline 4 & Complex 3 & $-40^{\circ} \mathrm{C}$ & $2 \mathrm{~h}$; & R.T. & $22 \mathrm{~h}$ & 1.14 & 228 & 34.2 \\
\hline 5 & Complex 2 & $-40^{\circ} \mathrm{C}$ & $2 \mathrm{~h}$ & R.T. & $22 \mathrm{~h}$ & 1.2 & 240 & 36.0 \\
\hline 6 & Complex 2 & $-90^{\circ} \mathrm{C}$ & $2 \mathrm{~h}$ & R.T. & $22 \mathrm{~h}$ & 1.1 & 219 & 32.9 \\
\hline
\end{tabular}




\begin{tabular}{|c|c|c|c|c|c|c|c|}
\hline 7 & Complex 2 & R.T. & $24 \mathrm{~h}$ & & 0.75 & 150 & 22.4 \\
\hline 8 & Complex 1 & $-40^{\circ} \mathrm{C} \quad 2 \mathrm{~h}$ & R.T. & $22 \mathrm{~h}$ & 0.95 & 190 & 28.5 \\
\hline 9 & 2.0eq. $\mathrm{CoCl}_{2}$ & $-40^{\circ} \mathrm{C} \quad 2 \mathrm{~h}$ & R.T. & $22 \mathrm{~h}$ & 0.58 & 58 & 17.4 \\
\hline 10 & 2.0eq. $\mathrm{CoCl}_{2}$ & R.T. & $24 \mathrm{~h}$ & & 0.1 & 10 & 3.0 \\
\hline 11 & None & $-40^{\circ} \mathrm{C} \quad 2 \mathrm{~h}$ & R.T. & $22 \mathrm{~h}$ & 0 & 0 & 0 \\
\hline
\end{tabular}

${ }^{a} \mathrm{~N}\left(\mathrm{SiMe}_{3}\right)_{3}$ was identified by GC MS and quantified by GC with cyclododecane as the internal standard. All values are an average of at least three trials. ${ }^{b}$ Turnover numbers (TON) were calculated as the molar ratio of $\mathrm{N}\left(\mathrm{SiMe}_{3}\right)_{3}$ to catalysts. ${ }^{c}$ The yields of $\mathrm{N}\left(\mathrm{SiMe}_{3}\right)_{3}$ were based on starting material $\mathrm{SiMe}_{3} \mathrm{Cl}$.

Table 2.10. Quantification of the by-products formed in the catalytic silylation reaction with catalyst 4, 2000 equiv. $\mathrm{Me}_{3} \mathrm{SiCl}, 2000$ equiv. $\mathrm{KC}_{8}$ in $\mathrm{THF}$ ( 1 atm of $\mathrm{N}_{2},-40^{\circ} \mathrm{C} 2 \mathrm{~h}$ and r.t. $22 \mathrm{~h}$; experiments performed by Dr. Sandeep K. Gupta).

\begin{tabular}{ccc}
\hline Products & TON $^{a}$ & ${\text { Yield }(\%)^{b}}^{b}$ \\
$\mathrm{~N}\left(\mathrm{SiMe}_{3}\right)_{3}$ & 232 & 34.8 \\
$\mathrm{Me}_{3} \mathrm{Si}_{-}-\mathrm{SiMe}_{3}$ & 144 & 9.3 \\
$\mathrm{CH}_{3}\left(\mathrm{CH}_{2}\right)_{3} \mathrm{OSiMe}_{3}$ & 72 & 3.6 \\
$\mathrm{Me}_{3} \mathrm{Si}\left(\mathrm{CH}_{2}\right)_{4} \mathrm{OSiMe}_{3}$ & 318 & 31.8 \\
\hline
\end{tabular}

${ }^{a}$ Turnover numbers (TON) were calculated as the molar ratio of $\mathrm{N}\left(\mathrm{SiMe}_{3}\right)_{3}$ to catalysts. ${ }^{b}$ The yields of $\mathrm{N}\left(\mathrm{SiMe}_{3}\right)_{3}$ were based on starting material $\mathrm{SiMe}_{3} \mathrm{Cl}$. 


\subsection{Conclusion}

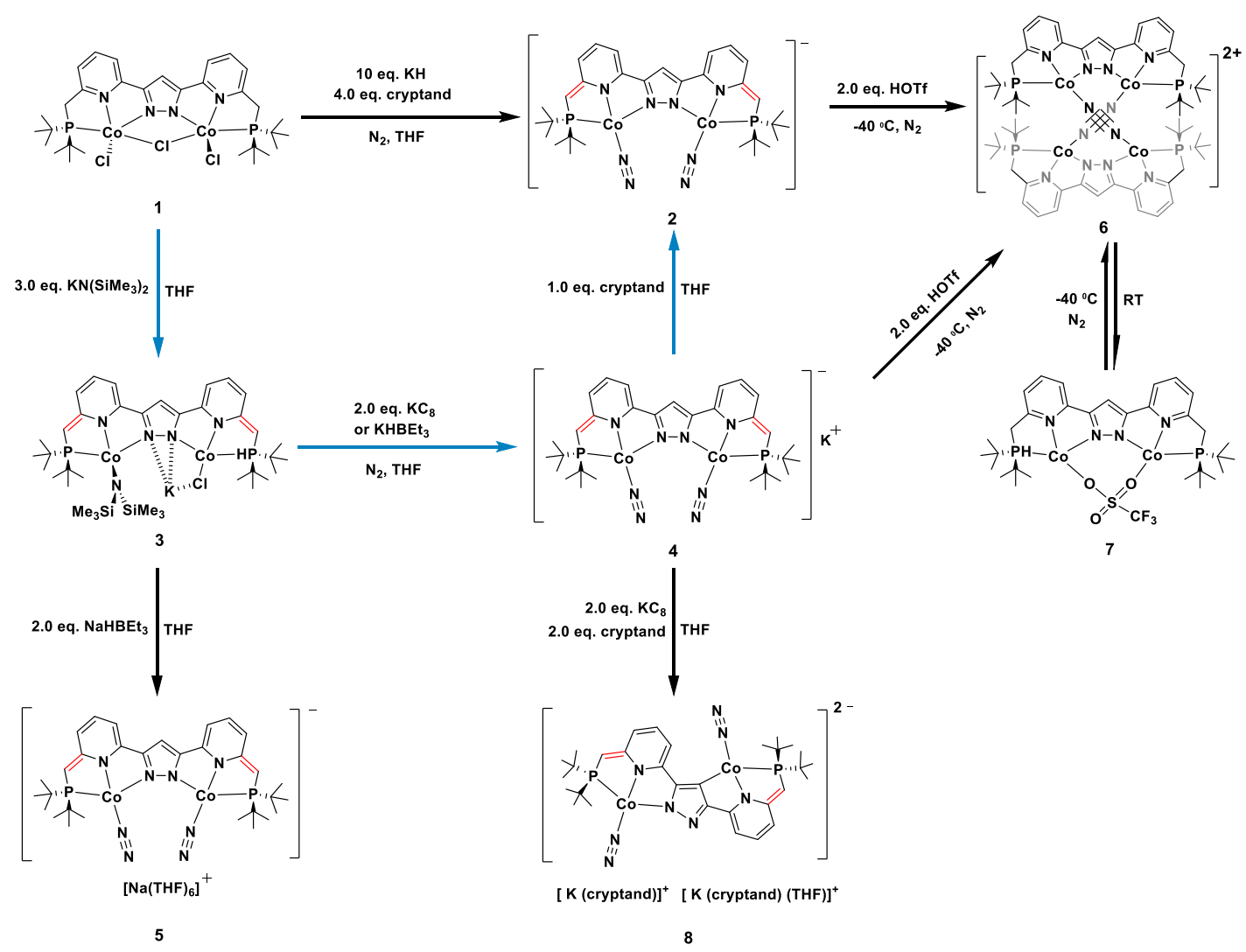

In summary, a series of cobalt complexes based on a two-in-one pincer ligand are presented, including five different cobalt dinitrogen complexes. An alternative way to synthesize the dicobalt dinitrogen complex $\mathbf{2}$ was successfully developed. The protonation of complex $\mathbf{4}$ gives rise to a triflate-bridged complex $\mathbf{7}$ at room temperature and a tetracobalt dinitrogen-bridged complex $\mathbf{6}$ at low temperature, a rare sample in the dinuclear system. Besides, the temperature-dependent speciation of complex 6 in THF was investigated by NMR and UV-vis measurements, and a reversible interconversion between complex 6 and complex 7 was discovered. The reduction of complex 2 resulted in an unexpected pyrazolate $\mathrm{C}-\mathrm{H}$ bond activation at the 4-position and part of the ligand including the pyridine moieties and $t \mathrm{Bu}_{2} \mathrm{P}$ groups has rolled over to form an uncommon dinuclear $\left\{(\mathrm{PNN}) \mathrm{Co}\left(\mathrm{N}_{2}\right)\right\}\left\{(\mathrm{PNC}) \mathrm{Co}\left(\mathrm{N}_{2}\right)\right\}^{2-}$ complex 8. By employing these cobalt complexes as catalysts, the catalytic silylation of dinitrogen into $\mathrm{N}\left(\mathrm{SiMe}_{3}\right)_{3}$ (using $\mathrm{KC}_{8}$ and $\mathrm{Me}_{3} \mathrm{SiCl}$ ) has been explored and high turnovers (up to 240) have been achieved. Furthermore, mechanic studies of the catalytic silylation and stoichiometric reaction for $\mathrm{N}_{2}$ functionalization are still in progress. 



\section{Chapter 3: Backbone Modification of the Two-In-One Pincer Ligand and Cobalt/Dinitrogen Coordination Chemistry}

\subsection{Motivation}

As mentioned in the last chapter, metal atoms in low oxidation state and low coordination numbers have advantages in $\mathrm{N}_{2}$ activation and functionalization, because of stronger $\pi$-back donations. ${ }^{10 \mathrm{c}}$ In the last chapter, five cobalt dinitrogen complexes have been successfully synthesized and all of the complexes show high productivity in catalyzing the silylation of $\mathrm{N}_{2}$ to $\mathrm{N}\left(\mathrm{SiMe}_{3}\right)_{3}$. In pursuit of low valent cobalt complexes which may realize $\mathrm{N}_{2}$ activation, the reduction of dicobalt dinitrogen complexes $\mathbf{2}$ or $\mathbf{4}$ with a strong reductant was carried out. However, this resulted in an unexpected pyrazolate $\mathrm{C}-\mathrm{H}$ bond activation at the 4-position, and part of the ligand including the pyridine moieties and $t \mathrm{Bu}_{2} \mathrm{P}$ groups rolled over to form an uncommon dinuclear $\left\{(\mathrm{PNN}) \mathrm{Co}\left(\mathrm{N}_{2}\right)\right\}\left\{(\mathrm{PNC}) \mathrm{Co}\left(\mathrm{N}_{2}\right)\right\}$ complex 8. To avoid this $\mathrm{C}-\mathrm{H}$ activation on the ligand, the 4-position of pyrazole has been modified by a methyl group and a new ligand $\mathbf{H L}^{\mathbf{M e}}$ has been exploited.

\subsection{Synthesis of Ligand $\mathrm{HL}^{\mathrm{Me}}$}

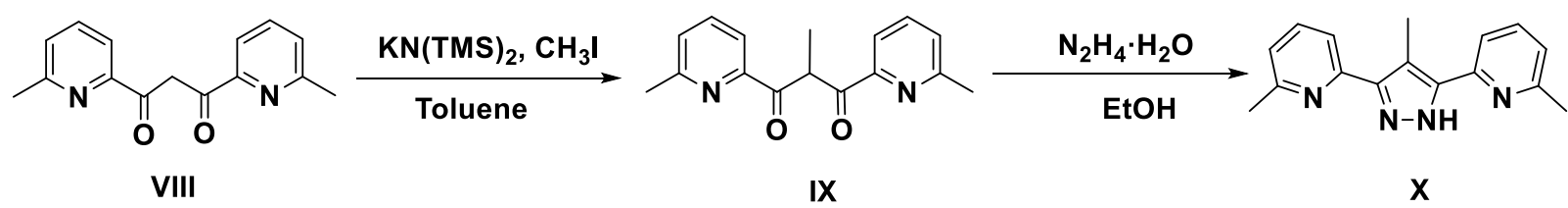

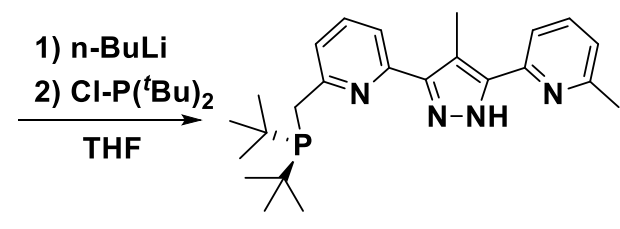

$\mathbf{X I}$

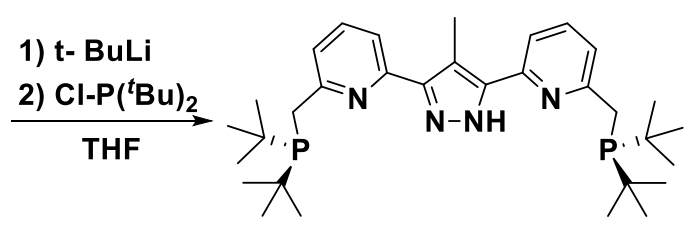

$\mathrm{HL}^{\mathrm{Me}}$

Scheme 3.1 Synthesis of the ligand $\mathbf{H L}^{\mathrm{Me}}$.

The synthesis of the ligand $\mathbf{H L} \mathbf{L}^{\mathrm{Me}}$ was quite similar to that of ligand $\mathbf{H L}$ and it contained four steps based on literature procedures. $\beta$-diketone 1,3-bis[2-(6-methyl)-pyridyl]-1,3-propanedione VIII was produced by a Claisen condensation of methyl-6-methyl-2-picolinate and 2-acetyl-6-methylpyridine. After methylation of VIII, the reaction with hydrazine monohydrate and then the two-step phosphorylation, the new pyrazolate-based two-in-one pincer ligand $\mathbf{H L}^{\mathrm{Me}}$ was isolated as off-white 
powder in $30 \%$ yield. In the ${ }^{1} \mathrm{H}-\mathrm{NMR}$ spectrum of $\mathrm{HL}^{\mathrm{Me}}$, three broad signals at $7.65,7.47$ and 7.35 ppm can be assigned to pyridine protons and the $\mathrm{CH}_{2}$ groups in the side arms were observed at 3.10 ppm as a broad singlet (Figure 9.4). A singlet at $2.72 \mathrm{ppm}$ and a doublet at $1.19 \mathrm{ppm}$ can be attributed to the methyl groups of pyrazole and $t \mathrm{Bu}$ groups respectively. The ${ }^{31} \mathrm{P}-\mathrm{NMR}$ spectrum revealed a doublet at 37.14 ppm (Figure 9.5).

\subsection{Synthesis of Dicobalt Chloride Complex 9}

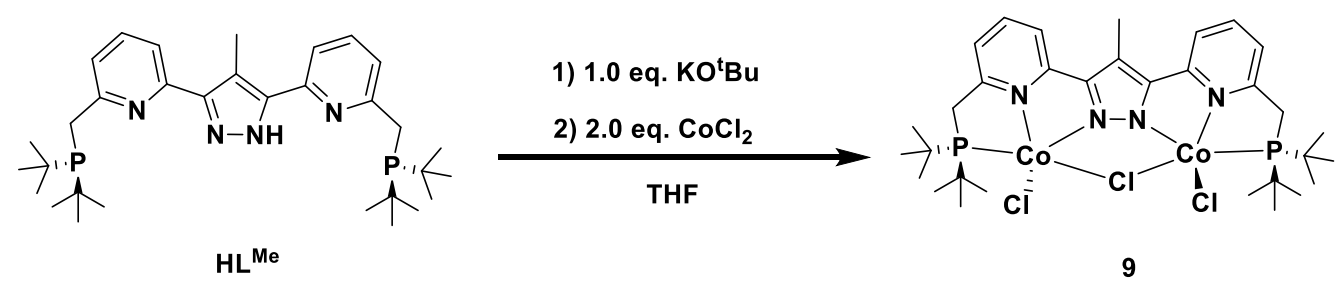

Scheme 3.2: Preparation of $\left[\mathrm{L}^{\mathrm{Me}}(\mathrm{CoCl})_{2}(\mu-\mathrm{Cl})\right]$ complex 9.

To synthesize a cobalt chloride complex as precursor, the treatment of ligand $\mathrm{HL}^{\mathrm{Me}}$ with one equivalent of $\mathrm{KO}^{t} \mathrm{Bu}$ in THF under inert atmosphere followed by subsequent addition of two equivalents of $\mathrm{CoCl}_{2}$ generated a blue suspension (Scheme 3.2). The solid residue after filtration was crystalized by slow diffusion of pentane into a saturated $\mathrm{CH}_{2} \mathrm{Cl}_{2}$ solution and gave rise to blue block crystals, which were authenticated to be the expected dinuclear $\left[\mathrm{L}^{\mathrm{Me}}(\mathrm{CoCl})_{2}(\mu-\mathrm{Cl})\right]$ complex 9 by $\mathrm{X}$-ray analysis.

Two crystallographically independent but similar molecules were found in the asymmetric unit, suggesting enantiomers in different conformations. The molecular structure of complex 9 is depicted in Figure 3.1 and selected bond lengths and angles are listed in Table 3.1. Complex 9 crystallized in the orthorhombic space group $P 2{ }_{1} 2_{1} 2_{1}$ with eight molecules in the unit cell. Similar to the structure of complex 1, the Co ions of complex 9 are in a slightly distorted square-pyramidal coordination environment with a Co $\cdots$ Co distance of $3.77 \AA$, which is about $0.04 \AA$ shorter than the distance in complex 1. Both Co ions are hosted in the PNN-tridentate binding site, bridged by pyrazolate and an exogenous chloride in the equatorial position and bound to another chloride atom in the axial positions trans respectively. The angles of $\angle \mathrm{N} 3-\mathrm{Co} 1-\mathrm{Cl} 2=155.22(7)^{\circ}$ and $\angle \mathrm{N} 4-\mathrm{Co} 2-\mathrm{Cl} 2=$ $160.49(7)^{\circ}$ deviate from ideal linear geometry, which is ascribed to the bridging chloride atom being pulling into the bimetallic cleft. The positive ion ESI mass spectrum shows a dominant peak at $\mathrm{m} / \mathrm{z}=$ 739.1 characteristic of the cation $\left[\mathrm{L}^{\mathrm{Me}} \mathrm{Co}_{2} \mathrm{Cl}_{2}\right]^{+}$(Figure 3.2). 


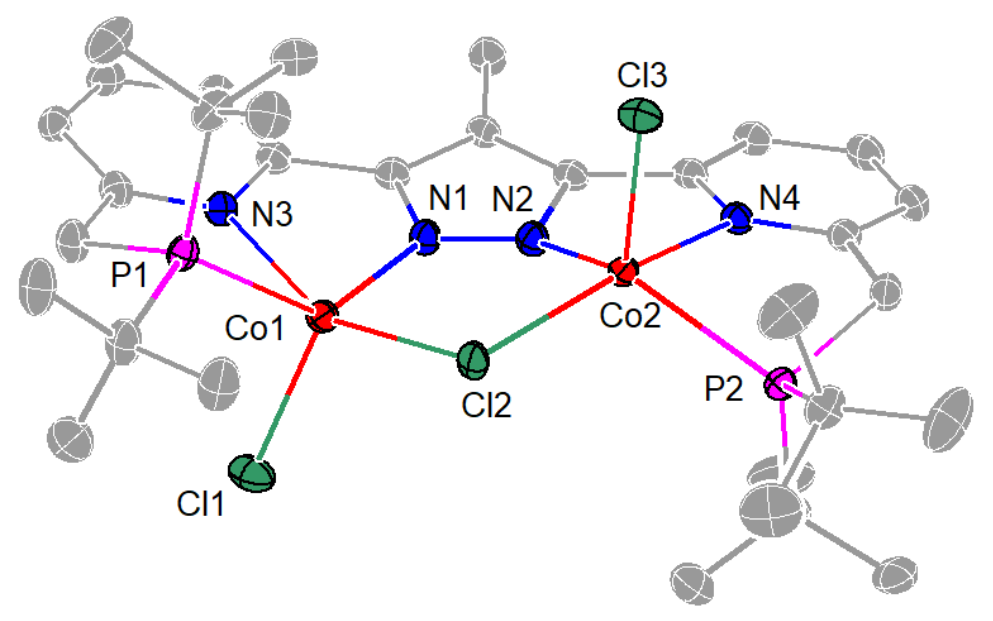

Figure 3.1: Molecular structure of complex 9 (30\% probability thermal ellipsoid). Hydrogen atoms omitted for clarity.

Table 3.1: Selected bond lengths and angles for complex 9.

\begin{tabular}{|c|c|c|c|}
\hline \multicolumn{2}{|c|}{ Bond lengths / $\AA$} & \multicolumn{2}{|c|}{ Angles / ${ }^{\circ}$} \\
\hline $\mathrm{Co}(1)-\mathrm{N}(1)$ & $1.996(3)$ & $\mathrm{N}(1)-\mathrm{Co}(1)-\mathrm{N}(3)$ & $73.06(10)$ \\
\hline $\mathrm{Co}(1)-\mathrm{N}(3)$ & $2.228(3)$ & $\mathrm{N}(1)-\mathrm{Co}(1)-\mathrm{Cl}(1)$ & $116.06(8)$ \\
\hline $\mathrm{Co}(1)-\mathrm{Cl}(1)$ & $2.2717(10)$ & $\mathrm{N}(3)-\mathrm{Co}(1)-\mathrm{Cl}(1)$ & $94.92(8)$ \\
\hline $\mathrm{Co}(1)-\mathrm{P}(1)$ & 2.3864(9) & $\mathrm{N}(1)-\mathrm{Co}(1)-\mathrm{P}(1)$ & $131.09(8)$ \\
\hline $\mathrm{Co}(1)-\mathrm{Cl}(2)$ & $2.4521(9)$ & $\mathrm{N}(3)-\mathrm{Co}(1)-\mathrm{P}(1)$ & $75.99(7)$ \\
\hline $\mathrm{Co}(2)-\mathrm{N}(2)$ & $1.991(3)$ & $\mathrm{Cl}(1)-\mathrm{Co}(1)-\mathrm{P}(1)$ & $103.38(4)$ \\
\hline $\mathrm{Co}(2)-\mathrm{N}(4)$ & $2.210(3)$ & $\mathrm{N}(1)-\mathrm{Co}(1)-\mathrm{Cl}(2)$ & $90.19(8)$ \\
\hline $\mathrm{Co}(2)-\mathrm{Cl}(3)$ & $2.2748(9)$ & $\mathrm{N}(3)-\mathrm{Co}(1)-\mathrm{Cl}(2)$ & $155.22(7)$ \\
\hline $\mathrm{Co}(2)-\mathrm{P}(2)$ & $2.4005(9)$ & $\mathrm{Cl}(1)-\mathrm{Co}(1)-\mathrm{Cl}(2)$ & $109.02(4)$ \\
\hline $\mathrm{Co}(2)-\mathrm{Cl}(2)$ & $2.4078(9)$ & $\mathrm{P}(1)-\mathrm{Co}(1)-\mathrm{Cl}(2)$ & $103.66(3)$ \\
\hline \multirow[t]{11}{*}{$\mathrm{Co} 1 \cdots \mathrm{Co} 2$} & $3.7706(7)$ & $\mathrm{N}(2)-\mathrm{Co}(2)-\mathrm{N}(4)$ & $73.66(10)$ \\
\hline & & $\mathrm{N}(2)-\mathrm{Co}(2)-\mathrm{Cl}(3)$ & $107.57(8)$ \\
\hline & & $\mathrm{N}(4)-\mathrm{Co}(2)-\mathrm{Cl}(3)$ & $93.91(7)$ \\
\hline & & $\mathrm{N}(2)-\mathrm{Co}(2)-\mathrm{P}(2)$ & $133.72(8)$ \\
\hline & & $\mathrm{N}(4)-\mathrm{Co}(2)-\mathrm{P}(2)$ & $77.10(7)$ \\
\hline & & $\mathrm{Cl}(3)-\mathrm{Co}(2)-\mathrm{P}(2)$ & $109.50(3)$ \\
\hline & & $\mathrm{N}(2)-\mathrm{Co}(2)-\mathrm{Cl}(2)$ & $91.26(8)$ \\
\hline & & $\mathrm{N}(4)-\mathrm{Co}(2)-\mathrm{Cl}(2)$ & $160.49(7)$ \\
\hline & & $\mathrm{Cl}(3)-\mathrm{Co}(2)-\mathrm{Cl}(2)$ & $102.57(3)$ \\
\hline & & $\mathrm{P}(2)-\mathrm{Co}(2)-\mathrm{Cl}(2)$ & $106.50(3)$ \\
\hline & & $\mathrm{Co}(2)-\mathrm{Cl}(2)-\mathrm{Co}(1)$ & $101.76(3)$ \\
\hline
\end{tabular}




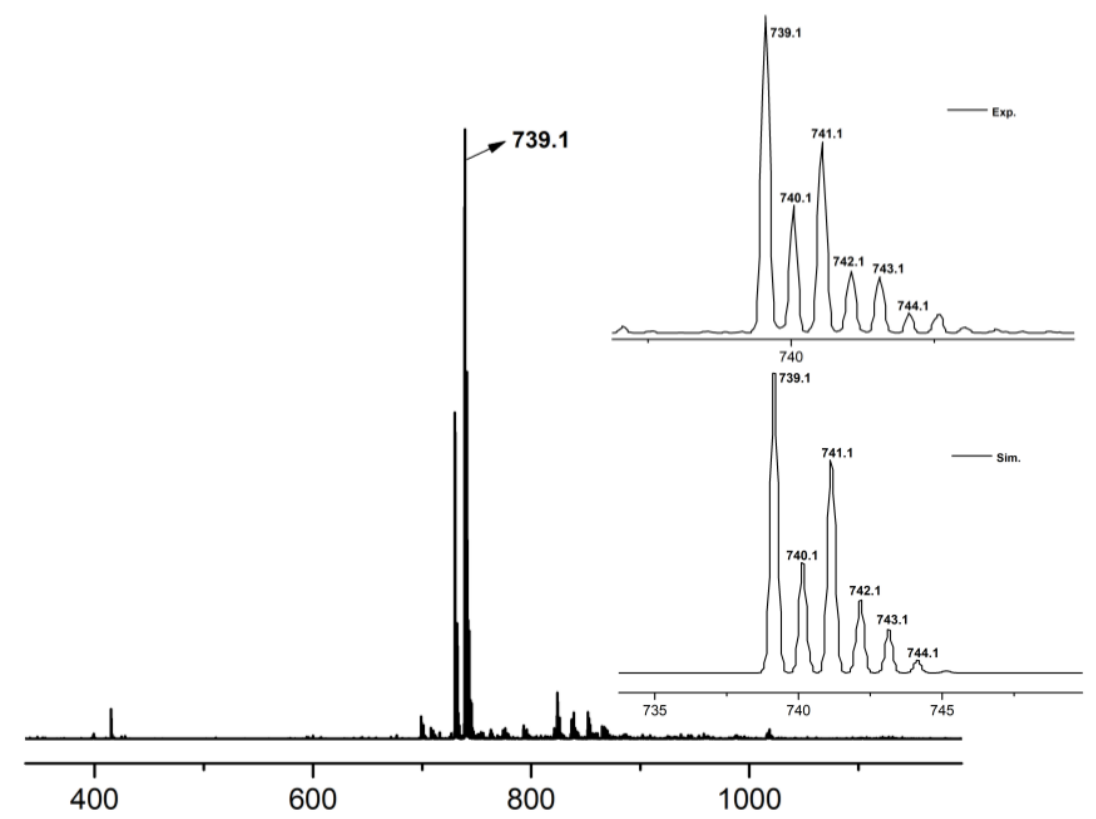

Figure 3.2: Positive ion ESI mass spectra of a solution of complex 9 in MeCN. The inset shows the experimental and simulated isotopic distribution patterns for $\left[\mathrm{L}^{\mathrm{Me}} \mathrm{Co}_{2} \mathrm{Cl}_{2}\right]^{+}$.

The ${ }^{1} \mathrm{H}-\mathrm{NMR}$ spectrum of complex 9 in $\mathrm{CDCl}_{3}$ shows somewhat broad and paramagnetically shifted resonances (Figure 3.3). In the ${ }^{1} \mathrm{H}-\mathrm{NMR}$ spectrum, based on the integration, two singlets at $\delta=32.95$ and $-10.97 \mathrm{ppm}$ can be attributed to the $t \mathrm{Bu}$ groups and one singlet at $\delta=31.24 \mathrm{ppm}$ can be assigned to the backbone methyl group of the bridging pyrazole. Three resonances at $\delta=54.64,43.78$ and $17.92 \mathrm{ppm}$ are assigned to pyridine protons based on a ${ }^{1} \mathrm{H}-{ }^{1} \mathrm{H}$ COSY spectrum (Figure 9.47). The remaining single peak at $\delta=53.73 \mathrm{ppm}$ and broad peak at $\delta=44.79 \mathrm{ppm}$ should be associated with the methylene spacer. The resonances in the ${ }^{13} \mathrm{C}-\mathrm{NMR}$ spectrum and ${ }^{31} \mathrm{P} \mathrm{NMR}$ spectrum are still unassignable or not detected due to the proximity of the nuclei to the paramagnetic $\mathrm{Co}^{\mathrm{II}}$ metal centers. Variable temperature magnetic susceptibility data recorded with a SQUID magnetometer (Figure 3.4) reveals that the $\chi_{M} T$ product rises to $4.43 \mathrm{~cm}^{3} \mathrm{~mol}^{-1} \mathrm{~K}$ at $300 \mathrm{~K}$, which represents the cobalt(II) ions are in high spin configuration with three unpaired electrons $(S=3 / 2)$. The data were fitted using $\hat{H}=-2 J \hat{S}_{1} \hat{S}_{2}+g \mu_{B} \vec{B}\left(\vec{S}_{1}+\vec{S}_{2}\right)$. The best fits leads to $g=2.277$. The decrease of the curve at low temperature indicates antiferromagnetic coupling $\left(J=-4.3 \mathrm{~cm}^{-1}\right)$. 


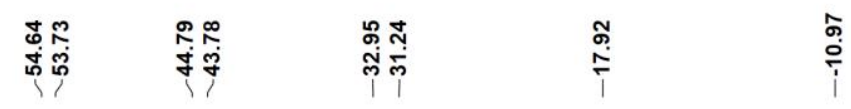

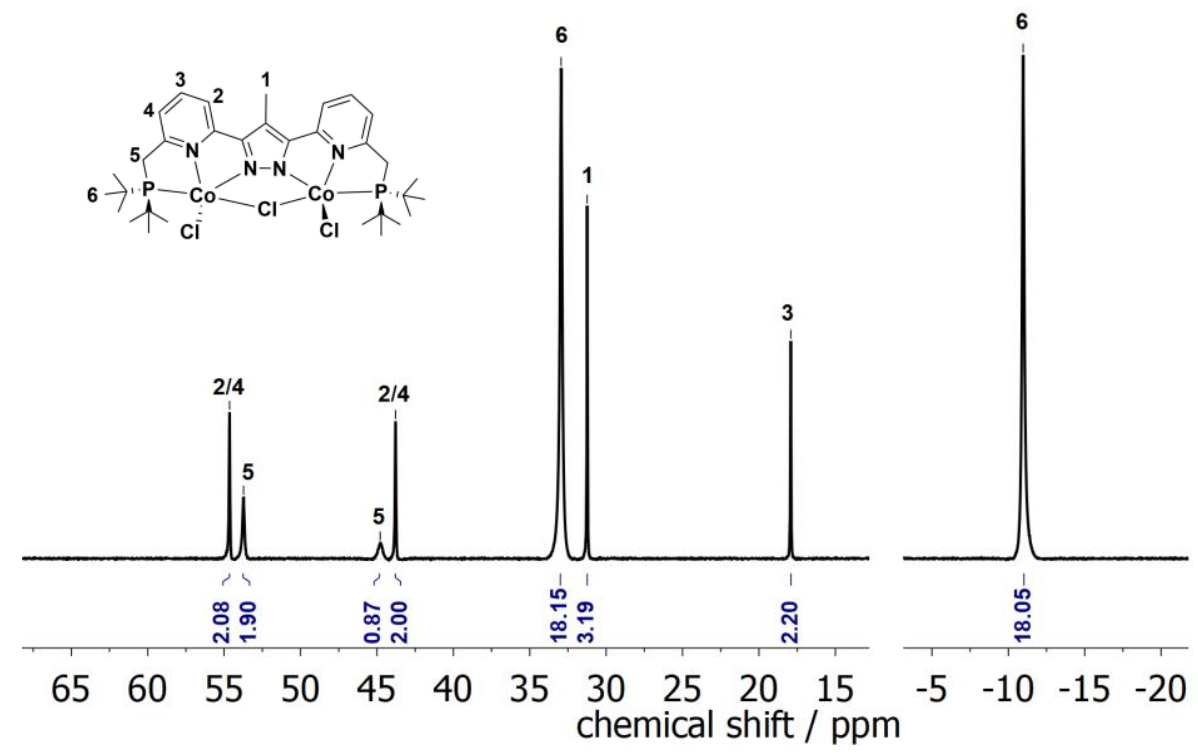

Figure 3.3: ${ }^{1} \mathrm{H}-\mathrm{NMR}$ spectrum $(400 \mathrm{MHz})$ of complex 9 in $\mathrm{CDCl}_{3}$.

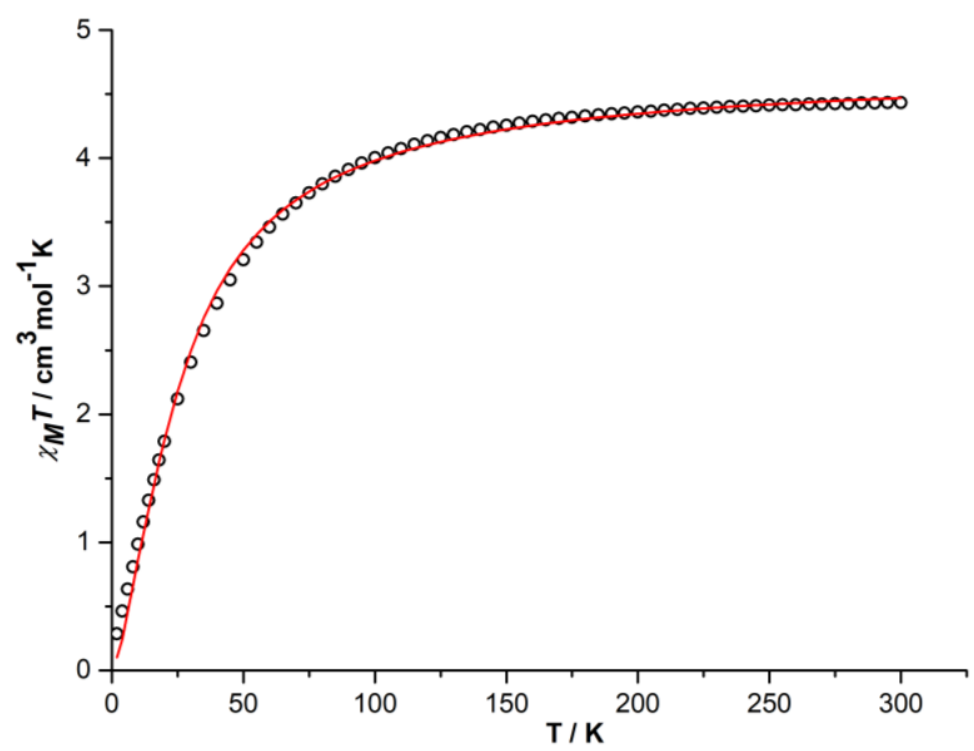

Figure 3.4: $\chi_{\mathrm{M}} T$ vs. $T$ plot in the temperature range of $2-300 \mathrm{~K}$ at $0.5 \mathrm{~T}$ for crystalline sample of complex 9. The red line corresponds to the best fits of the experimental magnetic results. The data were fitted using $\hat{H}=-2 J \hat{S}_{1} \hat{S}_{2}+g \mu_{B} \vec{B}\left(\vec{S}_{1}+\vec{S}_{2}\right)$ with $g=2.277$ and $J=-4.3 \mathrm{~cm}^{-1}$. 


\subsection{Synthesis of Dicobalt Dinitrogen Complex 10}

As described in the last chapter, a one-pot reaction has been exploited to reduce the cobalt chloride complex into a dicobalt dinitrogen complex. The treatment of complex 9 with ten equivalents of $\mathrm{KH}$ and four equivalents of cryptand led to a color change from purple to dark blue (Scheme 3.3). After filtration through glass fiber filters, crystals of complex $\mathbf{1 0}$ suitable for X-ray analysis were obtained by layering a concentrated THF solution with hexane at $-40{ }^{\circ} \mathrm{C}$ in $85 \%$ yield.

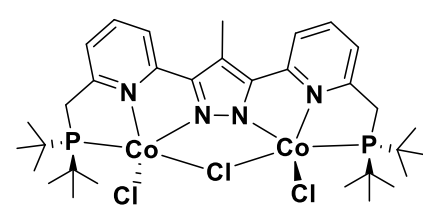

9

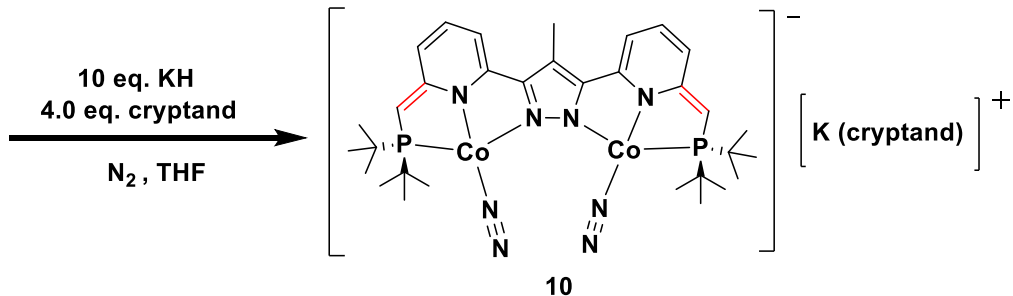

Scheme 3.3: Preparation of the dicobalt dinitrogen complex 10.

Complex 10 crystallized in the monoclinic space group $P 2_{1} / \mathrm{c}$ with four molecules in the unit cell. The potassium cation is encapsulated by [2,2,2]cryptand. As depicted in Figure 3.5, the X-ray analysis determined structure of the anion of complex $\mathbf{1 0}$ shows that the overall coordination environment of both cobalt ions is a distorted square planar geometry. Selected bond lengths and angels are listed in Table 3.2. The C-C bonds in the side arms are around $0.13 \AA$ shorter than those in complex 9, which is associated with deprotonation of the methylene group of pyridine moieties and subsequent dearomatization of the pyridine rings. The two cobalt ions are hosted in $\{\mathrm{PNN}\}$-tridentate binding pockets of the trianionic pincer ligand scaffold and bound to one terminal dinitrogen molecule with N-N bond lengths of 1.116(3) and 1.117(3) $\AA$, respectively. The N-N bond lengths in complex $\mathbf{1 0}$ are a bit shorter than those in complex $\mathbf{2}$, suggesting slightly weaker $\pi$-back bonding to the $\mathrm{N}_{2}$ molecules in complex 10. The Co...Co distance of $4.16 \AA$ is distinctly longer by $0.39 \AA$ than in complex 9 and it is also shorter than that in complex 2 (Co ‥Co distance: $4.30 \AA$ ), perhaps due to the steric repulsion among the methyl group and pyridines that two metal centers closer. The Co-N-N-Co torsion angle is $23.7^{\circ}$. 

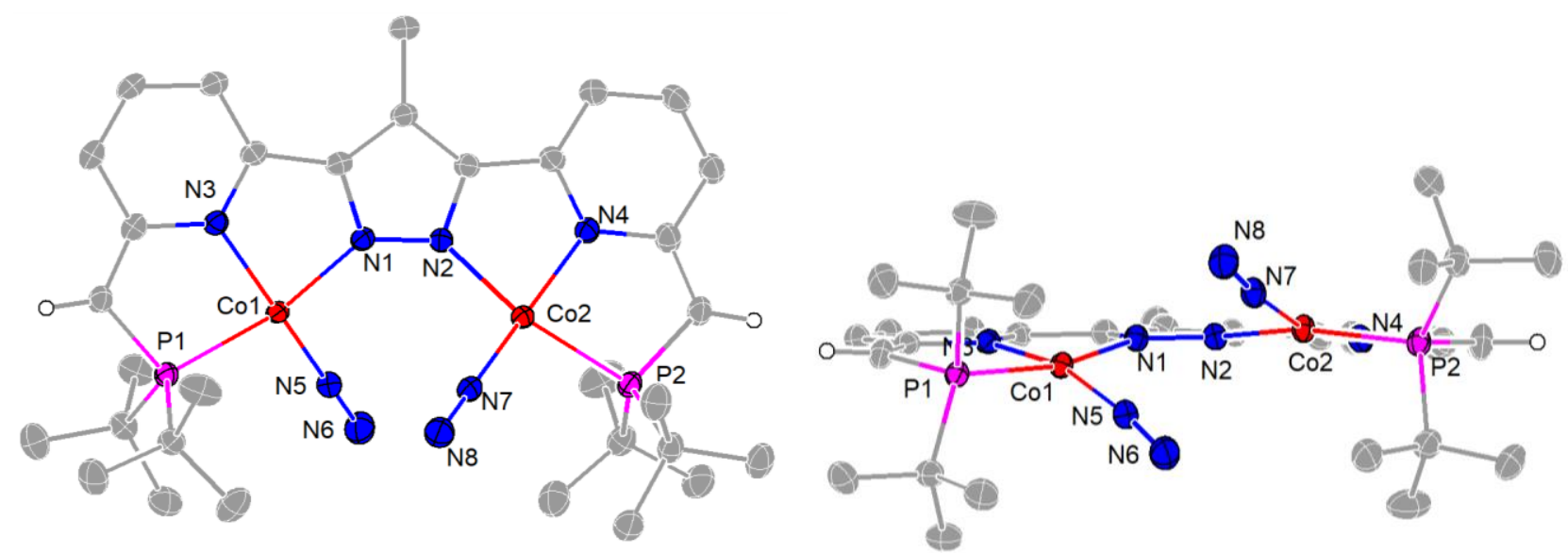

Figure 3.5: Top view (left) and front view (right) of the molecular structure of the anion of complex 10. Thermal displacement ellipsoids shown at $30 \%$ probability; most hydrogen atoms, the cation $(\mathrm{K}([2.2 .2] \text { cryptand }))^{+}$and solvent molecules omitted for clarity.

Table 3.2: Selected bond lengths and angles for complex $\mathbf{1 0}$.

\begin{tabular}{llll}
\hline \multicolumn{2}{c}{ Bond lengths / $\AA$} & \multicolumn{2}{c}{ Angles / } \\
\hline $\mathrm{Co}(1)-\mathrm{N}(5)$ & $1.739(2)$ & $\mathrm{N}(5)-\mathrm{Co}(1)-\mathrm{N}(3)$ & $163.86(8)$ \\
$\mathrm{Co}(1)-\mathrm{N}(3)$ & $1.9106(17)$ & $\mathrm{N}(5)-\mathrm{Co}(1)-\mathrm{N}(1)$ & $98.59(8)$ \\
$\mathrm{Co}(1)-\mathrm{N}(1)$ & $1.9290(18)$ & $\mathrm{N}(3)-\mathrm{Co}(1)-\mathrm{N}(1)$ & $81.61(7)$ \\
$\mathrm{Co}(1)-\mathrm{P}(1)$ & $2.1843(6)$ & $\mathrm{N}(5)-\mathrm{Co}(1)-\mathrm{P}(1)$ & $96.21(6)$ \\
$\mathrm{Co}(2)-\mathrm{N}(7)$ & $1.746(2)$ & $\mathrm{N}(3)-\mathrm{Co}(1)-\mathrm{P}(1)$ & $85.16(6)$ \\
$\mathrm{Co}(2)-\mathrm{N}(4)$ & $1.9114(18)$ & $\mathrm{N}(1)-\mathrm{Co}(1)-\mathrm{P}(1)$ & $164.78(6)$ \\
$\mathrm{Co}(2)-\mathrm{N}(2)$ & $1.9219(17)$ & $\mathrm{N}(7)-\mathrm{Co}(2)-\mathrm{N}(4)$ & $165.06(9)$ \\
$\mathrm{Co}(2)-\mathrm{P}(2)$ & $2.1883(6)$ & $\mathrm{N}(7)-\mathrm{Co}(2)-\mathrm{N}(2)$ & $98.63(8)$ \\
$\mathrm{Co} 1 \cdots \mathrm{Co} 2$ & $4.1635(4)$ & $\mathrm{N}(4)-\mathrm{Co}(2)-\mathrm{N}(2)$ & $81.52(7)$ \\
$\mathrm{N}(5)-\mathrm{N}(6)$ & $1.116(3)$ & $\mathrm{N}(7)-\mathrm{Co}(2)-\mathrm{P}(2)$ & $96.65(6)$ \\
$\mathrm{N}(7)-\mathrm{N}(8)$ & $1.117(3)$ & $\mathrm{N}(4)-\mathrm{Co}(2)-\mathrm{P}(2)$ & $84.97(6)$ \\
& & $\mathrm{N}(2)-\mathrm{Co}(2)-\mathrm{P}(2)$ & $163.96(6)$ \\
\hline
\end{tabular}

The ${ }^{1} \mathrm{H}-\mathrm{NMR}$ spectrum in THF-d $\mathrm{d}_{8}$ (Figure 3.6) reflects that complex $\mathbf{1 0}$ is a diamagnetic Co ${ }^{\mathrm{I}}$ species. It demonstrates one triplet at $\delta=6.08 \mathrm{ppm}$ and two doublets at $\delta=5.61$ and $5.24 \mathrm{ppm}$ for pyridine protons, one singlet at $\delta=2.93 \mathrm{ppm}$ for $\mathrm{CH}$ groups in the side arms, one singlet at $\delta=2.10 \mathrm{ppm}$ for the methyl group of the pyrazolate, and one doublet at $\delta=1.42 \mathrm{ppm}$ for the $t \mathrm{Bu}$ groups based on ${ }^{1} \mathrm{H}-{ }^{1} \mathrm{H}$ COSY and ${ }^{1} \mathrm{H}-{ }^{1} \mathrm{H}$ NOESY spectra (Figure 9.49 and 9.50). The ${ }^{31} \mathrm{P}-\mathrm{NMR}$ spectrum (Figure 3.7) revealed a peak at $80.87 \mathrm{ppm}$, obviously upfield shifted comparing to the chemical shift in complex $\mathbf{2}$, most likely benefitting from the electron donation of the backbone methyl group. 


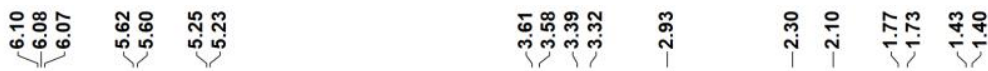

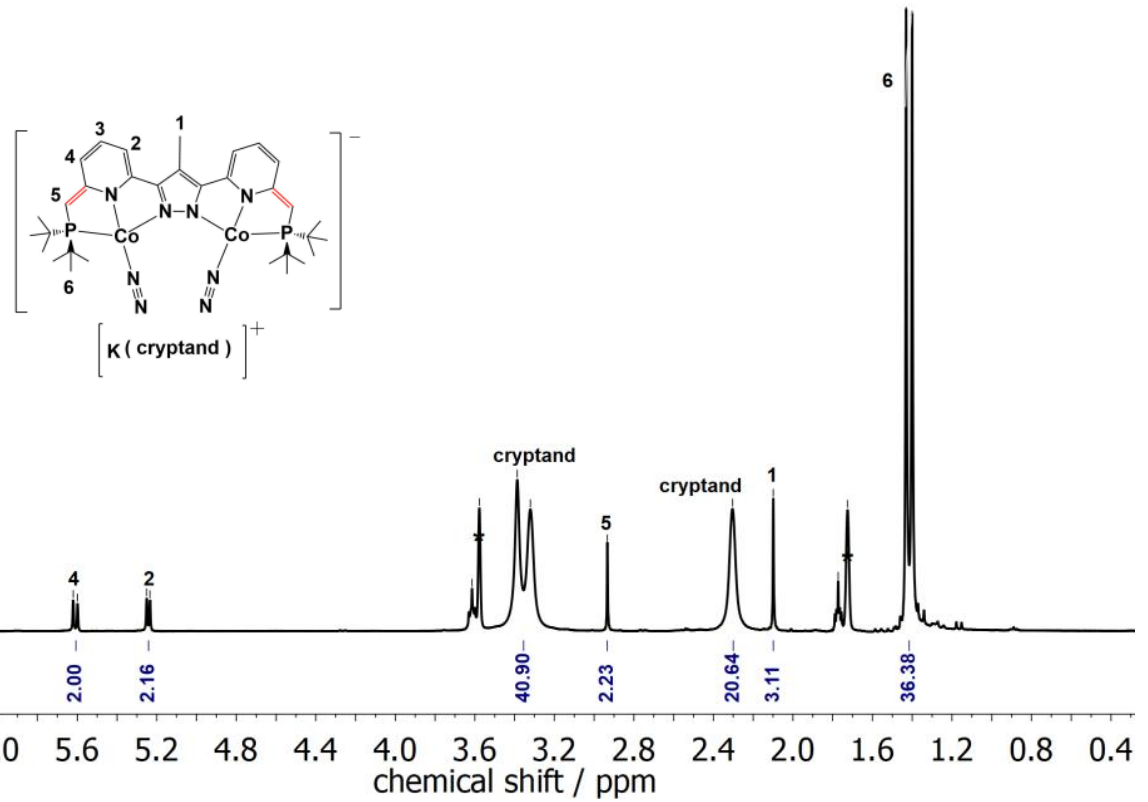

Figure 3.6: ${ }^{1} \mathrm{H}-\mathrm{NMR}$ spectrum of complex 10 in $\mathrm{THF}-\mathrm{d}_{8}$. Solvent signals are marked with an asterisk $(*)$.

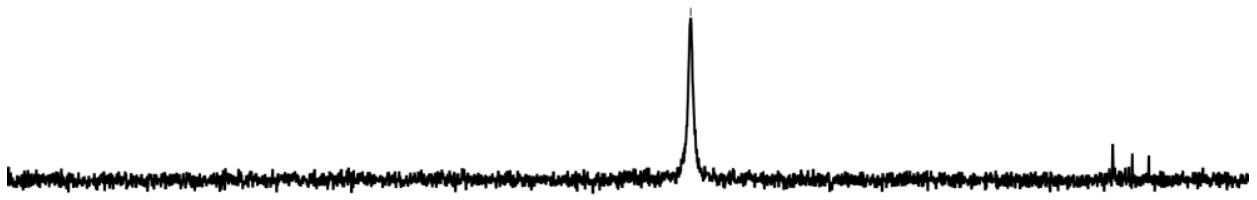

$\begin{array}{llllllllllll}150 & 140 & 130 & 120 & 110 & \begin{array}{c}100 \\ \text { chemical shift/ ppm }\end{array} & 90 & 80 & 50 & 40 & 30\end{array}$

Figure 3.7: ${ }^{31} \mathrm{P}-\mathrm{NMR}$ spectrum of complex 10 in $\mathrm{THF}-\mathrm{d}_{8}$.

As depicted in Figure 3.8, the IR spectrum in complex 10 shows two intense peaks at 2037 and 2013 
$\mathrm{cm}^{-1}$, which correspond to the asymmetric and symmetric N-N stretching vibrations, respectively. In contrast to complex $\mathbf{2}$, the dinitrogen molecules in complex $\mathbf{1 0}$ are less reduced according to the N-N bond length and N-N stretching vibrations. UV-vis spectroscopy of complex $\mathbf{1 0}$ was measured in THF solution in the temperature range from $293 \mathrm{~K}$ to $183 \mathrm{~K}$ (Figure 3.9) and the bands at 334, $482 \mathrm{~nm}$, $518 \mathrm{~nm}$ and $613 \mathrm{~nm}$ may be attributed to MLCT transitions. DFT calculation reveals that the optimized molecular structure of $\mathbf{1 0}$ is in good agreement with the experimental one and predicts N-N stretching vibrations in the calculated IR spectrum at 2078 and $2060 \mathrm{~cm}^{-1}$ (Figure 3.10 and 11).

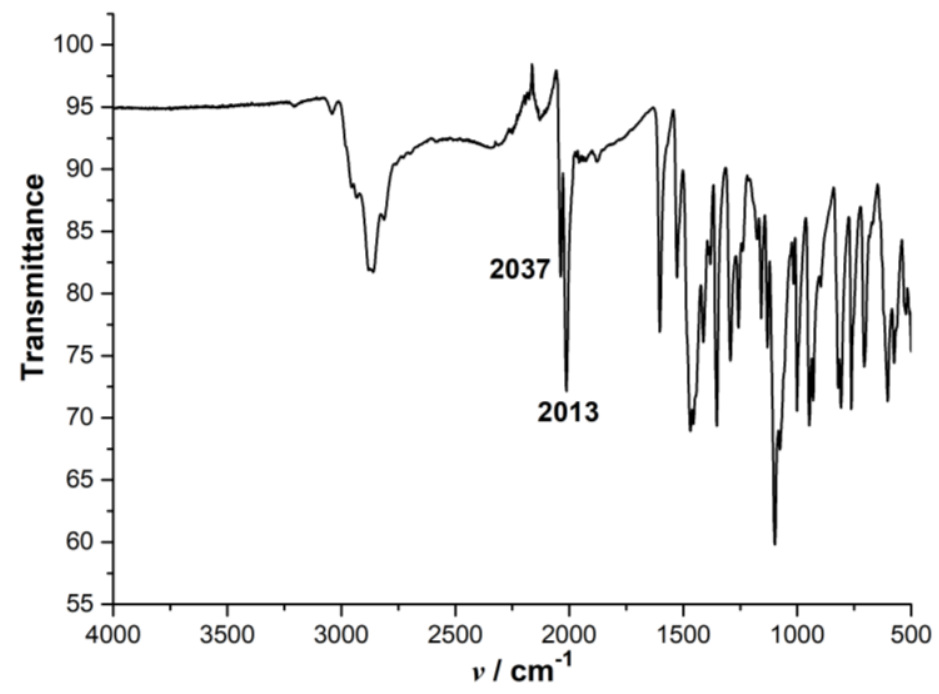

Figure 3.8: IR spectrum of complex 10 in solid state.

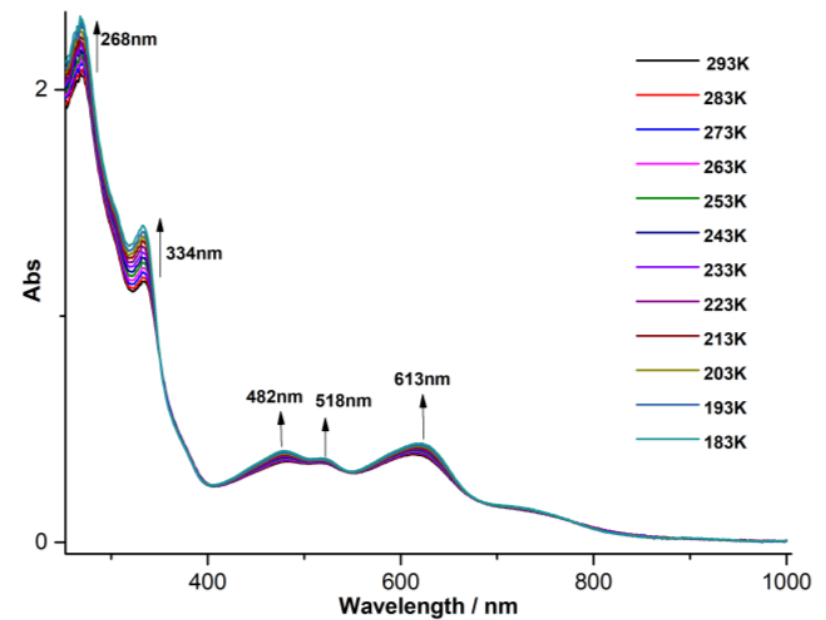

(a)

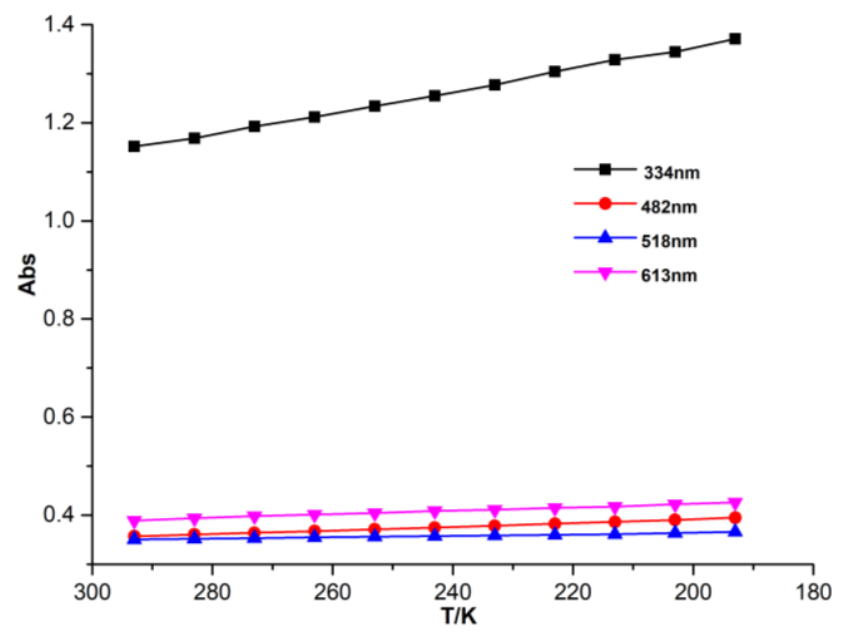

(b)

Figure 3.9: (a) Variable temperature UV-vis spectra of complex 10 in THF solution in the temperature range from $293 \mathrm{~K}$ to $183 \mathrm{~K}$. (b) Plots of absorption at different temperature. 


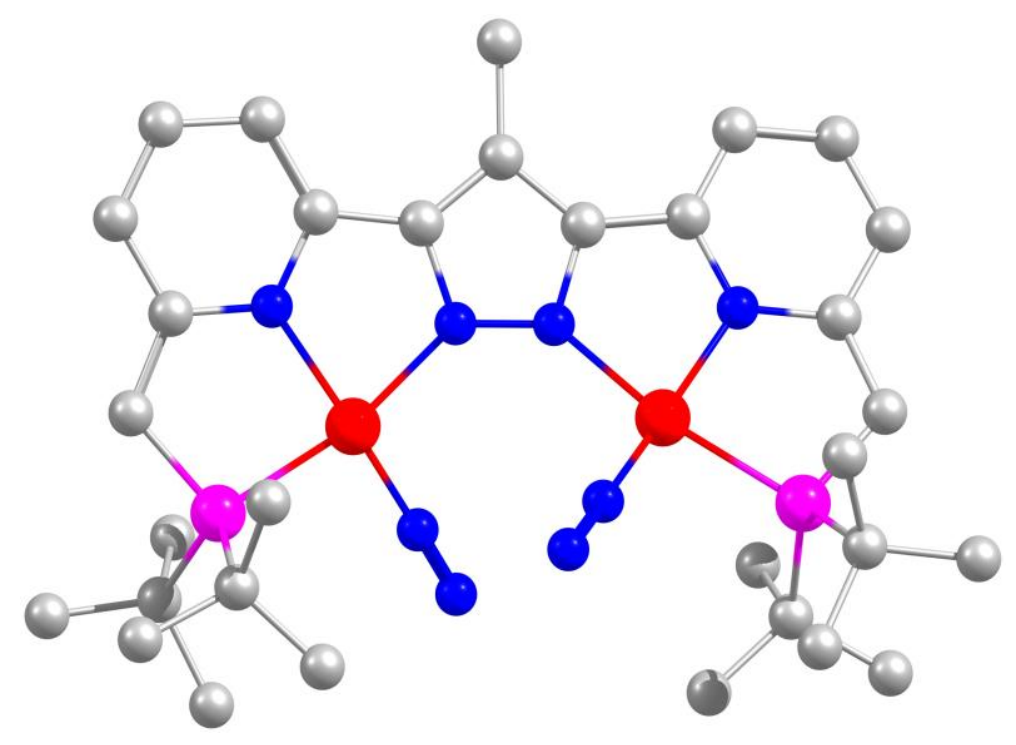

Figure 3.10: DFT optimized molecular structure of complex $10(\mathrm{Co}=\operatorname{red}, \mathrm{N}=$ blue, $\mathrm{P}=$ violet, $\mathrm{C}=$ grey). Spin restricted DFT calculations with ORCA 3.0.3, BP86 functional, def2-svp basis set, RI approximation using the auxiliary def2-svp/J basis set, D3 dispersion correction with Becke-Johnson damping, tight convergence and optimization criteria).

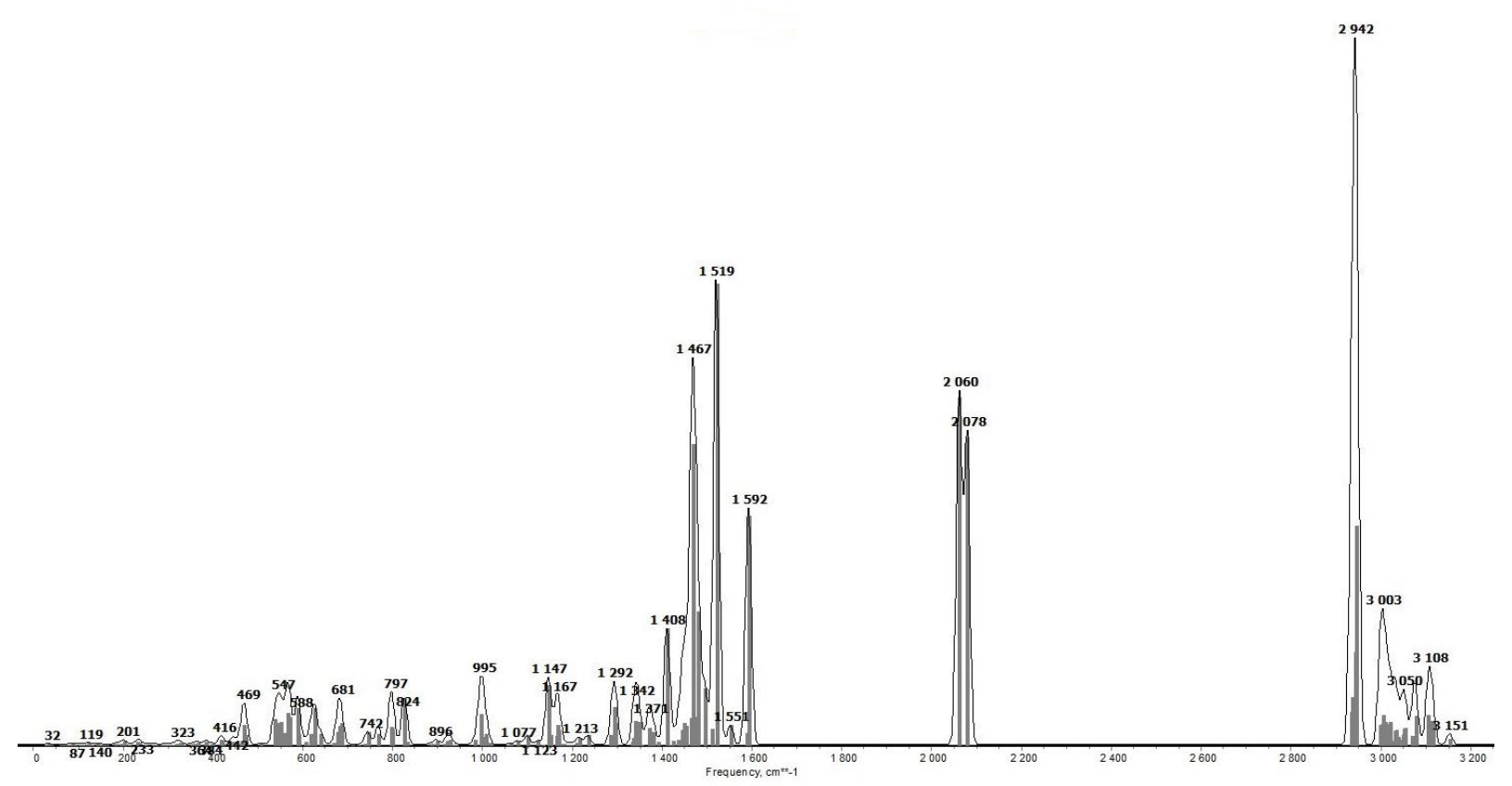

Figure 3.11: Calculated IR spectrum of 10. Predicted $\mathrm{N}_{2}$ stretching: $2060 / 2078 \mathrm{~cm}^{-1}$. The spectrum was convoluted using a Gaussian line shape function with a half-width of $15 \mathrm{~cm}^{-1}$.

Table 3.3: Comparison of experimental and DFT calculated metric parameters of 10; selected distances $[\AA]$ and angles $\left[{ }^{\circ}\right]$. 


\begin{tabular}{ccc}
\hline & $\mathbf{1 0}(\mathbf{e x p})$ & $\mathbf{1 0}$ (calculated) \\
\hline $\mathrm{Co}-\mathrm{N}^{\mathrm{pz}}$ & $1.9219(17)-1.9290(18)$ & $1.911-1.916$ \\
$\mathrm{Co}-\mathrm{N}^{\mathrm{py}}$ & $1.9106(17)-1.9114(18)$ & $1.913-1.914$ \\
$\mathrm{Co}-\mathrm{N}_{2}$ & $1.739(2)-1.746(2)$ & 1.726 \\
$\mathrm{Co}-\mathrm{P}$ & $2.1843(6)-2.1883(6)$ & $2.174-2.175$ \\
$\mathrm{Co} \cdots \mathrm{Co}$ & $4.1635(4)$ & 4.1371 \\
$\mathrm{~N}-\mathrm{N}$ & $1.116(3) / 1.117(3)$ & 1.135 \\
$\mathrm{Co}-\mathrm{N}-\mathrm{N}$ & $172.575-172.876$ & $172.219-172.598$ \\
\hline
\end{tabular}

\subsubsection{An Alternative Way to Synthesize Dicobalt Dinitrogen Complex 11}

Following the strategy described in Chapter 2.4, a multistep synthetic route was rendered which involved the addition of a strong base $\mathrm{KN}\left(\mathrm{SiMe}_{3}\right)_{2}$ and subsequent addition of $\mathrm{KC}_{8}(2.0$ eq.). This led to the dearomatization of the pyridine moieties and the change of oxidation state of the metal centers. Crystals suitable for X-ray analysis were obtained by layering the THF solution with hexane at $-40^{\circ}$ $\mathrm{C}$ in $75 \%$ yield (Scheme 3.4 ).

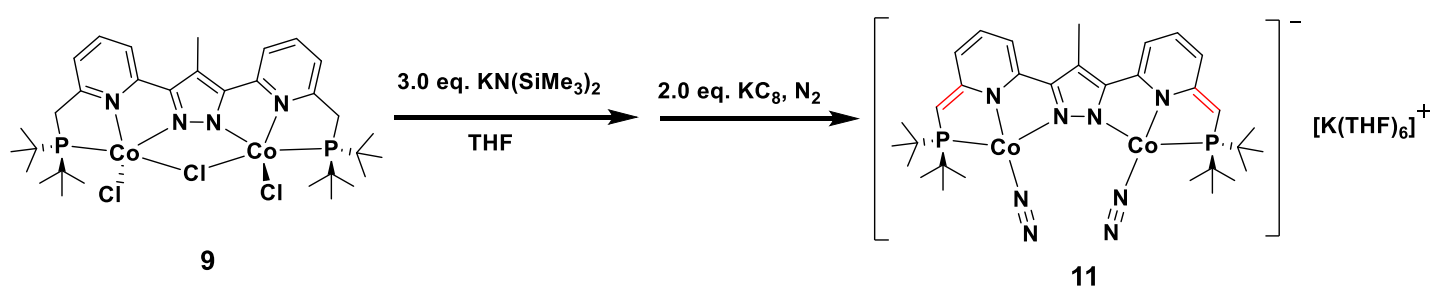

Scheme 3.4: An alternative way to synthesize the dicobalt dinitrogen complex 11.

Two crystallographically independent but similar molecules were found in the asymmetric unit, suggesting enantiomers in different conformations. Complex $\mathbf{1 1}$ crystallized in the monoclinic space group $C 2 / \mathrm{c}$ with eight molecules in the unit cell (Figure 3.12). The molecular structure of the anion of complex 11 shows that both cobalt (II) ions are in a distorted square planar geometry, hosted in the $\{\mathrm{PNN}\}$-tridentate binding pockets of the trianionic pincer ligand scaffold, bridged by the pyrazolate and coordinated to one terminal dinitrogen molecule with N-N bond lengths of $1.1126(4) \AA$, which are similar to those in complex 10. Selected bond lengths and angels are listed in Table 3.4. The C-C bonds in the side arms are $1.373 \AA$. The Co $\cdots$ Co distance of $4.22 \AA$ in complex 11 is marginally longer by $0.06 \AA$ than in complex $\mathbf{1 0}$ and the Co-N-N-Co torsion angle is $31.9^{\circ}$. Additionally, the potassium cation is coordinated with THF solvent molecules. Complex 11 shows crystallographic $C_{2}$ symmetry. 

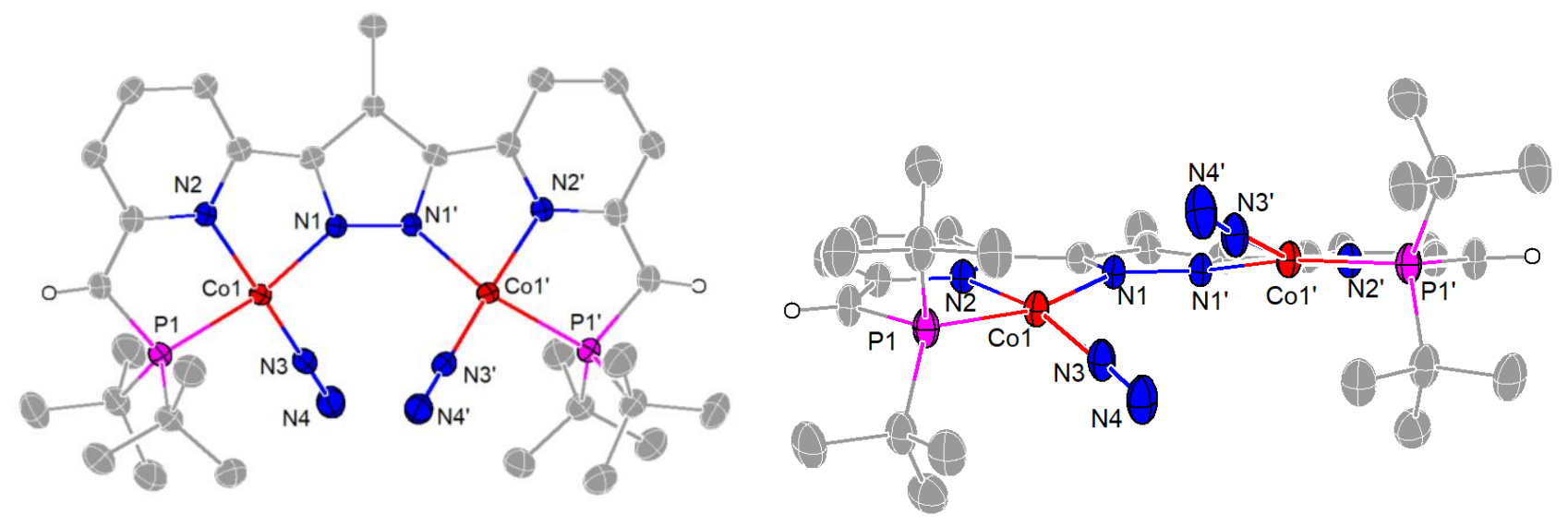

Figure 3.12: Top view (left) and front view (right) of the molecular structure of the anion of complex 11. Thermal displacement ellipsoids shown at $30 \%$ probability; most hydrogen atoms, the cation $\left(\mathrm{K}(\mathrm{THF})_{6}\right)^{+}$and solvent molecules omitted for clarity.

Table 3.4: Selected bond lengths and angles for complex 11.

\begin{tabular}{llll}
\hline \multicolumn{3}{c}{ Bond lengths / $\AA$} & \multicolumn{2}{c}{ Angles / } \\
\hline $\mathrm{Co}(1)-\mathrm{N}(3)$ & $1.731(3)$ & $\mathrm{N}(3)-\mathrm{Co}(1)-\mathrm{N}(1)$ & $99.56(11)$ \\
$\mathrm{Co}(1)-\mathrm{N}(1)$ & $1.898(2)$ & $\mathrm{N}(3)-\mathrm{Co}(1)-\mathrm{N}(2)$ & $167.29(14)$ \\
$\mathrm{Co}(1)-\mathrm{N}(2)$ & $1.901(2)$ & $\mathrm{N}(1)-\mathrm{Co}(1)-\mathrm{N}(2)$ & $81.10(10)$ \\
$\mathrm{Co}(1)-\mathrm{P}(1)$ & $2.1791(9)$ & $\mathrm{N}(3)-\mathrm{Co}(1)-\mathrm{P}(1)$ & $95.79(9)$ \\
$\mathrm{Co} 1 \cdots \mathrm{Co} 1^{\prime}$ & $4.2187(9)$ & $\mathrm{N}(1)-\mathrm{Co}(1)-\mathrm{P}(1)$ & $164.22(8)$ \\
$\mathrm{N}(3)-\mathrm{N}(4)$ & $1.1126(4)$ & $\mathrm{N}(2)-\mathrm{Co}(1)-\mathrm{P}(1)$ & $84.75(8)$ \\
\hline
\end{tabular}

The ${ }^{1} \mathrm{H}-\mathrm{NMR}$ spectrum in THF-d 8 (Figure 3.13) confirms complex $\mathbf{1 1}$ is a diamagnetic $\mathrm{Co}^{\mathrm{I}}$ species and it shows apparent $C_{2 v}$ symmetry in solution on the NMR timescale at room temperature. Variable temperature ${ }^{1} \mathrm{H}$-NMR spectra were recorded to investigate potential dynamic properties of complex 11 (Figure 3.14). As the temperature drops from $303 \mathrm{~K}$ to $193 \mathrm{~K}$, the resonances associated with the pyridine and pyrazolate moieties shift slightly and the proton signal attributed to side arms shows an inconspicuous upfield shift. Additionally, the doublet of the $t \mathrm{Bu}$ groups becomes broad at $233 \mathrm{~K}$ and finally splits into two broad peaks at low temperature, which may be attributed to the slow interconversion of the $C_{2}$ symmetric enantiomers that leads to inequivalent steric and electronic environments of the $t$ Bu protons. The ${ }^{31} \mathrm{P}-\mathrm{NMR}$ spectrum (Figure 3.15) reveals a peak at $81.17 \mathrm{ppm}$. 


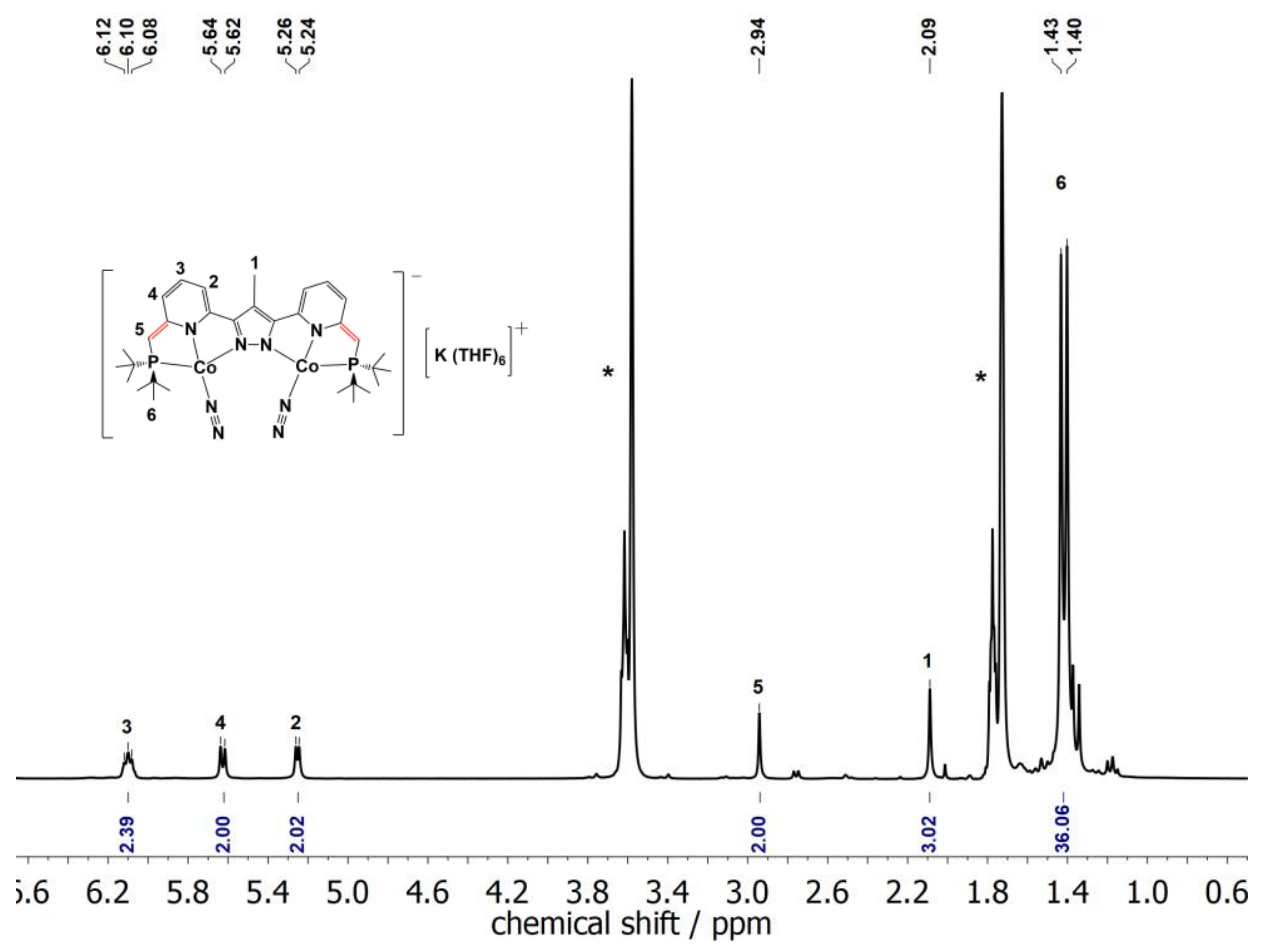

Figure 3.13: ${ }^{1} \mathrm{H}-\mathrm{NMR}$ spectrum of complex 11 in $\mathrm{THF}-\mathrm{d}_{8}$. Solvent signals are marked with an asterisk $(*)$.

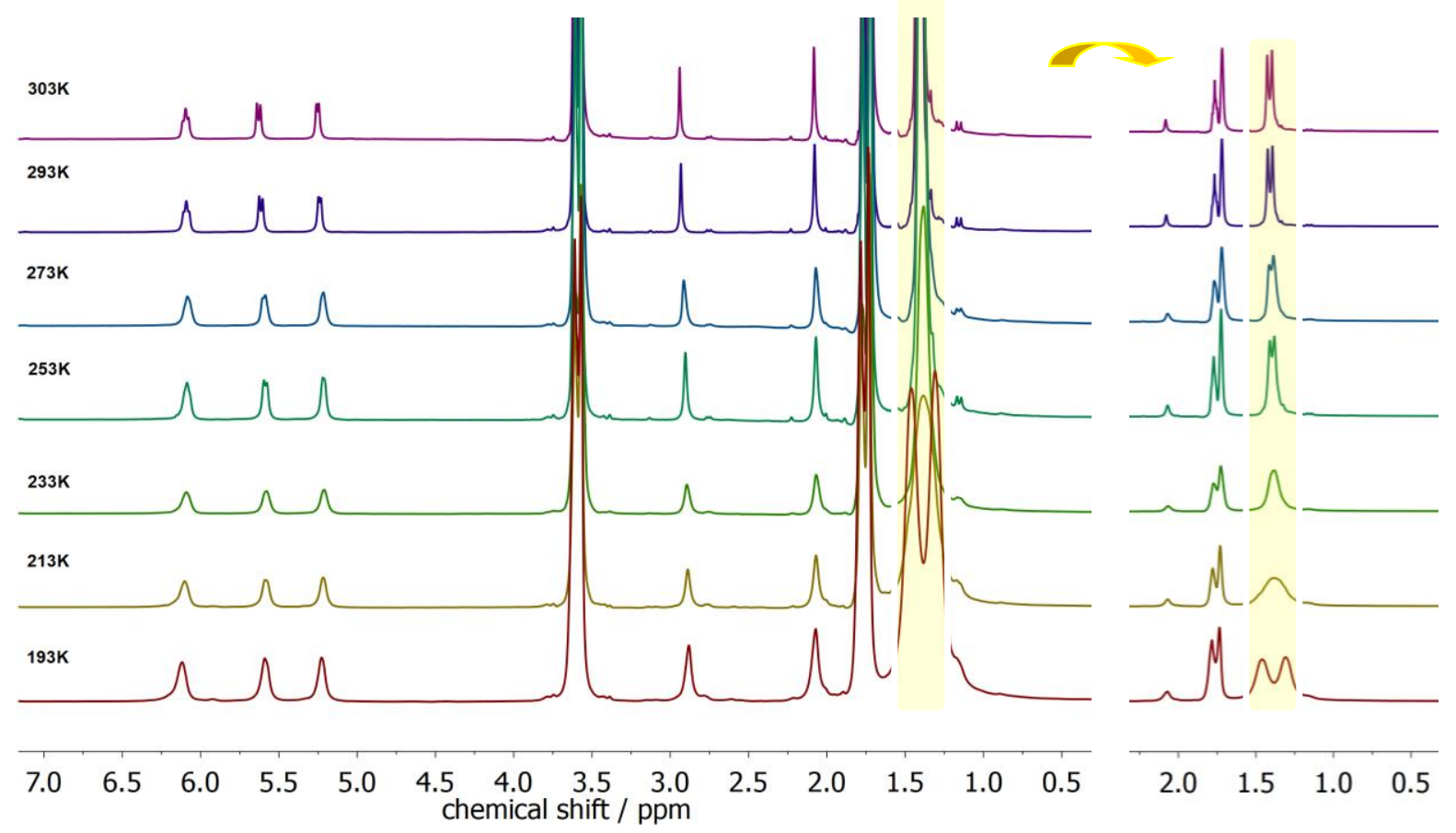

Figure 3.14: ${ }^{1} \mathrm{H}-\mathrm{NMR}$ spectrum of complex 11 in $\mathrm{THF}-\mathrm{d}_{8}$. 


\section{$\stackrel{5}{\stackrel{\infty}{\infty}}$}

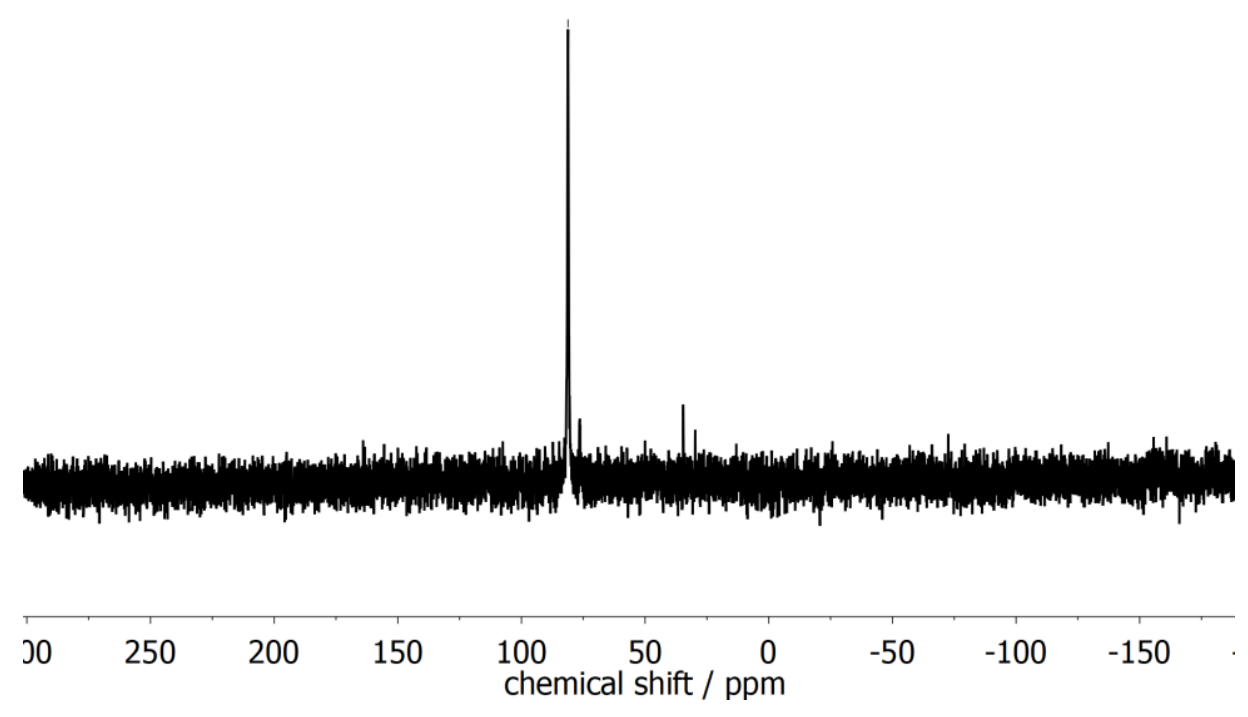

Figure 3.15: ${ }^{31} \mathrm{P}-\mathrm{NMR}$ spectrum of complex 11 in $\mathrm{THF}-\mathrm{d}_{8}$.

As shown in Figure 3.16, two intense peaks in the IR spectra of solid $\mathbf{1 1}$ correspond to the asymmetric and symmetric N-N stretching vibrations at 2049 and $1998 \mathrm{~cm}^{-1}$. Interestingly, two N-N stretching peaks of complex 11 show red- and blue-shift respectively in comparison to complex $\mathbf{2 , 4}$ and 10. UV-vis spectra of complex 11 were measured in THF solution in the temperature range of $293 \mathrm{~K}$ to $183 \mathrm{~K}$ (Figure 3.17) and bands at 332, $484 \mathrm{~nm}, 517 \mathrm{~nm}$ and $612 \mathrm{~nm}$ may be attributed to MLCT transitions.

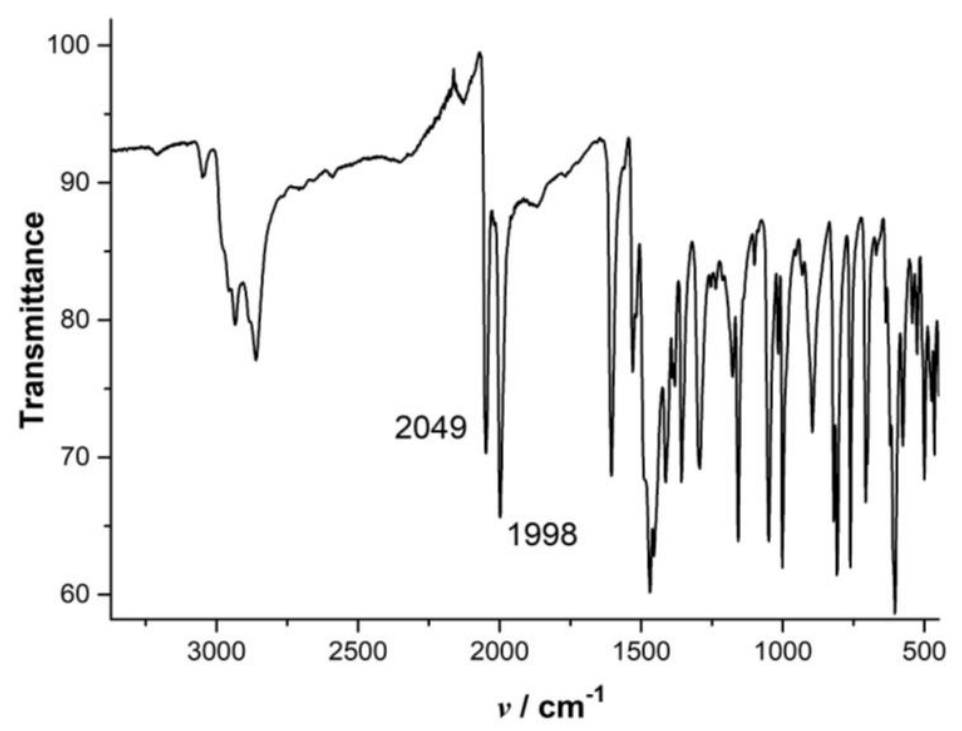

Figure 3.16: IR spectrum of complex 11 in solid state. 


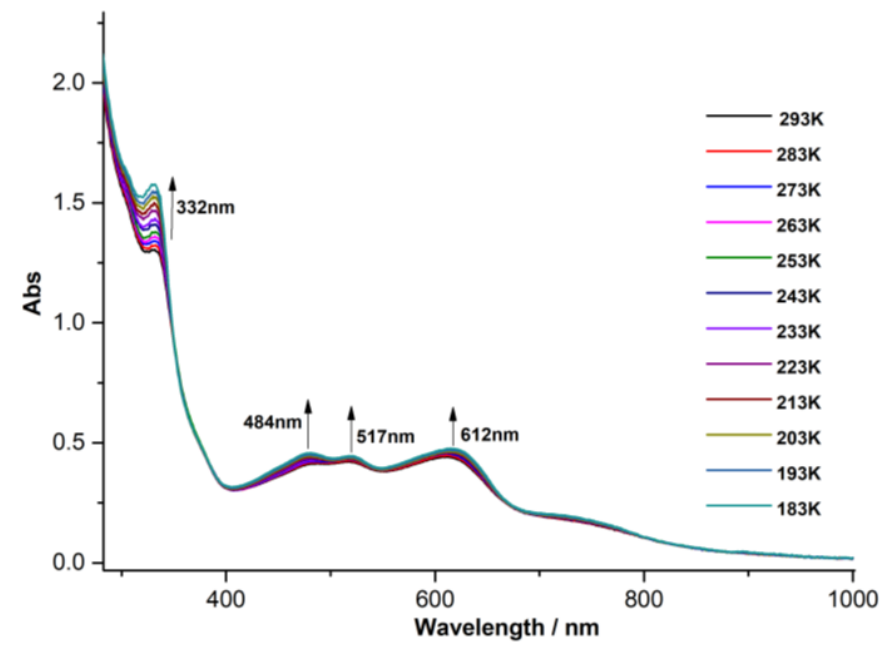

a

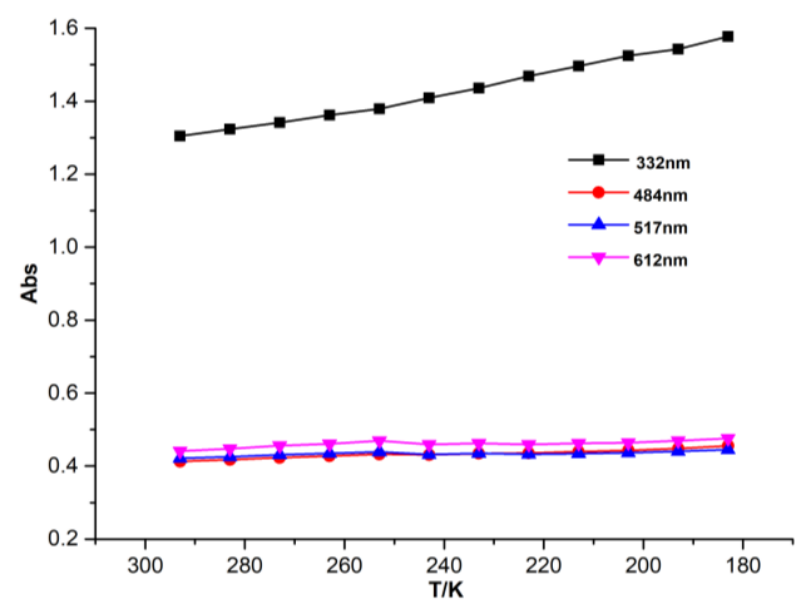

b

Figure 3.17: (a) Variable temperature UV-vis spectra of complex $\mathbf{1 1}$ in THF solution in the temperature range from $293 \mathrm{~K}$ to $183 \mathrm{~K}$. (b) Plots of absorption at different temperature.

\subsection{Reduction of Complex 11 to Give Complex 12}

As described in chapter 2.6, the reduction of dicobalt dinitrogen complexes $\mathbf{2}$ or $\mathbf{4}$ with $\mathrm{KC}_{8}$ occured on the ligand and led to unexpected pyrazolate $\mathrm{C}-\mathrm{H}$ activation at the 4-position and roll-over of part of the ligand. Thus, a new ligand was synthesized with modification on the 4-position of the pyrazole with methyl group, which could avoid the deprotonation of the pyrazole. So two equivalents of $\mathrm{KC}_{8}$ were added to the THF solution of complex 10, which ultimately afforded a dark brown solution (Scheme 3.5). After filtration of the solution, two equivalents of cryptand were added and crystals of complex 12 for X-ray diffraction analysis were obtained from the mixture of a THF solution and hexane at room temperature.
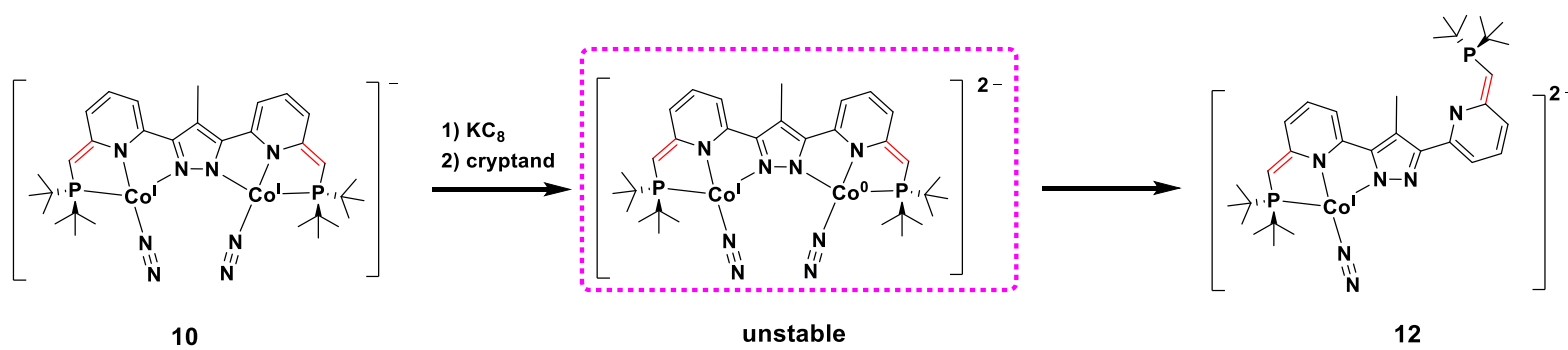

12

Scheme 3.5: Synthesis of cobalt dinitrogen complex 12.

Complex 12 crystallized in the triclinic space group $P-1$ with two molecules in the unit cell. As depicted in Figure 3.20, one cobalt ion was dissociated and one Co center adopts a square-planar geometry, coordinated with a terminal dinitrogen molecule. The N-N bond length is 1.117(4) A, 
which is similar to those in complexes $\mathbf{1 0}$ and 11. Selected bond lengths and angles are listed in Table 3.6. The $\mathrm{C}-\mathrm{C}$ bond in the side arm of the $\mathrm{Co}\{\mathrm{PNN}\}$ part is 1.367(6) $\AA$, which is shorter than that in complex 10/11, and the $\mathrm{C}-\mathrm{C}$ bond in the free ligand side arm is quite similar to those in complex 10/11. Apparently, in the reaction of complex 10 with $\mathrm{KC}_{8}$, one of cobalt ion was reduced to $\mathrm{Co}^{0}$ and the mixed-valent cobalt intermediate was not stable, which led to the dissociation of one cobalt ion. Half of the ligand rolled over to the other side.

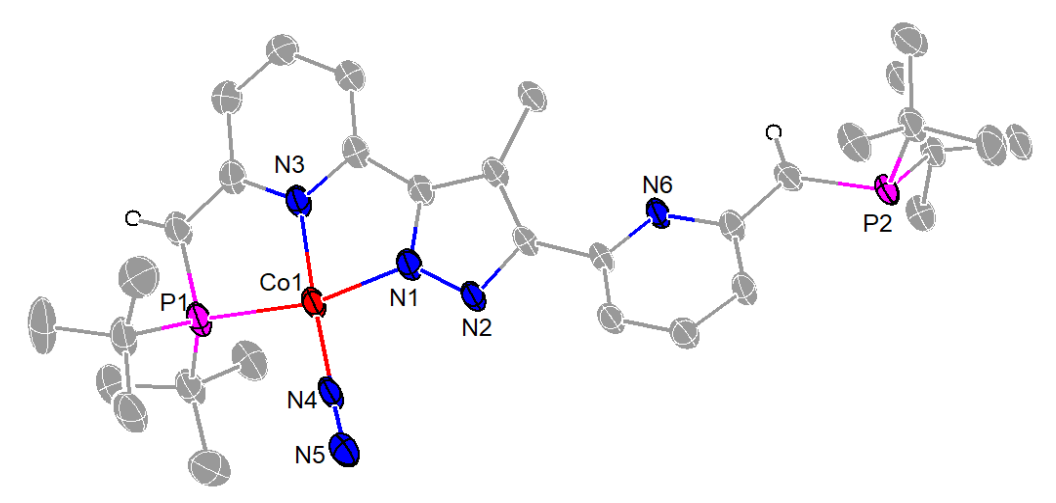

Figure 3.20: The molecular structure of the dianion of complex 12. Thermal displacement ellipsoids shown at $30 \%$ probability; most hydrogen atoms, the cations $(\mathrm{K}([2.2 .2] \text { cryptand }))^{+}$and solvent molecules omitted for clarity.

Table 3.6: Selected bond lengths and angles for complex 12.

\begin{tabular}{llll}
\hline \multicolumn{2}{c}{ Bond lengths / $\AA$} & \multicolumn{2}{c}{ Angles / } \\
\hline $\mathrm{Co}(1)-\mathrm{N}(4)$ & $1.727(4)$ & $\mathrm{N}(4)-\mathrm{Co}(1)-\mathrm{N}(1)$ & $94.80(14)$ \\
$\mathrm{Co}(1)-\mathrm{N}(1)$ & $1.901(3)$ & $\mathrm{N}(4)-\mathrm{Co}(1)-\mathrm{N}(3)$ & $176.20(14)$ \\
$\mathrm{Co}(1)-\mathrm{N}(3)$ & $1.911(3)$ & $\mathrm{N}(1)-\mathrm{Co}(1)-\mathrm{N}(3)$ & $82.01(13)$ \\
$\mathrm{Co}(1)-\mathrm{P}(1)$ & $2.1942(11)$ & $\mathrm{N}(4)-\mathrm{Co}(1)-\mathrm{P}(1)$ & $98.88(11)$ \\
& & $\mathrm{N}(1)-\mathrm{Co}(1)-\mathrm{P}(1)$ & $166.32(10)$ \\
& & $\mathrm{N}(3)-\mathrm{Co}(1)-\mathrm{P}(1)$ & $84.32(10)$ \\
\hline
\end{tabular}

As complex 12 is asymmetric, its ${ }^{1} \mathrm{H}-\mathrm{NMR}$ spectrum is more complicated. In the ${ }^{1} \mathrm{H}-\mathrm{NMR}$ spectrum of complex 12 in THF- $\mathrm{d}_{8}$ (Figure 3.21), the methyl group of the pyrazole can be assigned at $\delta=2.68$ ppm according to the integral. As there is only one coupling between pyridine protons and methyl group in ${ }^{1} \mathrm{H}-{ }^{1} \mathrm{H}$ NOESY spectrum, the chemical shift of $\mathrm{H} 2$ in pyridine is confirmed at $\delta=5.16 \mathrm{ppm}$. Based on ${ }^{1} \mathrm{H}-{ }^{1} \mathrm{H}$ COSY and ${ }^{1} \mathrm{H}-{ }^{1} \mathrm{H}$ NOESY spectra (Figure 9.61 and 9.62), all the resonances are successfully assigned except the resonance associated with $\mathrm{H}^{\prime}$ ' in the side arm of half free ligand, which overlaps with the THF solvent and cryptand signal. As shown in Figure 3.22, the IR spectrum shows one intense peak at $2014 \mathrm{~cm}^{-1}$, which is attributed to the N-N stretching vibration agreeing with what would be expected based on the crystallographically characterized structure of complex 12. 


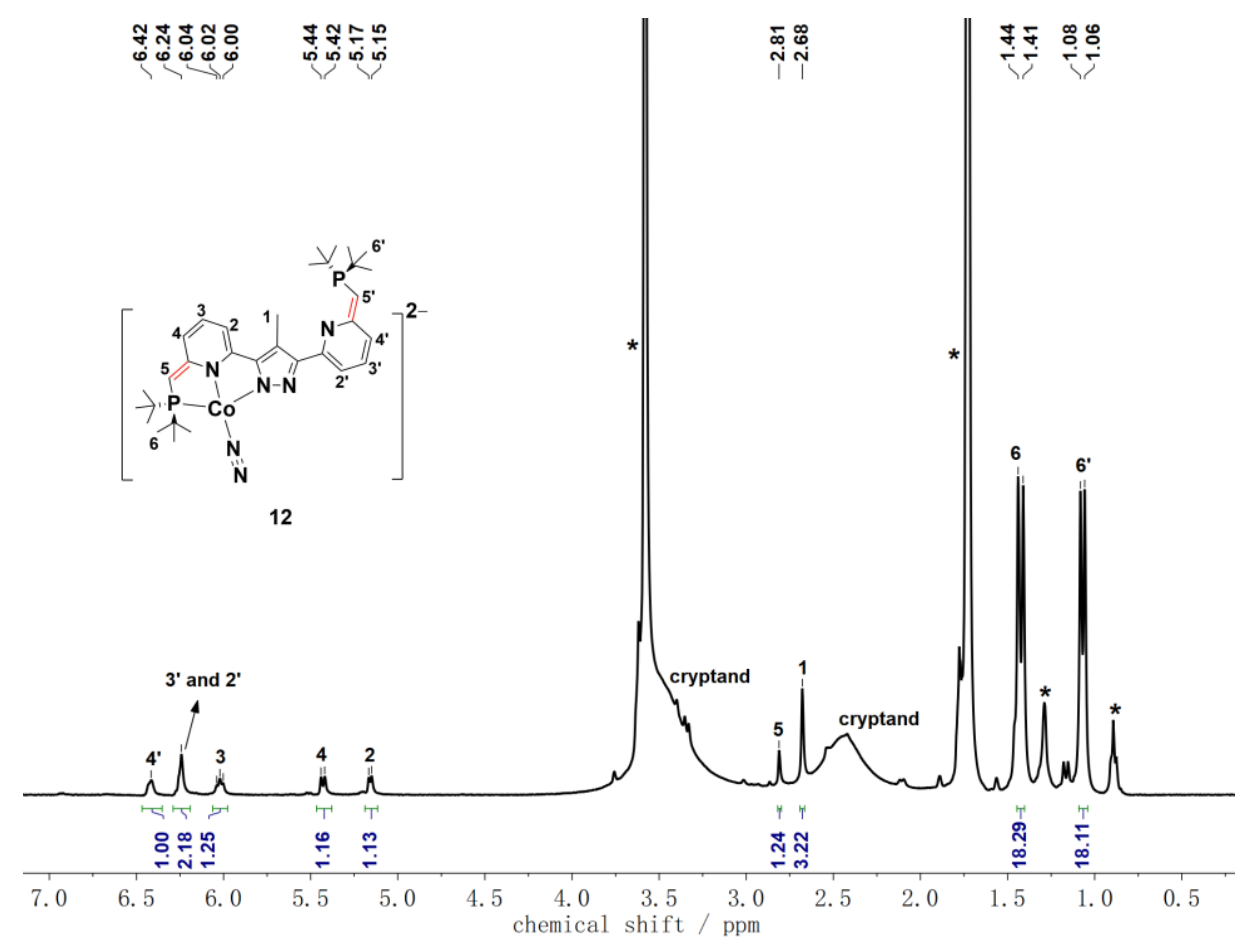

Figure 3.21: ${ }^{1} \mathrm{H}-\mathrm{NMR}$ spectrum of complex 12 in $\mathrm{THF}-\mathrm{d}_{8}$. Solvent signals are marked with an asterisk $(*)$.

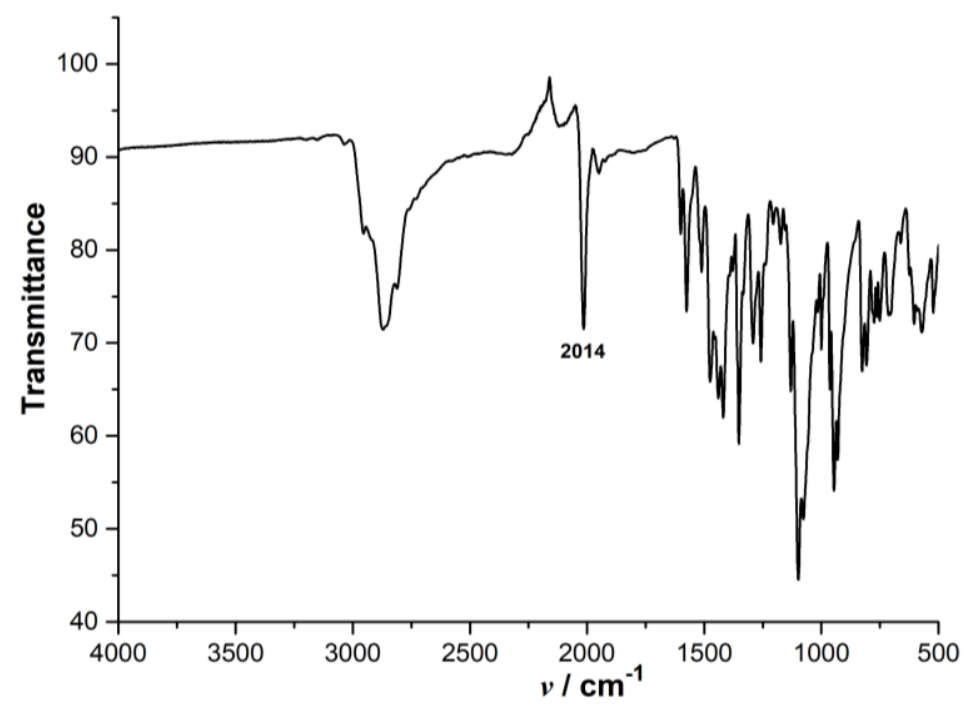

Figure 3.22: IR spectrum of complex 12 in solid state.

\subsection{Catalytic Silylation of $\mathbf{N}_{2}$ by Using Complexes 9-12 as Catalysts}

Catalytic silylation of $\mathrm{N}_{2}$ with excess $\mathrm{KC}_{8}$ (2000 equiv) and $\mathrm{SiMe}_{3} \mathrm{Cl}$ (2000 equiv) employing the complexes as catalysts in THF solvent at $-40{ }^{\circ} \mathrm{C}$ for $2 \mathrm{~h}$ before warming to r.t. was also studied. 
Under the same conditions as previously described, we found that with complex 9 as catalyst, silylation of $\mathrm{N}_{2}$ can generate $\mathrm{N}\left(\mathrm{SiMe}_{3}\right)_{3}$ in $29.4 \%$ yield (For 10: $35.4 \%, 11: 34.2 \%$ 12: $24 \%$ ).

Table 3.7: Catalytic reactions of $\mathrm{N}_{2}$ to silylamine $\mathrm{N}\left(\mathrm{SiMe}_{3}\right)_{3}$ using complexes $\mathbf{9}$ to 12 as catalysts.

\begin{tabular}{|c|c|c|c|c|c|c|}
\hline $\begin{array}{l}\mathrm{N}_{2} \\
1 \text { atm }\end{array}$ & $+\underset{2000 \text { eq. }}{\mathrm{KC}_{8}}+$ & $\begin{array}{l}\mathrm{SiMe}_{3} \mathrm{Cl} \\
2000 \text { eq. }\end{array}$ & \multicolumn{2}{|c|}{$\begin{array}{c}\mathrm{Co}_{2} \text {-catalyst } \\
(0.005 \mathrm{mmol}, 1.0 \text { eq. })\end{array}$} & \multicolumn{2}{|c|}{$\mathrm{N}\left(\mathrm{SiMe}_{3}\right)_{3}$} \\
\hline Entry & Catalyst & $\begin{array}{r}\text { Reaction Te } \\
\text { and T }\end{array}$ & $\begin{array}{l}\text { mperature } \\
\text { ime }\end{array}$ & $\begin{array}{c}\mathbf{N}\left(\mathrm{SiMe}_{3}\right)_{3} \\
(\mathrm{mmol})^{a} \\
\end{array}$ & $\mathbf{T O N} \mathbf{N}^{b}$ & $\begin{array}{l}\text { Yield } \\
(\%)^{c} \\
\end{array}$ \\
\hline 1 & Complex 12 & $-40^{\circ} \mathrm{C} 2 \mathrm{~h} ;$ & R.T. $22 \mathrm{~h}$ & 0.8 & 160 & 24 \\
\hline 2 & Complex 11 & $-40{ }^{\circ} \mathrm{C} 2 \mathrm{~h}$ & R.T. $22 \mathrm{~h}$ & 1.14 & 228 & 34.2 \\
\hline 3 & Complex 10 & $-40{ }^{\circ} \mathrm{C} 2 \mathrm{~h}$ & R.T. $22 \mathrm{~h}$ & 1.18 & 237 & 35.4 \\
\hline 4 & Complex 9 & $-40^{\circ} \mathrm{C} 2 \mathrm{~h}$ & R.T. $22 \mathrm{~h}$ & 0.98 & 196 & 29.4 \\
\hline 5 & None & $-40^{\circ} \mathrm{C} 2 \mathrm{~h}$ & R.T. $22 \mathrm{~h}$ & 0 & 0 & 0 \\
\hline
\end{tabular}

${ }^{a} \mathrm{~N}\left(\mathrm{SiMe}_{3}\right)_{3}$ was identified by GC MS and quantified by GC with cyclododecane as the internal standard. All values are an average of at least three trials. ${ }^{b}$ Turnover numbers (TON) were calculated as the molar ratio of $\mathrm{N}\left(\mathrm{SiMe}_{3}\right)_{3}$ to catalysts. ${ }^{c}$ The yields of $\mathrm{N}\left(\mathrm{SiMe}_{3}\right)_{3}$ were based on starting material $\mathrm{SiMe}_{3} \mathrm{Cl}$.

\subsection{Conclusion}

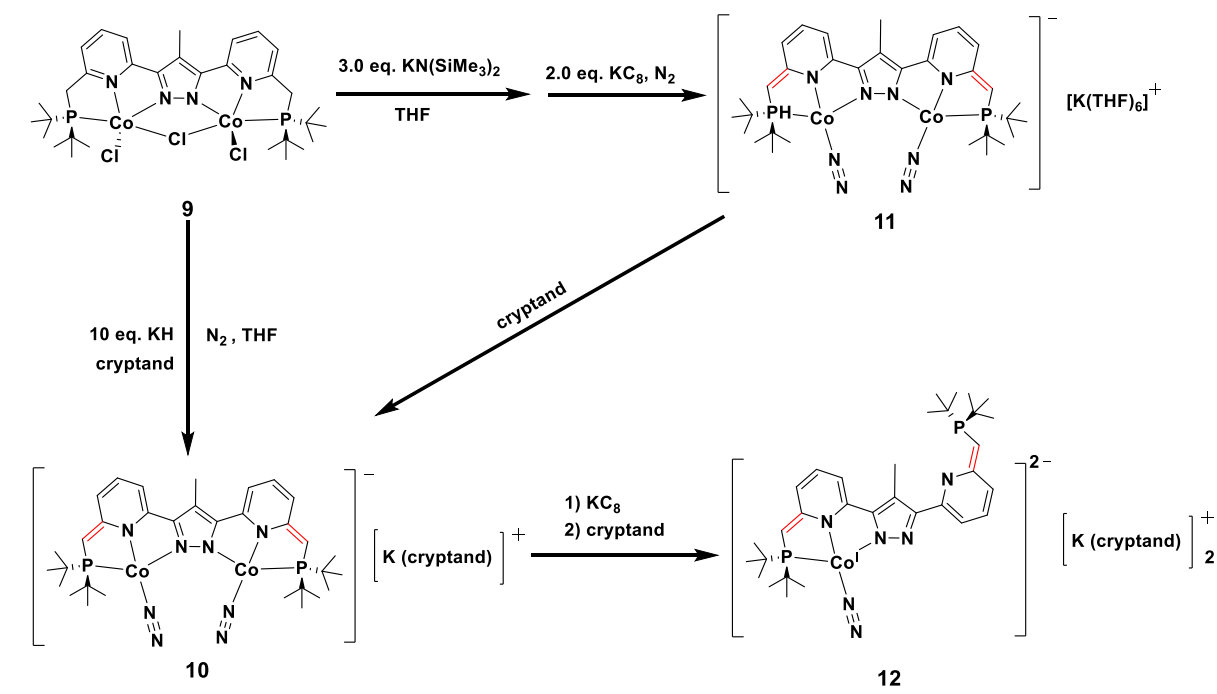

In summary, to avoid the backside $\mathrm{C}-\mathrm{H}$ activation of the pyrazolate ligand under strong reducing conditions, the 4-position of pyrazole has been modified by a methyl group and a new ligand $\mathrm{HL}^{\mathrm{Me}}$ has been synthesized. Using this methyl-modified ligand, we successfully synthesized two dicobalt dinitrogen complexes $\mathbf{1 0}$ and $\mathbf{1 1}$. The reduction of complex $\mathbf{1 0}$ with strong reductant did not lead to 
$\mathrm{N}_{2}$ activation but the formation of one mononuclear dinitrogen complex $\mathbf{1 2}$ and the dissociation of one cobalt(0) atom. By employing these cobalt complexes as catalysts, the catalytic silylation of dinitrogen into $\mathrm{N}\left(\mathrm{SiMe}_{3}\right)_{3}$ (using $\mathrm{KC}_{8}$ and $\mathrm{Me}_{3} \mathrm{SiCl}$ ) has been explored 



\section{Chapter 4: New Model Complexes as Possible Intermediates in}

\section{Dinitrogen Reduction using a Bimetallic Cobalt Dinitrogen Complex as \\ Platform}

\subsection{Introduction}

Molecular $\mathrm{N}_{2}$ fixation plays a crucial role in both the biosphere and the chemical industry. In nature, $\mathrm{N}_{2}$ can be reduced to ammonia $\left(\mathrm{NH}_{3}\right)$ by the iron-molybdenum cofactor (FeMoco) of MoFe-nitrogenase enzymes under ambient conditions. ${ }^{10 a}$ Industrially, this reaction is performed by Fe- or Ru-based catalysts under high pressure and temperature $\left(100-200\right.$ atm, 300-500 $\left.{ }^{\circ} \mathrm{C}\right)$ through the Haber-Bosch process. ${ }^{10 \mathrm{c}}$ Numerous mechanistic studies have been performed on these two transition metal-catalyzed nitrogen fixation processes. However, especially in biosphere, the exact mechanism of nitrogen fixation by nitrogenase is still unclear and elusive.

Nevertheless, as the cofactor was detected to give rise to hydrazine and diazene as minor products, an alternating pathway in $\mathrm{N}_{2}$ reduction may be viable, where protons and electrons are delivered alternately between two nitrogen atoms $\left(\mathrm{N} \equiv \mathrm{N} \rightarrow \mathrm{HN=N^{- }} \rightarrow \mathrm{HN}=\mathrm{NH} \rightarrow \mathrm{HN}=\mathrm{NH}_{2}{ }^{+} \rightarrow\right.$ $\left.\mathrm{H}_{2} \mathrm{~N}-\mathrm{NH}_{2} \rightarrow 2 \mathrm{NH}_{3}\right) .{ }^{10 a}, 15$ Nonbiological systems of $\mathrm{N}_{2}$ fixation to ammonia may also involve such intermediates. ${ }^{12}$ In addition, hydrazine is quite stable in the free state and well studied. ${ }^{30}$ However, diazene is extremely unstable in the free state $\left(\Delta H_{\mathrm{f}}^{0}(298)=212.3 \mathrm{k} \pm 8.4 \mathrm{kJmol}^{-1}\right)$, existing as two geometric isomers, trans and cis, with the cis isomer being more unstable. ${ }^{31}$ Fortunately, diazene can be crystallographically characterized through coordination to metals in mono- and dinuclear complexes. $^{30 \mathrm{a},} 32$ Unstable diazene complexes undergo various disproportionation reactions, primarily forming hydrazine and nitrogen gas, or undergo decomposion, forming nitrogen and hydrogen gas (Scheme 4.1). ${ }^{33}$

$$
\begin{aligned}
2 \mathrm{~N}_{2} \mathrm{H}_{2} & \longrightarrow \mathrm{N}_{2} \mathrm{H}_{4}+\mathrm{N}_{2} \\
\mathrm{~N}_{2} \mathrm{H}_{2} & \longrightarrow \mathrm{N}_{2}+2 \mathrm{H}_{2}
\end{aligned}
$$

Scheme 4.1: Two possible transformations from unstable diazene.

Within this context, in consideration of the instability of coordinated diazene, hydrazido and hydrazine complexes, synthetic models of $\mathrm{M}\left(\mathrm{N}_{2} \mathrm{H}_{\mathrm{x}} \mathrm{R}\right)$ species ${ }^{30 \mathrm{~b}}, 34$ including phenyl- and methyl-substituted complexes are of considerable importance to provide a better understanding of binding modes of $\mathrm{N}_{2}$ fixation intermediates in metalloenzymes in artificial catalysts (Figure 4.1). ${ }^{35}$ Moreover, $\mathrm{M}\left(\mathrm{N}_{2} \mathrm{H}_{\mathrm{x}} \mathrm{R}\right)$ complexes featuring substituted hydrazine $\left(\mathrm{N}_{2} \mathrm{R}_{4}\right)$, hydrazido $\left(\mathrm{N}_{2} \mathrm{R}_{3}{ }^{-}\right)$and diazene ligands can be studied to explore the chemical reactivity of the potential intermediates in the $\mathrm{N}_{2}$ fixation process. Numerous $\mathrm{M}\left(\mathrm{N}_{2} \mathrm{H}_{\mathrm{x}} \mathrm{R}\right)$ complexes have been synthesized recently. ${ }^{36}$ For example, Huttner reported the synthesis of hydrazido $\left(\mathrm{N}_{2} \mathrm{H}_{3}{ }^{-}\right)$complex from the reaction of tripod-cobalt 
template with hydrazine and its protonation into hydrazine $\left(\mathrm{N}_{2} \mathrm{H}_{4}\right)$ complex. ${ }^{37 a}$ Furthermore, he also described the transformation from analogue $\eta^{2}-\mathrm{NHNMe}_{2}$ complex to $\eta^{1}-\mathrm{NNMe}_{2}$ complex through deprotonation accompanied by a redox reaction. ${ }^{37 \mathrm{~b}}$ Limberg synthesized a phenylhydrazido(-1) $\mathrm{Ni}$ complex, which could be further reduced by potassium graphite to generate a deprotonated phenylhydrazido(-2) $\mathrm{Ni}$ complex or treated with 1,2-diisopropylazo dicarboxylate to form a phenyldiazenido Ni complex. ${ }^{38}$ Additionally, Field reported a series of tripodal phosphine Fe and $\mathrm{Ru}$ complexes which reacted with hydrazine, phenylhydrazine, and methylhydrazine. ${ }^{39}$ Especially, base treatment of phenylhydrazine and methylhydrazine $\mathrm{Ru}$ complexes based on the $\mathrm{P}\left(\mathrm{CH}_{2} \mathrm{CH}_{2} \mathrm{PPh}_{2}\right)_{3}$ ligand gave rise to a new hydrido ruthenaindazole complex containing a cyclometalated phenyldiazene ligand and a new hydrido methylenehydrazide complex, respectively. ${ }^{39 \mathrm{c}}$

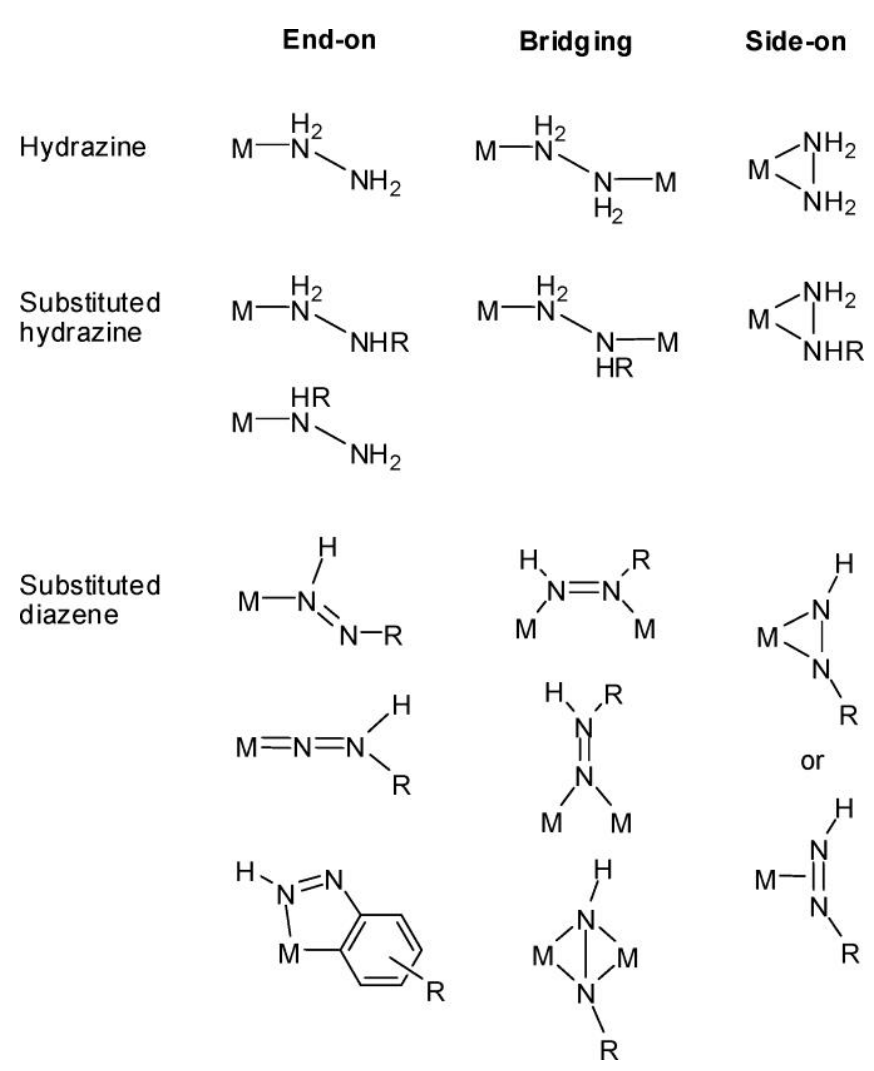

Figure 4.1: Binding modes of hydrazine, substituted hydrazine, and substituted diazene complexes.

Furthermore, two proximate metal active sites of metalloenzyme reveal the capability to mediate cooperativity in many enzymatic reactions. In MoFe-nitrogenase enzymes, nitrogen fixation possibly occurs on the coordinatively unsaturated iron atoms. Therefore, the synthesis of dinuclear or even multinuclear transition metal complexes featuring $\mathrm{N}_{2} \mathrm{H}_{x} \mathrm{R}$ ligand can play a crucial role in exploring nitrogen fixation process and mimicking potential intermediates. ${ }^{40}$ Peters characterized a series of structurally fascinating diiron $\mathrm{N}_{\mathrm{x}} \mathrm{H}_{\mathrm{y}}$ species featuring hydrazine, hydrazido, diazene, $\mu-\mathrm{NH}_{2}$ and $\mu$-NH ligands. ${ }^{41} \mathrm{Qu}$ and his co-workers reported a novel thiolate-bridged diiron complex containing $\mathrm{Fe}_{2} \mathrm{~S}_{2}$ core and after addition of hydrazine, it formed a diazene complex. ${ }^{42}$ Following reductions and protonations, $\mathrm{N}_{2} \mathrm{H}_{2}$ species was converted to $\mathrm{N}_{2} \mathrm{H}_{3}{ }^{-}$and $\mathrm{NH}_{2}{ }^{-}$complexes as potential intermediates 
during biological nitrogen fixation process and $\mathrm{NH}_{3}$ was also released finally. These results provided a better understanding of the possible mechanism of $\mathrm{N}_{2}$ fixation.

The study of nitrogen fixation in dinuclear or multinuclear transition metal systems is still limited but significant. In order for access to the $\mathrm{N}_{2} \mathrm{H}_{x} \mathrm{R}$ chemistry, we employ a dearomatized dicobalt dinitrogen complex $\left[\left(\mathrm{L}^{* *}\left(\mathrm{CoN}_{2}\right)_{2}\right)(\mathrm{K}([2.2 .2]\right.$ cryptand $\left.))\right] 2$, as a precursor, to react with hydrazine, methylhydrazine, 1,2-dimethylhydrazine and azobenzene. The reactions of complex 2 with hydrazine, methylhydrazine and 1,2-dimethylhydrazine give rise to diamagnetic diazene complexes with concomitant formation of ammonia or methylamine. Specifically, the dinitrogen complex 2 reacts with azobenzene to perform a two-electron reduction, which formally oxidizes the metal centers.

\subsection{Synthesis of An End-on Bridged Diazene Complex}

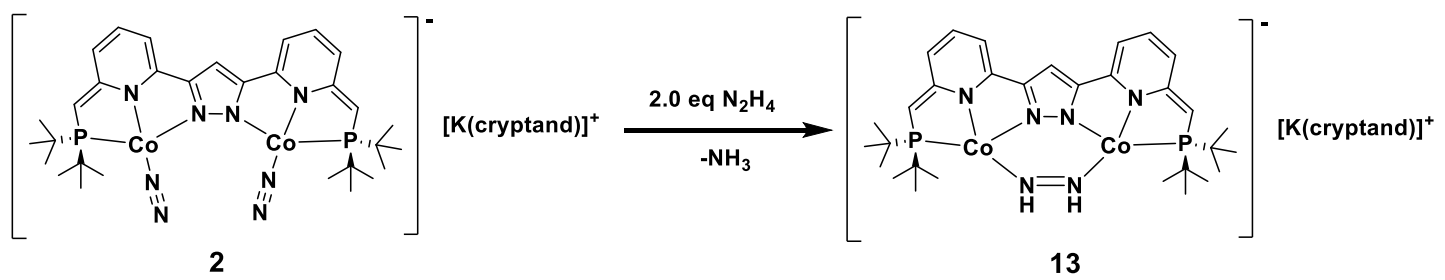

Scheme 4.2: Synthesis of the diazene complex 13.

As shown in Scheme 4.2, slow addition of two equivalents of hydrazine $\left(\mathrm{N}_{2} \mathrm{H}_{4}\right)$ to a stirred THF solution of complex 2 afforded an gradual color change from dark blue to green. After work up, crystals suitable for diffraction were grown from a saturated THF solution at $-40{ }^{\circ} \mathrm{C}$ and complex $\left[\mathrm{L}^{* *} \mathrm{Co}_{2}\left(\right.\right.$ cis $\left.-\mu-\eta^{l}: \eta^{l}-\mathrm{N}_{2} \mathrm{H}_{2}\right)(\mathrm{K}([2.2 .2]$ cryptand $\left.))\right] \mathbf{1 3}$ was ultimately isolated in $85 \%$ yield. Additionally, ammonia was found to be produced in this reaction concomitantly, suggesting that a disproportionation reaction of hydrazine to generate ammonia and diazene occurred (Scheme 4.3). Specifically, the solution from the reaction of complex 2 and hydrazine (2 eq.) was measured by ${ }^{1} \mathrm{H}-\mathrm{NMR}$ and no hydrogen gas was detected. When all volatiles were evaporated, collected and neutralized by hydrogen chloride/Et ${ }_{2} \mathrm{O}$ solution, ammonium chloride $\left(\mathrm{NH}_{4} \mathrm{Cl}\right)$ was detected as a triplet at $\delta=7.18 \mathrm{ppm}$ from ${ }^{1} \mathrm{H}-\mathrm{NMR}$ spectrum in DMSO-d 6 solution (Figure 9.70).

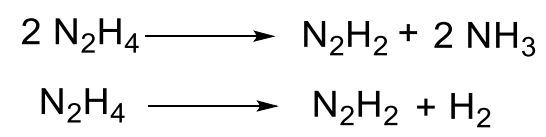

Scheme 4.3: Two possibilities to generate diazene from hydrazine. ${ }^{32 a, 33 a}$

The magnetic properties of complex 13 were elucidated by NMR spectroscopy and a SQUID measurement (Figure 4.2), which both reveal that complex 13 is a diamagnetic species. The ${ }^{1} \mathrm{H}-\mathrm{NMR}$ spectrum of complex 13 in THF- $\mathrm{d}_{8}$ exhibits apparent $C_{2 v}$ symmetry in solution on the NMR time 
scale at room temperature (Figure 4.3). The presence of a bridging cis diazene ligand in complex $\mathbf{1 3}$ is readily discerned by ${ }^{1} \mathrm{H}-\mathrm{NMR}$ and ${ }^{1} \mathrm{H}-{ }^{15} \mathrm{~N}-\mathrm{HMBC}$ spectra (Figure 4.4). A singlet at $\delta=8.29 \mathrm{ppm}$ is observed in the ${ }^{1} \mathrm{H}-\mathrm{NMR}$ spectrum, indicative of two protons of the diazene ligand. In addition, one triplet at $\delta=5.71 \mathrm{ppm}$ and one doublet at $\delta=5.33 \mathrm{ppm}$ can be assigned to pyridine protons, H3 and $\mathrm{H} 4$, respectively, which are shifted downfield in comparison to complex 2 . Nevertheless, other resonances are shifted upfield in contrast to those in complex 2 . In the ${ }^{1} \mathrm{H}-{ }^{15} \mathrm{~N}-\mathrm{HMBC}$ spectrum recorded at room temperature, the ${ }^{15} \mathrm{~N}$ correlation of ${ }^{1} \mathrm{H}$ signal occurs at $\delta=-166.35 \mathrm{ppm}\left({ }^{1} J_{\mathrm{NH}}=72\right.$ $\mathrm{Hz}$ ) confirming the assignment of $\mathrm{NH}$ in the diazene ligand. The ${ }^{31} \mathrm{P}-\mathrm{NMR}$ spectrum (Figure 4.5) revealed a peak at $\delta=55.26 \mathrm{ppm}$, characteristic of a symmetric diazene complex in solution, which is shifted upfield in contrast to that in complex 2.

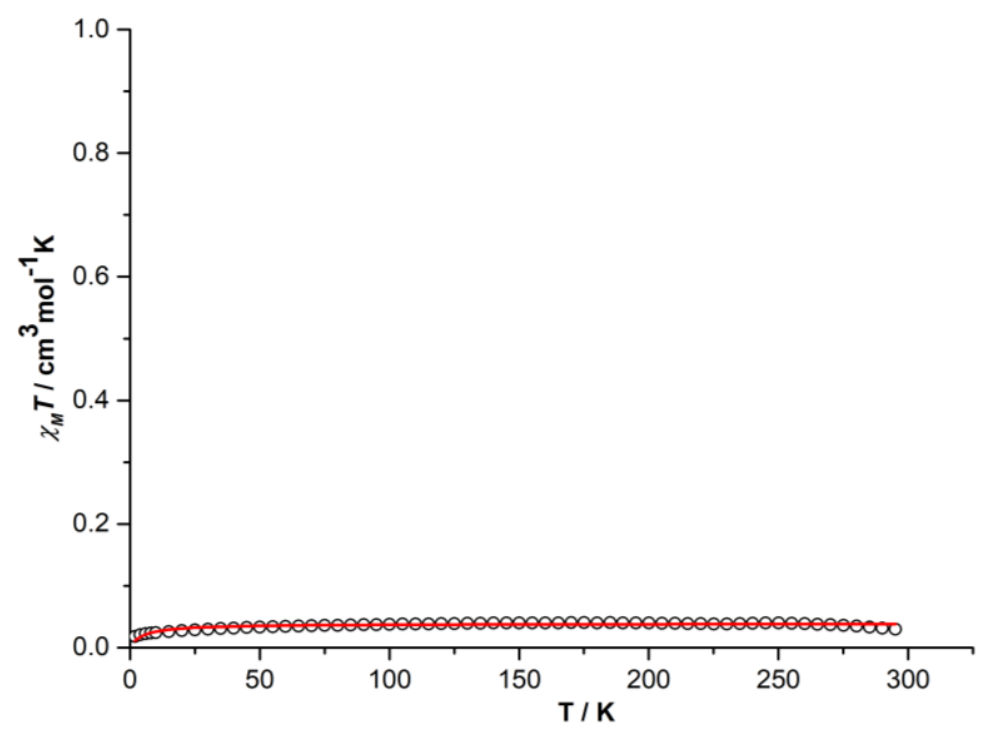

Figure 4.2: $\chi_{\mathrm{M}} T$ vs. $T$ plot in the temperature range of $2-295 \mathrm{~K}$ at $0.5 \mathrm{~T}$ of solid powder from complex 13. The red line corresponds to the best fits of the experimental magnetic results. 


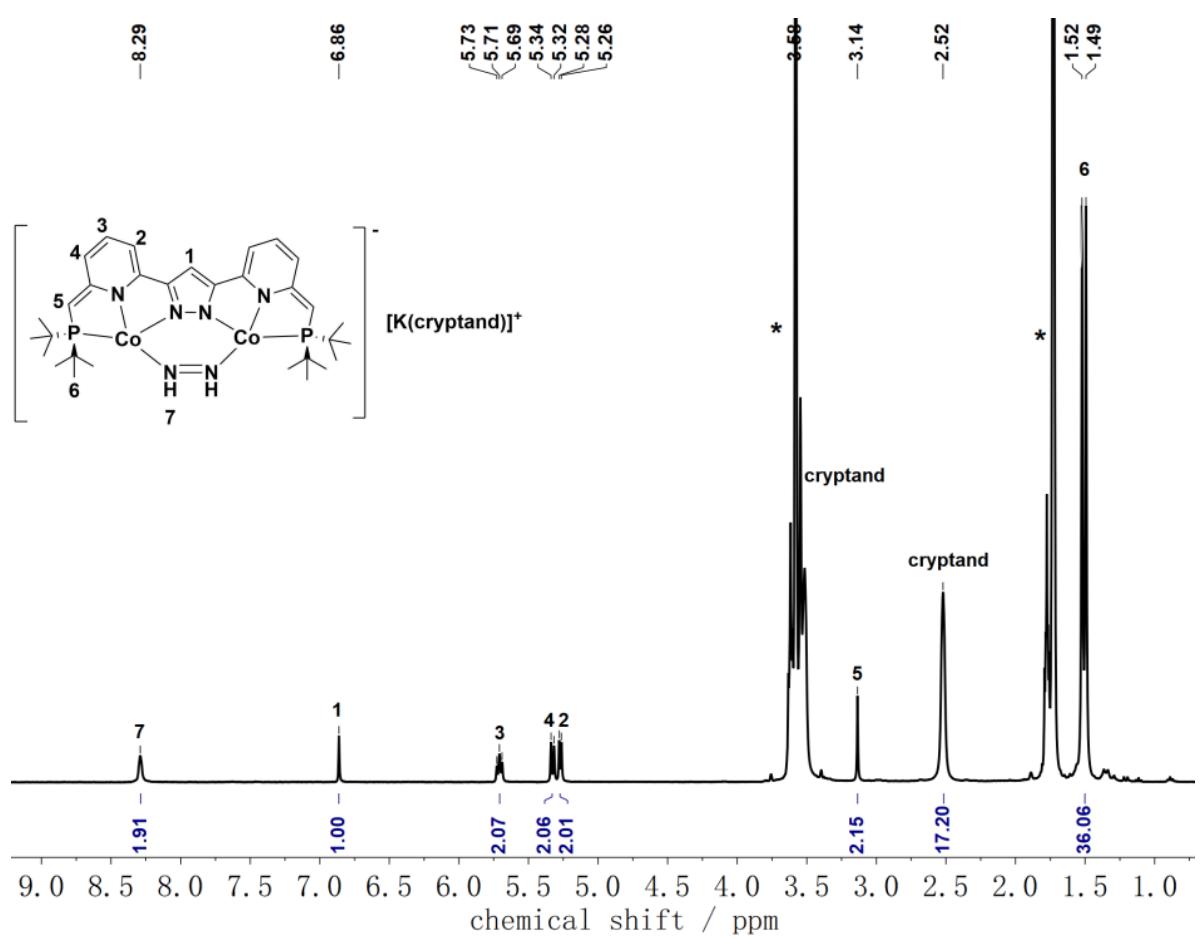

Figure 4.3: ${ }^{1} \mathrm{H}-\mathrm{NMR}$ spectrum of complex 13 in THF-d 8 . Solvent signals are marked with an asterisk $(*)$.

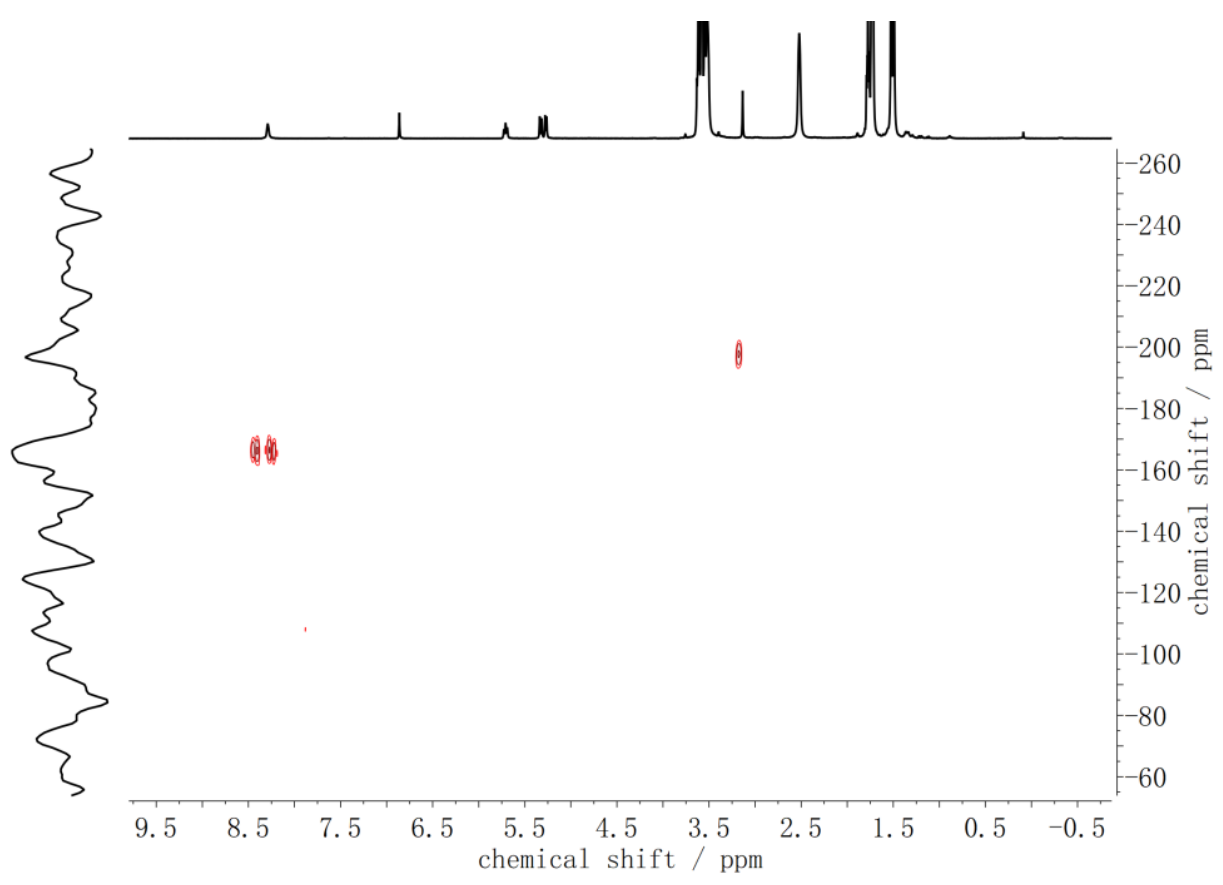

Figure 4.4: ${ }^{1} \mathrm{H}_{-}{ }^{15} \mathrm{~N}-\mathrm{HMBC}$ spectrum of complex 13 in $\mathrm{THF}-\mathrm{d}_{8}$. Solvent signals are marked with an asterisk $(*)$. 


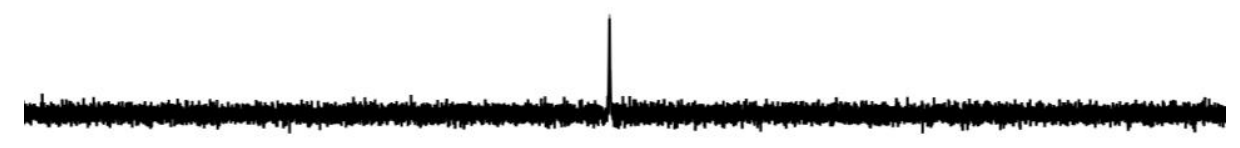

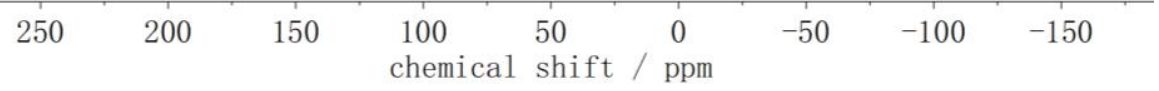

Figure 4.5: ${ }^{31} \mathrm{P}-\mathrm{NMR}$ spectrum of complex 13 in $\mathrm{THF}-\mathrm{d}_{8}$.

Complex 13 crystallized in the monoclinic space group $P 2_{1} / \mathrm{c}$ with four molecules in the unit cell. The potassium cation is encapsulated by [2.2.2]cryptand. The molecular structure of the anion of complex 13 (Figure 4.6) exhibits that both cobalt centers are coordinated in a slightly distorted square planar geometry with Co …Co separation of $3.85 \AA$, shorter by $0.45 \AA$ than that in complex 2 . The $\mu-\eta^{l}: \eta^{l}$ cis $-\mathrm{N}_{2} \mathrm{H}_{2}$ moiety is bridging the two metal centers in an end-on mode, where $\mathrm{N}-\mathrm{N}$ bond length amounts to $1.370(3) \AA$ and is in accordance with a $\mathrm{N}=\mathrm{N}$ double bond. ${ }^{36}$ The slight lengthening of the double bond may be attributed to back-bonding of two Co centers into the anti-bonding orbitals of the diazene ligand. The cis-H-N=N-H fragment is nearly planar. Consequently, complex 13 represents a novel structurally characterized dinuclear cobalt diazene complex. The Co-N-N-Co torsion angles are $7.4^{\circ}$ and $2.9^{\circ}$. Selected bond lengths and angels are listed in Table 4.1.
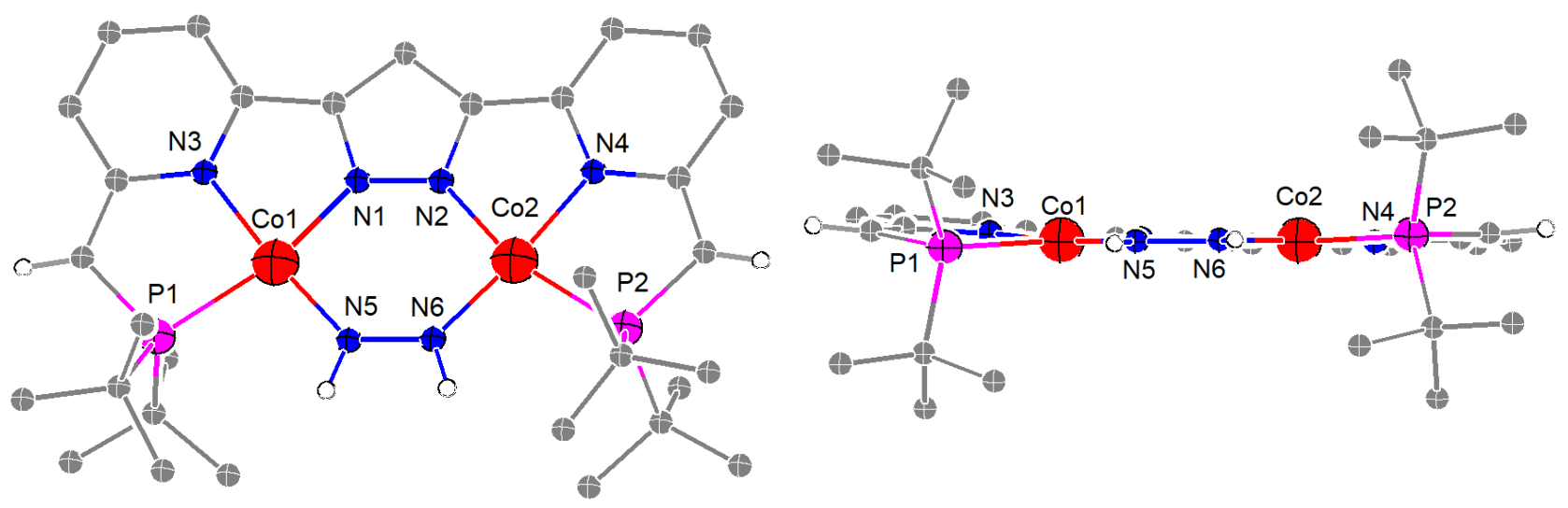

Figure 4.6: Top view (left) and front view (right) of the molecular structure of the anion of complex 
13. Thermal displacement ellipsoids shown at $30 \%$ probability; most hydrogen atoms, the cation $(\mathrm{K}([2.2 .2] \text { cryptand }))^{+}$and solvent molecules omitted for clarity.

Table 4.1: Selected bond lengths and angles for complex 13.

\begin{tabular}{llll}
\hline \multicolumn{2}{c}{ Bond lengths / $\AA$} & \multicolumn{2}{c}{ Angles / } \\
\hline $\mathrm{Co}(1)-\mathrm{N}(5)$ & $1.812(2)$ & $\mathrm{N}(5)-\mathrm{Co}(1)-\mathrm{N}(1)$ & $94.38(8)$ \\
$\mathrm{Co}(1)-\mathrm{N}(1)$ & $1.8555(19)$ & $\mathrm{N}(5)-\mathrm{Co}(1)-\mathrm{N}(3)$ & $174.47(9)$ \\
$\mathrm{Co}(1)-\mathrm{N}(3)$ & $1.9181(19)$ & $\mathrm{N}(1)-\mathrm{Co}(1)-\mathrm{N}(3)$ & $81.01(8)$ \\
$\mathrm{Co}(1)-\mathrm{P}(1)$ & $2.2083(7)$ & $\mathrm{N}(5)-\mathrm{Co}(1)-\mathrm{P}(1)$ & $100.33(6)$ \\
$\mathrm{Co}(2)-\mathrm{N}(6)$ & $1.812(2)$ & $\mathrm{N}(1)-\mathrm{Co}(1)-\mathrm{P}(1)$ & $165.10(6)$ \\
$\mathrm{Co}(2)-\mathrm{N}(2)$ & $1.8615(19)$ & $\mathrm{N}(3)-\mathrm{Co}(1)-\mathrm{P}(1)$ & $84.42(6)$ \\
$\mathrm{Co}(2)-\mathrm{N}(4)$ & $1.918(2)$ & $\mathrm{N}(6)-\mathrm{Co}(2)-\mathrm{N}(2)$ & $94.29(8)$ \\
$\mathrm{Co}(2)-\mathrm{P}(2)$ & $2.2061(7)$ & $\mathrm{N}(6)-\mathrm{Co}(2)-\mathrm{N}(4)$ & $174.87(9)$ \\
$\mathrm{Co} 1 \cdots \mathrm{Co} 2$ & $3.8518(4)$ & $\mathrm{N}(2)-\mathrm{Co}(2)-\mathrm{N}(4)$ & $80.59(8)$ \\
$\mathrm{N}(5)-\mathrm{N}(6)$ & $1.370(3)$ & $\mathrm{N}(6)-\mathrm{Co}(2)-\mathrm{P}(2)$ & $100.10(6)$ \\
& & $\mathrm{N}(2)-\mathrm{Co}(2)-\mathrm{P}(2)$ & $165.51(6)$ \\
& & $\mathrm{N}(4)-\mathrm{Co}(2)-\mathrm{P}(2)$ & $85.02(6)$ \\
\hline
\end{tabular}

An IR spectrum of complex 13 was recorded (Figure 9.76), but the N-N stretching vibration of the diazene ligand could not be assigned. Variable temperature UV-vis spectroscopy was performed from $193 \mathrm{~K}$ to $333 \mathrm{~K}$ (Figure 4.7) and it shows intense absorbance features at $\lambda_{\max }=315,495,665$ and 735 $\mathrm{nm}$ which decrease with increasing temperature. It may be attributed to metal to ligand and diazene charge transfer transitions. And more notably, complex $\mathbf{1 3}$ is unstable at slightly elevated temperatures and is prone to dissociation. Attempts to reduce complex $\mathbf{1 3}$ with $\mathrm{KC}_{8}$ under $\mathrm{N} 2$ atmosphere led to the loss of the diazene ligand and the formation of complex 2 .

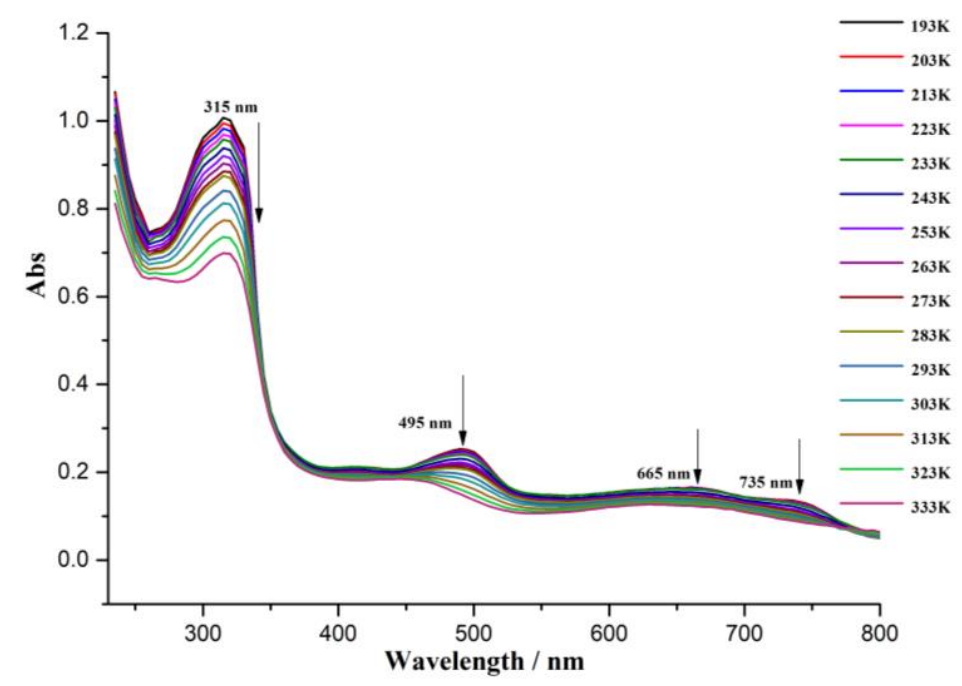

Figure 4.7: Variable temperature UV/vis spectra of complex 13 in THF solution in the temperature 
range from $293 \mathrm{~K}$ to $193 \mathrm{~K}$.

\subsection{Synthesis of An End-on Bridged Methyldiazene Complex}

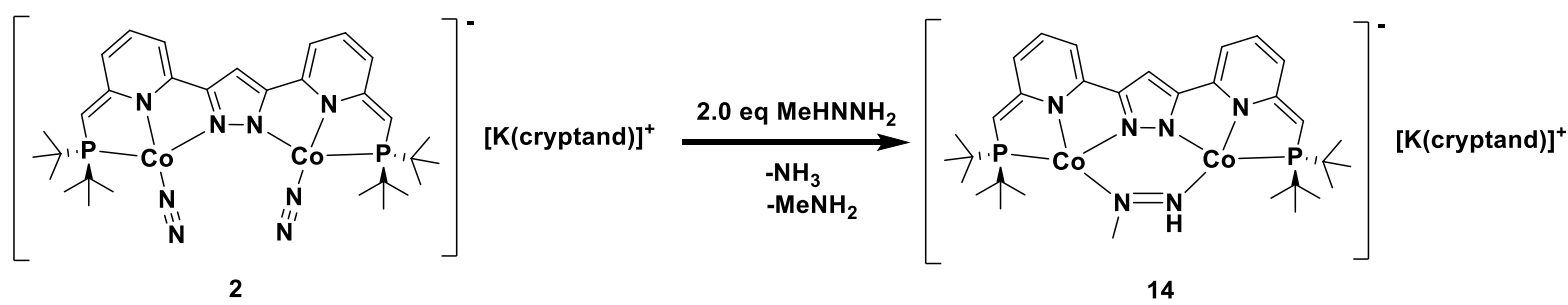

Scheme 4.4: Synthesis of the methyldiazene complex 14.

In an analogous reaction of complex 2 with two equivalents of methylhydrazine $\left(\mathrm{MeNHNH}_{2}\right)$ in THF solution, green needle-shape crystals were obtained at $-40{ }^{\circ} \mathrm{C}$ in $83 \%$ yield accompanied by the formation of methylamine and ammonia as byproducts. The product was characterized by X-ray analysis to be a methyldiazene complex $\left[\left(\mathrm{L}^{* *} \mathrm{Co}_{2}\left(\right.\right.\right.$ cis $\left.\left.-\mu-\eta^{1}: \eta^{1}-\mathrm{MeNNH}\right)(\mathrm{K}([2.2 .2] \operatorname{cryptand}))\right] 14$ (Scheme 4.4).

Complex 14 crystallized in the triclinic space group $P-1$ with two molecules in the unit cell. The potassium cation is encapsulated by [2.2.2]cryptand. As depicted in Figure 4.8, overall coordination environment of two cobalt centers in the molecular structure of complex $\mathbf{1 4}$ can be best described as slightly distorted square planar with a Co $\cdots$ Co separation of $3.87 \AA$, similar to that in complex $\mathbf{1 3}$. The $\mu-\eta^{l}: \eta^{l}$ cis- MeNNH moiety is bridging the two metal centers in an end-on mode, where the $\mathrm{N}-\mathrm{N}$ bond length amounts to $1.384(11) \AA$ corresponding to a N=N double bond. ${ }^{36}$ The Co-N-N-Co torsion angles are $4.9^{\circ}$ and $16.4^{\circ}$. Selected bond lengths and angles are listed in Table 4.2.
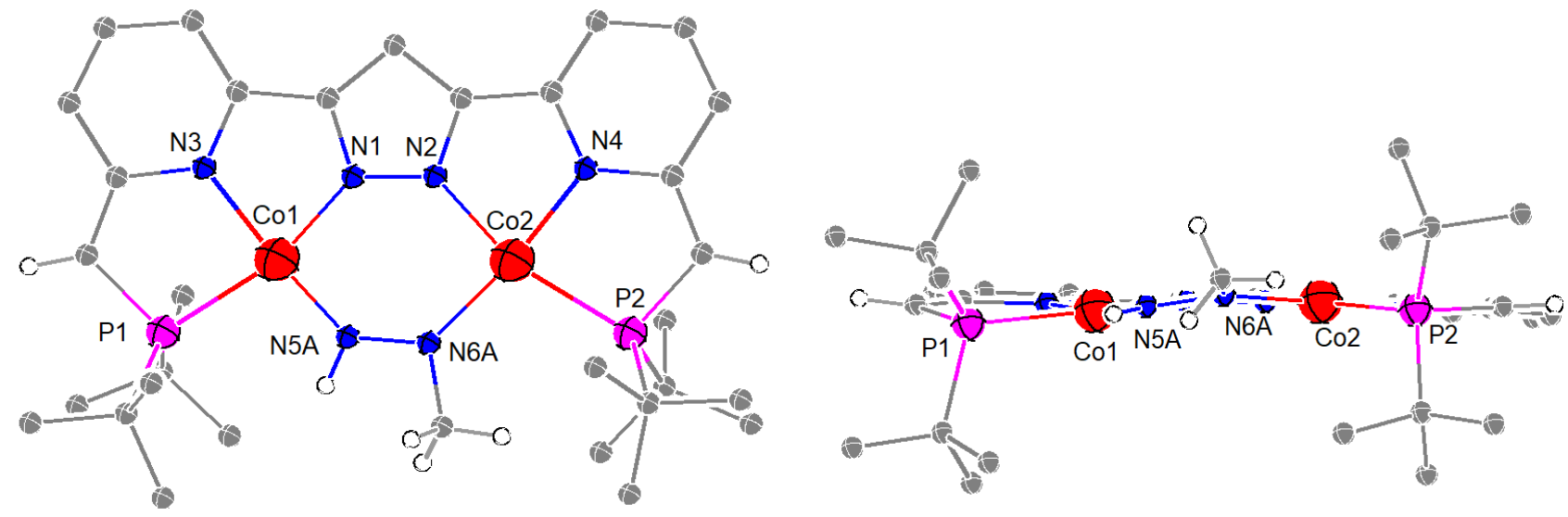

Figure 4.8: Top view (left) and front view (right) of the molecular structure of the anion of complex

14. Thermal displacement ellipsoids shown at $30 \%$ probability; most hydrogen atoms, the cation $(\mathrm{K}([2.2 .2] \text { cryptand }))^{+}$and solvent molecules omitted for clarity. 
Table 4.2: Selected bond lengths and angles for complex 14.

\begin{tabular}{llll}
\multicolumn{1}{c}{ Bond lengths / $\mathrm{A}$} & \multicolumn{3}{c}{ Angles / } \\
\hline $\mathrm{Co}(1)-\mathrm{N}(5 \mathrm{~A})$ & $1.737(14)$ & $\mathrm{N}(5 \mathrm{~A})-\mathrm{Co}(1)-\mathrm{N}(1)$ & $94.4(9)$ \\
$\mathrm{Co}(1)-\mathrm{N}(1)$ & $1.850(4)$ & $\mathrm{N}(5 \mathrm{~A})-\mathrm{Co}(1)-\mathrm{N}(3)$ & $172.5(13)$ \\
$\mathrm{Co}(1)-\mathrm{N}(3)$ & $1.919(4)$ & $\mathrm{N}(1)-\mathrm{Co}(1)-\mathrm{N}(3)$ & $80.53(16)$ \\
$\mathrm{Co}(1)-\mathrm{N}(6 \mathrm{~B})$ & $1.94(2)$ & $\mathrm{N}(1)-\mathrm{Co}(1)-\mathrm{N}(6 \mathrm{~B})$ & $92.6(14)$ \\
$\mathrm{Co}(1)-\mathrm{P}(1)$ & $2.2383(14)$ & $\mathrm{N}(3)-\mathrm{Co}(1)-\mathrm{N}(6 \mathrm{~B})$ & $172.4(18)$ \\
$\mathrm{Co}(2)-\mathrm{N}(5 \mathrm{~B})$ & $1.69(2)$ & $\mathrm{N}(5 \mathrm{~A})-\mathrm{Co}(1)-\mathrm{P}(1)$ & $100.5(9)$ \\
$\mathrm{Co}(2)-\mathrm{N}(2)$ & $1.882(4)$ & $\mathrm{N}(1)-\mathrm{Co}(1)-\mathrm{P}(1)$ & $165.08(12)$ \\
$\mathrm{Co}(2)-\mathrm{N}(6 \mathrm{~A})$ & $1.908(15)$ & $\mathrm{N}(3)-\mathrm{Co}(1)-\mathrm{P}(1)$ & $84.70(12)$ \\
$\mathrm{Co}(2)-\mathrm{N}(4)$ & $1.917(4)$ & $\mathrm{N}(6 \mathrm{~B})-\mathrm{Co}(1)-\mathrm{P}(1)$ & $102.3(14)$ \\
$\mathrm{Co}(2)-\mathrm{P}(2)$ & $2.2538(13)$ & $\mathrm{N}(5 \mathrm{~B})-\mathrm{Co}(2)-\mathrm{N}(2)$ & $95.8(17)$ \\
$\mathrm{Co} 1 \cdots \mathrm{Co} 2$ & $3.8721(8)$ & $\mathrm{N}(2)-\mathrm{Co}(2)-\mathrm{N}(6 \mathrm{~A})$ & $93.4(8)$ \\
$\mathrm{N}(5)-\mathrm{N}(6)$ & $1.384(11)$ & $\mathrm{N}(5 \mathrm{~B})-\mathrm{Co}(2)-\mathrm{N}(4)$ & $173.7(18)$ \\
& & $\mathrm{N}(2)-\mathrm{Co}(2)-\mathrm{N}(4)$ & $80.19(16)$ \\
& & $\mathrm{N}(6 \mathrm{~A})-\mathrm{Co}(2)-\mathrm{N}(4)$ & $173.0(7)$ \\
& & $\mathrm{N}(5 \mathrm{~B})-\mathrm{Co}(2)-\mathrm{P}(2)$ & $99.6(16)$ \\
& & $\mathrm{N}(2)-\mathrm{Co}(2)-\mathrm{P}(2)$ & $164.06(13)$ \\
& & $\mathrm{N}(6 \mathrm{~A})-\mathrm{Co}(2)-\mathrm{P}(2)$ & $102.4(8)$ \\
& & $\mathrm{N}(4)-\mathrm{Co}(2)-\mathrm{P}(2)$ & $84.11(12)$ \\
\hline
\end{tabular}

The diamagnetic character of complex 14 was confirmed by NMR spectroscopy and a SQUID measurement (Figure 4.9). Furthermore, the ${ }^{1} \mathrm{H}-\mathrm{NMR}$ spectrum of complex 14 in THF-d 8 reveals its asymmetric character in solution (Figure 4.10) and it also demonstrates that two singlets at $\delta=5.98$ and $-0.45 \mathrm{ppm}$ can be attributed to the proton and methyl group of the methyldiazene ligand, respectively, based on a ${ }^{1} \mathrm{H}-{ }^{1} \mathrm{H}$ NOESY spectrum (Figure 9.78). Moreover, two doublets at $\delta=1.59$ and $1.55 \mathrm{ppm}$ for the $t \mathrm{Bu}$ groups close to the Me-N moiety and NH moiety of methyldiazene ligand, respectively, are ascertained according to their proximity to the protons of the methyldiazene ligand. On the basis of ${ }^{1} \mathrm{H}-{ }^{1} \mathrm{H}$ COSY and ${ }^{1} \mathrm{H}-{ }^{1} \mathrm{H}$ NOESY spectra, the remaining resonances are all assigned successfully. The ${ }^{15} \mathrm{~N}$ shift of the Me-N moiety in methyldiazene ligand is determined by ${ }^{1} \mathrm{H}-{ }^{15} \mathrm{~N}-\mathrm{HMBC}$ spectrum as depicted in Figure 4.11 at $\delta=-183.18 \mathrm{ppm}$. And ${ }^{15} \mathrm{~N}$ correlation of ${ }^{1} \mathrm{H}$ signal occurs at $\delta=-153.90 \mathrm{ppm}\left({ }^{1} J_{\mathrm{NH}}=65 \mathrm{~Hz}\right)$ confirming the assignment of NH in methyldiazene ligand. Two peaks at $\delta=51.27$ and $35.27 \mathrm{ppm}$ are detected in ${ }^{31} \mathrm{P}-\mathrm{NMR}$ spectrum, confirming the asymmetric character of complex 14. These resonances are shifted upfield in contrast to that in complex 13 (Figure 4.12). 


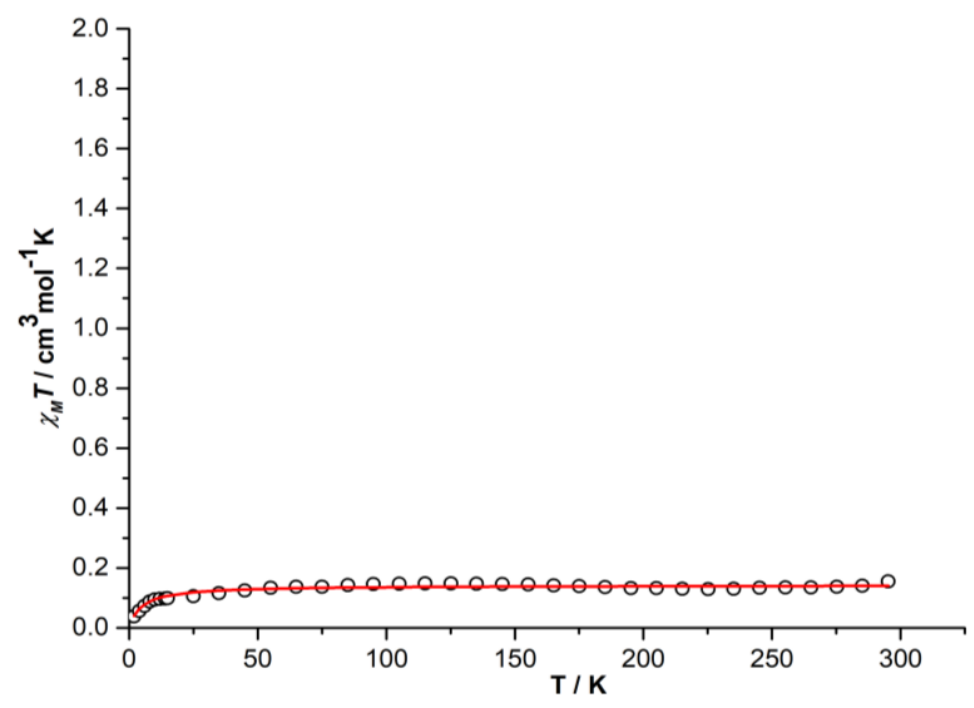

Figure 4.9: $\chi_{\mathrm{M}} T$ vs. $T$ plot in the temperature range of $2-295 \mathrm{~K}$ at $0.5 \mathrm{~T}$ of solid powder from complex 14. The red line corresponds to the best fits of the experimental magnetic results.

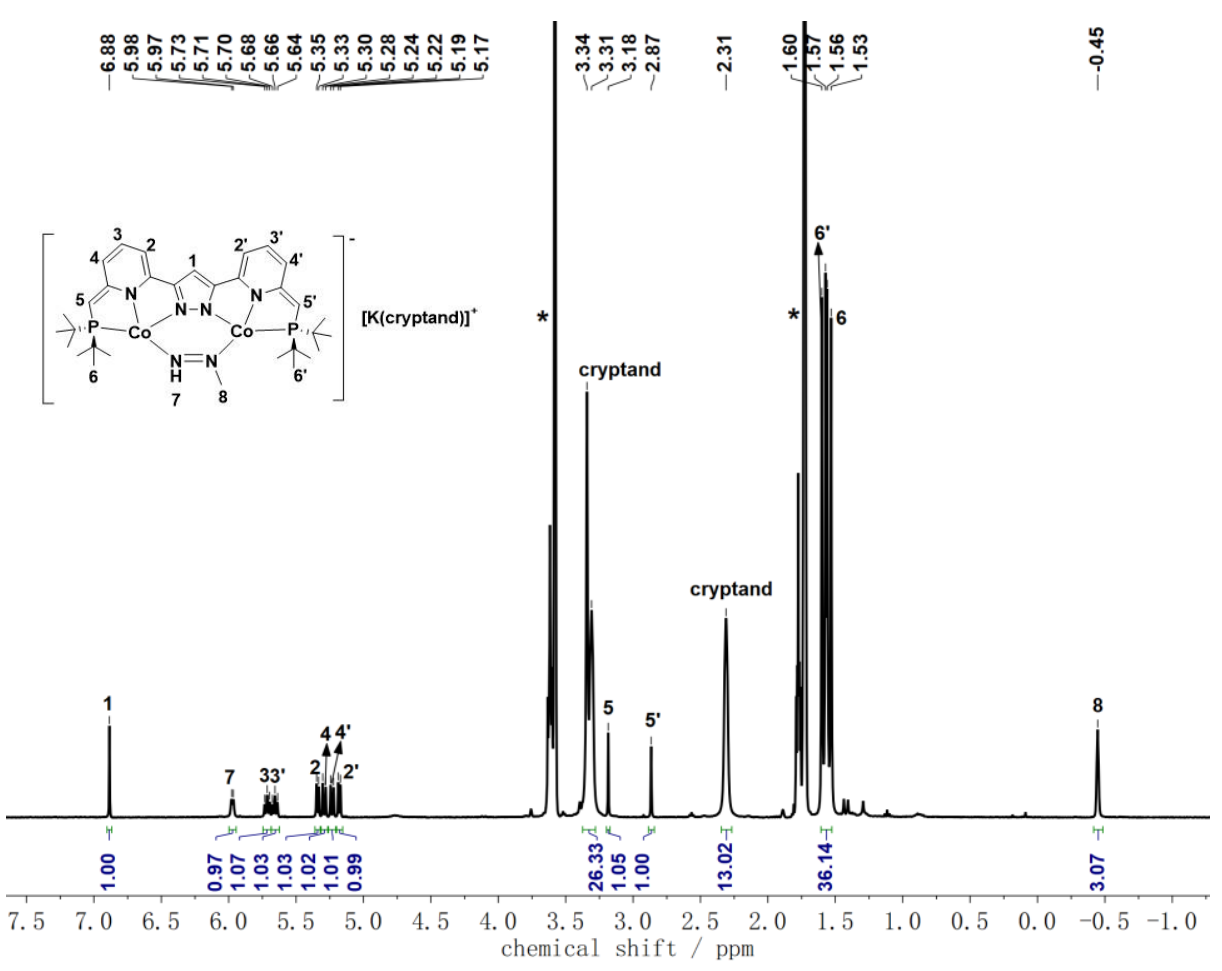

Figure 4.10: ${ }^{1} \mathrm{H}-\mathrm{NMR}$ spectrum of complex 14 in THF-d 8 . Solvent signals are marked with an asterisk $(*)$. 


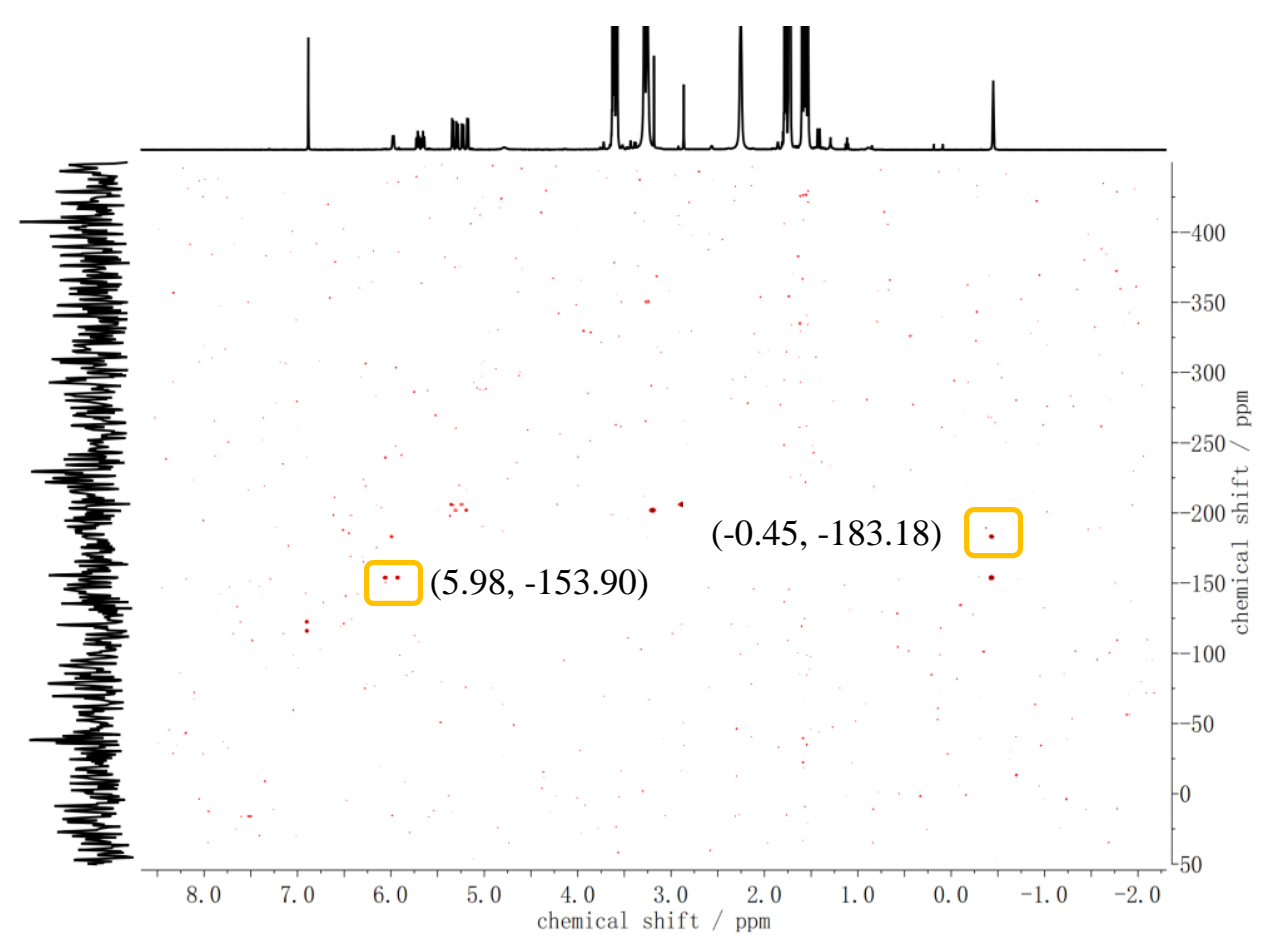

Figure 4.11: ${ }^{1} \mathrm{H}_{-}{ }^{15} \mathrm{~N}-\mathrm{HMBC}$ spectrum of complex 14 in $\mathrm{THF}-\mathrm{d}_{8}$.

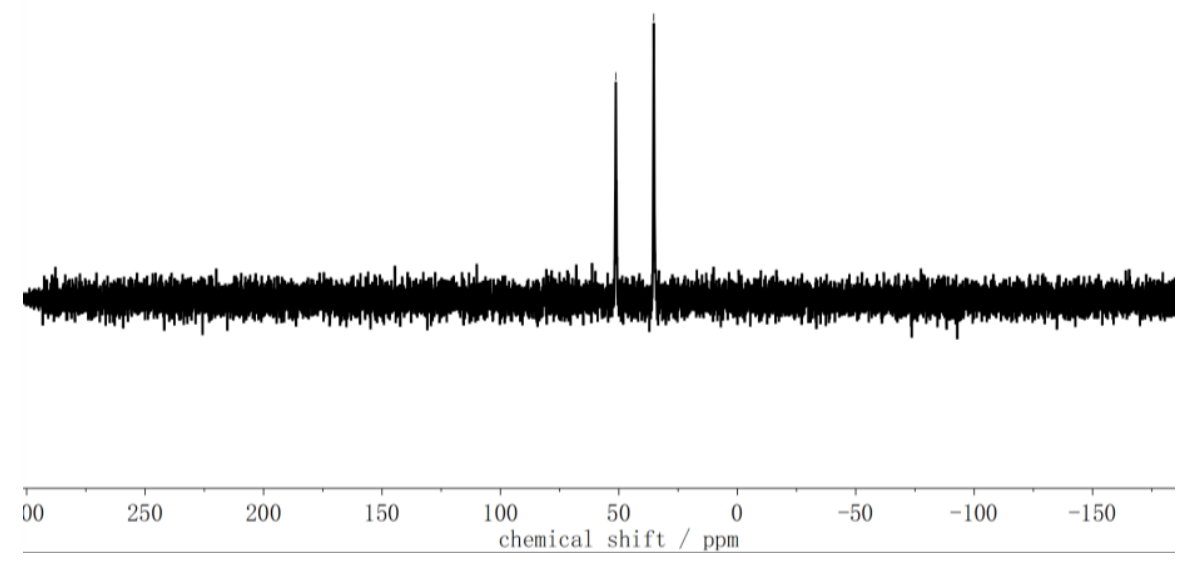

Figure 4.12: ${ }^{31} \mathrm{P}-\mathrm{NMR}$ spectrum of complex 14 in THF-d8.

The N-N stretching vibration of the methyldiazene in complex $\mathbf{1 4}$ could not be determined from the IR spectrum (Figure 9.83). As depicted in Figure 4.13, UV-vis spectroscopy shows the absorbance of complex 14 increases as temperature drops from $293 \mathrm{~K}$ to $193 \mathrm{~K}$ and the peaks at $\lambda_{\max }=320,414$, 505 and $667 \mathrm{~nm}$ may be attributed to charge transfer transitions including Co to the liand $\mathbf{L}^{-}$and the 
methyldiazene ligand.

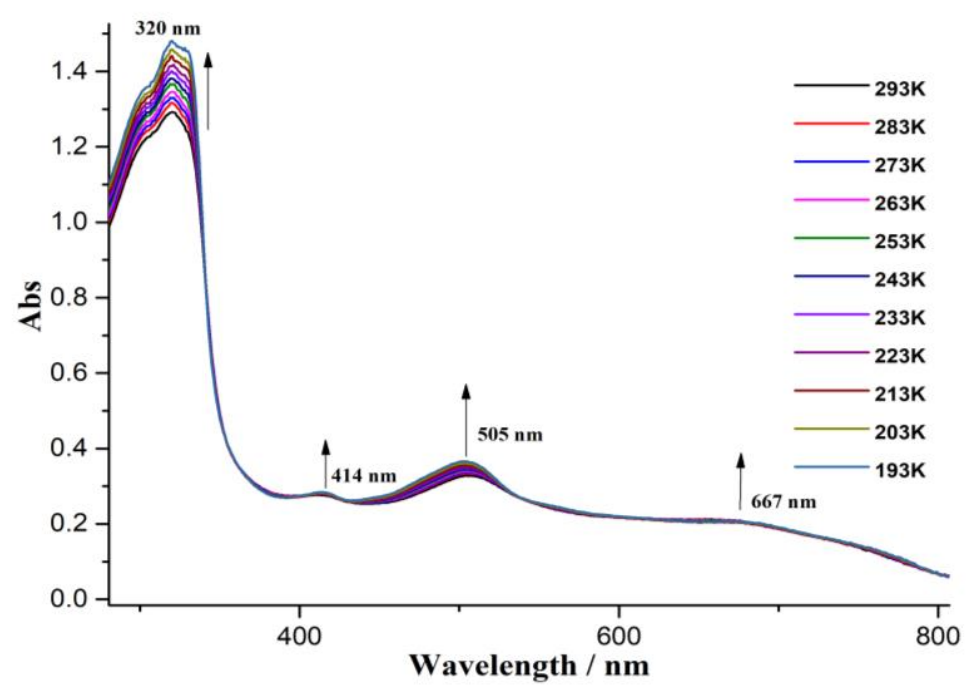

Figure 4.13: Variable temperature UV/vis spectra of complex 14 in THF solution in the temperature range from $293 \mathrm{~K}$ to $193 \mathrm{~K}$.

\subsection{Synthesis of An End-on Bridged 1,2-Dimethyldiazene Complex}

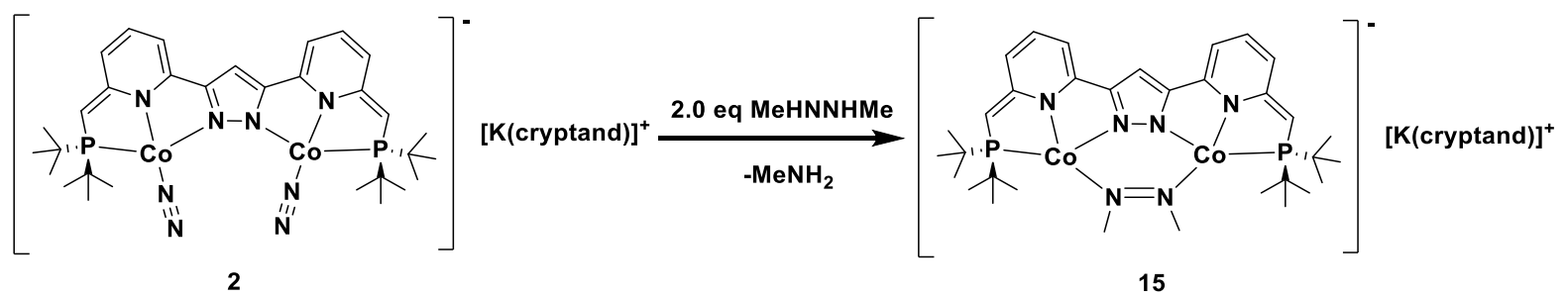

Scheme 4.5: Synthesis of the 1,2-dimethyldiazene complex 15.

As shown in Scheme 4.5, to a stirred THF solution of complex 2, two equivalents of 1,2-dimethylhydrazine (MeNHMeNH), which was synthesized from the reaction of 1,2-dimethylhydrazine dihydrochloride with ammonia in THF solution, were added and afforded a gradual color change from dark blue to red brown. After workup, block-shaped crystals suitable for $\mathrm{X}$-ray diffraction were grown from a concentrated THF solution at $-40{ }^{\circ} \mathrm{C}$ and characterized to be a 1,2-dimethyldiazene complex $\left[\left(\mathrm{L}^{* *} \mathrm{Co}_{2}\left(\right.\right.\right.$ trans $\left.-\mu-\eta^{l}: \eta^{l}-\mathrm{MeNNMe}\right)(\mathrm{K}([2.2 .2]$ cryptand $\left.))\right]$ 15. Moreover, the reaction was possibly accompanied by the formation of methylamine as a byproduct.

Complex 15 crystallized in the monoclinic space group $P 21 / c$ with four molecules in the unit cell. The potassium cation is encapsulated by [2.2.2]cryptand. The molecular structure of complex 15 confirms that two cobalt centers are in a distorted square planar geometry and bridged by trans dimethyldiazene with the Co...Co distance of $3.93 \AA$, which is longer than those in complex complexes 13 and 14. The MeNNMe ligand is bridging the two cobalt center in an end-on mode with 
N-N bond length of 1.303(6) $\AA$ for N5(A)-N6(A), which is shorter than those in complexes 13 and 14, suggesting a $\mathrm{N}=\mathrm{N}$ double bond. ${ }^{36}$ The $\mathrm{Co}-\mathrm{N}-\mathrm{N}-\mathrm{Co}$ torsion angles are $5.0^{\circ}$ and $78.1^{\circ}$. The methyl groups of MeNNMe ligand are bent out of the plane, which may be ascribed to the steric constraints of $\mathrm{L}^{-}$ligand. Selected bond lengths and angles are listed in Table 4.3.
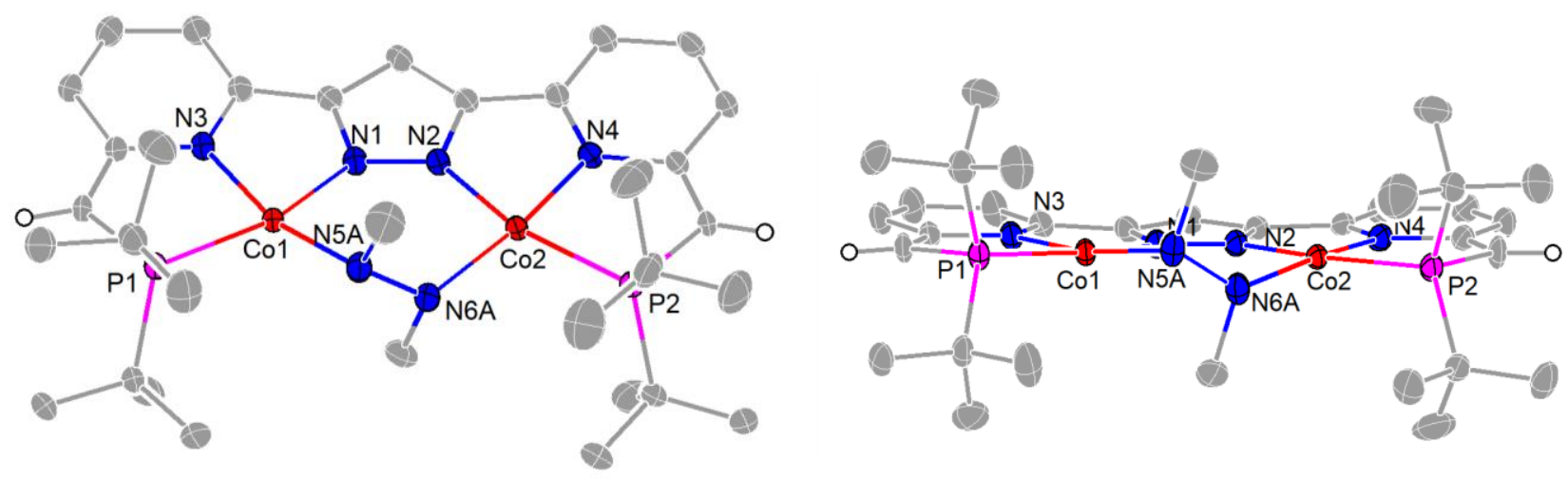

Figure 4.14: Top view (left) and front view (right) of the molecular structure of the anion of complex 15. Thermal displacement ellipsoids shown at $30 \%$ probability; most hydrogen atoms, the cation $(\mathrm{K}([2.2 .2] \text { cryptand }))^{+}$and solvent molecules omitted for clarity.

Table 4.3: Selected bond lengths and angles for complex 15.

\begin{tabular}{llll}
\hline \multicolumn{1}{c}{ Bond lengths / $\mathrm{A}$} & \multicolumn{3}{c}{ Angles / } \\
\hline $\mathrm{Co}(1)-\mathrm{N}(5 \mathrm{~A})$ & $1.867(4)$ & $\mathrm{N}(5 \mathrm{~A})-\mathrm{Co}(1)-\mathrm{N}(1)$ & $87.90(15)$ \\
$\mathrm{Co}(1)-\mathrm{N}(5 \mathrm{~B})$ & $1.873(14)$ & $\mathrm{N}(5 \mathrm{~B})-\mathrm{Co}(1)-\mathrm{N}(1)$ & $84.7(5)$ \\
$\mathrm{Co}(1)-\mathrm{N}(1)$ & $1.891(3)$ & $\mathrm{N}(5 \mathrm{~A})-\mathrm{Co}(1)-\mathrm{N}(3)$ & $164.94(16)$ \\
$\mathrm{Co}(1)-\mathrm{N}(3)$ & $1.921(3)$ & $\mathrm{N}(5 \mathrm{~B})-\mathrm{Co}(1)-\mathrm{N}(3)$ & $159.6(5)$ \\
$\mathrm{Co}(1)-\mathrm{P}(1)$ & $2.2104(9)$ & $\mathrm{N}(1)-\mathrm{Co}(1)-\mathrm{N}(3)$ & $80.31(11)$ \\
$\mathrm{Co}(2)-\mathrm{N}(6 \mathrm{~B})$ & $1.832(17)$ & $\mathrm{N}(5 \mathrm{~A})-\mathrm{Co}(1)-\mathrm{P}(1)$ & $106.52(13)$ \\
$\mathrm{Co}(2)-\mathrm{N}(2)$ & $1.889(3)$ & $\mathrm{N}(5 \mathrm{~B})-\mathrm{Co}(1)-\mathrm{P}(1)$ & $109.9(5)$ \\
$\mathrm{Co}(2)-\mathrm{N}(6 \mathrm{~A})$ & $1.899(4)$ & $\mathrm{N}(1)-\mathrm{Co}(1)-\mathrm{P}(1)$ & $165.19(9)$ \\
$\mathrm{Co}(2)-\mathrm{N}(4)$ & $1.913(3)$ & $\mathrm{N}(3)-\mathrm{Co}(1)-\mathrm{P}(1)$ & $84.91(8)$ \\
$\mathrm{Co}(2)-\mathrm{P}(2)$ & $2.2063(10)$ & $\mathrm{N}(6 \mathrm{~B})-\mathrm{Co}(2)-\mathrm{N}(2)$ & $87.3(5)$ \\
$\mathrm{N}(5 \mathrm{~A})-\mathrm{N}(6 \mathrm{~A})$ & $1.303(6)$ & $\mathrm{N}(2)-\mathrm{Co}(2)-\mathrm{N}(6 \mathrm{~A})$ & $87.99(15)$ \\
$\mathrm{N}(5 \mathrm{~B})-\mathrm{N}(6 \mathrm{~B})$ & $1.337(14)$ & $\mathrm{N}(6 \mathrm{~B})-\mathrm{Co}(2)-\mathrm{N}(4)$ & $163.2(5)$ \\
$\mathrm{Co} 1 \cdots \mathrm{Co} 2$ & $3.9277(6)$ & $\mathrm{N}(2)-\mathrm{Co}(2)-\mathrm{N}(4)$ & $80.23(12)$ \\
& & $\mathrm{N}(6 \mathrm{~A})-\mathrm{Co}(2)-\mathrm{N}(4)$ & $165.66(18)$ \\
& & $\mathrm{N}(6 \mathrm{~B})-\mathrm{Co}(2)-\mathrm{P}(2)$ & $107.2(5)$ \\
& & $\mathrm{N}(2)-\mathrm{Co}(2)-\mathrm{P}(2)$ & $165.27(9)$ \\
& & $\mathrm{N}(6 \mathrm{~A})-\mathrm{Co}(2)-\mathrm{P}(2)$ & $106.56(13)$ \\
& & $\mathrm{N}(4)-\mathrm{Co}(2)-\mathrm{P}(2)$ & $85.04(10)$ \\
\hline
\end{tabular}


The ${ }^{1} \mathrm{H}-\mathrm{NMR}$ spectrum in $\mathrm{THF}-\mathrm{d}_{8}$ (Figure 4.15) shows complex 15 is diamagnetic and it demonstrates one triplet at $\delta=5.71 \mathrm{ppm}$ and two doublets at $\delta=5.07$ and $4.98 \mathrm{ppm}$ for pyridine protons, one singlet at $\delta=2.72 \mathrm{ppm}$ for $\mathrm{CH}$ groups in the side arms and one doublet at $\delta=1.61 \mathrm{ppm}$ for the $t \mathrm{Bu}$ groups based on ${ }^{1} \mathrm{H}-{ }^{1} \mathrm{H}$ COSY and ${ }^{1} \mathrm{H}-{ }^{1} \mathrm{H}$ NOESY spectra (Figure 9.84 and 9.85), exhibitting an apparent $C_{2 v}$ symmetry on the NMR time scale at room temperature. Moreover, the doublet at $\delta=1.44 \mathrm{ppm}$ may be attributed to the methyl groups of the 1,2-dimethyldiazene ligand. The resonances of of complex 15 in the ${ }^{1} \mathrm{H}-\mathrm{NMR}$ spectrum are apparently shifted upfield in comparision to those in complexes 13 and 14, suggesting a higher electron density in complex 15. The ${ }^{31} \mathrm{P}-\mathrm{NMR}$ spectrum reveals a peak at $23.80 \mathrm{ppm}$, which is also shifted upfield in contrast to those in complexes 13 and 14 (Figure 4.16).
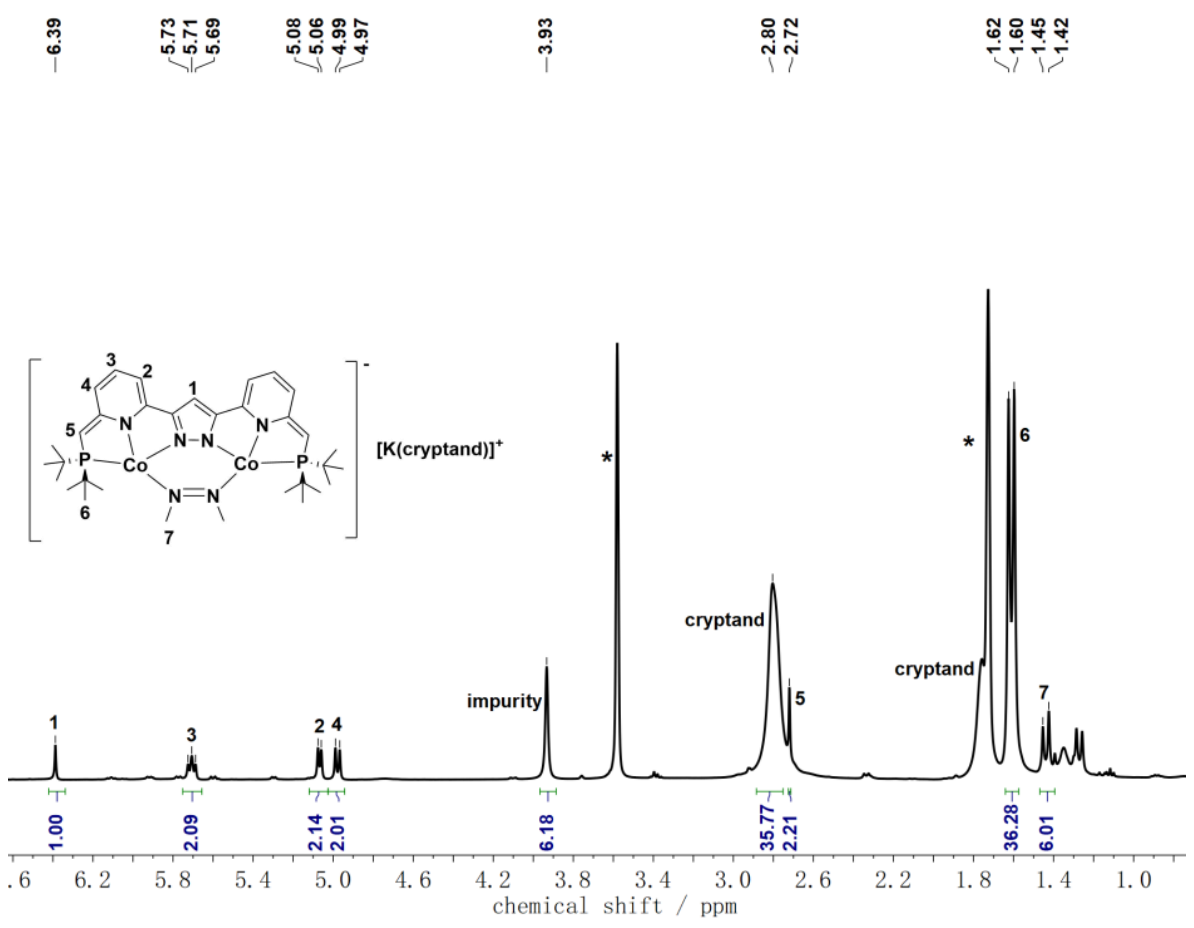

Figure 4.15: ${ }^{1} \mathrm{H}-\mathrm{NMR}$ spectrum of complex 15 in $\mathrm{THF}-\mathrm{d}_{8}$. Solvent signals are marked with an asterisk $(*)$. 


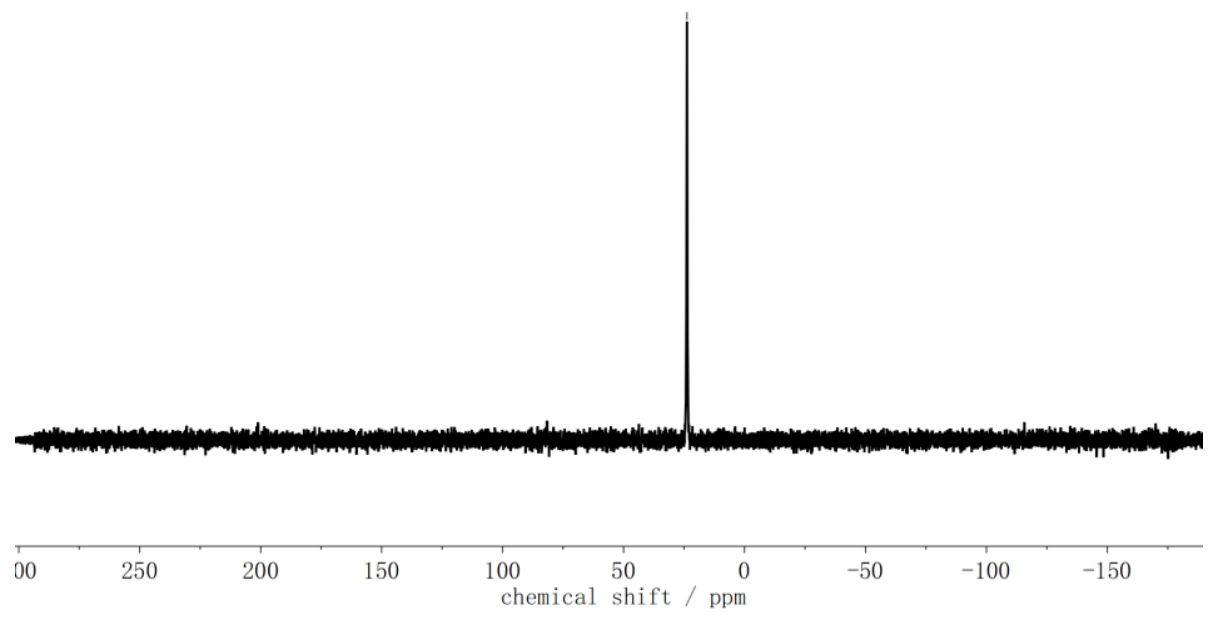

Figure 4.16: ${ }^{31} \mathrm{P}-\mathrm{NMR}$ spectrum of complex 15 in $\mathrm{THF}-\mathrm{d}_{8}$.

UV-vis spectroscopy exhibits that the absorbance of complex 15 increases slightly with temperature going down from $293 \mathrm{~K}$ to $193 \mathrm{~K}$ (Figure 4.17) and the absorption maximum at $\lambda_{\max }=322,395$, 450, 539 and $751 \mathrm{~nm}$ may be assigned to metal to ligand (including Co to the liand $\mathbf{L}^{-}$and the dimethyldiazene ligand) charge transfer transitions.

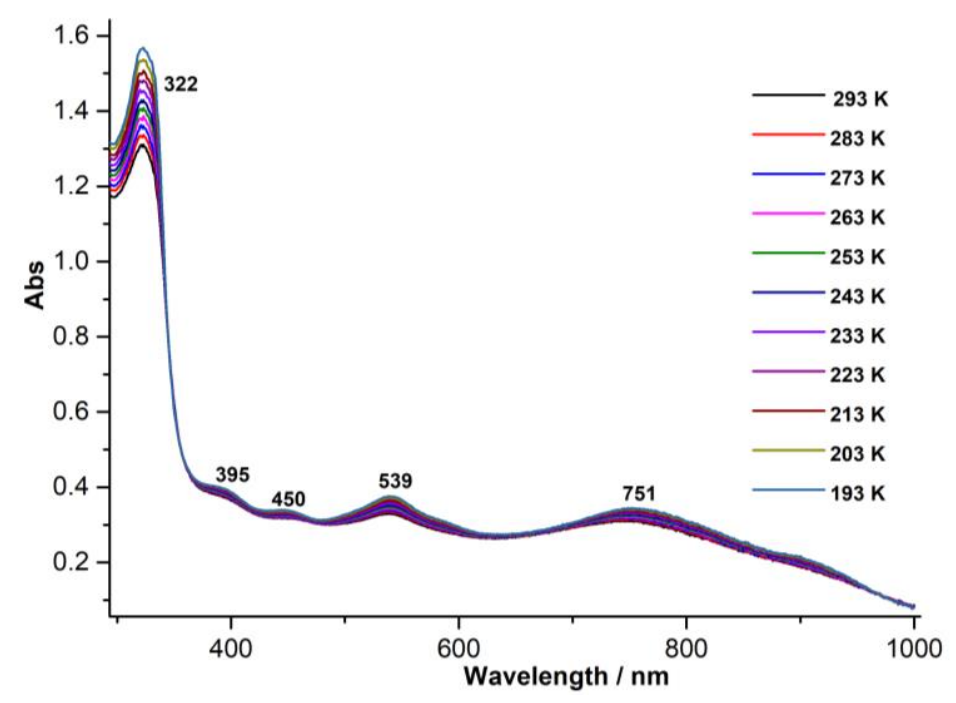

Figure 4.17: Variable temperature UV/vis spectra of complex 15 in THF solution in the temperature range from $293 \mathrm{~K}$ to $193 \mathrm{~K}$.

\subsection{Synthesis of An End-on Bridged Hydrazido Complex}




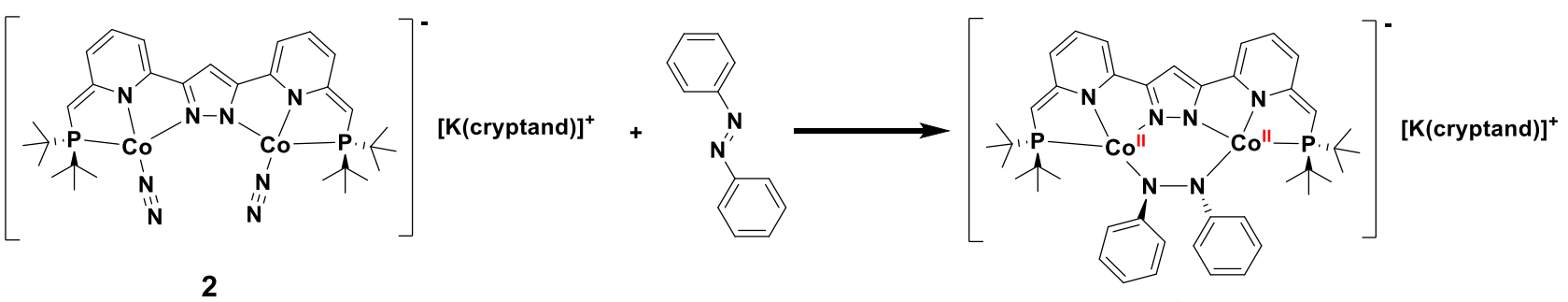

16

Scheme 4.6: Synthesis of the hydrazido complex 16.

Treatment of complex 2 with one equivalent of azobenzene dissolved in THF solution results in an immediate color change from dark blue to red brown. Crystals suitable for X-ray diffraction could be isolated from a concentrated THF solution at $-40{ }^{\circ} \mathrm{C}$ in $70 \%$ yield and were identified as an hydrazido complex $\left[\left(\mathrm{L}^{* *} \mathrm{Co}_{2}\left(\right.\right.\right.$ trans $\left.-\mu-\eta^{l}: \eta^{l}-\mathrm{PhNNPh}\right)(\mathrm{K}([2.2 .2]$ cryptand $\left.))\right] \quad \mathbf{1 6}$ (Scheme 4.6). Complex 16 crystallized in the triclinic space group $P-1$ with two molecules in the unit cell. Two cobalt ions are hosted in two $\{\mathrm{PNN}\}$-tridentate binding sites and bridged by trans $\mathrm{PhNNPh}$ ligand with nitrogen atoms in a distorted square planar fashion with a Co ‥Co separation of $3.93 \AA$ (Figure 4.18), which is similar to that in complex 15. The N-N bond length amounts to 1.431(4) $\AA$, corresponding to a typical N-N single bond, ${ }^{36}$ which can be explained by two electron transfer from the two cobalt centers to the azobenzene ligand. The phenyl rings are bent out of the plane, pointing to a $\mathrm{sp}^{3}$ hybridization of the NPh units. Co-N-N-Co torsion angles are $21.0^{\circ}$ and $77.0^{\circ}$. Selected bond lengths and angles are listed in Table 4.4. It suggests that complex 16 was formed by oxidation of the Co centers during a reduction of azobenzene. In contrast to complexes 13 and $\mathbf{1 4}$, the electron transfer from metal centers to azobenzene in complex $\mathbf{1 6}$ may be attributed to the electron withdrawing effect of phenyl groups in azobenzene or by steric constraints that do not allow the azobenzene to adopt a planar structure as seen in $\mathbf{1 3}$ and 14. While the methyl groups in complex $\mathbf{1 5}$ are also bent out of the plane because of steric constraints, which does not lead to the electron transfer to metal centers, it indicates that the electron withdrawing effect of phenyl groups of azobenzene results in the electron transfer from metal centers to azobenzene and the oxidation of the metal centers in complex 16.
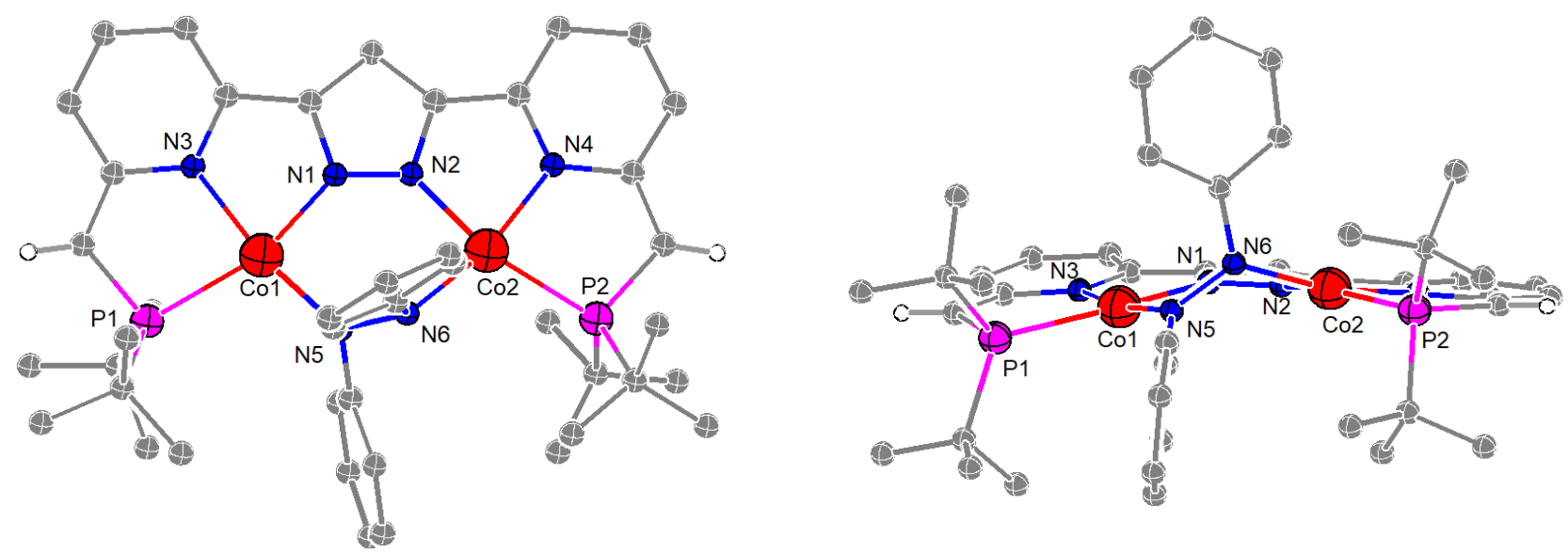

Figure 4.18: Top view (left) and front view (right) of the molecular structure of the anion of complex 
15. Thermal displacement ellipsoids shown at $30 \%$ probability; most hydrogen atoms, the cation $(\mathrm{K}([2.2 .2] \text { cryptand }))^{+}$and solvent molecules omitted for clarity.

Table 4.4: Selected bond lengths and angles for complex 16.

\begin{tabular}{llll}
\hline \multicolumn{2}{c}{ Bond lengths / $\AA$} & \multicolumn{3}{c}{ Angles / } \\
\hline $\mathrm{Co}(1)-\mathrm{N}(5)$ & $1.899(3)$ & $\mathrm{N}(5)-\mathrm{Co}(1)-\mathrm{N}(1)$ & $90.91(12)$ \\
$\mathrm{Co}(1)-\mathrm{N}(1)$ & $1.900(3)$ & $\mathrm{N}(5)-\mathrm{Co}(1)-\mathrm{N}(3)$ & $169.55(12)$ \\
$\mathrm{Co}(1)-\mathrm{N}(3)$ & $1.956(3)$ & $\mathrm{N}(1)-\mathrm{Co}(1)-\mathrm{N}(3)$ & $79.78(12)$ \\
$\mathrm{Co}(1)-\mathrm{P}(1)$ & $2.3152(10)$ & $\mathrm{N}(5)-\mathrm{Co}(1)-\mathrm{P}(1)$ & $106.81(9)$ \\
$\mathrm{Co}(2)-\mathrm{N}(2)$ & $1.883(3)$ & $\mathrm{N}(1)-\mathrm{Co}(1)-\mathrm{P}(1)$ & $162.21(9)$ \\
$\mathrm{Co}(2)-\mathrm{N}(6)$ & $1.935(3)$ & $\mathrm{N}(3)-\mathrm{Co}(1)-\mathrm{P}(1)$ & $82.67(9)$ \\
$\mathrm{Co}(2)-\mathrm{N}(4)$ & $1.940(3)$ & $\mathrm{N}(2)-\mathrm{Co}(2)-\mathrm{N}(6)$ & $87.55(12)$ \\
$\mathrm{Co}(2)-\mathrm{P}(2)$ & $2.2624(10)$ & $\mathrm{N}(2)-\mathrm{Co}(2)-\mathrm{N}(4)$ & $80.74(13)$ \\
$\mathrm{Co} 1 \cdots \mathrm{Co} 2$ & $3.9298(6)$ & $\mathrm{N}(6)-\mathrm{Co}(2)-\mathrm{N}(4)$ & $163.95(13)$ \\
$\mathrm{N}(5)-\mathrm{N}(6)$ & $1.431(4)$ & $\mathrm{N}(2)-\mathrm{Co}(2)-\mathrm{P}(2)$ & $163.05(9)$ \\
& & $\mathrm{N}(6)-\mathrm{Co}(2)-\mathrm{P}(2)$ & $108.88(9)$ \\
& & $\mathrm{N}(4)-\mathrm{Co}(2)-\mathrm{P}(2)$ & $83.86(10)$ \\
\hline
\end{tabular}

The ${ }^{1} \mathrm{H}-\mathrm{NMR}$ spectrum in THF- $\mathrm{d}_{8}$ confirms the paramagnetic character of complex $\mathbf{1 6}$ (Figure 4.19). Resonances at $\delta=6.60,-4.86$ and $-11.62 \mathrm{ppm}$ may be attributed to pyridine protons based on the ${ }^{1} \mathrm{H}-{ }^{1} \mathrm{H}$ COSY spectrum (Figure 9.89). The single peak at $\delta=12.74 \mathrm{ppm}$ can be attributed to the $\mathrm{H}$-atom of the pyrazole and two single peaks at $\delta=8.63$ and $4.36 \mathrm{ppm}$ can be assigned to the $t \mathrm{Bu}$ groups on the basis of the integral. The other proton resonances cannot be assigned, or are missing. No signals were observed in the ${ }^{31} \mathrm{P}$ NMR spectrum, presumably because of the vicinity of the nuclei to the paramagnetic metal centers. 


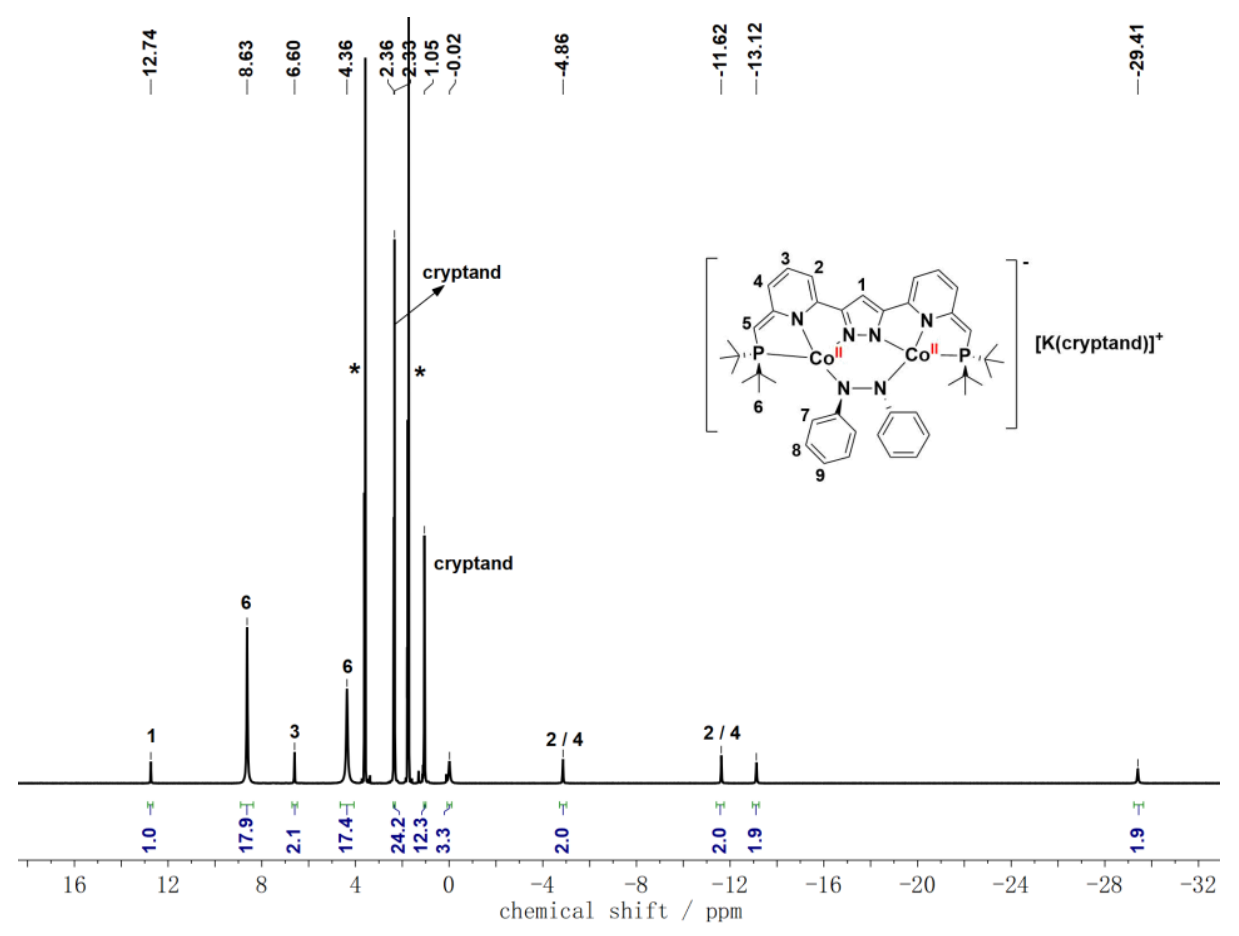

Figure 4.19: ${ }^{1} \mathrm{H}-\mathrm{NMR}$ spectrum of complex 16 in $\mathrm{THF}-\mathrm{d}_{8}$. Solvent signals are marked with an asterisk $(*)$.

A variable temperature magnetic susceptibility measurement with a SQUID magnetometer (Figure 4.20) reveals that the $\chi_{M} T$ product rises to $1.03 \mathrm{~cm}^{3} \mathrm{~mol}^{-1} \mathrm{~K}$ at $295 \mathrm{~K}$, which represents the cobalt(II) ions are in low spin configuration with one unpaired electron $(\mathrm{S}=1 / 2)$. The best fits lead to $g=2.26$. The decrease of the curve at low temperature indicates antiferromagnetic coupling $\left(J=-9.3 \mathrm{~cm}^{-1}\right)$. As shown in Figure 4.21, the X-band EPR spectroscopy of complex 16 in THF at $147 \mathrm{~K}$ shows a narrow and almost isotropic spectrum with $g_{l}=g_{2}=2.2$ (Gaussian line shapes) with no discernable hyperfine interactions to the central metal ions or the nitrogen atoms, nearly identical with the vales of SQUID measurement. Moreover, complex 16 in THF at $5 \mathrm{~K}$ becomes EPR-silent, which shows $\mathrm{S}=0$ ground state of complex 16 at $5 \mathrm{~K}$ and also confirms that the signal in EPR spectrum at $147 \mathrm{~K}$ originates from complex 16. 


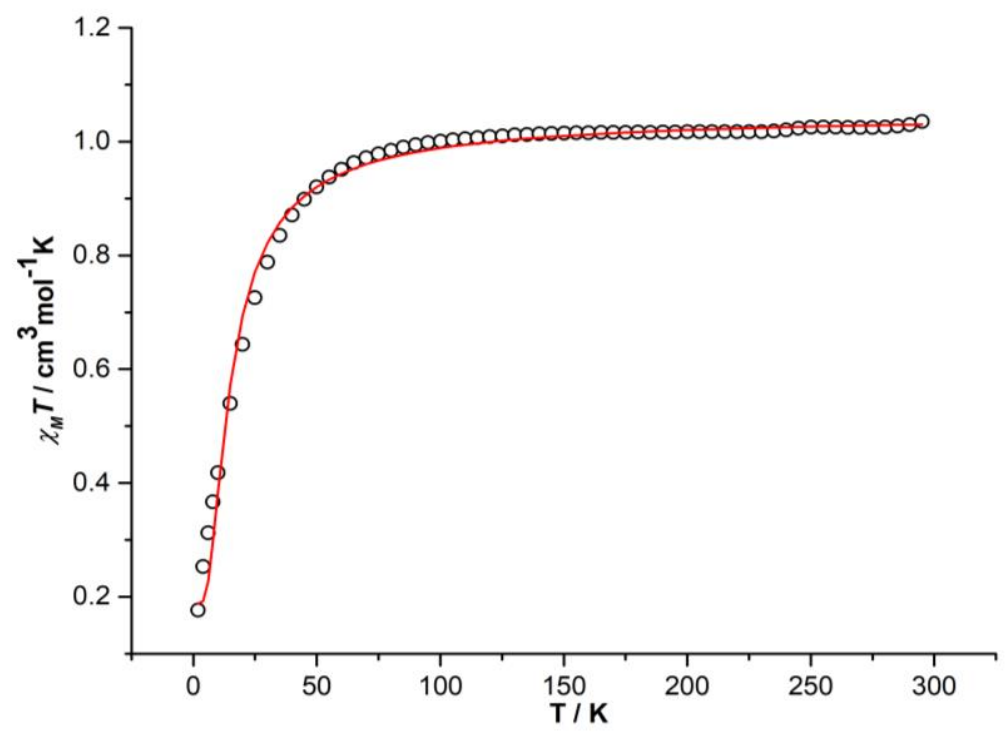

Figure 4.20: $\chi_{\mathrm{M}} T$ vs. $T$ plot in the temperature range of $2-295 \mathrm{~K}$ at $0.5 \mathrm{~T}$ of solid powder from complex 16. The red line corresponds to the best fits of the experimental magnetic results.

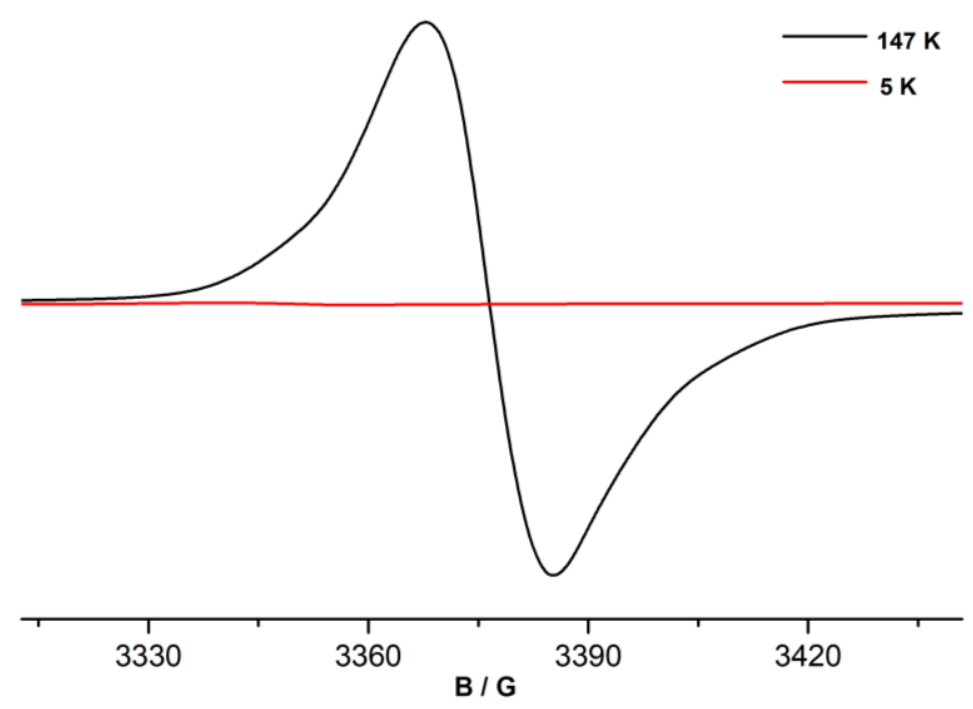

Figure 4.21: Experimental EPR spectrum of complex 16 in THF at $147 \mathrm{~K}$ and $5 \mathrm{~K}$.

Variable temperature UV-vis spectroscopy was measured in THF and it shows the absorbance features at $\lambda_{\max }=318,428,511,550$ and $595 \mathrm{~nm}$ that slightly decrease in intensity when the temperature is lowered from $193 \mathrm{~K}$ to $313 \mathrm{~K}$ (Figure 4.22). As shown in Figure 4.23, the energy-minimized DFT calculated structure of complex $\mathbf{1 6}$ is in good agreement with that obtained by X-ray diffraction. The unpaired electrons are located nearly entirely on the metal centers. 


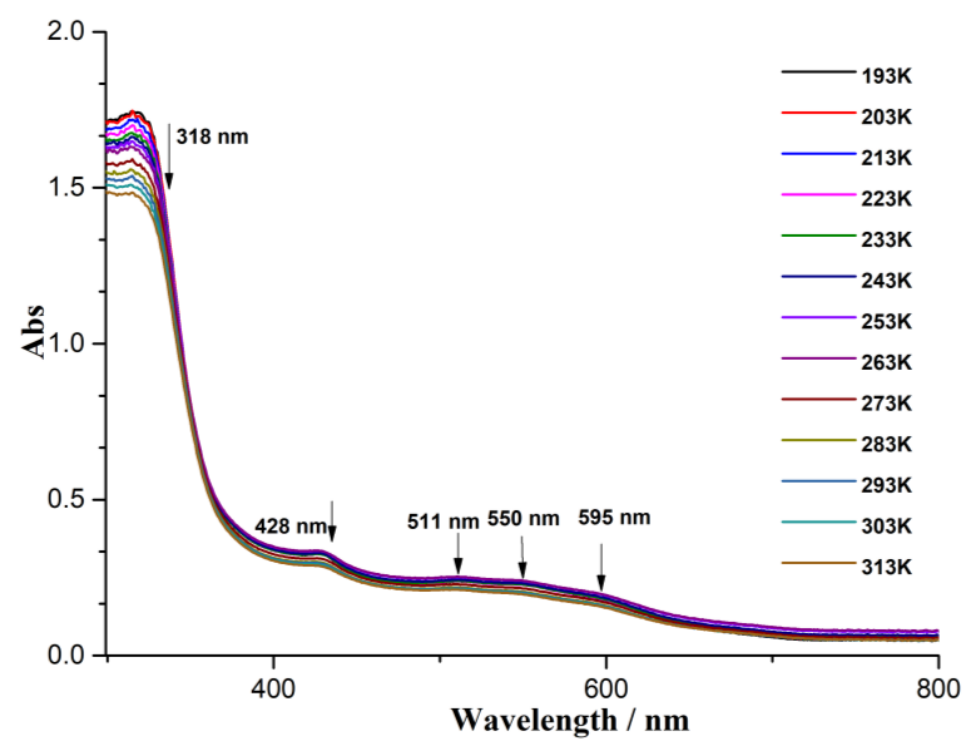

Figure 4.22: Variable temperature UV/vis spectra of complex 16 in THF solution in the temperature range from $193 \mathrm{~K}$ to $313 \mathrm{~K}$.

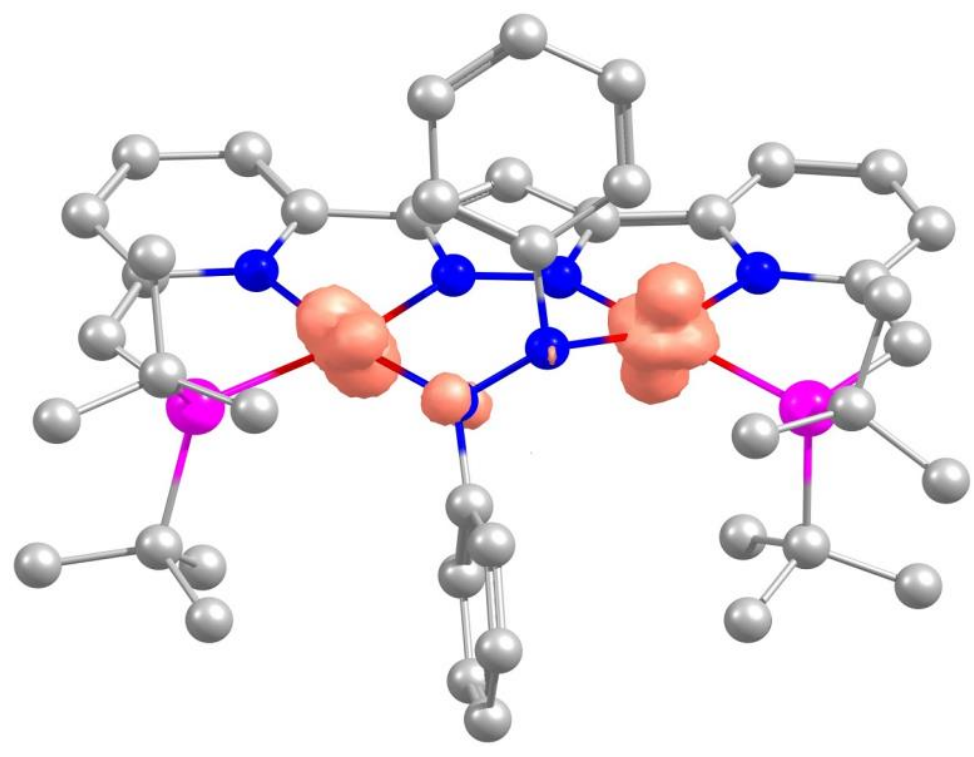

Figure 4.23: Spin Density (0.02 isosurface) of complex 16, Mulliken Spin Population (> 0.1): Co1 = $0.671785, \mathrm{Co} 2=1.089091, \mathrm{~N} 5=0.150811$. 


\subsection{Conclusion}

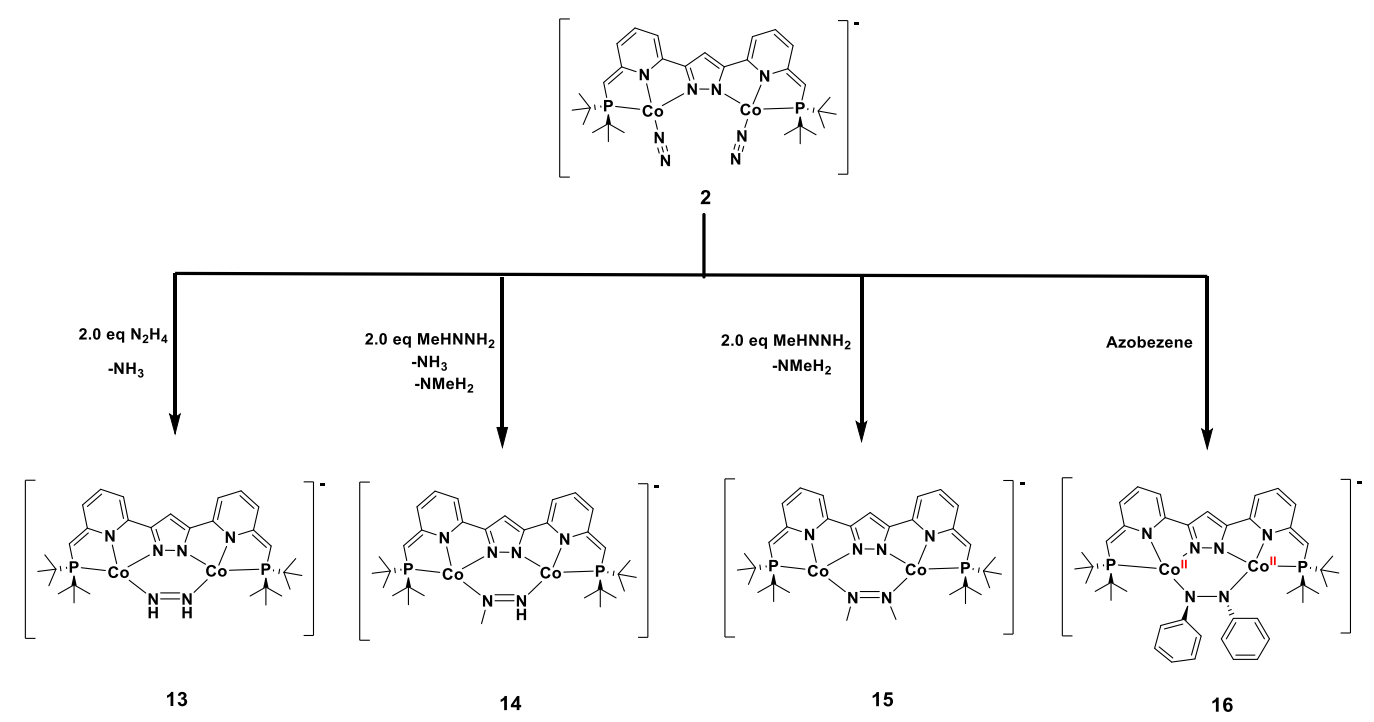

In summary, a series of $\mathrm{M}\left(\mathrm{N}_{2} \mathrm{H}_{\mathrm{x}} \mathrm{R}\right)$ complexes as potential intermediates in $\mathrm{N}_{2}$ fixation process have been successfully synthesized and all the complexes are structurally and spectroscopically characterized. The reactions of dearomatized dicobalt dinitrogen complex $\left[\left(\mathrm{L}^{* *}\left(\mathrm{CoN}_{2}\right)_{2}\right)(\mathrm{K}([2.2 .2]\right.$ cryptand $\left.))\right] \mathbf{2}$ with hydrazine, methylhydrazine and dimethylhydrazine give rise to diamagnetic diazene complexes with concomitant formation of ammonia or methylamine. Specifically, the dinitrogen complex 2 reacts with azobenzene to perform a two-electron reduction, which formally oxidizes the metal centers. In contrast to complexes 13, 14 and 15, the electron transfer from metal centers to azobenzene may be attributed to the electron withdrawing effect of phenyl group in azobenzene. The study of chemical reactivity and redox property of these diazene and hydrazido complexes is still in progress. 



\section{Chapter 5: $\mathrm{CO}_{2}$ Reductive Disproportionation and CO Reactions Mediated by the Dicobalt Dinitrogen Complex 6}

\subsection{Introduction}

$\mathrm{CO}_{2}$ is ubiquitous in the atmosphere generally emitted from fossil fuel combustion and respiration. As the main greenhouse gas, it has affected global climate change. ${ }^{43}$ However, $\mathrm{CO}_{2}$ plays an important role in biological and chemical catalysis. ${ }^{44}$ In nature, $\mathrm{CO}_{2}$ can be reduced to $\mathrm{CO}$ with two electrons and two protons using the enzyme [NiFe] carbon monoxide dehydrogenase $(\mathrm{CODH})$ as catalyst. ${ }^{45}$ The proposed mechanism is that coordination of $\mathrm{CO}_{2}$ on the $\mathrm{Ni}$ center gives rise to a hydroxycarbonyl bridged $\left\{\mathrm{Ni}\left(\mathrm{CO}_{2} \mathrm{H}\right) \mathrm{Fe}\right\}$ complex as intermediate and after continuous electron and proton transfer, it finally releases $\mathrm{CO}$ to accomplish a catalytic cycle. Furthermore, the utilization of $\mathrm{CO}_{2}$ mediated by metal catalysts to synthesize $\mathrm{C} 1$ feedstock of industrial chemicals is particularly important. ${ }^{46}$ As depicted in Figure 5.1, $\mathrm{CO}_{2}$ has been widely explored to be reduced into formate $\left(\mathrm{HCOO}^{-}\right)$, carbon monoxide $(\mathrm{CO})$, formaldehyde $\left(\mathrm{CH}_{2} \mathrm{O}\right)$, methanol $\left(\mathrm{CH}_{3} \mathrm{OH}\right)$, oxalate $\left(\mathrm{C}_{2} \mathrm{O}_{4}{ }^{2-}\right)$, and carbonate $\left(\mathrm{CO}_{3}{ }^{2-}\right){ }^{45 \mathrm{~b}}$ Moreover, methane $\left(\mathrm{CH}_{4}\right)$, ethylene $\left(\mathrm{CH}_{2} \mathrm{CH}_{2}\right)$, and ethanol $\left(\mathrm{CH}_{3} \mathrm{CH}_{2} \mathrm{OH}\right)$ are usually produced as byproducts. But due to the high thermodynamic stability and reaction barriers of $\mathrm{CO}_{2}$, selective chemical synthesis from $\mathrm{CO}_{2}$ is quite challenging in chemical catalysis, electrochemistry and photochemistry. ${ }^{47}$ In this regard, the reactivity of $\mathrm{CO}_{2}$ with transition metal complexes is distinctly indispensable to afford a platform to explore possible mechanisms.

$$
\begin{aligned}
& \mathrm{CO}_{2}(\mathrm{aq})+\mathrm{e}^{-} \rightarrow \mathrm{CO}_{2}^{-\bullet}(\mathrm{aq}) \quad E^{\circ \prime}=-1.9 \mathrm{~V} \\
& \mathrm{CO}_{2}(\mathrm{~g})+2 \mathrm{H}^{+}+2 \mathrm{e}^{-} \rightarrow \mathrm{CO}(\mathrm{g})+\mathrm{H}_{2} \mathrm{O} \\
& \mathrm{E}^{\circ \prime}=-0.52 \mathrm{~V} \\
& \mathrm{CO}_{2}(\mathrm{~g})+\mathrm{H}^{+}+2 \mathrm{e}^{-} \rightarrow \mathrm{HCO}_{2}^{-}(\mathrm{aq}) \quad E^{\circ \prime}=-0.43 \mathrm{~V} \\
& \mathrm{CO}_{2}(\mathrm{~g})+4 \mathrm{H}^{+}+4 \mathrm{e}^{-} \rightarrow \mathrm{HCHO}(\mathrm{aq})+\mathrm{H}_{2} \mathrm{O} \\
& E^{\circ \prime}=-0.51 \mathrm{~V} \\
& \mathrm{CO}_{2}(\mathrm{~g})+6 \mathrm{H}^{+}+6 \mathrm{e}^{-} \rightarrow \mathrm{CH}_{3} \mathrm{OH}(\mathrm{aq})+\mathrm{H}_{2} \mathrm{O} \\
& E^{\circ \prime}=-0.38 \mathrm{~V} \\
& \mathrm{CO}_{2}(\mathrm{~g})+8 \mathrm{H}^{+}+8 \mathrm{e}^{-} \rightarrow \mathrm{CH}_{4}(\mathrm{~g})+2 \mathrm{H}_{2} \mathrm{O} \\
& E^{\circ \prime}=-0.24 \mathrm{~V}
\end{aligned}
$$

Figure 5.1. Selected $\mathrm{CO}_{2}$ Reduction Processes and the Corresponding Standard Redox Potentials vs NHE. ${ }^{45 b, 47}$

$\mathrm{CO}_{2}$ is a $16 \mathrm{e}^{-}$(valence electrons) linear molecule in the ground state and belongs to $\mathrm{D}_{\infty \mathrm{h}}$ symmetry 
group. $\mathrm{CO}_{2}$ is nonpolar, but the carbon atom is electrophilic and the oxygen atoms are nucleophilic, represented as $\mathrm{O}^{-\delta}-\mathrm{C}^{+2 \delta}-\mathrm{O}^{-\delta}{ }^{47}$ The $\mathrm{CO}_{2}$ molecular orbital diagram is shown in Figure 5.2. The highest doubly occupied $1 \pi_{\mathrm{g}}$ molecular orbitals are HOMOs, which are mostly localized at the terminal oxygen atoms and the lowest unoccupied $2 \pi_{\mathrm{u}}$ molecular orbitals, LUMOs, are mainly centered on the carbon atom. The electrophilic property of the carbon atom is higher than the nucleophilic characters of the oxygen atoms, which makes $\mathrm{CO}_{2}$ susceptible to attack by nucleophiles. ${ }^{47,48}$ The activation of $\mathrm{CO}_{2}$ molecule with electron donors will cause a distortion of $\mathrm{CO}_{2}$ from linearity or reduction of $\mathrm{CO}_{2}$ molecule. The one electron reduction of linear $\mathrm{CO}_{2}$ to generate bent $\mathrm{CO}_{2}{ }^{\bullet}$ requires a very negative potential for structural rearrangement. On the contrary, multielectron reductions or proton-coupled multielectron reductions of $\mathrm{CO}_{2}$ can occur at very modest potentials, which makes them more favorable than single electron processes.

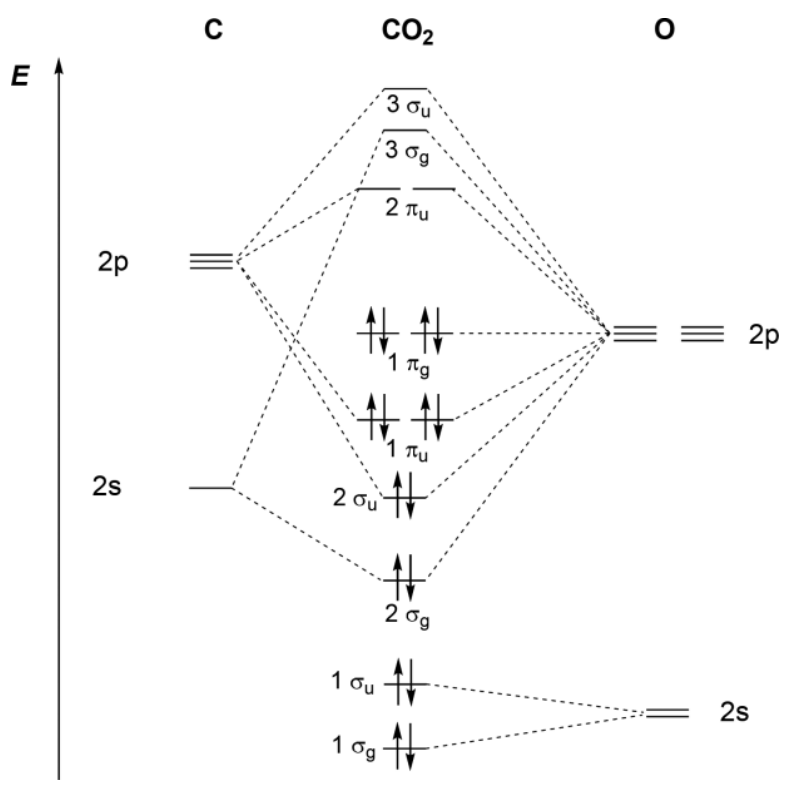

Figure 5.2: Simplified $\mathrm{CO}_{2}$ molecular orbital diagram.

\subsection{1 $\mathrm{CO}_{2}$ coordination to transition metal}

$\mathrm{CO}_{2}$ can be coordinated with metal centers in the following bonding modes (Figure 5.3). ${ }^{48}$ For the coordination of $\mathrm{CO}_{2}$ to a single metal center, the $\eta^{1}-\mathrm{C}$ and $\eta^{2}-\mathrm{C}, \mathrm{O}$ bonding modes are quite common, while the $\eta^{1}$-O bonding mode has been reported recently in a six-coordinate uranium(III) species, ${ }^{49}$ where $\mathrm{CO}_{2}$ molecule was weakly bent. For the coordination of $\mathrm{CO}_{2}$ to multiple metal centers, the bonding modes are more complicated. But the $\mathrm{C}-\mathrm{O}$ bonds are distinctly elongated, which demonstrates that the interactions between $\mathrm{CO}_{2}$ and multiple metal centers contribute to the activation of $\mathrm{CO}_{2}$ molecule. 


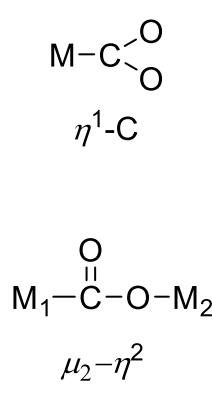

$$
\begin{array}{ll}
\mathrm{M}-\mathrm{O}=\mathrm{C}=\mathrm{O} & \mathrm{M}-\mathrm{C}=\mathrm{O} \\
\eta^{1}-\mathrm{O} & \eta^{2}-\mathrm{C}, \mathrm{O}
\end{array}
$$

$$
\begin{gathered}
\stackrel{\mathrm{O}}{\mathrm{M}}-\stackrel{\mathrm{C}}{\mathrm{C}}-\mathrm{O}-\mathrm{M}_{2} \\
\mu_{2}-\eta^{2}
\end{gathered}
$$<smiles>[M]OC(=[V])O[V]</smiles><smiles>[M]OC([M])O[Na]</smiles><smiles>[M]OC([M])O[Na]</smiles><smiles>[M]OC([M])O[Na]</smiles><smiles></smiles><smiles>[M]OC1ON(O[M])O1</smiles>

Figure 5.3: Bonding modes of $\mathrm{CO}_{2}$ to metal centers

\subsection{2 $\mathrm{CO}_{2}$ Reductive Disproportionation and Oxalate Formation}

$$
2 \mathrm{CO}_{2}+2 \mathrm{e}^{-} \longrightarrow \mathrm{CO}+\mathrm{O}^{2-} \stackrel{\mathrm{CO}_{2}}{\longrightarrow} \mathrm{CO}+\mathrm{CO}_{3}^{2-}
$$

Scheme 5.1: $\mathrm{CO}_{2}$ reductive disproportionation and oxalate formation.

Activation and reduction of $\mathrm{CO}_{2}$ mediated by transition metal complexes are of importance to explore the mechanisms of $\mathrm{C}-\mathrm{O}$ bond cleavage, and to synthesize sustainable chemical $\mathrm{C} 1$ resources. The reduction of $\mathrm{CO}_{2}$ with low-valent electron-rich transition-metal complexes to form $\mathrm{CO}$ and carbonate or oxalate has been widely studied as proton-free reduction pathways (Scheme 5.1). ${ }^{47,50}$ These two processes are inferred to proceed via single-electron reduction of $\mathrm{CO}_{2}$ to generate the $\mathrm{CO}_{2}$ radical $\left(\mathrm{CO}_{2}^{-\bullet}\right)$, which can further disproportionate to $\mathrm{CO}$ and carbonate or undergo $\mathrm{C}-\mathrm{C}$ coupling to form oxalate. The reduction of $\mathrm{CO}_{2}$ to form $\mathrm{CO}$ and carbonate is known as reductive disproportionation, where $\mathrm{CO}$ as a chemical feedstock can be then converted into liquid fuels via Fischer-Tropsch chemistry. The Holland group also reported the $\mathrm{CO}_{2}$ reductive disproportionation with $\mathrm{Co}$ and $\mathrm{Fe}$ complexes based on the nacnac ligand to form carbonyl and carbonate complexes. ${ }^{50 \mathrm{~b} \text {, }}$ ${ }^{50 c}$ Moreover, the reported carbonate complexes are quite similar, but the Fe complex is a dicarbonyl while the Co complex is found to be monocarbonyl, possibly attributed to the extent of backbonding. The Limberg group mediated $\mathrm{CO}_{2}$ reduction to form carbonyl and carbonate complexes or an oxalate complex by using different $\mathrm{Ni}$ precursors, an anionic dinuclear $\mathrm{Ni}(\mathrm{I})$ complex and a neutral dinuclear $\mathrm{Ni}(\mathrm{I})$ complex respectively. ${ }^{50 \mathrm{a}}$ In addition, the single-electron reduction of $\mathrm{CO}_{2}$ leads to $\mathrm{C}-\mathrm{O}$ bond cleavage to give rise to $\mathrm{CO}$ and an oxido species, an possible intermediate to generate carbonate. ${ }^{51}$ The Thomas group synthesized a zirconium oxoanion (THF) ${ }_{3} \mathrm{Na}-\mathrm{O}-\mathrm{Zr}\left(\mathrm{MesNP}^{\mathrm{i}} \mathrm{Pr}_{2}\right)_{3} \mathrm{Co}(\mathrm{CO})$ complex derived from stoichiometric $\mathrm{CO}_{2}$ reduction, which can also result in a carbonate complex after 
addition of another equivalent of $\mathrm{CO}_{2} .{ }^{51 \mathrm{a}}$ The Peters group reported the transformation from $\mathrm{CO}_{2}$ to a binuclear $\mu$-O: $\mu$-CO complex as main product and an oxalate complex in low yield. ${ }^{51 \mathrm{~b}}$ On the other side, as mentioned above, the reduction of $\mathrm{CO}_{2}$ with transition metal complexes can also produce oxalate, which can be hydrogenated to give ethylene glycol. In Bouwman's electrocatalytic system, a dicopper(I) complex reduced $\mathrm{CO}_{2}$ in air to yield a bis[( $\mu$-oxalato)dicopper(II)] complex. ${ }^{51 \mathrm{c}}$

\subsection{3 $\mathrm{CO}_{2}$ Insertion into $\mathrm{M}-\mathrm{H}$ bonds}

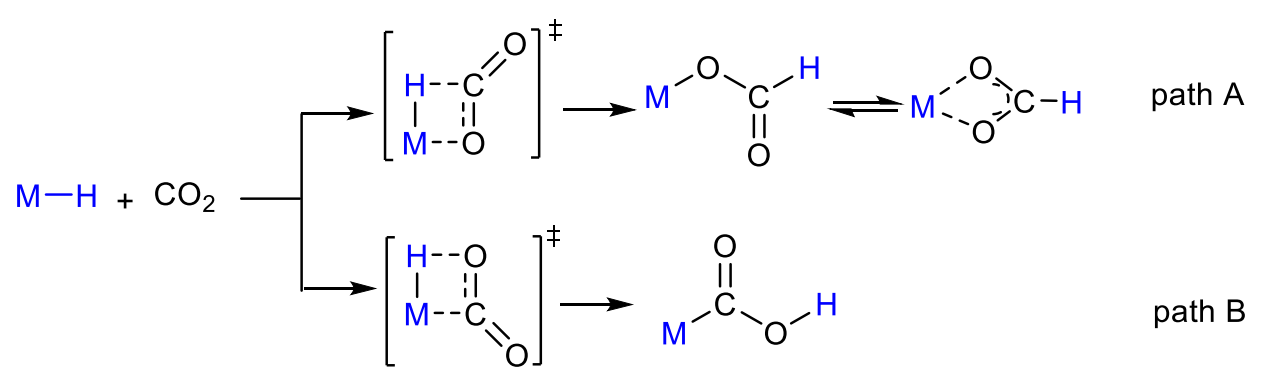

Scheme 5.2: $\mathrm{CO}_{2}$ insertion into $\mathrm{M}-\mathrm{H}$ bonds.

The insertion of $\mathrm{CO}_{2}$ into $\mathrm{M}-\mathrm{H}$ bonds plays a crucial role in catalytic reactions to produce formic acid. It contains two possibilities, path $\mathrm{A}$ and path $\mathrm{B}$ (Scheme 5.2). ${ }^{47}$ In path $\mathrm{A}$, the insertion of $\mathrm{CO}_{2}$ into $\mathrm{M}-\mathrm{H}$ bonds gives rise to a product $\mathrm{M}-\mathrm{OOCH}$ and in path $\mathrm{B}$, it forms a different product $\mathrm{M}-\mathrm{COOH}$. As the carbon atom of $\mathrm{CO}_{2}$ is electrophilic and the oxygen atoms are nucleophilic, the metal center of M-H complex is favorable to be coordinated with the oxygen atoms of $\mathrm{CO}_{2}$ and the hydride atom prefers to connect with the carbon atom, suggesting path A to form $\mathrm{M}-\mathrm{OOCH}$ is normal and path $\mathrm{B}$ to generate $\mathrm{M}-\mathrm{COOH}$ is abnormal. The Schneider group reported that a $\mathrm{Ni}-\mathrm{H}$ pincer complex reacted with $\mathrm{CO}_{2}(1-10$ bar) at room temperature giving rise to a formate complex $[\mathrm{Ni}(\mathrm{OOCH})(\mathrm{PNP})]$ as the product of normal insertion and a photo-driven $\left(\lambda_{\mathrm{exc}}>305 \mathrm{~nm}\right)$ inversion of $\mathrm{CO}_{2}$ insertion into a Ni-H pincer complex resulted in formation of the hydroxycarbonyl $(\mathrm{MCOOH})$ complex selectively as an abnormal product. ${ }^{52}$

\subsection{4 $\mathrm{CO}_{2}$ Activation with Proton Source}

$$
\begin{aligned}
& \mathrm{CO}_{2}+2 \mathrm{H}^{+}+2 \mathrm{e}^{-} \stackrel{\mathrm{L}-\mathrm{M}}{\longrightarrow} \mathrm{CO}+\mathrm{H}_{2} \mathrm{O}
\end{aligned}
$$

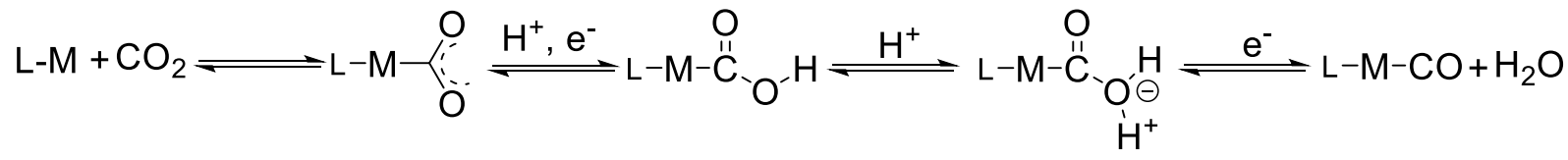

Scheme 5.3: $\mathrm{CO}_{2}$ activation with proton source and the possible mechanism.

Protons are also quite significant for catalytic reactions of $\mathrm{CO}_{2}$ to form $\mathrm{CO}$ or other organic products. The possible mechanism of the reaction of transition metal complexes with $\mathrm{CO}_{2}$ in presence of protons and electrons is shown in Scheme 5.3. ${ }^{47} \mathrm{CO}_{2}$ is coordinated with the active transition metal 
center in a $\eta^{1}$-C bonding mode and then activated by one proton donor following a push-pull mechanism, which may generate a possible intermediate hydroxycarbonyl (MCOOH) complex. Subsequent addition of one equivalent of proton and electron into the hydroxycarbonyl (MCOOH) complex liberates water and gives a carbonyl complex. Recently, the Lee group reported a closed synthetic cycle of converting $\mathrm{CO}_{2}$ to $\mathrm{CO}$ by using a nickel(0) monocarbonyl species and the possible intermediate products, including $\mathrm{Ni}-\mathrm{COONa}, \mathrm{Ni}-\mathrm{COOH}$ and $\mathrm{Ni}-\mathrm{CO}$ complexes, were successfully structurally characterized. ${ }^{53}$ This is important in understanding biological $\mathrm{CO}_{2}$ conversion to $\mathrm{CO}$ found in carbon monoxide dehydrogenase $(\mathrm{CODH})$ in nature. Furthermore, $\mathrm{CO}_{2}$ activation of transition metal complexes in presence of silyl groups, alkyl groups or isonitrile groups to generate possible intermediates for catalytic reactions has been reported. ${ }^{54}$

By employing the dimeric cobalt(I) dinitrogen complex $\mathbf{6}$ as a reactive platform, its reactivity with $\mathrm{CO}_{2}$ was explored and the products of $\mathrm{CO}_{2}$ reductive disproportionation were successfully synthesized, featuring a cobalt(II) carbonate complex and a dicobalt(I) dicarbonyl complex respectively. The dicobalt(I) dicarbonyl complex can be directly synthesized by the reaction of complex 6 with $\mathrm{CO}$ gas. Excess $\mathrm{CO}$ gas reacted with complex $\mathbf{6}$ leading to the formation of a tetracarbonyl complex.

\section{2 $\mathrm{CO}_{2}$ Reductive Disproportionation Mediated by Complex 6}

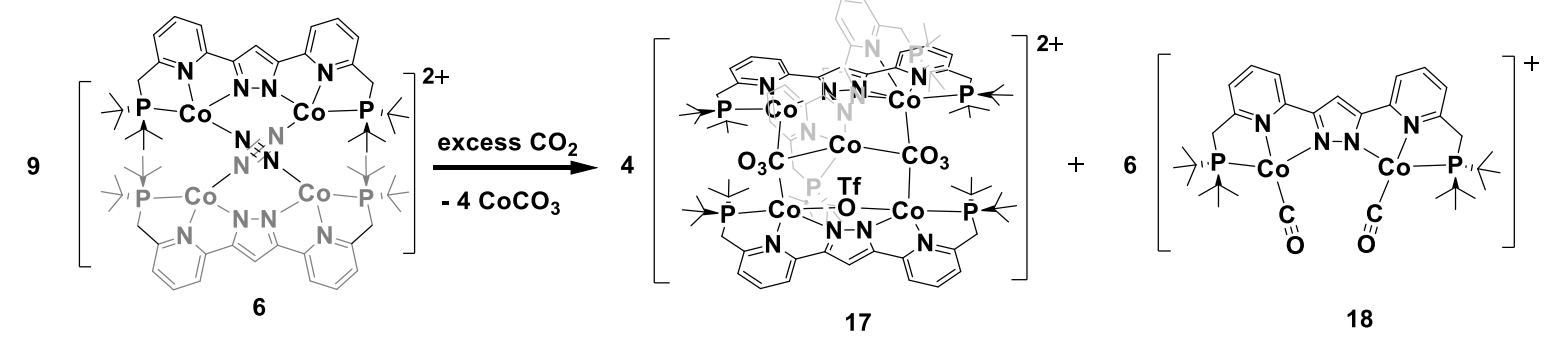

Scheme 5.4: $\mathrm{CO}_{2}$ reduction of complex 6 .

As depicted in Scheme 5.4, upon exposure of a suspension of dimeric cobalt(I) dinitrogen complex 6 in $\mathrm{THF}$ to a $\mathrm{CO}_{2}$ atmosphere at room temperature, the initial purple solution turned green immediately. After filtration through a glass fiber filter, two kinds of crystals suitable for X-ray diffraction were generated from a concentrated THF solution at room temperature, albeit very slowly. These are the cobalt(II) carbonate complex $\left[\left(\mathrm{L}_{3} \mathrm{Co}_{5}\left(\mu-\mathrm{CO}_{3}\right)_{2}(\mu\right.\right.$-OTf $\left.\left.)\right)\right](\mathrm{OTf})_{2} 17$ and the dicobalt(I) dicarbonyl complex $\left[\left(\mathrm{LCo}_{2}(\mathrm{CO})_{2}\right)\right](\mathrm{OTf}) \mathbf{1 8}$ respectively. Therefore, the employment of dimeric cobalt(I) dinitrogen complex 6 as an electron-rich reductant reacting with $\mathrm{CO}_{2}$ triggers $\mathrm{C}-\mathrm{O}$ cleavage and reductive disproportionation to form $\mathrm{CO}$ and carbonate: $2\left[\mathrm{Co}^{\mathrm{I}}\right]+2 \mathrm{CO}_{2} \rightarrow 2\left[\mathrm{Co}^{\mathrm{II}}\right]+\mathrm{CO}+\mathrm{CO}_{3}{ }^{2-}$. Apparently, one cobalt ion was dissociated to generate cobalt carbonate $\left(\mathrm{CoCO}_{3}\right)$ in this $\mathrm{CO}_{2}$ reduction.

The molecular structure of the cationic complex 17 is shown in Figure 5.4 and selected bond lengths and angles are listed in Table 5.1. Complex $\mathbf{1 7}$ crystallized in the triclinic space group $P-1$ with two 
molecules in the unit cell. In the dicationic complex 17, two carbonate anions bridge three fragments in $\mu-\eta^{1}: \eta^{1}: \eta^{2}$ and $\mu-\eta^{1}: \eta^{2}: \eta^{2}$ coordination modes respectively. $\mathrm{Co}(1)$ is in a distorted square pyramidal geometry, hosted in one $\{\mathrm{PNN}\}$-tridentate binding site of the anionic pincer ligand scaffold and coordinated with a carbonate anion. $\operatorname{Co}(2)$ adopts a distorted octahedral fashion, held with a $\{\mathrm{PNN}\}$-tridentate binding site, connected with a carbonate anion and a NN-binding site from another pincer ligand. $\operatorname{Co}(3)$ is coordinated with two carbonate anions. $\operatorname{Co}(4)$ and $\operatorname{Co}(5)$ are bridged with a $\mu-\eta^{l}: \eta^{l}$ triflate anion and bound to a carbonate anion, respectively, in different coordination numbers. $\mathrm{C}-\mathrm{O}$ bond lengths of two carbonate anions are in the range of $1.260 \AA$ to $1.309 \AA$. The Co-O distances from $1.984 \AA$ to $2.857 \AA$ are distinctly longer than the reported ones, indicating weaker $\pi$-bonding in Co-O interactions of complex 17. Complex 17 can also be synthesized from the reaction of complex 6 and isotopically labeled ${ }^{13} \mathrm{CO}_{2}$. IR spectrum of complex $\mathbf{1 7}\left({ }^{\mathbf{1 3}} \mathbf{C O}^{2-}\right)$ is depicted in Figure 5.5. Because of the low yield of complex 17, other characterizations are still in progress.
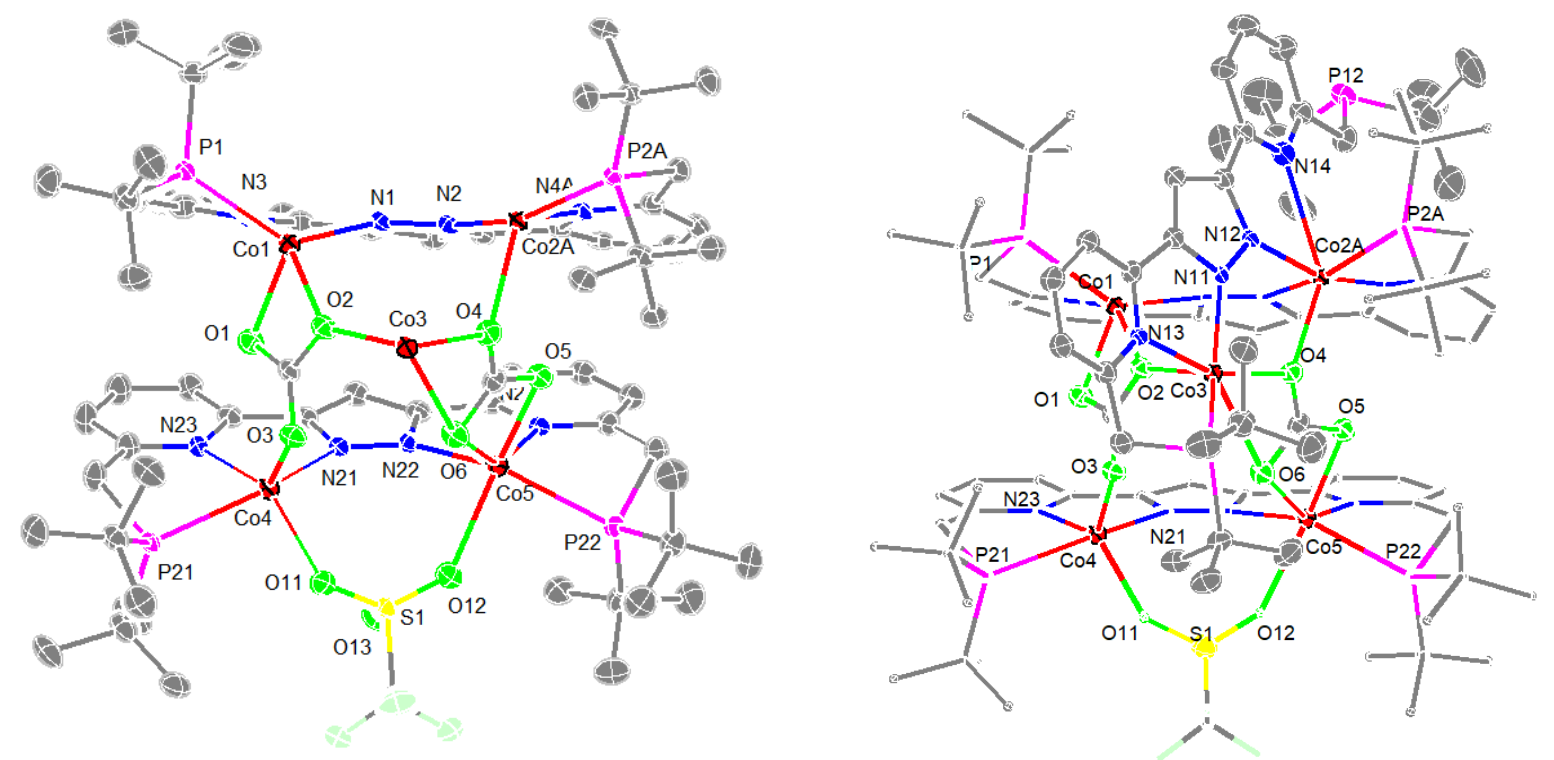

Figure 5.4: The molecular structures (left and right) of the cation of complex 17. Thermal displacement ellipsoids shown at $30 \%$ probability; most hydrogen atoms, the anions OTf $^{-}$and solvent molecules omitted for clarity.

Table 5.1: Selected bond lengths and angles for complex 17.

\begin{tabular}{llllll}
\hline \multicolumn{2}{c}{ Bond lengths / $\AA$} \\
\hline $\mathrm{Co}(1)-\mathrm{O}(1)$ & $2.023(2)$ & $\mathrm{O}(1)-\mathrm{Co}(1)-\mathrm{N}(1)$ & $113.80(9)$ & $\mathrm{O}(2)-\mathrm{Co}(3)-\mathrm{P}(11)$ & $122.54(6)$ \\
$\mathrm{Co}(1)-\mathrm{N}(1)$ & $2.042(2)$ & $\mathrm{O}(1)-\mathrm{Co}(1)-\mathrm{N}(3)$ & $85.87(9)$ & $\mathrm{N}(13)-\mathrm{Co}(3)-\mathrm{P}(11)$ & $72.41(7)$ \\
$\mathrm{Co}(1)-\mathrm{N}(3)$ & $2.100(3)$ & $\mathrm{N}(1)-\mathrm{Co}(1)-\mathrm{N}(3)$ & $78.37(10)$ & $\mathrm{O}(3)-\mathrm{Co}(4)-\mathrm{O}(11)$ & $104.26(9)$ \\
$\mathrm{Co}(1)-\mathrm{O}(2)$ & $2.162(2)$ & $\mathrm{O}(1)-\mathrm{Co}(1)-\mathrm{O}(2)$ & $62.75(8)$ & $\mathrm{O}(3)-\mathrm{Co}(4)-\mathrm{N}(21)$ & $102.63(9)$ \\
$\mathrm{Co}(1)-\mathrm{P}(1)$ & $2.4371(9)$ & $\mathrm{N}(1)-\mathrm{Co}(1)-\mathrm{O}(2)$ & $100.34(9)$ & $\mathrm{O}(11)-\mathrm{Co}(4)-\mathrm{N}(21)$ & $93.33(9)$ \\
$\mathrm{Co}(1)-\mathrm{C}(113)$ & $2.474(3)$ & $\mathrm{N}(3)-\mathrm{Co}(1)-\mathrm{O}(2)$ & $145.44(9)$ & $\mathrm{O}(3)-\mathrm{Co}(4)-\mathrm{N}(23)$ & $122.01(9)$ \\
\hline
\end{tabular}




\begin{tabular}{|c|c|c|c|c|c|}
\hline $\mathrm{Co}(2 \mathrm{~A})-\mathrm{N}(12)$ & $1.959(5)$ & $\mathrm{O}(1)-\mathrm{Co}(1)-\mathrm{P}(1)$ & $105.21(7)$ & $\mathrm{O}(11)-\mathrm{Co}(4)-\mathrm{N}(23)$ & $133.71(10)$ \\
\hline $\mathrm{Co}(2 \mathrm{~A})-\mathrm{N}(4 \mathrm{~A})$ & $1.999(15)$ & $\mathrm{N}(1)-\mathrm{Co}(1)-\mathrm{P}(1)$ & $131.46(8)$ & $\mathrm{N}(21)-\mathrm{Co}(4)-\mathrm{N}(23)$ & $79.05(10)$ \\
\hline $\mathrm{Co}(2 \mathrm{~A})-\mathrm{O}(4)$ & $2.246(4)$ & $\mathrm{N}(3)-\mathrm{Co}(1)-\mathrm{P}(1)$ & $76.75(7)$ & $\mathrm{O}(3)-\mathrm{Co}(4)-\mathrm{P}(21)$ & $99.30(6)$ \\
\hline $\mathrm{Co}(2 \mathrm{~A})-\mathrm{P}(2 \mathrm{~A})$ & $2.303(7)$ & $\mathrm{O}(2)-\mathrm{Co}(1)-\mathrm{P}(1)$ & $123.25(6)$ & $\mathrm{O}(11)-\mathrm{Co}(4)-\mathrm{P}(21)$ & $93.47(6)$ \\
\hline $\mathrm{Co}(3)-\mathrm{O}(4)$ & $2.012(2)$ & $\mathrm{O}(1)-\mathrm{Co}(1)-\mathrm{C}(113)$ & $31.06(9)$ & $\mathrm{N}(21)-\mathrm{Co}(4)-\mathrm{P}(21)$ & $154.64(7)$ \\
\hline $\mathrm{Co}(3)-\mathrm{N}(11)$ & $2.039(2)$ & $\mathrm{N}(1)-\mathrm{Co}(1)-\mathrm{C}(113)$ & $107.55(10)$ & $\mathrm{N}(23)-\mathrm{Co}(4)-\mathrm{P}(21)$ & $78.60(7)$ \\
\hline $\mathrm{Co}(3)-\mathrm{O}(2)$ & $2.040(2)$ & $\mathrm{N}(3)-\mathrm{Co}(1)-\mathrm{C}(113)$ & $114.96(10)$ & $\mathrm{O}(5)-\mathrm{Co}(5)-\mathrm{N}(22)$ & $112.65(9)$ \\
\hline $\mathrm{Co}(3)-\mathrm{N}(13)$ & $2.238(2)$ & $\mathrm{O}(2)-\mathrm{Co}(1)-\mathrm{C}(113)$ & $31.87(9)$ & $\mathrm{O}(5)-\mathrm{Co}(5)-\mathrm{O}(6)$ & $63.12(8)$ \\
\hline $\operatorname{Co}(3)-\mathrm{P}(11)$ & $2.6155(10)$ & $\mathrm{P}(1)-\mathrm{Co}(1)-\mathrm{C}(113)$ & $120.65(7)$ & $\mathrm{N}(22)-\mathrm{Co}(5)-\mathrm{O}(6)$ & $96.99(9)$ \\
\hline $\mathrm{Co}(4)-\mathrm{O}(3)$ & $1.984(2)$ & $\mathrm{N}(12)-\mathrm{Co}(2 \mathrm{~A})-\mathrm{N}(4 \mathrm{~A})$ & $156.8(4)$ & $\mathrm{O}(5)-\mathrm{Co}(5)-\mathrm{N}(24)$ & $87.18(9)$ \\
\hline $\mathrm{Co}(4)-\mathrm{O}(11)$ & $2.086(2)$ & $\mathrm{N}(12)-\mathrm{Co}(2 \mathrm{~A})-\mathrm{N}(2)$ & $93.5(2)$ & $\mathrm{N}(22)-\mathrm{Co}(5)-\mathrm{N}(24)$ & $75.72(10)$ \\
\hline $\mathrm{Co}(4)-\mathrm{N}(21)$ & $2.095(2)$ & $\mathrm{N}(4 \mathrm{~A})-\mathrm{Co}(2 \mathrm{~A})-\mathrm{N}(2)$ & $78.1(4)$ & $\mathrm{O}(6)-\mathrm{Co}(5)-\mathrm{N}(24)$ & $144.37(9)$ \\
\hline $\mathrm{Co}(4)-\mathrm{N}(23)$ & $2.097(3)$ & $\mathrm{N}(12)-\mathrm{Co}(2 \mathrm{~A})-\mathrm{O}(4)$ & $87.69(19)$ & $\mathrm{O}(5)-\mathrm{Co}(5)-\mathrm{O}(12)$ & $144.16(9)$ \\
\hline $\mathrm{Co}(4)-\mathrm{P}(21)$ & $2.5720(9)$ & $\mathrm{N}(4 \mathrm{~A})-\mathrm{Co}(2 \mathrm{~A})-\mathrm{O}(4)$ & $113.2(4)$ & $\mathrm{N}(22)-\mathrm{Co}(5)-\mathrm{O}(12)$ & $87.70(9)$ \\
\hline $\mathrm{Co}(5)-\mathrm{O}(5)$ & $2.071(2)$ & $\mathrm{N}(2)-\mathrm{Co}(2 \mathrm{~A})-\mathrm{O}(4)$ & $87.6(2)$ & $\mathrm{O}(6)-\mathrm{Co}(5)-\mathrm{O}(12)$ & $86.15(8)$ \\
\hline $\mathrm{Co}(5)-\mathrm{N}(22)$ & $2.083(3)$ & $\mathrm{N}(12)-\mathrm{Co}(2 \mathrm{~A})-\mathrm{P}(2 \mathrm{~A})$ & $97.3(2)$ & $\mathrm{N}(24)-\mathrm{Co}(5)-\mathrm{O}(12)$ & $127.49(9)$ \\
\hline $\mathrm{Co}(5)-\mathrm{O}(6)$ & $2.105(2)$ & $\mathrm{N}(4 \mathrm{~A})-\mathrm{Co}(2 \mathrm{~A})-\mathrm{P}(2 \mathrm{~A})$ & $83.1(4)$ & $\mathrm{O}(5)-\mathrm{Co}(5)-\mathrm{C}(112)$ & $31.86(9)$ \\
\hline $\mathrm{Co}(5)-\mathrm{N}(24)$ & $2.189(2)$ & $\mathrm{N}(2)-\mathrm{Co}(2 \mathrm{~A})-\mathrm{P}(2 \mathrm{~A})$ & $154.6(2)$ & $\mathrm{N}(22)-\mathrm{Co}(5)-\mathrm{C}(112)$ & $105.06(10)$ \\
\hline $\mathrm{Co}(5)-\mathrm{O}(12)$ & $2.316(2)$ & $\mathrm{O}(4)-\mathrm{Co}(2 \mathrm{~A})-\mathrm{P}(2 \mathrm{~A})$ & $115.7(2)$ & $\mathrm{O}(6)-\mathrm{Co}(5)-\mathrm{C}(112)$ & $31.41(9)$ \\
\hline $\mathrm{Co}(5)-\mathrm{C}(112)$ & $2.430(3)$ & $\mathrm{O}(4)-\mathrm{Co}(3)-\mathrm{N}(11)$ & $85.49(9)$ & $\mathrm{N}(24)-\mathrm{Co}(5)-\mathrm{C}(112)$ & $115.93(10)$ \\
\hline \multirow[t]{7}{*}{$\mathrm{Co}(5)-\mathrm{P}(22)$} & $2.5191(9)$ & $\mathrm{O}(4)-\mathrm{Co}(3)-\mathrm{O}(2)$ & $101.88(9)$ & $\mathrm{O}(12)-\mathrm{Co}(5)-\mathrm{C}(112)$ & $116.45(9)$ \\
\hline & & $\mathrm{N}(11)-\mathrm{Co}(3)-\mathrm{O}(2)$ & $89.57(9)$ & $\mathrm{O}(5)-\mathrm{Co}(5)-\mathrm{P}(22)$ & $94.55(6)$ \\
\hline & & $\mathrm{O}(4)-\mathrm{Co}(3)-\mathrm{N}(13)$ & $158.92(9)$ & $\mathrm{N}(22)-\mathrm{Co}(5)-\mathrm{P}(22)$ & $138.44(7)$ \\
\hline & & $\mathrm{N}(11)-\mathrm{Co}(3)-\mathrm{N}(13)$ & $74.39(9)$ & $\mathrm{O}(6)-\mathrm{Co}(5)-\mathrm{P}(22)$ & $123.79(7)$ \\
\hline & & $\mathrm{O}(2)-\mathrm{Co}(3)-\mathrm{N}(13)$ & $84.50(9)$ & $\mathrm{N}(24)-\mathrm{Co}(5)-\mathrm{P}(22)$ & $74.89(7)$ \\
\hline & & $\mathrm{O}(4)-\mathrm{Co}(3)-\mathrm{P}(11)$ & $118.39(7)$ & $\mathrm{O}(12)-\mathrm{Co}(5)-\mathrm{P}(22)$ & $87.44(6)$ \\
\hline & & $\mathrm{N}(11)-\mathrm{Co}(3)-\mathrm{P}(11)$ & $130.11(7)$ & $\mathrm{C}(112)-\mathrm{Co}(5)-\mathrm{P}(22)$ & $113.97(8)$ \\
\hline
\end{tabular}




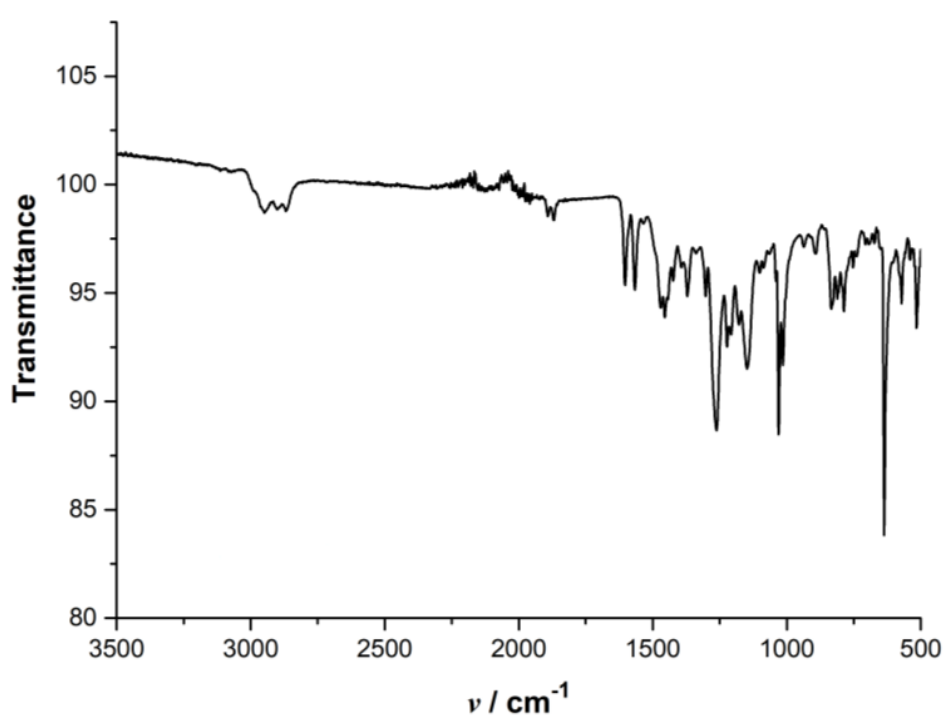

Figure 5.5: IR spectrum of complex $17\left({ }^{13} \mathrm{CO}_{3}{ }^{2-}\right)$ in solid state.

The dicobalt(I) dicarbonyl complex $\left[\left(\mathrm{LCo}_{2}(\mathrm{CO})_{2}\right)(\mathrm{OTf})\right] \mathbf{1 7}$ crystallized in the triclinic space group $P-1$ with two molecules in the unit cell. The molecular structure of the cationic of complex 17 established by X-ray analysis is shown in Figure 5.6. It reveals that the two cobalt ions adopt a distorted square planar geometry to be hosted in the $\{\mathrm{PNN}\}$ binding sites and coordinated with a $\mathrm{CO}$ molecule respectively, wherein the C-O bond lengths are 1.156 and $1.162 \AA$, nearly identical with the reported ones. ${ }^{50,51}$ Selected bond lengths and angles are listed in Table 5.2. The Co $\cdots$ Co separation of $4.223 \AA$ is similar to that in complex 2 and the Co-N-N-Co torsion angle is $37.9^{\circ}$. The Co-CO bond lengths are 1.713 and $1.711 \AA$, shorter than those in the reported Rh analogue (Rh-CO bond lengths: $1.827 \AA$ A). ${ }^{48}$ Actually, all the bonds to cobalt centers are shorter in comparison with Rh analogue, which are essentially ascribed to the smaller covalent radius of cobalt. The angles Co-C-O are $174.15^{\circ}$ and $175.67^{\circ}$, approximately in accordance with linearity. Possibly because of steric congestion, the two $\mathrm{CO}$ molecules are pointing below and above the equatorial plane defined by the pyrazolate heterocycle.
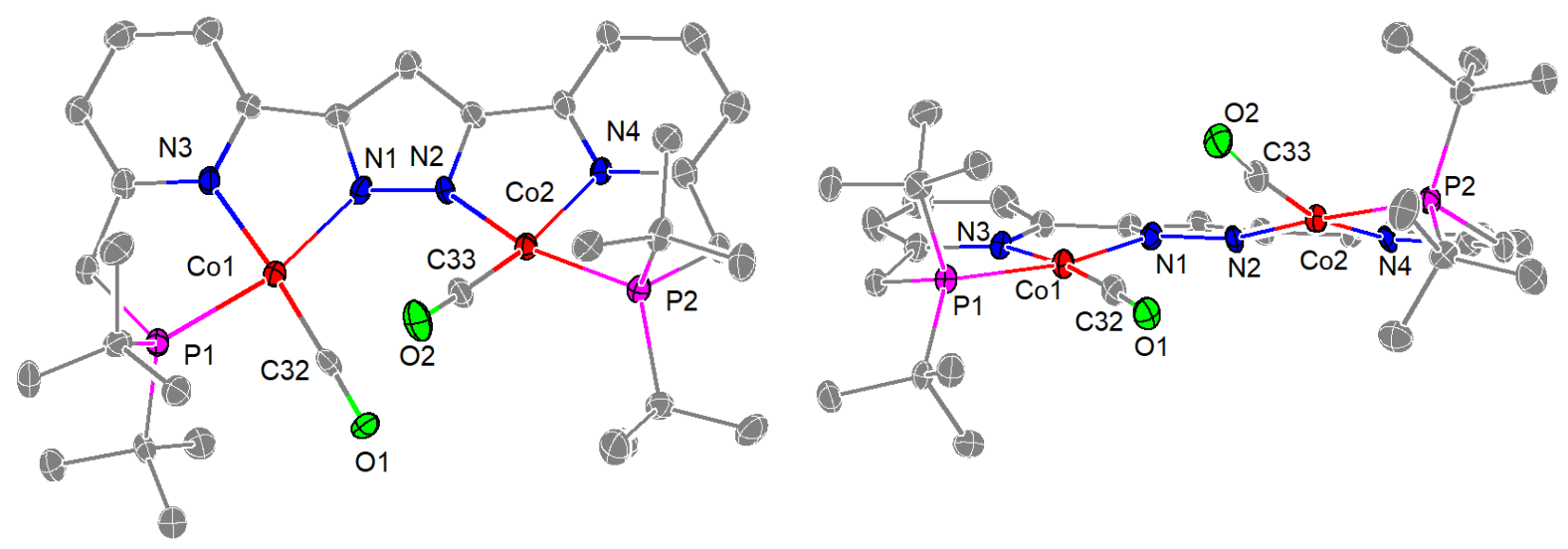

Figure 5.6: Top view (left) and front view (right) of the molecular structure of the cation of complex 
18. Thermal displacement ellipsoids shown at $30 \%$ probability; most hydrogen atoms, the anion OTf $^{-}$and solvent molecules omitted for clarity.

Table 5.2: Selected bond lengths and angles for complex 18.

\begin{tabular}{llll}
\hline \multicolumn{2}{c}{ Bond lengths / $\AA$} & \multicolumn{3}{c}{ Angles / } \\
\hline $\mathrm{Co}(1)-\mathrm{C}(32)$ & $1.713(3)$ & $\mathrm{C}(32)-\mathrm{Co}(1)-\mathrm{N}(1)$ & $99.85(11)$ \\
$\mathrm{Co}(1)-\mathrm{N}(1)$ & $1.932(2)$ & $\mathrm{C}(32)-\mathrm{Co}(1)-\mathrm{N}(3)$ & $166.29(11)$ \\
$\mathrm{Co}(1)-\mathrm{N}(3)$ & $1.945(2)$ & $\mathrm{N}(1)-\mathrm{Co}(1)-\mathrm{N}(3)$ & $81.55(9)$ \\
$\mathrm{Co}(1)-\mathrm{P}(1)$ & $2.1647(7)$ & $\mathrm{C}(32)-\mathrm{Co}(1)-\mathrm{P}(1)$ & $93.56(9)$ \\
$\mathrm{Co}(2)-\mathrm{C}(33)$ & $1.711(3)$ & $\mathrm{N}(1)-\mathrm{Co}(1)-\mathrm{P}(1)$ & $166.02(7)$ \\
$\mathrm{Co}(2)-\mathrm{N}(2)$ & $1.923(2)$ & $\mathrm{N}(3)-\mathrm{Co}(1)-\mathrm{P}(1)$ & $84.48(7)$ \\
$\mathrm{Co}(2)-\mathrm{N}(4)$ & $1.951(2)$ & $\mathrm{C}(33)-\mathrm{Co}(2)-\mathrm{N}(2)$ & $101.31(10)$ \\
$\mathrm{Co}(2)-\mathrm{P}(2)$ & $2.1573(7)$ & $\mathrm{C}(33)-\mathrm{Co}(2)-\mathrm{N}(4)$ & $174.05(11)$ \\
$\mathrm{Co} 1 \cdots \mathrm{Co} 2$ & $4.2226(4)$ & $\mathrm{N}(2)-\mathrm{Co}(2)-\mathrm{N}(4)$ & $81.76(9)$ \\
$\mathrm{O}(1)-\mathrm{C}(32)$ & $1.162(3)$ & $\mathrm{C}(33)-\mathrm{Co}(2)-\mathrm{P}(2)$ & $91.97(9)$ \\
$\mathrm{O}(2)-\mathrm{C}(33)$ & $1.156(3)$ & $\mathrm{N}(2)-\mathrm{Co}(2)-\mathrm{P}(2)$ & $166.10(7)$ \\
& & $\mathrm{N}(4)-\mathrm{Co}(2)-\mathrm{P}(2)$ & $85.38(6)$ \\
\hline
\end{tabular}

The ${ }^{1} \mathrm{H}-\mathrm{NMR}$ spectrum in acetone- $\mathrm{d}_{6}$ at room temperature (Figure 5.7) reveals that complex $\mathbf{1 8}$ is a diamagnetic $\mathrm{Co}^{\mathrm{I}}$ species. It also exhibits one doublet at $\delta=4.02 \mathrm{ppm}$ for the $\mathrm{CH}_{2}$ groups in the side arms and one doublet at $\delta=1.51 \mathrm{ppm}$ for the $t \mathrm{Bu}$ groups, which demonstrates an apparent $C_{2 v}$ symmetry of complex $\mathbf{1 8}$ in solution on the NMR time scale at room temperature. The ${ }^{31} \mathrm{P}-\mathrm{NMR}$ spectrum (Figure 5.8) features a peak at $\delta=107.08 \mathrm{ppm}$, indicative of a symmetric carbonyl complex in solution state. And a single peak at $\delta=-78.73 \mathrm{ppm}$ from the ${ }^{19} \mathrm{~F}-\mathrm{NMR}$ spectrum indicates the triflate anion is dissociated (Figure 5.9). The resonance of the methyl carbon atoms of the $t \mathrm{Bu}$ groups in the ${ }^{13} \mathrm{C}$-NMR spectrum is superimposed by the acetone- $\mathrm{d}_{6}$ signal (Figure 9.94) but observed in THF-d 8 solution at $40{ }^{\circ} \mathrm{C}$ (Figure 9.97). Furthermore, CO resonances are detected in neither of ${ }^{13} \mathrm{C}$-NMR spectra. Nevertheless, after complex 18 was prepared from the reaction of complex $\mathbf{6}$ with isotopically labeled ${ }^{13} \mathrm{CO}_{2}$ or isotopically labeled ${ }^{13} \mathrm{CO}$ (to be mentioned later), the ${ }^{13} \mathrm{C}-\mathrm{NMR}$ spectrum of complex $\mathbf{1 8}^{\mathbf{1 3}} \mathbf{C O}$ shows a broad peak at $201.42 \mathrm{ppm}$, which can be assigned to coordinated ${ }^{13} \mathrm{CO}$ (Figure 9.98). 


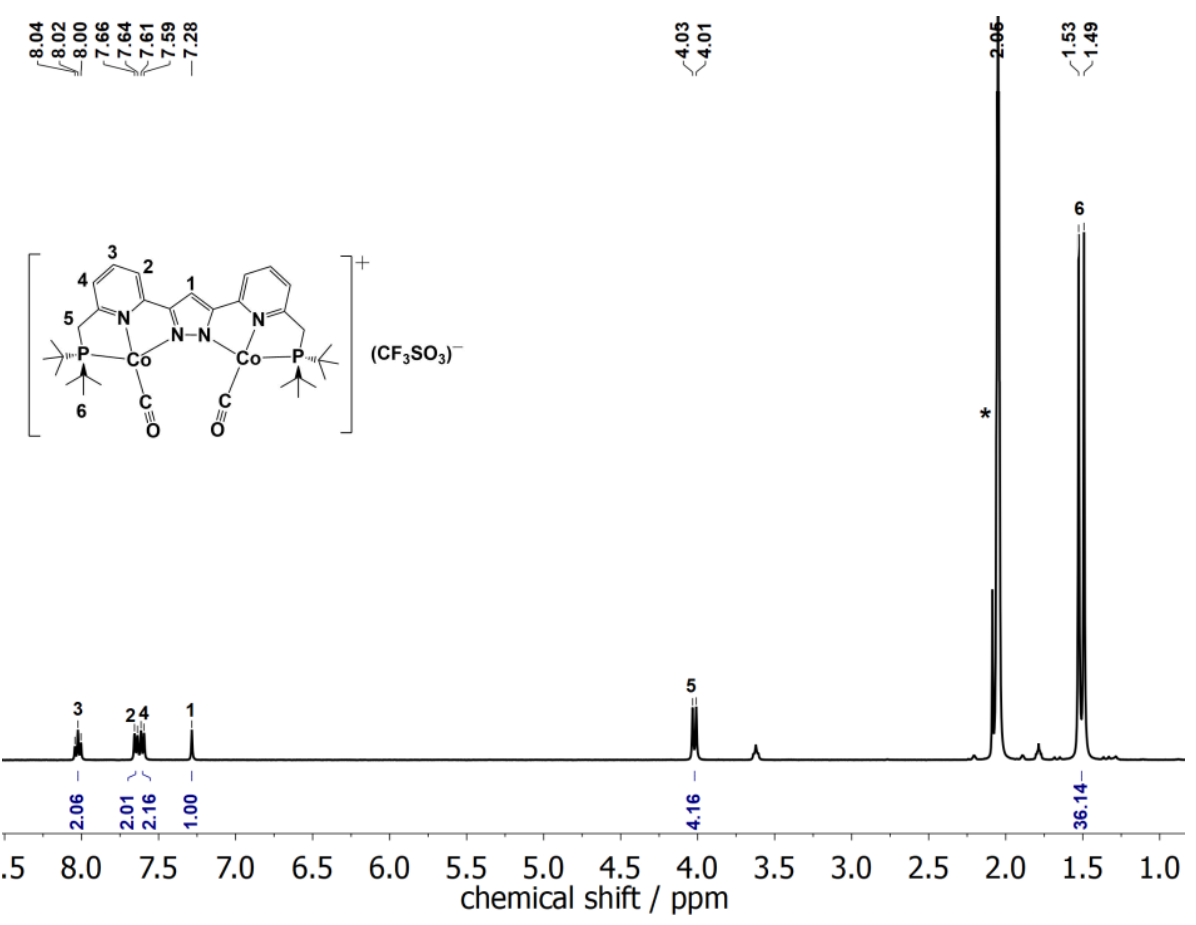

Figure 5.7: ${ }^{1} \mathrm{H}-\mathrm{NMR}$ spectrum of complex 18 in acetone- $\mathrm{d}_{6}$. Solvent signals are marked with an asterisk (*).

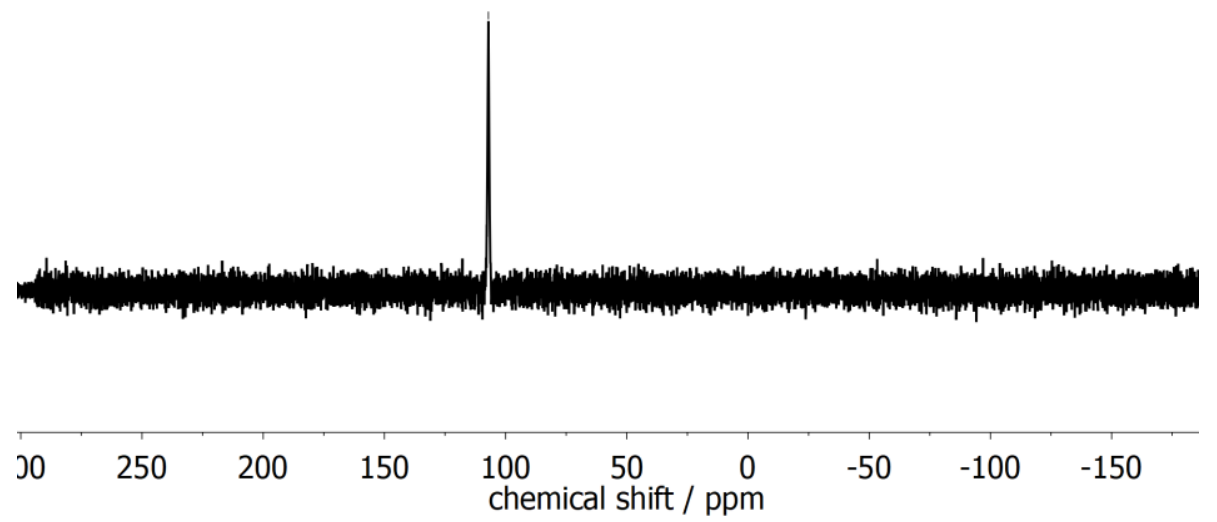

Figure 5.8: ${ }^{31} \mathrm{P}-\mathrm{NMR}$ spectrum of complex 18 in acetone- $\mathrm{d}_{6}$. 


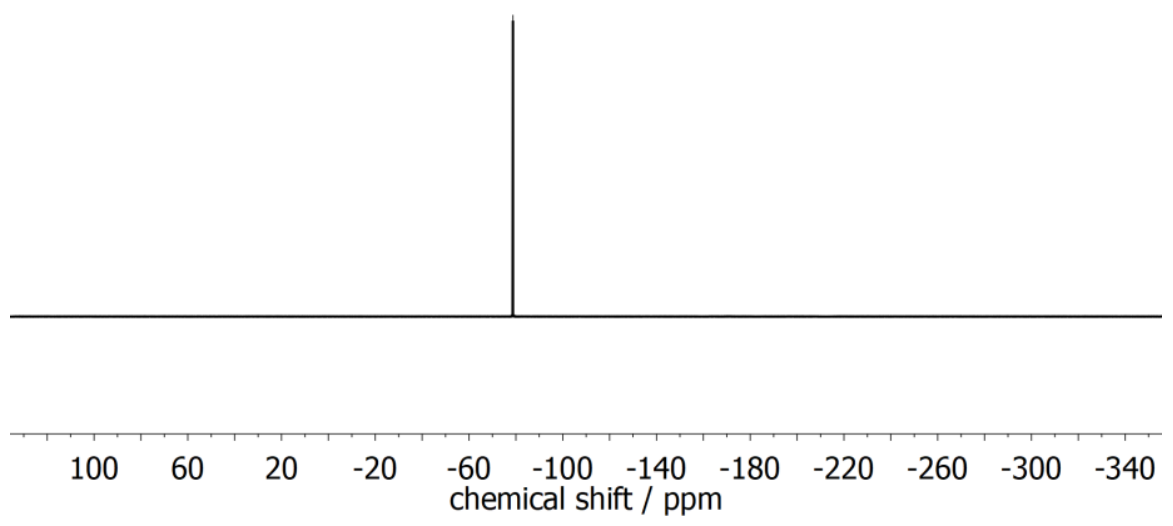

Figure 5.9: ${ }^{19} \mathrm{~F}-\mathrm{NMR}$ spectrum of complex $\mathbf{1 8}$ in acetone- $\mathrm{d}_{6}$.

The IR spectrum of solid complex $\mathbf{1 8}$ was measured (Figure 5.10) and direct evidence for the presence of carbonyl ligands was two intense peaks at 1934 and $1912 \mathrm{~cm}^{-1}$, attributed to asymmetric and symmetric C-O stretching vibrations. This shows the stretches of complex $\mathbf{1 8}$ are lower in energy in comparison to those in the $\mathrm{Rh}$ analogue ( $\mathrm{Rh}$ complex: 1964 and $1978 \mathrm{~cm}^{-1}$ ). The two C-O peaks shift to 1889 and $1867 \mathrm{~cm}^{-1}$ upon isotopic substitution of ${ }^{13} \mathrm{CO}$, which are quite close to the theoretical values (1891 and $1869 \mathrm{~cm}^{-1}$ ). UV-vis spectroscopy (Figure 5.11) shows absorbance features at $\lambda_{\max }=309,398,434$ and $646 \mathrm{~nm}$, which may be derived from MLCT transitions.

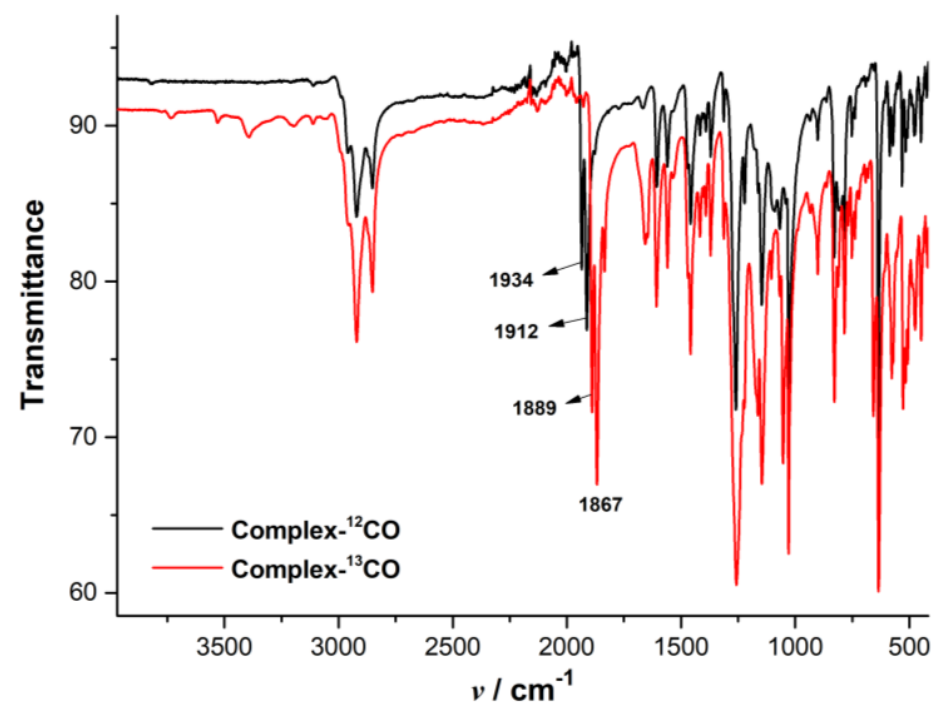

Figure 5.10: IR spectra of complex $18\left({ }^{12} \mathrm{CO}\right.$ and $\left.{ }^{13} \mathrm{CO}\right)$ in solid state. 


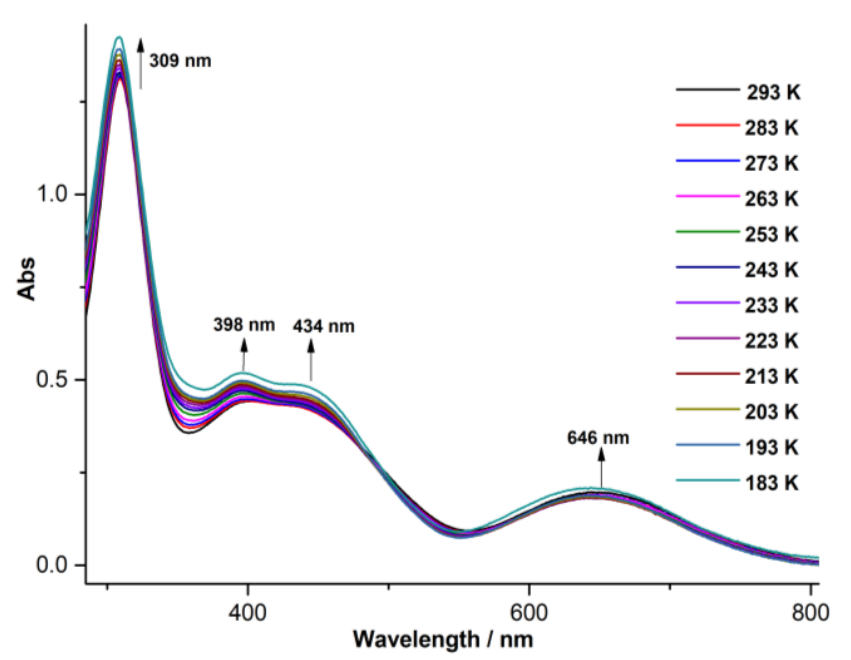

a

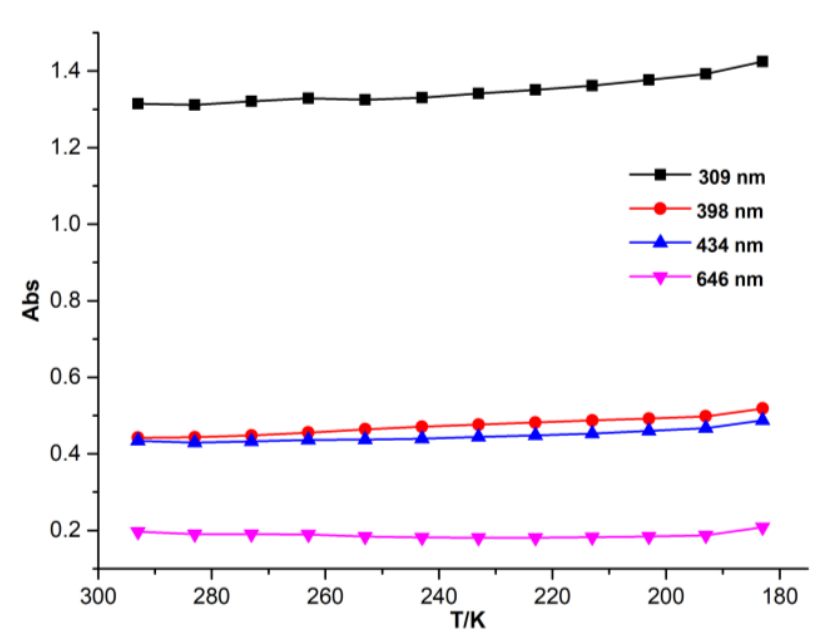

b

Figure 5.11: (a) Variable temperature UV/vis spectra of complex 18 in THF solution in the temperature range from $293 \mathrm{~K}$ to $183 \mathrm{~K}$. (b) Plots of absorption at different temperature.

\subsection{CO Reactions of Complex 6}

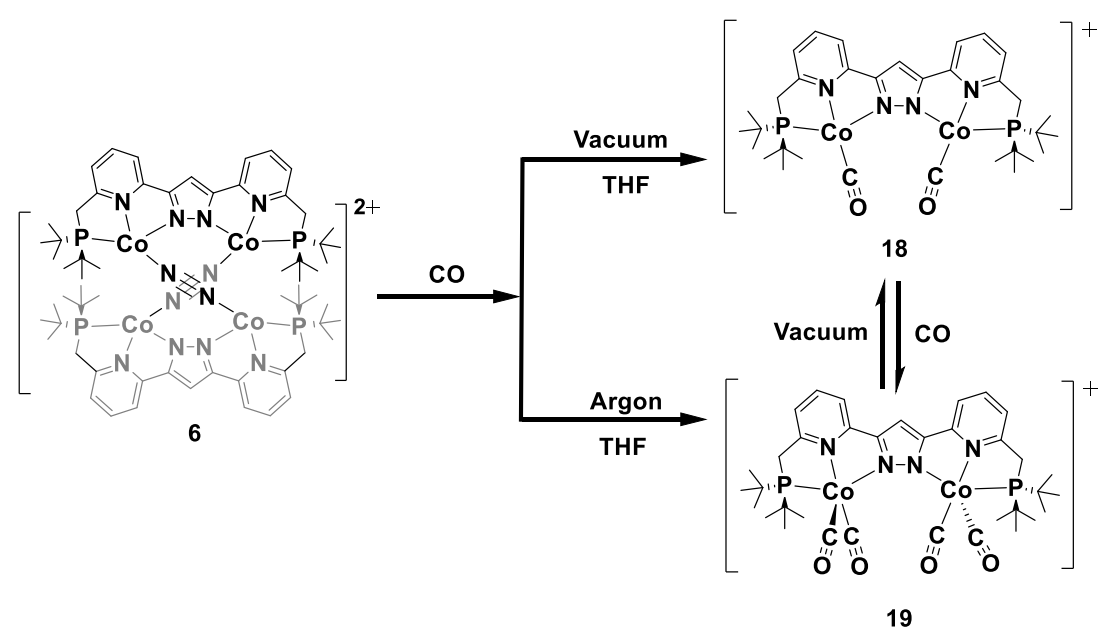

Scheme 5.5: CO reactions of complex 6.

The dicobalt(I) dicarbonyl complex 18 can be directly synthesized by the reaction of complex $\mathbf{6}$ with CO gas. To be specific, a suspension of complex 6 in THF was exposed to CO gas atmosphere, leading to an immediate color change from purple to red brown and after evaporation of the volatile components, the green solid was dissolved in THF again. Needle-shaped crystals of complex 18 suitable for X-ray diffraction analysis were grown by layering the THF solution with hexane at -40 ${ }^{\circ} \mathrm{C}$. Meanwhile, the red brown product was also studied. The red brown THF solution from the reaction of complex 17 with excess $\mathrm{CO}$ gas was flushed with argon for a while to exclude excess $\mathrm{CO}$ gas and after filtration through a glass fiber filters, red block-shaped crystals suitable for X-ray 
diffraction were obtained by layering the filtrate with hexane at $-40{ }^{\circ} \mathrm{C}$ to give rise to a dicobalt trtracarbonyl complex $\left[\left(\mathrm{LCo}_{2}(\mathrm{CO})_{4}\right)(\mathrm{OTf})\right] 19$.

Complex 19 crystallized in the monoclinic space group $P 2_{1} / \mathrm{n}$ with four molecules in the unit cell. The geometry of two cobalt ions can be described as a distorted square pyramid or a distorted trigonal bipyramid. As depicted in Figure 12, the $\mathrm{P}(1)-\mathrm{Co}(1)-\mathrm{N}(1)$ angle is $157.369^{\circ}$ and the $\mathrm{P}(2)-\mathrm{Co}(2)-\mathrm{N}(2)$ angle is $151.548^{\circ}$, which are closer to the ideal of $180^{\circ}$ for a square pyramid than $120^{\circ}$ for a trigonal bipyramid. And the $\mathrm{P}(1)-\mathrm{Co}(1)-\mathrm{C}(33)$ angle is $102.512^{\circ}$ and the $\mathrm{P}(2)-\mathrm{Co}(2)-\mathrm{C}(34)$ angle is $106.478^{\circ}$, which are closer to $90^{\circ}$ for a square pyramid than $120^{\circ}$ for a trigonal bipyramid. Therefore, two cobalt ions are both coordinated with two $\mathrm{CO}$ molecules respectively in a distorted square-pyramidal geometry with a Co $\cdots$ Co separation of $4.1410 \AA$, surprisingly even shorter than that in complex 18. $\mathrm{C}(33)-\mathrm{O}(2)$ and $\mathrm{C}(34)-\mathrm{O}(3)$ are in the axial position. The Co-N-N-Co torsion angle is $0.243^{\circ}$. In addition, Co-CO bond lengths are from 1.742 to $1.849 \AA$, longer than those in complex 18 and $\mathrm{C}-\mathrm{O}$ bond lengths are in the range of 1.128 to $1.156 \AA$, shorter that those in in complex 18, suggesting weaker back bonding in complex 19. Selected bond lengths and angels are listed in Table 5.3.
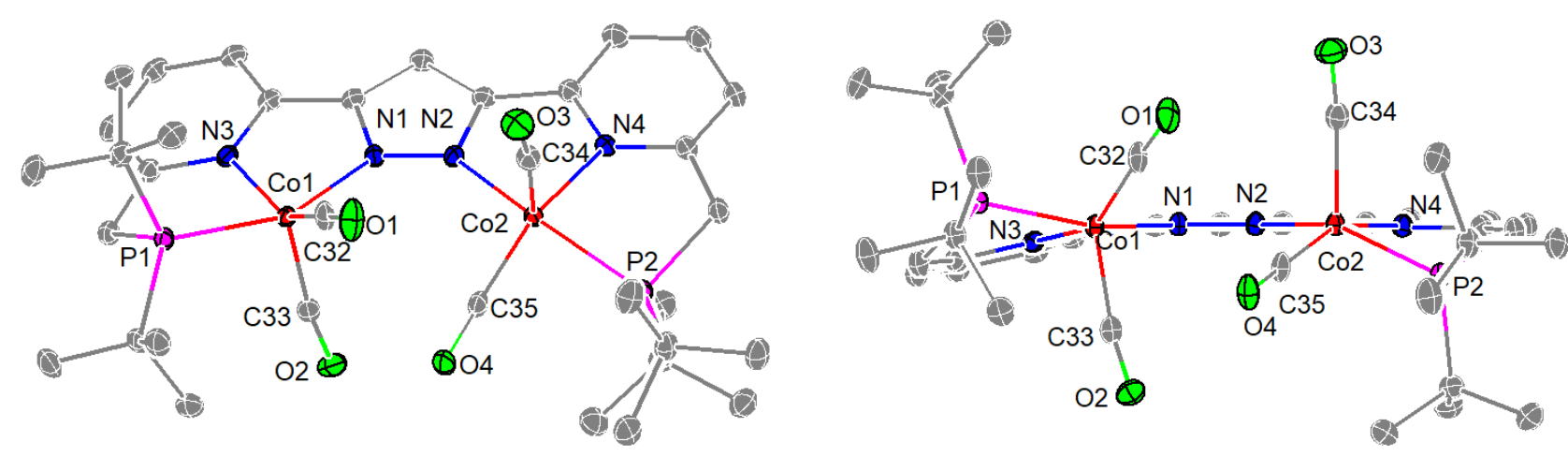

Figure 5.12: Top view (left) and front view (right) of the molecular structure of the cation of complex 19. Thermal displacement ellipsoids shown at $30 \%$ probability; most hydrogen atoms, the anion OTf ${ }^{-}$and solvent molecules omitted for clarity.

Table 5.3: Selected bond lengths and angles for complex 19.

\begin{tabular}{llll}
\hline \multicolumn{2}{c}{ Bond lengths / $\AA$} & \multicolumn{2}{c}{ Angles / } \\
\hline $\mathrm{Co}(1)-\mathrm{C}(32)$ & $1.742(3)$ & $\mathrm{C}(32)-\mathrm{Co}(1)-\mathrm{C}(33)$ & $113.67(13)$ \\
$\mathrm{Co}(1)-\mathrm{C}(33)$ & $1.832(3)$ & $\mathrm{C}(32)-\mathrm{Co}(1)-\mathrm{N}(1)$ & $95.18(11)$ \\
$\mathrm{Co}(1)-\mathrm{N}(1)$ & $1.939(2)$ & $\mathrm{C}(33)-\mathrm{Co}(1)-\mathrm{N}(1)$ & $94.88(11)$ \\
$\mathrm{Co}(1)-\mathrm{N}(3)$ & $1.967(2)$ & $\mathrm{C}(32)-\mathrm{Co}(1)-\mathrm{N}(3)$ & $145.92(12)$ \\
$\mathrm{Co}(1)-\mathrm{P}(1)$ & $2.1983(7)$ & $\mathrm{C}(33)-\mathrm{Co}(1)-\mathrm{N}(3)$ & $100.38(10)$ \\
$\mathrm{Co}(2)-\mathrm{C}(35)$ & $1.742(3)$ & $\mathrm{N}(1)-\mathrm{Co}(1)-\mathrm{N}(3)$ & $80.18(9)$ \\
$\mathrm{Co}(2)-\mathrm{C}(34)$ & $1.849(3)$ & $\mathrm{C}(32)-\mathrm{Co}(1)-\mathrm{P}(1)$ & $91.02(9)$ \\
$\mathrm{Co}(2)-\mathrm{N}(2)$ & $1.951(2)$ & $\mathrm{C}(33)-\mathrm{Co}(1)-\mathrm{P}(1)$ & $102.51(8)$ \\
$\mathrm{Co}(2)-\mathrm{N}(4)$ & $1.973(2)$ & $\mathrm{N}(1)-\mathrm{Co}(1)-\mathrm{P}(1)$ & $157.37(7)$ \\
$\mathrm{Co}(2)-\mathrm{P}(2)$ & $2.2023(8)$ & $\mathrm{N}(3)-\mathrm{Co}(1)-\mathrm{P}(1)$ & $82.51(7)$ \\
\hline
\end{tabular}




\begin{tabular}{llll}
\hline $\mathrm{Co} 1 \cdots \mathrm{Co} 2$ & $4.1410(6)$ & $\mathrm{C}(35)-\mathrm{Co}(2)-\mathrm{C}(34)$ & $105.91(13)$ \\
$\mathrm{O}(1)-\mathrm{C}(32)$ & $1.156(4)$ & $\mathrm{C}(35)-\mathrm{Co}(2)-\mathrm{N}(2)$ & $98.71(11)$ \\
$\mathrm{O}(2)-\mathrm{C}(33)$ & $1.134(3)$ & $\mathrm{C}(34)-\mathrm{Co}(2)-\mathrm{N}(2)$ & $98.52(11)$ \\
$\mathrm{O}(3)-\mathrm{C}(34)$ & $1.128(4)$ & $\mathrm{C}(35)-\mathrm{Co}(2)-\mathrm{N}(4)$ & $154.52(12)$ \\
$\mathrm{O}(4)-\mathrm{C}(35)$ & $1.147(3)$ & $\mathrm{C}(34)-\mathrm{Co}(2)-\mathrm{N}(4)$ & $99.39(11)$ \\
& & $\mathrm{N}(2)-\mathrm{Co}(2)-\mathrm{N}(4)$ & $80.23(9)$ \\
& & $\mathrm{C}(35)-\mathrm{Co}(2)-\mathrm{P}(2)$ & $87.48(9)$ \\
& & $\mathrm{C}(34)-\mathrm{Co}(2)-\mathrm{P}(2)$ & $106.48(9)$ \\
& & $\mathrm{N}(2)-\mathrm{Co}(2)-\mathrm{P}(2)$ & $151.54(7)$ \\
& & $\mathrm{N}(4)-\mathrm{Co}(2)-\mathrm{P}(2)$ & $82.44(7)$ \\
\hline
\end{tabular}

Table 5.4: Selected interatomic distance and angles of complexes 18 and 19.

\begin{tabular}{ccc}
\hline & 18 & 19 \\
\hline Co...Co $(\AA)$ & $4.2226(4)$ & $4.1410(6)$ \\
\hline $\mathrm{C}-\mathrm{O}(\AA)$ & $1.156(3) ; 1.162(3)$ & $1.128(4) ; 1.134(3) ; 1.147(3) ; 1.156(4)$ \\
$\mathrm{Co}-\mathrm{C}(\mathrm{CO})(\AA)$ & $1.711(3) ; 1.713(3)$ & $1.742(3) ; 1.832(3) ; 1.849(3)$ \\
$\mathrm{Co}-\mathrm{C}-\mathrm{O}(\mathrm{CO})\left(^{\circ}\right)$ & $174.2(2) ; 175.7(2)$ & $171.4(2) ; 173.1(3) ; 174.8(3) ; 175.7(3)$ \\
$v(\mathrm{C} \equiv \mathrm{O})\left(\mathrm{cm}^{-1}\right)$ & 1934,1912 & $1997,1940,1930$ \\
\hline
\end{tabular}

In analogy to complex 18, complex 19 is also diamagnetic as evidenced by ${ }^{1} \mathrm{H}-\mathrm{NMR}$ analysis in THF- $\mathrm{d}_{8}$ (Figure 5.13 and 5.14). Complex 19 possesses a $C_{2 v}$ symmetry in solution on the NMR time scale at room temperature. The single peak at $\delta=7.65 \mathrm{ppm}$ attributed to $\mathrm{H}$-atom of the bridging pyrazole and one doublet at $\delta=4.04 \mathrm{ppm}$ assigned to $\mathrm{CH}_{2}$ groups in side arms are shifted downfield in comparison to complex $18\left(\mathrm{H}_{\mathrm{pz}}: \delta=7.39 \mathrm{ppm}, \mathrm{CH}_{2}: \delta=3.94 \mathrm{ppm}\right.$ in THF- $\left.\mathrm{d}_{8}\right)$. The ${ }^{31} \mathrm{P}-\mathrm{NMR}$ spectrum (Figure 5.15) shows a peak at $\delta=117.55 \mathrm{ppm}$, which is also shifted downfield in contrast to that in complex 18. The peak at $\delta=-79.26 \mathrm{ppm}$ in the ${ }^{19} \mathrm{~F}-\mathrm{NMR}$ spectrum confirms the dissociated triflate anion (Figure 5.16). Fortunately, $\mathrm{CO}$ signals are observed as low-field resonances in ${ }^{13} \mathrm{C}-\mathrm{NMR}$ spectrum at $\delta=199.31 \sim 199.10 \mathrm{ppm}$ (Figure 5.17). 


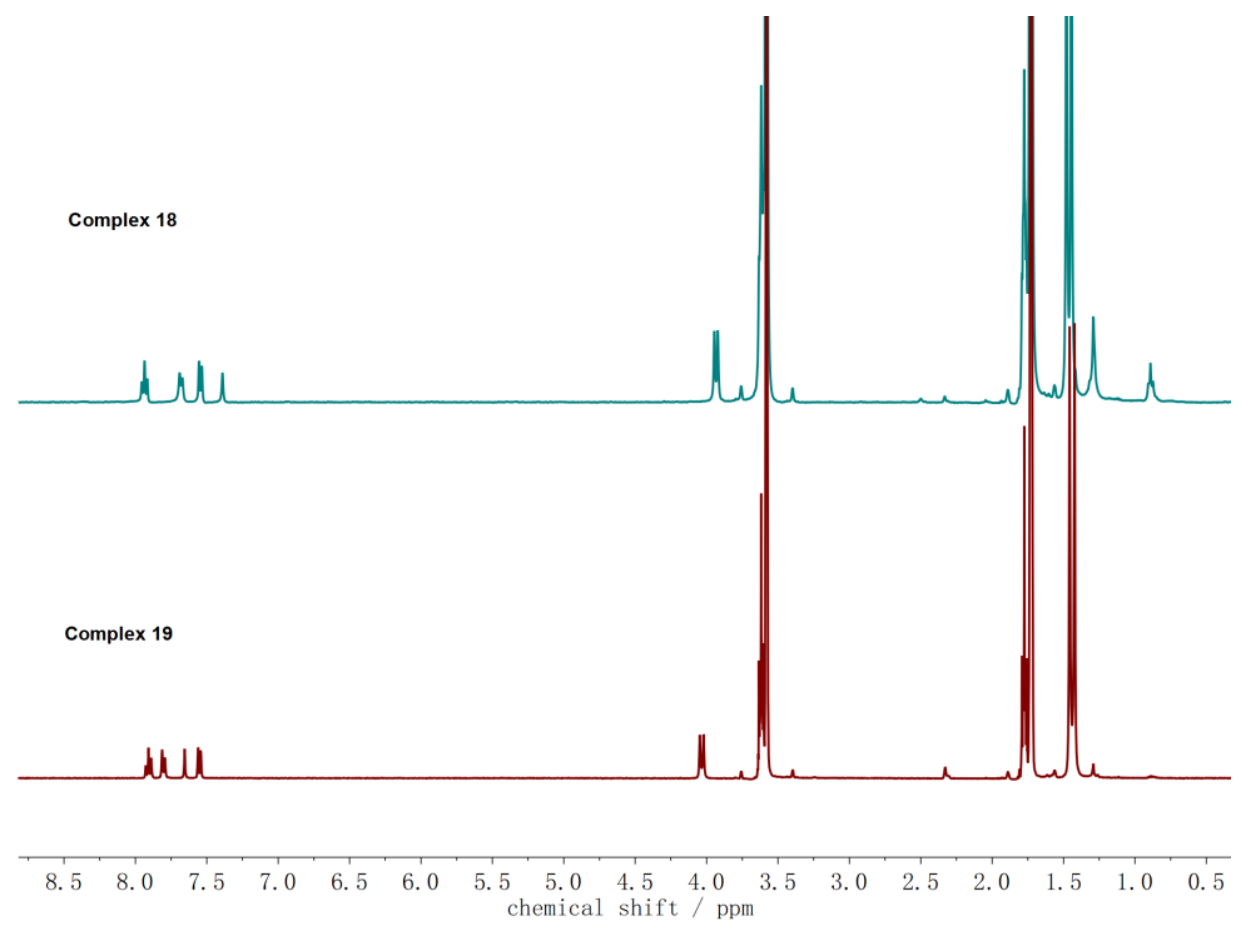

Figure 5.13: ${ }^{1} \mathrm{H}-\mathrm{NMR}$ spectra of complex 18 and 19 in $\mathrm{THF}-\mathrm{d}_{8}$.

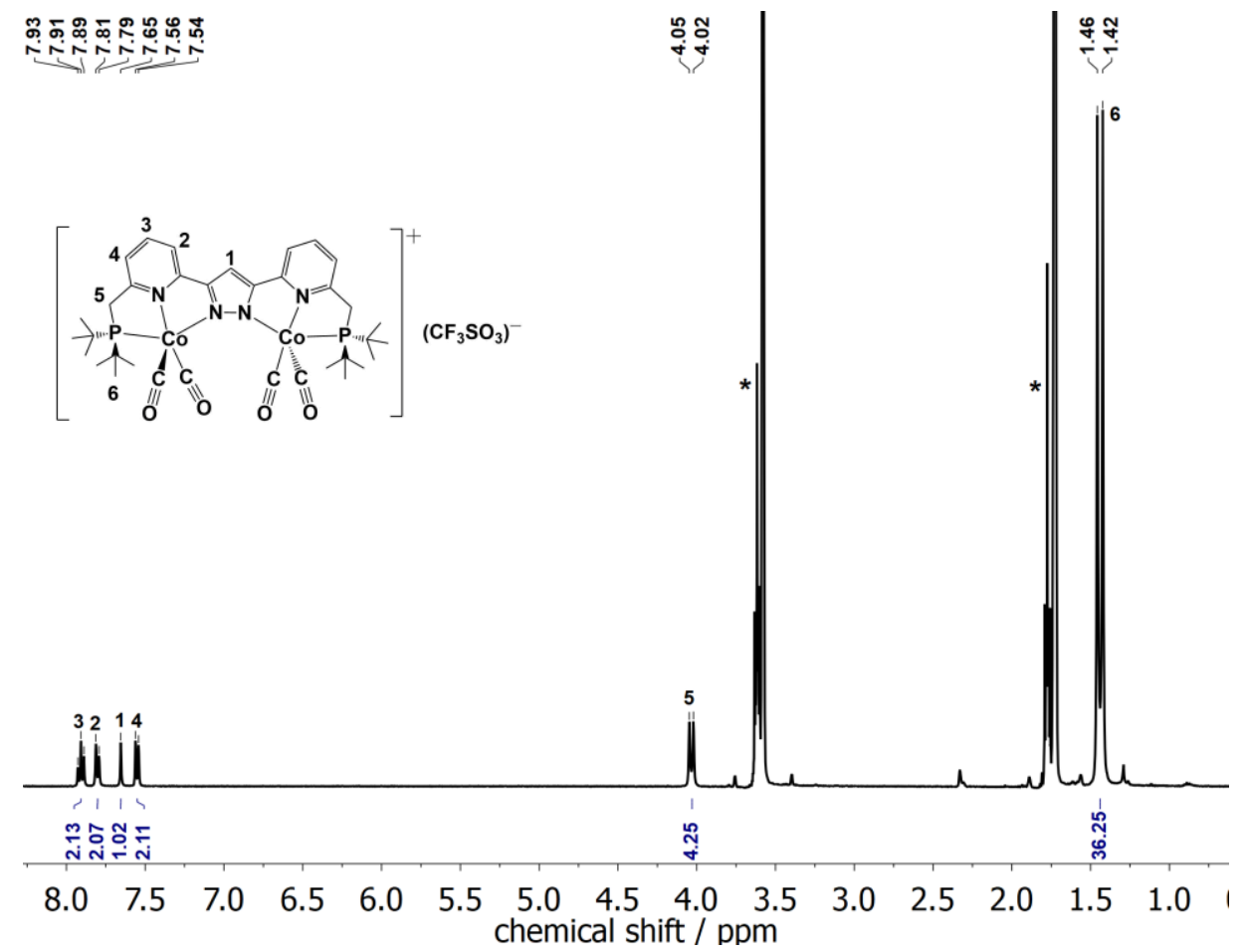

Figure 5.14: ${ }^{1} \mathrm{H}-\mathrm{NMR}$ spectrum of complex 19 in $\mathrm{THF}-\mathrm{d}_{8}$. Solvent signals are marked with an asterisk $(*)$. 


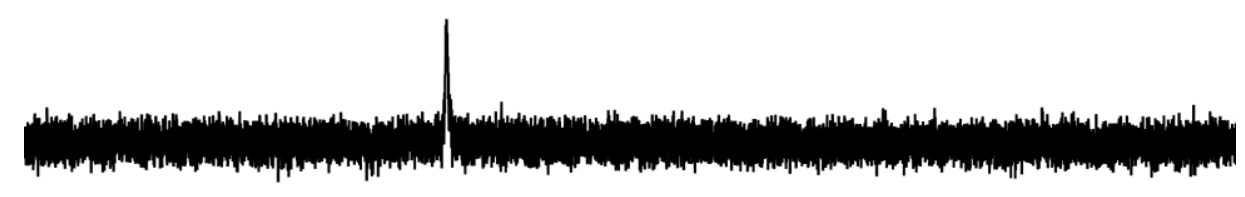

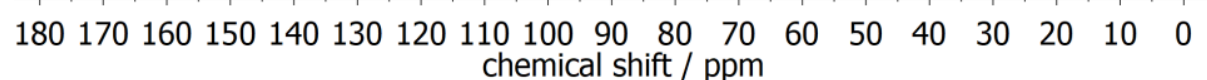

Figure 5.15: ${ }^{31} \mathrm{P}-\mathrm{NMR}$ spectrum of complex 19 in $\mathrm{THF}-\mathrm{d}_{8}$.

กั

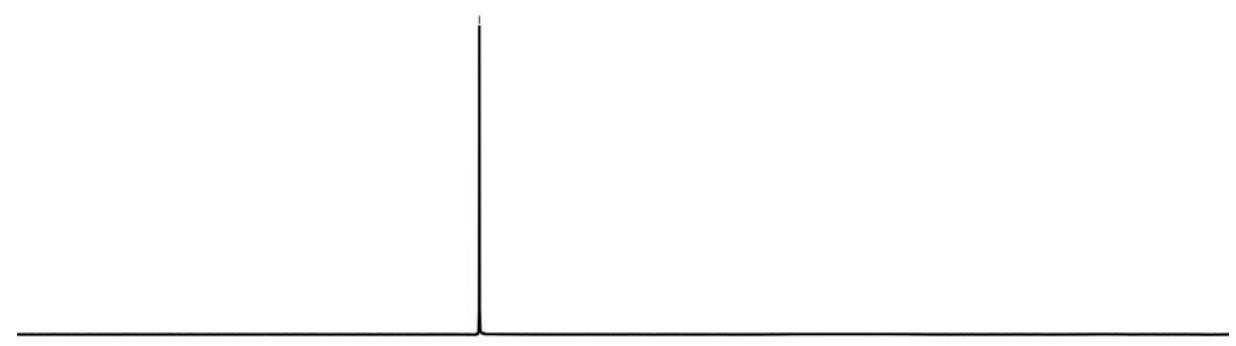

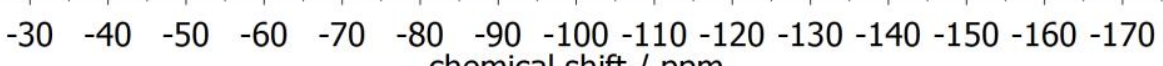
chemical shift / ppm

Figure 5.16: ${ }^{19}$ F-NMR spectrum of complex 19 in $\mathrm{THF}-\mathrm{d}_{8}$ 


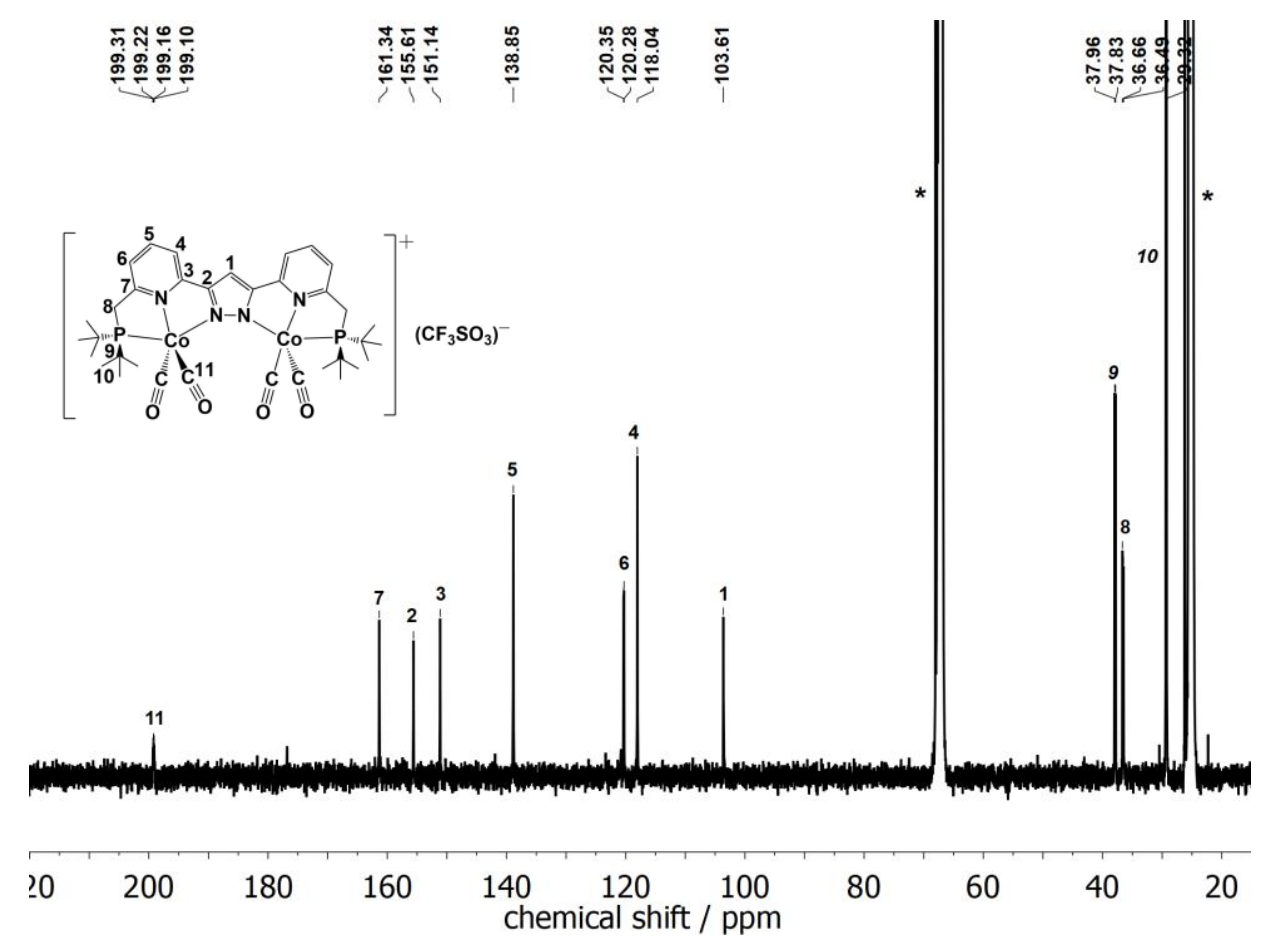

Figure 5.17: ${ }^{13} \mathrm{C}-\mathrm{NMR}$ spectrum of complex 19 in THF- $\mathrm{d}_{8}$. Solvent signals are marked with an asterisk (*).

As depicted in Figure 5.18, three sharp peaks assigned to C-O stretching vibrations in the carbonyl ligands of complex 19 were observed at 1997, 1940 and $1930 \mathrm{~cm}^{-1}$. The C-O peaks shift to 1951, 1889 and $1877 \mathrm{~cm}^{-1}$ when complex 19 was labeled by ${ }^{13} \mathrm{CO}$, which are quite close to the expected values (1952, 1897 and $\left.1887 \mathrm{~cm}^{-1}\right)$. UV-vis spectra of complex 19 at $233 \mathrm{~K}$ show intense absorption features at 298, 398 and $621 \mathrm{~nm}$ (Figure 5.19a). However, when the temperature rises from $233 \mathrm{~K}$ to $298 \mathrm{~K}$, the two peaks at 298 and $621 \mathrm{~nm}$ shift to 307 and $646 \mathrm{~nm}$ respectively, and the peak at $398 \mathrm{~nm}$ decreases in intensity, which means that with a rise of temperature, complex $\mathbf{1 9}$ is not stable and is gradually converted to complex 18. Additionally, putting the solution of complex 19 under vacuum also results in the loss of CO and the conversion to complex $\mathbf{1 8}$ (Figure 5.19b). On the contrary, the reaction of complex $\mathbf{1 8}$ with additional $\mathrm{CO}$ gas forms complex 19. 


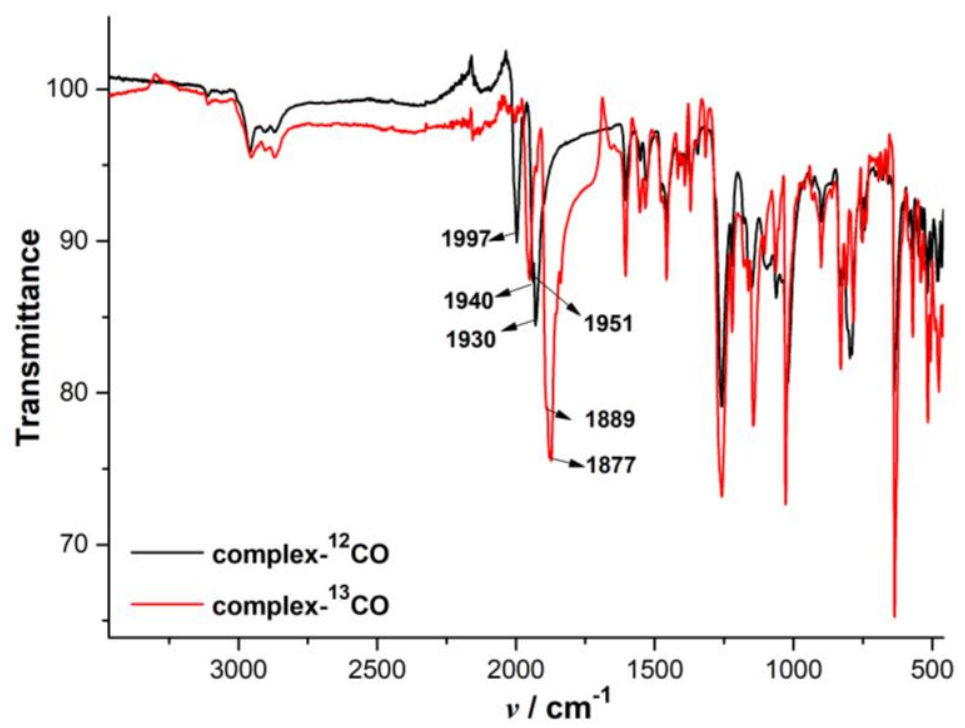

Figure 5.18: IR spectra of complex $19\left({ }^{12} \mathrm{CO}\right.$ and $\left.{ }^{13} \mathrm{CO}\right)$ in solid state.

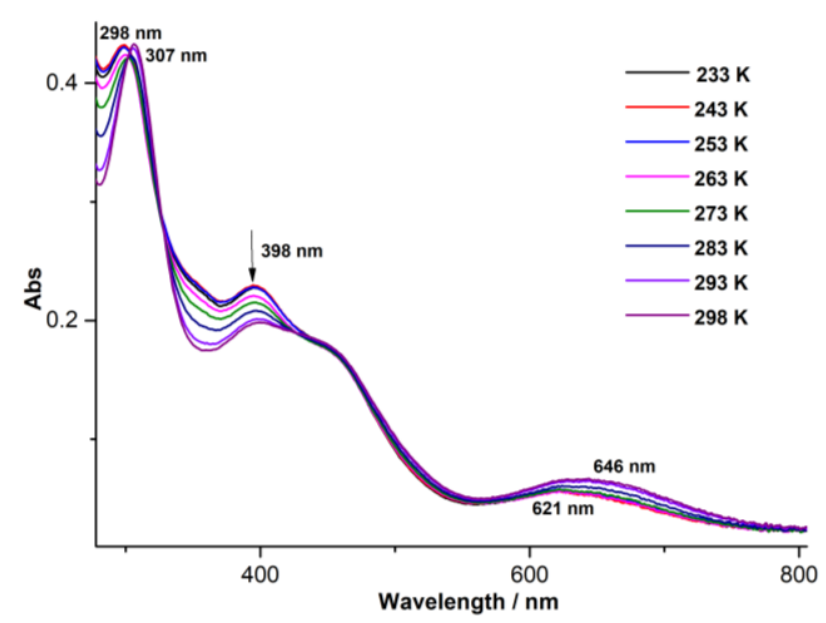

a

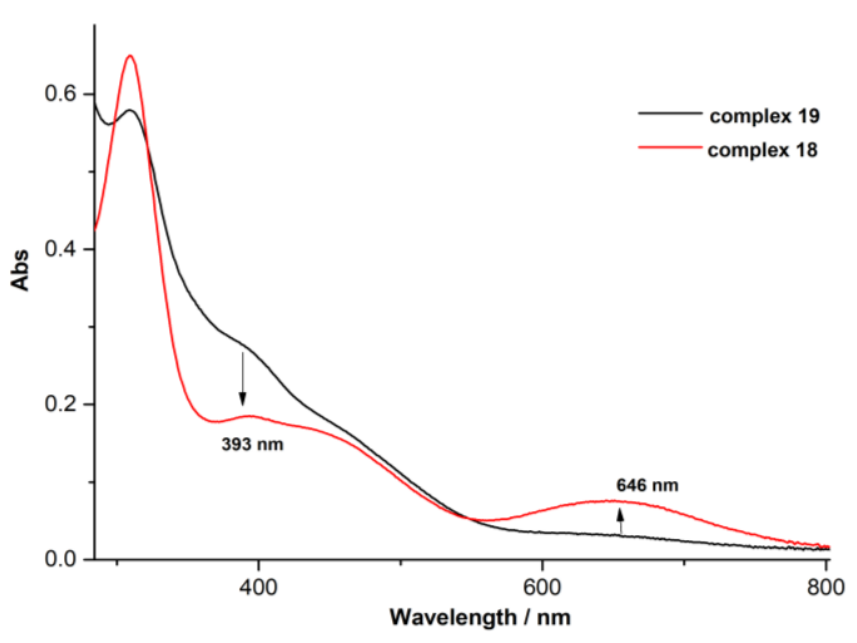

b

Figure 5.19: UV/vis spectra of the conversion from complex 19 to complex 18 in THF solution.

In previous examples, many (pincer) $\mathrm{Co}(\mathrm{CO})$ or (pincer) $\mathrm{Co}(\mathrm{CO})_{2}$ complexes have been reported (Figure 5.20). But the cases where both monocarbonyl and dicarbonyl complexes were structurally characterized are limited. For example, the Mindiola group reported a $\mathrm{Co}_{2} \mathrm{~N}_{2}$ diamond core behaving as a highly reactive three-coordinate $\mathrm{Co}^{\mathrm{I}}$ synthon could react with $\mathrm{CO}$ to generate a dicarbonyl complex $\left[(\mathrm{PNP}) \mathrm{Co}(\mathrm{CO})_{2}\right]\left(v_{\mathrm{CO}}=1957\right.$ and $\left.1893 \mathrm{~cm}^{-1}\right)$ in Figure 5.20a and 5.20b. ${ }^{22 \mathrm{a}}$ During the conversion, a possible monocarbonyl intermediate complex [(PNP)Co(CO)] was identified by NMR and IR spectroscopies $\left(v_{\mathrm{CO}}=1901 \mathrm{~cm}^{-1}\right)$ but could not be structurally characterized. The Caulton group reported a T-shaped (pincer)Co complex reacted with one atmosphere of $\mathrm{CO}$ to form a monocarbonyl adduct $(\mathrm{PNP}) \mathrm{Co}(\mathrm{CO})\left(v_{\mathrm{CO}}=1885 \mathrm{~cm}^{-1}\right)$ and the dicarbonyl complex $(\mathrm{PNP}) \mathrm{Co}(\mathrm{CO})_{2}$ was confirmed in CO-saturated pentane solution by IR $\left(v_{\mathrm{CO}}=1840\right.$ and $\left.1931 \mathrm{~cm}^{-1}\right)$ and observed at low temperature by NMR spectroscopy (Figure 5.20c and 5.20d). ${ }^{56}$ The equilibrium favors the 
monocarbonyl complex. The Kirchner group synthesized a dicarbonyl complex (PNCNP)Co(CO) $)_{2}$ $\left(v_{\mathrm{CO}}=1906\right.$ and $1963 \mathrm{~cm}^{-1}$ ), which was thermodynamically favorable, but unfortunately, the monocarbonyl complex (PNCNP)Co(CO) was not observed experimentally (Figure 5.20e and 5.20f). ${ }^{57}$ The Heinekey group reported that the reaction of monocarbonyl complex (POCOP)Co(CO) $\left(v_{\mathrm{CO}}=1899 \mathrm{~cm}^{-1}\right)$ in presence of greater than 2 equiv. of $\mathrm{CO}$ resulted in the formation of dicarbonyl complex (POCOP)Co(CO) $)_{2}\left(v_{\mathrm{CO}}=1915\right.$ and $\left.1969 \mathrm{~cm}^{-1}\right)$ and the dicarbonyl complex could be converted to monocarbonyl complex only under prolonged heating under dynamic vacuum (Figure $5.20 \mathrm{~g}$ and 5.20h). ${ }^{58}$ Compared with above carbonyl complexes, complexes 18 and 19 are less electron rich in terms of the $\mathrm{C}-\mathrm{O}$ stretching frequency in IR spectra.

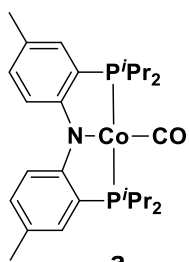

a

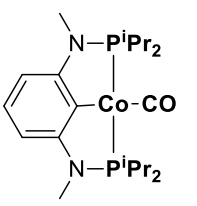

e

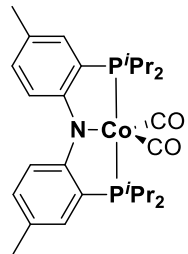

b

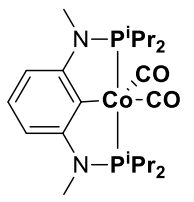

$\mathbf{f}$

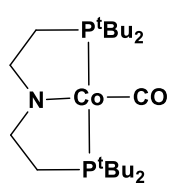

C

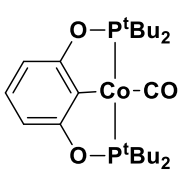

g

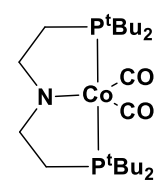

d

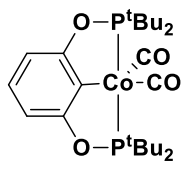

h

Figure 5.20: Reported cobalt monocarbonyl and dicarbonyl complexes.

\subsection{Conclusion}

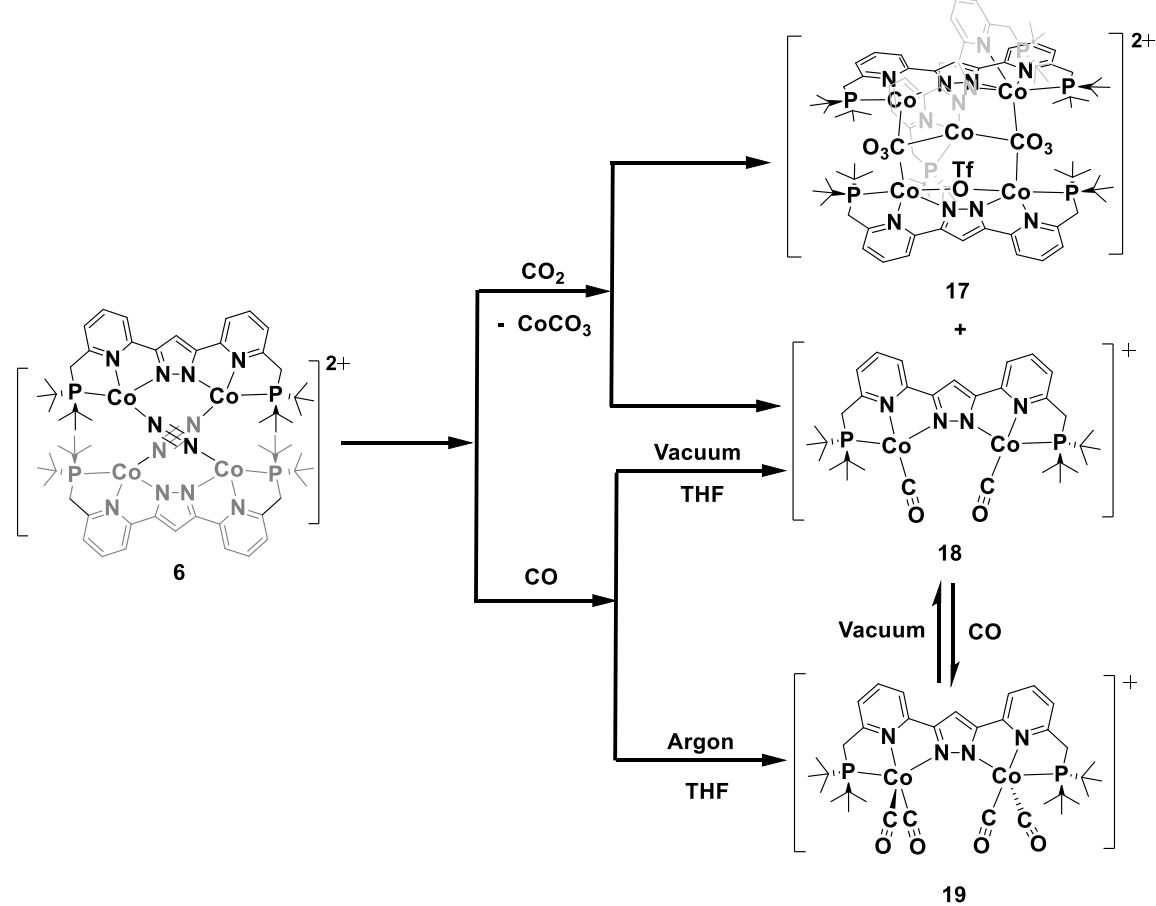


By employing the dimeric cobalt(I) dinitrogen complex $\mathbf{6}$ as a reactive platform, the reactivity with carbon dioxide has been explored and the products of $\mathrm{CO}_{2}$ reductive disproportionation are successfully synthesized, featuring a cobalt(II) carbonate complex $\left[\left(\mathrm{L}_{3} \operatorname{Co} 5\left(\mu-\mathrm{CO}_{3}\right)_{2}(\mu-\mathrm{OTf})\right)(\mathrm{OTf})_{2}\right]$ 17 and a dicobalt(I) dicarbonyl complex $\left[\left(\mathrm{LCo}_{2}(\mathrm{CO})_{2}\right)(\mathrm{OTf})\right] 18$ respectively. Both complexes were structurally characterized and complex 18 was also ascertained by NMR and IR spectroscopies. However, the exact stoichiometry of the reaction remains unknown. The dicobalt(I) dicarbonyl complex 18 can be directly synthesized by the reaction of complex 6 with $\mathrm{CO}$ gas. Excess $\mathrm{CO}$ gas reacted with complex 6 leading to the formation of a tetracarbonyl complex 19. Furthermore, putting the solution of complex 19 under vacuum also results in the loss of $\mathrm{CO}$ and the conversion to complex 18. In the reverse, the reaction of complex 18 with additional $\mathrm{CO}$ gas forms complex 19. In addition, $\mathrm{CO}_{2}$ reduction in the presence of the proton source is still in progress. 


\section{Chapter 6: Hydrosilane Reactions of Tetracobalt Dinitrogen Complex 6}

\subsection{Introduction}

Recently, the reactions of hydrosilanes (including $\mathrm{SiH}_{4}, \mathrm{RSiH}_{3}, \mathrm{R}_{2} \mathrm{SiH}_{2}$, and $\mathrm{R}_{3} \mathrm{SiH}$ ) with transition metal complexes have attracted significant attention in catalytic transformations to organosilanes, such as hydrosilylation and dehydrogenative polymerization, ${ }^{59}$ for their potential commercial or military applications. Furthermore, the reactions can break or form new bonds of silicon under ambient conditions ${ }^{60}$ which provides a model for the corresponding interactions of $\mathrm{C}-\mathrm{H}$ bonds. ${ }^{61}$ Generally, hydrosilanes react with transition metal complexes through classical oxidative additions or nonclassical interactions to form silyl complexes (Figure 6.1). ${ }^{62}$ As depicted in Figure 6.1A-C', nonclassical interactions of hydrosilanes and transition metal complexes can be categorized into $\sigma$-interactions, agostic interactions, IHI (Interligand Hypervalent Interaction) and SISHA (Secondary Interaction between a Silicon and a Hydrogen Atom). The assignment of different interactions is often made on the basis of the interatomic distance of $\mathrm{TM}-\mathrm{Si}, \mathrm{TM}-\mathrm{H}$, and $\mathrm{Si}-\mathrm{H}$ in crystal structures accompanied by the ${ }^{1} J_{\mathrm{SiH}}$ coupling in NMR spectra, the Si-H and TM-H stretching frequency in IR spectra, and on DFT calculations.

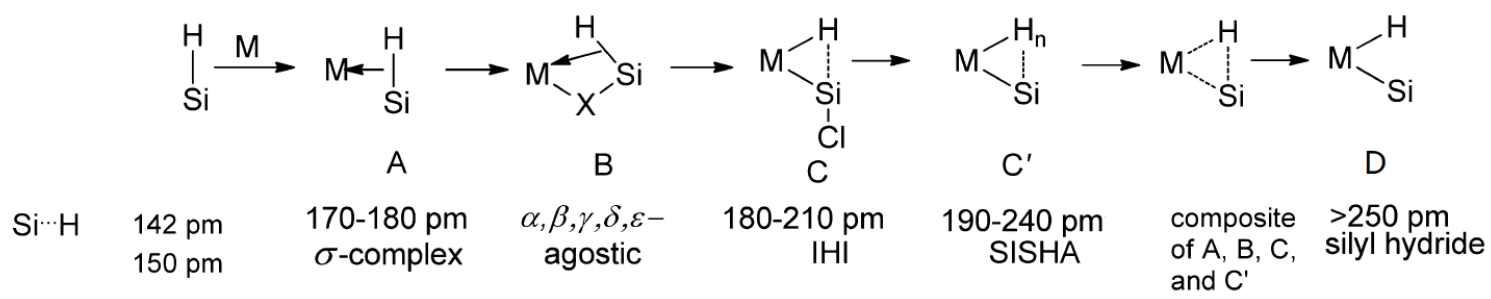

Figure 6.1: Different interactions of hydrosilanes and transition metal complexes with different characteristic $\mathrm{Si}-\mathrm{H}$ bond lengths. ${ }^{62}$

When the Si-H $\sigma^{*}$-antibonding orbital as an acceptor interacts with a d-orbital of the metal center, it forms a $\pi$-complex and sufficient $\pi$-back-bonding may lead to the cleavage of the $\mathrm{Si}-\mathrm{H}$ bonds and oxidative addition to the transition metal centers to generate a silyl hydride complex (Figure 6.1D). ${ }^{63}$ Therefore, the oxidation state and the coordination number of the metal center increases. ${ }^{64}$ Further $\alpha-\mathrm{H}$ migration from coordinated hydrosilanes to the metal center may result in the formation of $\mathrm{M}=\mathrm{Si}$ silylene complexes, while further reductive elimination of small molecules like RH (hydrocarbon), $\mathrm{H}_{2}$ and $\mathrm{HX}$ (halogen) may give rise to M-Si complexes (Figure 6.2). ${ }^{65}$ 


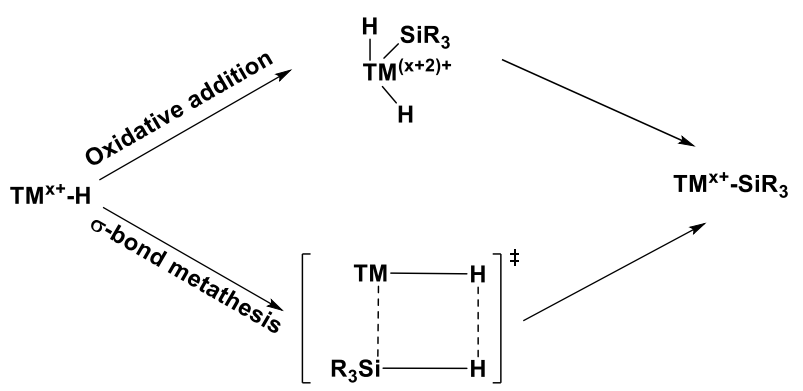

Figure 6.2: Simplified comparison of the oxidative addition pathway and the $\sigma$-bond metathesis pathway.

For instance, the Caulton group reported the oxidative addition reactions of phenylsilane with a three-coordinate T-shaped $\mathrm{Co}^{\mathrm{I}}$ species (PNP)Co to give rise to a formal $\mathrm{Co}^{\mathrm{V}}$ silylene complexes (Scheme 6.1). ${ }^{66}$ The T-shaped (PNP)Co was consumed by 4 equiv of $\mathrm{PhSiH}_{3}$ to form 1 equiv of $\mathrm{H}_{2}$ and $\mathrm{Ph}_{2} \mathrm{SiH}_{2}$ characterized by NMR spectra and a crystallographically characterized $\mathrm{Co}^{\mathrm{V}}$ silylene complex ligated by three hydrides, two primary silanes and a phosphine-stabilized silylene. Moreover, one intermediate during this process was also confirmed as a $\mathrm{Co}^{\mathrm{V}}$ silylene complex containing four hydrides and one $\mathrm{Ph}_{2} \mathrm{SiH}$ fragment according to NMR spectra. After further reductive elimination of diphenylsilane, the intermediate complex reacted with $\mathrm{PhSiH}_{3}$ to give the formation of the final $\mathrm{Co}^{\mathrm{V}}$ silylene product.

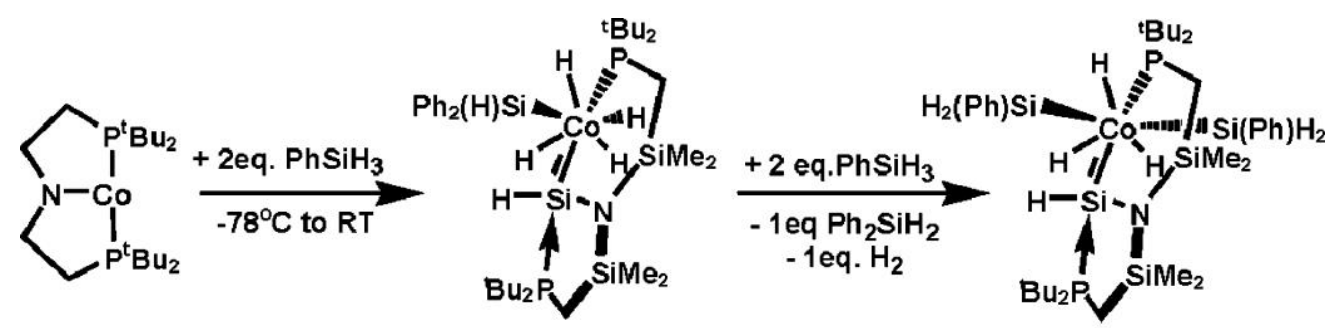

Scheme 6.1: The oxidative addition reactions of phenylsilane with a three-coordinate T-shaped $\mathrm{Co}^{\mathrm{I}}$ species. ${ }^{66}$

Another example comes from the Tilley group, which reported a reaction of $\mathrm{Na}(\mathrm{THF})_{6}\left\{\left[\mathrm{BP}{ }_{3}{ }^{\mathrm{iPr}}\right] \mathrm{CoI}\right\}$ $\left(\left[\mathrm{BP}_{3}{ }^{\mathrm{iPr}}\right]=\kappa^{3}-\mathrm{PhB}\left(\mathrm{CH}_{2} \mathrm{P}^{\mathrm{i}} \mathrm{Pr}_{2}\right)_{3}{ }^{-}\right)$, serving as a source of $\left[\mathrm{BP}_{3}{ }^{\mathrm{iPr}}\right] \mathrm{Co}$, with $\mathrm{PhSiH}_{3}$ or $\mathrm{SiH}_{4}$ to generate unusual $\left\{\left[\mathrm{BP}_{2}{ }^{\mathrm{iPr}}\right]\left(\mathrm{SiH}_{2} \mathrm{R}\right) \mathrm{CoH}_{2}\right\}=\mathrm{Si}=\left\{\mathrm{H}_{2} \mathrm{Co}\left[\mathrm{BP}_{3}{ }^{\mathrm{iPr}}\right]\right\}$ species $(\mathrm{R}=\mathrm{Ph}$ or $\mathrm{H})$ accompanied by $\mathrm{NaI}$, benzene or $\mathrm{H}_{2}$ and ${ }^{\mathrm{i}} \mathrm{Pr}_{2} \mathrm{PCH}_{2} \mathrm{SiH}_{2} \mathrm{R}$ as byproducts through all the $\mathrm{Si}-\mathrm{H}$ and $\mathrm{Si}-\mathrm{C}$ bond activations of silanes (Scheme 6.2) ${ }^{67}$ These $\mathrm{Co}=\mathrm{Si}=\mathrm{Co}$ complexes are the first silicide complexes, which were synthesized directly from silane precursors. In addition, the trapping study with addition of 4-dimethylaminopyridine (DMAP) formed a base-stabilized silylene complex $\left[\mathrm{BP}_{3}{ }^{\mathrm{iPr}}\right](\mathrm{H})_{2} \mathrm{CoSiHPh}(\mathrm{DMAP})$, suggesting a silylene dihydride intermediate was involved in the reaction of $\left[\mathrm{BP}_{3}{ }^{i \mathrm{Pr}}\right] \mathrm{Co}^{\mathrm{I}}$ with $\mathrm{PhSiH}_{3}$ to form $\mathrm{Co}=\mathrm{Si}=\mathrm{Co}$ complex. However, the exact mechanism is still unclear. 


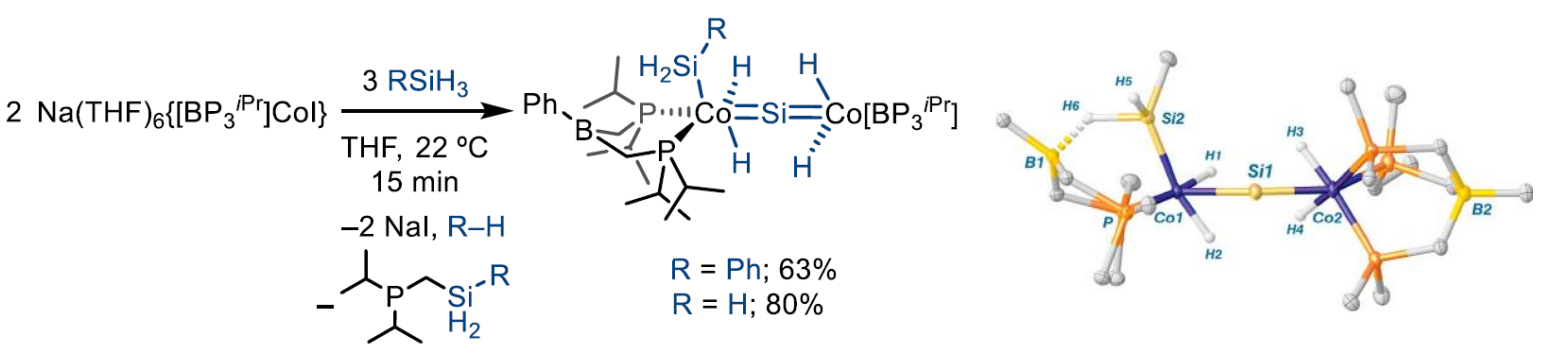

Scheme 6.2: The synthesis of the $\mathrm{Co}=\mathrm{Si}=\mathrm{Co}$ complexes and its molecular structure. ${ }^{67}$

On the other hand, when the $\mathrm{Si}-\mathrm{H} \sigma$-bonding orbital interacts as a donor with the empty d-orbital of the metal center, it forms a $\sigma$-complex via $\mathrm{Si}-\mathrm{H} \cdots \mathrm{M}$ interactions in $\eta^{1}-\mathrm{H}, \eta^{2}-\mathrm{HSi}$ or $\eta^{3}-\mathrm{H}_{2} \mathrm{Si}$ coordination modes. ${ }^{63,65}$ As shown in Figure 6.2, $\sigma$-complexes can also give rise to M-Si complexes via a $\sigma$-bond metathesis transition state, which provides a lower energy pathway to the formation of $\mathrm{M}$-Si complexes in comparison to the oxidative addition of $\pi$-complexes. Furthermore, as shown in Scheme 6.3, the Lee group reported another pathway, hydrogen atom transfer (HAT), to achieve the synthesis of a Co-Si complex and to test the hydrogen atom abstraction from the reaction of a ( ${ }^{\text {acripNP) }} \mathrm{Co}\left(\eta^{2}-\mathrm{SiH}_{3} \mathrm{Ph}\right) \sigma$-complex and a 3-coordinate cobalt(I) complex ( $\left.{ }^{\text {acriPNP}}\right) \mathrm{Co} .{ }^{67}$

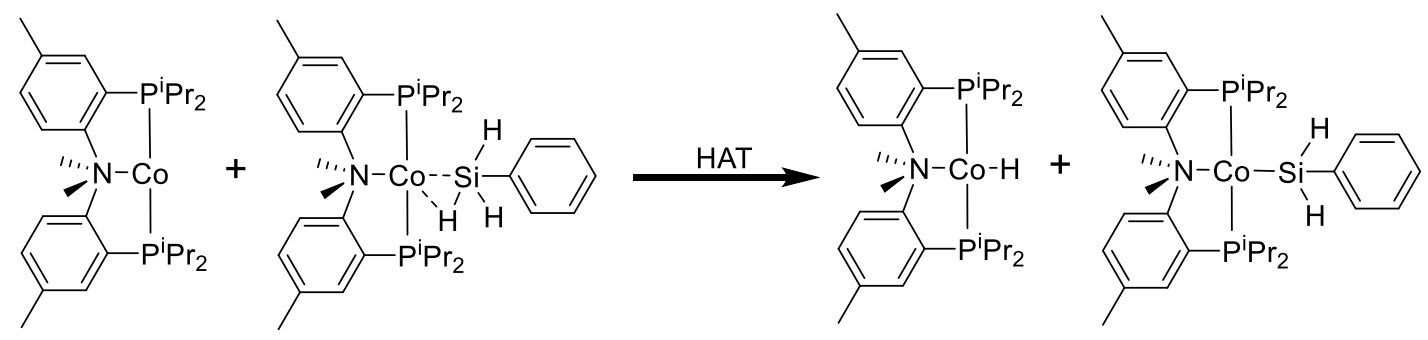

Scheme 6.3: HAT pathway to the synthesis of a Co-Si complex. ${ }^{67}$

\subsubsection{Redistribution in Transition Metal Silyl Complexes}

Redistribution is an important reaction in silane chemistry. This process has been reported in transition metal silyl complexes recently and has aroused a lot of interest in the construction of novel silyl complexes ${ }^{68}$ and the catalytic reaction of manufacturing organosilanes by employing transition metal silyl complexes as catalysts. ${ }^{69}$ In addition, redistribution provides an alternative way to the synthesis of silane $\left(\mathrm{SiH}_{4}\right)$, a pyrophoric and toxic gas, during the reactions of transition metal complexes with hydrosilanes such as $\mathrm{PhSiH}_{3}, \mathrm{H}_{2} \mathrm{SiMePh}$ and $\mathrm{Ph}_{2} \mathrm{SiH}_{2}{ }^{70}$, $68 \mathrm{c}$ The Sabo-Etienne group reported that the bis(dihydrogen) complex $\mathrm{RuH}_{2}\left(\eta^{2}-\mathrm{H}_{2}\right)_{2}\left(\mathrm{PCy}_{3}\right)_{2}$ reacted with 2 equiv. of $\mathrm{H}_{2} \mathrm{SiMePh}$ to produce $\mathrm{Ru}_{2} \mathrm{H}_{4}\left(\mu-\eta^{2}: \eta^{2}: \eta^{2}: \eta^{2}-\mathrm{SiH}_{4}\right)\left(\mathrm{PCy}_{3}\right)_{4}$ and $\mathrm{RuH}_{2}\left(\eta^{2}-\mathrm{H}_{2}\right)\left(\eta^{2}-\mathrm{HSiPh}_{3}\right)\left(\mathrm{PCy}_{3}\right)_{2}$ together with $\mathrm{HSiMePh}_{2}, \mathrm{HSiMe}_{2} \mathrm{Ph}$ and $\mathrm{HMe}_{2} \mathrm{SiSiMe}_{2} \mathrm{H}$ as a result of redistribution at silicon. ${ }^{61 \mathrm{a}}$ The Tilley group reported a samarium-mediated redistribution of silanes and the formation of novel samarium-silicon clusters. Reaction of $\mathrm{Cp}^{*}{ }_{2} \mathrm{SmCH}\left(\mathrm{SiMe}_{3}\right)_{2}$ with $\mathrm{Ph}_{2} \mathrm{SiH}_{2}$ gave rise to a planar $\left(\mathrm{Cp}_{2}{ }_{2} \mathrm{Sm}\right)_{3}\left(\mathrm{SiH}_{3}\right)\left(\mathrm{SiH}_{2} \mathrm{SiH}_{2}\right)$ cluster and $\mathrm{Ph}_{3} \mathrm{SiH}$, while the reaction with $\mathrm{PhSiH}_{3}$ not only formed this 
cluster, but also a $\left(\mathrm{Cp}_{2}{ }_{2} \mathrm{Sm}\right)_{3}\left(\mathrm{SiH}_{3}\right)_{3}$ cluster and a $\left(\mathrm{Cp}_{2}{ }_{2} \mathrm{Sm}\right)_{3}\left(\mathrm{SiH}_{3}\right)\left(\mathrm{SiH}_{2} \mathrm{SiH}_{2} \mathrm{SiH}_{2}\right)$ cluster, accompanied by release of $\mathrm{H}_{2}, \mathrm{Ph}_{2} \mathrm{SiH}_{2}, \mathrm{Ph}_{3} \mathrm{SiH}$ and $\mathrm{PhSiH}_{2} \mathrm{SiH}_{2} \mathrm{Ph}^{71}$ As shown in Scheme 6.4, the Parkin group reported a facile oxidative addition of $\mathrm{Mo}\left(\mathrm{PMe}_{3}\right)_{6}$ with $\mathrm{PhSiH}_{3}$ at room temperature to give the bis-(phenylsilyl) compound, $\mathrm{Mo}\left(\mathrm{PMe}_{3}\right)_{4}\left(\mathrm{SiH}_{2} \mathrm{Ph}\right)_{2} \mathrm{H}_{2}$. This exhibited limited stability and reacted with excess $\mathrm{PhSiH}_{3}$ to form the silyl $\left(\mathrm{SiH}_{3}\right)$ compounds $\mathrm{Mo}\left(\mathrm{PMe}_{3}\right)_{4}\left(\mathrm{SiH}_{2} \mathrm{Ph}\right)\left(\mathrm{SiH}_{3}\right) \mathrm{H}_{2}$, $\mathrm{Mo}\left(\mathrm{PMe}_{3}\right)_{4}\left(\mathrm{SiH}_{3}\right)_{2} \mathrm{H}_{2}$, and $\mathrm{Mo}\left(\mathrm{PMe}_{3}\right)_{4}\left(\mathrm{SiH}_{3}\right) \mathrm{H}_{3}$, thereinto, $\mathrm{PhSiH}_{3}$ underwent redistribution at silicon to produce $\mathrm{Ph}_{2} \mathrm{SiH}_{2}$ and $\mathrm{SiH}_{4}{ }^{68 \mathrm{~d}}$

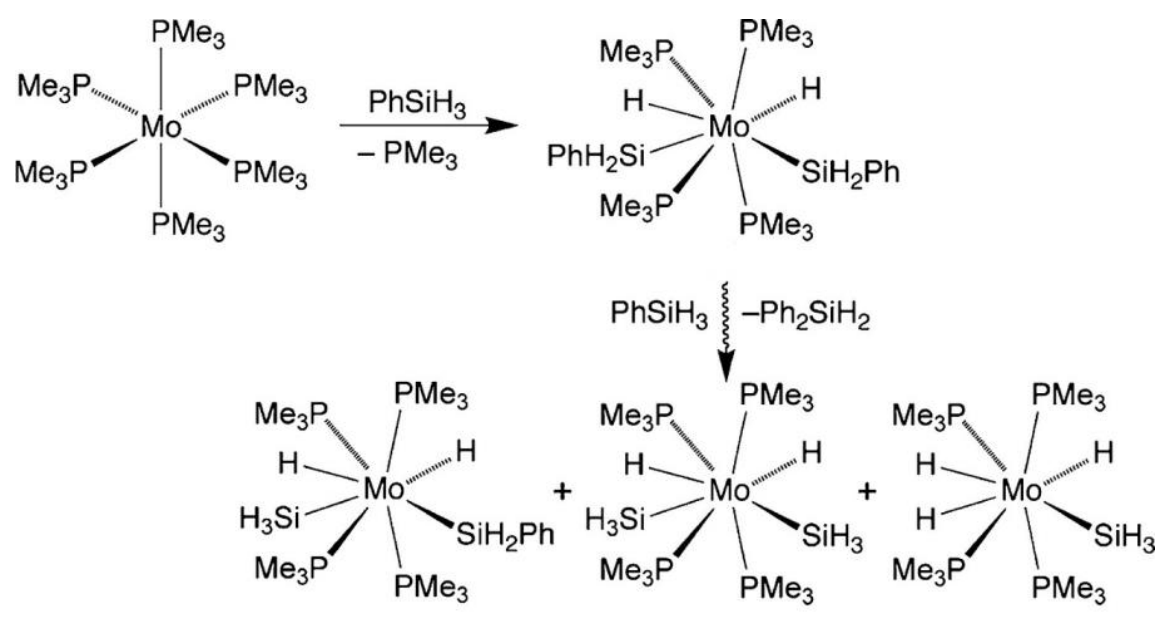

Scheme 6.4: The reaction of $\mathrm{Mo}\left(\mathrm{PMe}_{3}\right)_{6}$ with $\mathrm{PhSiH}_{3}$ undergoing redistribution at silicon. ${ }^{68 \mathrm{~d}}$

\subsubsection{Disilyne and Multiply Bonded Silylanionic Chemistry}

The field of multiply bonded silicon compounds, including disilenes and disilynes, has developed rapidly, and due to their different bonding and unusual structures in comparison to carbon analogues, the synthesis and characterization has been a hot topic. ${ }^{72}$ Numerous disilene derivatives have been isolated and characterized ${ }^{73}$ but examples of disilyne derivatives are still limited. The Sekiguchi group first reported a structurally characterized disilyne $\mathrm{R}-\mathrm{Si} \equiv \mathrm{Si}-\mathrm{R}$ compound, in which the $\mathrm{Si} \equiv \mathrm{Si}$ triple bond was kinetically and thermodynamically stabilized by two large silyl substituents (Figure $6.3 \mathrm{~A}) .{ }^{74}$ In the meantime, the Wiberg group also reported a relatively stable disilyne $\mathrm{RSi} \equiv \mathrm{SiR}(\mathrm{R}=$ $\left.\mathrm{SiMe}\left(\mathrm{Si} t \mathrm{Bu}_{3}\right)_{2}\right){ }^{75}$

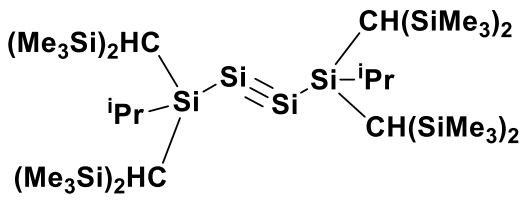

A

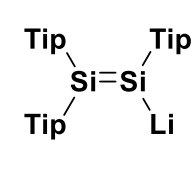

B

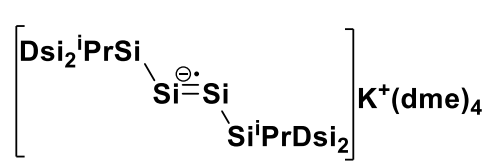

C

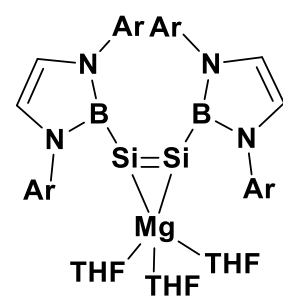

D

Figure 6.3: Selected examples of disilyne and anionic disilenes. 
On the other hand, multiply bonded silylanions, as important reagents in the synthesis of silicon-containing derivatives, are less explored. The Scheschkewitz group successfully crystallized the anionic disilenide $\mathrm{Tip}_{2} \mathrm{Si}=\mathrm{Si}$ (Tip) Li (Tip = 2, 4, 6-i $\mathrm{Pr}_{3} \mathrm{C}_{6} \mathrm{H}_{2}$ ) from the reduction of disilene by lithium metal (Figure 6.3B) ${ }^{76}$ In 2006, the Sekiguchi group isolated a disilyne anion radical upon the reduction of the disilyne $\mathrm{R}-\mathrm{Si} \equiv \mathrm{Si}-\mathrm{R}$ compound by $\mathrm{KC}_{8}$, a disilenyllithium upon the reduction of the disilyne compound by $t \mathrm{BuLi}$ and an anionic disilenide by the addition of 1, 2-dimethoxyethane (DME) to the disilenyllithium (Figure 6.3C). ${ }^{77} \mathrm{~A}$ few multiply bonded silylanions have also been reported $^{71}$ but dianionic disilynes are still scare. The only example is that the Cui group reported a dianionic disilyne in the form of a magnesium complex, which was synthesized from the treatment of (boryl) $\mathrm{SiBr}_{3}$ with activated magnesium in $\mathrm{THF}\left(\right.$ Figure 6.3D). ${ }^{72}$ Moreover, the dianionic disilyne contained significant $\pi-\pi$ bonding and noticeable electron delocalization over a unprecedented $\mathrm{Mg}-\mathrm{Si}-\mathrm{Si}$ three-membered ring.

In this chapter, we present a series of reactions of hydrosilanes with tetracobalt dinitrogen complex 6 and successfully obtained the mixed-valent $\mathrm{Co}^{\mathrm{I} / \mathrm{II}}$ diphenylsilyl $\sigma-$-complex $\mathbf{2 0}$ and methylphenylsilyl $\sigma$-complex 21. More interestingly, the reaction of phenylsilane (4.0 eq.) with complex $\mathbf{6}$ generated complex $\left[\mathrm{L}_{2} \mathrm{Co}_{4}\left(\mu-\mathrm{SiH}_{2} \mathrm{SiH}_{2}\right)\right](\mathrm{OTf})_{2} 22$ by redistribution accompanied by diphenylsilane and $\mathrm{H}_{2}$ as byproducts. Magnetic susceptibility measurements with a SQUID magnetometer provide some electronic structure insight for complex 22 and suggest that it is a mixed-valent $\mathrm{Co}^{\mathrm{I} / \mathrm{II}}$ disilyl complex. Moreover, the reaction of phenylsilane (6.0 eq.) and complex 6 generated a diamagnetic tetracobalt tetrasilyl complex $\left[\mathrm{L}_{2} \mathrm{Co}_{4}\left(\mu-\mathrm{PhSi}_{4} \mathrm{H}_{3}\right](\mathrm{OTf})_{2} 23\right.$.

\subsection{Reaction of Complex 6 with Diphenylsilane}

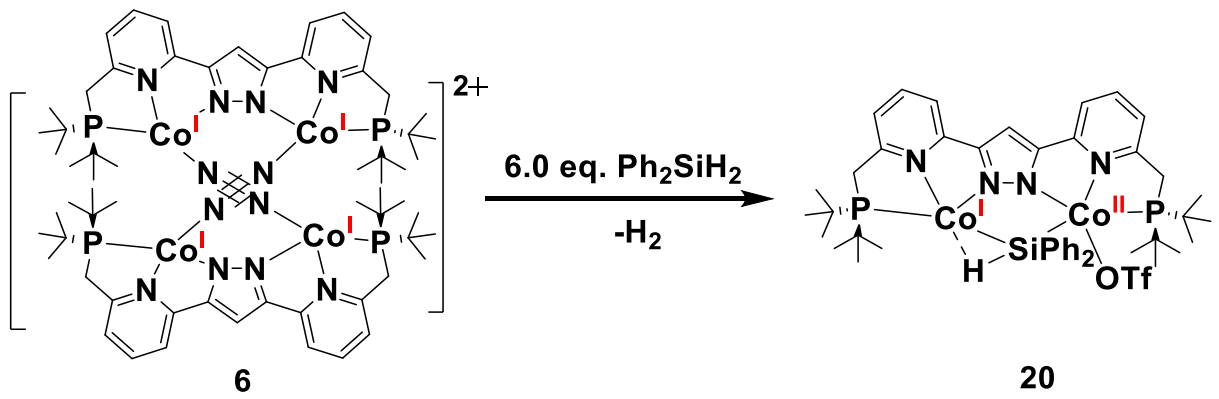

Scheme 6.5: Reaction of complex 6 with diphenylsilane.

As shown in Scheme 6.5, to a stirred suspension of tetracobalt dinitrogen complex 6 in THF, six equivalents of diphenylsilane were added dropwise, leading to an immediate color change from purple to red brown. After workup, slow diffusion of diethyl ether into the THF solution yielded needle-shaped crystals of complex 20, which were suitable for X-ray diffraction. Additionally, 20 was further identified by ${ }^{1} \mathrm{H}-\mathrm{NMR}$ spectroscopy, magnetic susceptibility measurement, IR and $\mathrm{UV}$-vis spectroscopy and elemental analysis. 
The ${ }^{1} \mathrm{H}-\mathrm{NMR}$ spectrum of complex 20 was recorded in THF- $\mathrm{d}_{8}$ and is depicted in Figure 6.4. It reveals the paramagnetic nature of complex $\mathbf{2 0}$. The proton resonances can not be assigned as there are no signals in 2D NMR experiments. Variable temperature magnetic susceptibility data recorded with a SQUID magnetometer in the range of $2 \mathrm{~K}$ to $295 \mathrm{~K}$ exhibit that the $\chi_{\mathrm{M}} T$ value is 0.35 $\mathrm{cm}^{3} \mathrm{~mol}^{-1} \mathrm{~K}$ (Figure 6.5), close to what is expected for an $\mathrm{S}=1 / 2$ system. This may suggest that one of the cobalt ions is in low spin state with no unpaired electrons $(S=0)$ and the other cobalt ion is in low spin state with one unpaired electron $(S=1 / 2)$. The best fit leads to $g=1.9$. The $\mathrm{X}$-band EPR spectrum of 20 in THF solution at $145 \mathrm{~K}$ displays a nearly isotropic pattern with obvious Co $(\mathrm{S}=1 / 2)$ and P hyperfine splitting (Figure 6.6). The signal could be well simulated with $\mathrm{g}$ factors $(\mathrm{g}=2.010$, $2.394,2.474)$. Hence, the magnetic measurement indicates that $\mathbf{2 0}$ is a mixed-valent $\mathrm{Co}^{\mathrm{I} / \mathrm{II}}$ complex.

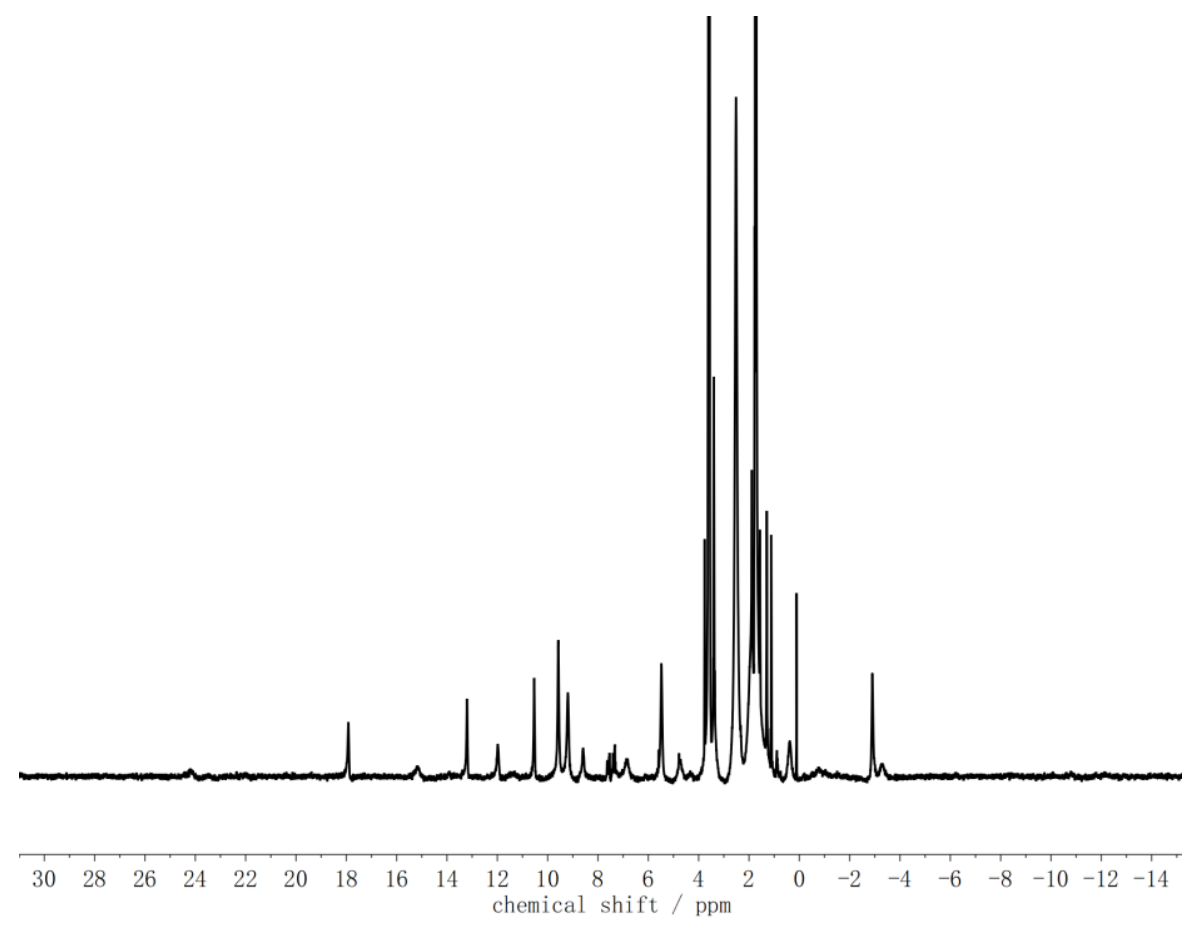

Figure 6.4: ${ }^{1} \mathrm{H}-\mathrm{NMR}$ spectrum of complex 20 in $\mathrm{THF}-\mathrm{d}_{8}$. 


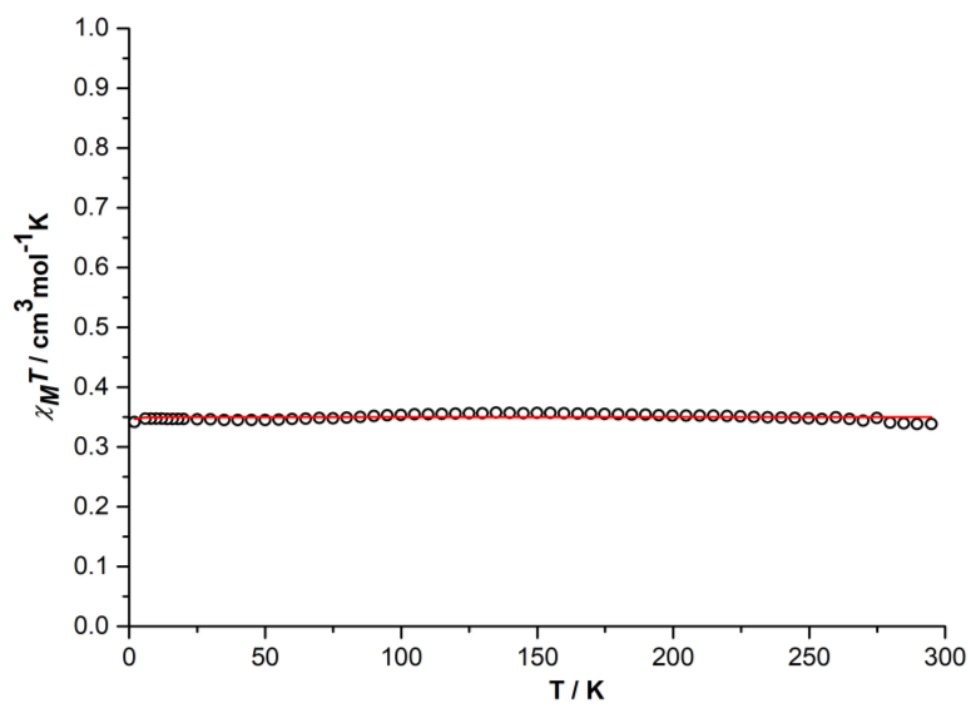

Figure 6.5: $\chi_{M} T$ vs. $T$ plot in the temperature range of $2-295 \mathrm{~K}$ at $0.5 \mathrm{~T}$ for crystalline sample of complex 20. $g=1$.9. The red line corresponds to the best fits of the experimental magnetic results.

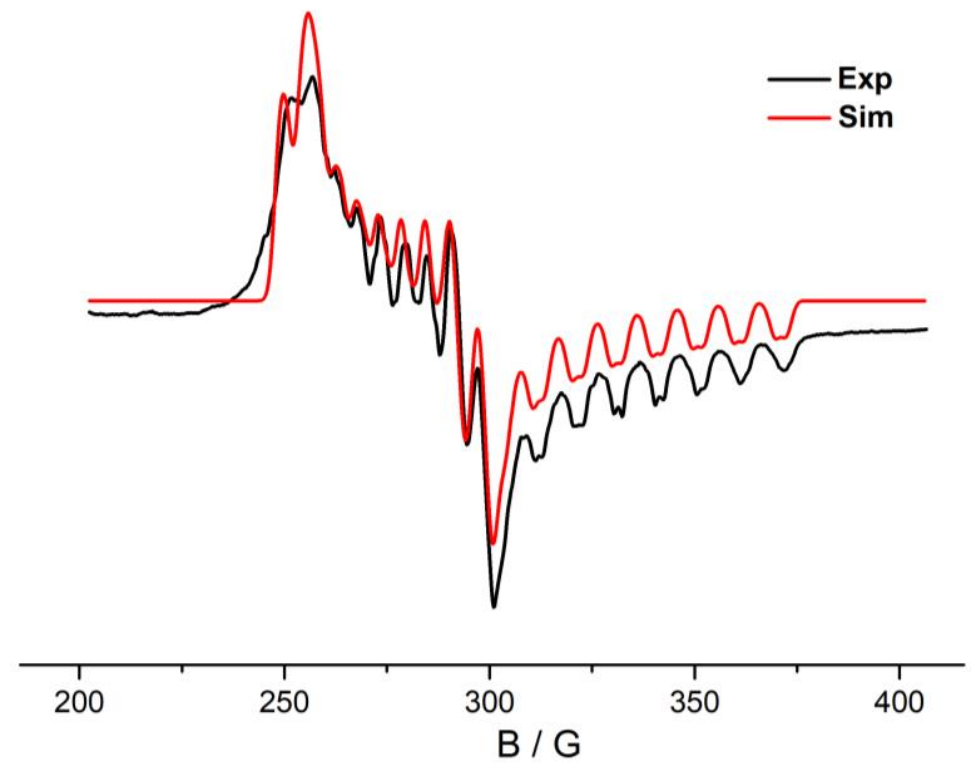

Figure 6.6: EPR spectrum of 20 recorded in THF solution at $145 \mathrm{~K}$ (black line) and a simulation ( $\mathrm{S}=$ $1 / 2 ; \mathrm{g}=2.010,2.394,2.474 ;$ A_Co $=256,177,180 \mathrm{MHz}$; A_P = 75, 51, $61 \mathrm{MHz}$ ).

Complex 20 crystallized in the monoclinic space group $C 2 / \mathrm{c}$ with eight molecules in the unit cell (Figure 6.7). Selected bond lengths and angles are listed in Table 6.1. The hydrogen atom, H1, could not easily be located from remaining electron density and have been fixed with one or more distance restraints (e.g. $\mathrm{d}(\mathrm{Si}-\mathrm{H})=1.4 \AA$ ) and a fixed isotropic temperature factor of $0.08 \AA^{2}$. The molecular structure of complex 20 displays that $\mathrm{Co}(1)$ is coordinated with $\mathrm{Si}$ and $\mathrm{H}$ via a 3c-2e $\sigma$-interaction and $\mathrm{Co}(2)$ is coordinated with one triflate anion and bridged by diphenylsilane with $\operatorname{Co}(1)$ in a distorted square-pyramidal coordination environment with Co $\cdots$ Co separation of $3.84 \AA$. The 
Co2-Si1 bond length is $2.33 \AA$, which is in accordance with the previously reported Co-Si bond lengths $(2.11-2.405 \AA),{ }^{79}$ whereas the Co1-Si1 bond length is $2.50 \AA$ and a bit longer than the typical $\mathrm{Co}-\mathrm{Si}$ bond lengths. The Co-N-N-Co torsion angle is $11.0^{\circ}$. The reaction of complex 6 and diphenylsilane may result in the formation of $\mathrm{Co}^{\mathrm{III}}$ hydride intermediate at one of the metal centers, $(\operatorname{Co}(2))$, by oxidative addition or the formation of $\sigma$-complex by $\sigma$-interaction. Afterwards, the reaction of complex 6 with diphenylsilane results in the oxidation of one of the metal centers, $(\mathrm{Co}(2))$, and gives rise to a mixed-valent $\mathrm{Co}^{\mathrm{I} / \mathrm{II}}$ nonclassical $\sigma$-complex $\left[\mathrm{L}\{\mathrm{Co}(\mathrm{OTf})\} \mathrm{Co}\left(\mu-\mathrm{SiHPh}_{2}\right)\right]$ 20 likely accompanied by the evolution of $\mathrm{H}_{2}$ gas.

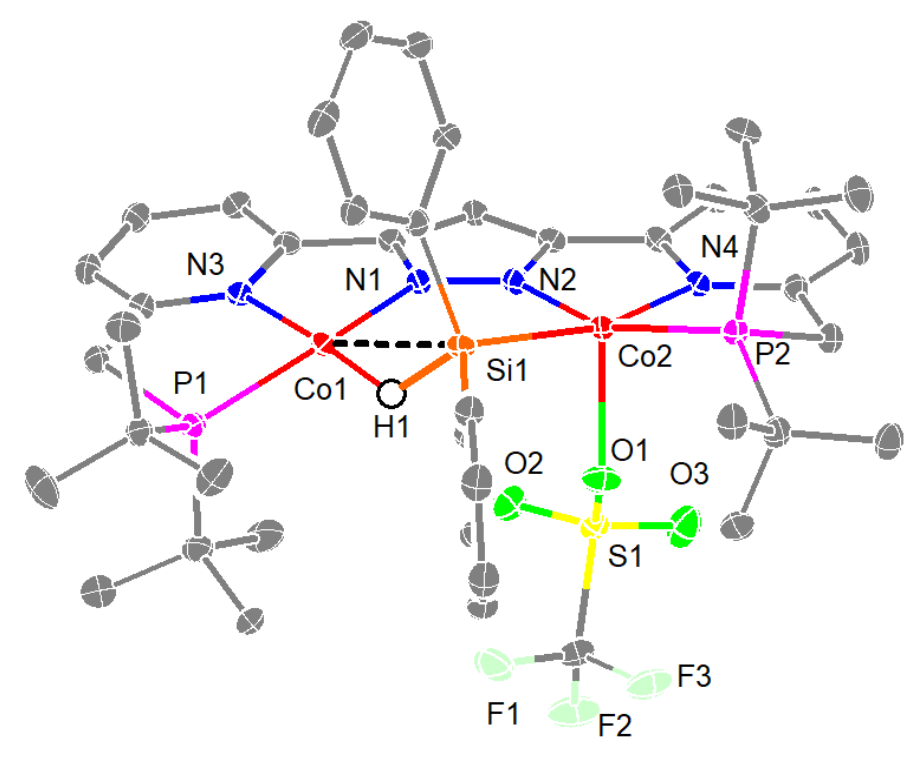

Figure 6.7: The molecular structure of complex 20. Thermal displacement ellipsoids shown at $30 \%$ probability; most hydrogen atoms and solvent molecules omitted for clarity.

Table 6.1: Selected bond lengths and angles for complex 20.

\begin{tabular}{llll}
\hline \multicolumn{1}{c}{ Bond lengths / $\AA$} & \multicolumn{3}{c}{ Angles / } \\
\hline $\mathrm{Co}(1)-\mathrm{N}(1)$ & $1.870(2)$ & $\mathrm{N}(1)-\mathrm{Co}(1)-\mathrm{N}(3)$ & $80.22(9)$ \\
$\mathrm{Co}(1)-\mathrm{N}(3)$ & $1.980(2)$ & $\mathrm{N}(1)-\mathrm{Co}(1)-\mathrm{P}(1)$ & $161.26(7)$ \\
$\mathrm{Co}(1)-\mathrm{P}(1)$ & $2.1884(7)$ & $\mathrm{N}(3)-\mathrm{Co}(1)-\mathrm{P}(1)$ & $84.45(6)$ \\
$\mathrm{Co}(1)-\mathrm{Si}(1)$ & $2.5015(8)$ & $\mathrm{N}(1)-\mathrm{Co}(1)-\mathrm{Si}(1)$ & $81.25(7)$ \\
$\mathrm{Co}(2)-\mathrm{N}(2)$ & $1.885(2)$ & $\mathrm{N}(3)-\mathrm{Co}(1)-\mathrm{Si}(1)$ & $157.40(6)$ \\
$\mathrm{Co}(2)-\mathrm{N}(4)$ & $2.010(2)$ & $\mathrm{P}(1)-\mathrm{Co}(1)-\mathrm{Si}(1)$ & $115.93(3)$ \\
$\mathrm{Co}(2)-\mathrm{O}(1)$ & $2.195(2)$ & $\mathrm{N}(2)-\mathrm{Co}(2)-\mathrm{N}(4)$ & $79.44(9)$ \\
$\mathrm{Co}(2)-\mathrm{P}(2)$ & $2.2393(7)$ & $\mathrm{N}(2)-\mathrm{Co}(2)-\mathrm{O}(1)$ & $96.50(8)$ \\
$\mathrm{Co}(2)-\mathrm{Si}(1)$ & $2.3323(8$ & $\mathrm{N}(4)-\mathrm{Co}(2)-\mathrm{O}(1)$ & $95.21(8)$ \\
$\mathrm{Co} 1 \cdots \mathrm{Co} 2$ & $3.8372(4)$ & $\mathrm{N}(2)-\mathrm{Co}(2)-\mathrm{P}(2)$ & $158.51(7)$ \\
$\mathrm{Co}(1)-\mathrm{H}(1)$ & $1.46(8)$ & $\mathrm{N}(4)-\mathrm{Co}(2)-\mathrm{P}(2)$ & $83.94(6)$ \\
& & $\mathrm{O}(1)-\mathrm{Co}(2)-\mathrm{P}(2)$ & $98.50(6)$ \\
& & $\mathrm{N}(2)-\mathrm{Co}(2)-\mathrm{Si}(1)$ & $84.40(7)$ \\
\hline
\end{tabular}




$\begin{array}{ll}\mathrm{N}(4)-\mathrm{Co}(2)-\mathrm{Si}(1) & 162.69(7) \\ \mathrm{O}(1)-\mathrm{Co}(2)-\mathrm{Si}(1) & 92.74(6) \\ \mathrm{P}(2)-\mathrm{Co}(2)-\mathrm{Si}(1) & 110.06(3)\end{array}$

Variable temperature UV-vis spectroscopy was performed in THF and it showed that when the temperature dropped from $293 \mathrm{~K}$ to $193 \mathrm{~K}$, the absorption bands at $\lambda_{\max }=303,379,418,486,582$ and $775 \mathrm{~nm}$ increased slightly in intensity (Figure 6.8).

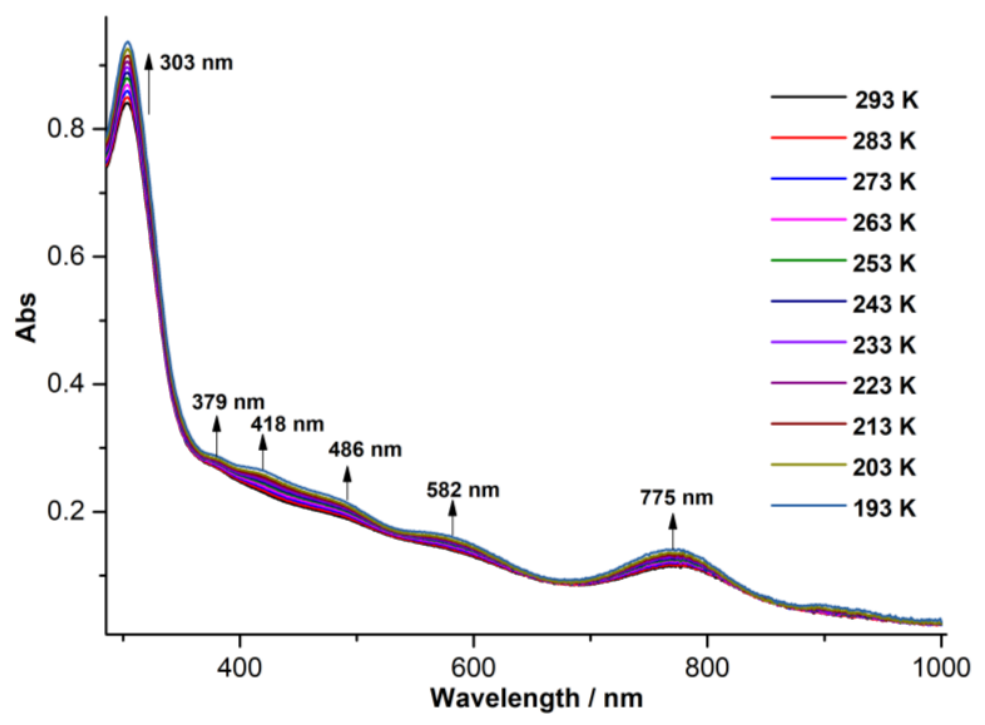

Figure 6.8: Variable temperature UV/vis spectra of complex 20 in THF solution in the temperature range from $293 \mathrm{~K}$ to $193 \mathrm{~K}$.

\subsection{Oxidation and $\sigma$-Complex Formation of Complex 6 with Methylphenylsilane}

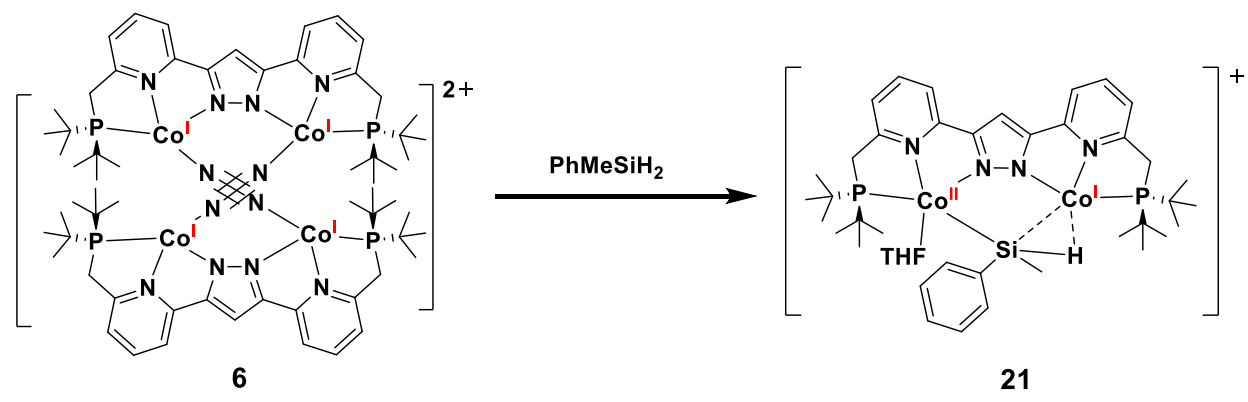

Scheme 6.6: Oxidation and $\sigma-$-complex formation of complex 6 with methylphenylsilane.

As depicted in Scheme 6.6, the treatment of a THF suspension of complex 6 with four equivalents of methylphenylsilane led to an immediate color change from purple to brown. After stirring overnight, 
the solution was filtered and block-shaped crystals of complex [ $\left.\mathrm{LCo}_{2}(\mu-\mathrm{SiHMePh})\right](\mathrm{OTf}) \mathbf{2 1}$ suitable for X-ray diffraction were obtained from a concentrated THF solution at room temperature. It formally represents a mixed-valent $\mathrm{Co}^{\mathrm{I} / \mathrm{II}}$ nonclassical $\sigma$-complex after oxidation reaction of one metal center and $\sigma$-bonding at the other one.

Complex 21 crystallized in the triclinic space group $P-1$ with two molecules in the unit cell. The molecular structure of complex 21 shows that $\operatorname{Co}(1)$ adopts a distorted square-pyramidal geometry (Figure 6.9). As Si-H bond length is $1.490 \AA$ suggesting no obvious activation, Co(2) interacts with Si1-H1 to form a 3c-2e $\sigma$-bond. The Co $\cdots$ Co separation of $3.96 \AA$ is longer than that in complex 20 and the Co-N-N-Co torsion angle is $1.5^{\circ}$. Selected bond lengths and angels are listed in Table 6.2. The Co1-Sil bond length is 2.303(2) $\AA$, which is in the range of typical Co-Si bonds. ${ }^{79}$ However, the Co2-Si1 bond length is 2.744(2) $\AA$, which is longer by $0.24 \AA$ than the longer Co-Si bond length in complex 20. The ${ }^{1} \mathrm{H}-\mathrm{NMR}$ spectrum in THF- $\mathrm{d}_{8}$ confirms that complex 21 is paramagnetic, and the proton resonances could not be assigned (Figure 6.10).

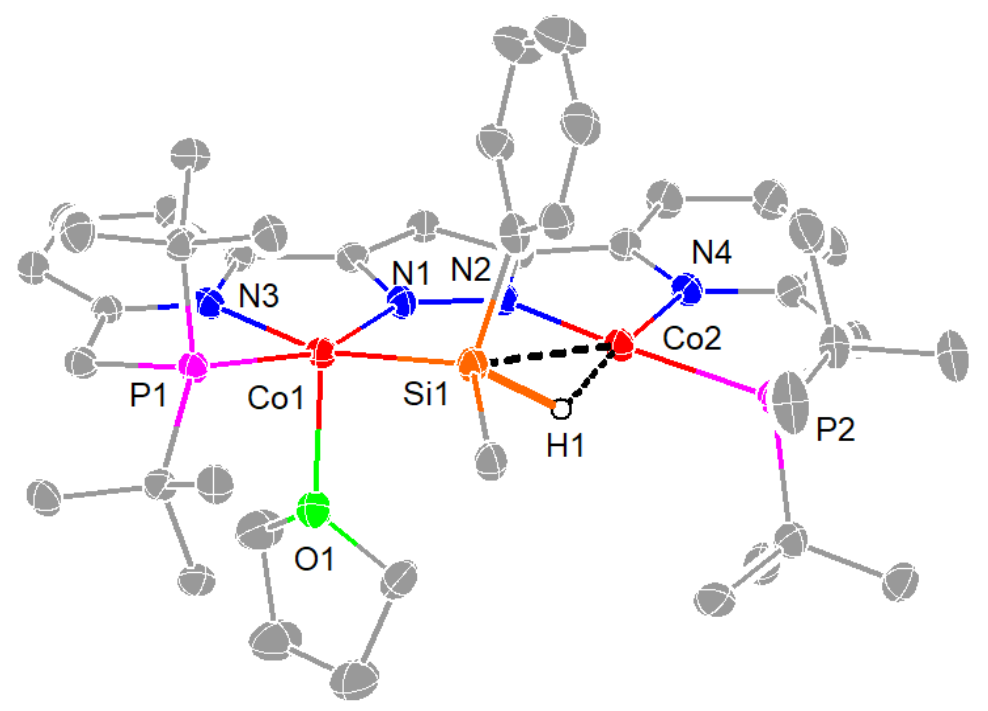

Figure 6.9: The molecular structure of the cation of complex 21. Thermal displacement ellipsoids shown at $30 \%$ probability; most hydrogen atoms, triflate anion and solvent molecules omitted for clarity.

Table 6.2: Selected bond lengths and angles for complex 21.

\begin{tabular}{llll}
\hline \multicolumn{2}{c}{ Bond lengths / $\AA$} & \multicolumn{2}{c}{ Angles $/{ }^{\circ}$} \\
\hline $\mathrm{Co}(1)-\mathrm{N}(1)$ & $1.889(6)$ & $\mathrm{N}(1)-\mathrm{Co}(1)-\mathrm{N}(3)$ & $79.9(2)$ \\
$\mathrm{Co}(1)-\mathrm{N}(3)$ & $2.002(6)$ & $\mathrm{N}(1)-\mathrm{Co}(1)-\mathrm{O}(1)$ & $91.8(2)$ \\
$\mathrm{Co}(1)-\mathrm{O}(1)$ & $2.214(5)$ & $\mathrm{N}(3)-\mathrm{Co}(1)-\mathrm{O}(1)$ & $90.8(2)$ \\
$\mathrm{Co}(1)-\mathrm{P}(1)$ & $2.249(2)$ & $\mathrm{N}(1)-\mathrm{Co}(1)-\mathrm{P}(1)$ & $160.79(18)$ \\
$\mathrm{Co}(1)-\mathrm{Si}(1)$ & $2.303(2)$ & $\mathrm{N}(3)-\mathrm{Co}(1)-\mathrm{P}(1)$ & $84.24(18)$ \\
$\mathrm{Co}(2)-\mathrm{H}(1)$ & $1.66(8)$ & $\mathrm{O}(1)-\mathrm{Co}(1)-\mathrm{P}(1)$ & $99.31(15)$ \\
$\mathrm{Co}(2)-\mathrm{N}(2)$ & $1.872(6)$ & $\mathrm{N}(1)-\mathrm{Co}(1)-\mathrm{Si}(1)$ & $87.11(18)$ \\
\hline
\end{tabular}




\begin{tabular}{llll}
\hline $\mathrm{Co}(2)-\mathrm{N}(4)$ & $1.924(6)$ & $\mathrm{N}(3)-\mathrm{Co}(1)-\mathrm{Si}(1)$ & $163.15(19)$ \\
$\mathrm{Co}(2)-\mathrm{P}(2)$ & $2.180(2)$ & $\mathrm{O}(1)-\mathrm{Co}(1)-\mathrm{Si}(1)$ & $100.40(14)$ \\
$\mathrm{Co}(2)-\mathrm{Si}(1)$ & $2.744(2)$ & $\mathrm{P}(1)-\mathrm{Co}(1)-\mathrm{Si}(1)$ & $106.04(8)$ \\
$\mathrm{Co} 1 \cdots \operatorname{Co} 2$ & $3.9557(14)$ & $\mathrm{H}(1)-\mathrm{Co}(2)-\mathrm{N}(2)$ & $100(2)$ \\
& & $\mathrm{H}(1)-\mathrm{Co}(2)-\mathrm{N}(4)$ & $172(2)$ \\
& $\mathrm{N}(2)-\mathrm{Co}(2)-\mathrm{N}(4)$ & $81.0(2)$ \\
& $\mathrm{H}(1)-\mathrm{Co}(2)-\mathrm{P}(2)$ & $93(2)$ \\
& $\mathrm{N}(2)-\mathrm{Co}(2)-\mathrm{P}(2)$ & $166.02(19)$ \\
& $\mathrm{N}(4)-\mathrm{Co}(2)-\mathrm{P}(2)$ & $85.89(18)$ \\
& $\mathrm{H}(1)-\mathrm{Co}(2)-\operatorname{Si}(1)$ & $28(2)$ \\
& $\mathrm{N}(2)-\mathrm{Co}(2)-\operatorname{Si}(1)$ & $79.65(19)$ \\
& $\mathrm{N}(4)-\mathrm{Co}(2)-\operatorname{Si}(1)$ & $157.85(17)$ \\
& $\mathrm{P}(2)-\mathrm{Co}(2)-\mathrm{Si}(1)$ & $114.13(8)$ \\
\hline
\end{tabular}

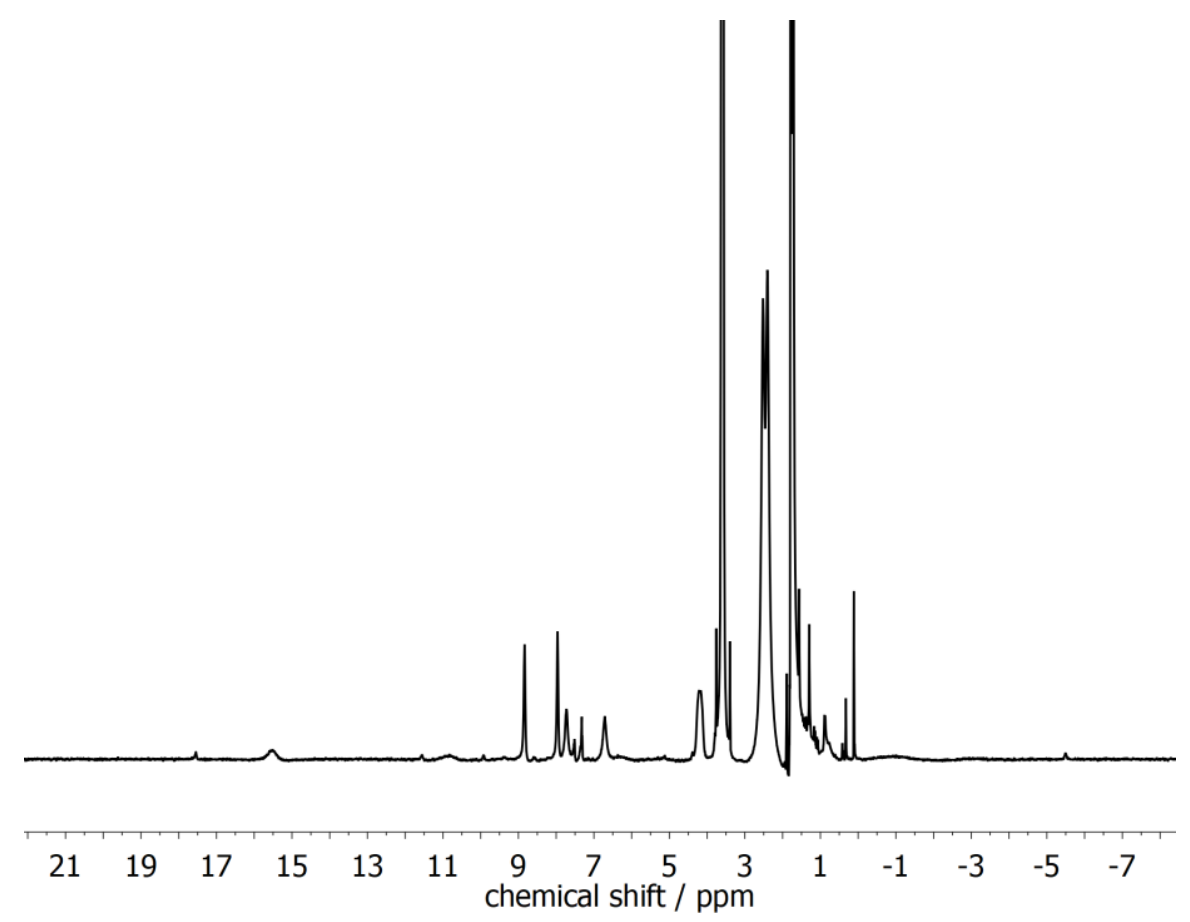

Figure 6.10: ${ }^{1} \mathrm{H}-\mathrm{NMR}$ spectrum of complex 21 in $\mathrm{THF}-\mathrm{d}_{8}$.

\subsection{Reaction of Complex 6 with Phenylsilane}

\subsubsection{The Synthesis of Tetracobalt Disilyl Complex 22}




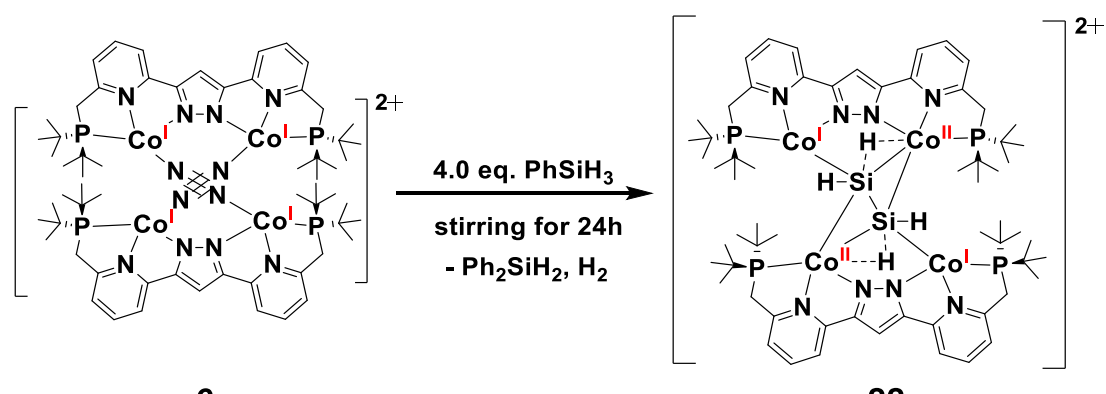

6

22

Scheme 6.7: Oxidation reaction of complex 6 with phenylsilane.

In pursuit of intriguing silane complexes, as shown in Scheme 6.7, phenylsilane (4 equiv.) was introduced into the THF suspension of complex $\mathbf{6}$, which resulted in a gradual color change from purple to brown after stirring for $24 \mathrm{~h}$. After filtration and quiescence for two days at room temperature, complex 22 was crystallized from the concentrated THF solution and identified by X-ray diffraction analysis. 22 was further characterized by ${ }^{1} \mathrm{H}-\mathrm{NMR}$ spectroscopy, magnetic susceptibility measurement, IR and UV-vis spectroscopy and elemental analysis. The ${ }^{1} \mathrm{H}-\mathrm{NMR}$ spectrum in THF- $\mathrm{d}_{8}$ indicates the paramagnetic nature of complex 22, and the proton resonances could not be assigned (Figure 6.11). As complex 22 is not dissolved well in THF, the ${ }^{1} \mathrm{H}-\mathrm{NMR}$ spectrum in $\mathrm{CD}_{3} \mathrm{CN}$ was measured quickly and shows similar chemical shifts as in THF-d 8 (Figure 6.12). However, the signals of the ${ }^{1} \mathrm{H}-\mathrm{NMR}$ spectrum in $\mathrm{CD}_{3} \mathrm{CN}$ got broad soon, suggesting complex 22 decomposed or reacted with $\mathrm{MeCN}$ to give rise to a new species.

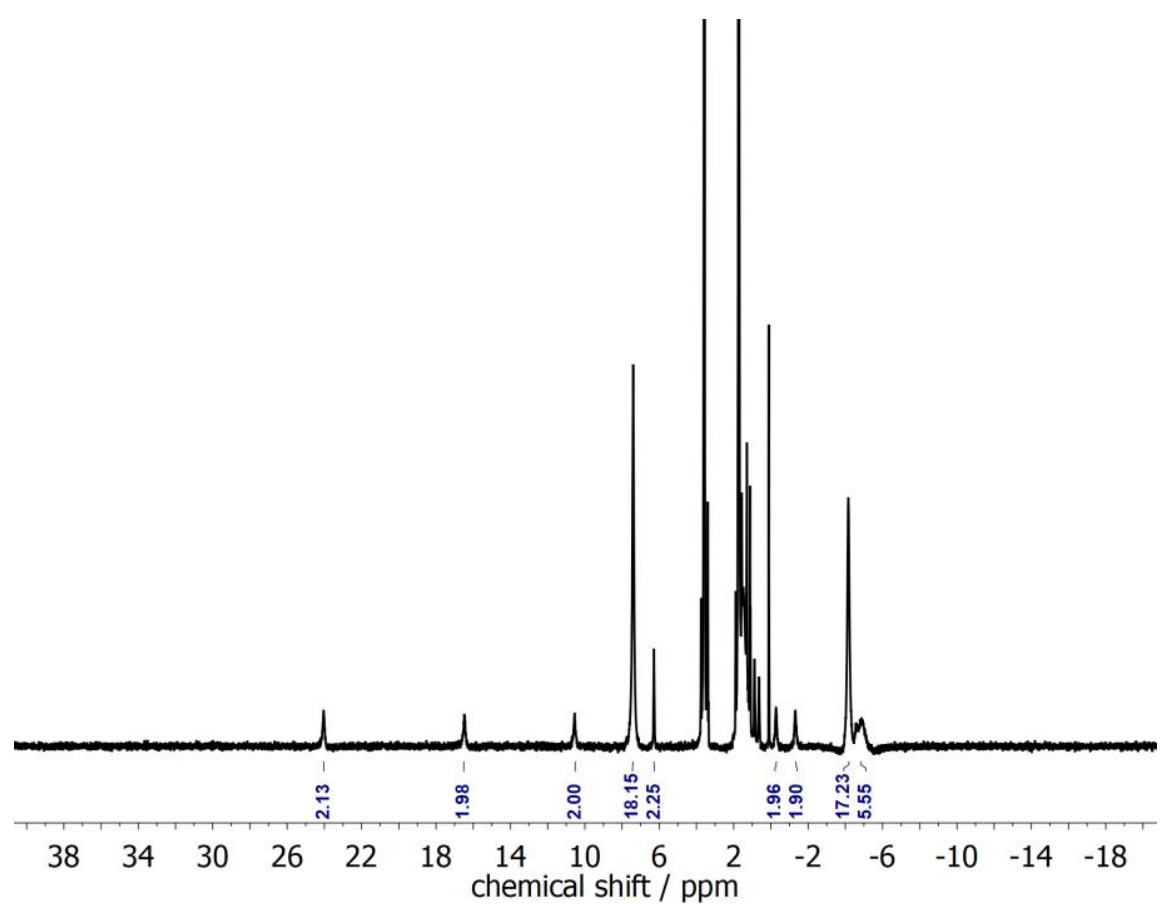

Figure 6.11: ${ }^{1} \mathrm{H}-\mathrm{NMR}$ spectrum of complex 22 in THF-d 8. 


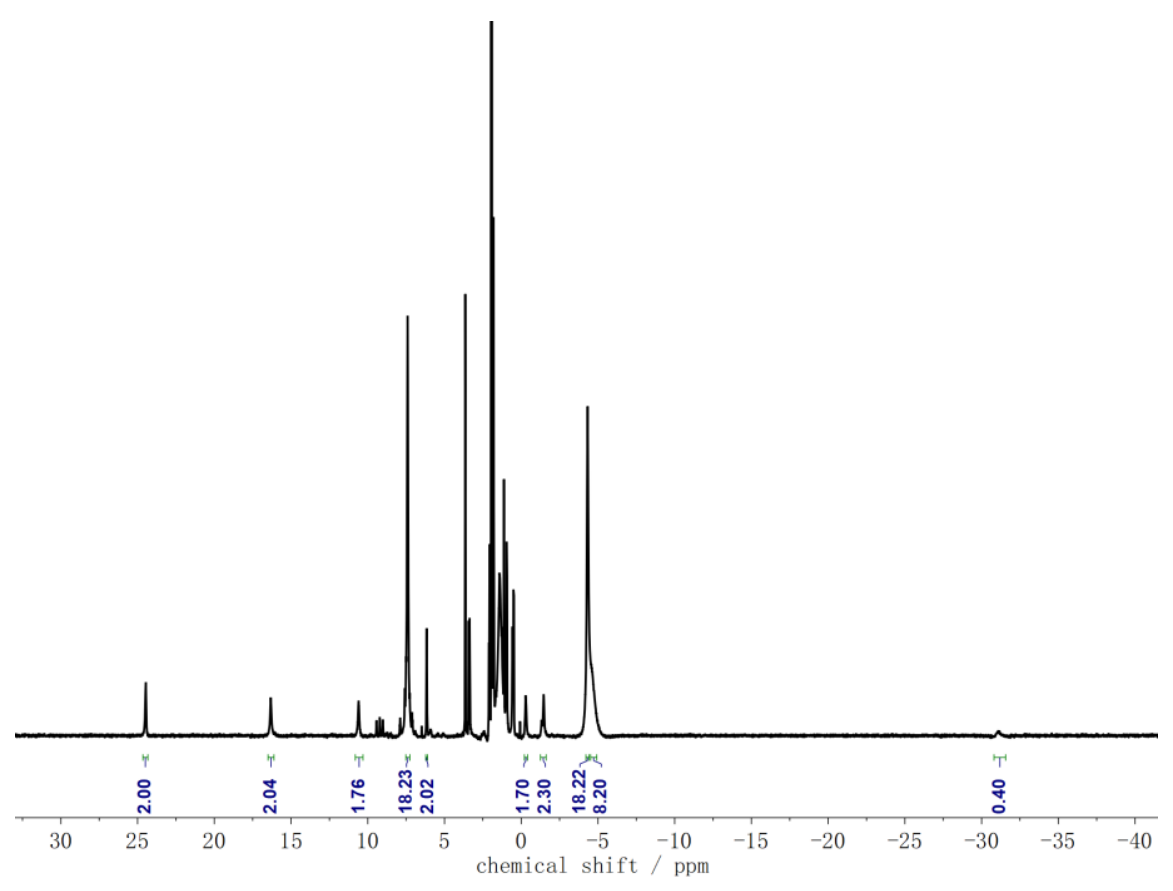

Figure 6.12: ${ }^{1} \mathrm{H}-\mathrm{NMR}$ spectrum of complex 22 in $\mathrm{CD}_{3} \mathrm{CN}$ measured quickly after dissolving the complex.

The variable temperature magnetic susceptibility measurement of microcrystalline 22 with a SQUID magnetometer (Figure 6.13) shows that the $\chi_{\mathrm{M}} T$ value is $1.09 \mathrm{~cm}^{3} \mathrm{~mol}^{-1} \mathrm{~K}$ in the range of $295-50 \mathrm{~K}$, in accordance with two unpaired electrons. This may be explained by the presence of two $\mathrm{S}=1 / 2$ cobalt(II) centers and two $S=0$ cobalt(I) centers. The data were fitted using the Heisenberg-Dirac-van-Vleck Hamiltonian $\hat{H}=-2 J \hat{S}_{1} \hat{S}_{2}+g \mu_{B} \vec{B}\left(\vec{S}_{1}+\vec{S}_{2}\right)$. The $\chi_{\mathrm{M}} T$ value increases gradually with decreasing temperature below $50 \mathrm{~K}$ and reaches a maximum value of $1.17 \mathrm{~cm}^{3} \mathrm{~mol}^{-1} \mathrm{~K}$ at $8 \mathrm{k}$, which may be attributed to ferromagnetic coupling of two cobalt(II) centers $\left(J=3.74 \mathrm{~cm}^{-1}\right)$, while the decrease of the curve from $8 \mathrm{~K}$ to $2 \mathrm{~K}$ likely indicates intermolecular antiferromagnetic interaction $(\theta=-0.86 \mathrm{~K})$ or zero-field splitting of the $\mathrm{S}_{\mathrm{T}}=1$ ground state. The best fit leads to $g=$ 2.39. Therefore, it suggests that complex 22 can be decribed as a mixed-valent $\mathrm{Co}^{\mathrm{I} / \mathrm{II}}$ complex. 


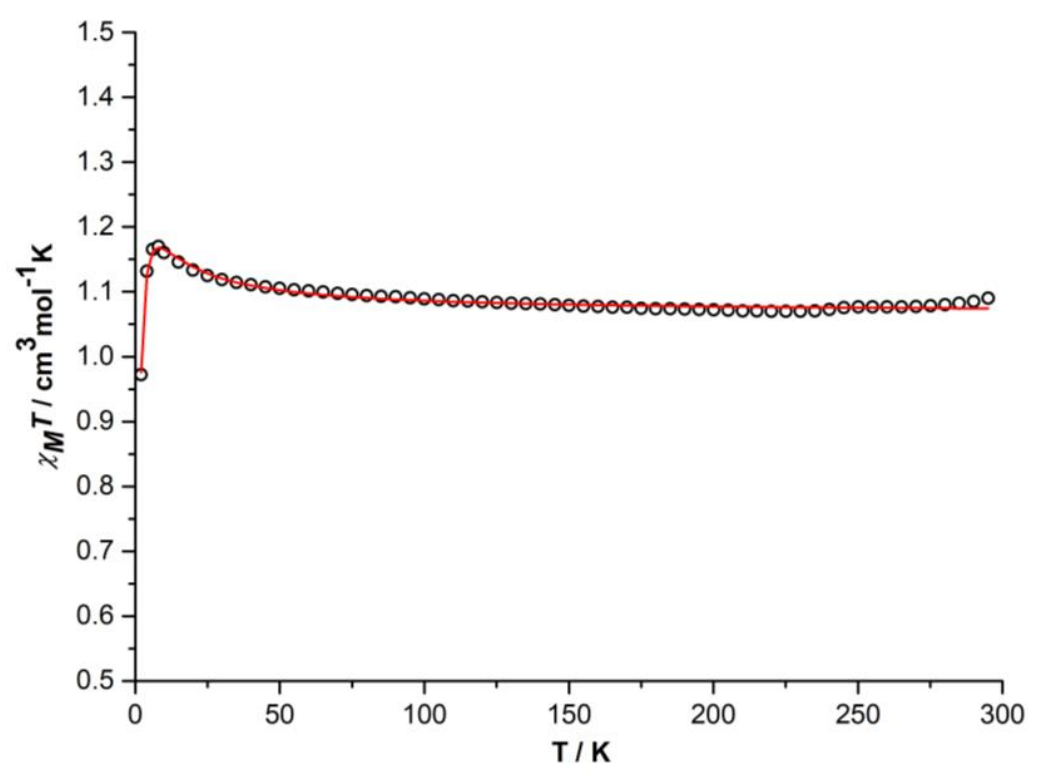

Figure 6.13: $\chi_{\mathrm{M}} T$ vs. $T$ plot in the temperature range of $2-295 \mathrm{~K}$ at $0.5 \mathrm{~T}$ for crystalline sample of complex 22. The red line corresponds to the best fits of the experimental magnetic results.

The molecular structure of complex 22 is represented in Figure 6.14 and it shows that a disilyl moiety, $\mathrm{SiH}_{\mathrm{x}}-\mathrm{SiH}_{\mathrm{x}}$ is bridging two [ $\mathrm{LCo}_{2}$ ] moieties to form a dimeric complex. As the magnetic measurement suggests that complex 22 is a mixed-valent $\mathrm{Co}^{\mathrm{I} / \mathrm{II}}$ complex, it further indicates that the disilyl moiety of complex $\mathbf{2 2}$ is dianionic according to charge balance. The Si-Si bond length is 2.49 $\AA$, which is out of the range for a typical $\mathrm{Si}-\mathrm{Si}$ double bond $(2.14-2.29 \AA),{ }^{80}$ but still shorter than the reported longest $\mathrm{Si}-\mathrm{Si}$ double bond $(2.62 \AA) .{ }^{81}$ Hence, the disilyl moiety, $\mathrm{SiH}_{\mathrm{x}}-\mathrm{SiH}_{\mathrm{x}}$ may be a cis- $\mathrm{SiH}_{2}-\mathrm{SiH}_{2}{ }^{2-}$ moiety or a $c i s-\mathrm{SiH}=\mathrm{SiH}^{2-}$ moiety. However, comparing to the $\mathrm{Si}-\mathrm{Si}$ single bond lengths in complex 23 (2.47 $\AA$, to be mentioned below), the Si-Si bond (2.49 $\AA$ ) in complex 22 is a bit longer and should be a single bond. So the disilyl moiety is quite possibly a cis- $\mathrm{SiH}_{2}-\mathrm{SiH}_{2}{ }^{2-}$ moiety and is bridging two [LCo 2$]$ moieties via a $\mu-\eta^{1}: \eta^{1}: \eta^{3}: \eta^{3}$ coordination mode to form a dimeric complex. Some of the hydrogen atom on silicon atoms could not easily be located from remaining electron density and have been fixed with one or more distance restraints (e.g. $\mathrm{d}(\mathrm{Si}-\mathrm{H})=1.4 \AA$ ) and a fixed isotropic temperature factor of $0.08 \AA^{2}$. Furthermore, complex 21 crystallized in the monoclinic space group $P 2{ }_{1} / \mathrm{n}$ with four molecules in the unit cell. And it shows that $\operatorname{Co}(1)$ and $\operatorname{Co}(3)$ are in a distorted square planar geometry, while $\mathrm{Co}(2)$ and $\mathrm{Co}(4)$ are coordinated with $\mathrm{Si}$ and $\mathrm{H}$ via a 3c-2e $\sigma$-interaction. Selected bond lengths and angels are listed in Table 6.3. Co-Si bond lengths vary in the range of 2.33-2.40 $\AA$, which are consist with those in the reported papers $(2.11-2.40 \AA) .{ }^{72}$ The Co $\cdots$ Co separations within the $\left[\mathrm{LCo}_{2}\right]$ subunits are $3.69 \AA$ and $3.67 \AA$, which are much shorter in contrast to those in complexes 20 and 21. The Co-N-N-Co torsion angle is $6.9^{\circ}$ and $9.6^{\circ}$. So complex 22 is a mixed-valent $\mathrm{Co}^{\mathrm{I} / \mathrm{II}}$ disilyl complex $\left[\mathrm{L}_{2} \mathrm{Co}_{4}\left(\mu-\mathrm{SiH}_{2} \mathrm{SiH}_{2}\right)\right](\mathrm{OTf})_{2}$. 


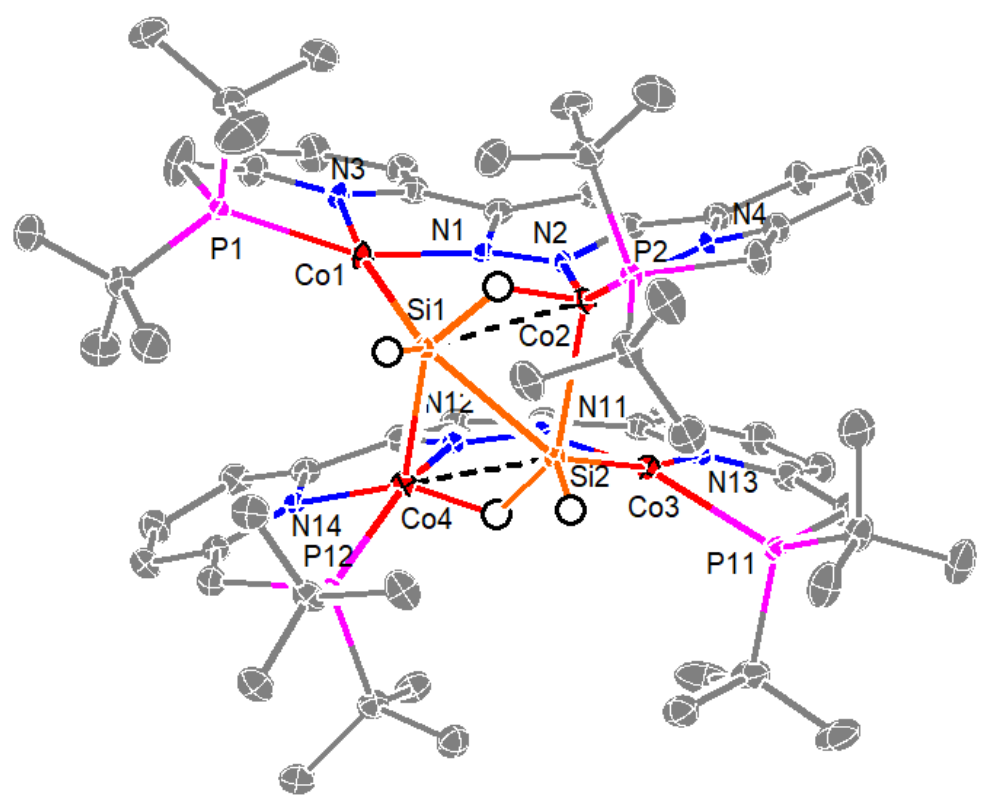

Figure 6.14: The molecular structure of the cation of complex 22. Thermal displacement ellipsoids shown at $30 \%$ probability; most hydrogen atoms, triflate anions and solvent molecules omitted for clarity.

Table 6.3: Selected bond lengths and angles for complex 22.

\begin{tabular}{llll}
\hline \multicolumn{1}{c}{ Bond lengths / $\mathrm{A}$} & \multicolumn{1}{c}{ Angles / } \\
\hline $\mathrm{Co}(1)-\mathrm{N}(1)$ & $1.8745(17)$ & $\mathrm{N}(1)-\mathrm{Co}(1)-\mathrm{N}(3)$ & $78.98(7)$ \\
$\mathrm{Co}(1)-\mathrm{N}(3)$ & $2.0094(18)$ & $\mathrm{N}(1)-\mathrm{Co}(1)-\mathrm{P}(1)$ & $158.01(5)$ \\
$\mathrm{Co}(1)-\mathrm{P}(1)$ & $2.2153(6)$ & $\mathrm{N}(3)-\mathrm{Co}(1)-\mathrm{P}(1)$ & $84.28(5)$ \\
$\mathrm{Co}(1)-\mathrm{Si}(1)$ & $2.3370(6)$ & $\mathrm{N}(1)-\mathrm{Co}(1)-\mathrm{Si}(1)$ & $85.86(5)$ \\
$\mathrm{Co}(2)-\mathrm{N}(2)$ & $1.8631(17)$ & $\mathrm{N}(3)-\mathrm{Co}(1)-\mathrm{Si}(1)$ & $162.65(5)$ \\
$\mathrm{Co}(2)-\mathrm{N}(4)$ & $2.0096(17)$ & $\mathrm{P}(1)-\mathrm{Co}(1)-\mathrm{Si}(1)$ & $112.43(2)$ \\
$\mathrm{Co}(2)-\mathrm{P}(2)$ & $2.2026(6)$ & $\mathrm{N}(2)-\mathrm{Co}(2)-\mathrm{N}(4)$ & $78.68(7)$ \\
$\mathrm{Co}(2)-\mathrm{Si}(2)$ & $2.3349(6)$ & $\mathrm{N}(2)-\mathrm{Co}(2)-\mathrm{P}(2)$ & $151.86(6)$ \\
$\mathrm{Co}(2)-\mathrm{Si}(1)$ & $2.4020(6)$ & $\mathrm{N}(4)-\mathrm{Co}(2)-\mathrm{P}(2)$ & $83.48(5)$ \\
$\mathrm{Co}(3)-\mathrm{N}(11)$ & $1.8779(17)$ & $\mathrm{N}(2)-\mathrm{Co}(2)-\mathrm{Si}(2)$ & $98.46(5)$ \\
$\mathrm{Co}(3)-\mathrm{N}(13)$ & $2.0167(17)$ & $\mathrm{N}(4)-\mathrm{Co}(2)-\mathrm{Si}(2)$ & $122.14(5)$ \\
$\mathrm{Co}(3)-\mathrm{P}(11)$ & $2.2081(6)$ & $\mathrm{P}(2)-\mathrm{Co}(2)-\mathrm{Si}(2)$ & $109.47(2)$ \\
$\mathrm{Co}(3)-\mathrm{Si}(2)$ & $2.3291(6)$ & $\mathrm{N}(2)-\mathrm{Co}(2)-\mathrm{Si}(1)$ & $85.64(5)$ \\
$\mathrm{Co}(4)-\mathrm{N}(12)$ & $1.8682(17)$ & $\mathrm{N}(4)-\mathrm{Co}(2)-\mathrm{Si}(1)$ & $163.94(5)$ \\
$\mathrm{Co}(4)-\mathrm{N}(14)$ & $2.0123(17)$ & $\mathrm{P}(2)-\mathrm{Co}(2)-\mathrm{Si}(1)$ & $109.61(2)$ \\
$\mathrm{Co}(4)-\mathrm{P}(12)$ & $2.2150(6)$ & $\mathrm{Si}(2)-\mathrm{Co}(2)-\mathrm{Si}(1)$ & $63.38(2)$ \\
$\mathrm{Co}(4)-\mathrm{Si}(1)$ & $2.3371(6)$ & $\mathrm{N}(11)-\mathrm{Co}(3)-\mathrm{N}(13)$ & $79.13(7)$ \\
$\mathrm{Co}(4)-\mathrm{Si}(2)$ & $2.3943(6)$ & $\mathrm{N}(11)-\mathrm{Co}(3)-\mathrm{P}(11)$ & $155.53(5)$ \\
& & $\mathrm{N}(13)-\mathrm{Co}(3)-\mathrm{P}(11)$ & $83.90(5)$ \\
& & $\mathrm{N}(11)-\mathrm{Co}(3)-\mathrm{Si}(2)$ & $86.28(5)$ \\
& & $\mathrm{N}(13)-\mathrm{Co}(3)-\mathrm{Si}(2)$ & $164.24(5)$ \\
\hline
\end{tabular}




\begin{tabular}{ll}
\hline $\mathrm{P}(11)-\mathrm{Co}(3)-\operatorname{Si}(2)$ & $111.80(2)$ \\
$\mathrm{N}(12)-\mathrm{Co}(4)-\mathrm{N}(14)$ & $78.84(7)$ \\
$\mathrm{N}(12)-\mathrm{Co}(4)-\mathrm{P}(12)$ & $152.09(5)$ \\
$\mathrm{N}(14)-\mathrm{Co}(4)-\mathrm{P}(12)$ & $83.11(5)$ \\
$\mathrm{N}(12)-\mathrm{Co}(4)-\operatorname{Si}(1)$ & $96.92(5)$ \\
$\mathrm{N}(14)-\mathrm{Co}(4)-\operatorname{Si}(1)$ & $121.60(5)$ \\
$\mathrm{P}(12)-\mathrm{Co}(4)-\operatorname{Si}(1)$ & $110.69(2)$ \\
$\mathrm{N}(12)-\mathrm{Co}(4)-\operatorname{Si}(2)$ & $85.77(5)$ \\
$\mathrm{N}(14)-\mathrm{Co}(4)-\operatorname{Si}(2)$ & $164.21(5)$ \\
$\mathrm{P}(12)-\mathrm{Co}(4)-\operatorname{Si}(2)$ & $109.77(2)$ \\
$\mathrm{Si}(1)-\mathrm{Co}(4)-\operatorname{Si}(2)$ & $63.466(19)$ \\
\hline
\end{tabular}

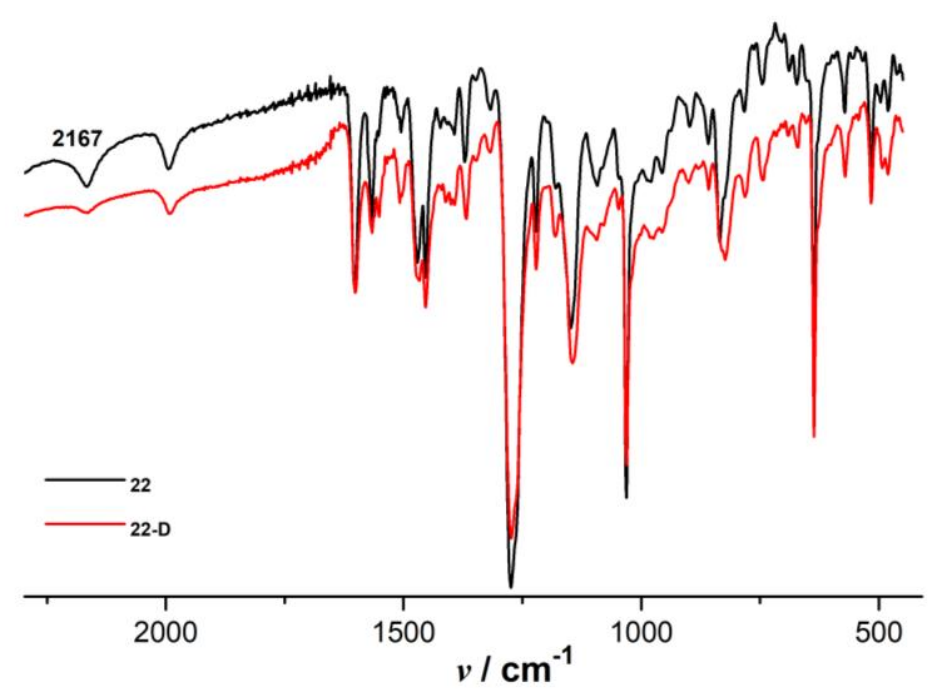

Figure 6.15: IR spectra of complexes 22 and $\left[\mathrm{L}_{2} \mathrm{Co}_{4}\left(\mu-\mathrm{SiD}_{2} \mathrm{SiD}_{2}\right)\right](\mathrm{OTf})_{2}, \mathbf{2 2}-\mathrm{D}$ on $\mathrm{KBr}$ pallets in solid state at room temperature.

IR spectra of complex 22 and $\left[\mathrm{L}_{2} \mathrm{Co}_{4}\left(\mu-\mathrm{SiD}_{2} \mathrm{SiD}_{2}\right)\right](\mathrm{OTf})_{2}, 22-\mathrm{D}$ which was synthesized by the reaction of complex 6 and $\mathrm{PhSiD}_{3}$ display that the peak at $2167 \mathrm{~cm}^{-1}$ is in the region expected for $\mathrm{Si}-\mathrm{H}$ (Figure 6.15). In addition, variable temperature UV-vis spectra shows there are absorption peaks at 307, 420, 487, 598 and $759 \mathrm{~nm}$ (Figure 6.16). DFT calculations that may help to unravel the electronic structure of complex 22 are still in progress. 


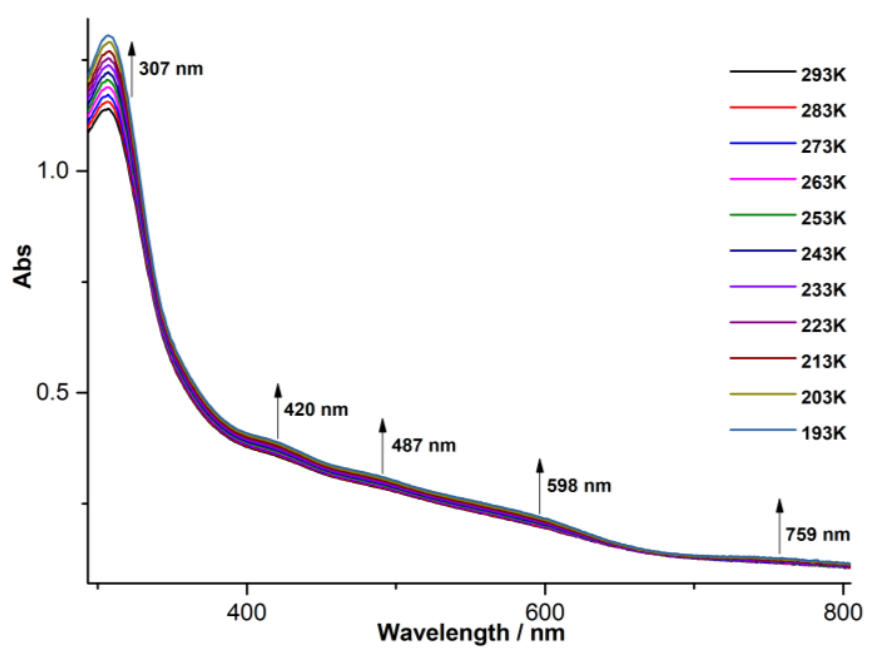

Figure 6.16: Variable temperature UV/vis spectra of complex 22 in THF solution in the temperature range from $293 \mathrm{~K}$ to $193 \mathrm{~K}$.

Distinct from the reactions of diphenylsilane or methylphenylsilane with complex $\mathbf{6}$, the reaction of phenylsilane and complex 6 led to the activation of the $\mathrm{Si}-\mathrm{C}$ bonds and redistribution at silicon. Obviously, the missing phenyl groups from complex 22 reacted with excess phenylsilane to form diphenylsilane as byproduct. Formation of diphenylsilane was confirmed by GC-MS measurement and ${ }^{2} \mathrm{H}$ and ${ }^{1} \mathrm{H}-{ }^{29} \mathrm{Si}-\mathrm{HSQC}$ NMR spectra (Figures 6.17 and 6.18). Diphenylsilane- $\mathrm{d}_{2}\left(\mathrm{Ph}_{2} \mathrm{SiD}_{2}\right)$ from the reaction of complex 6 and $\mathrm{PhSiD}_{3}$ (synthesized by the reaction of $\mathrm{LiAlD}_{4}$ and $\mathrm{PhSiCl}_{3}$ ) was identified by ${ }^{2} \mathrm{H}-\mathrm{NMR}$ as shown in Figures 6.15. Additionally, one resonance associated with $\mathrm{D}_{2}$ was observed at $\delta=4.54 \mathrm{ppm}$ at $0 \mathrm{~h}, 2 \mathrm{~h}$, and $4 \mathrm{~h}$, which shows that the reaction of phenylsilane and complex $\mathbf{6}$ to form complex 22 is a comparatively slow process.

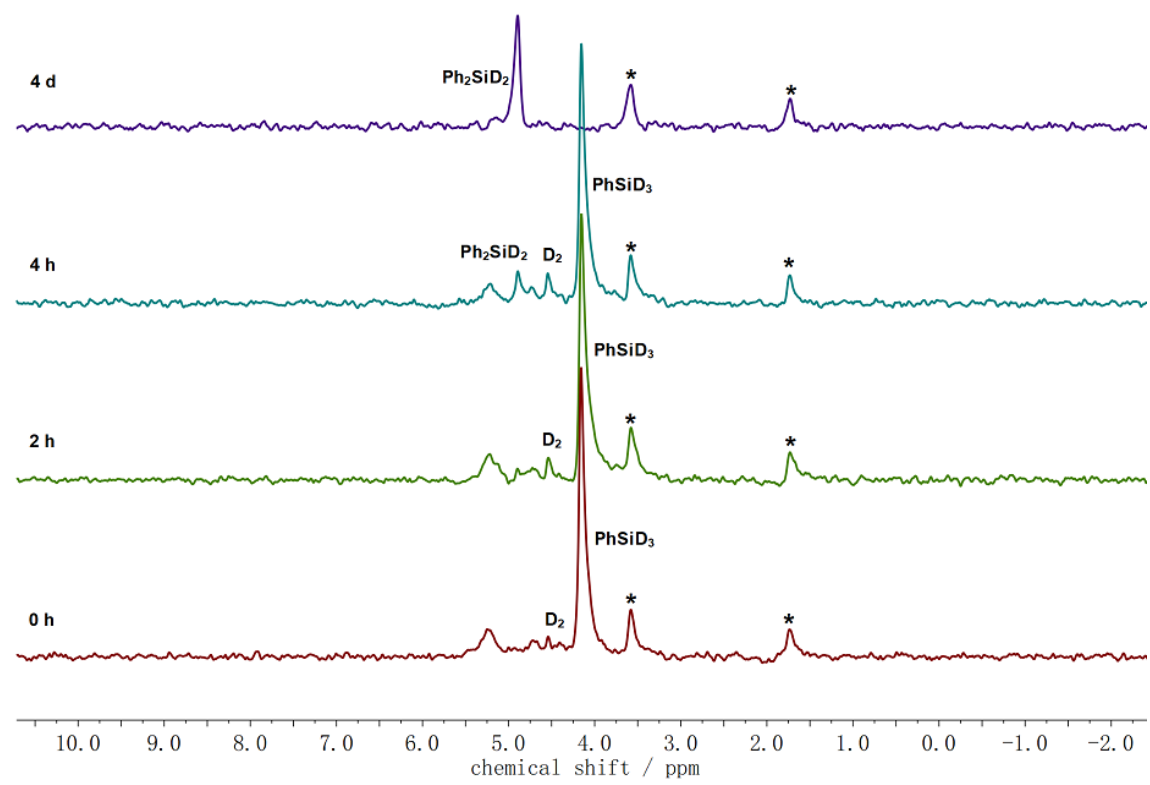

Figure 6.17: ${ }^{2} \mathrm{H}-\mathrm{NMR}$ spectra of the reactions of complex 6 with $\mathrm{PhSiD}_{3}$ (4 eq.) in THF. Solvent 
signals are marked with an asterisk (*).

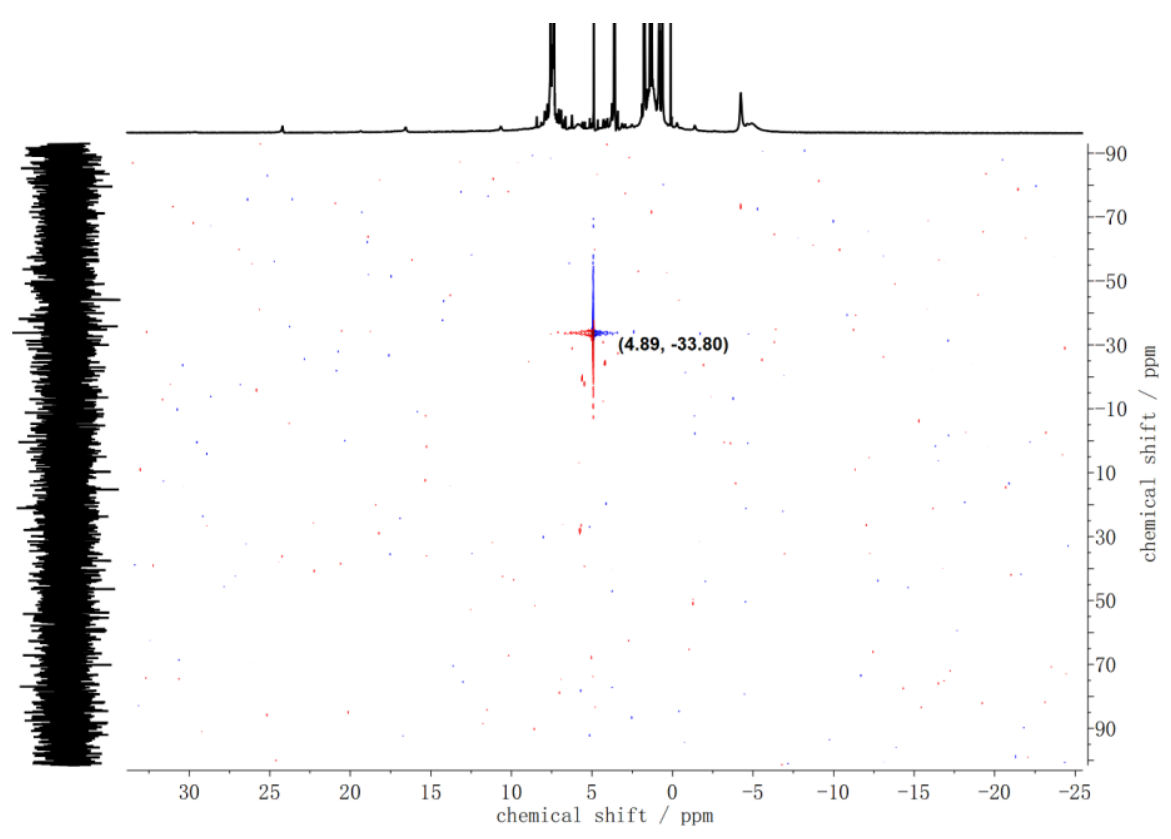

Figure 6.18: ${ }^{1} \mathrm{H}_{-}^{29} \mathrm{Si}-\mathrm{HSQC}$ spectrum of the reaction of complex 6 with $\mathrm{PhSiH}_{3}$ in $\mathrm{THF}-\mathrm{d}_{8}$.

A plausible mechanism is presented in Scheme 6.8. It is assumed that the addition of phenylsilane into the suspension of complex $\mathbf{6}$ in THF initially generates an intermediate, A by oxidative addition of one metal center or generates an intermediate, $\mathbf{B}$ by $\sigma$-bonding. After extrusion of $\mathrm{H}_{2}$ gas, one of the mental centers are oxidized and the reaction forms an intermediate, $\mathbf{C}$. Followed by subsequent redistribution at the silicon of bridged silane, the reaction gives rise to an intermediate $\mathbf{D}$ and diphenylsilane. Then $\mathbf{D}$ eventually forms the unusual mixed-valent $\mathrm{Co}^{\mathrm{I} / \mathrm{II}}$ disilyl complex $\left[\mathrm{L}_{2} \mathrm{Co}_{4}\left(\mu-\mathrm{SiH}_{2} \mathrm{SiH}_{2}\right)\right](\mathrm{OTf})_{2} 22$ by dimerization with extrusion of $\mathrm{H}_{2}$ gas.

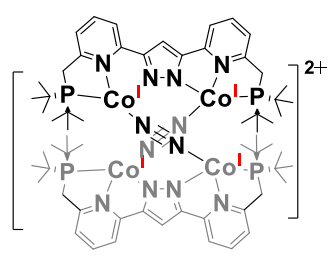

6

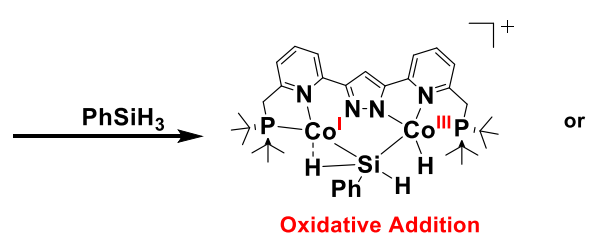

A

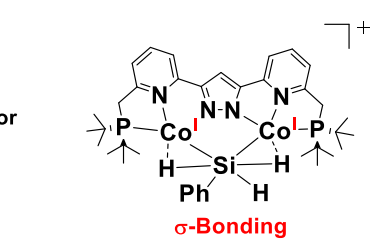

B

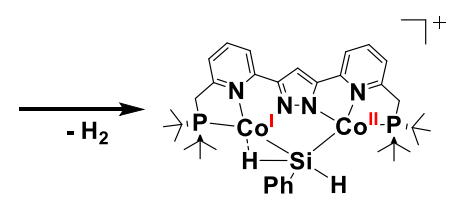

C

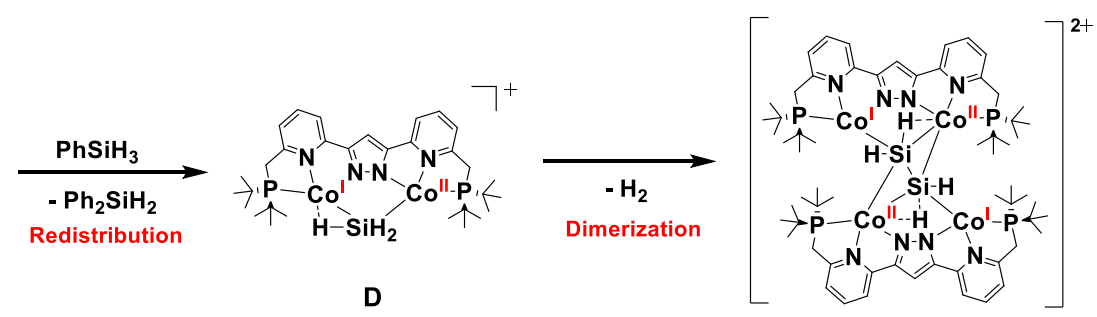

22

Scheme 6.8: Proposed mechanism for the formation of complex 22. 


\subsubsection{The Synthesis of Tetracobalt Tetrasilyl Complex 23}

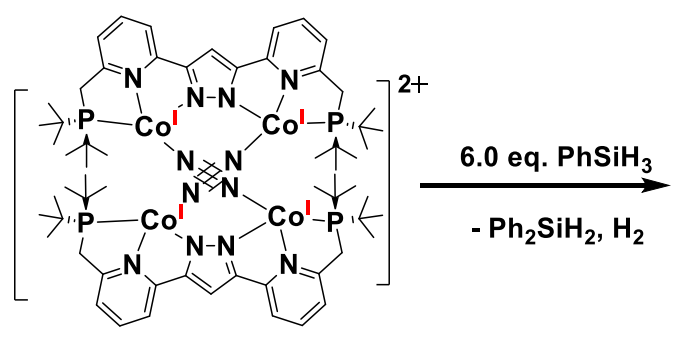

6

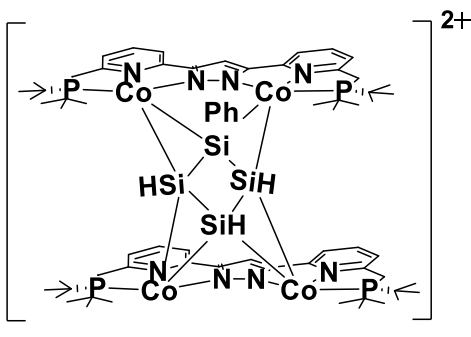

23

Scheme 6.9: The synthesis of tetrasilyl complex 23 .

As depicted in Scheme 6.9, the treatment of complex 6 with six equivalents of phenylsilane in THF without stirring gave rise to a dark block-shaped product, complex $\mathbf{2 3}$ after 4d. Complex $\mathbf{2 3}$ was suitable for X-ray diffraction and also further characterized by elemental analysis, IR and UV-vis spectroscopy.

Complex 23 crystallized in the orthorhombic space group $P b c n$ with four molecules in the unit cell. The molecular structure of complex 23 shows that a tetrasilyl cluster, $\mu-\mathrm{PhSi}_{4} \mathrm{H}_{3}$, with an almost planar $\left\{\mathrm{Si}_{4}\right\}$ arrangement is bridging two $\left[\mathrm{LCo}_{2}\right]$ fragements via a $\mu_{4}-\eta^{2}: \eta^{2}: \eta^{2}: \eta^{2}$ coordination mode to form a dimeric complex $\left[\mathrm{L}_{2} \mathrm{Co}_{4}\left(\mu-\mathrm{PhSi}_{4} \mathrm{H}_{3}\right](\mathrm{OTf})_{2}\right.$ (Figure 6.19). The phenyl moiety and the hydrogen atom on Si1' in the tetrasilyl cluster are disordered. Selected bond lengths and angels are listed in Table 6.4. The Si-Si bond lengths are around 2.47 $\AA$, which is in accordance with other Si-Si single bond lengths. ${ }^{64}$ All the Co ions adopt a distorted square-pyramidal geometry. The Co $\cdots$ Co separations within the [ $\left.\mathrm{LCO}_{2}\right]$ subunits are $3.737 \AA$, which are much shorter than those in complexes 20 and 21, but longer than those in complex 22. The Co-N-N-Co torsion angles are $0.2^{\circ}$. The Co-Si bond lengths are in the range of 2.29-2.35 $\AA$, which are consistent with the typical Co-Si bond lengths. ${ }^{72}$ Therefore, the tetrasilyl cluster is possibly a $\left(\mu-\mathrm{PhSi}_{4} \mathrm{H}_{3}\right)^{2-}$ ion and complex 23 is a dimeric $\mathrm{Co}^{\mathrm{II}}$ complex. The variable temperature magnetic susceptibility measurement of microcrystalline $\mathbf{2 3}$ with a SQUID magnetometer (Figure 6.20) shows that complex 23 in solid state is diamagnetic. The ${ }^{1} \mathrm{H}-\mathrm{NMR}$ spectrum in $\mathrm{CD}_{3} \mathrm{CN}$ confirms that complex 23 is a diamagnetic species but as $2 \mathrm{D}$ NMR spectra are missing, the proton resonances could not be assigned (Figure 6.21). The diamagnetic character of complex $\mathbf{2 3}$ may be contributed to very strong antiferromagnetic coupling between the cobalt(II) ions mediated by the central $\mu-\mathrm{PhSi}_{4} \mathrm{H}_{3}$ cluster. 

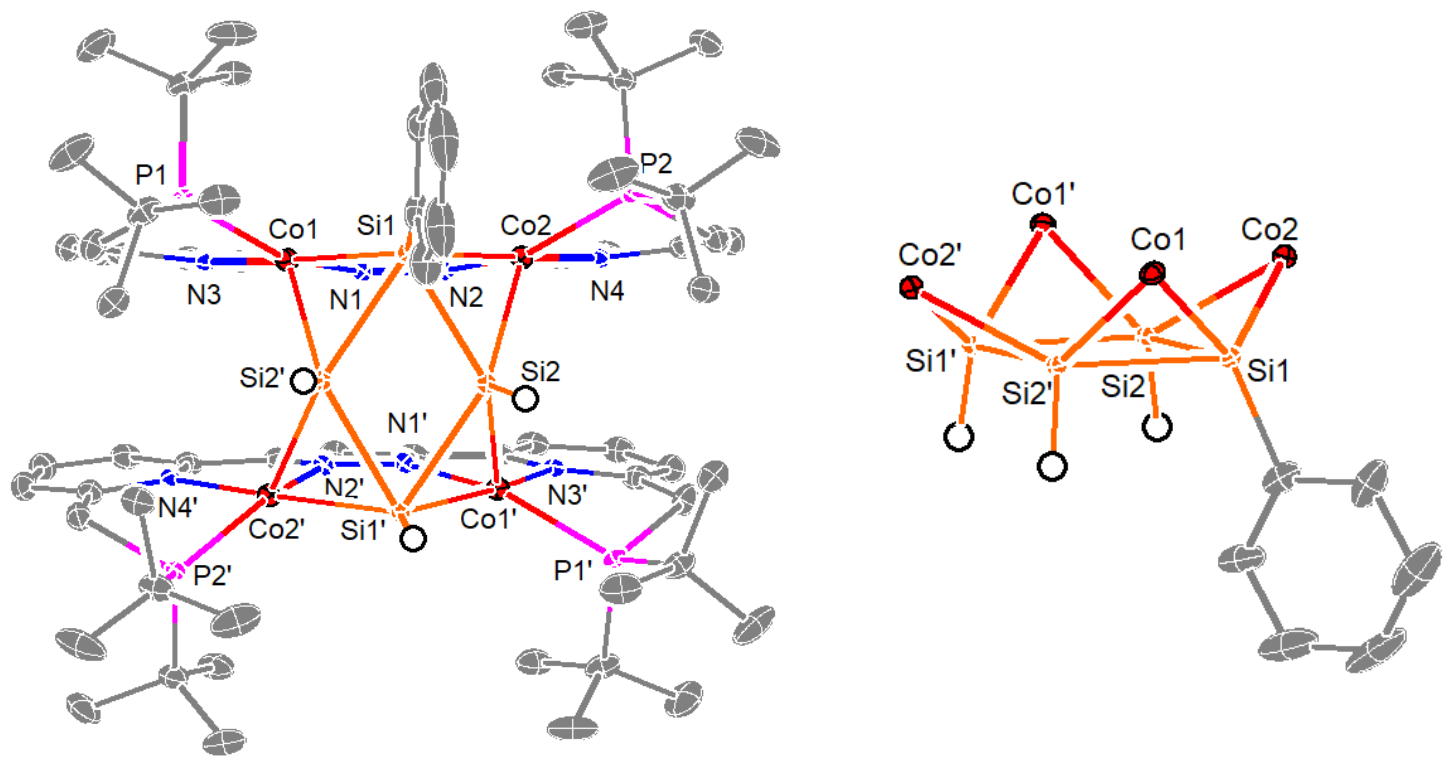

Figure 6.19: The molecular structures of the cation of complex 23 (left) and the $\left\{\mathrm{Co}_{4}\left(\mu-\mathrm{PhSi}_{4} \mathrm{H}_{3}\right\}\right.$ core (right). Thermal displacement ellipsoids shown at $30 \%$ probability; most hydrogen atoms, triflate anions and solvent molecules omitted for clarity.

Table 6.4: Selected bond lengths and angles for complex 23 .

\begin{tabular}{|c|c|c|c|}
\hline \multicolumn{2}{|c|}{ Bond lengths / $\AA$} & \multicolumn{2}{|l|}{ Angles $/^{\circ}$} \\
\hline $\mathrm{Co}(1)-\mathrm{N}(1)$ & $1.877(2)$ & $\mathrm{N}(1)-\mathrm{Co}(1)-\mathrm{N}(3)$ & $78.98(8)$ \\
\hline $\mathrm{Co}(1)-\mathrm{N}(3)$ & $1.9965(19)$ & $\mathrm{N}(1)-\mathrm{Co}(1)-\mathrm{P}(1)$ & $152.39(6)$ \\
\hline $\mathrm{Co}(1)-\mathrm{P}(1)$ & $2.2012(7)$ & $\mathrm{N}(3)-\mathrm{Co}(1)-\mathrm{P}(1)$ & $82.86(6)$ \\
\hline $\operatorname{Co}(1)-\operatorname{Si}(1)$ & $2.2921(7)$ & $\mathrm{N}(1)-\mathrm{Co}(1)-\mathrm{Si}(1)$ & $84.84(6)$ \\
\hline $\mathrm{Co}(1)-\mathrm{Si}(2) \# 1$ & $2.3537(7)$ & $\mathrm{N}(3)-\mathrm{Co}(1)-\mathrm{Si}(1)$ & $163.41(6)$ \\
\hline $\mathrm{Co}(2)-\mathrm{N}(2)$ & $1.8599(19)$ & $\mathrm{P}(1)-\mathrm{Co}(1)-\mathrm{Si}(1)$ & $110.77(3)$ \\
\hline $\mathrm{Co}(2)-\mathrm{N}(4)$ & $1.986(2)$ & $\mathrm{N}(1)-\mathrm{Co}(1)-\mathrm{Si}(2) \# 1$ & $100.66(6)$ \\
\hline $\mathrm{Co}(2)-\mathrm{P}(2)$ & $2.2304(7)$ & $\mathrm{N}(3)-\mathrm{Co}(1)-\mathrm{Si}(2) \# 1$ & $122.31(6)$ \\
\hline $\mathrm{Co}(2)-\operatorname{Si}(1)$ & $2.2863(7)$ & $\mathrm{P}(1)-\mathrm{Co}(1)-\mathrm{Si}(2) \# 1$ & $106.61(3)$ \\
\hline $\mathrm{Co}(2)-\operatorname{Si}(2)$ & $2.3342(7)$ & $\mathrm{Si}(1)-\mathrm{Co}(1)-\mathrm{Si}(2) \# 1$ & $64.20(2)$ \\
\hline $\operatorname{Si}(1)-\operatorname{Si}(2) \# 1$ & $2.4694(9)$ & $\mathrm{N}(2)-\mathrm{Co}(2)-\mathrm{N}(4)$ & $79.78(8)$ \\
\hline \multirow[t]{9}{*}{$\operatorname{Si}(1)-\operatorname{Si}(2)$} & $2.4724(9)$ & $\mathrm{N}(2)-\mathrm{Co}(2)-\mathrm{P}(2)$ & $152.59(6)$ \\
\hline & & $\mathrm{N}(4)-\mathrm{Co}(2)-\mathrm{P}(2)$ & $82.36(6)$ \\
\hline & & $\mathrm{N}(2)-\mathrm{Co}(2)-\operatorname{Si}(1)$ & $85.55(6)$ \\
\hline & & $\mathrm{N}(4)-\mathrm{Co}(2)-\mathrm{Si}(1)$ & $165.02(6)$ \\
\hline & & $\mathrm{P}(2)-\mathrm{Co}(2)-\mathrm{Si}(1)$ & $110.13(3)$ \\
\hline & & $\mathrm{N}(2)-\mathrm{Co}(2)-\mathrm{Si}(2)$ & $94.02(6)$ \\
\hline & & $\mathrm{N}(4)-\mathrm{Co}(2)-\mathrm{Si}(2)$ & $119.09(6)$ \\
\hline & & $\mathrm{P}(2)-\mathrm{Co}(2)-\mathrm{Si}(2)$ & $112.86(3)$ \\
\hline & & $\operatorname{Si}(1)-\operatorname{Co}(2)-\operatorname{Si}(2)$ & $64.69(2)$ \\
\hline
\end{tabular}




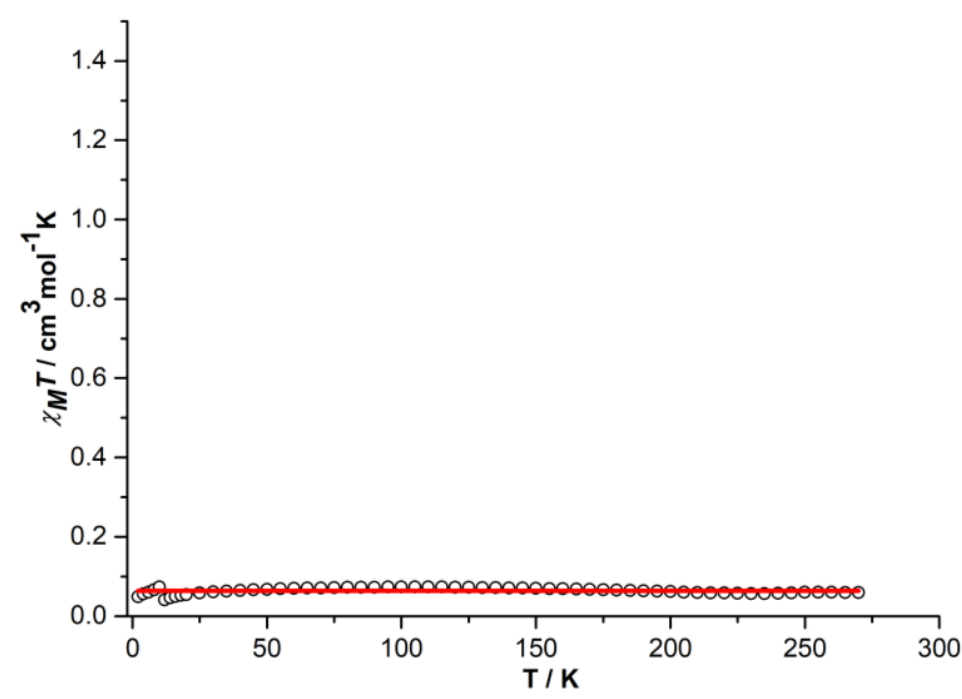

Figure 6.20: $\chi_{\mathrm{M}} T$ vs. $T$ plot in the temperature range of $2-270 \mathrm{~K}$ at $0.5 \mathrm{~T}$ for crystalline sample of complex 23. The red line corresponds to the best fits of the experimental magnetic results.

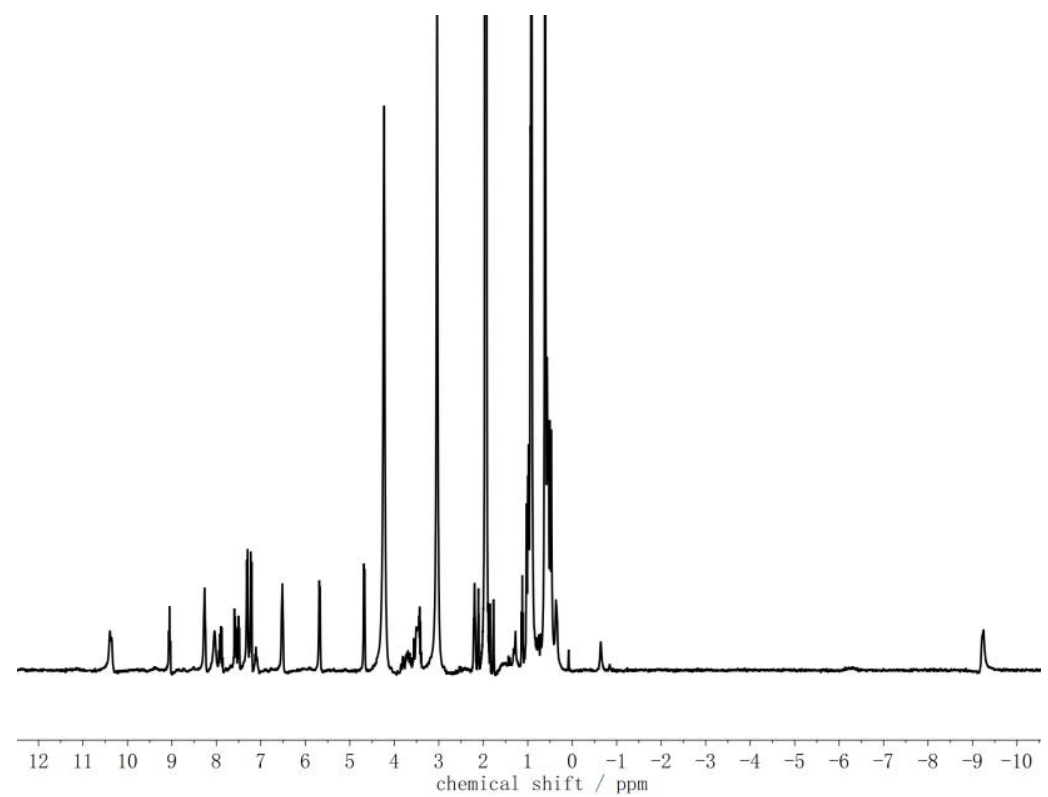

Figure 6.21: ${ }^{1} \mathrm{H}-\mathrm{NMR}$ spectrum of complex 23 in $\mathrm{CD}_{3} \mathrm{CN}$.

IR spectra of complex 23 and $\left[\mathrm{L}_{2} \mathrm{Co}_{4}\left(\mu-\mathrm{PhSi}_{4} \mathrm{D}_{3}\right](\mathrm{OTf})_{2}, 23-\mathrm{D}\right.$ which was synthesized by the reaction of complex 6 and $\mathrm{PhSiD}_{3}$ (6.0 eq.) show that the peaks at 2036 and $2020 \mathrm{~cm}^{-1}$ are in the region expected for Si-H (Figure 6.22). UV-vis spectrum shows there are absorption peaks at 290, 471, 660 and $991 \mathrm{~nm}$ in MeCN (Figure 6.23). ${ }^{2} \mathrm{H}-\mathrm{NMR}$ spectra of the reaction of $\mathrm{PhSiD}_{3}(6.0$ eq.) and complex 6 show that $\mathrm{Ph}_{2} \mathrm{SiD}_{2}$ and $\mathrm{D}_{2}$ are generated as byproducts (Figure 6.24). However, different from the reaction to form complex 22, $\mathrm{PhSiD}_{3}$ was not consumed completely after $40 \mathrm{~h}$ in the reaction to form complex $\mathbf{2 3}$. The possible mechanism is still unclear. Complex $\mathbf{2 3}$ was possibly synthesized from further reaction of complex 22 and phenylsilane. 


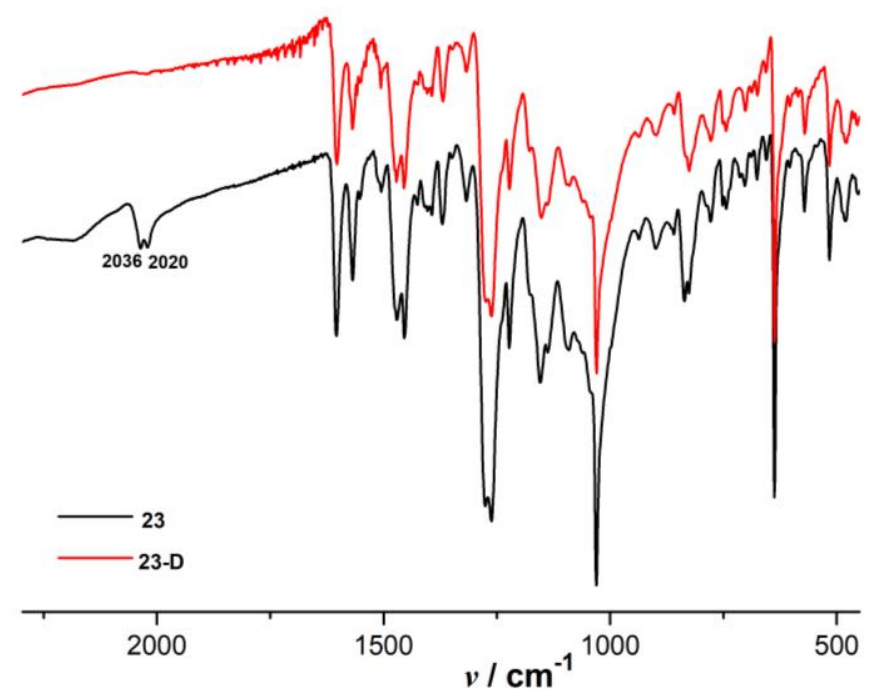

Figure 6.22: IR spectra of complexes 23 and $\left[\mathrm{L}_{2} \mathrm{Co}_{4}\left(\mu-\mathrm{PhSi}_{4} \mathrm{D}_{3}\right](\mathrm{OTf})_{2}, \mathbf{2 3}-\mathrm{D}\right.$ on $\mathrm{KBr}$ pallets in solid state at room temperature.

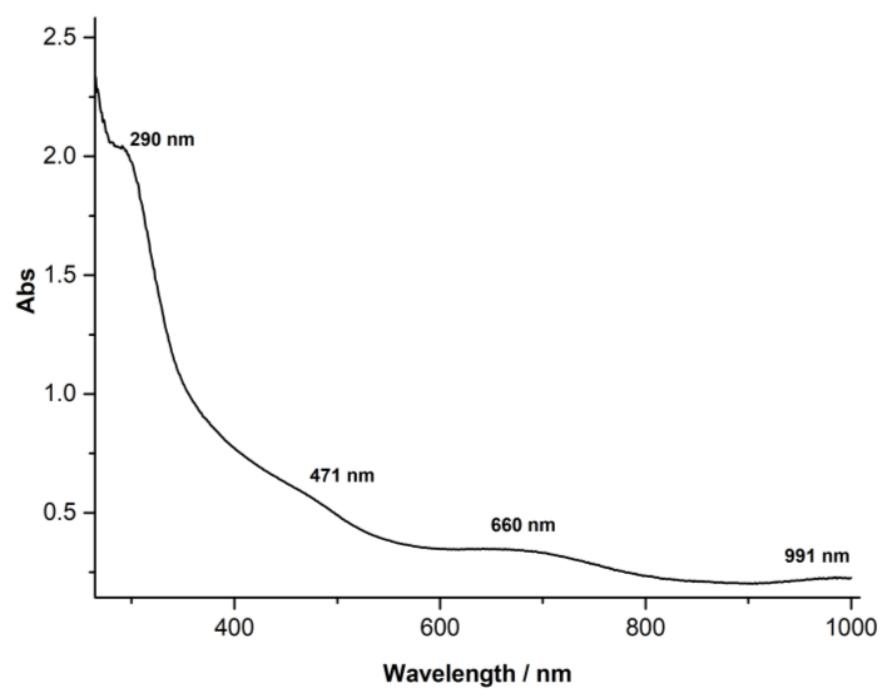

Figure 6.23: UV-vis spectrum of complex 23 in $\mathrm{MeCN}$ solution at room temperature. 


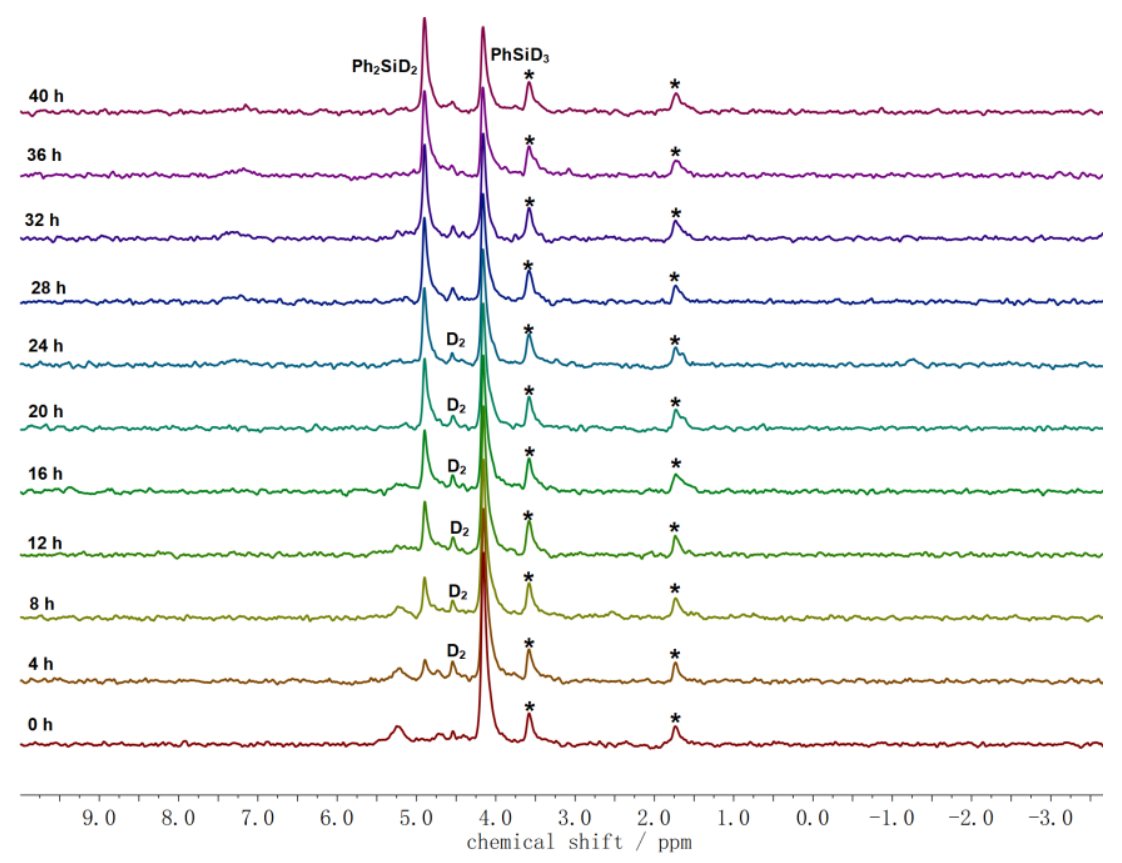

Figure 6.24: ${ }^{2} \mathrm{H}-\mathrm{NMR}$ spectra of the reactions of complex 6 with $\mathrm{PhSiD}_{3}$ (6 eq.) without stirring in THF. Solvent signals are marked with an asterisk $(*)$.

\subsection{Conclusion}

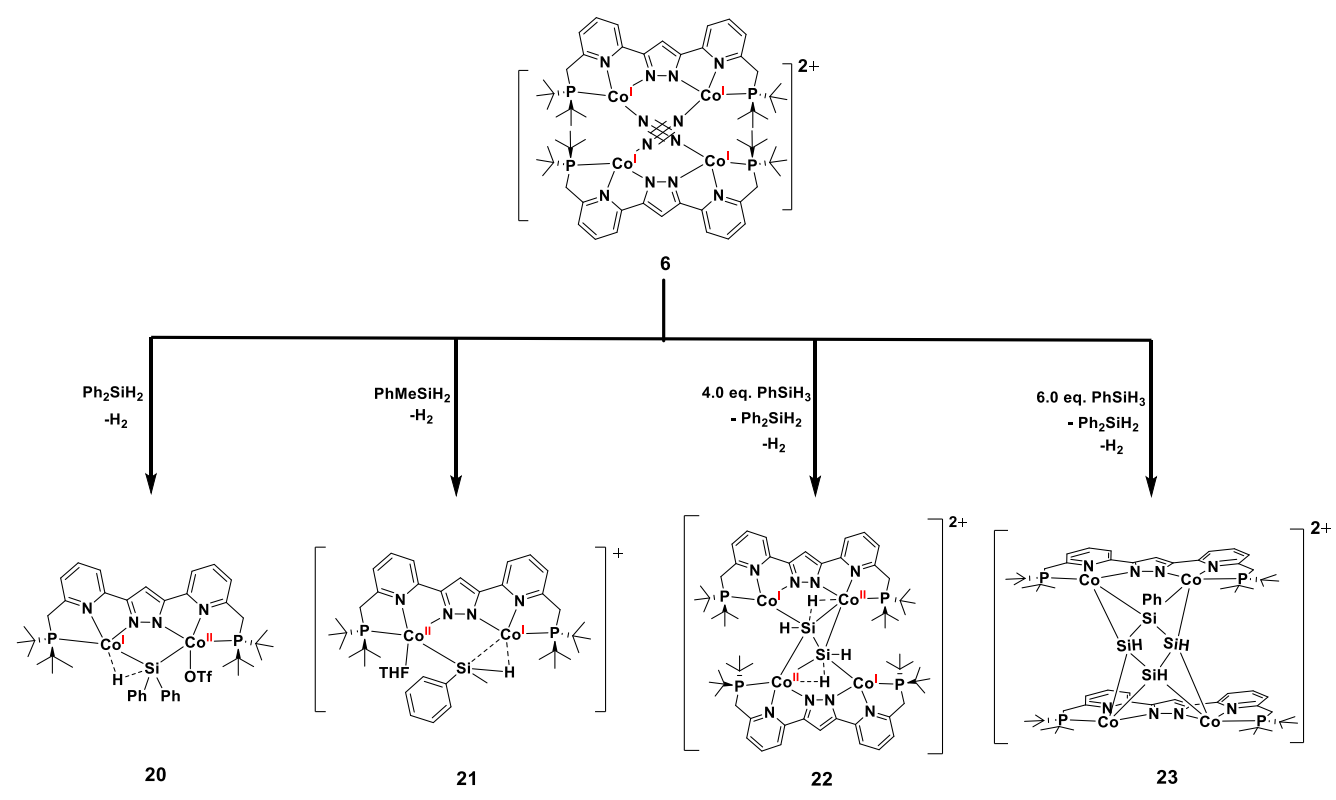

In summary, a series of reactions of silanes with the tetracobalt(I) dinitrogen complex $\mathbf{6}$ were performed and four silane complexes 20-23 could be successfully isolated. It shows that the addition of diphenylsilane or methylphenylsilane into a THF solution of complex $\mathbf{6}$ results in the formation of a mixed-valent $\mathrm{Co}^{\mathrm{I} / \mathrm{II}}$ diphenylsilyl complex $\mathbf{2 0}$ or methylphenylsilyl $\sigma$-complex 21, likely 
accompanied by the release of $\mathrm{H}_{2}$. Interestingly, phenylsilane reacts with complex $\mathbf{6}$ and generates a mixed-valent $\mathrm{Co}^{\mathrm{I} / \mathrm{II}}$ disilyl complex $\left[\mathrm{L}_{2} \mathrm{Co}_{4}\left(\mu-\mathrm{SiH}_{2} \mathrm{SiH}_{2}\right)\right](\mathrm{OTf})_{2} 22$ by redistribution accompanied by diphenylsilane and $\mathrm{H}_{2}$ as byproducts. DFT calculations that may help to unravel the electronic structure of complex $\mathbf{2 2}$ are still in progress. Moreover, the reaction of phenylsilane and complex 6 without stirring formed a tetracobalt tetrasilyl complex $\left[\mathrm{L}_{2} \mathrm{Co}_{4}\left(\mu-\mathrm{PhSi}_{4} \mathrm{H}_{3}\right](\mathrm{OTf})_{2} 23\right.$. 


\section{Chapter 7: Experimental Section}

\subsection{Materials and Methods}

General Considerations. All manipulations were carried out using standard Schlenk techniques or in a glove box $\left(\mathrm{O}_{2}<0.1 \mathrm{ppm}, \mathrm{H}_{2} \mathrm{O}<0.1 \mathrm{ppm}\right)$ under an anhydrous $\mathrm{N}_{2}$ or argon atmosphere. Unless otherwise stated, all chemicals used were purchased from commercial sources. All solvents were dried by standard methods and freshly distilled prior use. THF, toluene, diethyl ether, pentane and hexane were dried over sodium in presence of benzophenone. Ethyl acetate was dried over $\mathrm{P}_{4} \mathrm{O}_{10}$. Dichloromethane, acetonitrile and trimethylsilyl chloride $\left(\mathrm{SiMe}_{3} \mathrm{Cl}\right)$ were dried over calcium hydride. Deuterated solvents (THF-d $\mathrm{d}_{8}, \mathrm{CD}_{3} \mathrm{CN}, \mathrm{CD}_{2} \mathrm{Cl}_{2}$ and $\mathrm{CDCl}_{3}$ ) were dried and distilled just as the undeuterated analogues and stored over $3 \AA$ molecular sieves. Acetone- $\mathrm{d}_{6}$ was dried over $\mathrm{B}_{2} \mathrm{O}_{3}$ and distilled. $\mathrm{Na}$ and $\mathrm{K}$ were purchased as dispersions in mineral oil, washed repetitively with hexane and dried in vacuum prior to use. $\mathrm{KC}_{8}$ was synthesized according to the literature. ${ }^{81} \mathrm{PhSiD}_{3}$ was synthesized from the reaction of $\mathrm{LiAlD}_{4}$ and $\mathrm{PhSiCl}_{3}$ in diethyl ether. ${ }^{82} \mathrm{Na}$ and $\mathrm{K}$ were purchased as dispersions in mineral oil and they were washed with hexane.

\section{Instrumentation.}

${ }^{1} \mathrm{H}$ NMR, ${ }^{2} \mathrm{H}$ NMR, ${ }^{13} \mathrm{C}$ NMR, ${ }^{31} \mathrm{P}$ NMR, ${ }^{19} \mathrm{~F}$ NMR, ${ }^{29} \mathrm{Si}$ NMR, ${ }^{15} \mathrm{~N}$ NMR, NOESY, COSY, ${ }^{1} \mathrm{H}_{-}{ }^{13} \mathrm{C}$ HSQC, ${ }^{1} \mathrm{H}_{-}-{ }^{13} \mathrm{C},{ }^{1} \mathrm{H}_{-}{ }^{15} \mathrm{~N}$ HMBC, ${ }^{1} \mathrm{H}_{-}{ }^{29} \mathrm{Si} \mathrm{HMBC}$ and DOSY spectra were recorded on Bruker Avance $300,400,500$ or 600 spectrometers at room temperature or low temperature. Chemical shifts are reported in parts per million relative to residual proton and carbon signals of the solvent.

UV-vis spectra were recorded on an Agilent Cary 60 equipped with an Unisoku Cryostat (CoolSpek). UV-vis spectra at low temperature were measured with a quartz transmission probe $(1 \mathrm{~mm}$, Hellma analytics). Solid state spectra were recorded using the cary 5000 Bio spectrophotometer but with a Praying Mantis ${ }^{\mathrm{TM}}$ diffuse reflection attachment equipped with a sample chamber with quartz window.

Infrared spectra of all complexes on $\mathrm{KBr}$ pallets were recorded on a Vertex 70 (Bruker) instrument or performed inside a glovebox on a Cary 630 FTIR spectrometer equipped with Dial Path Technology and analyzed by FTIR MicroLab software. IR signals were analyzed according to their relative intensity as strong (s), medium (m) and weak (w).

ESI mass spectra were collected on Bruker HCT ultra spectrometer.

Elemental analyses were performed by the analytical laboratory of the Institute of Inorganic Chemistry at the University of Göttingen using an Elementar Vario EL III instrument.

GC-MS mass spectra were recorded on Thermo Finnigan spectrometers TRACE (Varian GC 
Capillary Column; wcot fused silica coated CP-SIL 8CB for amines; $30 \mathrm{~m} \mathrm{x} 0.25 \mathrm{~mm}$ x $0.25 \mu \mathrm{m}$ ) and DSQ (Varian FactorFour Capillary Column; VF-5ms 30 m x 0.25 mm x $0.25 \mu \mathrm{m}$ ). Gas chromatography was performed on an Agilent Technologies chromatograph 7890A GC System (Supelcowax 10 Fused Silica Capillary Column; $30 \mathrm{~m}$ x $0.32 \mathrm{~mm}$ x $0.25 \mu \mathrm{m}$ ).

GC calibrations were carried out with authentic samples and cyclododecane as an internal standard.

Raman spectra have been recorded using a HORIBA Scientific LabRAM HR 800 (400-1100 nm) spectrometer with open-electrode CCD detector and a confocal pinhole with user controlled variable aperture in combination with a free space optical microscope, and a He:Ne-laser $(633 \mathrm{~nm})$ for excitation. All spectra were recorded at room temperature using solid samples.

Continuous-wave (cw) EPR measurements were performed on a Bruker E500 Elexsys Q-band spectrometer equipped with an Oxford ESR910 flow cryostat and an ER4102ST rec-tangular cavity.

Magnetic Measurements Temperature-dependent magnetic susceptibility measurements for cobalt complexes were carried out with a Quantum-Design MPMS-XL-5 SQUID magnetometer equipped with a $5 \mathrm{~T}$ magnet in the range from 295 or $210 \mathrm{~K}$ to $2.0 \mathrm{~K}$ at a magnetic field of $0.5 \mathrm{~T}$. Each raw data file for the measured magnetic moment was corrected for the diamagnetic contribution of the Teflon bucket according to $M^{\text {dia }}$ (bucket) $=\chi_{\mathrm{g}} \cdot m \cdot H$, with an ex-perimentally obtained gram susceptibility of the Teflon bucket. Experimental data were modelled with the $j u l X$ program $^{[83]}$ using a fitting procedure to the spin Hamiltonians:

$$
\hat{H}=-2 J \hat{S}_{1} \hat{S}_{2}+g \mu_{B} \vec{B}\left(\vec{S}_{1}+\vec{S}_{2}\right)
$$

or

$$
\hat{H}=-2 J \hat{S}_{1} \cdot \hat{S}_{2}+D_{1}\left(\hat{S}_{z, 1}^{2}-1 / 3 \hat{S}_{1}\left(\hat{S}_{1}+1\right)\right)+g_{1} \beta \hat{S}_{1} \cdot \hat{B}+g_{2} \beta \hat{S}_{2} \cdot \hat{B}
$$

Temperature-independent paramagnetism $(T I P)$ and paramagnetic impurities $(P I)$ were included according to $c_{\text {calc }}=(1-P I) \cdot c+P I \cdot c_{\text {mono }}+T I P$.

DFT Calculations. The ORCA package (version 3.0.3) was employed. A geometry optimization was performed based on the crystallographic structure determination (spin unrestricted DFT calculations, BP86 functional, def2-tzvp basis set, RI approximation using the auxiliary def2-tzvp/J basis set, D3 dispersion correction with zero damping, tight convergence, and optimization criteria).

Single-Crystal X-ray Structure Determinations. X-ray data were collected on a STOE IPDS II diffractometer (graphite mono-chromated Mo-K $\alpha$ radiation, $\lambda=0.71073 \AA$ ) by use of $\omega$ scans at $-140^{\circ} \mathrm{C}$. The structures were solved by SHELXT and refined on $F^{2}$ using all reflections with SHELXL-2014. Non-hydrogen atoms were refined anisotropically. Most hydrogen atoms were placed in calculated positions and assigned to an isotropic displacement parameter of 1.2/1.5 Ueq(C). Face-indexed absorption corrections were performed numerically with the program X-RED. 


\subsection{Synthetic Procedures}

\subsubsection{Synthesis of ligand HL}

Ligand HL was prepared according to the literature. ${ }^{5,6,7}$<smiles>CC(=O)c1cccc(C)n1</smiles>

IV

6-Methyl-2-pyridinecarbonitrile, VII $(0.6 \mathrm{~g}, 5.08 \mathrm{mmol})$ was dissolved in THF (40 mL)under argon atmosphere and cooled to $-15{ }^{\circ} \mathrm{C}$. Then $\mathrm{MeMgBr}$ solution (3 $\mathrm{M}$ in $\mathrm{Et}_{2} \mathrm{O}, 2.5 \mathrm{~mL}$ ) was added dropwise into the reaction and was stirred at $-15^{\circ} \mathrm{C}$ for two hours and at room temperature overnight. Then saturated $\mathrm{NH}_{4} \mathrm{Cl}$ solution $(20 \mathrm{~mL})$ was added dropwise into the solution, which was extracted with DCM. The organic phase was dried by anhydrous $\mathrm{MgSO}_{4}$ and filtered. The solvent was evaporated under vacuum and left red brown oil, as compound IV. ${ }^{1} \mathrm{H}-\mathrm{NMR}\left(300 \mathrm{MHz}, \mathrm{CDCl}_{3}\right) \delta$ $(\mathrm{ppm})=7.82(\mathrm{~d}, J=9 \mathrm{~Hz}, 1 \mathrm{H}, \mathrm{Py} 3-H), 7.69(\mathrm{t}, J=7.5 \mathrm{~Hz}, 1 \mathrm{H}, \mathrm{Py} 4-\mathrm{H}), 7.30(\mathrm{~d}, J=6 \mathrm{~Hz}, 1 \mathrm{H}, \mathrm{Py}$ 5-H), $2.69\left(\mathrm{~s}, 3 \mathrm{H}, \mathrm{COCH}_{3}\right), 2.60\left(\mathrm{~s}, 3 \mathrm{H}, \mathrm{CH}_{3}\right)$.

\subsubsection{Synthesis of ligand HL $\mathrm{He}^{\mathrm{Me}}$}

Ligand precursor VIII was prepared according to the literature. ${ }^{5,6}$<smiles>Cc1cccc(C(=O)C(C)C(=O)c2cccc(C)n2)n1</smiles>

\section{IX}

Under an atmosphere of argon compound VIII (0.76 g, $3.0 \mathrm{mmol})$ and potassium bis(trimethylsilyl)-amide $(0.90 \mathrm{~g}, 3.0 \mathrm{mmol})$ were suspended in toluene $(50 \mathrm{~mL})$. The suspension was heated to $75{ }^{\circ} \mathrm{C}$ and the color changed from orange to green, then methyl iodide $(0.92 \mathrm{~mL}, 15.0$ mmol) was added. The reaction was refluxing for 4 hours and then yellow solid precipitated. After filtration and washing with toluene $(2 \times 10 \mathrm{~mL})$, a yellowish solid was obtained. .

${ }^{1} \mathbf{H}$ NMR $\left(400 \mathrm{MHz}, \mathrm{CDCl}_{3}\right): \delta(\mathrm{ppm})=7.87(\mathrm{~d}, 2 \mathrm{H}, \mathrm{Py}$ 5- $H), 7.67(\mathrm{t}, 2 \mathrm{H}, \mathrm{Py} 4-H), 7.20(\mathrm{~d}, 2 \mathrm{H}, \mathrm{Py}$ 3- $\mathrm{H}), 5.65(\mathrm{~m}, 1 \mathrm{H}, \mathrm{CH}), 2.29$ (s, 6H, $\left.\mathrm{Py}-\mathrm{CH}_{3}\right), 1.53$ (d, 3H, $\left.\mathrm{CH}_{3}\right)$. 


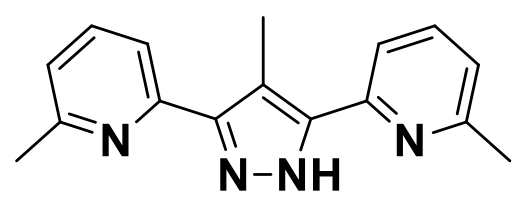

\section{$\mathbf{X}$}

The solid IX (26 mg, $50 \mathrm{mmol})$ and hydrazine monohydrate $(6.2 \mathrm{~mL}, 125 \mathrm{mmol}, 2.5 \mathrm{eq})$ were added into ethanol $(80 \mathrm{~mL})$. The red solution was heated to reflux for $20 \mathrm{~h}$. The volatiles were removed in vасио, the crude product was suspended in water $(10 \mathrm{~mL})$ and filtered. After drying in vacuo, a light brown solid was obtained.

${ }^{1}$ H-NMR $\left(400 \mathrm{MHz}, \mathrm{CDCl}_{3}\right) \delta(\mathrm{ppm})=7.65(\mathrm{t}, 2 \mathrm{H}, \mathrm{Py} 4-H), 7.60$ (d, 2H, Py 5-H), 7.09 (d, 2H, Py 3- $\mathrm{H}$ ), 2.67 (s, 3H, Pz-CH3), 2.59 (s, 6H, $\left.\mathrm{Py}-\mathrm{CH}_{3}\right)$.

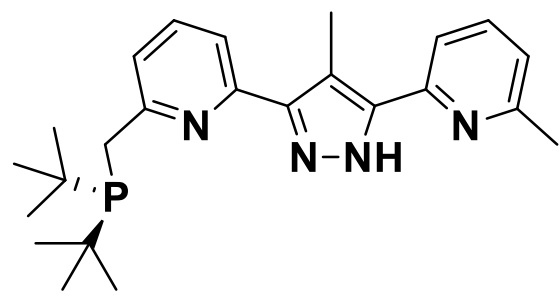

\section{$\mathbf{X I}$}

A solution of $\mathbf{X}$ (4.15 g, $15.7 \mathrm{mmol}, 1.0 \mathrm{eq})$ in THF $(20 \mathrm{~mL})$ was cooled to $-90{ }^{\circ} \mathrm{C}$. $\mathrm{n}$-BuLi $(2.7 \mathrm{M}$ in toluene, $14.6 \mathrm{~mL}, 39.4 \mathrm{mmol}, 2.5 \mathrm{eq}$ ) was slowly added over the course of $30 \mathrm{~min}$. The dark red solution was stirred at low temperature for $3 \mathrm{~h}$ and allowed to warm to ambient temperature overnight. Chloro-di-tert-butyl-phosphine (2.85 g, $15.7 \mathrm{mmol}, 1.0 \mathrm{eq})$ in THF (3 mL) was added slowly in $1 \mathrm{~h}$. The reaction mixture was stirred at ambient temperature for $1 \mathrm{~d}$ and then quenched by addition of degassed water $(15 \mathrm{~mL})$. After virgous stirring for $30 \mathrm{~min}$ the aqueous layer was removed via a syringe. The organic layer was dried in vacuo overnight.

${ }^{1}$ H-NMR $\left(400 \mathrm{MHz}, \mathrm{CDCl}_{3}\right) \delta(\mathrm{ppm})=7.64$ (br, 2H, Py 4-H), 7.35 (d, 2H, Py 5-H), 7.09 (d, 2H, Py 3- $H$ ), 3.11 (d, 2H, $\mathrm{CH}_{2}$ ), 2.69 (s, 3H, Pz-CH3), 2.60 (s, 6H, Py-CH $), 1.39$ (d, $18 \mathrm{H}, t \mathrm{Bu}_{2} \mathrm{P}$ ).

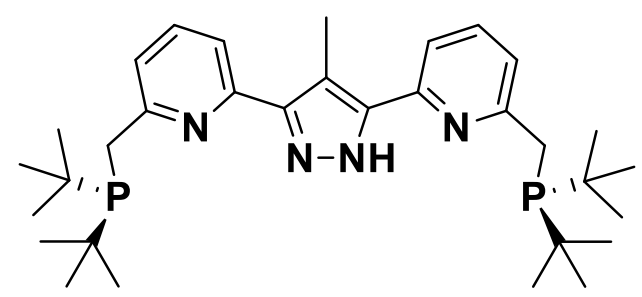

$\mathrm{HL}^{\mathrm{Me}}$

The THF solution of XI $(6.4 \mathrm{~g} 15.7 \mathrm{mmol})$ was cooled to $-90{ }^{\circ} \mathrm{C}$ and t-BuLi $(1.7 \mathrm{M}$ in pentane, 27.8 
$\mathrm{mL}, 47.2 \mathrm{mmol}, 3.0 \mathrm{eq})$ was slowly added over the course of $1 \mathrm{~h}$. The dark red solution was stirred at low temperature for $6 \mathrm{~h}$ and allowed to warm to ambient temperature overnight. Chloro-di-tert-butyl-phosphine (2.85 g, $15.7 \mathrm{mmol}, 1.0 \mathrm{eq})$ in THF (3 mL) was added slowly in $2 \mathrm{~h}$. The reaction mixture was stirred at ambient temperature for $1 \mathrm{~d}$ and then quenched by addition of degassed water $(15 \mathrm{~mL})$. After virgous stirring for $30 \mathrm{~min}$ the aqueous layer was removed via a syringe. The organic layer was dried in vacuo overnight. The crude product was washed with $\mathrm{Et}_{2} \mathrm{O}$ and a yellow powder was obtained.

${ }^{1} \mathbf{H}-N M R\left(400 \mathrm{MHz}, \mathrm{CDCl}_{3}\right) \delta(\mathrm{ppm})=7.65-7.35$ (br, 6H, Py), 3.10 (d, 4H, CH$), 2.72(\mathrm{~s}, 3 \mathrm{H}$, $\left.\mathrm{Pz}-\mathrm{CH}_{3}\right), 1.39$ (d, 36H, $\left.t \mathrm{Bu}_{2} \mathrm{P}\right)$.

${ }^{31} \mathbf{P}-\mathbf{N M R}\left(400 \mathrm{MHz}, \mathrm{CDCl}_{3}\right) \delta(\mathrm{ppm})=37.67,36.60$.

\subsubsection{Complex Synthesis}

Synthesis of $\left[\mathbf{L}(\mathbf{C o C l})_{2}(\boldsymbol{\mu}-\mathbf{C l})\right](\mathbf{1}) . \mathrm{KO}^{\mathrm{t} B u}(0.4 \mathrm{mmol}, 44.9 \mathrm{mg}, 1.0$ equiv) was dissolved in THF (2 $\mathrm{mL})$ and then added dropwise to the solution of ligand HL (0.4 mmol, $215.5 \mathrm{mg}, 1.0$ equiv) in THF $(3 \mathrm{~mL})$ at room temperature. After stirring the red solution for 2 hours, $\mathrm{CoCl}_{2}(0.8 \mathrm{mmol}, 103.9 \mathrm{mg}$, 2.0 equiv) was added. The resulting blue solid began to precipitate and the mixture was stirred overnight. After filtration through glass fiber filters, the residue was dissolved in $\mathrm{CH}_{2} \mathrm{Cl}_{2}$ and a slow diffusion of pentane into the solution yielded blue, rod-shaped crystals suitable for X-ray diffraction (Yield: $274.3 \mathrm{mg}, 90 \%) .{ }^{1} \mathrm{H}-\mathrm{NMR}\left(500 \mathrm{MHz}, \mathrm{CDCl}_{3}\right): \delta(\mathrm{ppm})=85.11(\mathrm{~s}, 1 \mathrm{H}, \mathrm{Pz} 4-H), 55.08(\mathrm{~s}, 2 \mathrm{H}$, $\left.\mathrm{CH}_{2}\right), 52.34$ (s, 2H, Py 3-H or 5-H), 44.75 (s, 2H, Py 3-H or 5- $H$ ), 44.14 (br, 2H, CH$\left.H_{2}\right), 33.03$ (s, 18H, $\left.\mathrm{C}\left(\mathrm{CH}_{3}\right)_{3}\right), 17.57\left(\mathrm{~s}, 2 \mathrm{H}\right.$, py 4-H), $-10.57\left(\mathrm{~s}, 18 \mathrm{H}, \mathrm{C}\left(\mathrm{CH}_{3}\right)_{3}\right) .{ }^{13} \mathrm{C}-\mathrm{NMR}\left(126 \mathrm{MHz}, \mathrm{CD}_{2} \mathrm{Cl}_{2}\right): \delta(\mathrm{ppm})=$ 1012.91, 818.32, 783.39 (d, Py 3-C or 5-C), 772.40 (d, Py 3-C or 5-C), 525.38, 460.17 (pz $C-4$ ), $272.01\left(\mathrm{~d}, \mathrm{C}\left(\mathrm{CH}_{3}\right)_{3}\right), 194.03$ (d, $\left.\mathrm{C}\left(\mathrm{CH}_{3}\right)_{3}\right)$. ATR-IR (solid): $\left(v / \mathrm{cm}^{-1}\right)=1598(\mathrm{~s}), 1565(\mathrm{~s}), 1522(\mathrm{w})$, 1464 (s), 1449 (s), 1418 (m), 1403 (w), 1389 (m), 1369 (s), 1315 (m), 1295 (w), 1267 (m), 1230 (w), 1176 (s), 1161 (s), 1151 (m), 1094 (w), 1074 (m), 1043 (m), 1024 (w), 1004 (m), 936 (m), 895 (m), $887(\mathrm{w}), 861(\mathrm{w}), 831(\mathrm{~s}), 817(\mathrm{~m}), 798(\mathrm{~m}), 789(\mathrm{~m}), 777(\mathrm{~s}), 754(\mathrm{w}), 747(\mathrm{w}), 743(\mathrm{w}), 735(\mathrm{~m})$, $694(\mathrm{~m}), 686(\mathrm{w}), 672(\mathrm{~m}), 621(\mathrm{w}), 603(\mathrm{w}), 578(\mathrm{~m}), 542(\mathrm{~m}), 499(\mathrm{w}), 472(\mathrm{~s}), 446(\mathrm{w}), 444(\mathrm{w})$, $436(\mathrm{w}), 429(\mathrm{w}), 419(\mathrm{w}), 414(\mathrm{w}) . \mathrm{UV}$-vis $\left(\mathrm{CH}_{2} \mathrm{Cl}_{2}\right): 5.6 \mu \mathrm{M}, \lambda_{\max }=260,314,533,627 \mathrm{~nm} ; 0.7 \mu \mathrm{M}$, $\lambda_{\max }=534,575$ and $624 \mathrm{~nm}$. Elemental analysis (\%) Calc. for $\mathrm{C}_{31} \mathrm{H}_{47} \mathrm{Cl}_{3} \mathrm{Co}_{2} \mathrm{~N}_{4} \mathrm{P}_{2}: \mathrm{C} 48.87, \mathrm{H} 6.22, \mathrm{~N}$ 7.35; Found: C 48.44, H 6.26, N 7.19. ESI-MS $\left(\mathrm{CH}_{3} \mathrm{CN}\right): \mathrm{m} / \mathrm{z}(\%)=725.1\left[\mathrm{LCo}_{2} \mathrm{Cl}_{2}\right]^{+}$.

Synthesis of $\left[\left(\mathbf{L}^{* *}\left(\mathbf{C o N}_{2}\right) 2\right)(\mathbf{K}([\mathbf{2} .2 .2]\right.$ cryptand $\left.))\right](2)$. Method A: to a stirred suspension of complex $1(0.25 \mathrm{mmol}, 190.5 \mathrm{mg}, 1.0$ equiv) in THF (3 mL), KH (2.50 mmol, $100 \mathrm{mg}, 10.0$ equiv) and cryptand (1.00 mmol, $376.4 \mathrm{mg}, 4.0$ equiv) were added in a dinitrogen atmosphere at room temperature. The resulting blue suspension was stirred for 4 hours and after filtration through glass fiber filters. Layering a THF solution with hexane/Et $2 \mathrm{O}$ at $-40{ }^{\circ} \mathrm{C}$ forms block-shaped dark blue crystals suitable for X-ray diffraction analysis. (Yield: $174.8 \mathrm{mg}, 55 \%$ ). Method B: to a stirred solution of complex 4 ( $0.25 \mathrm{mmol}, 187.2 \mathrm{mg}, 1.0$ equiv) in THF, cryptand (0.25 mmol, $94.1 \mathrm{mg}, 1.0$ equiv) was added and the solution was stired for 4 hours. Block-shaped dark blue crystals suitable for X-ray diffraction analysis were grown by layering THF solution with hexane/Et $2 \mathrm{O}$ at $-40{ }^{\circ} \mathrm{C}$ (Yield: $301.9 \mathrm{mg}, 95 \%) .2$ (20.0 mg) was dissolved in THF (4 mL) and the solution was degassed by three pump-freeze-thaw cycles before addition of ${ }^{15} \mathrm{~N}_{2}$ gas (atmospheric pressure). After stirring 
overnight, the solution was layered with hexane under Ar atmosphere at $-40{ }^{\circ} \mathrm{C}$ to give rise to $\mathbf{2 -}^{\mathbf{1 5}} \mathbf{N}_{\mathbf{2}}$ (Yield: $18.0 \mathrm{mg}, 90 \%) .{ }^{1} \mathrm{H}-\mathrm{NMR}\left(400 \mathrm{MHz}, \mathrm{THF}-\mathrm{d}_{8}\right): \delta(\mathrm{ppm})=6.07$ (t, J=6 Hz, 2H, Pydearom 4-H), 5.92 (s, 1H, Pz 4-H), 5.60 (d, $J=8 \mathrm{~Hz}, 2 \mathrm{H}$, Pydearom 3-H), 5.14 (d, $J=8 \mathrm{~Hz}, 2 \mathrm{H}$, Pydearom 5-H), 3.20 (d, $J=20 \mathrm{~Hz}, 30 \mathrm{H}$, cryptand), 2.93 (s, 2H, CH), 2.18 (s, 30H, cryptand), 1.43 (d, $J=12 \mathrm{~Hz}, 36 \mathrm{H}$, $\left.\mathrm{C}\left(\mathrm{CH}_{3}\right)_{3}\right) .{ }^{13} \mathrm{C}-\mathrm{NMR}\left(100 \mathrm{MHz}, \mathrm{THF}-\mathrm{d}_{8}\right): \delta(\mathrm{ppm})=170.37\left(\mathrm{~d}, J=84 \mathrm{~Hz}, \mathrm{y}_{\text {dearom }} \mathrm{C}-2\right), 157.28$ (s, Pz $C$-3/C-5), 152.28 (s, Pydearom $C-6$ ), 131.91 (s, Pydearom $C-4$ ), 111.64 (d, $J=64$ Hz, Pydearom $C-3$ ), 94.76 (s, Pz C-4), 94.15(s, Pydearom $C-5), 70.86$ (s, cryptand), 60.81 (d, $J=53 \mathrm{~Hz}, C \mathrm{H}$ ), 54.35 (s, cryptand), $35.96\left(\mathrm{~d}, J=20 \mathrm{~Hz}, C\left(\mathrm{CH}_{3}\right)_{3}\right), 30.09$ (d, $\left.J=4 \mathrm{~Hz}, \mathrm{C}\left(\mathrm{CH}_{3}\right)_{3}\right) .{ }^{31} \mathrm{P}-\mathrm{NMR}(162 \mathrm{MHz}$, THF-d $\left.\mathrm{d}_{8}\right): \delta(\mathrm{ppm})=81.36\left(\mathrm{~s}, \mathrm{P}_{\text {dearom }}\right) .{ }^{15} \mathrm{~N}-\mathrm{NMR}\left(50 \mathrm{MHz}, \mathrm{THF}-\mathrm{d}_{8}\right): \delta(\mathrm{ppm})=-28.86,-58.13$. ATR-IR (solid): $\left(v / \mathrm{cm}^{-1}\right)=2031\left(\mathrm{~s}, \mathrm{~N}_{2}\right), 2007\left(\mathrm{~s}, \mathrm{~N}_{2}\right), 1606(\mathrm{~s}), 1543(\mathrm{~s}), 1492(\mathrm{w}), 1469(\mathrm{~s}), 1455(\mathrm{w})$, 1443(w), 1415(s), 1390(m), 1380(m), 1352(s), 1295(s), 1257(s), 1238(m), 1212(m), 1173(m), 1156(s), 1130(s), 1098(s), 1076(m), 1017(m), 996(m), 989(m),946(s), 929(s), 886(m), 819(s), 808(m), 791(w), 763(s), 751(s), 709(s), 629(s), 603(s), 579(s), 561(w), 532(s), 524(s), 498(s). ${ }^{15} \mathrm{~N}_{2}$ : $1973\left(\mathrm{~s},{ }^{15} \mathrm{~N}_{2}\right), 1951\left(\mathrm{~s},{ }^{15} \mathrm{~N}_{2}\right)$. UV-vis (THF): $\lambda_{\max }=267,335,479,521,621 \mathrm{~nm}$. Elemental analysis (\%) Calc. for $\mathrm{C}_{53} \mathrm{H}_{89} \mathrm{KCo}_{2} \mathrm{~N}_{10} \mathrm{P}_{2} \mathrm{O}_{7}$ : C 53.17, H 7.49, N 11.69; Found: C 52.80, H 7.17, N 11.02.

Synthesis of [L**(CoN(TMS)2)(CoCl)(K(THF)3)] (3). To a stirred suspension of complex 1 (0.25 mmol, $190.5 \mathrm{mg}, 1.0$ equiv) in THF (3 mL), KN(TMS) 2 (0.75 mmol, $150 \mathrm{mg}, 3.0$ equiv) in THF (2 $\mathrm{mL}$ ) was added dropwise at room temperature. The resulting red solution was stirred overnight and then all volatile substances were removed in vacuo. The remaining reside was washed with hexane twice. Crystals suitable for X-ray diffraction analysis were grown by layering a concentrated THF solution with hexane at $-40{ }^{\circ} \mathrm{C}$ (Yield: $\left.85 \%\right) .{ }^{1} \mathrm{H}-\mathrm{NMR}\left(400 \mathrm{MHz}, \mathrm{THF}-\mathrm{d}_{8}\right): \delta(\mathrm{ppm})=55.64,47.83$, 25.73, 19.96, 18.49, 16.83, 12.54, 5.53, 2.65, 2.27, -1.07, -1.84, -4.49, -5.54, -13.64, -32.42, -46.35, -50.04. ATR-IR (solid): $\left(\mathrm{v} / \mathrm{cm}^{-1}\right)=1619(\mathrm{w}), 1607(\mathrm{~s}), 1546(\mathrm{w}), 1486(\mathrm{~m}), 1460(\mathrm{~s}), 1416(\mathrm{~m})$, 1394 (w), 1386 (m), 1360 (w), 1353 (w), 1312 (m), 1290 (m), 1250 (m), 1236 (s), 1180 (m), 1151 (m), 1157 (s), 1089 (w), 1069 (w), $1051(\mathrm{~s}), 1017(\mathrm{w}), 978(\mathrm{~s}), 908(\mathrm{w}), 885(\mathrm{w}), 868(\mathrm{~s}), 839(\mathrm{~m})$, 808 (s), 775 (m), 766 (s), 750 (m), 724 (m), $713(\mathrm{~m}), 703$ (m), 665 (s), 610 (s), 576 (m), $542(\mathrm{w}), 501$ (w), $482(\mathrm{w}), 472(\mathrm{~s}), 457(\mathrm{~m}), 431(\mathrm{w})$. UV-vis $(\mathrm{THF}): \lambda_{\max }=271,327,483,511,547 \mathrm{~nm}$. Elemental analysis (\%) Calc. for $\mathrm{C}_{45} \mathrm{H}_{79} \mathrm{ClKCo}_{2} \mathrm{~N}_{5} \mathrm{P}_{2} \mathrm{O}_{2} \mathrm{~S}_{\mathrm{i} 2}$ : C 52.34, H 7.71, N 6.78; Found: C 51.92, H 7.53, N 6.45 .

Synthesis of $\left[\left(\mathbf{L}^{* *}(\mathbf{C o N})_{2}\right) \mathbf{K}\right](4)$. To a stirred solution of complex 3 (0.25 mmol, $276.2 \mathrm{mg}, 1.0$ equiv) in THF ( $5 \mathrm{~mL})$, solid $\mathrm{KC}_{8}\left(0.50 \mathrm{mmol}, 67.6 \mathrm{mg}, 2.0\right.$ equiv) or $\mathrm{KHBEt}_{3}(1.0 \mathrm{M}$ in THF, $0.5 \mathrm{~mL}$, 2.0 equiv) was added in a dinitrogen atmosphere. The red solution turned to dark blue and was stired for 5 hours. After filtration through glass fiber filters, hexane $(5 \mathrm{~mL})$ was added to the filtrate and the resulting mixture was cooled to $-40{ }^{\circ} \mathrm{C}$ overnight to yield a dark blue solid (Yield: $95 \%$ ). $4-{ }^{\mathbf{1 5}} \mathbf{N}_{\mathbf{2}}$ was synthesized by the same procedure as described for $\mathbf{2}^{-15} \mathbf{N}_{2} .{ }^{1} \mathrm{H}-\mathrm{NMR}\left(400 \mathrm{MHz}, \mathrm{THF}-\mathrm{d}_{8}\right): \delta(\mathrm{ppm})=$ $6.08(\mathrm{t}, J=6 \mathrm{~Hz}, 2 \mathrm{H}$, pydearom $4-H), 5.92(\mathrm{~s}, 1 \mathrm{H}, \mathrm{pz} 4-H), 5.62(\mathrm{~d}, J=12 \mathrm{~Hz}, 2 \mathrm{H}$, pydearom 3-H), $5.15(\mathrm{~d}$, $J=4 \mathrm{~Hz}, 2 \mathrm{H}$, pydearom 5-H), $2.94(\mathrm{~s}, 2 \mathrm{H}, \mathrm{CH}), 1.43\left(\mathrm{~d}, \mathrm{~J}=12 \mathrm{~Hz}, 36 \mathrm{H}, \mathrm{C}\left(\mathrm{CH}_{3}\right)_{3}\right) .{ }^{13} \mathrm{C}-\mathrm{NMR}(100 \mathrm{MHz}$, THF-d 8$): \delta(\mathrm{ppm})=170.39(\mathrm{~d}, J=21 \mathrm{~Hz}$, pydearom $C-2), 157.49(\mathrm{~s}, \mathrm{pz} C-3 / C-5), 152.12(\mathrm{~s}$, py dearom $C-6$ ), 131.93 (s, pydearom $C$-4), 111.84 (d, $J=16 \mathrm{~Hz}$, pydearom $C-3$ ), 94.54 (s, pz $C-4$ ), 94.18(s, pydearom $C-5), 60.90(\mathrm{~d}, J=53 \mathrm{~Hz}, C \mathrm{H}), 35.95\left(\mathrm{~d}, J=20 \mathrm{~Hz}, C\left(\mathrm{CH}_{3}\right)_{3}\right), 30.00\left(\mathrm{~d}, J=4 \mathrm{~Hz}, \mathrm{C}\left(C \mathrm{H}_{3}\right)_{3}\right) .{ }^{31} \mathrm{P}-\mathrm{NMR}$ $\left(162 \mathrm{MHz}, \mathrm{THF}-\mathrm{d}_{8}\right) \delta(\mathrm{ppm})=81.42\left(\mathrm{~s}, P_{\text {dearom }}\right) .{ }^{15} \mathrm{~N}-\mathrm{NMR}\left(50 \mathrm{MHz}, \mathrm{THF}-\mathrm{d}_{8}\right): \delta(\mathrm{ppm})=-28.92$ and -57.87. ATR-IR (solid): $\left(v / \mathrm{cm}^{-1}\right)=2044\left(\mathrm{~s}, \mathrm{~N}_{2}\right), 2004\left(\mathrm{~s}, \mathrm{~N}_{2}\right), 1606(\mathrm{~s}), 1588(\mathrm{w}), 1568(\mathrm{~m})$, 
1546(m), 1528(w), 1470(s), 1456(w), 1441(w), 1414(m), 1389(w), 1383(w), 1359(s), 1295(s), 1248(s), 1177(s), 1156(s), 1090(m), 1050(s), 1016(s), 995(s), 989(s), 930(s), 883(m), 862(w), 809(s), 757(s), 705(s), 681(w), 668(w), 618(m), 602(m), 577(w), 560(w), 532(m), 502(m). ${ }^{15} \mathrm{~N}_{2}: 1979(\mathrm{~s}$, $\left.{ }^{15} \mathrm{~N}_{2}\right), 1953\left(\mathrm{~s},{ }^{15} \mathrm{~N}_{2}\right.$ ). UV-vis (THF): $\lambda_{\max }=267,337,482,520$ and $614 \mathrm{~nm}$.

Synthesis of $\left[\left(\mathbf{L}^{* *}\left(\mathbf{C o N}_{2}\right)_{2}\right)\left(\mathbf{N a}(\mathbf{T H F})_{6}\right)\right]$ (5). To a stirred solution of complex 3 (0.25 mmol, 276.2 $\mathrm{mg}, 1.0$ equiv) in THF (5 mL), $\mathrm{NaHBEt}_{3}(1.0 \mathrm{M}$ in THF, $0.5 \mathrm{~mL}, 2.0$ equiv) was added in a dinitrogen atmosphere. The red solution turned to dark blue and was stirred for 5 hours. After filtration through glass fiber filters, hexane $(5 \mathrm{~mL})$ was added to the filtrate and the resulting mixture was cooled to $-40{ }^{\circ} \mathrm{C}$ overnight to yield a dark blue solid (Yield: $95 \%$ ). ${ }^{1} \mathrm{H}-\mathrm{NMR}$ (400 MHz, THF-d $\left.)_{8}\right): \delta(\mathrm{ppm})=6.06(\mathrm{t}, J=6 \mathrm{~Hz}, 2 \mathrm{H}$, pydearom $4-H), 5.87(\mathrm{~s}, 1 \mathrm{H}, \mathrm{pz} 4-H), 5.59(\mathrm{~d}, J=8 \mathrm{~Hz}, 2 \mathrm{H}$,

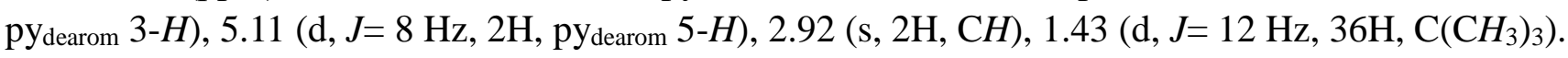
${ }^{13} \mathrm{C}-\mathrm{NMR}\left(100 \mathrm{MHz}, \mathrm{THF}-\mathrm{d}_{8}\right): \delta(\mathrm{ppm})=170.41(\mathrm{~d}, J=21 \mathrm{~Hz}$, pydearom $C-2), 157.22(\mathrm{~s}, \mathrm{pz} C-3 / C-5)$, 152.41 (s, pydearom $C-6$ ), 131.87 (s, pydearom $C-4$ ), 111.51 (d, $J=16 \mathrm{~Hz}$, pydearom $C-3$ ), 94.31 (s, pz $C-4$ ), 93.93(s, pydearom $C-5), 60.57(\mathrm{~d}, J=53 \mathrm{~Hz}, C \mathrm{H}), 35.91\left(\mathrm{~d}, J=20 \mathrm{~Hz}, C\left(\mathrm{CH}_{3}\right)_{3}\right), 30.04(\mathrm{~d}, J=4 \mathrm{~Hz}$, $\left.\mathrm{C}\left(\mathrm{CH}_{3}\right)_{3}\right) .{ }^{31} \mathrm{P}-\mathrm{NMR}\left(162 \mathrm{MHz}, \mathrm{THF}-\mathrm{d}_{8}\right) \delta(\mathrm{ppm})=81.31\left(\mathrm{~s}, P_{\text {dearom }}\right)$. ATR-IR (solid): $\left(v / \mathrm{cm}^{-1}\right)=$ 2037 (s, N $)_{2}$, 2028 (s, N $\left.)_{2}\right), 2014$ (s, N $), 1845(\mathrm{~s}), 1605(\mathrm{~s}), 1546(\mathrm{w}), 1528(\mathrm{~m}), 1467(\mathrm{~s}), 1414(\mathrm{~m})$, 1388(w), 1383(w), 1351(m), 1323(w), 1295(s), 1227(w), 1179(m), 1155(s), 1117(w), 1091(m), 1047(s), 1017(m), 993(m), 988(m), 934(w), 884(m), 809(s), 756(s), 705(s), 621(m), 601(m), 590(m), 578(w), 531(w), 506(w), 485(w), 471(m), 447(w), 414(s). UV-vis (THF): $\lambda_{\max }=267,336,482,521$ and $619 \mathrm{~nm}$.

Synthesis of $\left[\left(\mathbf{L}_{2} \mathbf{C o 4}\left(\mu-\mathbf{N}_{2}\right)_{2}\right)(\mathbf{O T f})_{2}\right](\mathbf{6})$. To a stirred solution of complex 2 (0.044 mmol, $55.9 \mathrm{mg}$, 1.0 equiv) or 4 (0.044 mmol, $32.9 \mathrm{mg}, 1.0$ equiv) in THF $(3 \mathrm{~mL})$ at $-40{ }^{\circ} \mathrm{C}$, $\operatorname{HOTf}(0.088 \mathrm{mmol}, 13.2$ mg, 2.0 equiv) was added dropwise and the resulting red solution was stirred for 1 hour. Block-shaped crystals suitable for X-ray diffraction analysis were grown in concentrated THF solution at $-35{ }^{\circ} \mathrm{C}$ (Yield: $\left.60 \%\right) .6(10.0 \mathrm{mg})$ was dissolved in THF (4 mL) and the solution was degassed by three pump-freeze-thaw cycles before addition of ${ }^{15} \mathrm{~N}_{2}$ gas (atmospheric pressure). After stirring for $4 \mathrm{~h}$, the solution was stored at $-40{ }^{\circ} \mathrm{C}$ overnight to form $\mathbf{6}^{-15} \mathbf{N}_{2}$ (Yield: $8.8 \mathrm{mg}, 88 \%$ ). ${ }^{1} \mathrm{H}-\mathrm{NMR}\left(500 \mathrm{MHz}, \mathrm{THF}-\mathrm{d}_{8},-35{ }^{\circ} \mathrm{C}\right.$, under $\left.\mathrm{N}_{2}\right): \delta(\mathrm{ppm})=7.78(\mathrm{t}, J=7.5 \mathrm{~Hz}, 2 \mathrm{H}$, py 4-H), $7.45(\mathrm{~d}$, $J=10 \mathrm{~Hz}, 2 \mathrm{H}$, py $5-H), 7.35(\mathrm{~d}, J=10 \mathrm{~Hz}, 2 \mathrm{H}$, py $3-H), 7.32(\mathrm{~s}, 1 \mathrm{H}, \mathrm{pz} 4-H), 3.81$ (dd, $J=20,5 \mathrm{~Hz}$, $\left.2 \mathrm{H}, \mathrm{CH}_{2}\right), 1.68\left(\mathrm{~d}, J=10 \mathrm{~Hz}, 18 \mathrm{H}, \mathrm{C}\left(\mathrm{CH}_{3}\right)_{3}\right), 1.25\left(\mathrm{~d}, J=10 \mathrm{~Hz}, 18 \mathrm{H}, \mathrm{C}\left(\mathrm{CH}_{3}\right)_{3}\right) .{ }^{13} \mathrm{C}-\mathrm{NMR}(126 \mathrm{MHz}$, THF- $\mathrm{d}_{8},-35^{\circ} \mathrm{C}$, under $\left.\mathrm{N}_{2}\right): \delta(\mathrm{ppm})=164.96(\mathrm{~d}, J=3.78 \mathrm{~Hz}$, py $C-2), 156.39(\mathrm{~s}, \mathrm{pz} C-3 / C-5), 153.10$ (s, py $C-6), 138.74$ (s, py $C-4), 121.11$ (d, $J=16 \mathrm{~Hz}$, py $C-3), 116.70(\mathrm{~s}$, py $C-5), 100.71$ (s, pz $C-4)$, $36.89\left(\mathrm{~d}, J=13.86 \mathrm{~Hz}, C\left(\mathrm{CH}_{3}\right)_{3}\right), 34.47\left(\mathrm{~d}, J=15.12 \mathrm{~Hz}, C\left(\mathrm{CH}_{3}\right)_{3}\right), 30.56\left(\mathrm{~s}, \mathrm{C}\left(\mathrm{CH}_{3}\right)_{3}\right) .{ }^{31} \mathrm{P}-\mathrm{NMR}$ $\left(202 \mathrm{MHz}, \mathrm{THF}-\mathrm{d}_{8},-35{ }^{\circ} \mathrm{C}\right.$, under $\left.\mathrm{N}_{2}\right) \delta(\mathrm{ppm})=99.49(\mathrm{~s}, P) .{ }^{19} \mathrm{~F}-\mathrm{NMR}\left(471 \mathrm{MHz}, \mathrm{THF}-\mathrm{d}_{8},-35{ }^{\circ} \mathrm{C}\right.$, under $\left.\mathrm{N}_{2}\right) \delta(\mathrm{ppm})=-76.99\left(\mathrm{~s}, \mathrm{CF}_{3} \mathrm{SO}_{3}{ }^{-}\right)$. ATR-IR (solid): $\left(v / \mathrm{cm}^{-1}\right)=1605(\mathrm{~m}), 1550(\mathrm{~m}), 1528(\mathrm{~m})$, 1456(s), 1414(m), 1391(w), 1368(m), 1360(w), 1348(w), 1309(m), 1262(s), 1220(m), 1178(w), 1146(m), 1028(s), 1021(m), 1009(m), 934(w), 896(m), 829(m), 812(w), 783(m), 751(w), 690(w), 679(w), 636(s), 628(s), 567(m), 542(m), 534(m), 516(m), 486(w), 474(m). UV-vis (THF): $\lambda_{\max }=313$, 510 and $774 \mathrm{~nm}$. Raman (solid): $\left(v / \mathrm{cm}^{-1}\right)=2000\left({ }^{14} \mathrm{~N} \equiv{ }^{14} \mathrm{~N}\right) ; 1935\left({ }^{15} \mathrm{~N} \equiv{ }^{15} \mathrm{~N}\right)$.

Synthesis of [(LCo2( $\boldsymbol{\mu}$-OTf $)](7)$. The solid powder of complex $6(0.014 \mathrm{mmol}, 25.3 \mathrm{mg})$ was dissolved in THF $(5 \mathrm{~mL})$ at room temperature and block-shaped crystals suitable for X-ray 
diffraction analysis were obtained by slow diffusion of pentane into the THF solution at room temperature (Yield: $75 \%) .{ }^{1} \mathrm{H}-\mathrm{NMR}\left(500 \mathrm{MHz}, \mathrm{THF}-\mathrm{d}_{8},-35{ }^{\circ} \mathrm{C}\right.$, under Argon): $\delta(\mathrm{ppm})=8.57(\mathrm{t}, J=$ $7.5 \mathrm{~Hz}, 2 \mathrm{H}$, py 4-H), $7.73(\mathrm{~s}, 1 \mathrm{H}, \mathrm{pz} 4-H), 6.78(\mathrm{~d}, J=5 \mathrm{~Hz}, 2 \mathrm{H}$, py $5-H), 6.61(\mathrm{~d}, J=5 \mathrm{~Hz}, 2 \mathrm{H}$, py 3-H), 2.08 (s, 4H, CH $), 1.57$ (s, 36H, C $\left.\left(\mathrm{CH}_{3}\right)_{3}\right) .{ }^{13} \mathrm{C}-\mathrm{NMR}\left(126 \mathrm{MHz}, \mathrm{THF}-\mathrm{d}_{8},-35{ }^{\circ} \mathrm{C}\right.$, under Argon): $\delta(\mathrm{ppm})=160.39(\mathrm{~s}, \mathrm{pz} C-3 / C-5), 153.18(\mathrm{~s}$, py $C-2), 145.25$ (s, py $C-6), 126.46$ (s, py $C-3), 125.99$ (s, py $C-5), 118.55$ (s, py $C-4), 96.69$ (s, pz $C-4), 33.04\left(\mathrm{~s}, C\left(\mathrm{CH}_{3}\right)_{3}\right), 31.29\left(\mathrm{~s}, \mathrm{C}\left(\mathrm{CH}_{3}\right)_{3}\right) .{ }^{31} \mathrm{P}-\mathrm{NMR}$ $\left(202 \mathrm{MHz}, \mathrm{THF}-\mathrm{d}_{8},-35{ }^{\circ} \mathrm{C}\right.$, under Argon) $\delta(\mathrm{ppm})=218.97 .{ }^{19} \mathrm{~F}-\mathrm{NMR}\left(470 \mathrm{MHz}, \mathrm{THF}-\mathrm{d}_{8},-35{ }^{\circ} \mathrm{C}\right.$, under Argon) $\delta(\mathrm{ppm})=-77.05\left(\mathrm{~s}, \mathrm{CF}_{3} \mathrm{SO}_{3}{ }^{-}\right),-78.82\left(\mathrm{br}, \mathrm{CF}_{3} \mathrm{SO}_{3}{ }^{-}\right)$. ATR-IR (solid): $\left(v / \mathrm{cm}^{-1}\right)=$ 1532(m), 1520(s), 1472(m), 1399(m), 1390(m), 1369(s), 1341(s), 1312(s), 1275(m), 1232(m), 1222(s), 1176(s), 1170(s), 1153(s), 1038(s), 1021(w), 1007(s), 959(w), 947(w), 890(m), 856(w), 811(s), 782(w), 767(s), 750(m), 722(w), 697(w), 682(w), 674(w), 663(w), 620(s), 600(w), 578(s), 553(m), 539(w), 509(m), 480(w), 470(m). UV-vis (THF): $\lambda_{\max }=313,509$ and $774 \mathrm{~nm}$. Elemental analysis (\%) Calc. for $\mathrm{C}_{32} \mathrm{H}_{46} \mathrm{Co}_{2} \mathrm{~N}_{4} \mathrm{P}_{2} \mathrm{~F}_{3} \mathrm{O}_{3} \mathrm{~S}$ : C 47.83, $\mathrm{H}$ 5.77, $\mathrm{N}$ 6.97, S 3.99; Found: $\mathrm{C} 47.97, \mathrm{H}$ 5.93, N 6.88, S 4.09.

\section{Synthesis of $\left[\left(\mathrm{L}^{* * *}\left(\mathrm{CoN}_{2}\right)_{2}\right)(\mathrm{K}([\right.$ 2.2.2]cryptand $))(\mathrm{K}(\mathrm{THF})([2.2 .2]$ cryptand $))](8)$.}

To a stirred solution of complex $2(0.044 \mathrm{mmol}, 55.9 \mathrm{mg}, 1.0$ equiv) or 4 (0.044 mmol, $43.0 \mathrm{mg}, 1.0$ equiv) in $\mathrm{THF}(3 \mathrm{~mL})$ at $-40{ }^{\circ} \mathrm{C}, \mathrm{KC}_{8}(0.088 \mathrm{mmol}, 11.9 \mathrm{mg}, 2.0$ equiv) was added and the solution was stirred overnight. After filtration of the solution through a glass fibre filter, two equivalents of cryptand were added and dark blue solid of complex $\mathbf{8}$ precipitated from the solution immediately. Block-shaped crystals were obtained from the filtrate after filtration again. ${ }^{31} \mathrm{P}-\mathrm{NMR}$ (202 MHz, THF-d 8$) \delta(\mathrm{ppm})=80.65,68.32(\mathrm{~s}, P)$. ATR-IR (solid): $\left(v / \mathrm{cm}^{-1}\right)=2017\left(\mathrm{~s}, \mathrm{~N}_{2}\right), 1966\left(\mathrm{~s}, \mathrm{~N}_{2}\right)$, 1590(s), 1512(s), 1462(s), 1443(s), 1403(m), 1388(m), 1357(s), 1353(s), 1292(m), 1281(s), 1257(s), 1179(m), 1158(w), 1146(m), 1132(m), 11501(s), 1071(s), 1012(s), 995(s), 979(m), 948(s), 931(s), 831(s), 808(s), 770(s), 751(m), 727(m), 710(m), 624(m), 602(s), 573(m), 540(w), 522(s), 505(w). UV-vis (THF) : $\lambda_{\max }=295,327,482,521$ and $584 \mathrm{~nm}$.

\section{Synthesis of $\left[\mathrm{L}^{\mathrm{Me}}(\mathrm{CoCl})_{2}(\mu-\mathrm{Cl})\right](9)$.}

To the stirred solution of ligand $\mathrm{HL}^{\mathrm{Me}}(0.4 \mathrm{mmol}, 221.1 \mathrm{mg}, 1.0$ equiv) in THF ( $3 \mathrm{~mL})$ under inert gas atmosphere, the solution of $\mathrm{KO}^{\mathrm{t}} \mathrm{Bu}(0.4 \mathrm{mmol}, 44.9 \mathrm{mg}, 1.0$ equiv) in THF $(2 \mathrm{~mL})$ was added dropwise. After stirring the solution for 2 hours, $\mathrm{CoCl}_{2}(0.8 \mathrm{mmol}, 103.9 \mathrm{mg}, 2.0$ equiv) was added. The resulting blue solid began to precipitate and the mixture was stirred overnight. After filtration through glass fiber filters, the residue was dissolved in $\mathrm{CH}_{2} \mathrm{Cl}_{2}$ and a slow diffusion of pentane into the solution yielded blue, block-shaped crystals suitable for X-ray diffraction (Yield: $90 \%$ ). ${ }^{1} \mathrm{H}-\mathrm{NMR}\left(400 \mathrm{MHz}, \mathrm{CDCl}_{3}\right): \delta(\mathrm{ppm})=54.64(\mathrm{~s}, 2 \mathrm{H}, \mathrm{Py} 3-\mathrm{H}$ or $5-H), 53.73\left(\mathrm{~s}, 2 \mathrm{H}, \mathrm{CH}_{2}\right), 44.79(\mathrm{br}$, 2H, $\mathrm{CH}_{2}$ ), 43.78 (s, 2H, Py 3-H or 5-H), 32.95 (s, 18H, C(CH3)3), 31.24 (s, 3H, Pz-CH3), 17.92 (s, 2H, Pz 4-H), 10.97 (s, 18H, C(CH3) $)_{3}$. ATR-IR (solid): $\left(v / \mathrm{cm}^{-1}\right)=1594(\mathrm{~s}), 1565(\mathrm{~s}), 1496(\mathrm{~m})$, 1471 (s), 1452 (s), 1416 (m), 1401 (w), 1393 (m), 1369 (s), 1303 (s), 1272 (w), 1264 (w), 1236 (m), 1205 (w), 1182 (s), 1160 (s), 1141 (m), 1107 (w), 1083 (m), 1066 (m), 1023 (m), 1005 (s), 994 (s), $935(\mathrm{~m}), 902(\mathrm{~s}), 837(\mathrm{~s}), 814(\mathrm{w}), 809(\mathrm{w}), 796(\mathrm{~s}), 751(\mathrm{~m}), 746(\mathrm{~m}), 720(\mathrm{~s}), 699(\mathrm{~m}), 690(\mathrm{~m}), 664$ $(\mathrm{m}), 620(\mathrm{w}), 611(\mathrm{w}), 593(\mathrm{~m}), 577(\mathrm{~m}), 500(\mathrm{~m}), 480(\mathrm{~s})$. UV-vis $\left(\mathrm{CH}_{2} \mathrm{Cl}_{2}\right): \lambda_{\max }=261,316,531$ and $623 \mathrm{~nm}$. ESI-MS $\left(\mathrm{CH}_{3} \mathrm{CN}\right): \mathrm{m} / \mathrm{z}(\%)=73.1\left[\mathrm{~L}^{\mathrm{Me}} \mathrm{Co}_{2} \mathrm{Cl}_{2}\right]^{+}$. 


\section{Synthesis of $\left[\left(\mathrm{L}^{\mathrm{Me**}}\left(\mathrm{CoN}_{2}\right)_{2}\right)(\mathrm{K}([2.2 .2] \operatorname{cryptand}))\right](10)$.}

KH (2.50 mmol, $100 \mathrm{mg}, 10.0$ equiv) and cryptand (1.00 mmol, $376.4 \mathrm{mg}, 4.0$ equiv) were added to a stirred suspension of complex $9(0.25 \mathrm{mmol}, 194.0 \mathrm{mg}, 1.0$ equiv) in THF (4 mL) under a dinitrogen atmosphere at room temperature. After being stirred overnight, the mixture was filtered through glass fiber filters. Block-shaped blue crystals suitable for X-ray diffraction analysis were obtained by layering THF solution with hexane at $-40{ }^{\circ} \mathrm{C}$ (Yield: $85 \%$ ). ${ }^{1} \mathrm{H}-\mathrm{NMR}(400 \mathrm{MHz}$, THF-d 8$): \delta(\mathrm{ppm})=6.08\left(\mathrm{t}, J=6 \mathrm{~Hz}, 2 \mathrm{H}, \mathrm{Py}_{\text {dearom }} 4-H\right), 5.61\left(\mathrm{~d}, J=8 \mathrm{~Hz}, 2 \mathrm{H}, \mathrm{P}_{\text {dearom }} 3-H\right), 5.24(\mathrm{~d}, J$ $=8 \mathrm{~Hz}, 2 \mathrm{H}$, Pydearom $_{\text {f- }}$ ), $3.36(\mathrm{~d}, J=28 \mathrm{~Hz}, 40.9 \mathrm{H}$, cryptand), $2.93(\mathrm{~s}, 2 \mathrm{H}, \mathrm{CH}), 2.30$ (s, 20.6H, cryptand), 2.10 (s, 3H, Pz-CH $), 1.42$ (d, $\left.J=12 \mathrm{~Hz}, 36 \mathrm{H}, \mathrm{C}\left(\mathrm{CH}_{3}\right)_{3}\right) .{ }^{13} \mathrm{C}-\mathrm{NMR}\left(100 \mathrm{MHz}, \mathrm{THF}-\mathrm{d}_{8}\right)$ : $\delta(\mathrm{ppm})=170.64\left(\mathrm{~d}, J=21 \mathrm{~Hz}, \mathrm{Py}_{\text {dearom }} C-2\right), 154.59(\mathrm{~d}, J=2 \mathrm{~Hz}, \mathrm{Pz} C-3 / C-5), 153.11(\mathrm{~d}, J=3 \mathrm{~Hz}$,

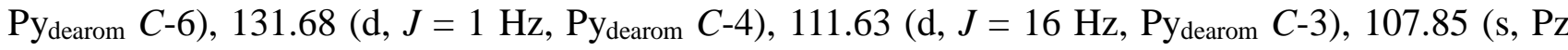
$C$-4), 95.28 (s, Pydearom $C$-5), 71.06 (s, cryptand), 61.05 (d, $J=52 \mathrm{~Hz}, C H$ ), 54.59 (s, cryptand), 35.95 $\left(\mathrm{d}, J=20 \mathrm{~Hz}, C\left(\mathrm{CH}_{3}\right)_{3}\right), 30.08\left(\mathrm{~d}, J=5 \mathrm{~Hz}, \mathrm{C}\left(\mathrm{CH}_{3}\right)_{3}\right), 9.71\left(\mathrm{~s}, \mathrm{Pz}-\mathrm{CH}_{3}\right) .{ }^{31} \mathrm{P}-\mathrm{NMR}(162 \mathrm{MHz}$, THF-d 8 ): $\delta(\mathrm{ppm})=80.87\left(\mathrm{~s}, \mathrm{P}_{\text {dearom}}\right)$. ATR-IR (solid): $\left(v / \mathrm{cm}^{-1}\right)=2037\left(\mathrm{~s}, \mathrm{~N}_{2}\right), 2013\left(\mathrm{~s}, \mathrm{~N}_{2}\right)$, 1602(s), 1527(s), 1468(s), 1455(s), 1411(s), 1389(w), 1380(w), 1352(s), 1293(s), 1257(s), 1239(m), 1176(m), 1158(s), 1131(s), 1099(s), 1076(s), 1017(m), 1002(s), 947(s), 930(s), 897(w), 819(s), 808(s), 762(s), 706(s), 604(s), 574(s), 530(w), 525(w), 499(m), 472(w), $464(\mathrm{~m})$. UV-vis (THF): $\lambda_{\max }$ $=268,334,482,518,613 \mathrm{~nm}$.

\section{Synthesis of $\left[\left(\mathrm{L}^{\mathrm{Me} * *}\left(\mathrm{CoN}_{2}\right)_{2}\right)\left(\mathrm{K}(\mathrm{THF})_{6}\right)\right](11)$.}

To a stirred suspension of complex $9(0.25 \mathrm{mmol}, 194.0 \mathrm{mg}, 1.0$ equiv) in THF ( $3 \mathrm{~mL})$, KN(TMS $)_{2}$ ( $0.75 \mathrm{mmol}, 150 \mathrm{mg}, 3.0$ equiv) in THF $(2 \mathrm{~mL})$ was added dropwise at room temperature and the solution turned red immediately. After stirring for $3 \mathrm{~h}$, solid $\mathrm{KC}_{8}(0.50 \mathrm{mmol}, 67.6 \mathrm{mg}, 2.0$ equiv) or $\mathrm{KHBEt}_{3}$ (1.0 M in THF, $0.5 \mathrm{~mL}, 2.0$ equiv) was added in a dinitrogen atmosphere. The red solution turned to dark blue and was stirred for 5 hours. After filtration through glass fiber filters, hexane ( 5 $\mathrm{mL}$ ) was added to the filtrate and the resulting mixture was cooled to $-40{ }^{\circ} \mathrm{C}$ overnight to yield a dark blue solid (Yield: $80 \%) .{ }^{1} \mathrm{H}-\mathrm{NMR}\left(400 \mathrm{MHz}, \mathrm{THF}-\mathrm{d}_{8}\right): \delta(\mathrm{ppm})=6.10\left(\mathrm{t}, J=8 \mathrm{~Hz}, 2 \mathrm{H}, \mathrm{y}_{\text {dearom }}\right.$ 4-H), $5.63\left(\mathrm{~d}, J=8 \mathrm{~Hz}, 2 \mathrm{H}, \mathrm{y}_{\text {dearom }} 3-H\right), 5.25$ (d, $J=8 \mathrm{~Hz}, 2 \mathrm{H}$, Pydearom 5-H), 2.94 (s, 2H, CH), $2.09\left(\mathrm{~s}, 3 \mathrm{H}, \mathrm{Pz}-\mathrm{CH}_{3}\right), 1.42\left(\mathrm{~d}, J=12 \mathrm{~Hz}, 36 \mathrm{H}, \mathrm{C}\left(\mathrm{CH}_{3}\right)_{3}\right) .{ }^{13} \mathrm{C}-\mathrm{NMR}\left(100 \mathrm{MHz}, \mathrm{THF}-\mathrm{d}_{8}\right): \delta(\mathrm{ppm})=$ 170.66 (d, $J=21 \mathrm{~Hz}, \mathrm{y}_{\text {dearom }} C-2$ ), 154.92 (s, Pz C-3/C-5), 152.84 (s, Pydearom $C-6$ ), 131.75 (s, Pydearom $C$-4), 111.89 (d, $J=16$ Hz, Pydearom $C$-3), 107.83 (s, Pz C-4), 95.47 (s, Pydearom $C-5$ ), 61.12 (d, $J=52 \mathrm{~Hz}, C \mathrm{H}), 35.96\left(\mathrm{~d}, J=20 \mathrm{~Hz}, C\left(\mathrm{CH}_{3}\right)_{3}\right), 29.96\left(\mathrm{~d}, J=4 \mathrm{~Hz}, \mathrm{C}\left(\mathrm{CH}_{3}\right)_{3}\right), 9.53\left(\mathrm{~s}, \mathrm{Pz}-\mathrm{CH}_{3}\right)$.

${ }^{31}$ P-NMR $(162 \mathrm{MHz}$, THF-d 8$): \delta(\mathrm{ppm})=81.17$ (s, Pdearom). ATR-IR (solid): $\left(\mathrm{v} / \mathrm{cm}^{-1}\right)=2049\left(\mathrm{~s}, \mathrm{~N}_{2}\right)$, 1998 (s, N2), 1605 (s), 1530 (s), 1519 (m), 1489 (m), 1469 (s), 1456 (s), 1413 (s), 1390 (w), 1380(w), 1356 (s), 1295 (s), 1255 (w), 1236 (w), 1178 (m), 1157 (s), 1100 (w), 1049 (s), 1016 (m), 1000 (s), 895 (s), 820 (s), 808 (s), 761 (s), 707 (s), 701 (s), $636(\mathrm{w}), 621(\mathrm{~m}), 604(\mathrm{~s}), 575$ (s), 542 (m), 526 (m), 500 (s), $474(\mathrm{~m}), 464$ (s), 447(s). UV-vis (THF): $\lambda_{\max }=332,484,517$ and $612 \mathrm{~nm}$.

\section{Synthesis of $\left[\left(\mathrm{L}^{\mathrm{Me} * *}\left(\mathrm{CoN}_{2}\right)\right)(\mathrm{K}([2.2 .2] \operatorname{cryptand}))_{2}\right](12)$.}

To a stirred solution of complex $10\left(0.044 \mathrm{mmol}, 53.3 \mathrm{mg}, 1.0\right.$ equiv) in $\mathrm{THF}(4 \mathrm{~mL})$ at $-40{ }^{\circ} \mathrm{C}, \mathrm{KC}_{8}$ 
( $0.088 \mathrm{mmol}, 11.9 \mathrm{mg}, 2.0$ equiv) was added and the solution was stirred overnight. After filtration of the solution through glass fibre filters, one equivalent of cryptand $(0.044 \mathrm{mmol}, 16.6 \mathrm{mg}, 1.0$ equiv) was added and stirred for $1 \mathrm{~h}$. After filtration again, block-shaped crystals were obtained by layering the filtrate with hexane at $-40{ }^{\circ} \mathrm{C}$ (Yield: $\left.65 \%\right) .{ }^{1} \mathrm{H}-\mathrm{NMR}\left(400 \mathrm{MHz}, \mathrm{THF}-\mathrm{d}_{8}\right): \delta(\mathrm{ppm})=$ 6.42 (br, 1H, Py'dearom 3-H), 6.24 (br, 2H, Py'dearom 4- $H$ and 5-H), 6.02 (t, $J=8 \mathrm{~Hz}, 1 \mathrm{H}, \mathrm{Py}$ dearom 4-H), $5.43\left(\mathrm{~d}, J=8 \mathrm{~Hz}, 1 \mathrm{H}, \mathrm{Py}_{\text {dearom }} 3-H\right), 5.16\left(\mathrm{~d}, J=8 \mathrm{~Hz}, 1 \mathrm{H}, \mathrm{P} \mathrm{y}_{\text {dearom }} 5-H\right), 2.81(\mathrm{~s}, 1 \mathrm{H}, \mathrm{CH}), 2.68$ (s, $\left.3 \mathrm{H}, \mathrm{Pz}-\mathrm{CH}_{3}\right), 2.41$ (br, cryptand) 1.43 (d, $\left.J=12 \mathrm{~Hz}, 18 \mathrm{H}, \mathrm{C}\left(\mathrm{CH}_{3}\right)_{3}\right), 1.07$ (d, $J=12 \mathrm{~Hz}, 18 \mathrm{H}$, $\left.\mathrm{C}^{\prime}\left(\mathrm{CH}_{3}\right)_{3}\right) .{ }^{13} \mathrm{C}-\mathrm{NMR}\left(100 \mathrm{MHz}, \mathrm{THF}-\mathrm{d}_{8}\right): \delta(\mathrm{ppm})=171.19,170.96,170.30,157.03\left(\mathrm{~s}, \mathrm{Py}_{\text {dearom }}\right.$ $C$-6), 155.76 (s, Pydearom C-6), 153.06, 151.58, 132.28 (s, Pydearom C-4), 131.46 (s, Py'dearom $C-4$ ), 110.80, 109.46 (d, $J=17$ Hz, Pydearom $C-3$ ), 107.18 (d, $J=25$ Hz, Py'dearom $C-3$ ), 96.66 (s, Py'dearom $C$-3), 93.33 (s, Pydearom $C$-3), 71.25 (br, cryptand), 58.79 (s, $C H$ ), 58.58 (d, $J=4$ Hz, $C^{\prime} \mathrm{H}$ ), 54.75 (br, cryptand), 35.65 (d, $\left.J=19 \mathrm{~Hz}, C\left(\mathrm{CH}_{3}\right)_{3}\right), 33.26\left(\mathrm{~d}, J=21 \mathrm{~Hz}, C^{\prime}\left(\mathrm{CH}_{3}\right)_{3}\right), 31.21(\mathrm{~d}, J=15 \mathrm{~Hz}$, $\left.\mathrm{C}^{\prime}\left(\mathrm{CH}_{3}\right)_{3}\right), 30.29\left(\mathrm{~d}, J=4 \mathrm{~Hz}, \mathrm{C}\left(\mathrm{CH}_{3}\right)_{3}\right), 12.14\left(\mathrm{~s}, \mathrm{Pz}-\mathrm{CH}_{3}\right) .{ }^{31} \mathrm{P}-\mathrm{NMR}\left(162 \mathrm{MHz}, \mathrm{THF}-\mathrm{d}_{8}\right)$ : $\delta(\mathrm{ppm})=80.71\left(\mathrm{~s}, \mathrm{P}_{\text {dearom }}\right), 34.24,18.25$. ATR-IR (solid): $\left(v / \mathrm{cm}^{-1}\right)=2014\left(\mathrm{~s}, \mathrm{~N}_{2}\right), 1599(\mathrm{~m}), 1575$ (s), 1511 (s), 1473 (s), 1439 (s), 1418 (s), 1379 (w), 1350 (s), 1292 (m), 1258 (m), 1239 (w), 1207 (w), $1174(\mathrm{w}), 1131(\mathrm{~m}), 1099$ (s), 1077 (s), $1016(\mathrm{w}), 999$ (m), 964 (m), 946 (s), 930 (s), 826 (m), $807(\mathrm{~m}), 781(\mathrm{w}), 775(\mathrm{w}), 763(\mathrm{w}), 750(\mathrm{w}), 714(\mathrm{~m}), 704(\mathrm{~m}), 661(\mathrm{w}), 625(\mathrm{w}), 604(\mathrm{w}), 570(\mathrm{w})$, $523(\mathrm{~m}), 478(\mathrm{w}), 463(\mathrm{w})$. UV-vis (THF): $\lambda_{\max }=331,455,484,550$ and $584 \mathrm{~nm}$.

\section{Synthesis of $\left[\left(\mathrm{L}^{* *}\left(\operatorname{Co}\left(\right.\right.\right.\right.$ cis $\left.\left.\left.-\mu-\eta^{1}: \eta^{1}-\mathrm{N}_{2} \mathrm{H}_{2}\right)\right) 2\right)(\mathrm{K}([2.2 .2]$ cryptand $\left.))\right](13)$.}

A $10 \mathrm{~mL}$ scintillation vial was charged with complex $\left[\left(\mathrm{L}^{* *}\left(\mathrm{CoN}_{2}\right)_{2}\right)(\mathrm{K}([2.2 .2]\right.$ cryptand $\left.))\right] 2(0.027$ mmol, $34.3 \mathrm{mg}, 1.0$ equiv) and $3 \mathrm{~mL}$ THF solvent. Then to the stirred THF solution of complex 2 , hydrazine $(0.054 \mathrm{mmol}, 1 \mathrm{M}, 54 \mu \mathrm{L}, 2.0$ equiv) was added, leading to an immediate color change from dark blue to brown. After stirring for $4 \mathrm{~h}$ and filtration through glass fiber filters, blue block-shaped crystals were obtained by concentrated THF solution at $-40{ }^{\circ} \mathrm{C}$ (Yield: $87 \%$ ). ${ }^{1} \mathrm{H}-\mathrm{NMR}$ $\left(400 \mathrm{MHz}, \mathrm{THF}-\mathrm{d}_{8}\right): \delta(\mathrm{ppm})=8.29(\mathrm{~s}, 2 \mathrm{H}, \mathrm{NH}$ of diazene), $6.86(\mathrm{~s}, 1 \mathrm{H}, \mathrm{pz} 4-H), 5.71(\mathrm{t}, \mathrm{J}=8 \mathrm{~Hz}$, $2 \mathrm{H}$, py dearom $4-H), 5.33(\mathrm{~d}, J=8 \mathrm{~Hz}, 2 \mathrm{H}$, py dearom $3-H), 5.27$ (d, $J=8 \mathrm{~Hz}, 2 \mathrm{H}$, py dearom $5-H), 3.14(\mathrm{~s}, 2 \mathrm{H}$, $\mathrm{CH}), 1.51\left(\mathrm{~d}, J=12 \mathrm{~Hz}, 36 \mathrm{H}, \mathrm{C}\left(\mathrm{CH}_{3}\right)_{3}\right) .{ }^{13} \mathrm{C}-\mathrm{NMR}\left(100 \mathrm{MHz}, \mathrm{THF}-\mathrm{d}_{8}\right): \delta(\mathrm{ppm})=170.24(\mathrm{~d}, J=19$

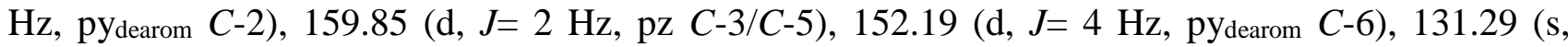
pydearom $C-4), 110.81$ (d, $J=15 \mathrm{~Hz}$, pydearom $C-3), 95.97$ (s, pz $C-4), 93.63$ (s, pydearom $C-5), 64.30$ (d, $J=51 \mathrm{~Hz}, C \mathrm{H}), 34.90\left(\mathrm{~d}, J=15 \mathrm{~Hz}, C\left(\mathrm{CH}_{3}\right)_{3}\right), 30.62\left(\mathrm{~d}, J=5 \mathrm{~Hz}, \mathrm{C}\left(\mathrm{CH}_{3}\right)_{3}\right) .{ }^{31} \mathrm{P}-\mathrm{NMR}(162 \mathrm{MHz}$, $\left.\mathrm{THF}_{-} \mathrm{d}_{8}\right) \delta(\mathrm{ppm})=55.26\left(\mathrm{~s}, P_{\text {dearom }}\right) .{ }^{15} \mathrm{~N}$ NMR $\left(41 \mathrm{MHz}, \mathrm{THF}-\mathrm{d}_{8}\right): \delta(\mathrm{ppm})=-166.35\left({ }^{1} J_{\mathrm{NH}}=72 \mathrm{~Hz}\right.$, $\mathrm{N}_{2} \mathrm{H}_{2}$ ). ATR-IR (solid): $\left(v / \mathrm{cm}^{-1}\right)=1596(\mathrm{~s}), 1515(\mathrm{~s}), 1484(\mathrm{w}), 1456(\mathrm{~s}), 1443(\mathrm{~m}), 1408(\mathrm{~m}), 1388$ (w), 1379 (w), 1351 (s), 1320 (w), 1288 (s), 1279(s), 1257 (m), 1172 (m), 1151 (m), 1156(s), 1129 (m), 1095 (s), 1083 (s), 1063 (s), 1050 (w), 1014 (s), 991 (s), 983(s), 945 (s), 929(s), 829 (w), 806 (s), $748(\mathrm{~s}), 702(\mathrm{~m}), 670(\mathrm{~m}), 615(\mathrm{~m}), 600(\mathrm{~s}), 580(\mathrm{~s}), 561(\mathrm{~m}), 538(\mathrm{~m}), 524(\mathrm{~m}), 476(\mathrm{~s}), 443(\mathrm{~s})$. UV-vis (THF): $\lambda_{\max }=315,495,482,665$ and 735nm. Elemental analysis (\%) Calc. for $\mathrm{C}_{65} \mathrm{H}_{115} \mathrm{Co}_{2} \mathrm{KN}_{8} \mathrm{O}_{10} \mathrm{P}_{2}$ : C 56.26, H 8.35, N 8.08; Found: C 55.90, H 8.11, N 7.63.

\section{Synthesis of $\left[\left(\mathrm{L}^{* *}\left(\operatorname{Co}\left(\right.\right.\right.\right.$ cis- $\left.\left.\left.\left.\mu-\eta^{1}: \eta^{1}-\mathrm{MeNNH}\right)\right) 2\right)(\mathrm{K}([2.2 .2] \mathrm{cryptand}))\right](14)$.}

To a stirred solution of complex $2(0.027 \mathrm{mmol}, 34.3 \mathrm{mg}, 1.0$ equiv) in THF ( $3 \mathrm{~mL})$ at room temperature, methylhydrazine $(0.054 \mathrm{mmol}, 1 \mathrm{M}, 54 \mu \mathrm{L}, 2.0$ equiv) was added dropwise and the 
resulting brown solution was stirred for 3 hours. Needle-shaped crystals suitable for X-ray diffraction analysis were grown in concentrated THF solution at $-40{ }^{\circ} \mathrm{C}$ (Yield: $\left.63 \%\right) .{ }^{1} \mathrm{H}-\mathrm{NMR}(400 \mathrm{MHz}$, THF-d $\left._{8}\right): \delta(\mathrm{ppm})=6.88(\mathrm{~s}, 1 \mathrm{H}, \mathrm{pz} 4-H), 5.98(\mathrm{~s}, 1 \mathrm{H}, \mathrm{NH}$ of methyldiazene), $5.71(\mathrm{t}, J=8 \mathrm{~Hz}, 1 \mathrm{H}$,

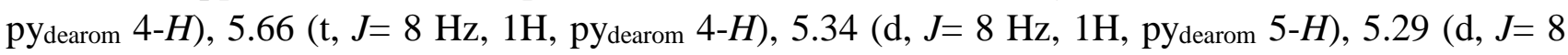
$\mathrm{Hz}, 1 \mathrm{H}$, pydearom $3-H), 5.23(\mathrm{~d}, J=8 \mathrm{~Hz}, 1 \mathrm{H}$, py dearom $3-H), 5.18\left(\mathrm{~d}, J=8 \mathrm{~Hz}, 1 \mathrm{H}, \mathrm{y}_{\text {dearom }} 5-H\right), 3.18$ (s, $1 \mathrm{H}, \mathrm{CH}), 2.87(\mathrm{~s}, 1 \mathrm{H}, \mathrm{CH}), 1.59\left(\mathrm{~d}, J=12 \mathrm{~Hz}, 18 \mathrm{H}, \mathrm{C}\left(\mathrm{CH}_{3}\right)_{3}\right), 1.55\left(\mathrm{~d}, J=12 \mathrm{~Hz}, 18 \mathrm{H}, \mathrm{C}\left(\mathrm{CH}_{3}\right)_{3}\right)$, -0.45 (s, 3H, $\mathrm{CH}_{3} \mathrm{~N}$ of methyldiazene). ${ }^{13} \mathrm{C}-\mathrm{NMR}\left(100 \mathrm{MHz}, \mathrm{THF}-\mathrm{d}_{8}\right): \delta(\mathrm{ppm})=169.94(\mathrm{~d}, J=20$ $\mathrm{Hz}$, pydearom $C-2), \delta(\mathrm{ppm})=169.69(\mathrm{~d}, J=19 \mathrm{~Hz}$, pydearom $C-2), 160.47(\mathrm{~d}, J=2 \mathrm{~Hz}, \mathrm{pz} C-5), 159.44$ (d, $J=2 \mathrm{~Hz}$, pz $C-C-3$ ), 152.22 (d, $J=4 \mathrm{~Hz}$, pydearom $C-6$ ), 151.79 (d, $J=4 \mathrm{~Hz}$, pydearom $C-6), 131.62$ (d, $J=2 \mathrm{~Hz}$, py dearom $C-4), 131.08$ (d, $J=2 \mathrm{~Hz}$, pydearom $\left._{\text {de }}-4\right), 110.84$ (d, $J=14 \mathrm{~Hz}$, py dearom $\left.C-3\right), 110.40$ (d, $J=13 \mathrm{~Hz}$, pydearom $C-3$ ), 96.23 (s, pz $C-4$ ), 93.63 (s, pydearom $C-5$ ), 93.33 (s, pydearom $C-5$ ), 76.88 (d, $\left.J=14 \mathrm{~Hz}, C \mathrm{H}_{3}-\mathrm{N}\right), 64.77(\mathrm{~d}, J=49 \mathrm{~Hz}, C \mathrm{H}), 64.45(\mathrm{~d}, J=52 \mathrm{~Hz}, C \mathrm{H}), 35.04\left(\mathrm{~d}, J=15 \mathrm{~Hz}, C\left(\mathrm{CH}_{3}\right)_{3}\right)$, $34.34\left(\mathrm{~d}, J=11 \mathrm{~Hz}, C\left(\mathrm{CH}_{3}\right)_{3}\right), 30.95\left(\mathrm{~d}, J=5 \mathrm{~Hz}, \mathrm{C}\left(C \mathrm{H}_{3}\right)_{3}\right), 30.58\left(\mathrm{~d}, J=6 \mathrm{~Hz}, \mathrm{C}\left(C_{3}\right)_{3}\right) .{ }^{31} \mathrm{P}-\mathrm{NMR}$ $\left(162 \mathrm{MHz}, \mathrm{THF}-\mathrm{d}_{8}\right) \delta(\mathrm{ppm})=51.27$ and 35.27. ${ }^{15} \mathrm{~N}$ NMR $\left(52 \mathrm{MHz}, \mathrm{THF}-\mathrm{d}_{8}\right): \delta(\mathrm{ppm})=-183.18$ $\left(\mathrm{CH}_{3} \mathrm{~N}\right),-153.90\left({ }^{1} J_{\mathrm{NH}}=65 \mathrm{~Hz}, \mathrm{NH}\right)$. ATR-IR (solid): $\left(v / \mathrm{cm}^{-1}\right)=1597(\mathrm{~s}), 1517(\mathrm{~m}), 1498(\mathrm{w})$, 1466 (s), 1457 (s), 1442 (m), 1411 (m), 1380 (m), 1351 (s), 1322 (w), 1294 (s), 1276 (s), 1258 (s), 1235 (w), 1172 (m), 1151 (m), 1129 (m), 1095 (s), 1075 (s), 1064 (s), 1022 (w), 1014 (m), 990 (m), 980 (s), 946 (s), 930 (s), 830 (w), 805 (s), 752 (s), 703 (s), 670 (m), 690 (w), 607 (s), 578 (m), 557 (m), $521(\mathrm{~m}), 471(\mathrm{~s}) . \mathrm{UV}$-vis (THF): $\lambda_{\max }=320,414,505,667 \mathrm{~nm}$. Elemental analysis $(\%)$ Calc. for $\mathrm{C}_{58} \mathrm{H}_{101} \mathrm{Co}_{2} \mathrm{KN}_{8} \mathrm{O}_{8} \mathrm{P}_{2}$ : C 55.40, H 8.10, N 8.91; Found: C 55.10, H 7.88, N 8.56.

\section{Synthesis of $\left[\left(\mathrm{L}^{* *}\left(\mathrm{Co}\left(\operatorname{trans}-\mu-\eta^{1}: \eta^{1}-\mathrm{MeNNMe}\right)\right)_{2}\right)(\mathrm{K}([2.2 .2] \operatorname{cryptand}))\right](15)$.}

To a stirred solution of complex $2(0.027 \mathrm{mmol}, 34.3 \mathrm{mg}, 1.0$ equiv) in THF $(3 \mathrm{~mL})$ at room temperature, 1,2-dimethylhydrazine $(0.054 \mathrm{mmol}, 0.6 \mathrm{M}, 90 \mu \mathrm{L}, 2.0$ equiv) was added dropwise and the resulting red brown solution was stirred for 3 hours. Block-shaped crystals suitable for X-ray diffraction analysis were grown in concentrated THF solution at $-40{ }^{\circ} \mathrm{C}$ (Yield: $\left.55 \%\right) .{ }^{1} \mathrm{H}-\mathrm{NMR}(400$ MHz, THF-d 8$): \delta(\mathrm{ppm})=6.39(\mathrm{~s}, 1 \mathrm{H}, \mathrm{pz} 4-H), 5.71(\mathrm{t}, J=8 \mathrm{~Hz}, 2 \mathrm{H}$, pydearom 4-H), $5.07(\mathrm{t}, J=8 \mathrm{~Hz}$, $2 \mathrm{H}$, pydearom 5-H), 4.98 (d, $J=8 \mathrm{~Hz}, 2 \mathrm{H}$, pydearom $3-H), 2.72(\mathrm{~s}, 2 \mathrm{H}, \mathrm{CH}), 1.61$ (d, J=8 Hz, 36H, $\left.\mathrm{C}\left(\mathrm{CH}_{3}\right)_{3}\right), 1.44\left(\mathrm{~d}, J=12 \mathrm{~Hz}, 6 \mathrm{H}, \mathrm{CH}_{3}\right.$ of dimethyldiazene). ${ }^{13} \mathrm{C}-\mathrm{NMR}\left(100 \mathrm{MHz}, \mathrm{THF}-\mathrm{d}_{8}\right)$ : $\delta(\mathrm{ppm})=169.29(\mathrm{~d}), 156.11,148.50,130.26(\mathrm{~s}$, pydearom $C-4), 106.35(\mathrm{~d}, J=14 \mathrm{~Hz}$, pydearom $C-3)$, 98.72 (s, pz $C-4), 94.56$ (s, pydearom $C-5$ ), 59.90 (d, $J=53 \mathrm{~Hz}, C H$ ), 56.98, 34.64 (d), 31.16 (d, $J=4$ $\left.\mathrm{Hz}, \mathrm{C}\left(\mathrm{CH}_{3}\right)_{3}\right), 29.59\left(\mathrm{~d}, J=5 \mathrm{~Hz}, \mathrm{CH}_{3} \mathrm{~N}\right) .{ }^{31} \mathrm{P}-\mathrm{NMR}\left(162 \mathrm{MHz}, \mathrm{THF}-\mathrm{d}_{8}\right) \delta(\mathrm{ppm})=23.80$. ATR-IR (solid): $\left(v / \mathrm{cm}^{-1}\right)=1879(\mathrm{~m}), 1592(\mathrm{~s}), 1511(\mathrm{~s}), 1484(\mathrm{w}), 1455(\mathrm{~s}), 1444(\mathrm{~m}), 1408(\mathrm{~s}), 1379(\mathrm{~m})$, 1351 (s), 1324 (w), 1280 (s), 1258 (s), 1237 (m), 1170 (m), 1151 (s), 1131 (s), 1098 (s), 1059 (s), 1016 (m), 985 (s), 947 (s), 930 (s), 903 (s), 831 (w), 815 (s), 805 (s), 747 (s), 703 (s), 687 (m), 619 (m), 601 (s), 578 (s), $562(\mathrm{w}), 524(\mathrm{~m}), 472$ (s), 442 (s), 433 (m). UV-vis (THF): $\lambda_{\max }=3202,395$, $450,539,751 \mathrm{~nm}$.

\section{Synthesis of $\left[\left(\mathrm{L}^{* *}\left(\mathrm{Co}\left(\operatorname{trans}-\mu-\eta^{1}: \eta^{1}-\mathrm{PhNNPh}\right)\right) 2\right)(\mathrm{K}([2.2 .2] \mathrm{cryptand}))\right](16)$.}

A $10 \mathrm{~mL}$ scintillation vial was charged with complex $\left[\left(\mathrm{L}^{* *}\left(\mathrm{CoN}_{2}\right)_{2}\right)(\mathrm{K}([2.2 .2]\right.$ cryptand $\left.))\right] 2(0.027$ mmol, $34.3 \mathrm{mg}, 1.0$ equiv) and $3 \mathrm{~mL}$ THF solvent. Treatment of complex 2 in THF with one equivalent of azobenzene $(0.027 \mathrm{mmol}, 4.9 \mathrm{mg}, 1.0$ equiv) results in an immediate color change from 
dark blue to red brown. Crystals suitable for X-ray diffraction could be isolated from concentrated THF solution at $-40{ }^{\circ} \mathrm{C}$ in $70 \%$ yield and also identified as an azobezene complex $\left[\left(\mathrm{L}^{* *}\left(\mathrm{Co}\left(\text { trans }-\mu-\eta^{1}: \eta^{1}-\mathrm{PhNNPh}\right)\right)_{2}\right)(\mathrm{K}([2.2 .2]\right.$ cryptand $\left.))\right] \quad$ 16. ${ }^{1} \mathrm{H}-\mathrm{NMR} \quad\left(400 \mathrm{MHz}, \quad \mathrm{THF}-\mathrm{d}_{8}\right)$ : $\delta(\mathrm{ppm})=12.74(\mathrm{~s}, 1 \mathrm{H}, \mathrm{pz} 4-H), 8.63\left(\mathrm{~s}, 18 \mathrm{H}, \mathrm{C}\left(\mathrm{CH}_{3}\right)_{3}\right), 6.60(\mathrm{~s}$, py dearom $4-H), 4.36(\mathrm{~s}, 18 \mathrm{H}$, $\left.\mathrm{C}\left(\mathrm{CH}_{3}\right)_{3}\right),-0.02,-4.86$ (s, pydearom 3-H /5- $\left.H\right),-11.62$ (s, pydearom 3-H/5- $H$ ), -13.12, -29.41. ATR-IR (solid): $\left(v / \mathrm{cm}^{-1}\right)=1615(\mathrm{~m}), 1609(\mathrm{~m}), 1580(\mathrm{~s}), 1536(\mathrm{~m}), 1507(\mathrm{w}), 1474(\mathrm{~s}), 1445(\mathrm{~m}), 1418(\mathrm{~m})$, 1391 (w), 1384 (w), 1354 (s), 1327 (w), 1298 (m), 1273 (m), 1259 (m), 1235 (m), 1156 (m), 1131 (m), 1101 (s), 1078 (m), 1068 (m), 1017 (s), 992 (s), 982 (s), 949 (s), 932 (s), 884 (m), 865 (w), 830 (w), $810(\mathrm{~s}), 755(\mathrm{~s}), 734(\mathrm{~m}), 706(\mathrm{~s}), 683(\mathrm{~m}), 624(\mathrm{~m}), 612(\mathrm{~s}), 572(\mathrm{w}), 511(\mathrm{w}), 479(\mathrm{~s})$. UV-vis (THF) : $\lambda_{\max }=318,428,511,550$, and 595nm. Elemental analysis $(\%)$ Calc. for $\mathrm{C}_{65} \mathrm{H}_{99} \mathrm{Co}_{2} \mathrm{KN}_{8} \mathrm{P}_{2} \mathrm{O}_{7}$ : C 58.99, H 7.54, N 8.47; Found: C 58.75, H 7.60, N 8.03.

Catalytic reactions of dinitrogen to $\mathbf{N}\left(\mathrm{SiMe}_{3}\right)_{3}$. A typical experimental procedure is described below. In a $50 \mathrm{ml}$ Schlenk flask were placed catalysts (complexes 1-12 $0.005 \mathrm{mmol}, \mathrm{CoCl}_{2} 0.01 \mathrm{mmol}$ ) and $\mathrm{KC}_{8}(1351.8 \mathrm{mg}, 10.00 \mathrm{mmol})$. When the reagents were in a dinitrogen atmosphere frozen by liquid nitrogen, $\mathrm{Me}_{3} \mathrm{SiCl}(1086.4 \mathrm{mg}, 10.00 \mathrm{mmol})$ in $25 \mathrm{~mL}$ THF was added dropwise. Then the reactions were stirred at various temperatures $\left(25^{\circ} \mathrm{C},-40{ }^{\circ} \mathrm{C},-90^{\circ} \mathrm{C}\right)$ for $2 \mathrm{~h}$ and room temperature for $22 \mathrm{~h}$ with a color change to black. After addition of cyclododecane $(200 \mathrm{mg}$ ), graphite and $\mathrm{KCl}$ were removed by filtration. The product $\mathrm{N}\left(\mathrm{SiMe}_{3}\right)_{3}$ was identified by $\mathrm{GC}$ MS and quantified by GC with cyclododecane as the internal standard.

\section{Synthesis of $\left[\left(\mathrm{L}_{3} \mathrm{Cos}\left(\mu-\mathrm{CO}_{3}\right)_{2}(\mu-\mathrm{OTf})\right)(\mathrm{OTf})_{2}\right](17)$.}

Upon exposure of a stirred suspension of complex $6(0.01 \mathrm{mmol}, 54.8 \mathrm{mg}, 1.0$ equiv) in THF ( $3 \mathrm{~mL})$ to $1 \mathrm{~atm} \mathrm{CO}_{2}$ atmosphere at room temperature, an initial purple solution turned green immediately. After being stirred for $3 \mathrm{~h}$, the solution was filtered through a glass fiber filter. Two kinds of crystals suitable for X-ray diffraction were generated from a concentrated THF solution at room temperature. One is brown plate-like crystal (Yield: $20 \%$ ) and another is blue needle-shaped crystal (Yield: $40 \%$ ), featuring a cobalt(II) carbonate complex $\left[\left(\mathrm{L}_{3} \mathrm{Co} 5\left(\mu-\mathrm{CO}_{3}\right)_{2}(\mu\right.\right.$-OTf $\left.\left.)\right)(\mathrm{OTf})_{2}\right] 17$ and a dicobalt(I) monocarbonyl complex $\left[\left(\mathrm{LCo}_{2}(\mathrm{CO})_{2}\right)(\mathrm{OTf})\right] \mathbf{1 8}$ respectively. Because of the low yield of complex 17, other characterizations are still in progress.

\section{Synthesis of $\left[\left(\mathrm{LCo}_{2}(\mathrm{CO})_{2}\right)(\mathrm{OTf})\right](18)$.}

Method A: Upon exposure of a stirred suspension of complex 6 (0.01 mmol, $54.8 \mathrm{mg}, 1.0$ equiv $)$ in THF (3 mL) to $1 \mathrm{~atm} \mathrm{CO}_{2}$ atmosphere at room temperature, an initial purple solution turned green immediately. After being stirred for $3 \mathrm{~h}$, the solution was filtered through a glass fiber filter. Two types of crystals suitable for X-ray diffraction were generated from a concentrated THF solution at room temperature. One is brown plate-like crystal (Yield: $20 \%$ ) and another is blue needle-shaped crystal (Yield: $40 \%)$, featuring a cobalt(II) carbonate complex $\left[\left(\mathrm{L}_{3} \mathrm{Co}_{5}\left(\mu-\mathrm{CO}_{3}\right)_{2}(\mu \text {-OTf)) (OTf })_{2}\right] 17\right.$ and a dicobalt(I) monocarbonyl complex $\left[\left(\mathrm{LCo}_{2}(\mathrm{CO})_{2}\right)(\mathrm{OTf})\right] 18$ respectively. Method B: a suspension of complex 6 ( $0.01 \mathrm{mmol}, 54.8 \mathrm{mg}, 1.0$ equiv.) in THF (3 mL) was exposed to $1 \mathrm{~atm} \mathrm{CO}$ gas atmosphere, leading to an immediate color change from purple to red brown. The solution was stirred overnight and then the volatile was removed in vacuo. The rest green solid was dissolved into 
THF again. Needle-shaped crystals of complex 18 suitable for X-ray diffraction analysis were grown by layering the THF solution with hexane at $-40{ }^{\circ} \mathrm{C}$ (Yield: $\left.80 \%\right) .{ }^{1} \mathrm{H}-\mathrm{NMR}(400 \mathrm{MHz}$, acetone-d 6 ): $\delta(\mathrm{ppm})=8.02(\mathrm{t}, J=8 \mathrm{~Hz}, 2 \mathrm{H}$, py $4-H), 7.65(\mathrm{~d}, J=8 \mathrm{~Hz}, 2 \mathrm{H}$, py $5-H), 7.60(\mathrm{~d}, J=8 \mathrm{~Hz}, 2 \mathrm{H}$, py 3-H), 7.28 (s, $1 \mathrm{H}, \mathrm{pz} 4-H), 4.02\left(\mathrm{~d}, J=8 \mathrm{~Hz}, 4 \mathrm{H}, \mathrm{CH}_{2}\right), 1.51$ (d, $\left.J=16 \mathrm{~Hz}, 36 \mathrm{H}, \mathrm{C}\left(\mathrm{CH}_{3}\right)_{3}\right) .{ }^{13} \mathrm{C}-\mathrm{NMR}$ $\left(126 \mathrm{MHz}, \mathrm{THF}-\mathrm{d}_{8}\right): \delta(\mathrm{ppm})=163.35$ (s, py $\left.C-2\right), 157.04$ (s, pz $\left.C-3 / C-5\right), 152.70(\mathrm{~d}, J=5.04 \mathrm{~Hz}$, py $C-6), 140.92$ (d, $J=6.3 \mathrm{~Hz}$, py $C-4), 121.44$ (d, $J=8.82 \mathrm{~Hz}$, py $C-3), 117.71$ (s, py $C-5), 102.76$ (s, pz $C-4), 36.73\left(\mathrm{~d}, J=18.9 \mathrm{~Hz}, C\left(\mathrm{CH}_{3}\right)_{3}\right), 35.82\left(\mathrm{~d}, J=20.16 \mathrm{~Hz}, C \mathrm{H}_{2}\right), 29.33\left(\mathrm{~d}, J=2.52 \mathrm{~Hz}, \mathrm{C}\left(C \mathrm{CH}_{3}\right)_{3}\right)$. ${ }^{31} \mathrm{P}-\mathrm{NMR}\left(162 \mathrm{MHz}\right.$, acetone- $\left.\mathrm{d}_{6}\right) \delta(\mathrm{ppm})=107.08(\mathrm{~s}, P) .{ }^{19} \mathrm{~F}-\mathrm{NMR}\left(376 \mathrm{MHz}\right.$, acetone- $\left.\mathrm{d}_{6}\right)$ $\delta(\mathrm{ppm})=-78.73\left(\mathrm{~s}, \mathrm{CF}_{3} \mathrm{SO}_{3}{ }^{-}\right) . \operatorname{ATR}-\mathrm{IR}(\mathrm{solid}):\left(v / \mathrm{cm}^{-1}\right)=1934(\mathrm{~s}, \mathrm{CO}), 1912(\mathrm{~s}, \mathrm{CO}), 1665(\mathrm{w})$, 1606 (m), 1559 (m), 1469 (w), 1458 (m), 1417 (w), 1402 (w), 1391 (w), 1370 (m), 1313 (m), 1260 (s), $1222(\mathrm{~m}), 1162(\mathrm{w}), 1147(\mathrm{~s}), 1088(\mathrm{~m}), 1067(\mathrm{~m}), 1029(\mathrm{~s}), 902(\mathrm{w}), 830(\mathrm{~m}), 810(\mathrm{w}), 799(\mathrm{w})$, $786(\mathrm{~m}), 751(\mathrm{w}), 738(\mathrm{w}), 636(\mathrm{~s}), 586(\mathrm{~m}), 571(\mathrm{~m}), 532(\mathrm{~s}), 516(\mathrm{~m}), 508(\mathrm{~m}), 479(\mathrm{~m}), 474(\mathrm{~m})$, 449 (m), 423 (w), 415 (w), 410 (w). ${ }^{13} \mathrm{CO}: 1889$ (s, $\left.{ }^{13} \mathrm{CO}\right), 1867$ (s, $\left.{ }^{13} \mathrm{CO}\right)$. UV-vis (THF): $\lambda_{\max }=310$, $401,427,647 \mathrm{~nm}$.

\section{Synthesis of $\left[\left(\mathrm{LCo}_{2}(\mathrm{CO})_{4}\right)(\mathrm{OTf})\right](19)$.}

A suspension of complex $6(0.01 \mathrm{mmol}, 54.8 \mathrm{mg}, 1.0$ equiv) in THF ( $3 \mathrm{~mL})$ was exposed to $1 \mathrm{~atm}$ $\mathrm{CO}$ gas atmosphere, leading to an immediate color change from purple to red brown. Then the red brown solution was flushed with argon for a while to exclude excess $\mathrm{CO}$ gas and after filtration through a glass fiber filters, red block-shaped crystals suitable for X-ray diffraction were obtained by layering the filtrate with hexane at $-40{ }^{\circ} \mathrm{C}$ to give rise to a dicobalt dicarbonyl complex $\left[\left(\mathrm{LCo}_{2}(\mathrm{CO})_{4}\right)(\mathrm{OTf})\right] 19$ (Yield: $\left.85 \%\right) .{ }^{1} \mathrm{H}-\mathrm{NMR}\left(400 \mathrm{MHz}, \mathrm{THF}-\mathrm{d}_{8}\right): \delta(\mathrm{ppm})=7.91(\mathrm{t}, J=8 \mathrm{~Hz}, 2 \mathrm{H}$, py $4-H), 7.80(\mathrm{~d}, J=8 \mathrm{~Hz}, 2 \mathrm{H}$, py $5-H), 7.65(\mathrm{~s}, 1 \mathrm{H}, \mathrm{pz} 4-H), 7.55(\mathrm{~d}, J=8 \mathrm{~Hz}, 2 \mathrm{H}$, py $3-H), 4.04(\mathrm{~d}$, $\left.J=12 \mathrm{~Hz}, 4 \mathrm{H}, \mathrm{CH}_{2}\right), 1.44\left(\mathrm{~d}, J=16 \mathrm{~Hz}, 36 \mathrm{H}, \mathrm{C}\left(\mathrm{CH}_{3}\right)_{3}\right) .{ }^{13} \mathrm{C}-\mathrm{NMR}\left(126 \mathrm{MHz}, \mathrm{THF}-\mathrm{d}_{8}\right): \delta(\mathrm{ppm})=$ 199.31-199.10 (CO), 161.34 (s, py $C$-2), 155.61 (s, pz $C-3 / C-5), 151.14$ (s, py $C-6), 138.85$ (s, py $C-4), 120.32$ (d, $J=8.82 \mathrm{~Hz}$, py $C-3$ ), 118.04 (s, py $C-5$ ), 103.61 (s, pz $C-4$ ), 37.90 (d, $J=16.38 \mathrm{~Hz}$, $\left.C\left(\mathrm{CH}_{3}\right)_{3}\right), 36.58\left(\mathrm{~d}, J=21.42 \mathrm{~Hz}, \mathrm{CH}_{2}\right), 29.32\left(\mathrm{~s}, \mathrm{C}\left(\mathrm{CH}_{3}\right)_{3}\right) .{ }^{31} \mathrm{P}-\mathrm{NMR}\left(162 \mathrm{MHz}, \mathrm{THF}-\mathrm{d}_{8}\right) \delta(\mathrm{ppm})=$ $117.55(\mathrm{~s}, P) .{ }^{19} \mathrm{~F}-\mathrm{NMR}\left(376 \mathrm{MHz}, \mathrm{THF}-\mathrm{d}_{8}\right) \delta(\mathrm{ppm})=-79.26\left(\mathrm{~s}, \mathrm{CF}_{3} \mathrm{SO}_{3}{ }^{-}\right)$. ATR-IR (solid): $\left(\mathrm{v} / \mathrm{cm}^{-1}\right)$ = $1997(\mathrm{~s}, \mathrm{CO}), 1940(\mathrm{~s}, \mathrm{CO}), 1930(\mathrm{~s}, \mathrm{CO}), 1603(\mathrm{~m}), 1551(\mathrm{w}), 1530(\mathrm{~m}), 1479(\mathrm{~m}), 1457(\mathrm{~m})$, 1417 (w), 1406 (w), 1390 (m), 1370 (m), 1344 (w), 1316 (w), 1259 (s), 1222 (s), 1180 (w), 1161 (m), $1150(\mathrm{~m}), 1061(\mathrm{~m}), 1027(\mathrm{~s}), 899(\mathrm{~m}), 829(\mathrm{~s}), 797(\mathrm{~s}), 789(\mathrm{~s}), 753(\mathrm{~m}), 743(\mathrm{~m}), 636(\mathrm{~s}), 630(\mathrm{~s})$, $586(\mathrm{~m}), 571(\mathrm{~m}), 556(\mathrm{w}), 548(\mathrm{~m}), 534(\mathrm{~m}), 517(\mathrm{~m}), 503(\mathrm{~m}), 481(\mathrm{~m}), 466(\mathrm{~m}), 446(\mathrm{~m}) .{ }^{13} \mathrm{CO}$ : $1951\left(\mathrm{~s},{ }^{13} \mathrm{CO}\right), 1889\left(\mathrm{~s},{ }^{13} \mathrm{CO}\right), 1877\left(\mathrm{~s},{ }^{13} \mathrm{CO}\right)$.

\section{Synthesis of $\left[\mathrm{L}\{\mathrm{Co}(\mathrm{OTf})\} \mathrm{Co}\left(\mu-\mathrm{SiHPh}_{2}\right)\right](20)$.}

To a stirred suspension of complex $6(0.01 \mathrm{mmol}, 54.8 \mathrm{mg}, 1.0$ equiv) in THF ( $3 \mathrm{~mL})$, three equivalents of diphenylsilane were added dropwise. After being stirred overnight, the solution was filtered. Slow diffusion of diethyl ether into the THF solution yielded needle-shaped crystals of the complex $\left[\mathrm{L}\{\mathrm{Co}(\mathrm{OTf})\} \mathrm{Co}\left(\mu-\mathrm{SiHPh}_{2}\right)\right] 20$ suitable for X-ray diffraction (Yield: $\left.50 \%\right) .{ }^{1} \mathrm{H}-\mathrm{NMR}(400$ MHz, THF-d 8$): \delta(\mathrm{ppm})=17.93,13.20,11.98,10.53,9.58,9.18,8.59,5.48,2.52,0.37,-2.90$. ATR-IR (solid): $\left(v / \mathrm{cm}^{-1}\right)=1602(\mathrm{~m}), 1558(\mathrm{~m}), 1516(\mathrm{~m}), 1462(\mathrm{~m}), 1452(\mathrm{~m}), 1423(\mathrm{w}), 1414(\mathrm{w})$, 1403 (w), 1388 (w), 1365 (m), 1341 (m), 1318 (w), 1290 (s), 1237 (s), 1219 (s), 1178 (m), 1155 (s), 
1151 (s), 1106 (w), 1092 (w), 1082 (w), 1048 (m), 1025 (s), 1005 (m), $934(\mathrm{w}), 906$ (m), $826(\mathrm{~s}), 819$ (s), $782(\mathrm{~s}), 772(\mathrm{~s}), 755(\mathrm{w}), 751(\mathrm{w}), 746(\mathrm{w}), 733(\mathrm{~s}), 731(\mathrm{~s}), 706(\mathrm{w}), 698(\mathrm{~s}), 681(\mathrm{w}), 677(\mathrm{w})$, $672(\mathrm{w}), 660(\mathrm{~m}), 635$ (s), $624(\mathrm{~s}), 603(\mathrm{~m}), 580(\mathrm{~s}), 543(\mathrm{~m}), 517$ (s), 479 (s), 471 (s). UV-vis (THF): $\lambda_{\max }=303,379,418,486,582,775 \mathrm{~nm}$. Calc. for $\mathrm{C}_{44} \mathrm{H}_{58} \mathrm{Co}_{2} \mathrm{~N}_{4} \mathrm{P}_{2} \mathrm{~F}_{3} \mathrm{O}_{3} \mathrm{SSi}$ : C 53.49, H 5.92, N 5.67, S 3.25; Found: C 53.10, H 6.02, N 5.33, S 3.87.

\section{Synthesis of $[\mathrm{LCo}(\mu-\mathrm{SiHMePh})(\mathrm{OTf})] 21$.}

two equivalents of methylphenylsilane was added into a stirred suspension of complex $\mathbf{6}$ in THF. After reacting overnight, the solution was filtered and block-shaped crystals of complex [ $\left.\mathrm{LCo}_{2}(\mu-\mathrm{SiHMePh})(\mathrm{OTf})\right] 21$ suitable for X-ray diffraction were obtained from concentrated THF solution at room temperature. (Yield: $80 \%) .{ }^{1} \mathrm{H}-\mathrm{NMR}\left(400 \mathrm{MHz}, \mathrm{THF}-\mathrm{d}_{8}\right): \delta(\mathrm{ppm})=15.58,8.84$, 7.96, 7.74, 7.52, 7.32, 6.71, 4.19, 2.52, 2.40. ATR-IR (solid): $\left(v / \mathrm{cm}^{-1}\right)=1600(\mathrm{~m}), 1555(\mathrm{~m}), 1517$ (w), $1463(\mathrm{~m}), 1453(\mathrm{~m}), 1440(\mathrm{~m}), 1387(\mathrm{w}), 1366(\mathrm{~m}), 1353(\mathrm{~m}), 1310(\mathrm{~m}), 1256(\mathrm{~s}), 1223(\mathrm{~s})$, 1150 (s), 1029 (s), 1005 (s), 896 (m), 826 (m), 810 (m), 775 (m), 749 (w), 699 (m), 636 (s), 572 (s), $516(\mathrm{~s}), 475(\mathrm{~s}), 445(\mathrm{~m})$.

\section{Synthesis of $\left[\mathrm{L}_{2} \mathrm{Co}_{4}\left(\mu-\mathrm{SiH}_{2} \mathrm{SiH}_{2}\right)(\mathrm{OTf})_{2}\right] 22$.}

Phenylsilane ( $0.04 \mathrm{mmol}, 17.3 \mathrm{mg}, 4.0$ equiv) was added into a stirred suspension of complex 6 ( 0.01 mmol, $54.8 \mathrm{mg}, 1.0$ equiv) in THF. After stirring overnight, the solution was filtered through a glass fiber filters and block-shaped crystals of complex $\left[\mathrm{L}_{2} \mathrm{Co}_{4}\left(\mu-\mathrm{SiH}_{2} \mathrm{SiH}_{2}\right)(\mathrm{OTf})_{2}\right] 22$ suitable for X-ray diffraction were obtained from concentrated THF solution at room temperature (Yield: $45 \%$ ). ${ }^{1} \mathrm{H}-\mathrm{NMR}\left(400 \mathrm{MHz}, \mathrm{THF}-\mathrm{d}_{8}\right): \delta(\mathrm{ppm})=24.03,16.44,10.56,7.40,6.28,0.87,0.64,0.27,1.32,-4.17$, -4.87. ATR-IR (solid): $\left(v / \mathrm{cm}^{-1}\right)=1683(\mathrm{w}), 1658(\mathrm{~m}), 1632(\mathrm{~m}), 1600(\mathrm{~m}), 1550(\mathrm{~m}), 1501(\mathrm{~m})$, 1467 (m), 1454 (m), 1424 (w), 1411 (m), 1394 (w), 1368 (m), 1333 (m), 1271 (s), 1255 (s), 1220 (m), 1157 (s), 1151 (s), $1104(\mathrm{w}), 1066$ (w), 1028 (s), 1006 (m), 937 (w), 905 (w), 857 (w), 830 (s), 814 (m), $781(\mathrm{~m}), 745(\mathrm{~m}), 738(\mathrm{~m}), 700(\mathrm{~m}), 635(\mathrm{~s}), 573(\mathrm{~m}), 517(\mathrm{~m}), 481(\mathrm{~m})$. IR (KBr pellet, solid): $\left(v / \mathrm{cm}^{-1}\right)=2167(\mathrm{~m}), 1992(\mathrm{~m}), 1603(\mathrm{~s}), 1566(\mathrm{~s}), 1506(\mathrm{~m}), 1471(\mathrm{~s}), 1454(\mathrm{~s}), 1421(\mathrm{w}), 1393(\mathrm{w})$, 1371 (m), 1347 (w), 1318 (m), 1275 (s), 1223 (s), 1178 (m), 1147 (s), 1093 (m), 1031 (s), 983 (w), $955(\mathrm{w}), 897(\mathrm{~m}), 857(\mathrm{~m}), 835(\mathrm{~s}), 783(\mathrm{~m}), 745(\mathrm{~m}), 689(\mathrm{~m}), 672(\mathrm{~m}), 637(\mathrm{~s}), 572(\mathrm{~m}), 516(\mathrm{~m})$, $497(\mathrm{w}), 480(\mathrm{w})$. UV-vis (THF): $\lambda_{\max }=307,420,487,598,759 \mathrm{~nm}$. Elemental analysis (\%) Calc. for $\mathrm{C}_{64} \mathrm{H}_{96} \mathrm{Co}_{4} \mathrm{~N}_{8} \mathrm{P}_{4} \mathrm{~F}_{6} \mathrm{O}_{6} \mathrm{~S}_{2} \mathrm{Si}_{2}$ : C 46.10, H 5.80, N 6.72, S 3.85; Found: C 45.98, H 5.58, N 6.47, S 4.21 .

\section{Synthesis of $\left[\mathrm{L}_{2} \mathrm{Co}_{4}\left(\mu-\mathrm{PhSi}_{4} \mathrm{H}_{3}\right](\mathrm{OTf})_{2} 23\right.$.}

Phenylsilane ( $0.06 \mathrm{mmol}, 26.0 \mathrm{mg}, 6.0$ equiv) was added into a stirred suspension of complex 6 ( 0.01 mmol, $54.8 \mathrm{mg}, 1.0$ equiv) in THF. After stirring overnight, the solution was filtered through a glass fiber filters and big block-shaped crystals of complex $\left[\mathrm{L}_{2} \mathrm{Co}_{4}\left(\mu-\mathrm{PhSi}_{4} \mathrm{H}_{3}\right](\mathrm{OTf})_{2} 23\right.$ suitable for X-ray diffraction were obtained after four days from concentrated THF solution at room temperature (Yield: $55 \%)$. ATR-IR (solid): $\left(v / \mathrm{cm}^{-1}\right)=1601(\mathrm{~m}), 1550(\mathrm{~m}), 1506(\mathrm{~m}), 1472(\mathrm{~s}), 1425(\mathrm{w}), 1410(\mathrm{~m})$, 1403 (m), 1394 (w), 1367 (m), 1349 (w), 1319 (w), 1259 (s), 1222 (s), 1178 (m), 1151 (m), 1134 (s), 1060 (w), 1030 (s), 936 (w), 926 (w), 904 (m), 859 (m), 823 (s), 776 (s), 752 (m), 744 (m), 735 (m), 
$704(\mathrm{~m}), 688(\mathrm{~m}), 676(\mathrm{~m}), 636(\mathrm{~s}), 627$ (s), 603 (w), 570 (s), $514(\mathrm{~s}), 478(\mathrm{~m})$. IR (KBr pellet, solid): $\left(v / \mathrm{cm}^{-1}\right)=2036(\mathrm{~m}), 2020(\mathrm{~m}), 1603(\mathrm{~s}), 1568(\mathrm{~s}), 1505(\mathrm{~m}), 1472(\mathrm{~s}), 1453(\mathrm{~s}), 1403(\mathrm{~m}), 1393(\mathrm{~m})$, $1370(\mathrm{~m}), 1318$ (m), 1275 (s), 1263 (s), 1223 (s), 1155 (s), 1138 (s), 1092 (m), 1030 (s), 937 (w), 898 (m), $860(\mathrm{w}), 837(\mathrm{~m}), 825(\mathrm{~m}), 778(\mathrm{~m}), 860(\mathrm{w}), 835(\mathrm{~s}), 825(\mathrm{~s}), 778(\mathrm{~m}), 750(\mathrm{~m}), 743(\mathrm{~m}), 703$ (m), 675 (m), 655 (m), 637 (s), 572 (s), 515 (s), 482 (m). UV-vis (MeCN): $\lambda_{\max }=290$, 471, 660, 991 nm. Calc. for $\mathrm{C}_{74} \mathrm{H}_{110} \mathrm{Co}_{4} \mathrm{~N}_{8} \mathrm{P}_{4} \mathrm{~F}_{6} \mathrm{O}_{7} \mathrm{~S}_{2} \mathrm{Si}_{2}$ : C 47.43, H 5.92, N 5.98, $\mathrm{S}$ 3.42; Found: $\mathrm{C} 47.04, \mathrm{H}$ 5.78, $\mathrm{N}$ 5.98, S 3.99 . 



\section{Chapter 8: Crystallographic Details}

Table 8.1: Crystal data and refinement details.

\begin{tabular}{|c|c|c|c|}
\hline Compound & 1 & 2 & 3 \\
\hline Empirical formula & $\mathrm{C}_{31} \mathrm{H}_{47} \mathrm{Cl}_{3} \mathrm{Co}_{2} \mathrm{~N}_{4} \mathrm{P}_{2}$ & $\begin{array}{c}\mathrm{C}_{57} \mathrm{H}_{99} \mathrm{Co}_{2} \mathrm{KN}_{10} \mathrm{O} \\
{ }_{8} \mathrm{P}_{2} \\
\end{array}$ & $\begin{array}{c}\mathrm{C}_{53} \mathrm{H}_{95} \mathrm{ClCo}_{2} \mathrm{KN}_{5} \mathrm{O} \\
{ }_{4} \mathrm{P}_{2} \mathrm{Si}_{2}\end{array}$ \\
\hline Formula weight & 761.87 & 1271.36 & 1176.86 \\
\hline$T[\mathrm{~K}]$ & 133 & $133(2)$ & $133(2)$ \\
\hline Crystal size & $0.380 \times 0.320 \times 0.300$ & $\begin{array}{c}0.500 \times 0.280 \times \\
0.240\end{array}$ & $\begin{array}{c}0.400 \times 0.380 \times \\
0.290\end{array}$ \\
\hline Crystal system & Monoclinic & Triclinic & Orthorhombic \\
\hline Space group & $\mathrm{P} 2_{1} / \mathrm{n}$ & $\mathrm{P} 21 / \mathrm{n}$ & Pbca \\
\hline$a[\AA]$ & $16.0431(7)$ & $13.5542(6)$ & $20.5370(3)$ \\
\hline$b[\AA]$ & $13.4865(7)$ & $20.7264(12)$ & $23.3588(3)$ \\
\hline$c[\AA]$ & $16.9427(7)$ & $23.6882(11)$ & $26.0429(4)$ \\
\hline$\alpha\left[^{\circ}\right]$ & 90 & 90 & 90 \\
\hline$\beta\left[^{\circ}\right]$ & $102.957(3)$ & $90.782(4)^{\circ}$ & 90 \\
\hline$\gamma\left[^{\circ}\right]$ & 90 & 90 & 90 \\
\hline$V\left[\AA^{3}\right]$ & $3572.5(3)$ & $6654.1(6)$ & 12493.3(3) \\
\hline$Z$ & 4 & 4 & 8 \\
\hline$\rho\left[\mathrm{g} / \mathrm{cm}^{3}\right]$ & 1.417 & 1.269 & 1.251 \\
\hline$F(000)$ & 1584.0 & 2712 & 5024 \\
\hline$\mu\left[\mathrm{mm}^{-1}\right]$ & 1.270 & 0.665 & 0.774 \\
\hline$T_{\min } / T_{\max }$ & $0.632 / 0.726$ & $0.6506 / 0.8612$ & $0.7783 / 0.8792$ \\
\hline$\theta$ range $\left[{ }^{\circ}\right]$ & 1.950 to 26.791 & 1.305 to 25.736 & 1.534 to 25.804 \\
\hline$h k l$-range & $\pm 20, \pm 17, \pm 21$ & $-15,16, \pm 25, \pm 28$ & $\pm 25,-25,28, \pm 31$ \\
\hline Measured refl. & 31902 & 85632 & 101899 \\
\hline Unique refl. $\left[R_{\text {int }}\right]$ & $7441[0.0422]$ & $12565[0.0555]$ & 11808 [0.0375] \\
\hline Observed refl. $(I>2(I))$ & 5905 & 10443 & 9822 \\
\hline Data / Res. / Param. & 7441 / 0 / 391 & $12565 / 129 / 781$ & $11808 / 266 / 787$ \\
\hline Goodness-of-fit $\left(F^{2}\right)$ & 0.978 & 1.037 & 1.049 \\
\hline$R_{1}, w R_{2}(I>2(I))$ & $0.0340,0.0735$ & $0.0357,0.0902$ & $0.0285,0.0678$ \\
\hline$R_{1}, w R_{2}$ (all data) & $0.0489,0.0770$ & $0.0474,0.0979$ & $0.0403,0.0743$ \\
\hline Resid. el. dens. [e/ $\left./ \AA^{3}\right]$ & $0.457 /-0.210$ & $0.450 /-0.239$ & $0.475 /-0.225$ \\
\hline
\end{tabular}


Table 8.2: Crystal data and refinement details.

\begin{tabular}{|c|c|c|c|}
\hline Compound & 6 & 7 & 9 \\
\hline Empirical formula & $\mathrm{C}_{72} \mathrm{H}_{110} \mathrm{Co}_{4} \mathrm{~F}_{6} \mathrm{~N}_{12} \mathrm{O}_{8} \mathrm{P}_{4} \mathrm{~S}_{2}$ & $\begin{array}{c}\mathrm{C}_{32} \mathrm{H}_{46} \mathrm{Co}_{2} \mathrm{~F}_{3} \mathrm{~N}_{4} \mathrm{O} \\
{ }_{3} \mathrm{P}_{2} \mathrm{~S}\end{array}$ & $\begin{array}{c}\mathrm{C}_{32} \mathrm{H}_{49} \mathrm{Cl}_{3} \mathrm{Co}_{2} \mathrm{~N}_{4} \\
\mathrm{P}_{2}\end{array}$ \\
\hline Formula weight & 1809.43 & 803.59 & 775.90 \\
\hline$T[\mathrm{~K}]$ & $133(2)$ & $133(2)$ & $133(2)$ \\
\hline Crystal size & $0.490 \times 0.130 \times 0.080$ & $\begin{array}{c}0.240 \times 0.210 \mathrm{x} \\
0.190\end{array}$ & $\begin{array}{c}0.380 \times 0.150 \times \\
0.140\end{array}$ \\
\hline Crystal system & Triclinic & Monoclinic & Orthorhombic \\
\hline Space group & P-1 & $\mathrm{P} 2_{1}$ & $\mathrm{P} 2_{1} 2_{1} 2_{1}$ \\
\hline$a[\AA]$ & $16.7558(6)$ & $11.5036(4)$ & $13.6440(2)$ \\
\hline$b[\AA]$ & $17.6252(7)$ & $12.5214(4)$ & $15.8692(2)$ \\
\hline$c[\AA]$ & $21.2978(8)$ & $12.8792(5)$ & $34.1793(6)$ \\
\hline$\alpha\left[^{\circ}\right]$ & $66.765(3)$ & 90 & 90 \\
\hline$\beta\left[^{\circ}\right]$ & $83.024(3)$ & $93.022(3)$ & 90 \\
\hline$\gamma\left[^{\circ}\right]$ & $71.563(3)$ & 90 & 90 \\
\hline$V\left[\AA^{3}\right]$ & $5482.9(4)$ & $1852.56(11)$ & $7400.48(19)$ \\
\hline$Z$ & 2 & 2 & 8 \\
\hline$\rho\left[\mathrm{g} / \mathrm{cm}^{3}\right]$ & 1.096 & 1.441 & 1.393 \\
\hline$F(000)$ & 188 & 834 & 3232 \\
\hline$\mu\left[\mathrm{mm}^{-1}\right]$ & 0.746 & 1.090 & 1.227 \\
\hline$T_{\min } / T_{\max }$ & $0.4918 / 0.9418$ & $0.7498 / 0.8247$ & $0.6306 / 0.8563$ \\
\hline$\theta$ range $\left[{ }^{\circ}\right]$ & 1.281 to 25.808 & 1.583 to $26.147^{\circ}$. & 1.415 to 25.690 \\
\hline$h k l$-range & $\begin{array}{c}-18,20 \\
\pm 21 \\
-26,25\end{array}$ & $\begin{array}{l} \pm 14 \\
\pm 15 \\
\pm 15\end{array}$ & $\begin{array}{c}-16,15 \\
\pm 19 \\
\pm 41\end{array}$ \\
\hline Measured refl. & 56474 & 37940 & 88658 \\
\hline Unique refl. $\left[R_{\text {int }}\right]$ & $20691[0.1035]$ & 37940 & $13964[0.0371]$ \\
\hline Observed refl. $(I>2(I))$ & 12435 & 30823 & 13021 \\
\hline Data / Res. / Param. & $20691 / 171 / 1022$ & 37940 / 154 / 436 & 13964 / 0 / 801 \\
\hline Goodness-of-fit $\left(F^{2}\right)$ & 1.015 & 1.114 & 1.046 \\
\hline$R_{1}, w R_{2}(I>2(I))$ & $0.0681,0.1488$ & $0.0609,0.1656$ & $0.0242,0.0567$ \\
\hline$R_{1}, w R_{2}$ (all data) & $0.0681,0.1488$ & $0.0791,0.1765$ & $0.0282,0.0584$ \\
\hline Resid. el. dens. $\left[\mathrm{e} / \AA^{3}\right]$ & $1.005 /-0.665$ & $0.841 / 0.508$ & $0.534 /-0.239$ \\
\hline
\end{tabular}


Table 8.3: Crystal data and refinement details.

\begin{tabular}{|c|c|c|c|}
\hline Compound & 10 & 11 & 12 \\
\hline Empirical formula & $\mathrm{C}_{54} \mathrm{H}_{91} \mathrm{Co}_{2} \mathrm{~K} \mathrm{~N}_{10} \mathrm{O}_{7} \mathrm{P}_{2}$ & $\begin{array}{c}\mathrm{C}_{56} \mathrm{H}_{95} \mathrm{Co}_{2} \mathrm{~K} \mathrm{~N}_{8} \\
\mathrm{O}_{6} \mathrm{P}_{2}\end{array}$ & $\begin{array}{c}\mathrm{C}_{72} \mathrm{H}_{127} \mathrm{Co} \mathrm{K}_{2} \mathrm{~N}_{10} \\
\mathrm{O}_{13} \mathrm{P}_{2}\end{array}$ \\
\hline Formula weight & 1211.26 & 1195.29 & 1539.90 \\
\hline$T[\mathrm{~K}]$ & $133(2)$ & $133(2)$ & $133(2)$ \\
\hline Crystal size & $0.500 \times 0.240 \times 0.160$ & $\begin{array}{c}0.500 \times 0.360 \times \\
0.280\end{array}$ & $\begin{array}{c}0.360 \times 0.260 \times \\
0.240\end{array}$ \\
\hline Crystal system & Monoclinic & Monoclinic & Triclinic \\
\hline Space group & $\mathrm{P} 2_{1} / \mathrm{c}$ & $\mathrm{C} 2 / \mathrm{c}$ & $\mathrm{P}-1$ \\
\hline$a[\AA]$ & $14.4834(3)$ & $24.5900(4)$ & $13.4123(6)$ \\
\hline$b[\AA]$ & $20.1028(3)$ & $22.0487(5)$ & $16.6281(7)$ \\
\hline$c[\AA]$ & $25.3446(5)$ & $28.4295(5)$ & $23.1691(10)$ \\
\hline$\alpha\left[^{\circ}\right]$ & 90 & 90 & $109.669(3)$ \\
\hline$\beta\left[^{\circ}\right]$ & $95.018(2)$ & $110.9430(10)$ & $96.389(3)$ \\
\hline$\gamma\left[^{\circ}\right]$ & 90 & 90 & $90.700(3)$ \\
\hline$V\left[\AA^{3}\right]$ & $7351.0(2)$ & $14395.5(5)$ & $4828.7(4)$ \\
\hline Z & 4 & 8 & 2 \\
\hline$\rho\left[\mathrm{g} / \mathrm{cm}^{3}\right]$ & 1.094 & 1.103 & 1.059 \\
\hline$F(000)$ & 2576 & 5104 & 1656 \\
\hline$\mu\left[\mathrm{mm}^{-1}\right]$ & 0.598 & 0.608 & 0.350 \\
\hline$T_{\min } / T_{\max }$ & $0.7645 / 0.9444$ & $0.7954 / 0.9113$ & $0.4059 / 0.6523$ \\
\hline$\theta$ range $\left[{ }^{\circ}\right]$ & 1.295 to 25.821 & 1.280 to 25.754 & 1.302 to 25.798 \\
\hline$h k l$-range & $\begin{array}{c} \pm 17 \\
-24,23 \\
\pm 30\end{array}$ & $\begin{array}{c}-28,29 \\
\pm 26 \\
\pm 34\end{array}$ & $\begin{array}{l} \pm 16 \\
\pm 20 \\
\pm 28 \\
\end{array}$ \\
\hline Measured refl. & 91552 & 90831 & 60861 \\
\hline Unique refl. $\left[R_{\text {int }}\right]$ & $13903[0.0535]$ & $13602[0.0557]$ & $18242[0.0887]$ \\
\hline Observed refl. $(I>2(I))$ & 10830 & 9754 & 10902 \\
\hline Data / Res. / Param. & $13903 / 70 / 744$ & $13602 / 417 / 794$ & $18242 / 0 / 914$ \\
\hline Goodness-of-fit $\left(F^{2}\right)$ & 1.019 & 1.035 & 1.012 \\
\hline$R_{1}, w R_{2}(I>2(I))$ & $0.0367,0.0884$ & $0.0536,0.1437$ & $0.0726,0.1883$ \\
\hline$R_{1}, w R_{2}$ (all data) & $0.0547,0.0976$ & $0.0773,0.1596$ & $0.1169,0.2220$ \\
\hline Resid. el. dens. $\left[\mathrm{e} / \AA^{3}\right]$ & $0.513 /-0.188$ & $1.308 /-1.026$ & $0.632 /-1.222$ \\
\hline
\end{tabular}


Table 8.4: Crystal data and refinement details.

\begin{tabular}{|c|c|c|c|c|}
\hline Compound & 13 & 14 & 15 & 16 \\
\hline Empirical formula & $\mathrm{C}_{65} \mathrm{H}_{115} \mathrm{Co}_{2} \mathrm{~K} \mathrm{~N}_{8} \mathrm{O}_{10} \mathrm{P}_{2}$ & $\begin{array}{c}\mathrm{C}_{58} \mathrm{H}_{101} \mathrm{Co}_{2} \mathrm{~K} \\
\mathrm{~N}_{8} \mathrm{O}_{8} \mathrm{P}_{2}\end{array}$ & $\begin{array}{c}\mathrm{C}_{51} \mathrm{H}_{87} \mathrm{Co}_{2} \mathrm{~K} \mathrm{~N}_{8} \\
\mathrm{O}_{6} \mathrm{P}_{2}\end{array}$ & $\begin{array}{c}\mathrm{C}_{77} \mathrm{H}_{123} \mathrm{Co}_{2} \mathrm{~K} \mathrm{~N}_{8} \\
\mathrm{O}_{10} \mathrm{P}_{2} \\
\end{array}$ \\
\hline Formula weight & 1387.54 & 1257.36 & 1127.18 & 1539.73 \\
\hline$T[\mathrm{~K}]$ & $133(2)$ & $133(2)$ & $133(2)$ & $133(2)$ \\
\hline Crystal size & $0.500 \times 0.280 \times 0.220$ & $\begin{array}{c}0.497 \times 0.067 \times \\
0.066\end{array}$ & $\begin{array}{c}0.253 \times 0.233 \times \\
0.191\end{array}$ & $\begin{array}{c}0.250 \times 0.230 \times \\
0.140\end{array}$ \\
\hline Crystal system & Monoclinic & Triclinic & Monoclinic & Triclinic \\
\hline Space group & $\mathrm{P} 2{ }_{1} / \mathrm{c}$ & $\mathrm{P}-1$ & $\mathrm{P} 2_{1} / \mathrm{c}$ & $\mathrm{P}-1$ \\
\hline$a[\AA]$ & $14.7140(3)$ & $11.1407(6)$ & $14.6766(4)$ & $14.5596(5)$ \\
\hline$b[\AA]$ & 24.8841(4) & $12.4976(6)$ & 20.0796(7) & $17.1522(7)$ \\
\hline$c[\AA]$ & $19.8712(5)$ & $27.5234(14)$ & $24.5499(8)$ & $17.3559(6)$ \\
\hline$\alpha\left[^{\circ}\right]$ & 90 & $88.853(4)$ & 90 & $97.703(3)$ \\
\hline$\beta\left[^{\circ}\right]$ & $103.140(2)$ & $78.786(4)$ & $93.4730(10)$ & $104.275(3)$ \\
\hline$\gamma\left[^{\circ}\right]$ & 90 & $69.737(4)$ & 90 & $103.062(3)$ \\
\hline$V\left[\AA^{3}\right]$ & $7085.2(3)$ & $3521.7(3)$ & $7221.6(4)$ & 4008.2(3) \\
\hline$Z$ & 4 & 2 & 4 & 2 \\
\hline$\rho\left[\mathrm{g} / \mathrm{cm}^{3}\right]$ & 1.300 & 1.186 & 1.037 & 1.276 \\
\hline$F(000)$ & 2972 & 1344 & 2400 & 1648 \\
\hline$\mu\left[\mathrm{mm}^{-1}\right]$ & 0.632 & 0.627 & 0.603 & 0.566 \\
\hline$T_{\min } / T_{\max }$ & $0.7457 / 0.8857$ & $0.6358 / 0.9506$ & & $0.7841 / 0.9838$ \\
\hline$\theta$ range $\left[{ }^{\circ}\right]$ & 1.333 to 26.870 & 1.511 to 25.613 & 2.028 to 27.933 & 1.499 to 26.938 \\
\hline$h k l$-range & $\begin{array}{c} \pm 18 \\
-29,31 \\
\pm 25\end{array}$ & $\begin{array}{c} \pm 13 \\
-14,15 \\
\pm 15\end{array}$ & $\begin{array}{c}-19,18 \\
\pm 26 \\
\pm 32\end{array}$ & $\begin{array}{c} \pm 18 \\
-21,20 \\
\pm 21\end{array}$ \\
\hline Measured refl. & 82307 & 44491 & 193782 & 57105 \\
\hline Unique refl. $\left[R_{\text {int }}\right]$ & $15061[0.0445]$ & 13278 [0.1237] & $17298[0.0731]$ & $17015[0.0846]$ \\
\hline Observed refl. $(I>2(I))$ & 11825 & 6417 & 12937 & 10567 \\
\hline Data / Res. / Param. & $15061 / 223$ / 905 & 13278 / 104 / 788 & $17298 / 582$ / 900 & $\begin{array}{c}17015 \text { / } 2329 / \\
1341 \\
\end{array}$ \\
\hline Goodness-of-fit $\left(F^{2}\right)$ & 1.025 & 0.830 & 1.066 & 1.049 \\
\hline$R_{1}, w R_{2}(I>2(I))$ & $0.0442,0.1092$ & $0.0617,0.1120$ & $0.0672,0.1737$ & $0.0596,0.1166$ \\
\hline$R_{1}, w R_{2}$ (all data) & $0.0612,0.1208$ & $0.1393,0.1765$ & $0.0903,0.1882$ & $0.1190,0.1430$ \\
\hline Resid. el. dens. [e/ $\left./ \AA^{3}\right]$ & $1.020 /-0.427$ & $0.458 /-0.379$ & $0.760 /-0.589$ & $0.515 /-0.369$ \\
\hline
\end{tabular}


Table 8.5: Crystal data and refinement details.

\begin{tabular}{|c|c|c|c|}
\hline Compound & 18 & 19 & 20 \\
\hline Empirical formula & $\mathrm{C}_{38} \mathrm{H}_{55} \mathrm{Co}_{2} \mathrm{~F}_{3} \mathrm{~N}_{4} \mathrm{O}_{6} \mathrm{P}_{2} \mathrm{~S}$ & $\begin{array}{c}\mathrm{C}_{40} \mathrm{H}_{55} \mathrm{Co}_{2} \mathrm{~F}_{3} \\
\mathrm{~N}_{4} \mathrm{O}_{8} \mathrm{P}_{2} \mathrm{~S}\end{array}$ & $\begin{array}{c}\mathrm{C}_{46} \mathrm{H}_{62} \mathrm{Co}_{2} \mathrm{~F}_{3} \mathrm{~N}_{4} \\
\mathrm{O}_{3.50} \mathrm{P}_{2} \mathrm{~S} \mathrm{Si}\end{array}$ \\
\hline Formula weight & 932.72 & 988.74 & 1023.94 \\
\hline$T[\mathrm{~K}]$ & $133(2)$ & $133(2)$ & $133(2)$ \\
\hline Crystal size & $0.396 \times 0.059 \times 0.042$ & $\begin{array}{c}0.380 \times 0.360 \times \\
0.110\end{array}$ & $\begin{array}{c}0.494 \times 0.269 \times \\
0.251\end{array}$ \\
\hline Crystal system & Triclinic & Monoclinic & Monoclinic \\
\hline Space group & $\mathrm{P}-1$ & $\mathrm{P} 2_{1} / \mathrm{n}$ & $\mathrm{C} 2 / \mathrm{c}$ \\
\hline$a[\AA]$ & $9.0382(3)$ & $10.1455(3)$ & $35.5587(12)$ \\
\hline$b[\AA]$ & $15.6434(6)$ & $19.4086(7)$ & $12.3896(2)$ \\
\hline$c[\AA]$ & $16.9647(6)$ & $22.6275(7)$ & $22.9218(8)$ \\
\hline$\alpha\left[^{\circ}\right]$ & 63.1830(10) & 90 & 90 \\
\hline$\beta\left[^{\circ}\right]$ & $84.8920(10)$ & $97.072(2)$ & $106.761(3)$ \\
\hline$\gamma\left[^{\circ}\right]$ & $77.4380(10)$ & 90 & 90 \\
\hline$V\left[\AA^{3}\right]$ & 2089.29(13) & $4421.7(2)$ & $9669.4(5)$ \\
\hline$Z$ & 2 & 4 & 8 \\
\hline$\rho\left[\mathrm{g} / \mathrm{cm}^{3}\right]$ & 1.483 & 1.485 & 1.407 \\
\hline$F(000)$ & 972 & 2056 & 4280 \\
\hline$\mu\left[\mathrm{mm}^{-1}\right]$ & 0.983 & 0.937 & 0.877 \\
\hline$T_{\min } / T_{\max }$ & $0.87 / 0.96$ & $0.7286 / 0.9111$ & $0.8141 / 0.6648$ \\
\hline$\theta$ range $\left[{ }^{\circ}\right]$ & 2.309 to 27.892 & 1.387 to 26.876 & 1.196 to 25.748 \\
\hline$h k l$-range & $\begin{array}{l} \pm 11 \\
\pm 20 \\
\pm 22 \\
\end{array}$ & $\begin{array}{l} \pm 12 \\
\pm 24 \\
\pm 28 \\
\end{array}$ & $\begin{array}{c} \pm 43 \\
-15,13 \\
\pm 27\end{array}$ \\
\hline Measured refl. & 55778 & 55986 & 32721 \\
\hline Unique refl. $\left[R_{\text {int }}\right]$ & 9975 [0.0833] & $9401[0.0660]$ & $9100[0.0481]$ \\
\hline Observed refl. $(I>2(I))$ & 7573 & 7079 & 7431 \\
\hline Data / Res. / Param. & 9975 / $109 / 594$ & $9401 / 0 / 553$ & $9100 / 22 / 611$ \\
\hline Goodness-of-fit $\left(F^{2}\right)$ & 1.054 & 1.066 & 1.030 \\
\hline$R_{1}, w R_{2}(I>2(I))$ & $0.0404,0.0911$ & $0.0405,0.0961$ & $0.0394,0.1010$ \\
\hline$R_{1}, w R_{2}$ (all data) & $0.0664,0.1086$ & $0.0642,0.1076$ & $0.0525,0.1108$ \\
\hline Resid. el. dens. $\left[\mathrm{e} / \AA^{3}\right]$ & $0.779 /-0.618$ & $0.841 / 0.508$ & $0.864 /-0.383$ \\
\hline
\end{tabular}


Table 8.6: Crystal data and refinement details.

\begin{tabular}{|c|c|c|c|}
\hline Compound & 21 & 22 & 23 \\
\hline Empirical formula & $\begin{array}{c}\mathrm{C}_{49} \mathrm{H}_{76} \mathrm{Co}_{2} \mathrm{~F}_{3} \mathrm{~N}_{4} \mathrm{O}_{5} \mathrm{P}_{2} \mathrm{~S} \\
\mathrm{Si}\end{array}$ & $\begin{array}{l}\mathrm{C}_{64} \mathrm{H}_{98} \mathrm{Co}_{4} \mathrm{~F}_{6} \\
\mathrm{~N}_{8} \mathrm{O}_{6} \mathrm{P}_{4} \mathrm{~S}_{2} \mathrm{Si}_{2}\end{array}$ & $\begin{array}{l}\mathrm{C}_{74} \mathrm{H}_{110} \mathrm{Co}_{4} \mathrm{~F}_{6} \\
\mathrm{~N}_{8} \mathrm{O}_{7} \mathrm{P}_{4} \mathrm{~S}_{2} \mathrm{Si}_{4} \\
\end{array}$ \\
\hline Formula weight & 1106.08 & 1669.40 & 1873.77 \\
\hline$T[\mathrm{~K}]$ & $133(2)$ & $133(2)$ & $133(2)$ \\
\hline Crystal size & $0.350 \times 0.140 \times 0.080$ & $\begin{array}{c}0.500 \times 0.490 \times \\
0.420 \\
\end{array}$ & $\begin{array}{c}0.460 \times 0.325 \times \\
0.262 \\
\end{array}$ \\
\hline Crystal system & Triclinic & Monoclinic & Orthorhombic \\
\hline Space group & P-1 & $\mathrm{P} 21 / \mathrm{n}$ & Pbcn \\
\hline$a[\AA]$ & $11.2329(6)$ & $16.6525(2)$ & $27.2102(9)$ \\
\hline$b[\AA]$ & $14.9003(8)$ & $20.7913(4)$ & $15.2439(5)$ \\
\hline$c[\AA]$ & $15.9314(10)$ & $22.5177(3)$ & $20.2076(7)$ \\
\hline$\alpha\left[^{\circ}\right]$ & $99.840(5)$ & 90 & 90 \\
\hline$\beta\left[^{\circ}\right]$ & $91.294(5)$ & $107.3430(10)$ & 90 \\
\hline$\gamma\left[^{\circ}\right]$ & $96.403(4)$ & 90 & 90 \\
\hline$V\left[\AA^{3}\right]$ & $2608.5(3)$ & $7441.8(2)$ & $8381.9(5)$ \\
\hline$Z$ & 2 & 4 & 4 \\
\hline$\rho\left[\mathrm{g} / \mathrm{cm}^{3}\right]$ & 1.408 & 1.488 & 1.485 \\
\hline$F(000)$ & 1166 & 3464 & 3904 \\
\hline$\mu\left[\mathrm{mm}^{-1}\right]$ & 0.821 & 1.119 & 1.031 \\
\hline$T_{\min } / T_{\max }$ & $0.5414 / 0.8507$ & $0.5982 / 0.7766$ & $0.77 / 0.66$ \\
\hline$\theta$ range $\left[{ }^{\circ}\right]$ & 1.298 to 26.031 & 1.347 to 26.896. & 2.150 to 27.923 \\
\hline$h k l$-range & $\begin{array}{c} \pm 13 \\
-18,17 \\
\pm 19\end{array}$ & $\begin{array}{l} \pm 21 \\
\pm 26 \\
\pm 28\end{array}$ & $\begin{array}{l}-34,35 \\
-20,19 \\
-26,26\end{array}$ \\
\hline Measured refl. & 52665 & 105869 & 92850 \\
\hline Unique refl. $\left[R_{\text {int }}\right]$ & 52665 & $15806[0.0356]$ & 10019 [0.0484] \\
\hline Observed refl. $(I>2(I))$ & 25810 & 13252 & 8243 \\
\hline Data / Res. / Param. & 52665 / $30 / 649$ & $15806 / 0$ / 897 & $10019 / 88 / 548$ \\
\hline Goodness-of-fit $\left(F^{2}\right)$ & 1.008 & 1.043 & 1.098 \\
\hline$R_{1}, w R_{2}(I>2(I))$ & $0.0773,0.1821$ & $0.0295,0.0749$ & $0.0384,0.0894$ \\
\hline$R_{1}, w R_{2}$ (all data) & $0.1715,0.2269$ & $0.0400,0.0810$ & $0.0527,0.0974$ \\
\hline Resid. el. dens. $\left[\mathrm{e} / \AA^{3}\right]$ & $0.533 /-0.545$ & $1.205 /-0.460$ & $0.474 /-0.490$ \\
\hline
\end{tabular}




\section{Chapter 9: Appendix}

\subsection{Further Analytical Data for Ligand Synthesis}

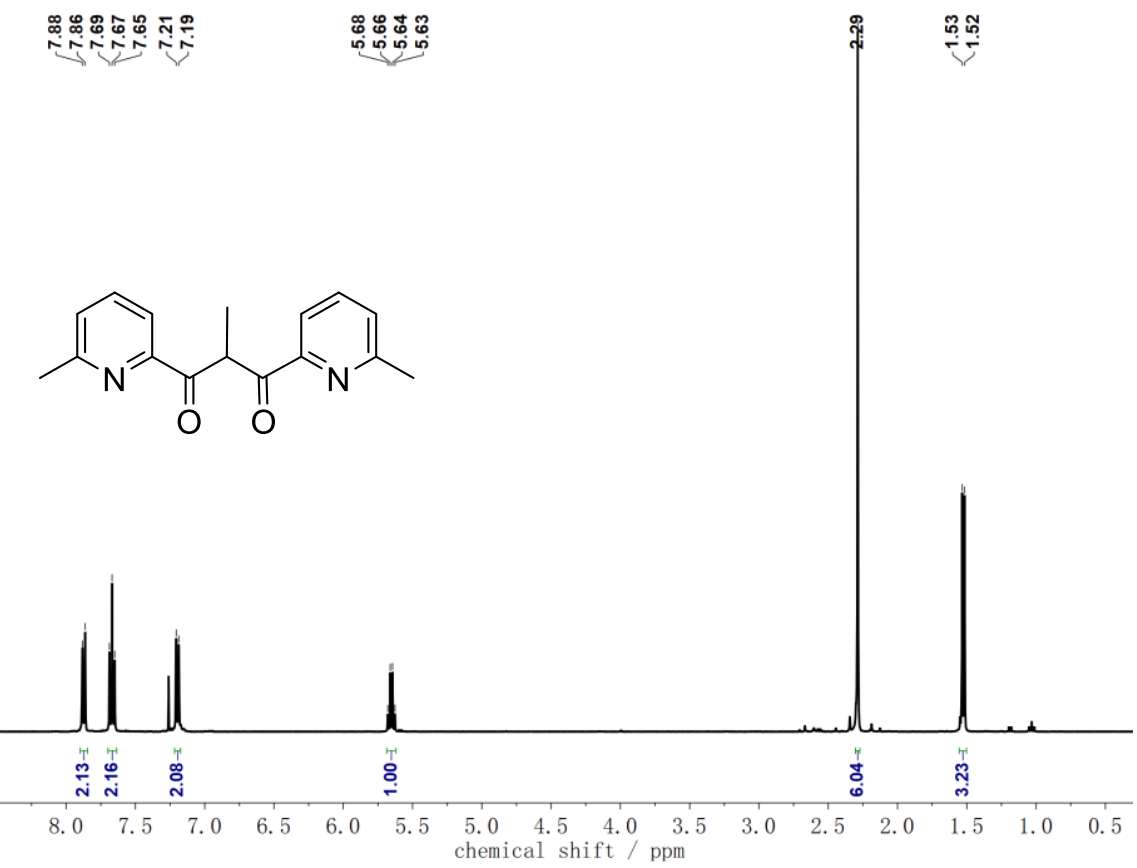

Figure 9.1: ${ }^{1} \mathrm{H}-\mathrm{NMR}(300 \mathrm{MHz})$ of VIII in $\mathrm{CDCl}_{3}$.

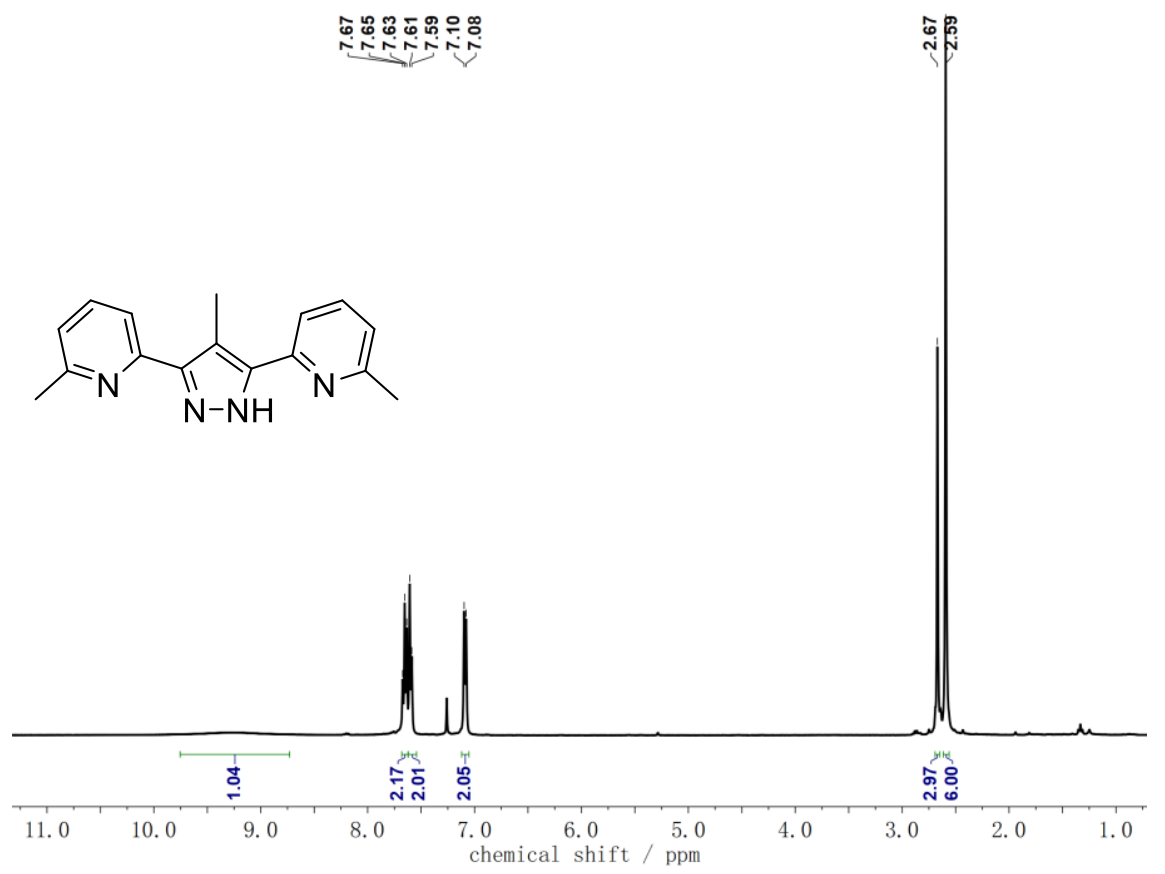

Figure 9.2: ${ }^{1} \mathrm{H}-\mathrm{NMR}(300 \mathrm{MHz})$ of $\mathbf{I X}$ in $\mathrm{CDCl}_{3}$. 


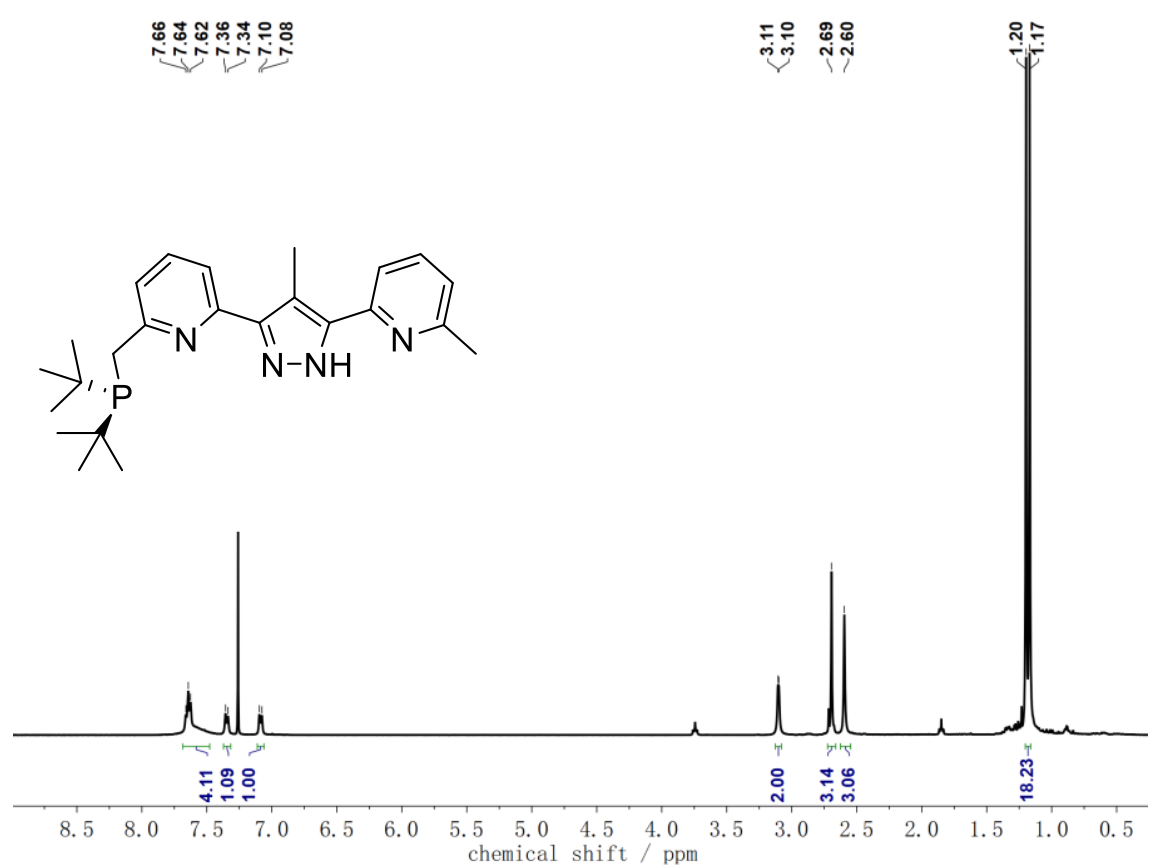

Figure 9.3: ${ }^{1} \mathrm{H}-\mathrm{NMR}(400 \mathrm{MHz})$ of $\mathbf{X}$ in $\mathrm{CDCl}_{3}$.

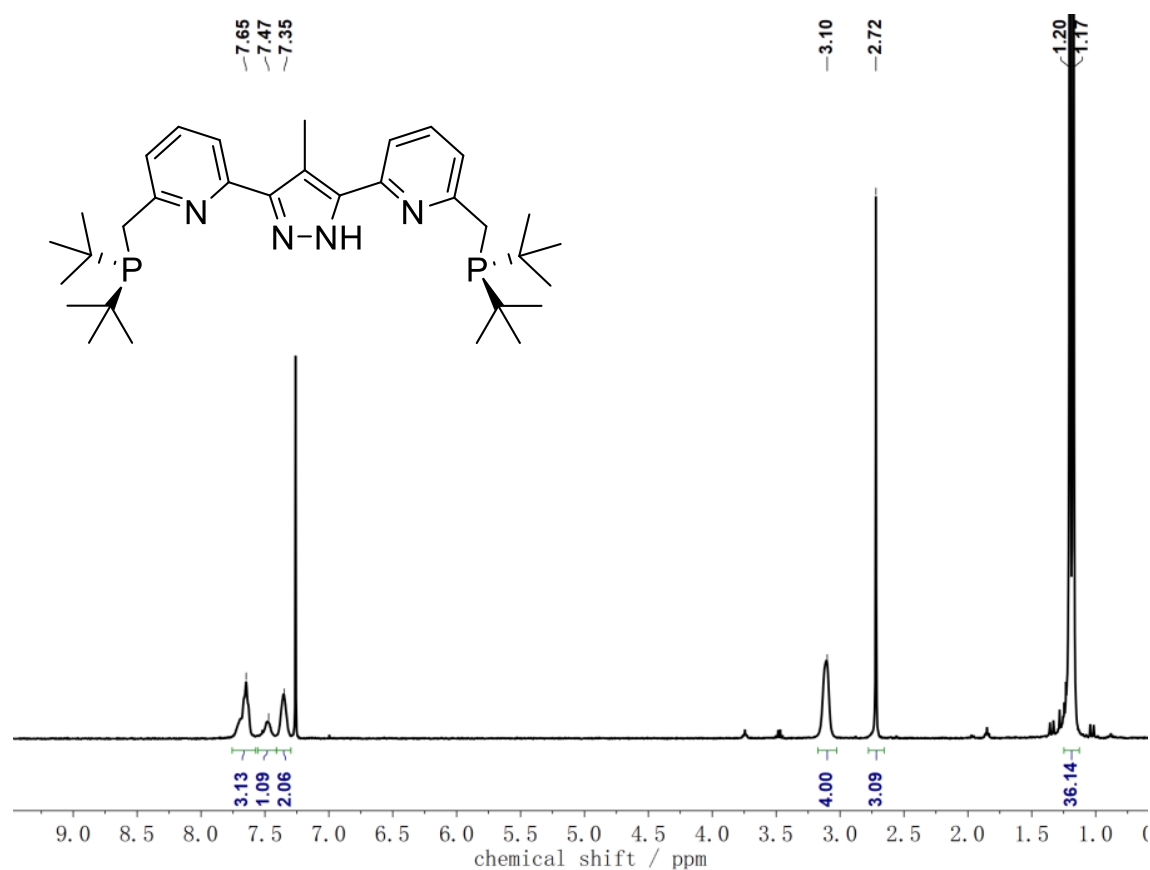

Figure 9.4: ${ }^{1} \mathrm{H}-\mathrm{NMR}(400 \mathrm{MHz})$ of $\mathbf{H L}^{\mathbf{M e}}$ in $\mathrm{CDCl}_{3}$. 


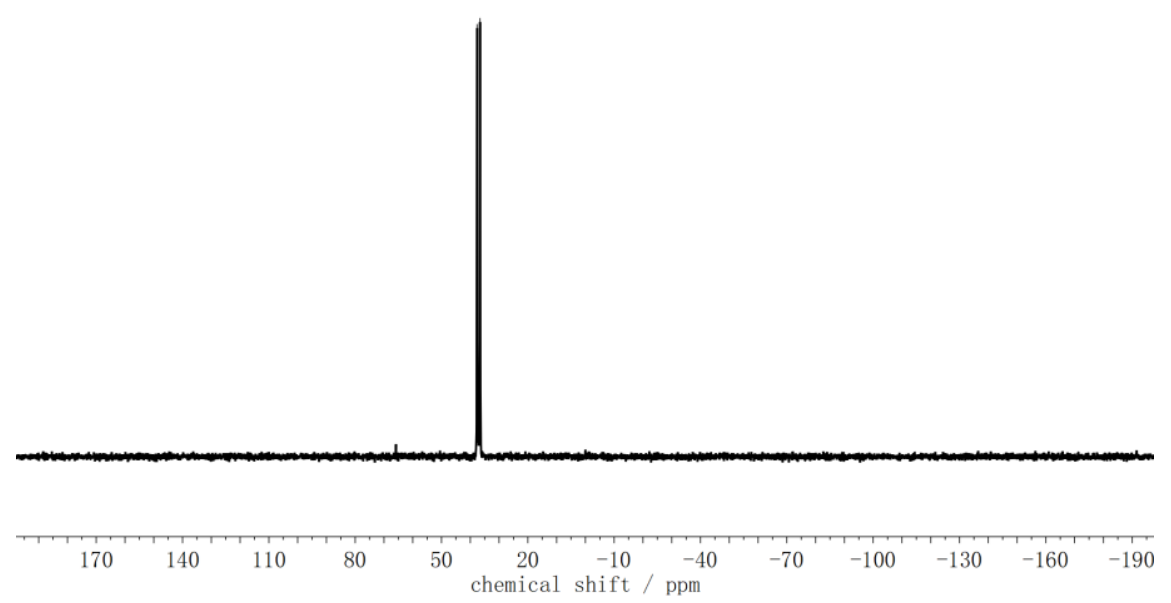

Figure 9.5: ${ }^{31} \mathrm{P}-\mathrm{NMR}(400 \mathrm{MHz})$ of $\mathbf{H L}^{\mathrm{Me}}$ in $\mathrm{CDCl}_{3}$.

\subsection{Further Analytical Data for Complexes}

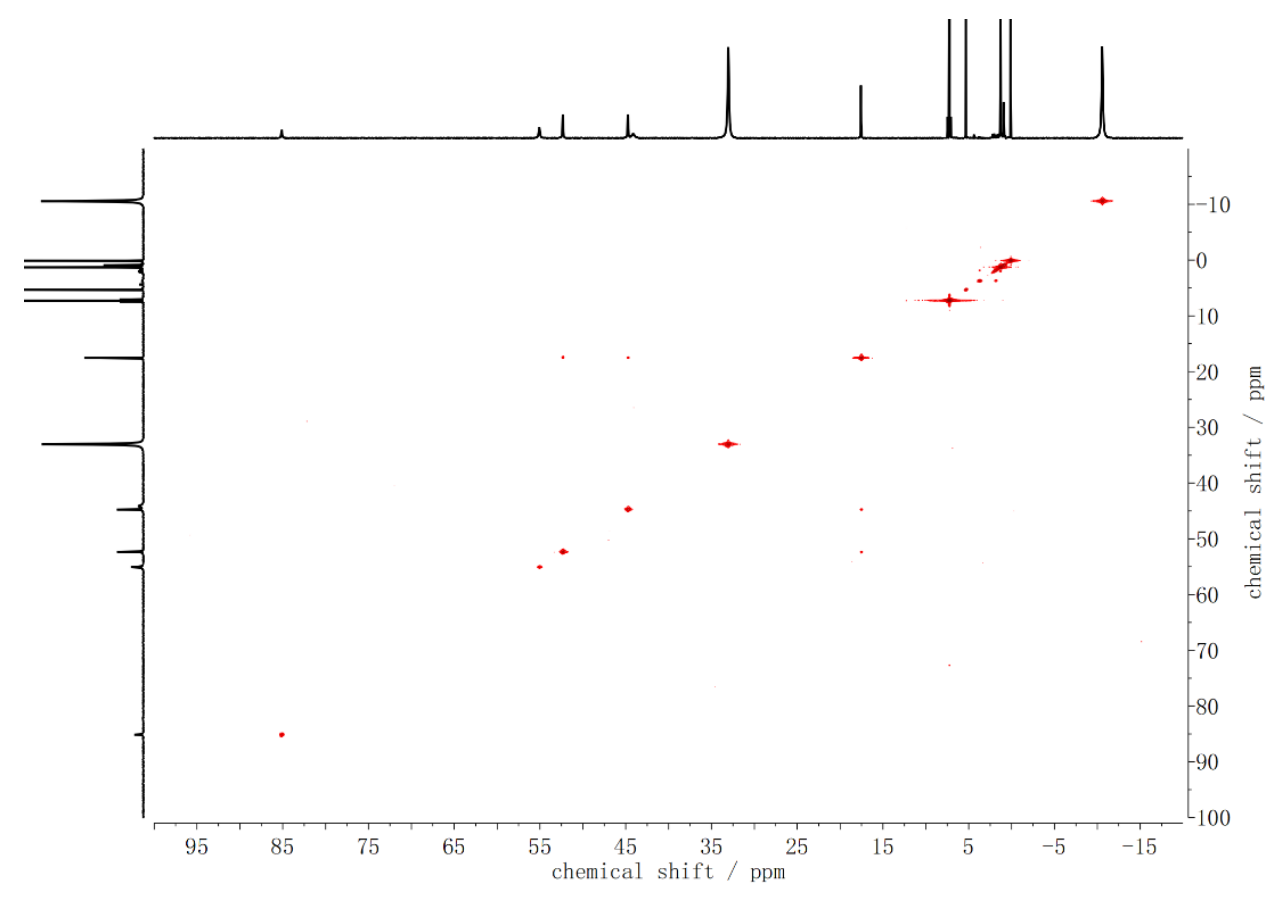

Figure 9.6: ${ }^{1} \mathrm{H}-{ }^{1} \mathrm{H}$ COSY $(500 \mathrm{MHz})$ of complex $\mathbf{1}$ in $\mathrm{CDCl}_{3}$. 


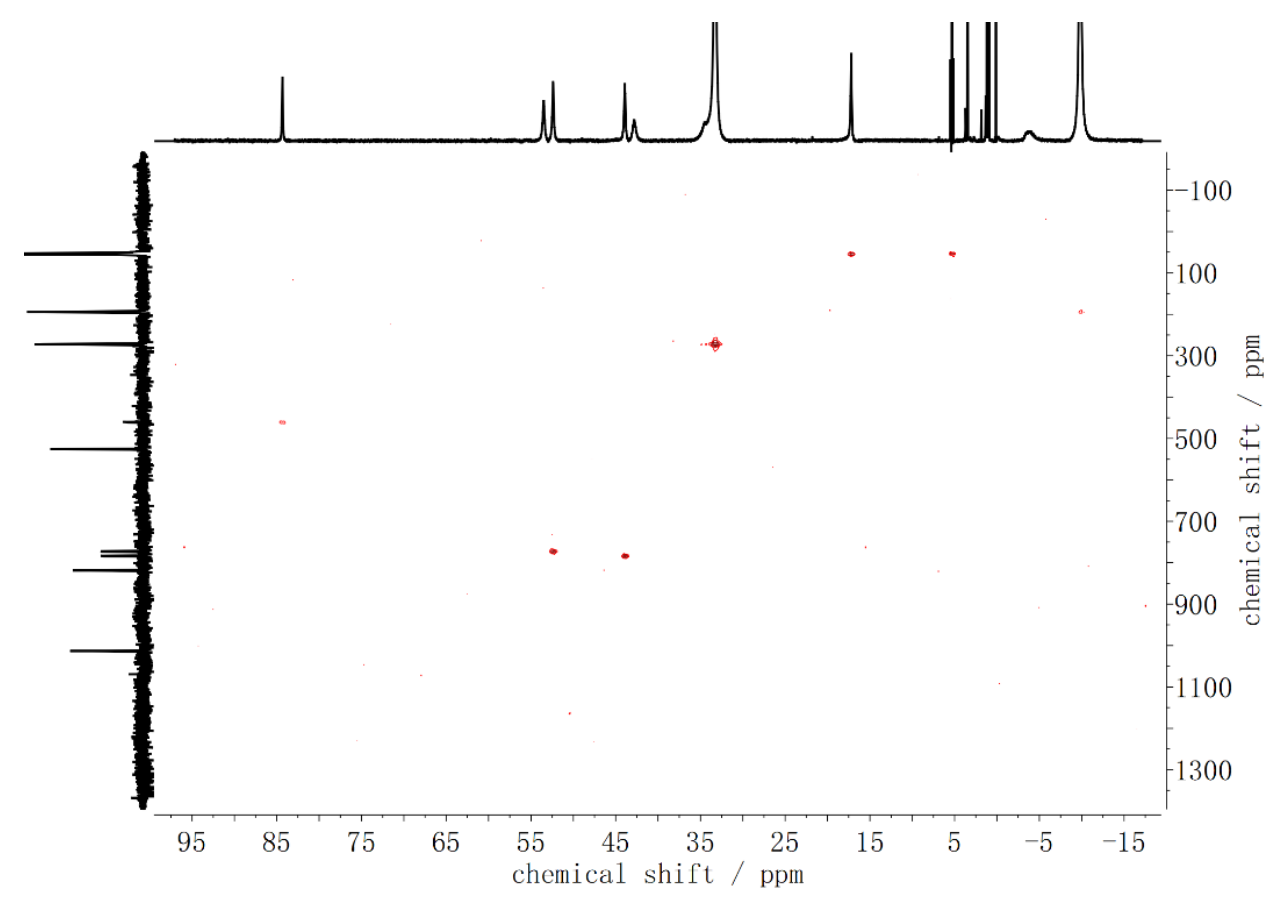

Figure 9.7: ${ }^{1} \mathrm{H}-{ }^{13} \mathrm{C}$ HSQC (500 MHz) of complex 1 in $\mathrm{CD}_{2} \mathrm{Cl}_{2}$.

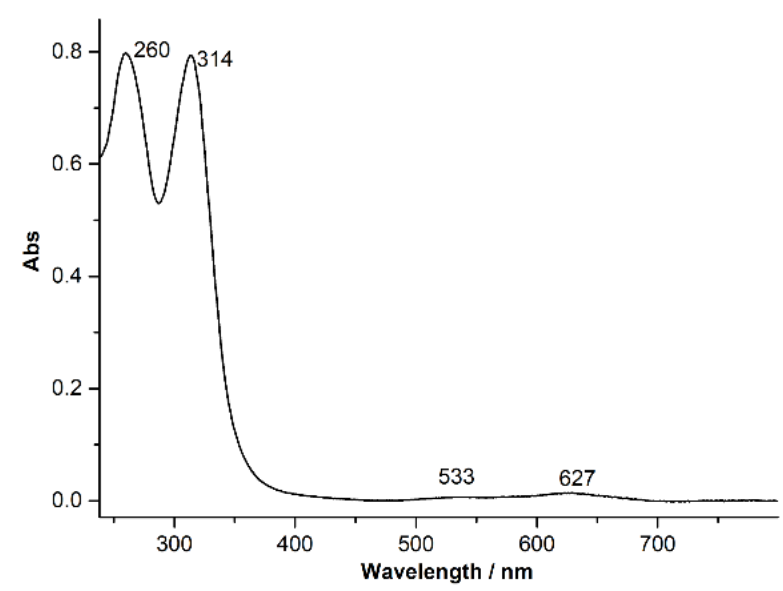

a

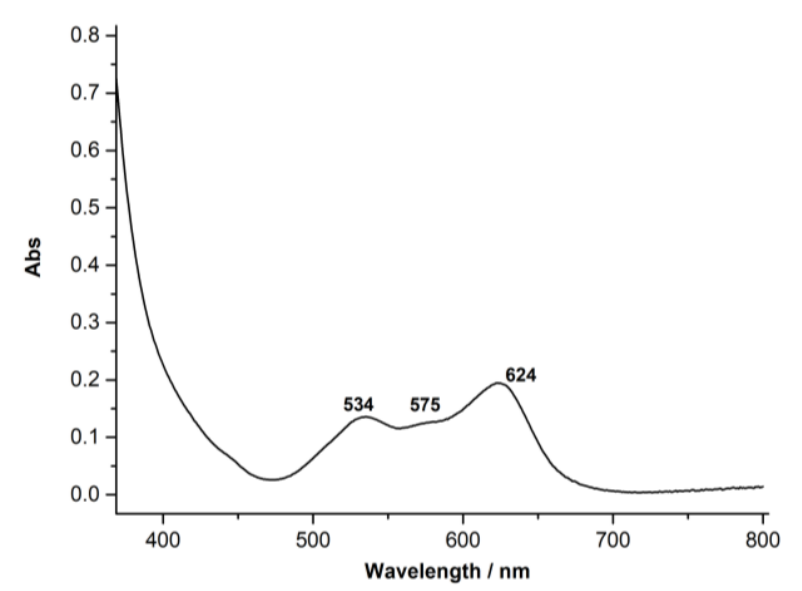

b

Figure 9.8: (a): UV-vis absorption spectrum of complex $1(0.7 \mu \mathrm{M})$ in $\mathrm{CH}_{2} \mathrm{Cl}_{2}$ solution. (b): visible spectrum of complex $\mathbf{1}(5.6 \mu \mathrm{M})$ in $\mathrm{CH}_{2} \mathrm{Cl}_{2}$ solution. 


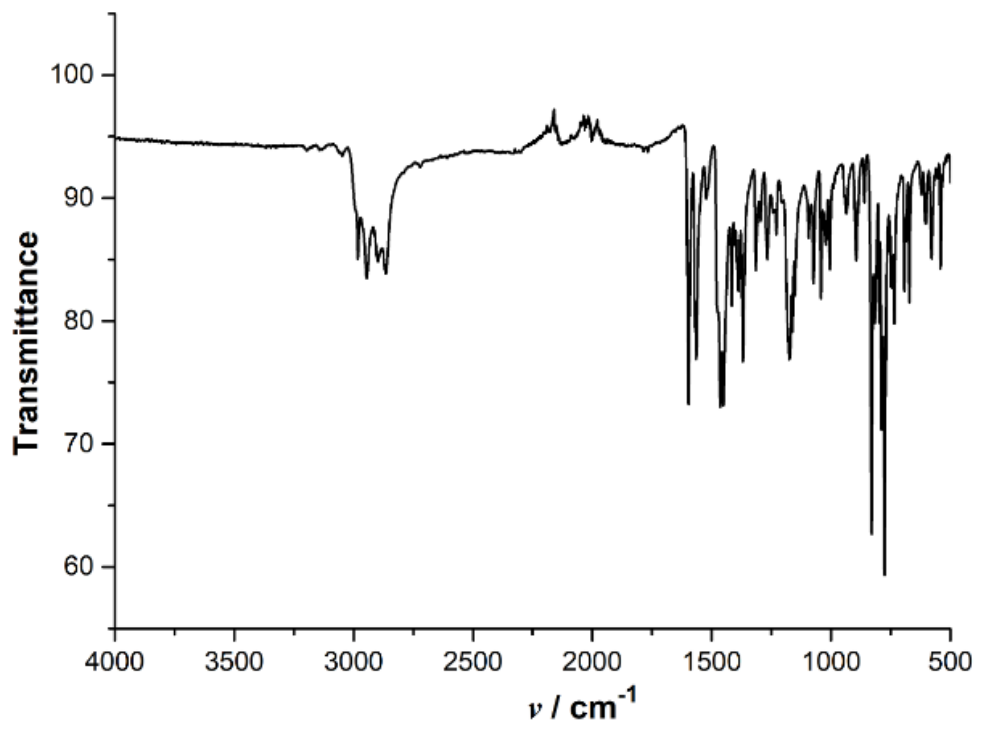

Figure 9.9: IR spectrum of complex 1 in solid state.

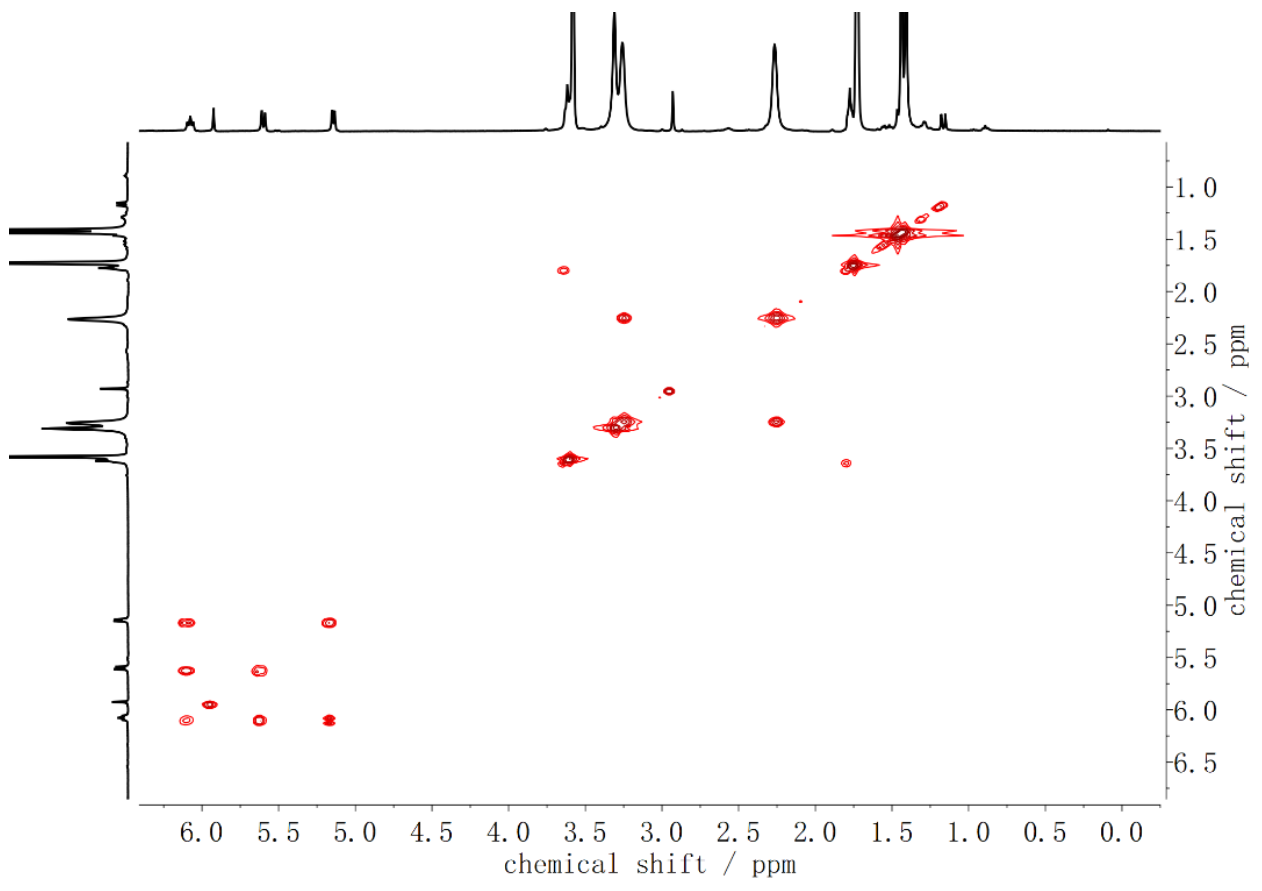

Figure 9.10: ${ }^{1} \mathrm{H}-{ }^{1} \mathrm{H}$ COSY $(400 \mathrm{MHz})$ of complex 2 in $\mathrm{THF}-\mathrm{d}_{8}$. 


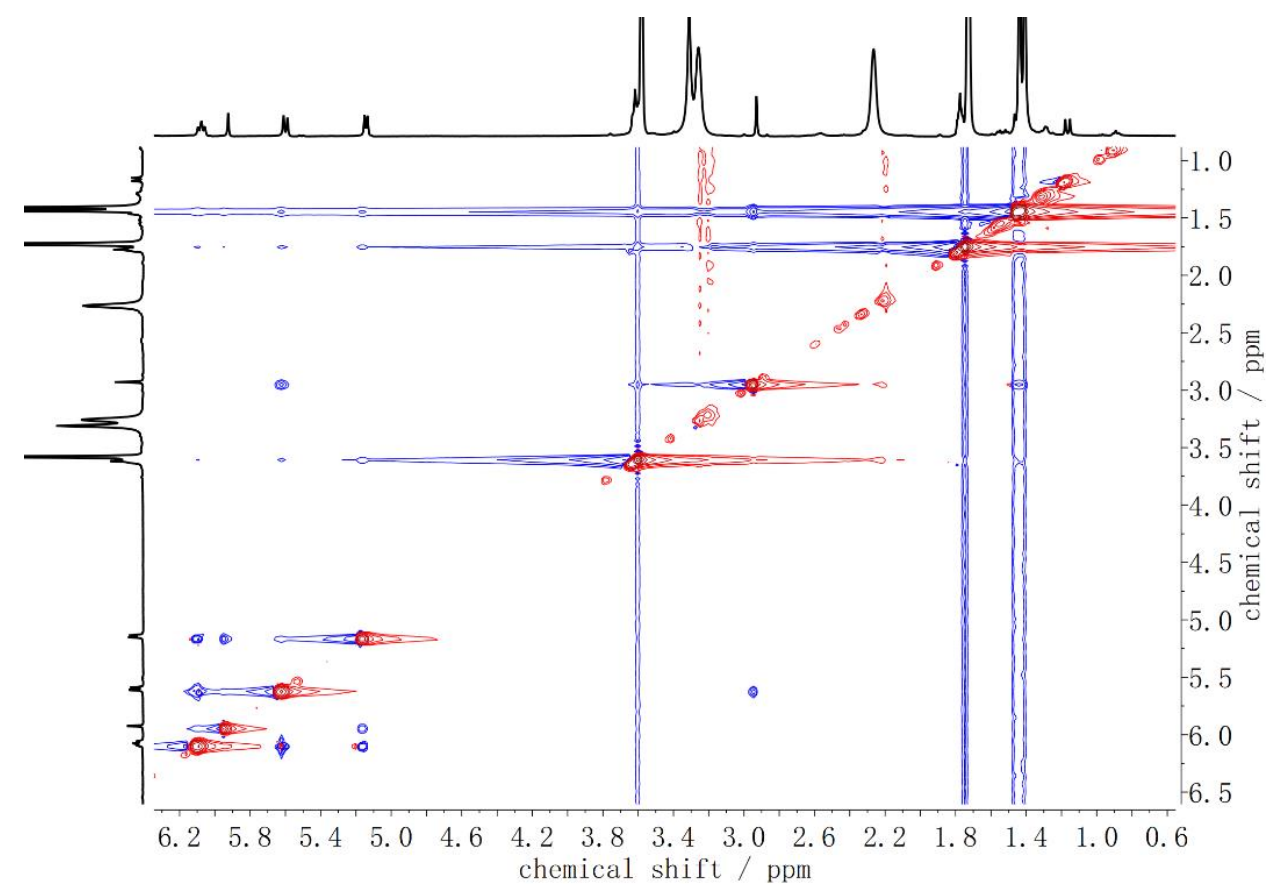

Figure 9.11: ${ }^{1} \mathrm{H}-{ }^{1} \mathrm{H}$ NOESY $(400 \mathrm{MHz})$ of complex 2 in THF-d8.

$$
\text { 疍 }
$$

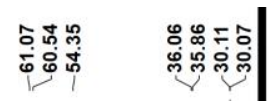
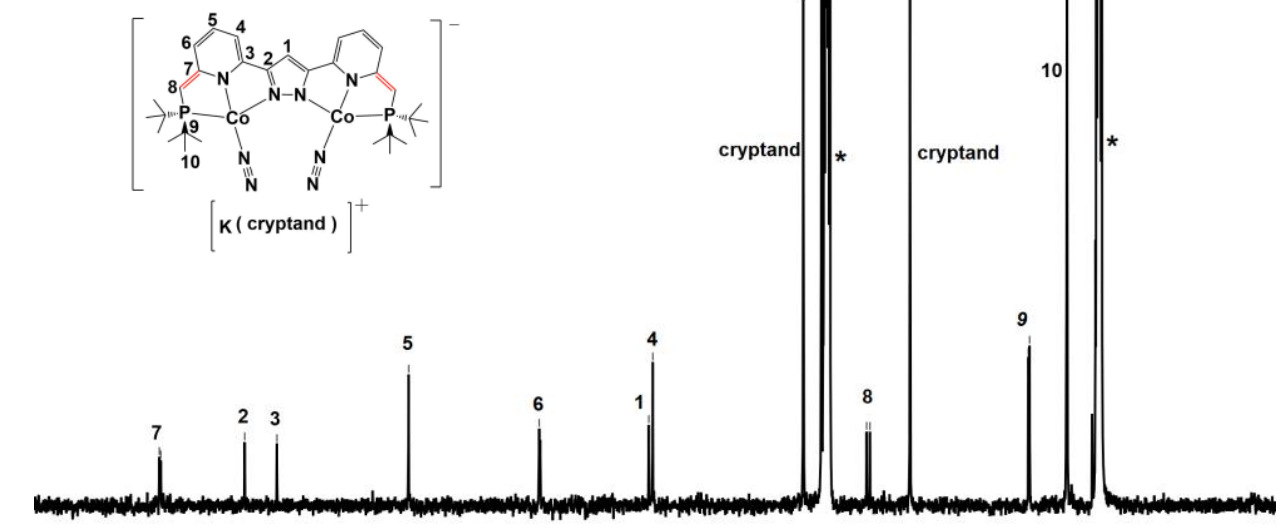

$\begin{array}{lllllllllllllllllll}180 & 170 & 160 & 150 & 140 & 130 & 120 & 110 & 100 & 90 & 80 & 70 & 60 & 50 & 40 & 30 & 20 & 10 & 0\end{array}$ chemical shift / ppm

Figure 9.12: ${ }^{13} \mathrm{C}-\mathrm{NMR}$ spectrum $(400 \mathrm{MHz})$ of complex 2 in THF-d 8 . Solvent signals are marked with an asterisk $(*)$. 


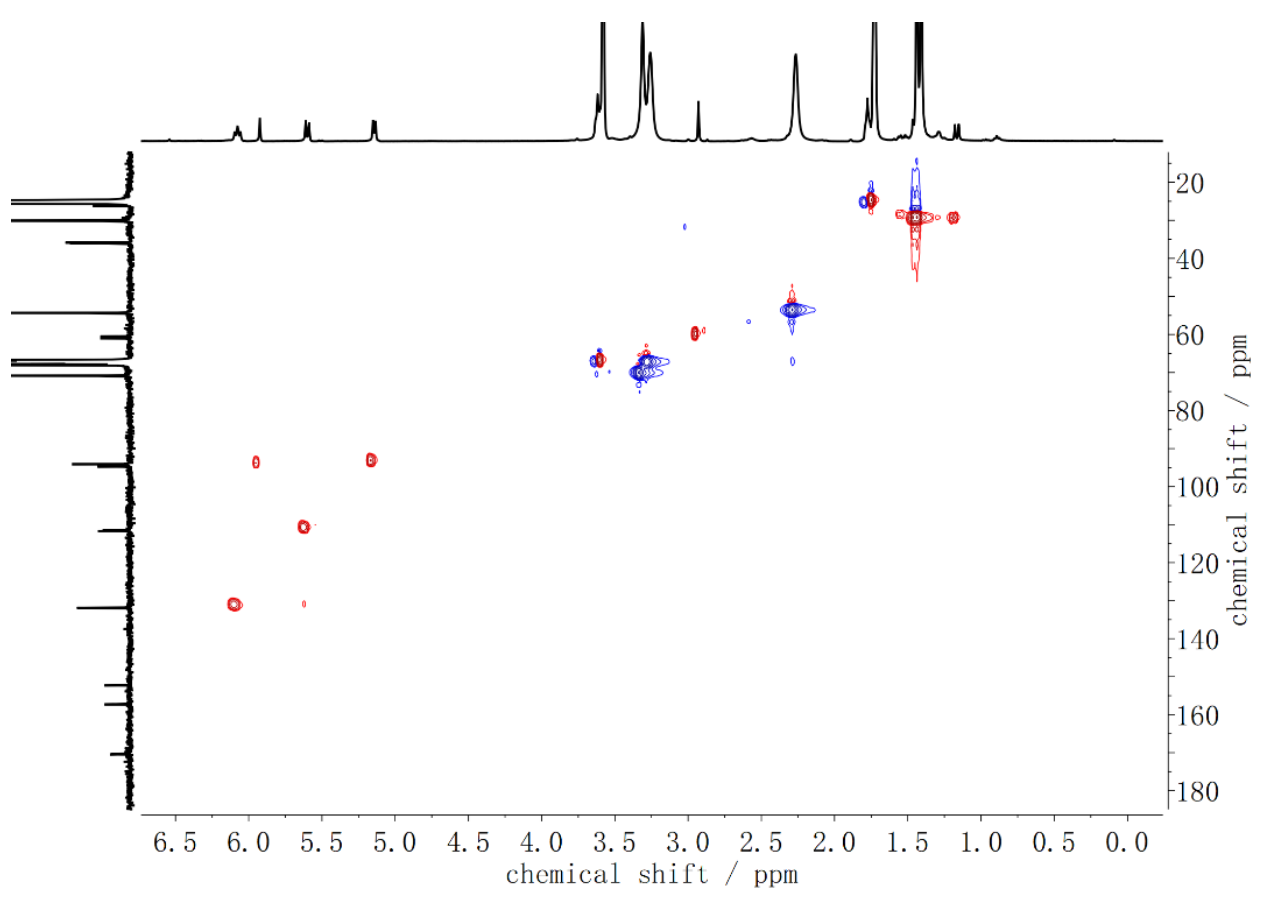

Figure 9.13: ${ }^{1} \mathrm{H}-{ }^{13} \mathrm{C}$ HSQC (400 MHz) of complex 2 in THF-d8.

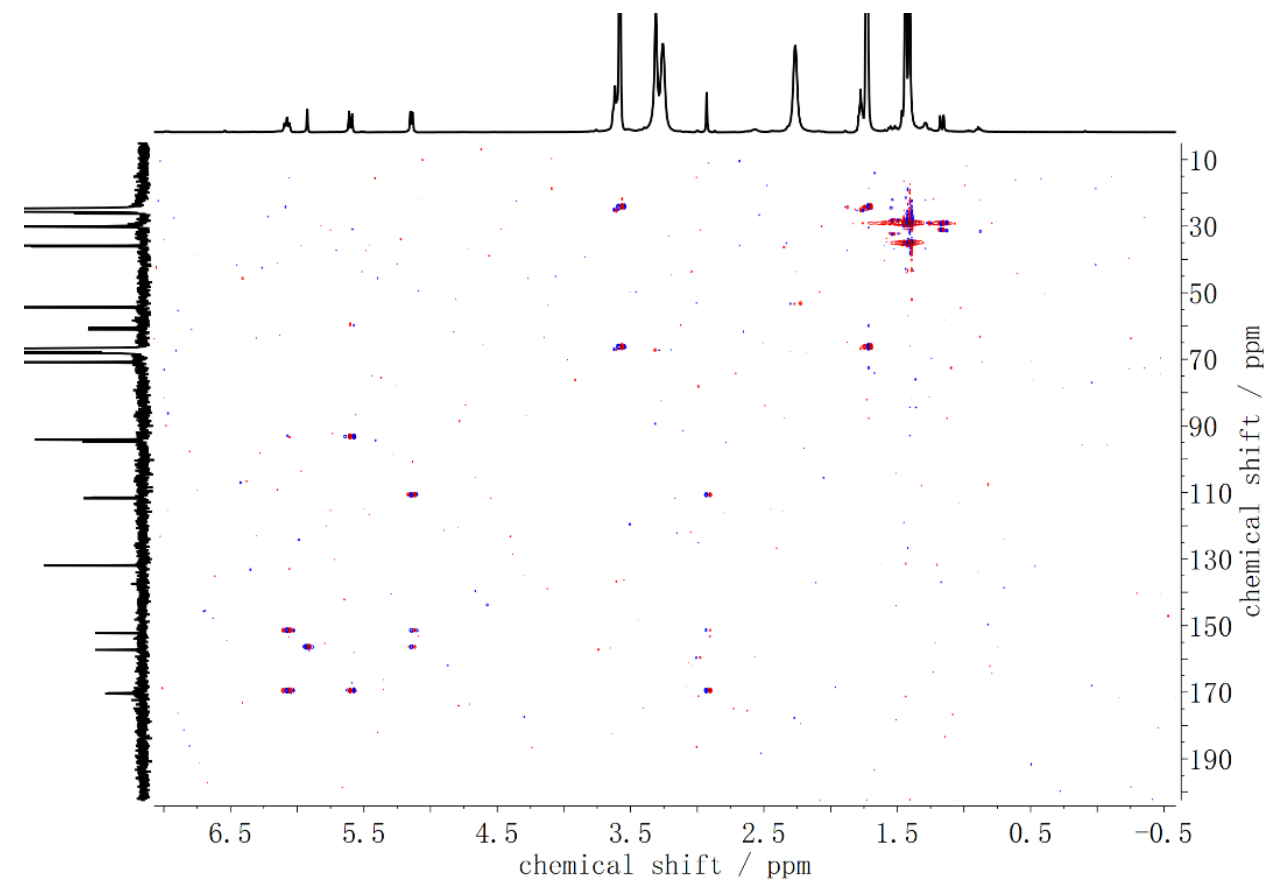

Figure 9.14: ${ }^{1} \mathrm{H}^{-13} \mathrm{C}$ HMBC $(400 \mathrm{MHz})$ of complex 2 in THF-d 8. 


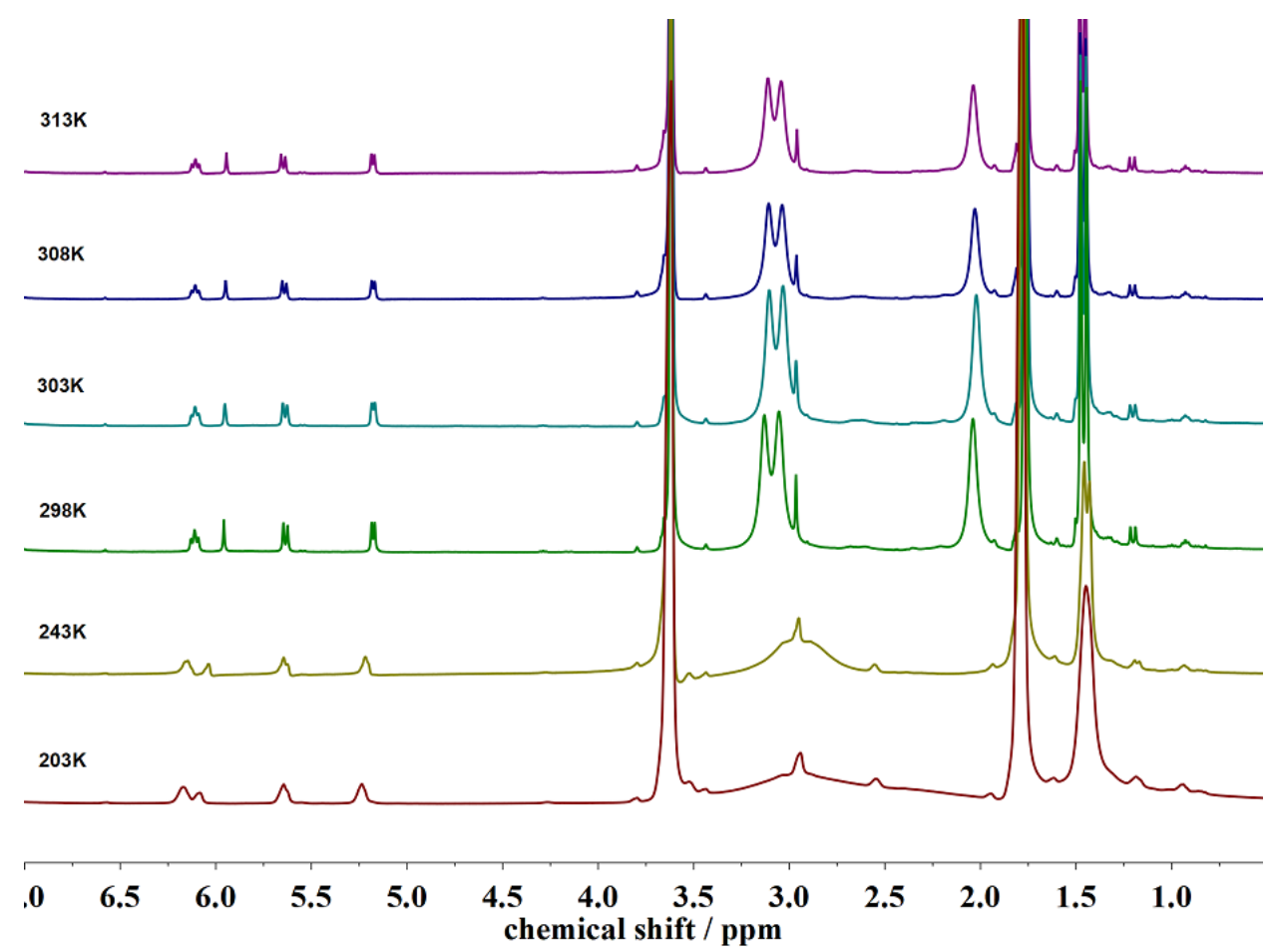

Figure 9.15: Variable temperature ${ }^{1} \mathrm{H}-\mathrm{NMR}$ spectra of complex 2 in THF- $\mathrm{d}_{8}$.

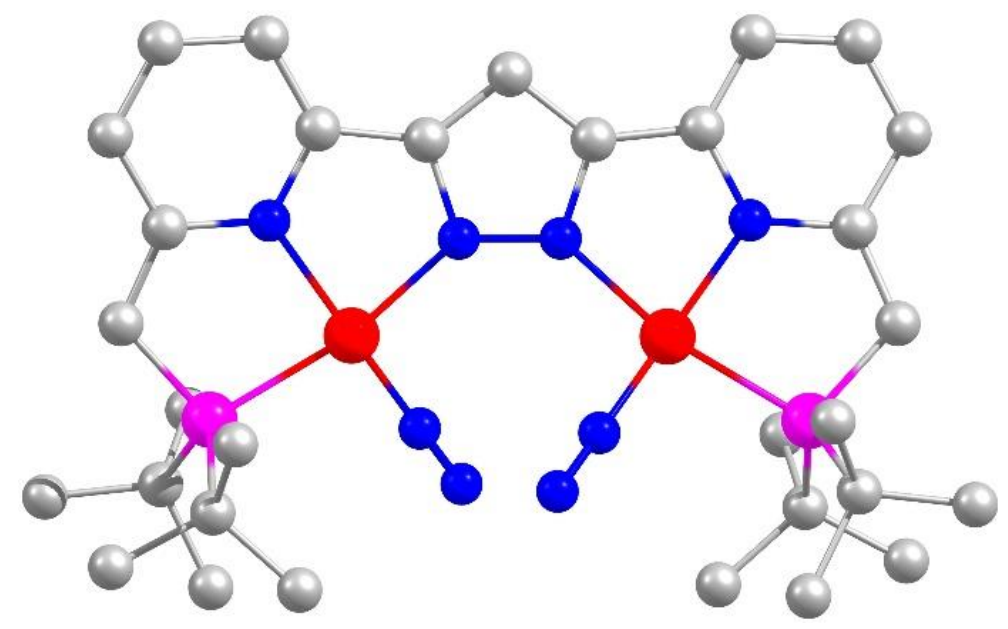

Figure 9.16: DFT optimized molecular structure of $2(\mathrm{Co}=\mathrm{red}, \mathrm{N}=$ blue, $\mathrm{P}=$ violet, $\mathrm{C}=$ grey). Spin restricted DFT calculations with ORCA 4.1.1, BP86 functional, def2-tzvp basis set, RI approximation using the auxiliary def2/J basis set, D3 dispersion correction with Becke-Johnson damping, tight convergence and optimization criteria).

Table 9.1: Comparison of experimental and DFT calculated metric parameters of 2; selected distances $[\AA]$ and angles $\left[{ }^{\circ}\right]$. 


\begin{tabular}{ccc}
\hline Co-N $\mathrm{N}^{\mathrm{pz}}$ & $1.9395(16) / 1.9509(16)$ & $1.91896 / 1.91834$ \\
$\mathrm{Co}-\mathrm{N}^{\mathrm{py}}$ & $1.9076(17) / 1.9135(16)$ & $1.91469 / 1.91507$ \\
$\mathrm{Co}-\mathrm{N}_{2}$ & $1.7419(17) / 1.7422(19)$ & $1.72609 / 1.72603$ \\
$\mathrm{Co}-\mathrm{P}$ & $2.1889(6) / 2.1970(6)$ & $2.17467 / 2.17503$ \\
$\mathrm{Co} \cdots \mathrm{Co}$ & $4.2987(7)$ & 4.17449 \\
$\mathrm{~N}-\mathrm{N}$ & $1.125(3) / 1.124(3)$ & $1.13512 / 1.13512$ \\
$\mathrm{Co}-\mathrm{N}-\mathrm{N}$ & $174.7(2) / 173.8(2)$ & $172.308 / 172.388$ \\
\hline
\end{tabular}

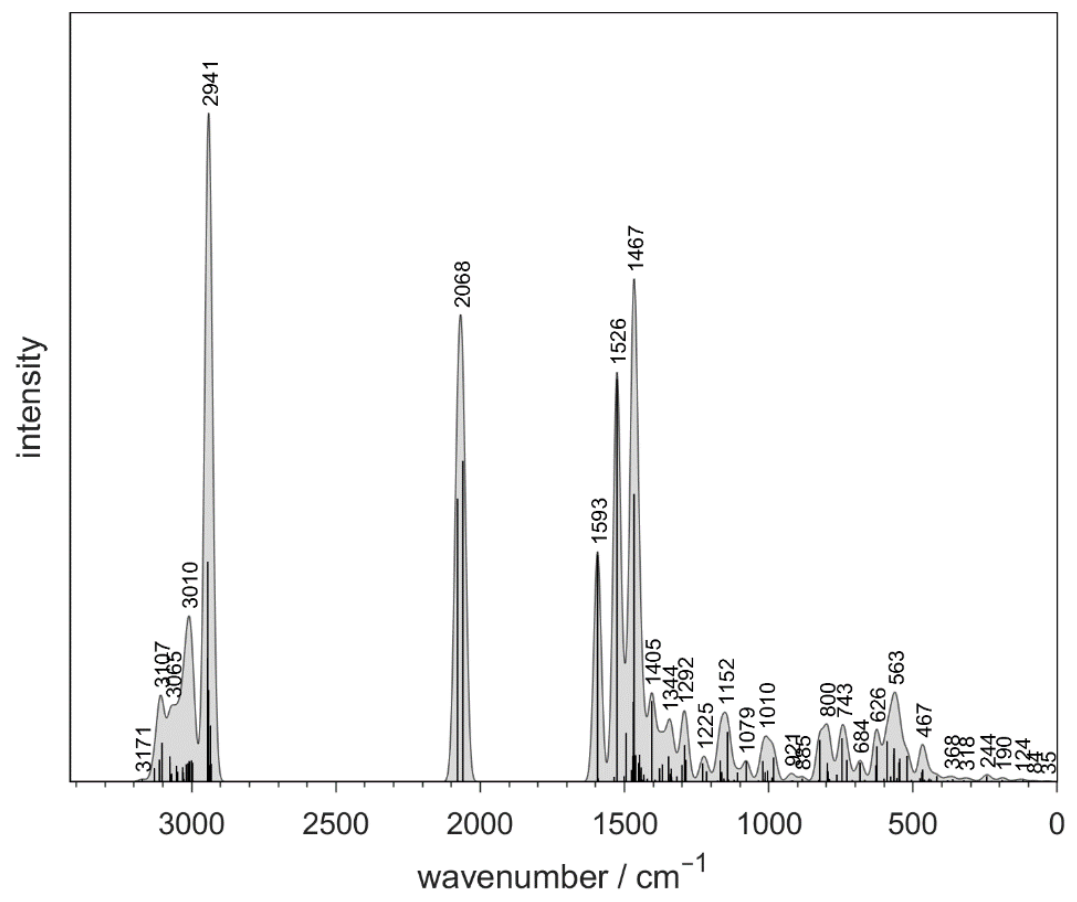

Figure 9.17: Calculated IR spectrum of 2. Predicted $\mathrm{N}_{2}$ stretching: $2060 / 2079 \mathrm{~cm}^{-1}$. The spectrum was convoluted using a Gaussian line shape function with a half-width of $15 \mathrm{~cm}^{-1}$. 


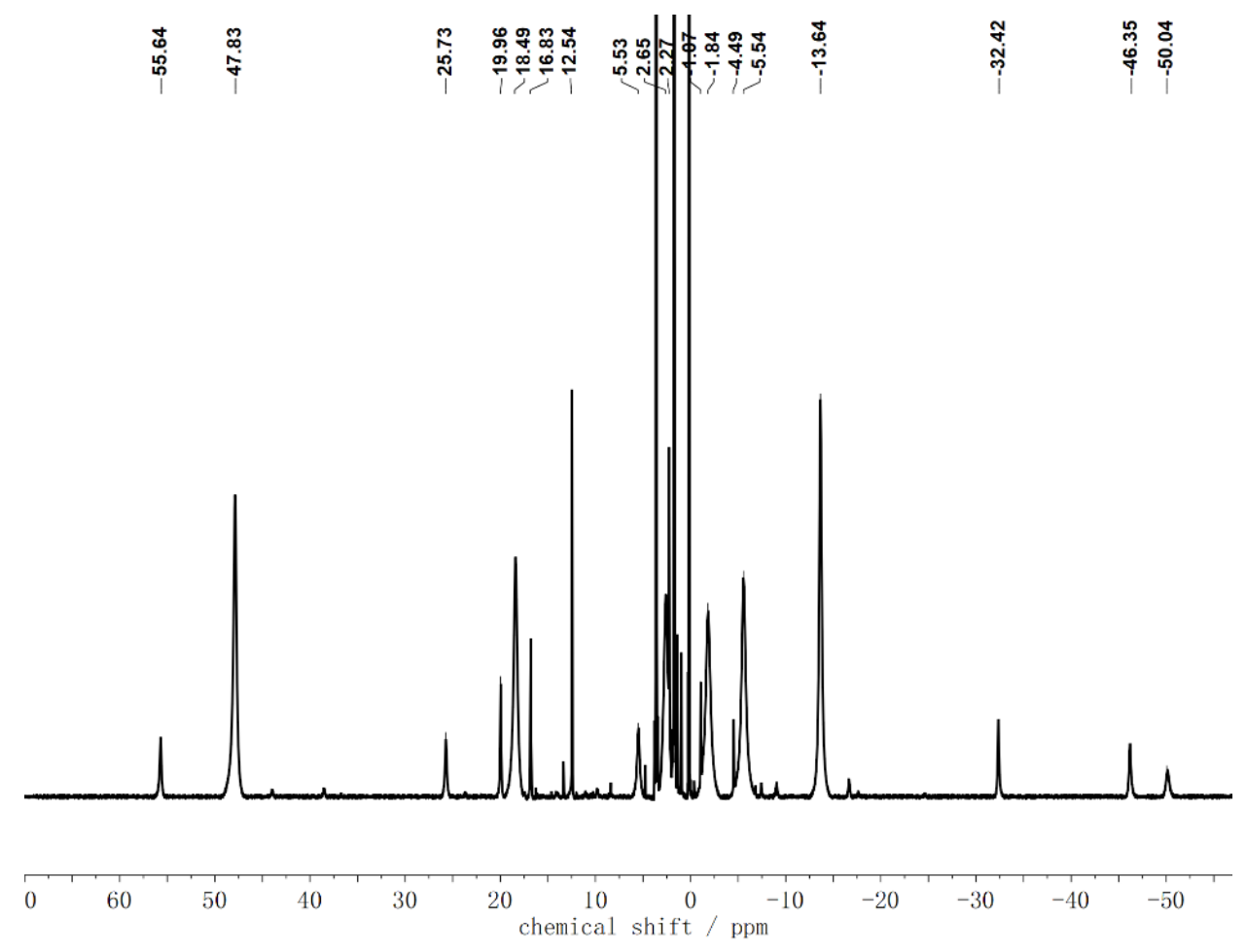

Figure 9.18: ${ }^{1} \mathrm{H}-\mathrm{NMR}$ spectrum of complex 3 in $\mathrm{THF}-\mathrm{d}_{8}$.

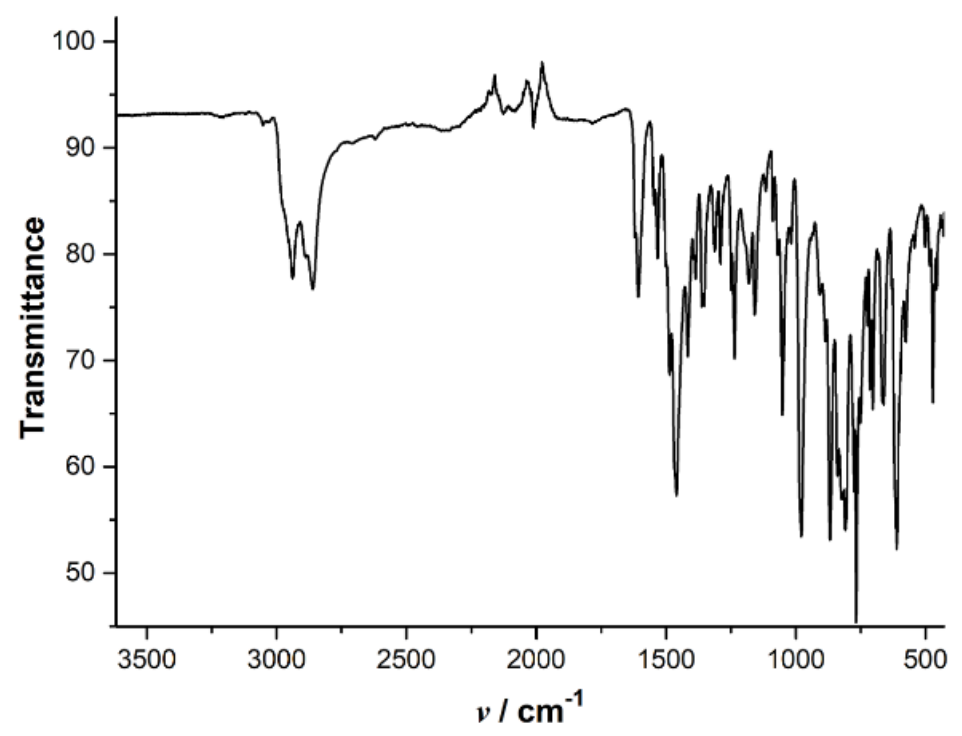

Figure 9.19: IR spectrum of complex 3 in solid state. 


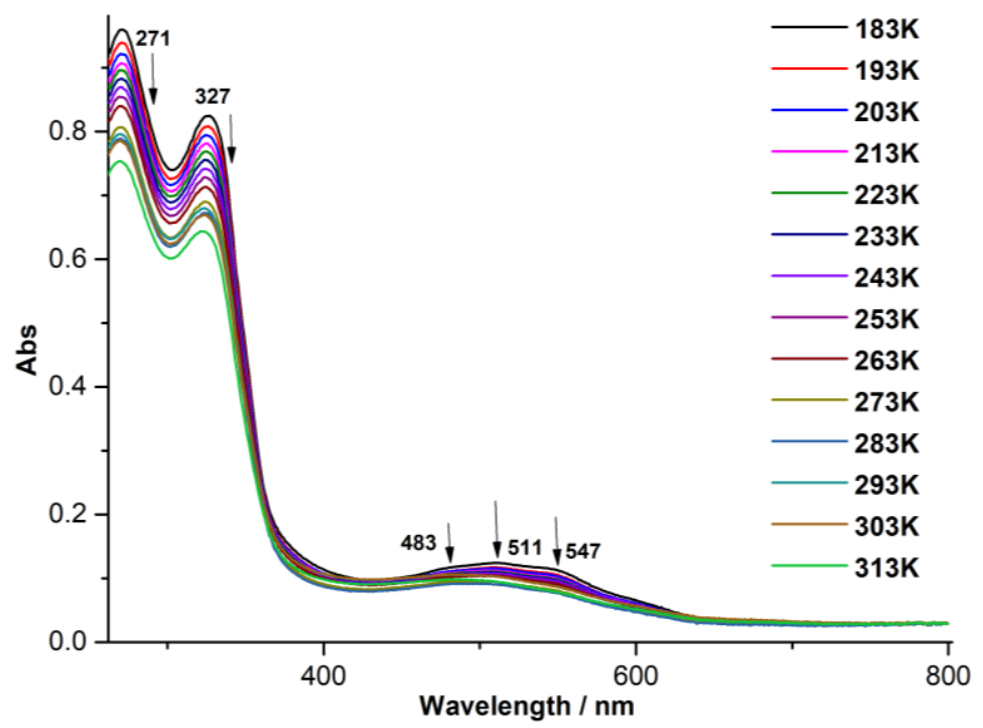

Figure 9.20: UV-vis spectrum of complex 3 in THF solution.

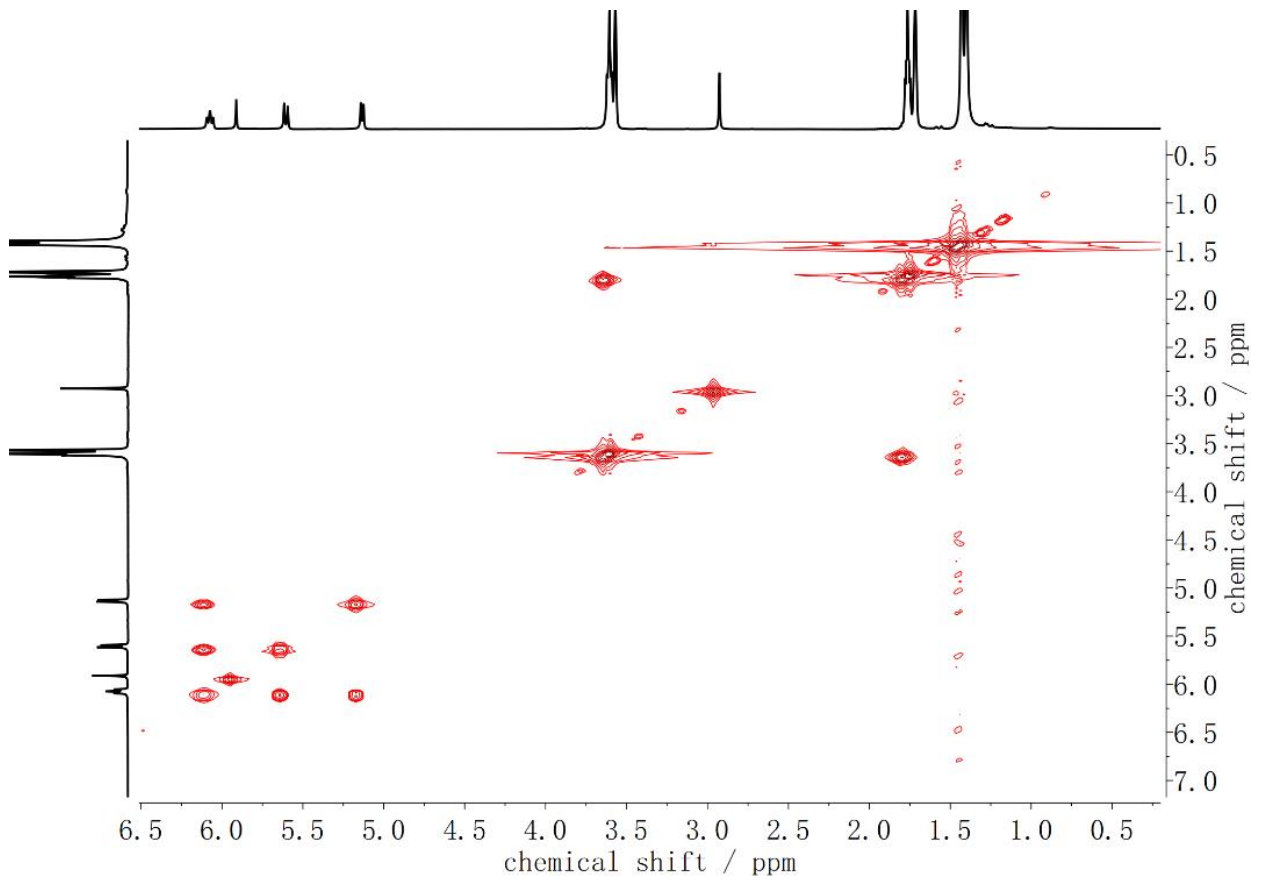

Figure 9.21: ${ }^{1} \mathrm{H}-{ }^{1} \mathrm{H}$ COSY (400 MHz) of complex 4 in THF-d 8. 


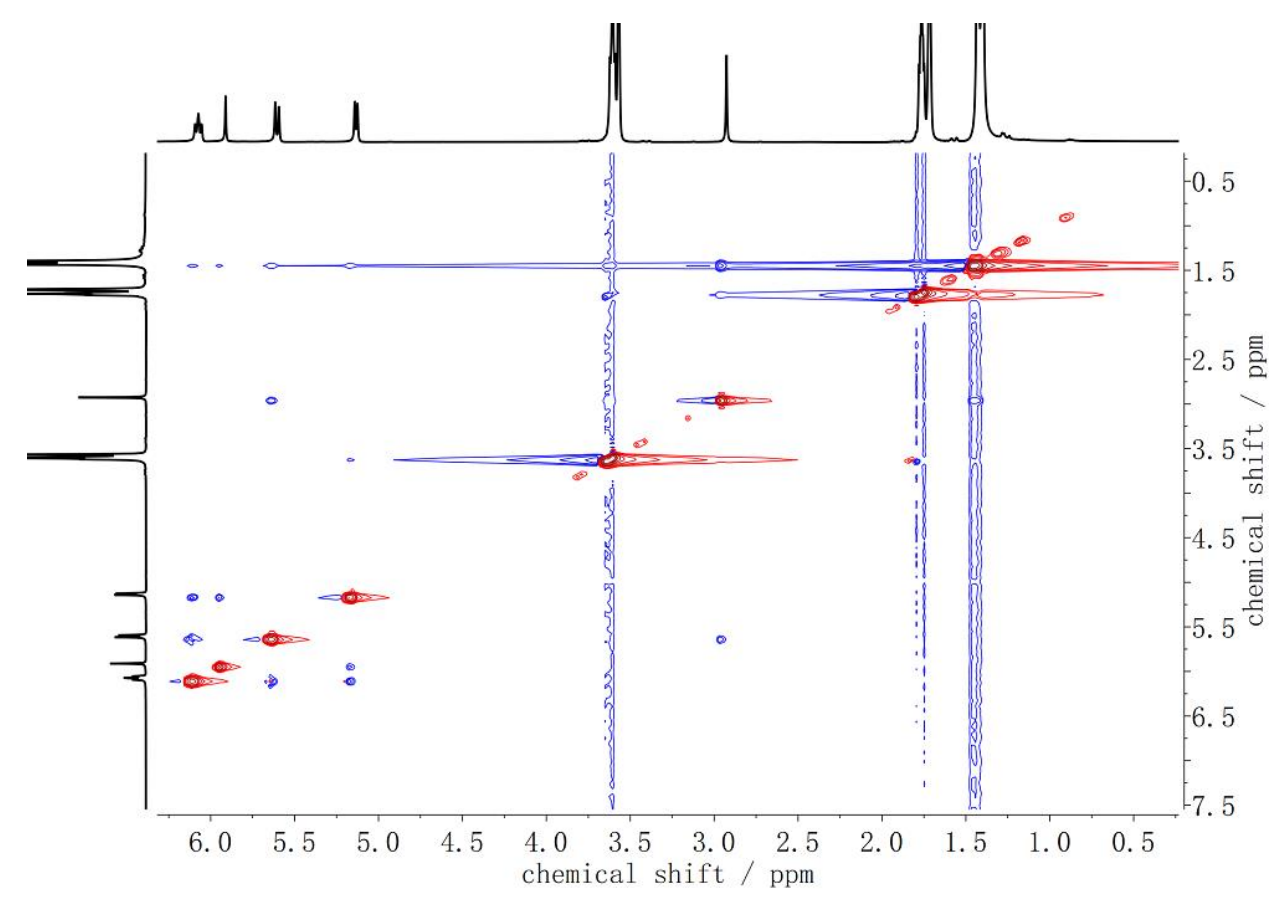

Figure 9.22: ${ }^{1} \mathrm{H}-{ }^{1} \mathrm{H}$ NOESY $(400 \mathrm{MHz})$ of complex 4 in THF-d8.

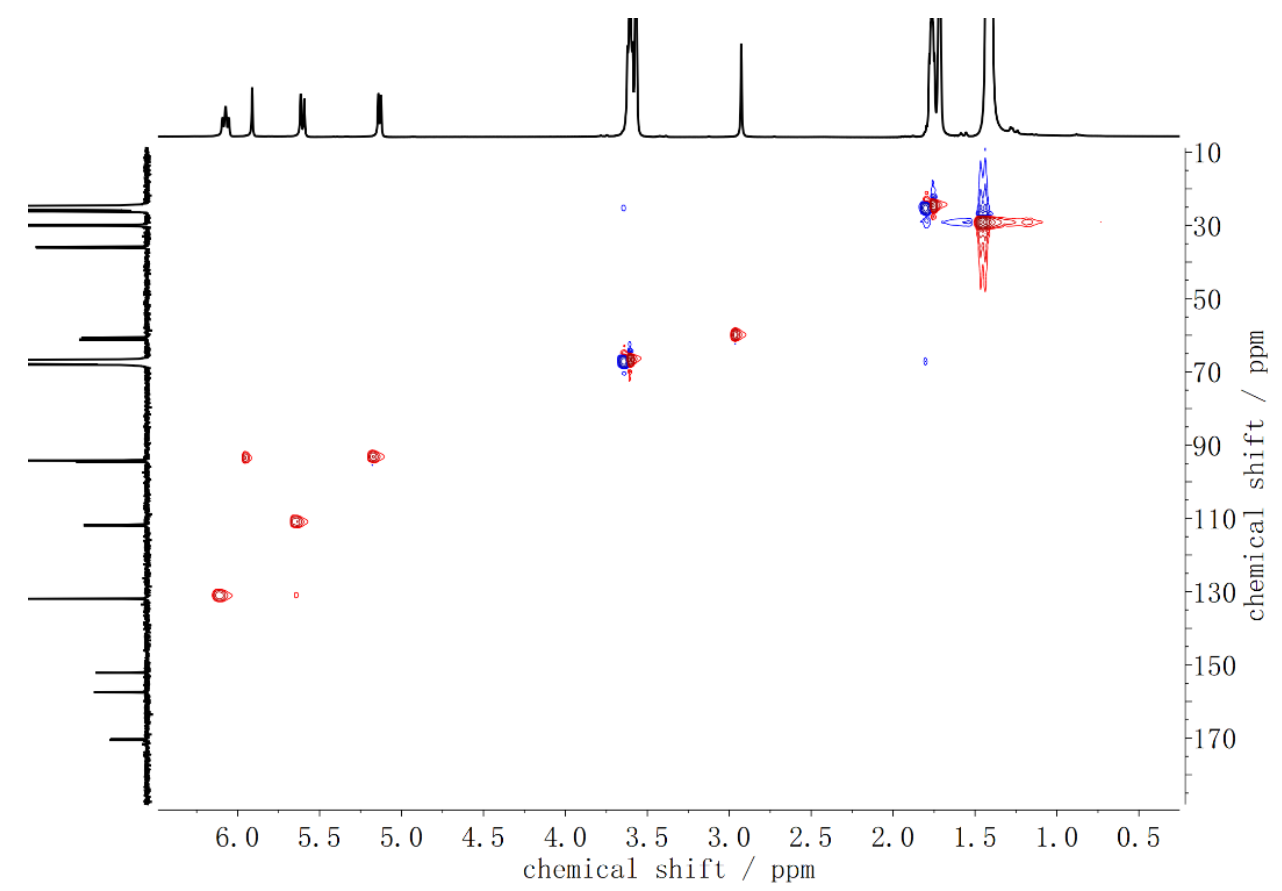

Figure 9.23: ${ }^{1} \mathrm{H}-{ }^{13} \mathrm{C}$ HSQC $(400 \mathrm{MHz})$ of complex 4 in THF- $\mathrm{d}_{8}$. 


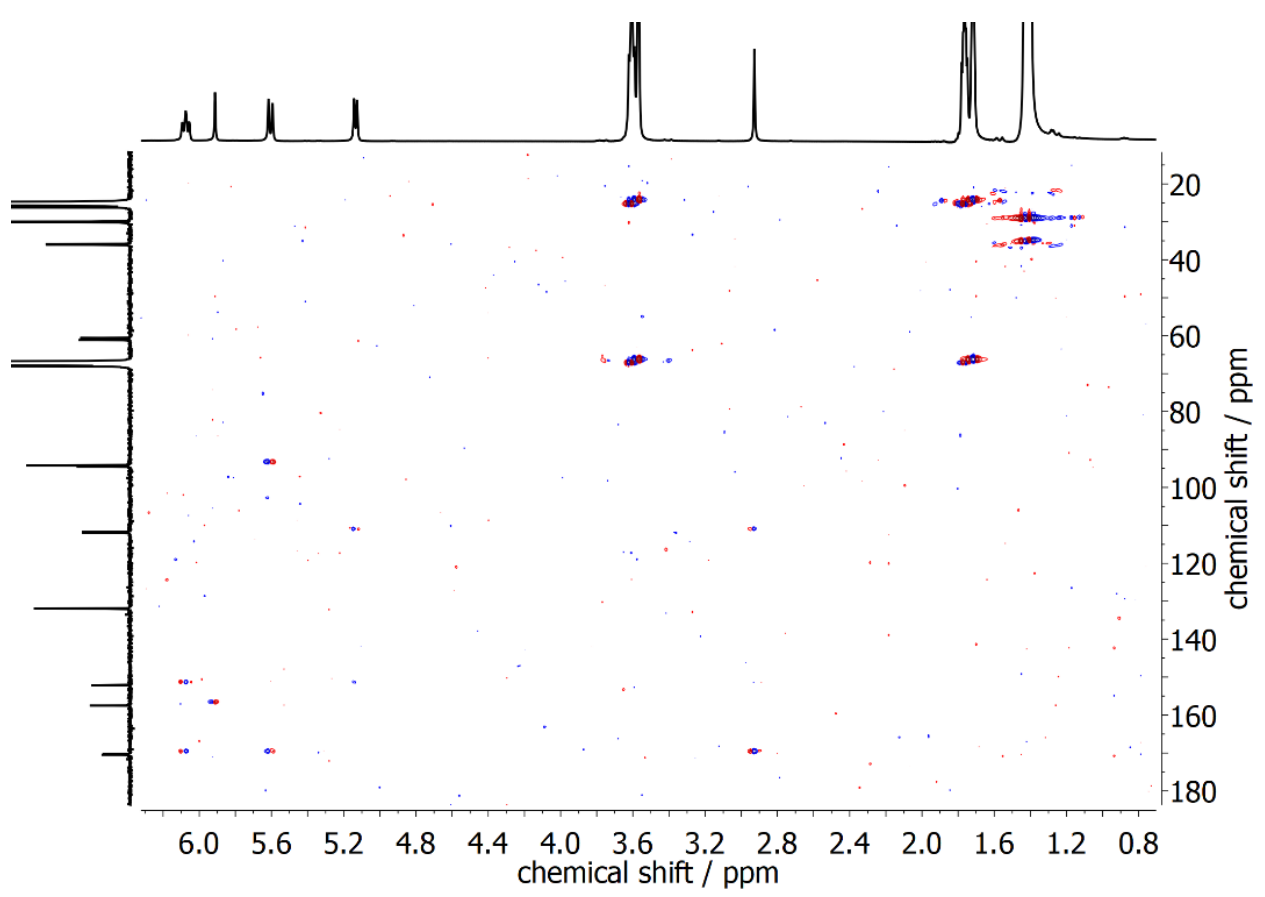

Figure 9.24: ${ }^{1} \mathrm{H}^{-13} \mathrm{C}$ HMBC $(400 \mathrm{MHz})$ of complex 4 in THF-d8.

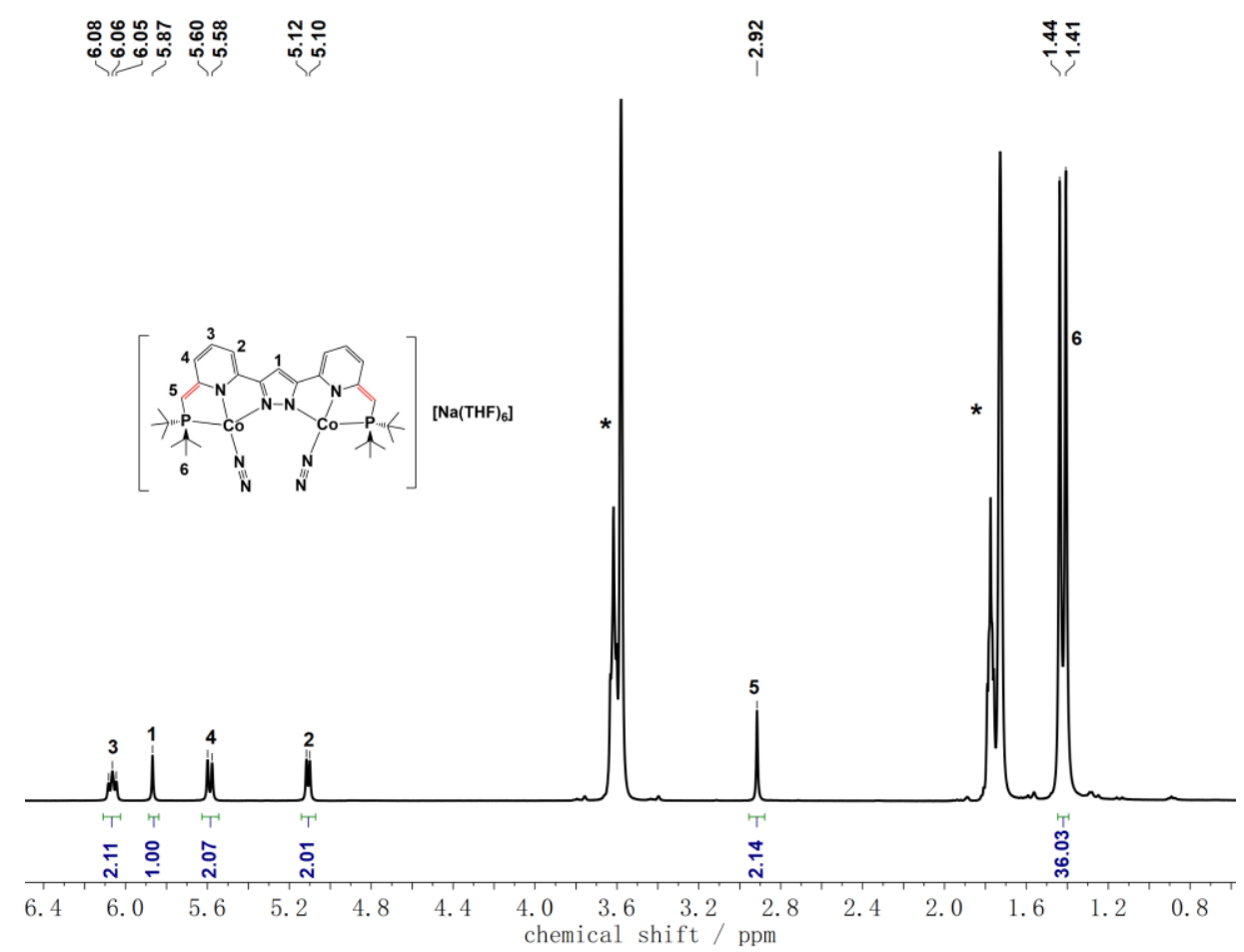

Figure 9.25: ${ }^{1} \mathrm{H}-\mathrm{NMR}$ spectrum $(400 \mathrm{MHz})$ of complex 5 in THF-d8. Solvent signals are marked with an asterisk $(*)$. 


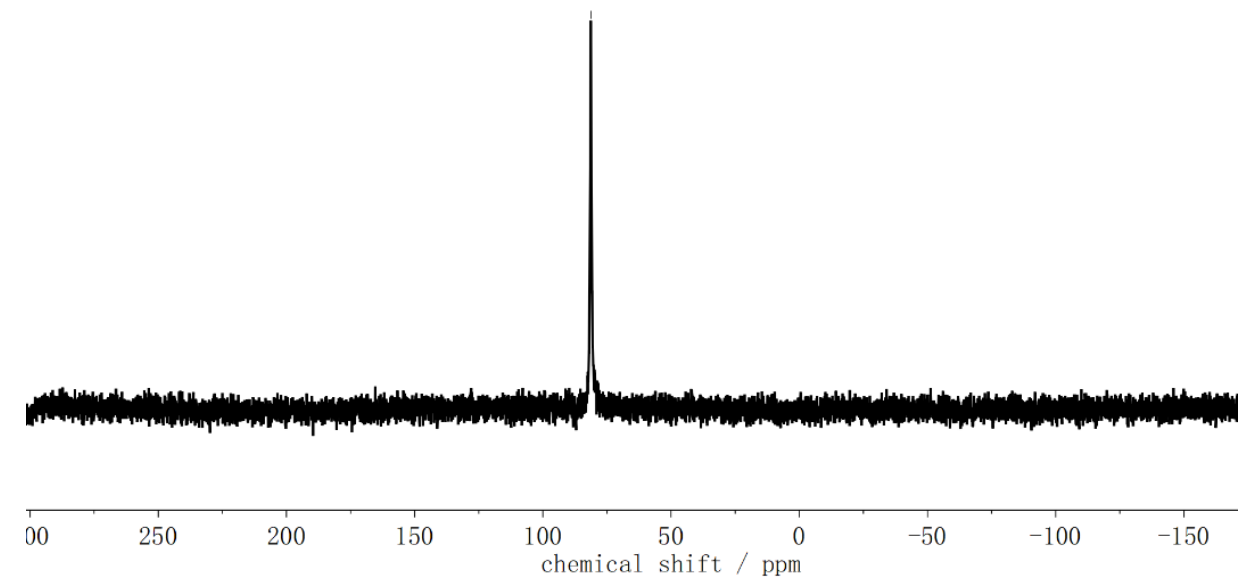

Figure 9.26: ${ }^{31} \mathrm{P}-\mathrm{NMR}$ spectrum $(400 \mathrm{MHz})$ of complex 5 in THF-d 8.

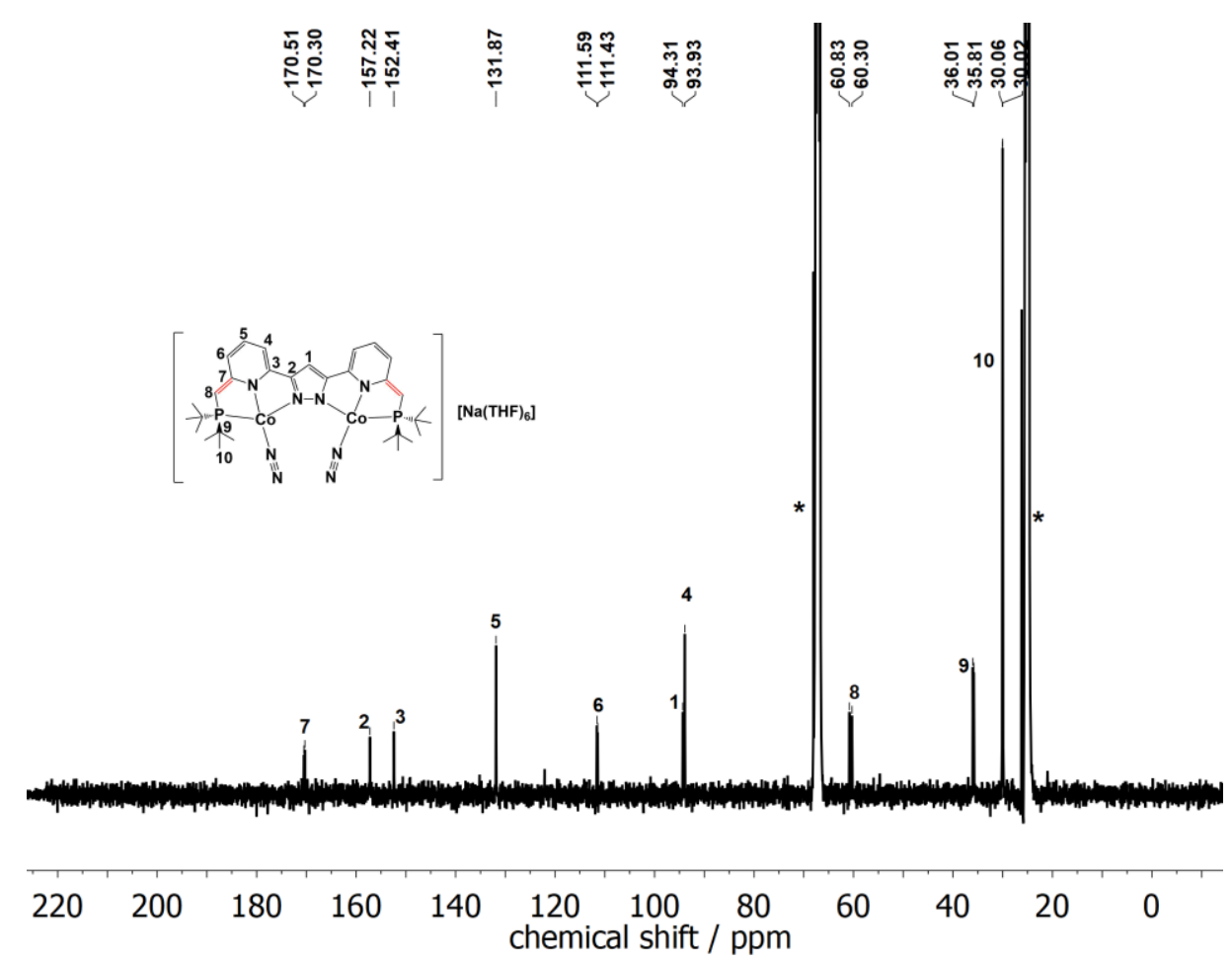

Figure 9.27: ${ }^{13} \mathrm{C}-\mathrm{NMR}$ spectrum $(400 \mathrm{MHz})$ of complex 5 in THF-d 8 . Solvent signals are marked with an asterisk $(*)$. 


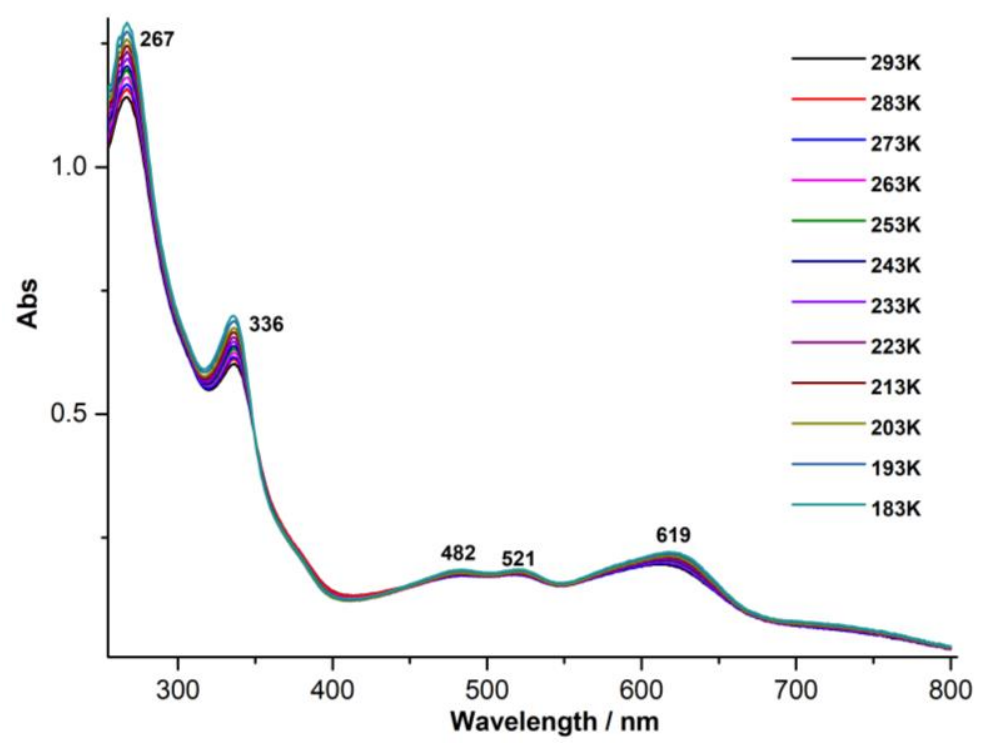

Figure 9.28: Variable temperature UV-vis spectra of complex 5 in THF solution from 293 K to 183 K.

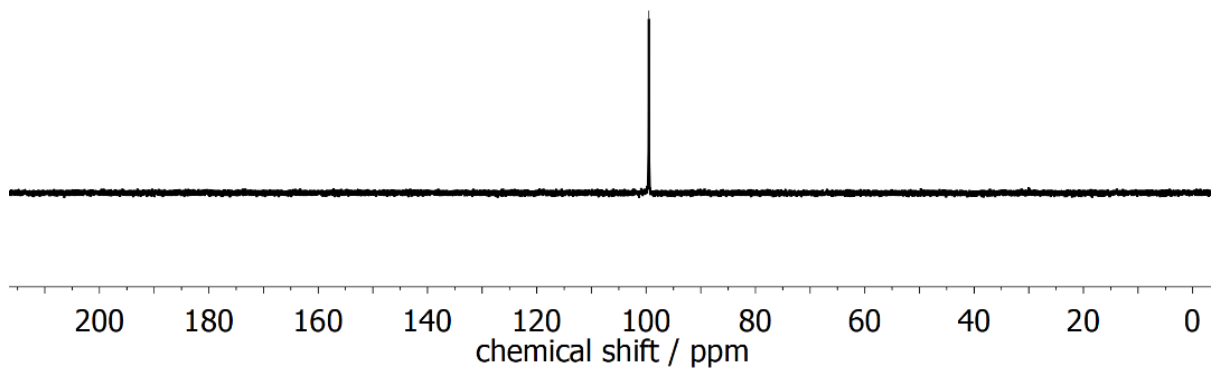

Figure 9.29: ${ }^{31} \mathrm{P}-\mathrm{NMR}$ spectrum of complex 6 in THF- $\mathrm{d}_{8}$ under $\mathrm{N}_{2}$ atmosphere at $238 \mathrm{~K}$. 


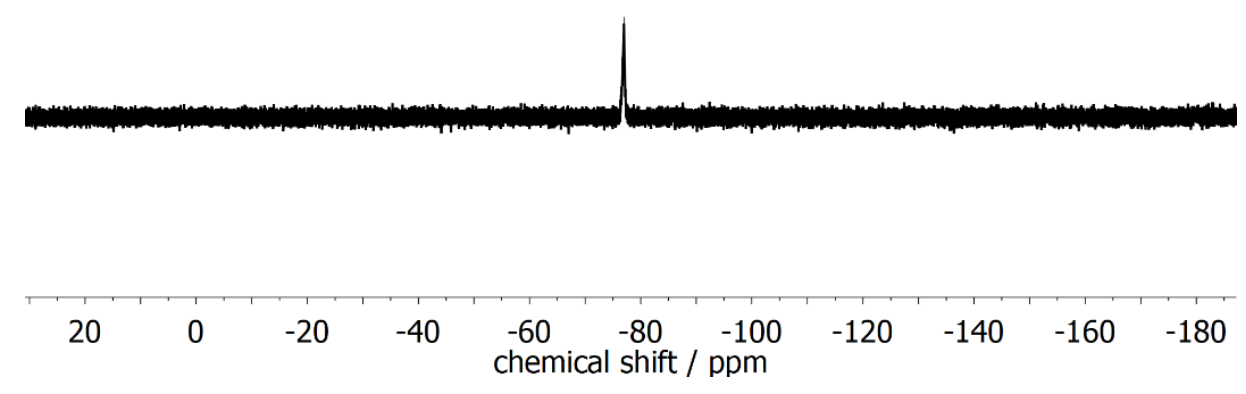

Figure 9.30: ${ }^{19} \mathrm{~F}-\mathrm{NMR}$ spectrum of complex 6 in THF-d $\mathrm{d}_{8}$ under $\mathrm{N}_{2}$ atmosphere at $238 \mathrm{~K}$.

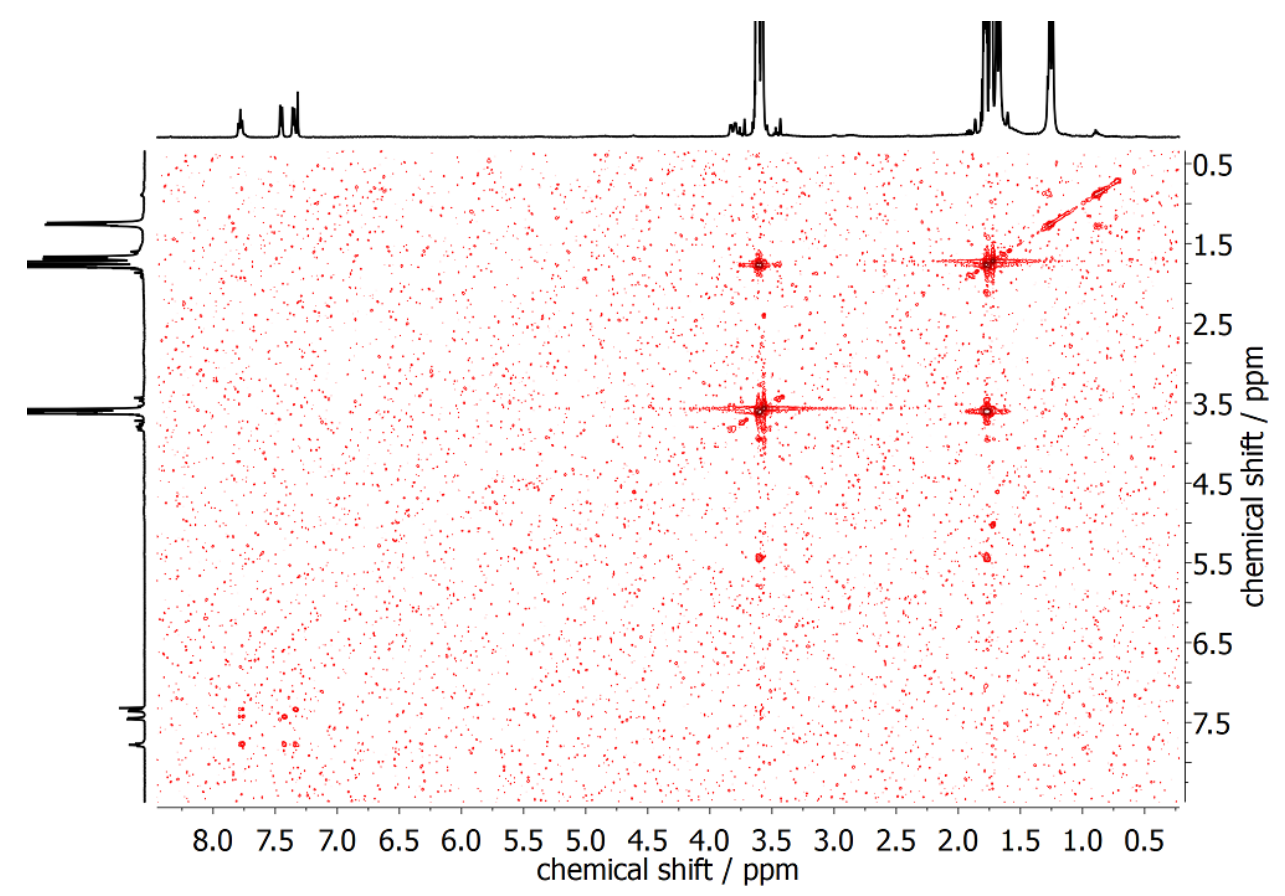

Figure 9.31: COSY spectrum of complex 6 in THF-d $\mathrm{d}_{8}$ under $\mathrm{N}_{2}$ atmosphere at $238 \mathrm{~K}$. 


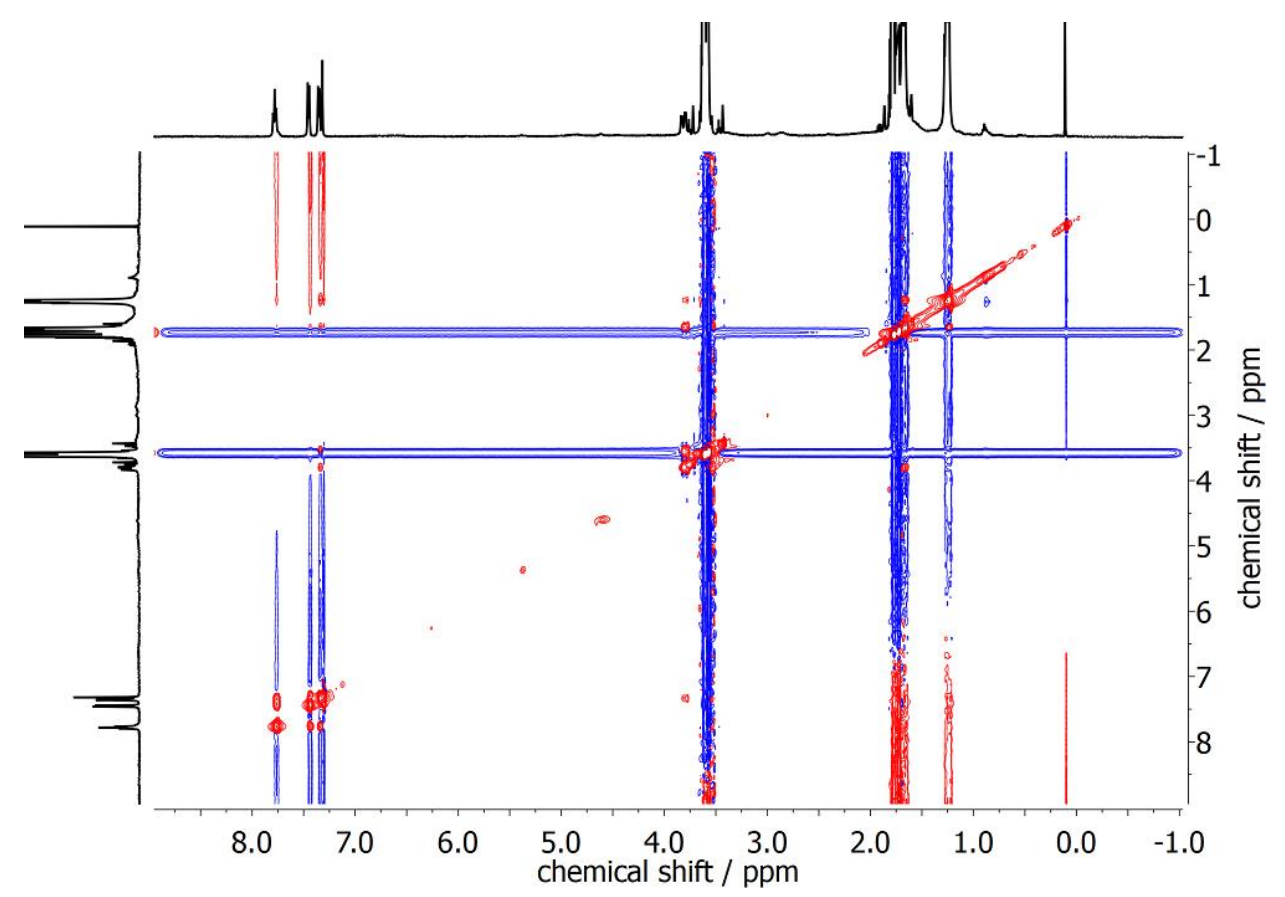

Figure 9.32: NOESY spectrum of complex 6 in THF-d $\mathrm{d}_{8}$ under $\mathrm{N}_{2}$ atmosphere at $238 \mathrm{~K}$.

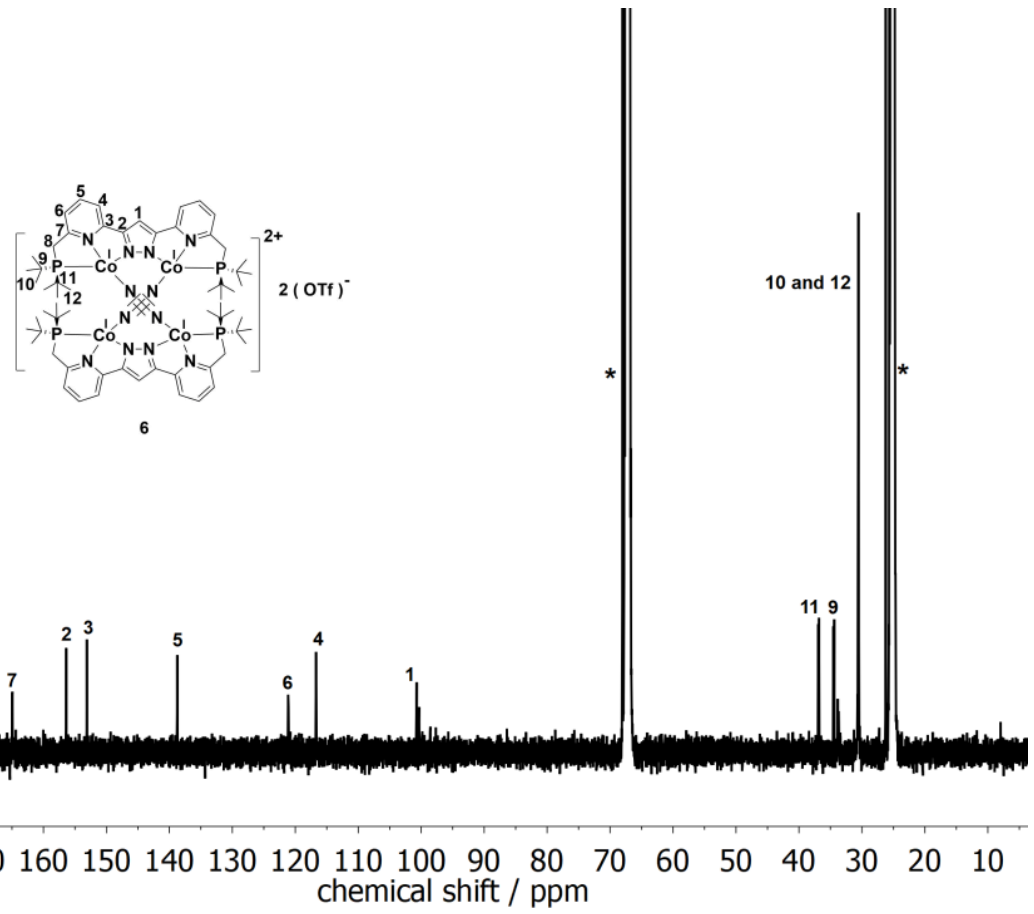

Figure 9.33: ${ }^{13} \mathrm{C}-\mathrm{NMR}$ spectrum of complex 6 in $\mathrm{THF}-\mathrm{d}_{8}$ under $\mathrm{N}_{2}$ atmosphere at $238 \mathrm{~K}$. 


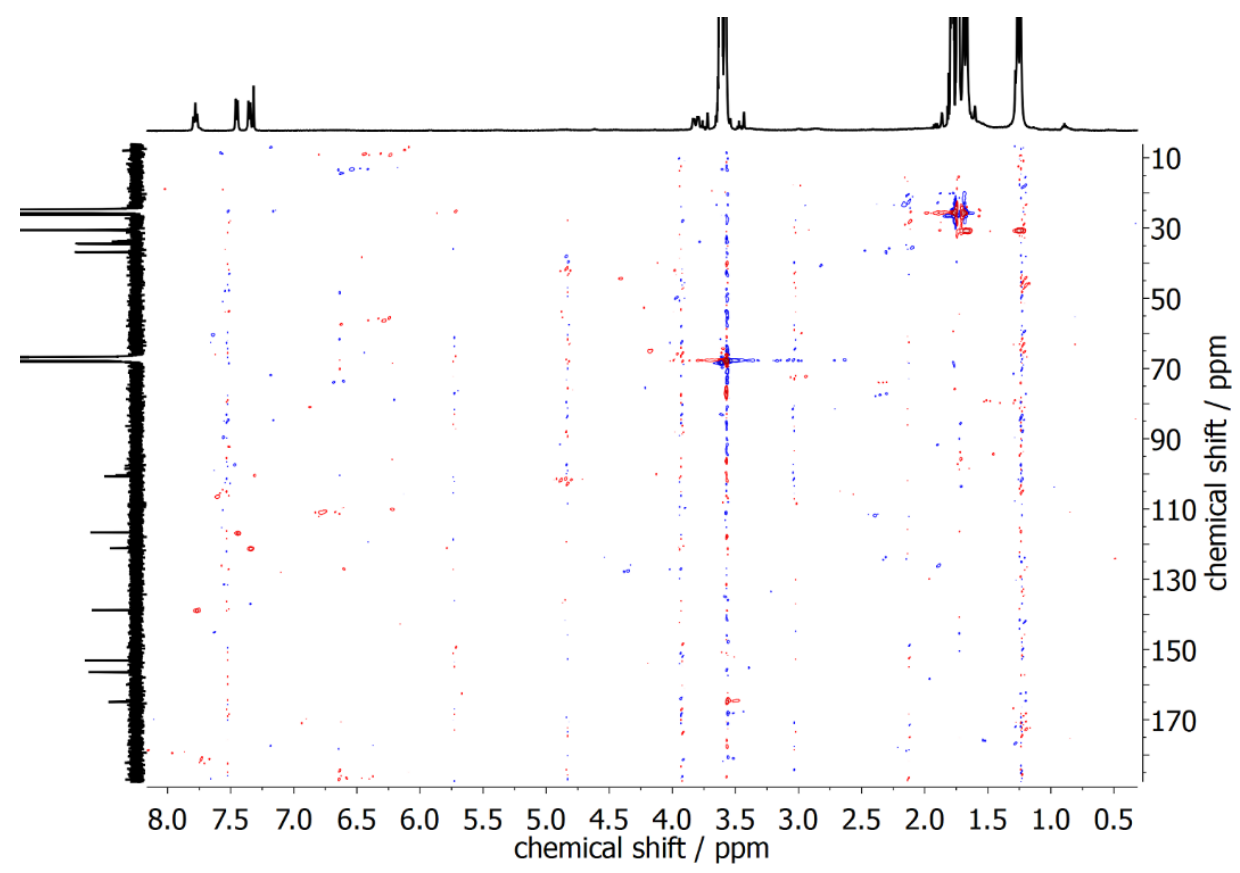

Figure 9.34: ${ }^{1} \mathrm{H}_{-}{ }^{13} \mathrm{C}$ HSQC spectrum of complex 6 in THF- $\mathrm{d}_{8}$ under $\mathrm{N}_{2}$ atmosphere at $238 \mathrm{~K}$.

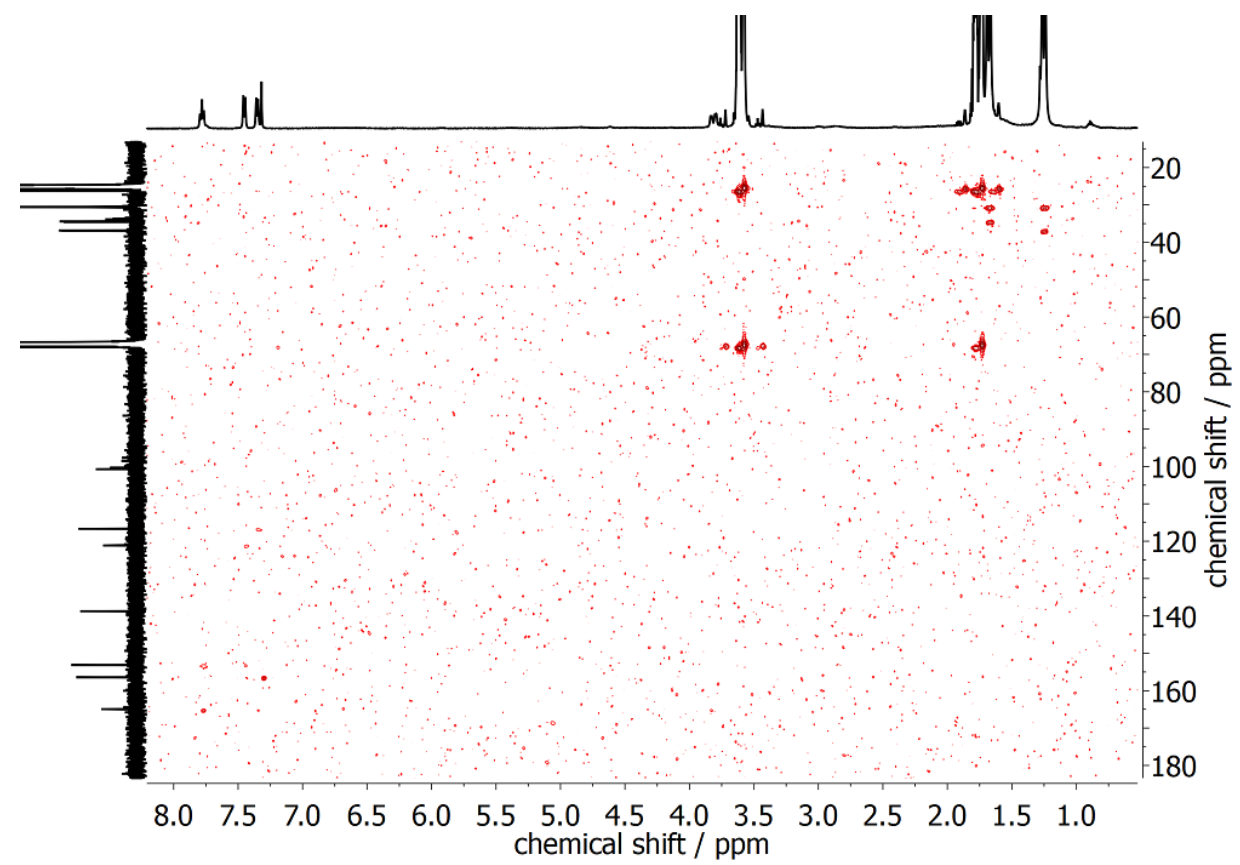

Figure 9.35: ${ }^{1} \mathrm{H}-{ }^{13} \mathrm{C}$ HMBC spectrum of complex 6 in $\mathrm{THF}-\mathrm{d}_{8}$ under $\mathrm{N}_{2}$ atmosphere at $238 \mathrm{~K}$. 


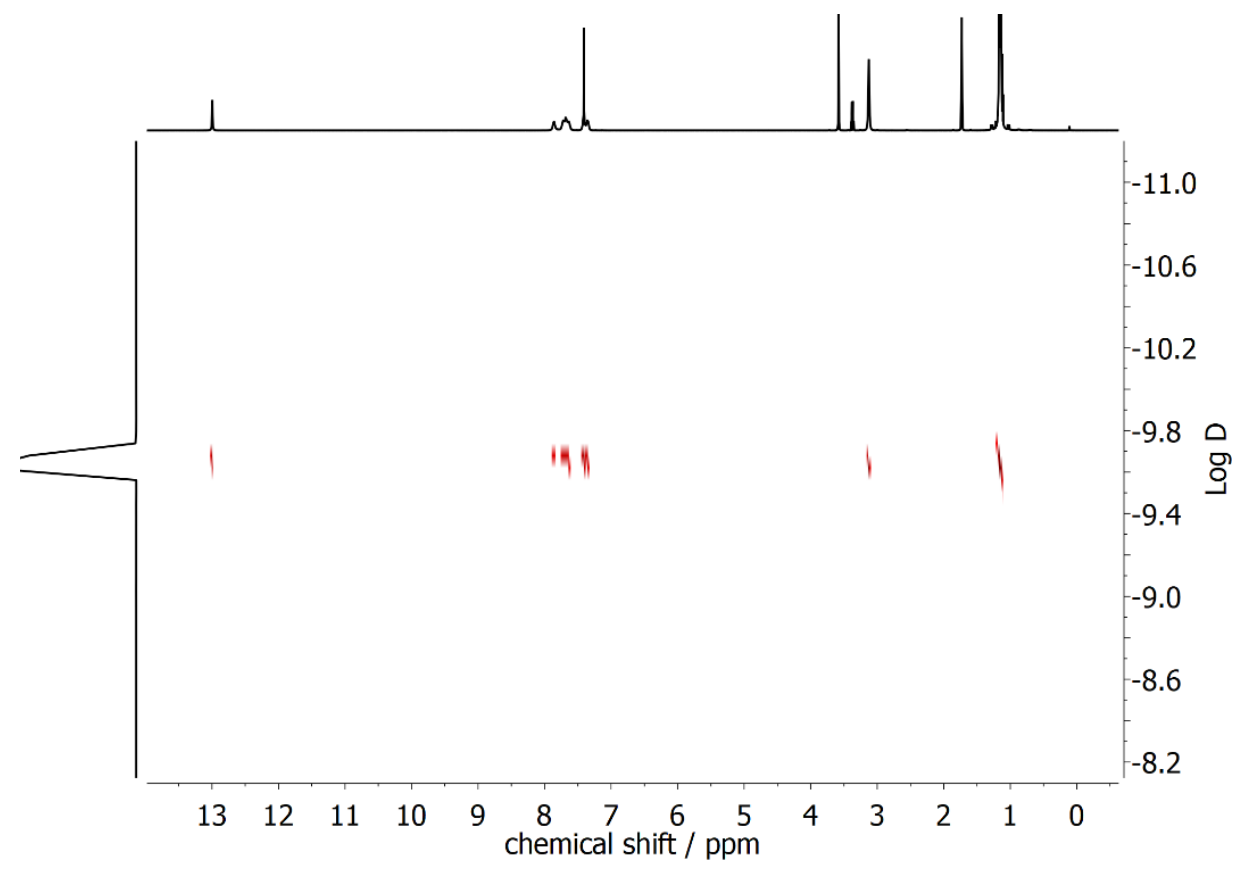

Figure 9.36: DOSY spectrum of ligand HL in THF-d 8 at $238 \mathrm{~K}$.

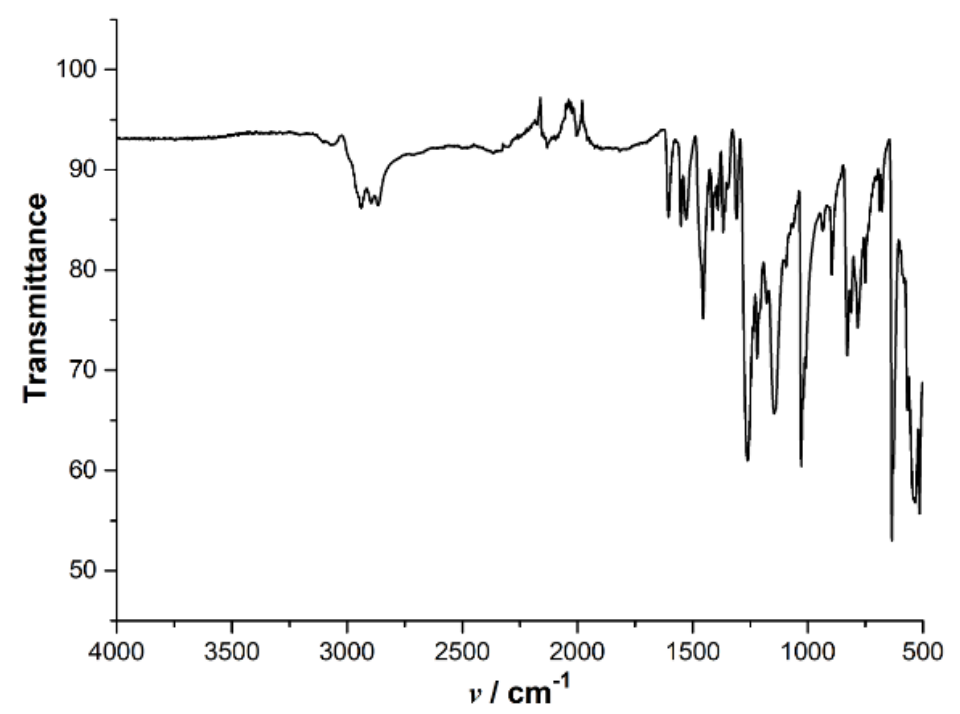

Figure 9.37: IR spectrum of complex 6 in solid state. 


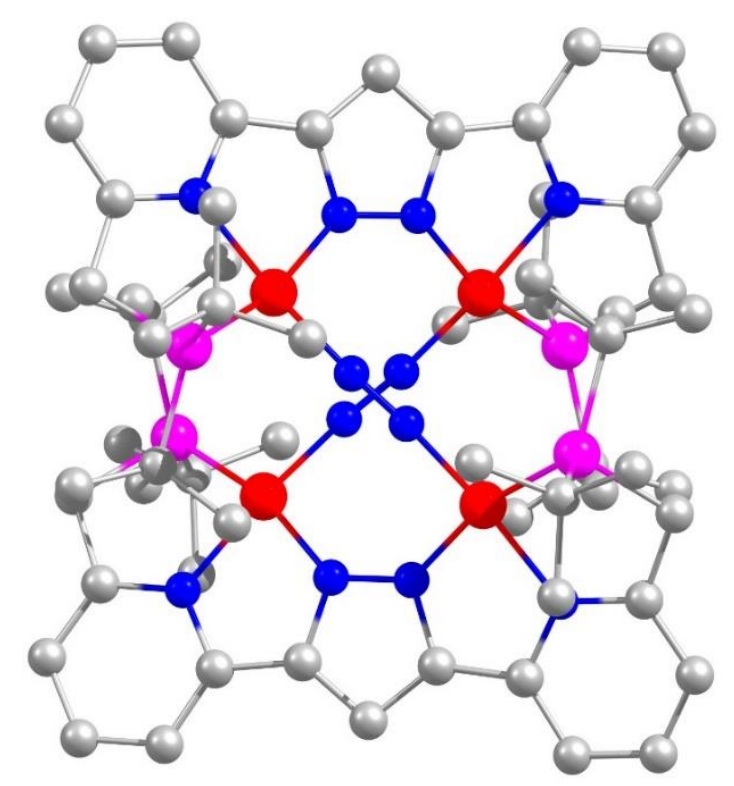

Figure 9.38: DFT optimized molecular structure of complex $6(\mathrm{Co}=\mathrm{red}, \mathrm{N}=$ blue, $\mathrm{P}=$ violet, $\mathrm{C}=$ grey). Spin restricted DFT calculations with ORCA 3.0.3, BP86 functional, def2-svp basis set, RI approximation using the auxiliary def2-svp/J basis set, D3 dispersion correction with Becke-Johnson damping, tight convergence and optimization criteria).

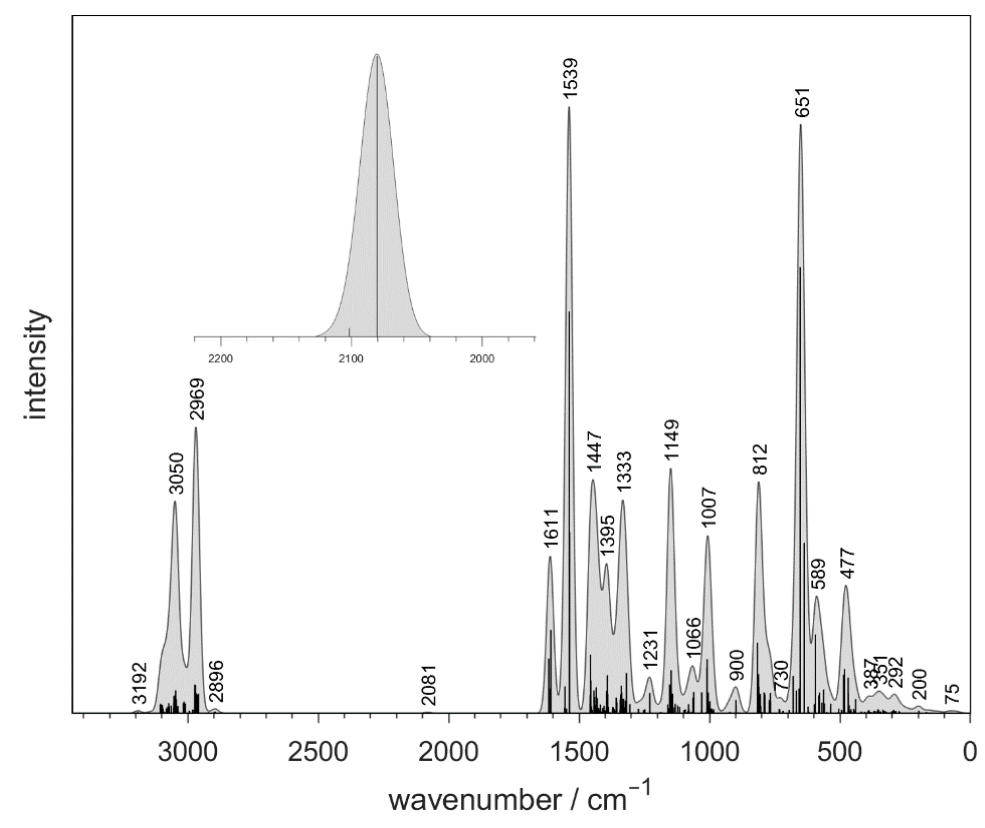

Figure 9.39: Calculated IR spectrum of 6. Predicted $\mathrm{N}_{2}$ stretching: $2080 / 2102 \mathrm{~cm}^{-1}$. The spectrum was convoluted using a Gaussian line shape function with a half-width of $15 \mathrm{~cm}^{-1}$.

Table 9.2: Comparison of experimental and DFT calculated metric parameters of 6; selected distances $[\AA]$ and angles $\left[{ }^{\circ}\right]$. 


\begin{tabular}{ccc}
\hline & 6 (exp) & 6 (calculated) \\
\hline Co- $-\mathrm{N}^{\mathrm{pz}}$ & $1.928(4)-1.965(4)$ & $1.92830-1.92851$ \\
Co--N & $1.899(4)-1.914(4)$ & $1.91272-1.91488$ \\
$\mathrm{Co}-\mathrm{N}_{2}$ & $1.764(4)-1.783(4)$ & $1.73603-1.73778$ \\
$\mathrm{Co}-\mathrm{P}$ & $2.1810(15)-2.1915(15)$ & $2.17199-2.17310$ \\
$\mathrm{Co} \cdots \mathrm{Co}$ & $4.3481(11) / 4.4417(12)$ & $4.28244 / 4.29122$ \\
$\mathrm{~N}-\mathrm{N}$ & $1.140(5) / 1.142(6)$ & $1.15385 / 1.15389$ \\
$\mathrm{Co}-\mathrm{N}-\mathrm{N}$ & $174.4(4)-176.9(4)$ & $173.796-175.216$ \\
\hline
\end{tabular}

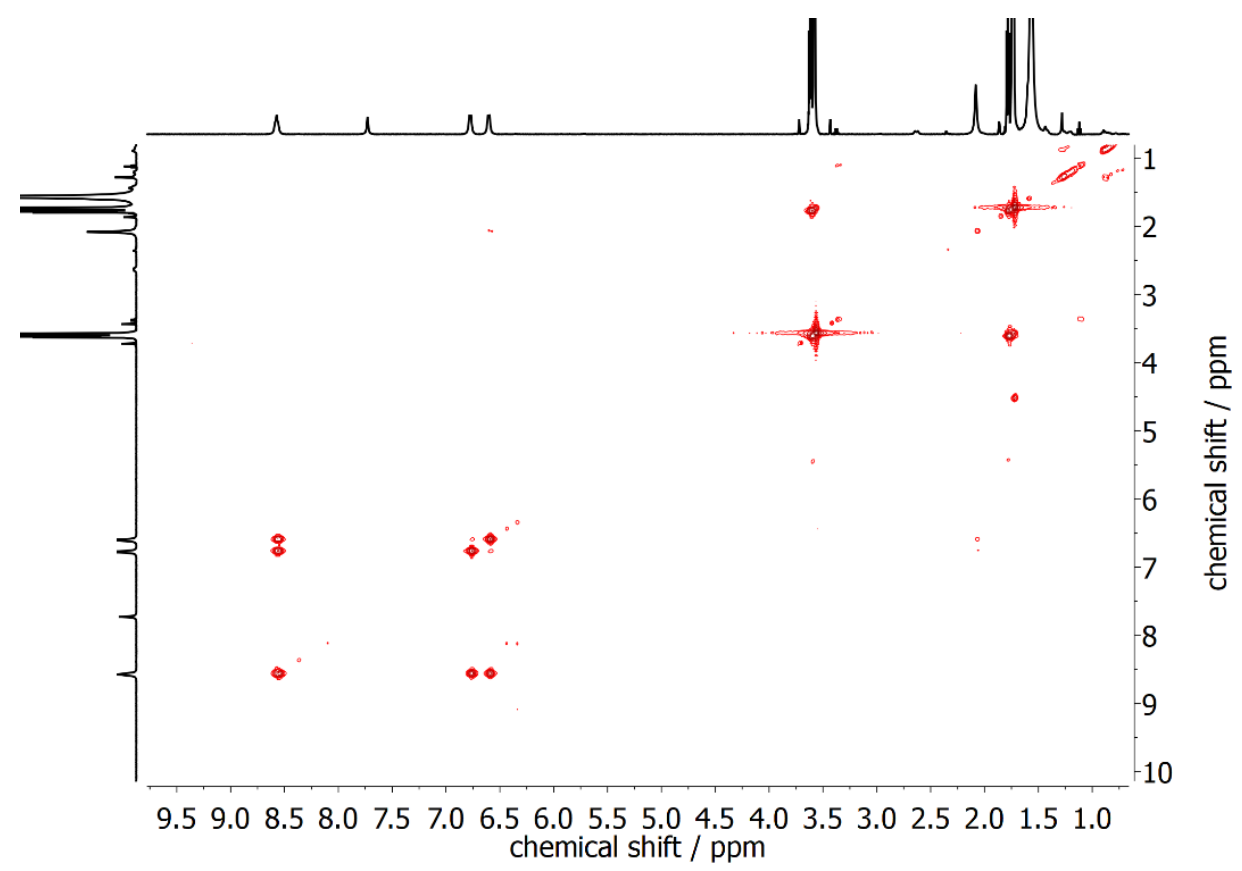

Figure 9.40: COSY spectrum of complex 7 in THF- $d_{8}$ under an argon atmosphere at $238 \mathrm{~K}$. 


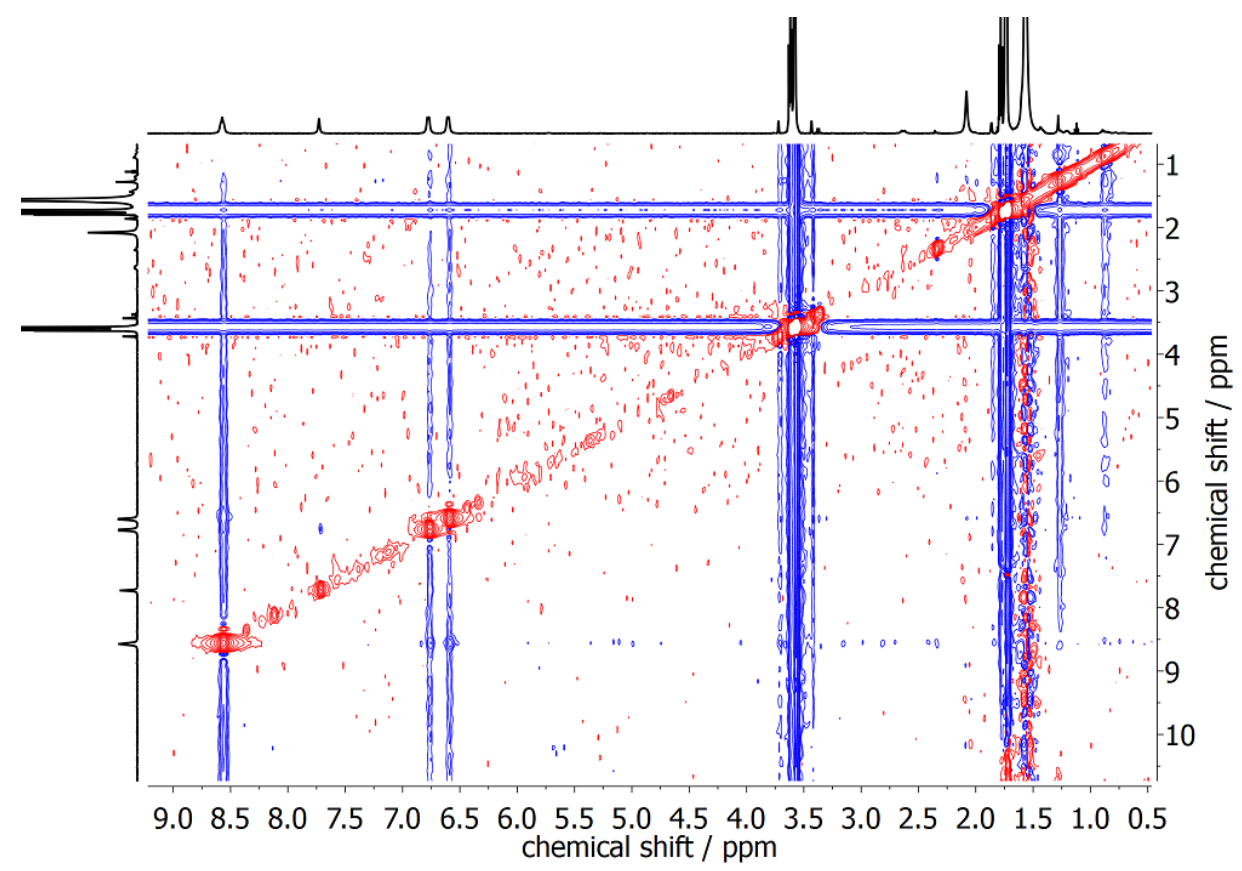

Figure 9.41: NOESY spectrum of complex 7 in THF-d $\mathrm{d}_{8}$ under an argon atmosphere at $238 \mathrm{~K}$.

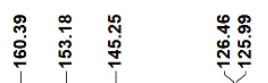

\section{$\stackrel{8}{\circ}$}
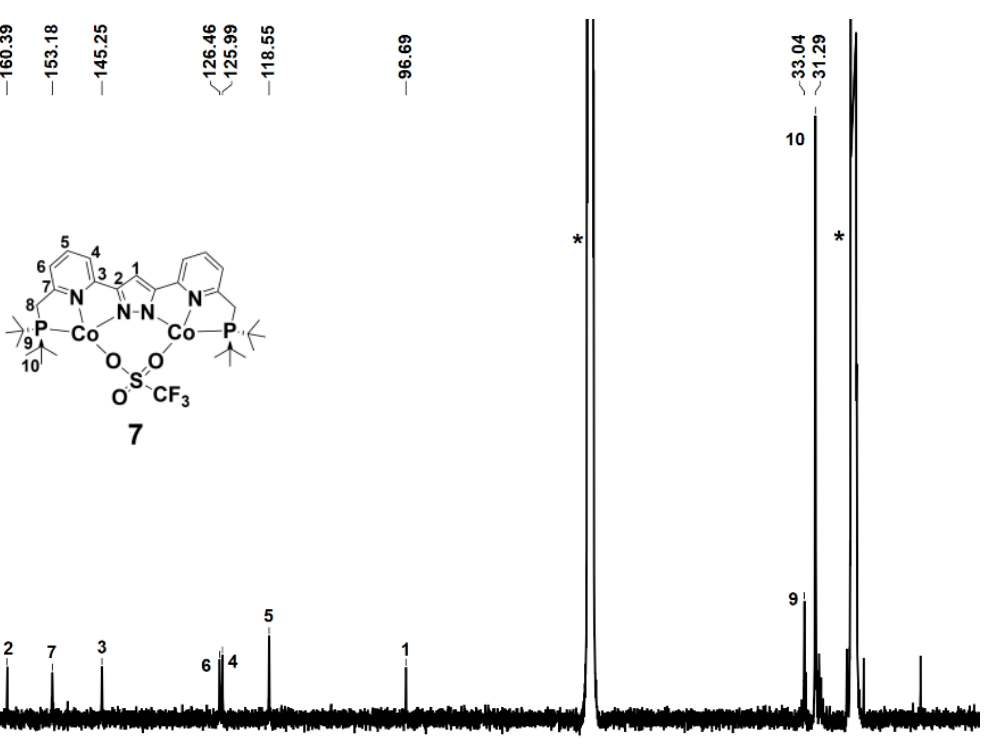

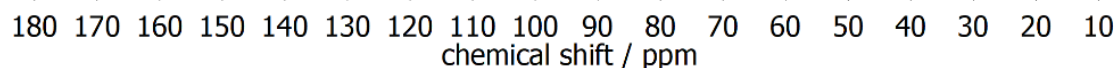

Figure 9.42: ${ }^{13} \mathrm{C}-\mathrm{NMR}$ spectrum of complex 7 in THF-d 8 under an argon atmosphere at $238 \mathrm{~K}$. 


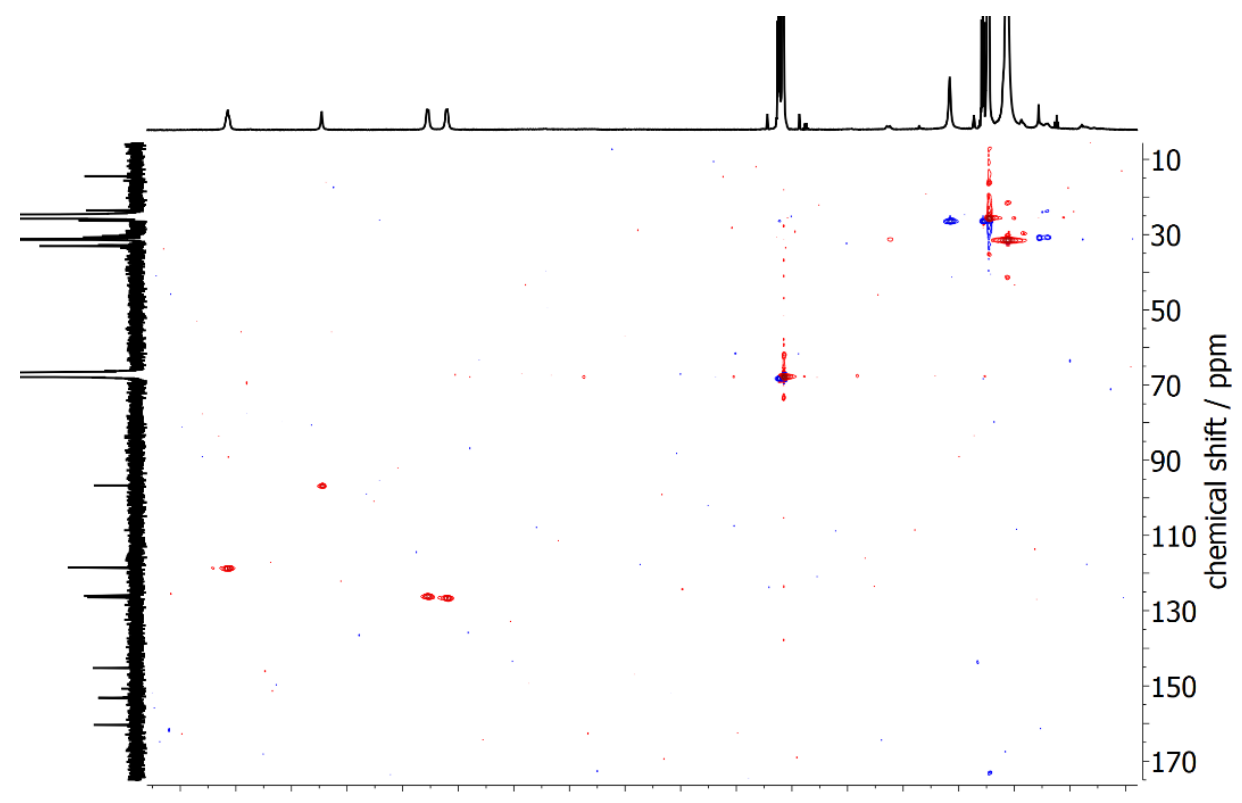

$\begin{array}{lllllllllllllllllll}9.0 & 8.5 & 8.0 & 7.5 & 7.0 & 6.5 & 6.0 & 5.5 & 5.0 & 4.5 & 4.0 & 3.5 & 3.0 & 2.5 & 2.0 & 1.5 & 1.0 & 0.5\end{array}$ chemical shift / ppm

Figure 9.43: ${ }^{1} \mathrm{H}-{ }^{13} \mathrm{C}$ HSQC spectrum of complex 7 in THF- $\mathrm{d}_{8}$ under an argon atmosphere at $238 \mathrm{~K}$.

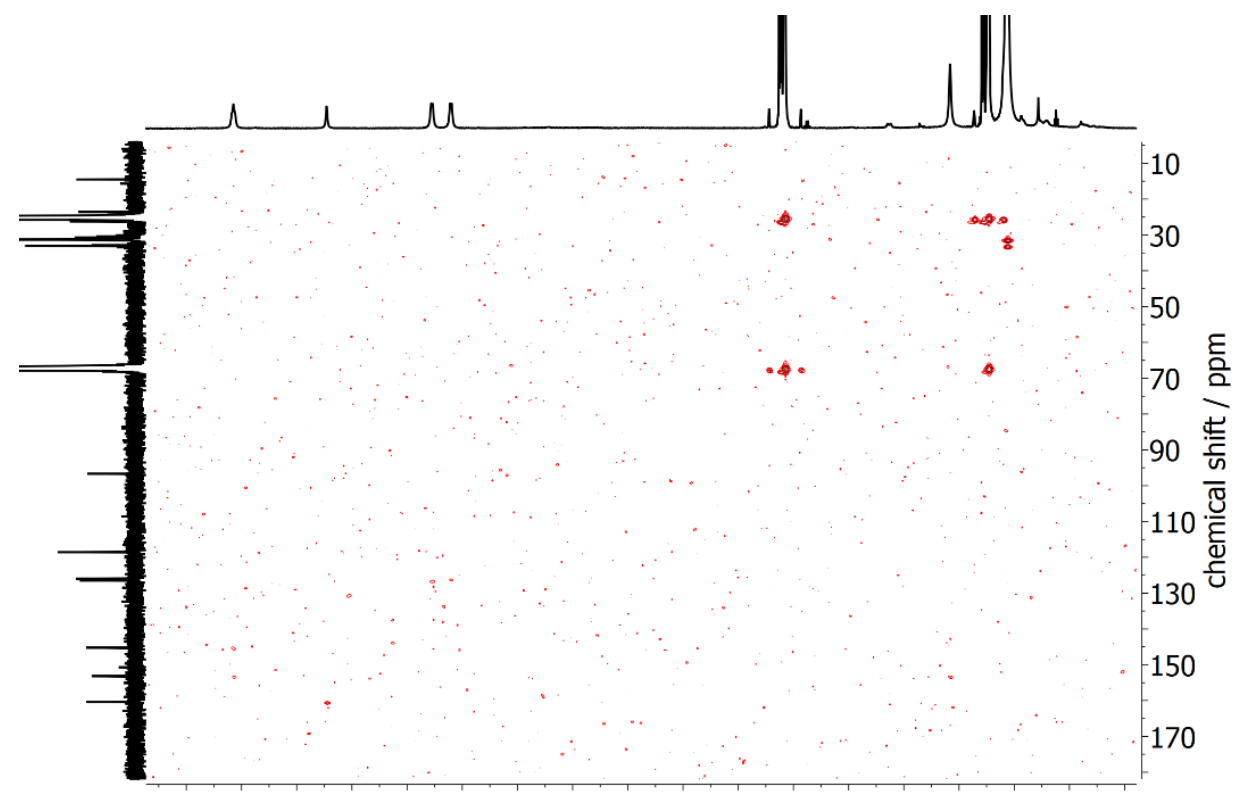

$\begin{array}{llllllllllllllllll}9.0 & 8.5 & 8.0 & 7.5 & 7.0 & 6.5 & 6.0 & 5.5 & 5.0 & 4.5 & 4.0 & 3.5 & 3.0 & 2.5 & 2.0 & 1.5 & 1.0 & 0.5\end{array}$ chemical shift / ppm

Figure 9.44: ${ }^{1} \mathrm{H}_{-}{ }^{13} \mathrm{C}$ HMBC spectrum of complex 7 in $\mathrm{THF}-\mathrm{d}_{8}$ under an argon atmosphere at $238 \mathrm{~K}$. 

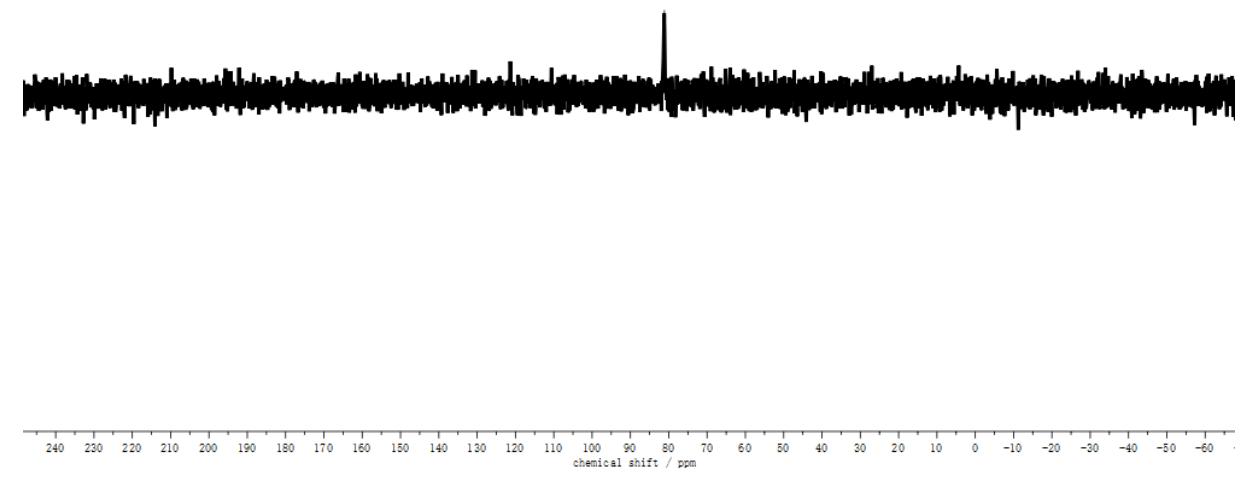

Figure 9.45: ${ }^{31} \mathrm{P}-\mathrm{NMR}$ spectrum of complex 7 in THF-d 8 under an argon atmosphere at $238 \mathrm{~K}$.

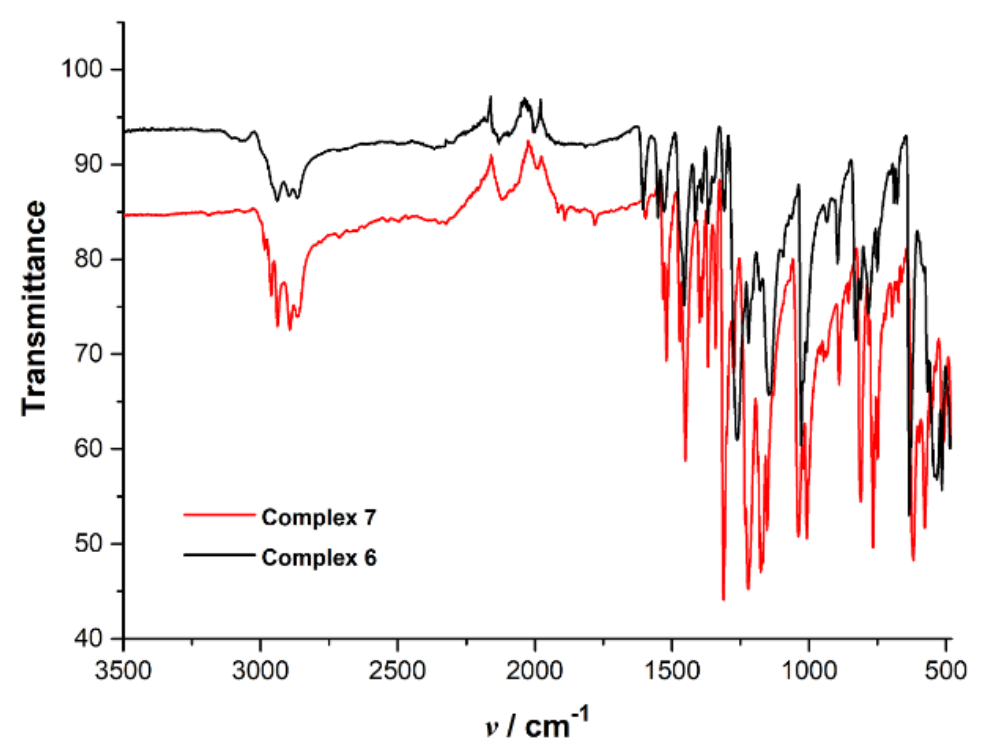

Figure 9.46: IR spectrum of complex 7 comparing to complex 6 in solid state. 


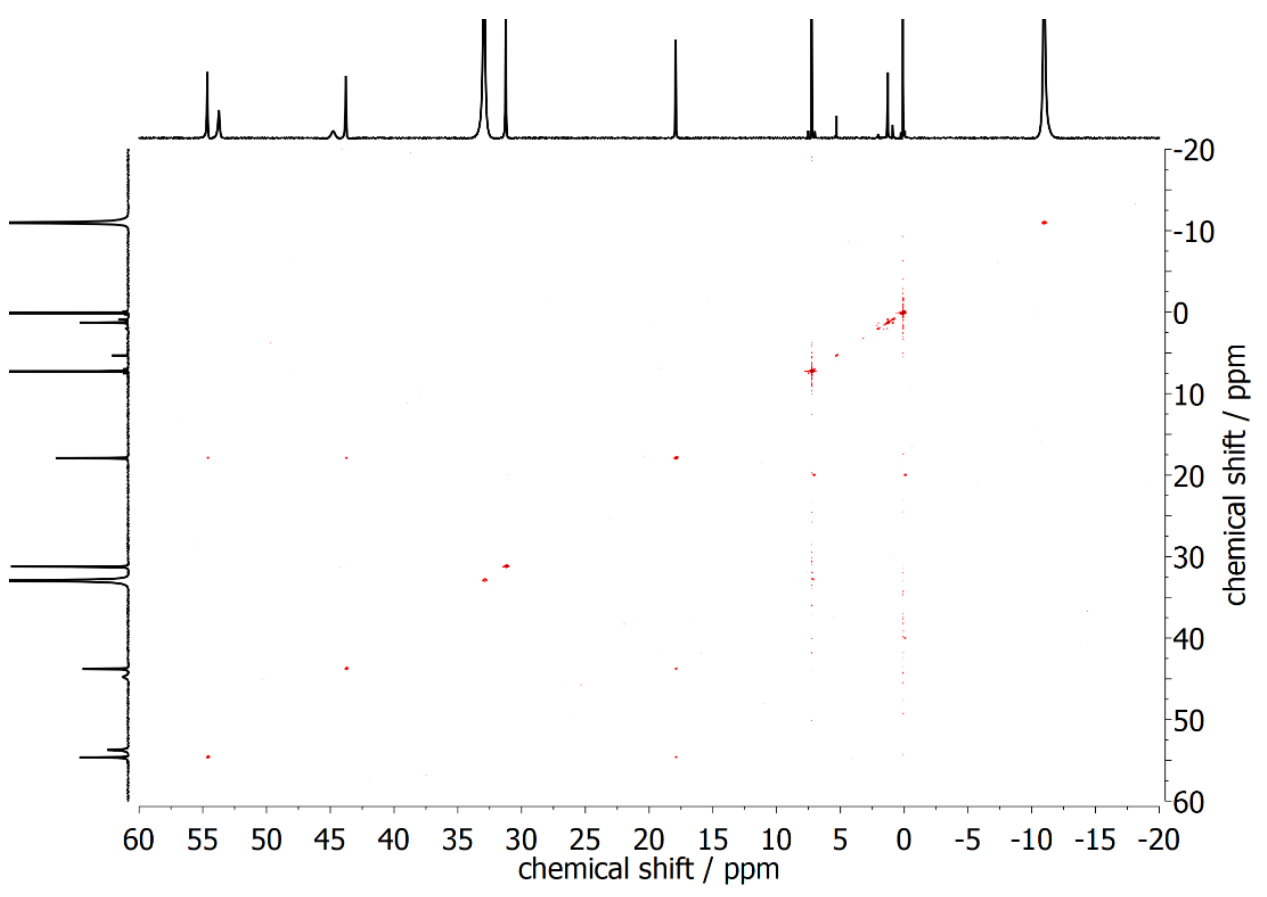

Figure 9.47: ${ }^{1} \mathrm{H}-{ }^{1} \mathrm{H} \operatorname{COSY}(500 \mathrm{MHz})$ of complex 9 in $\mathrm{CDCl}_{3}$.

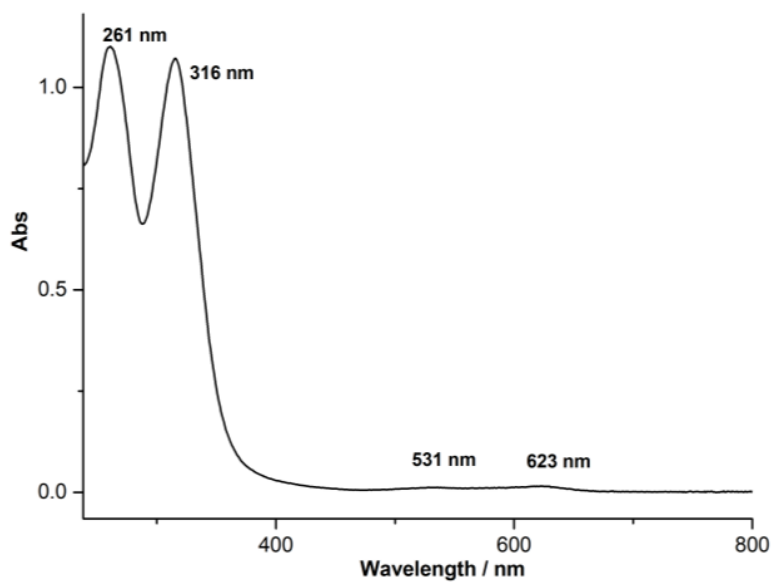

a

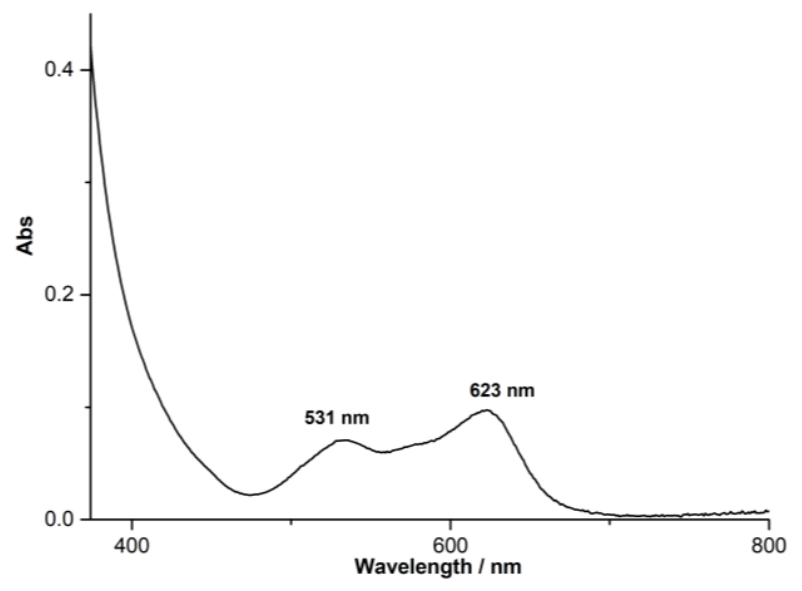

b

Figure 9.48: (a): UV-vis absorption spectrum of complex $9(0.8 \mu \mathrm{M})$ in $\mathrm{CH}_{2} \mathrm{Cl}_{2}$ solution. (b): visible spectrum of complex $9(6.2 \mu \mathrm{M})$ in $\mathrm{CH}_{2} \mathrm{Cl}_{2}$ solution. 


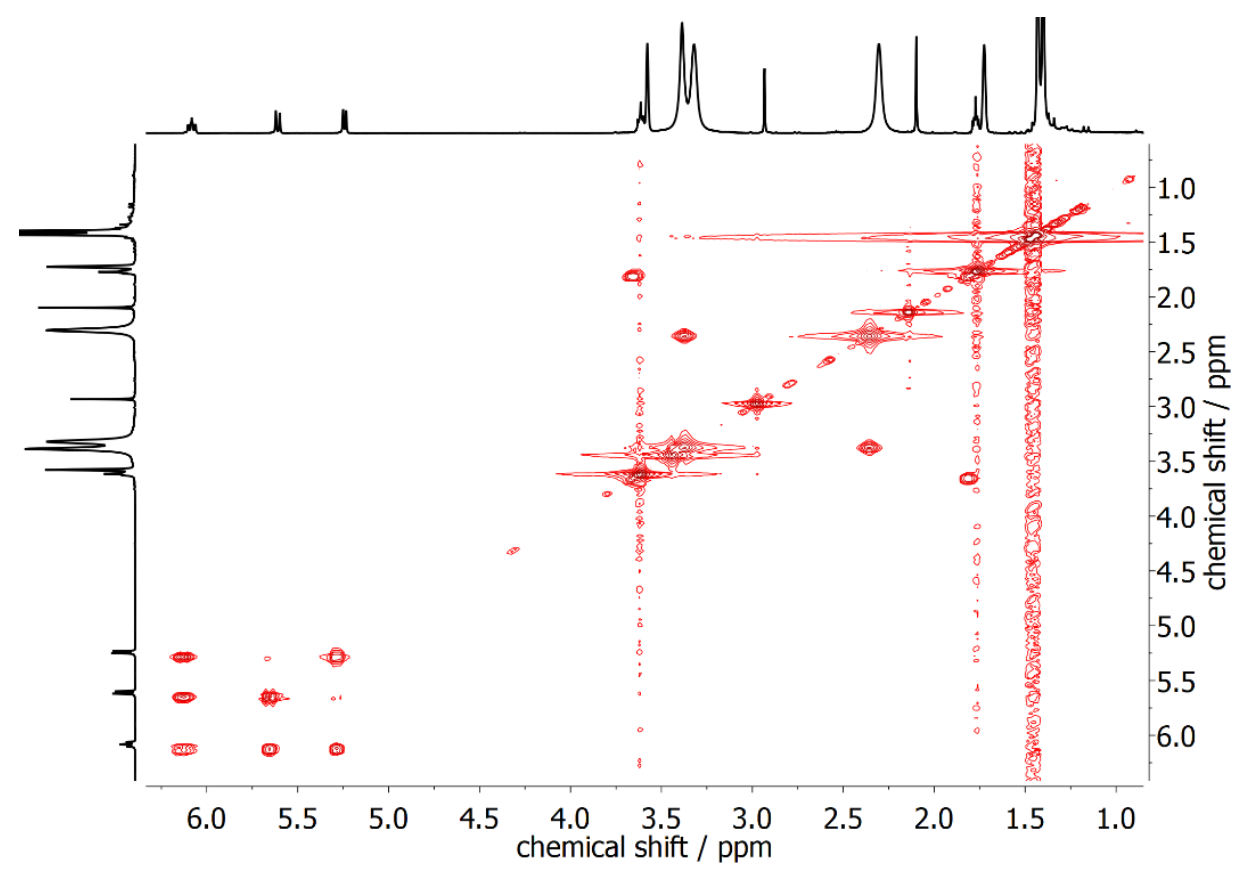

Figure 9.49: ${ }^{1} \mathrm{H}-{ }^{1} \mathrm{H}$ COSY $(400 \mathrm{MHz})$ of complex 10 in $\mathrm{THF}-\mathrm{d}_{8}$.

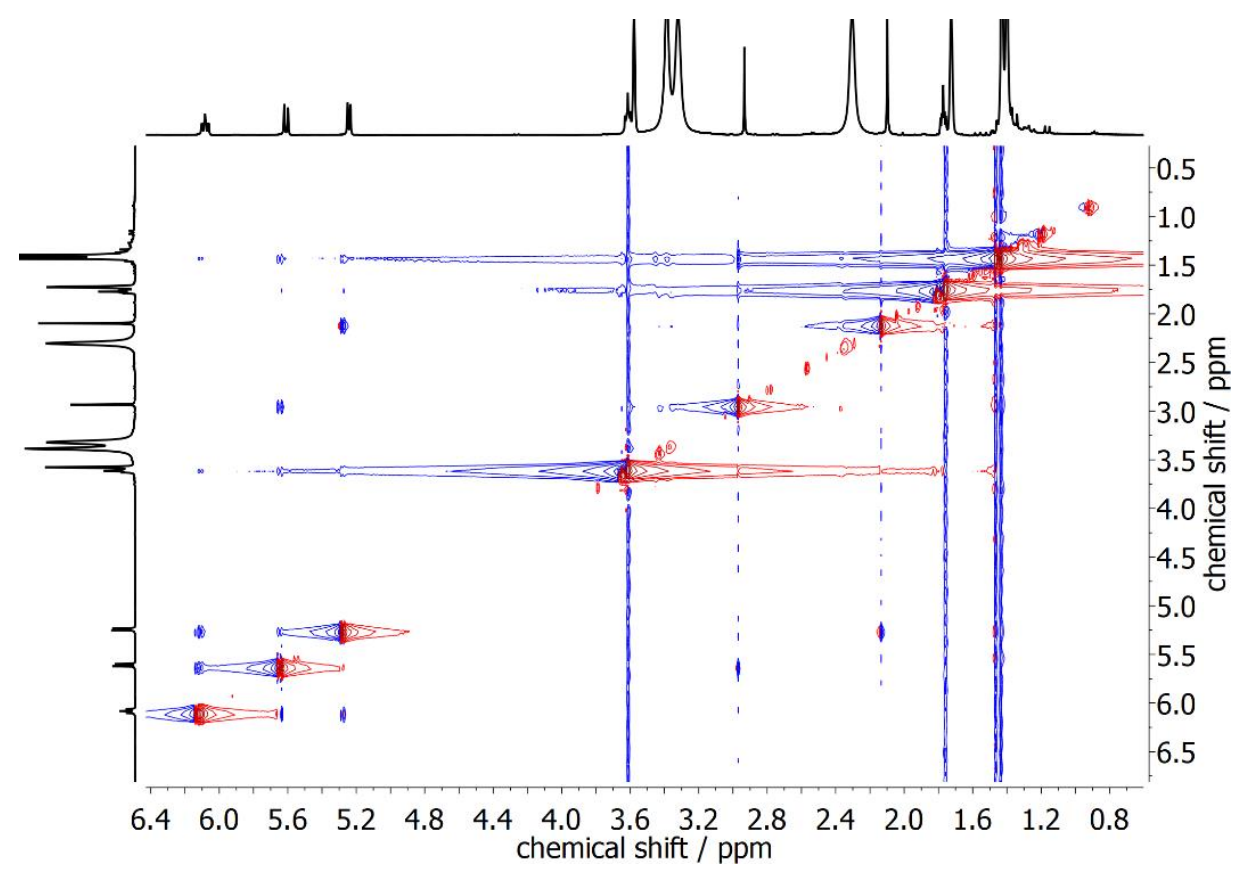

Figure 9.50: ${ }^{1} \mathrm{H}-{ }^{1} \mathrm{H}$ NOESY $(400 \mathrm{MHz})$ of complex 10 in THF-d 8 . 


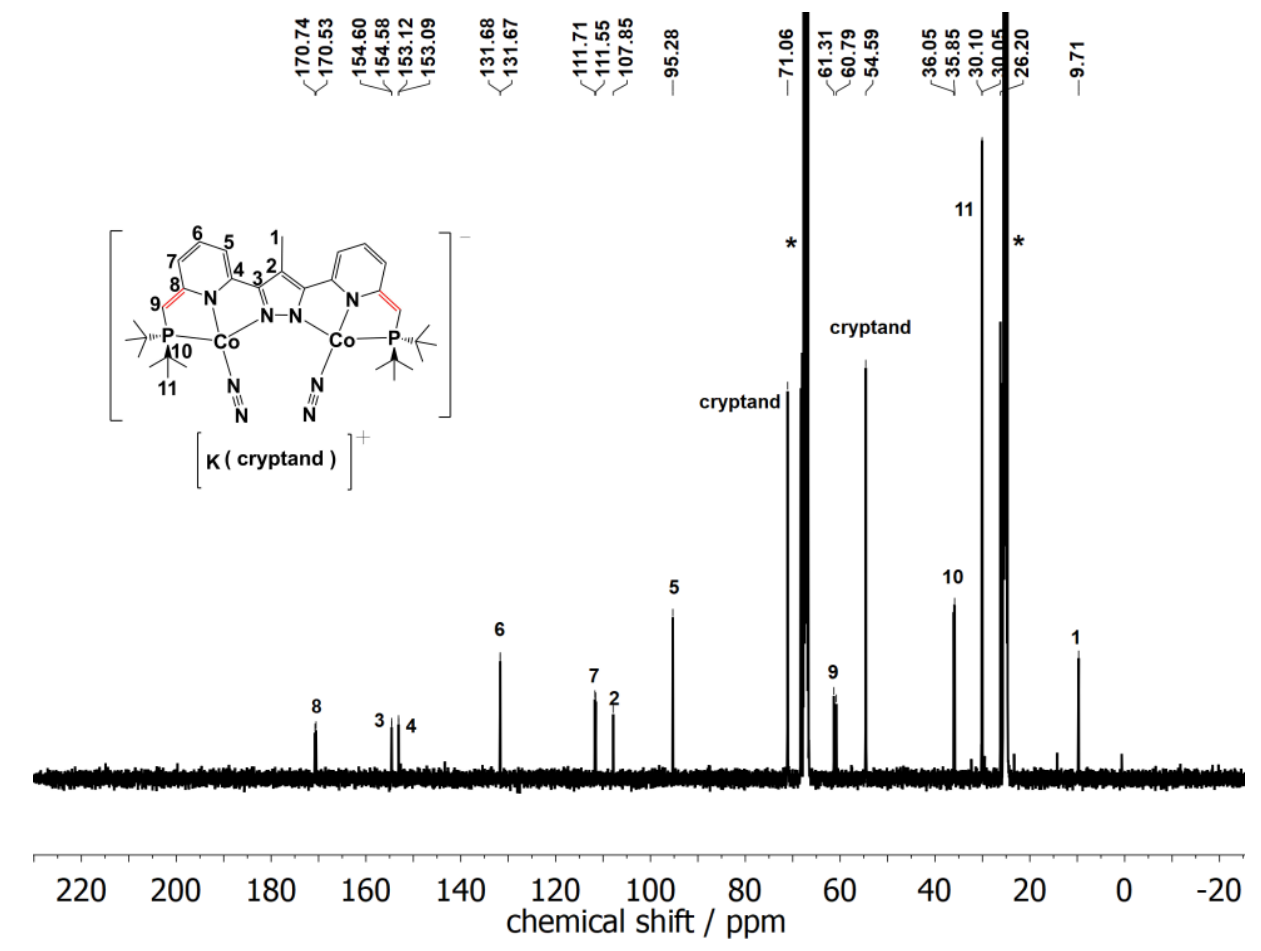

Figure 9.51: ${ }^{13} \mathrm{C}-\mathrm{NMR}$ spectrum of complex 10 in $\mathrm{THF}-\mathrm{d}_{8}$. Solvent signals are marked with an asterisk $(*)$.

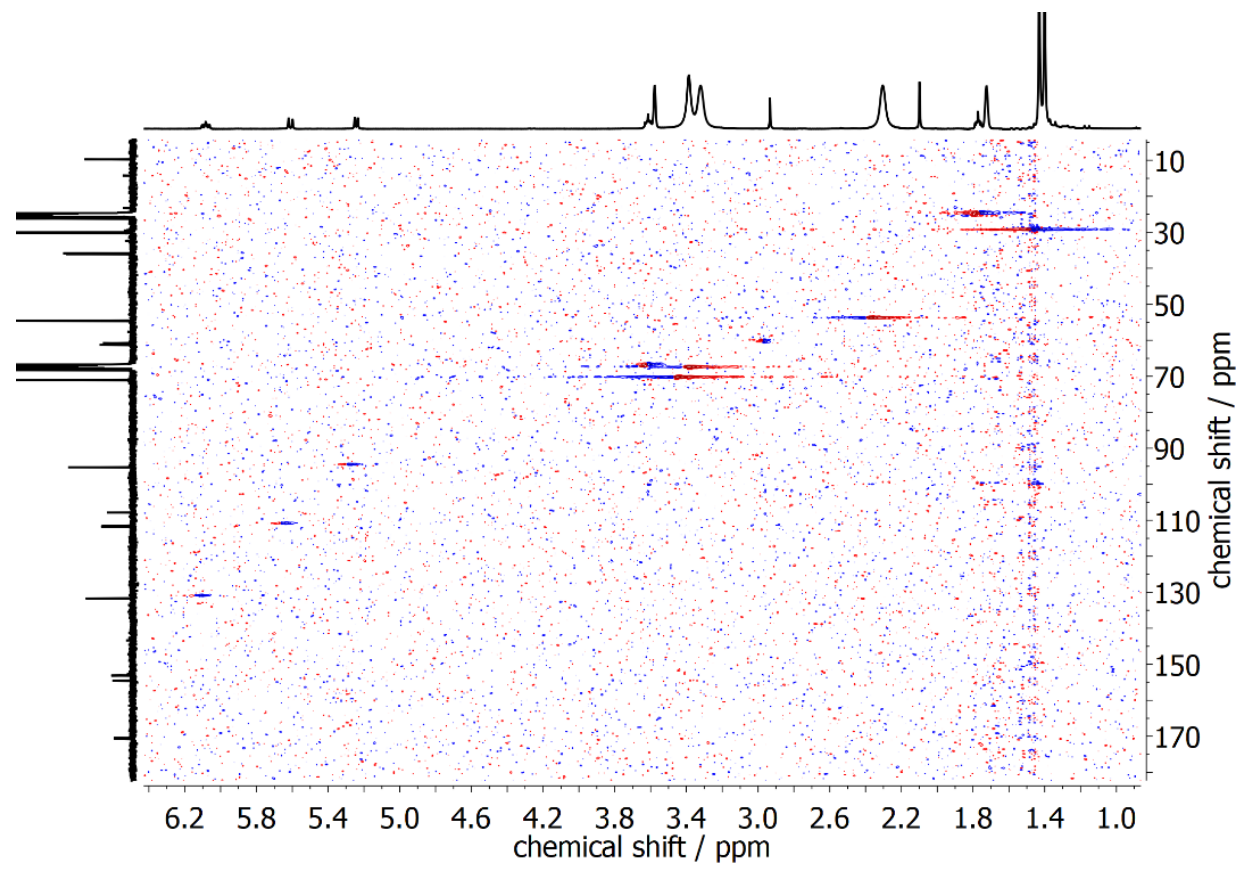

Figure 9.52: ${ }^{1} \mathrm{H}^{-13} \mathrm{C}$ HSQC $(400 \mathrm{MHz})$ of complex 10 in THF-d 8. 


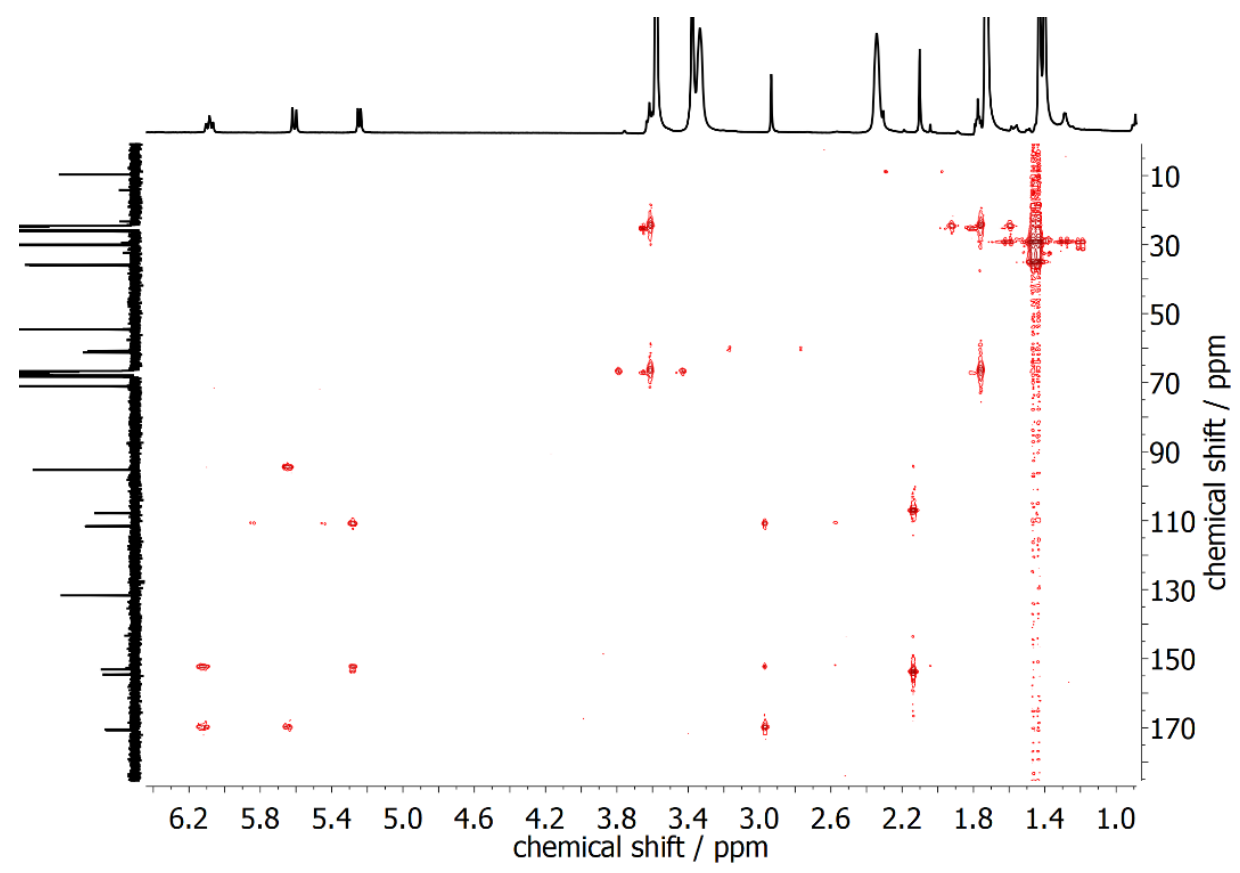

Figure 9.53: ${ }^{1} \mathrm{H}^{13} \mathrm{C}$ HMBC $(400 \mathrm{MHz})$ of complex 10 in THF-d8.

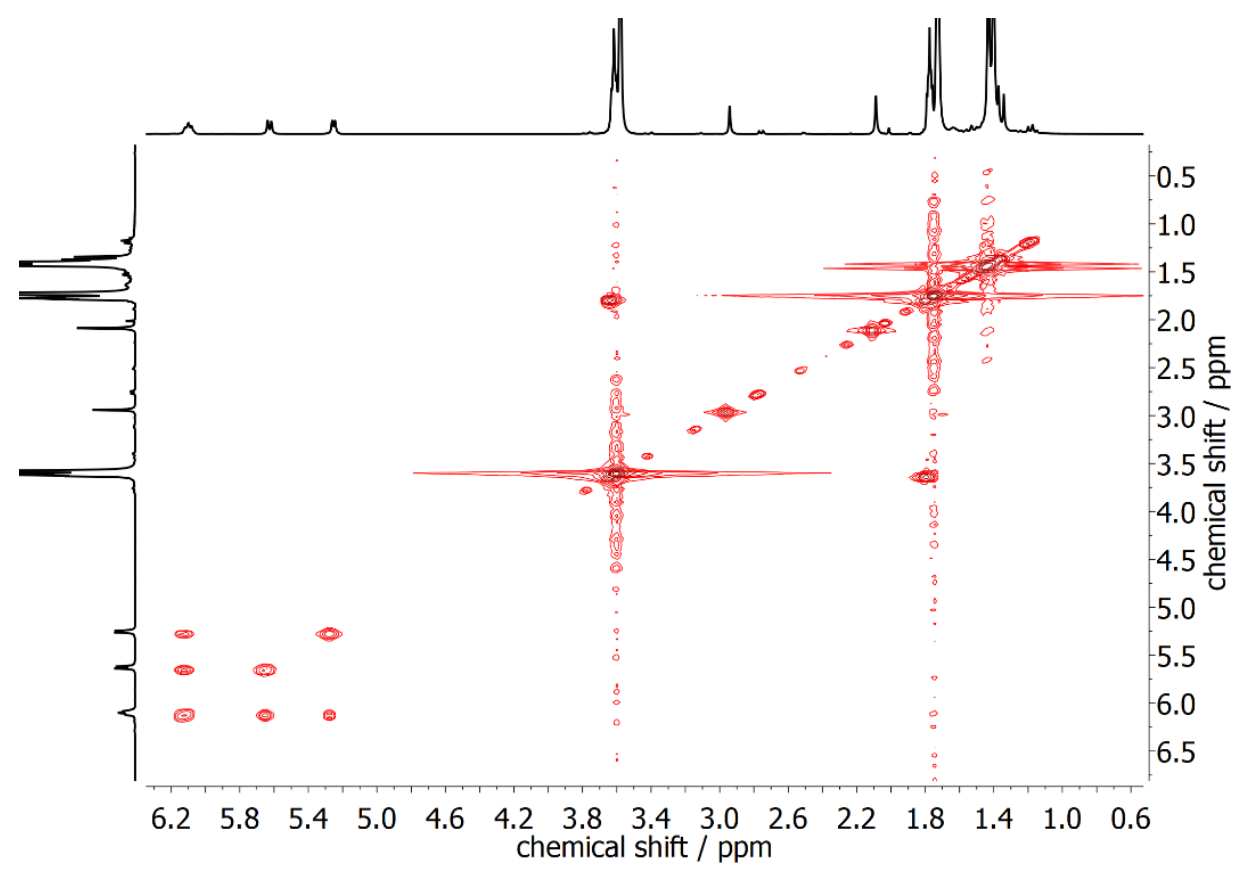

Figure 9.54: ${ }^{1} \mathrm{H}-{ }^{1} \mathrm{H}$ COSY $(400 \mathrm{MHz})$ of complex 11 in $\mathrm{THF}-\mathrm{d}_{8}$. 


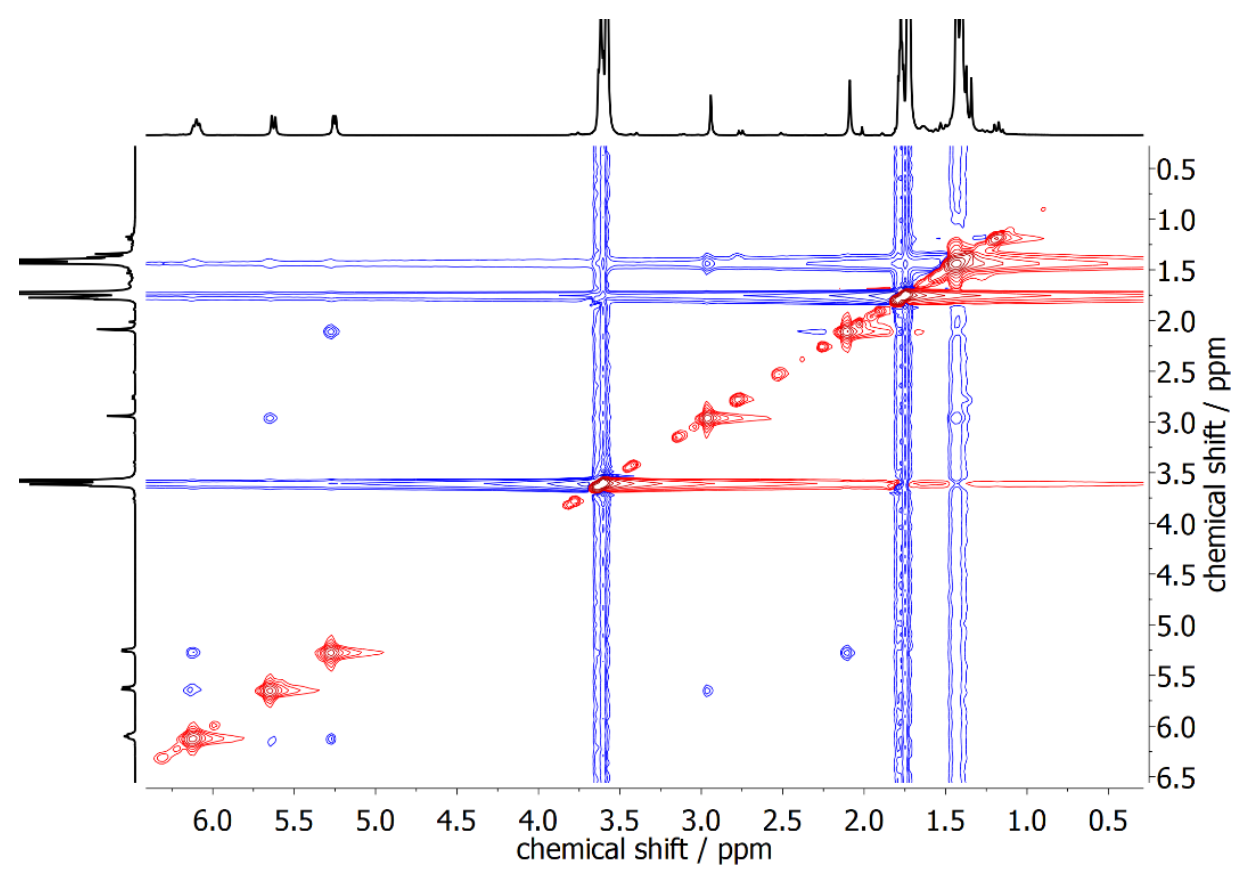

Figure 9.55: ${ }^{1} \mathrm{H}-{ }^{1} \mathrm{H}$ NOESY $(400 \mathrm{MHz})$ of complex 11 in THF-d8.

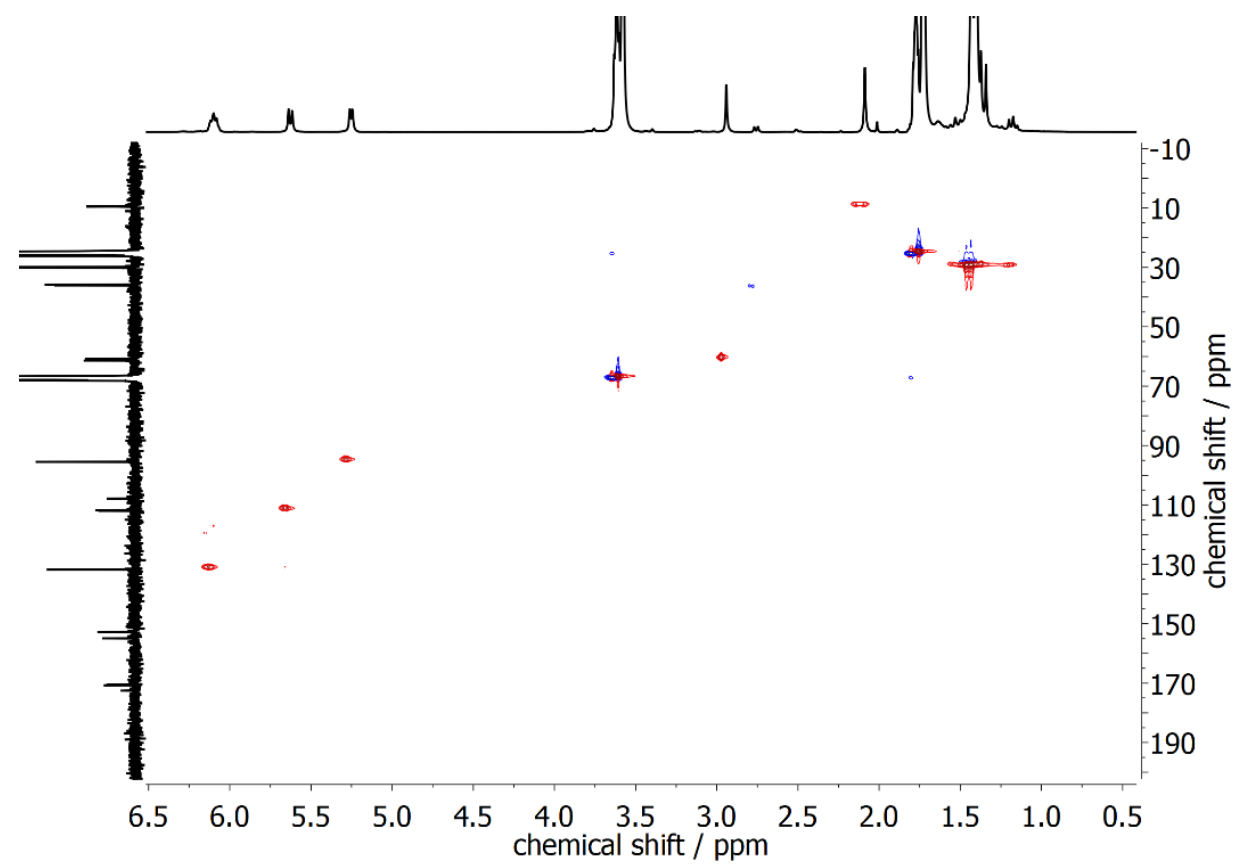

Figure 9.56: ${ }^{1} \mathrm{H}^{-13} \mathrm{C}$ HSQC (400 MHz) of complex 11 in THF-d 8 . 


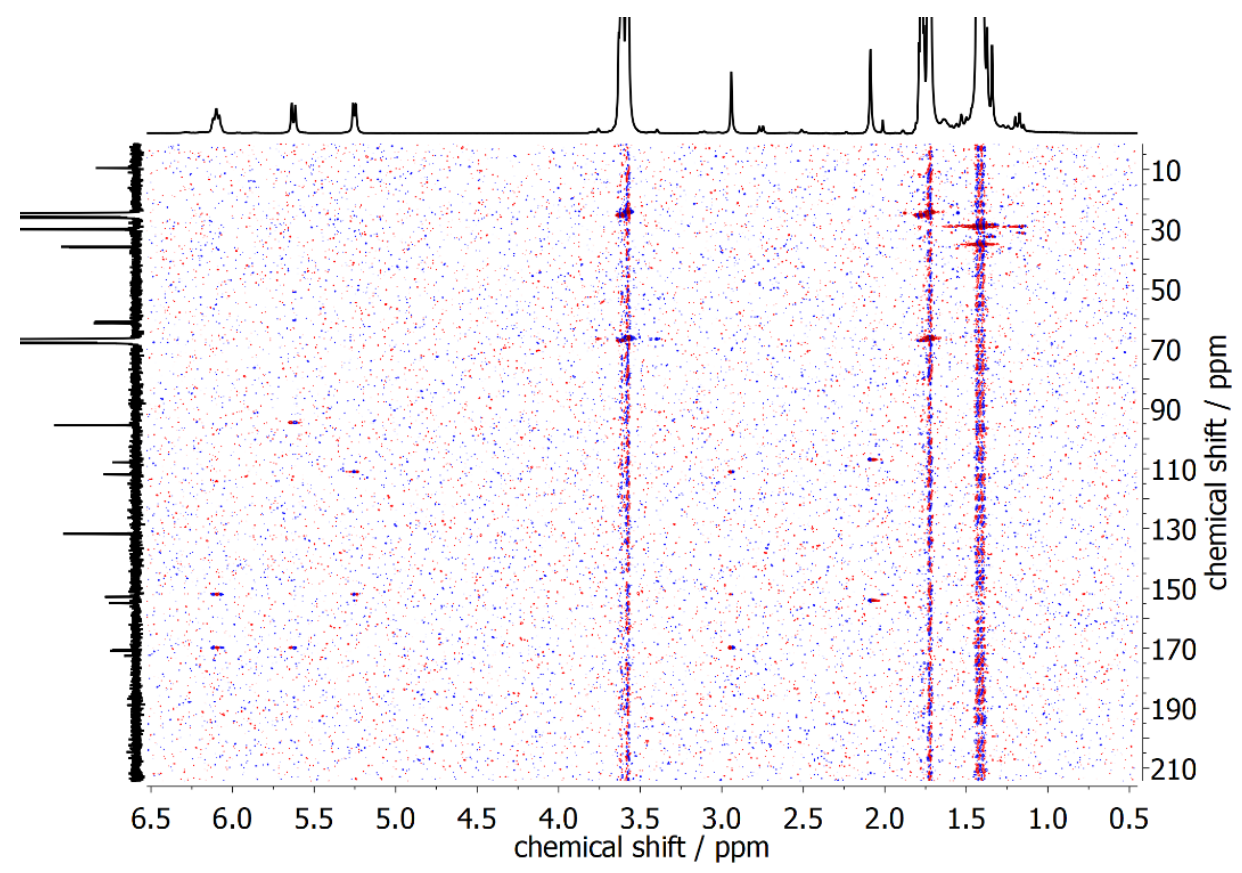

Figure 9.57: ${ }^{1} \mathrm{H}^{13} \mathrm{C}$ HMBC $(400 \mathrm{MHz})$ of complex 11 in THF-d8.

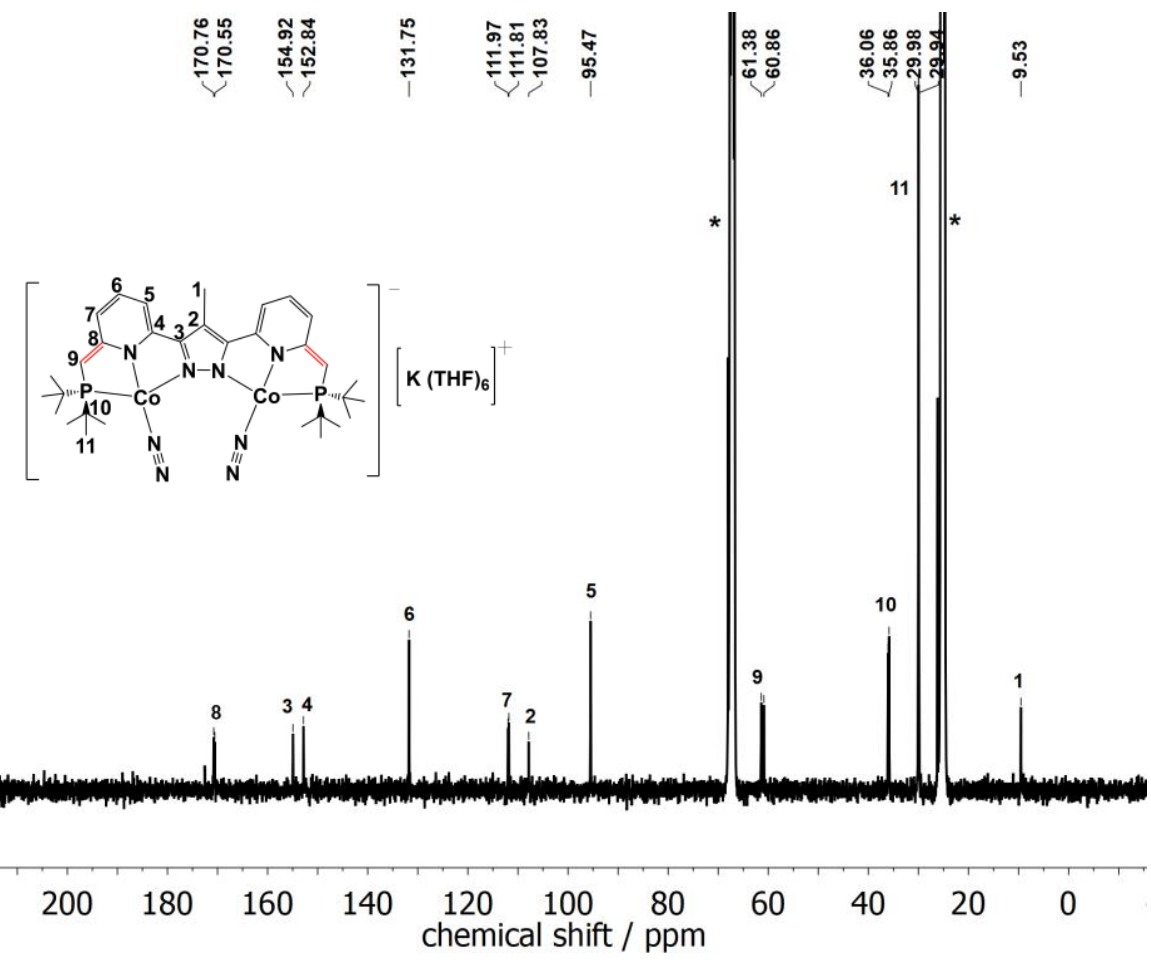

Figure 9.58: ${ }^{13} \mathrm{C}-\mathrm{NMR}$ spectrum $(400 \mathrm{MHz})$ of complex 11 in $\mathrm{THF}-\mathrm{d}_{8}$. Solvent signals are marked with an asterisk $(*)$. 


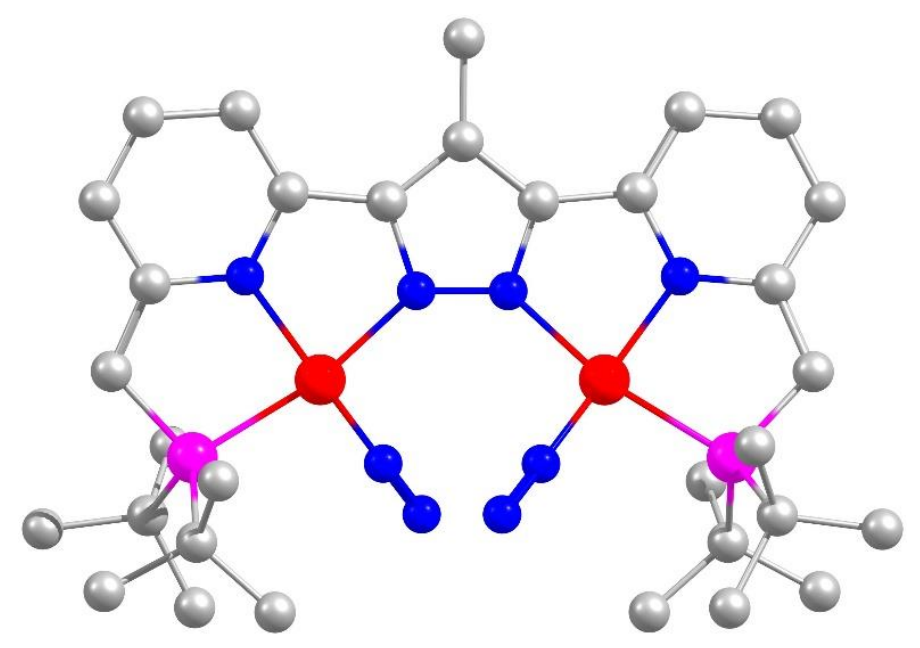

Figure 9.59: DFT optimized molecular structure of complex $11(\mathrm{Co}=\operatorname{red}, \mathrm{N}=$ blue, $\mathrm{P}=$ violet, $\mathrm{C}=$ grey). Spin restricted DFT calculations with ORCA 3.0.3, BP86 functional, def2-svp basis set, RI approximation using the auxiliary def2-svp/J basis set, D3 dispersion correction with Becke-Johnson damping, tight convergence and optimization criteria).

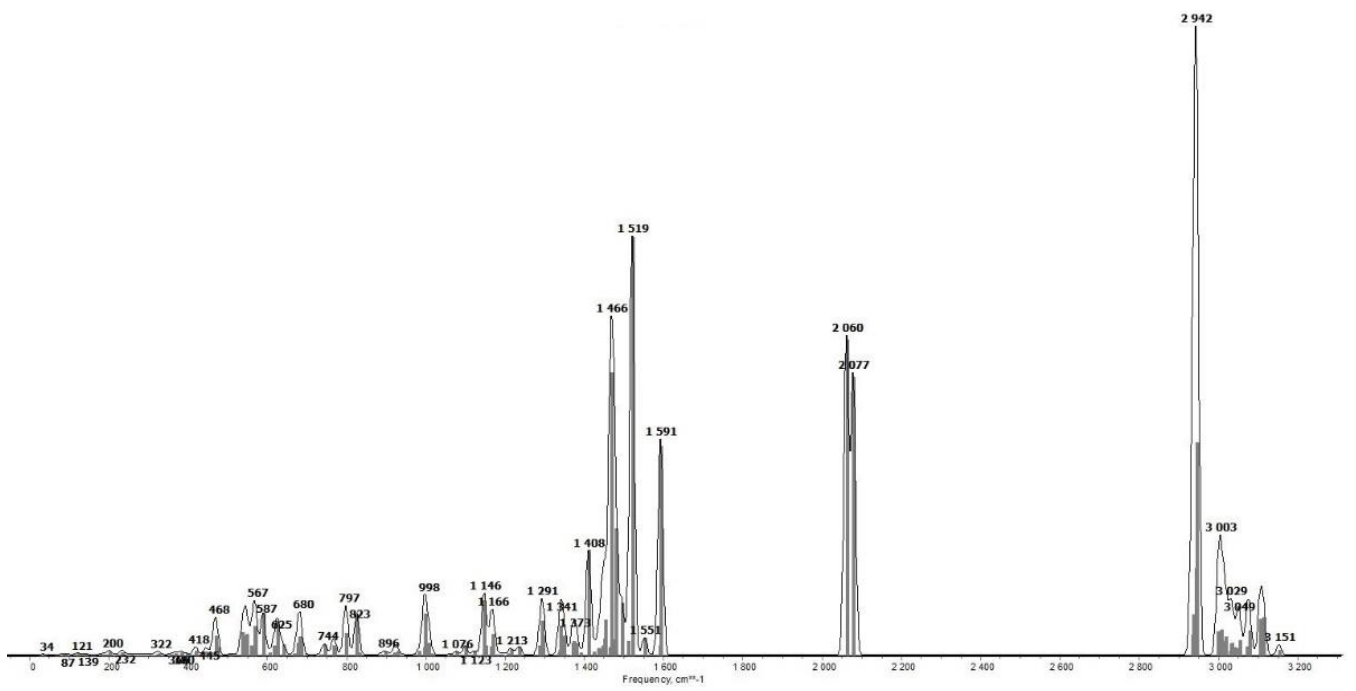

Figure 9.60: Calculated IR spectrum of 11. Predicted $\mathrm{N}_{2}$ stretching: $2060 / 2077 \mathrm{~cm}^{-1}$. The spectrum was convoluted using a Gaussian line shape function with a half-width of $15 \mathrm{~cm}^{-1}$.

Table 9.3: Comparison of experimental and DFT calculated metric parameters of 11; selected distances $[\AA]$ and angles $\left[{ }^{\circ}\right]$.

\begin{tabular}{ccc}
\hline & $\mathbf{1 1}(\mathbf{e x p})$ & $\mathbf{1 1}$ (calculated) \\
\hline $\mathrm{Co}-\mathrm{N}^{\mathrm{pz}}$ & $1.898(2)$ & 1.911 \\
$\mathrm{Co}-\mathrm{N}^{\mathrm{py}}$ & $1.901(2)$ & 1.914 \\
$\mathrm{Co}-\mathrm{N}_{2}$ & $1.731(3)$ & 1.726
\end{tabular}




$\begin{array}{ccc}\mathrm{Co}-\mathrm{P} & 2.1791(9) & 2.175 \\ \mathrm{Co} \cdots \mathrm{Co} & 4.2187(9) & 4.137 \\ \mathrm{~N}-\mathrm{N} & 1.1126(4) & 1.135 \\ \mathrm{Co}-\mathrm{N}-\mathrm{N} & 173.90 & 172.66\end{array}$

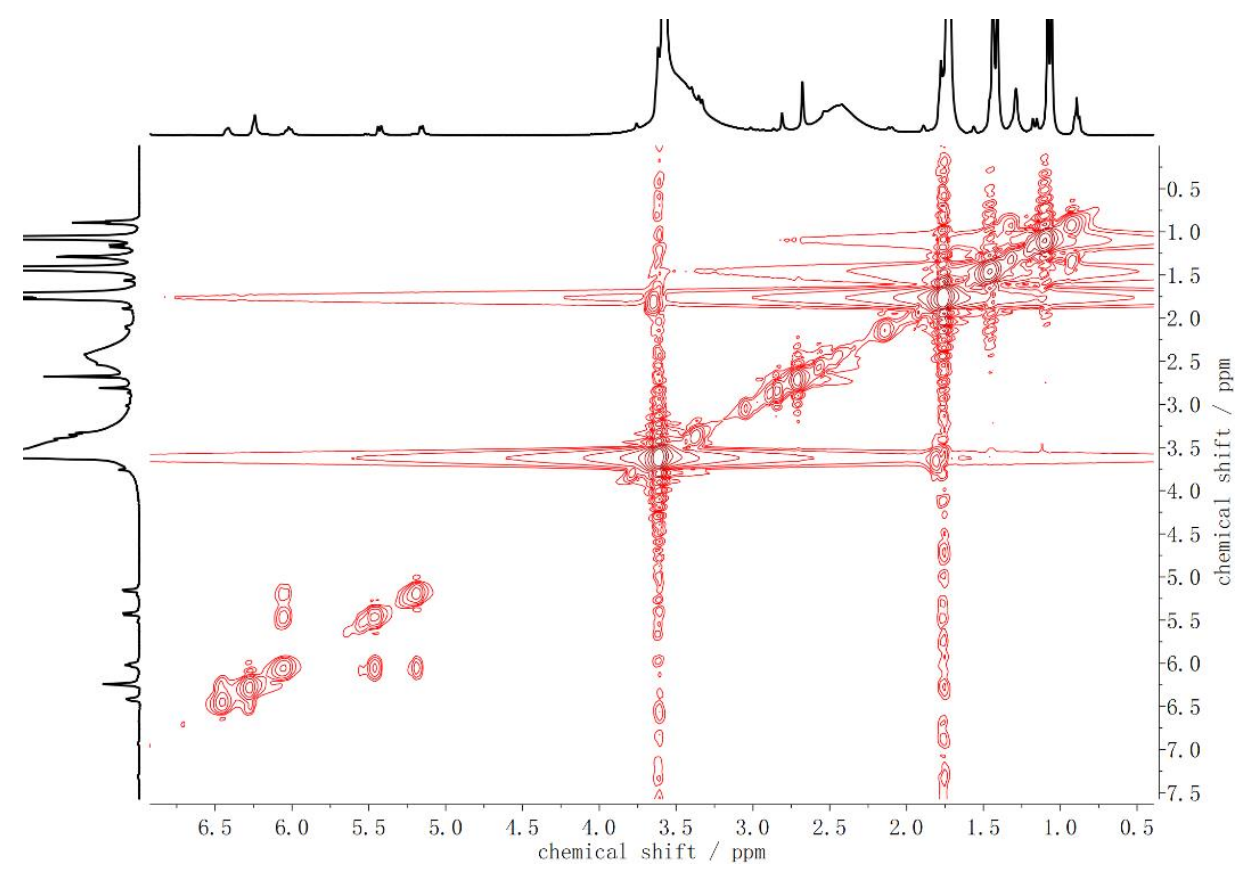

Figure 9.61: COSY spectrum of complex 12 in THF-d 8 .

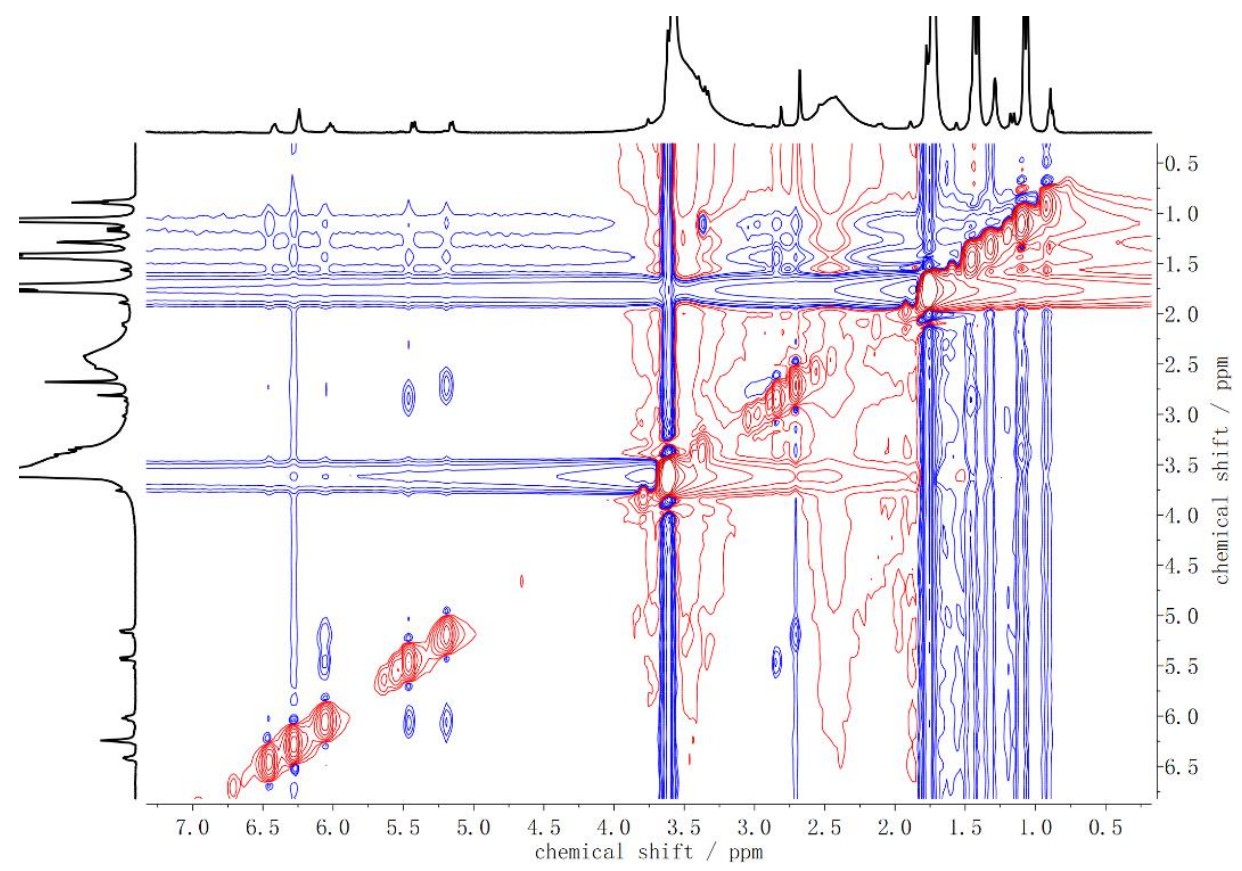

Figure 9.62: NOESY spectrum of complex 12 in THF-d 8. 

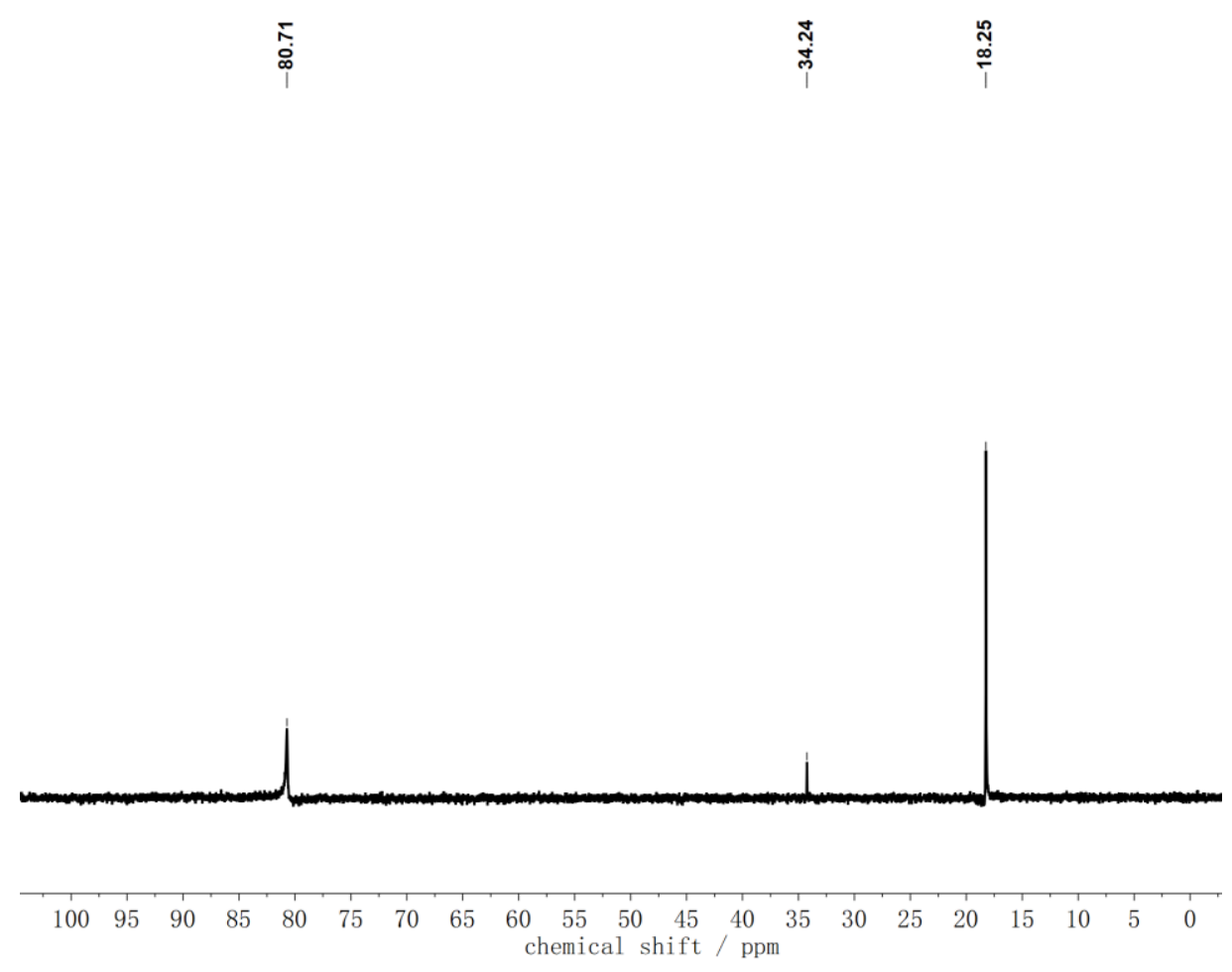

Figure 9.63: ${ }^{31} \mathrm{P}-\mathrm{NMR}$ spectrum of complex 12 in THF-d 8 .
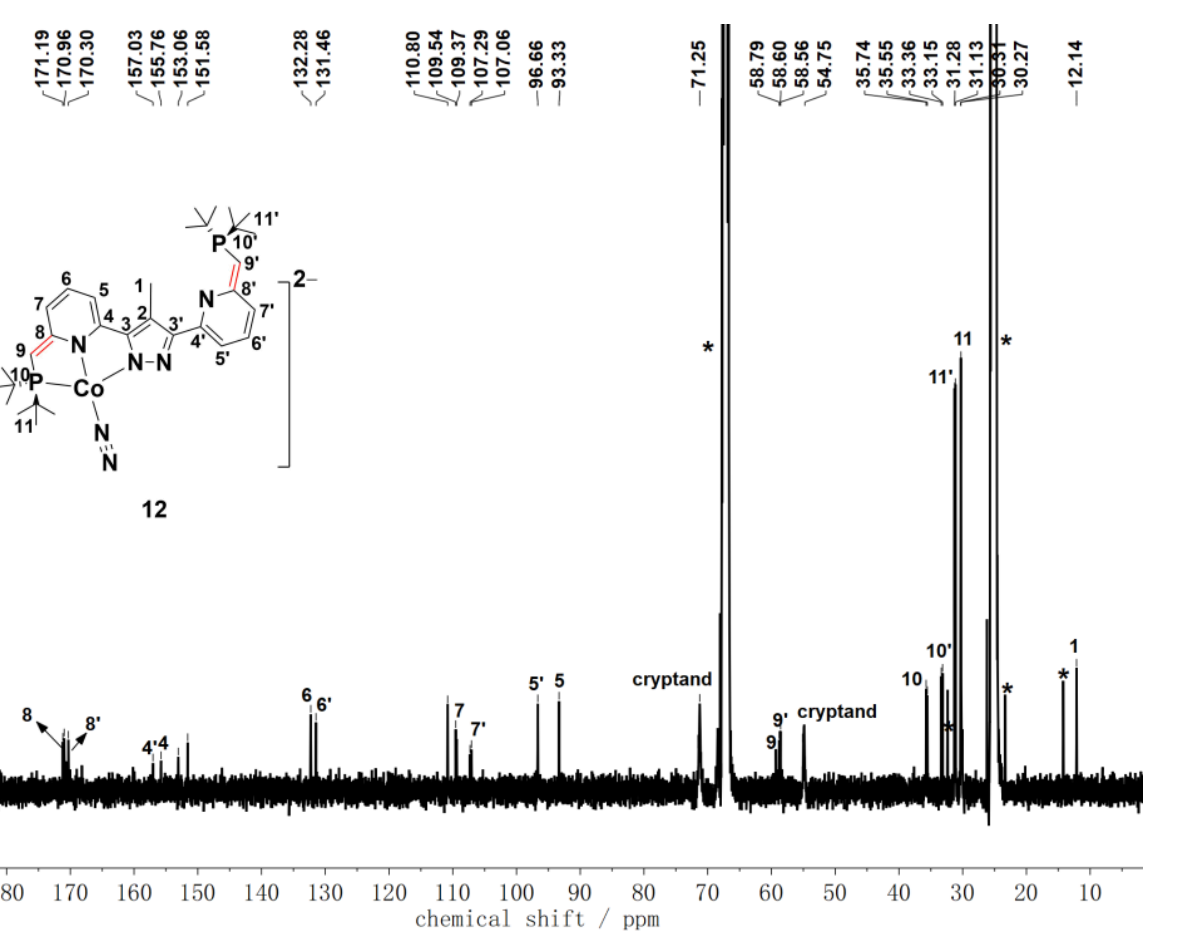

Figure 9.64: ${ }^{13} \mathrm{C}-\mathrm{NMR}$ spectrum of complex 12 in $\mathrm{THF}-\mathrm{d}_{8}$. 


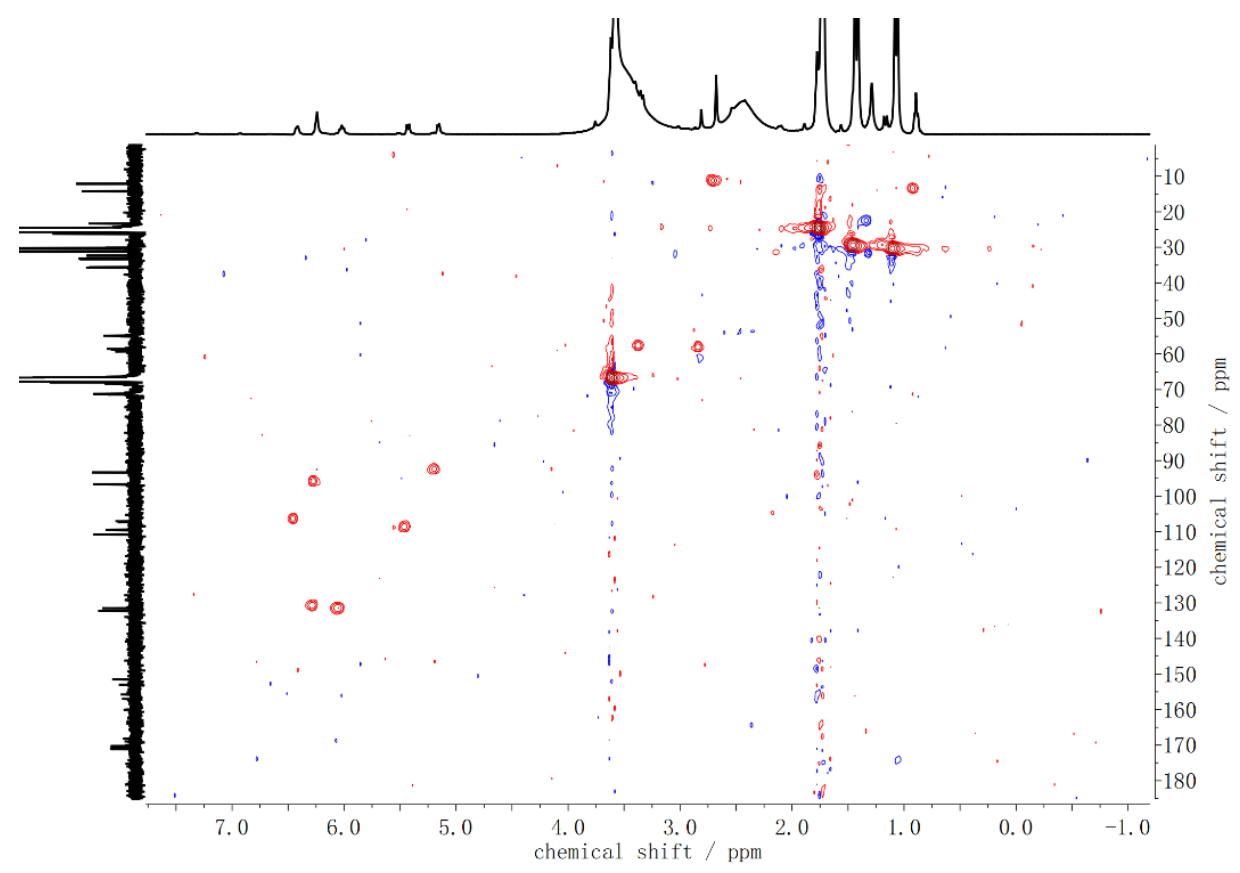

Figure 9.65: ${ }^{1} \mathrm{H}-{ }^{13} \mathrm{C}$ HSQC spectrum of complex 12 in $\mathrm{THF}-\mathrm{d}_{8}$.

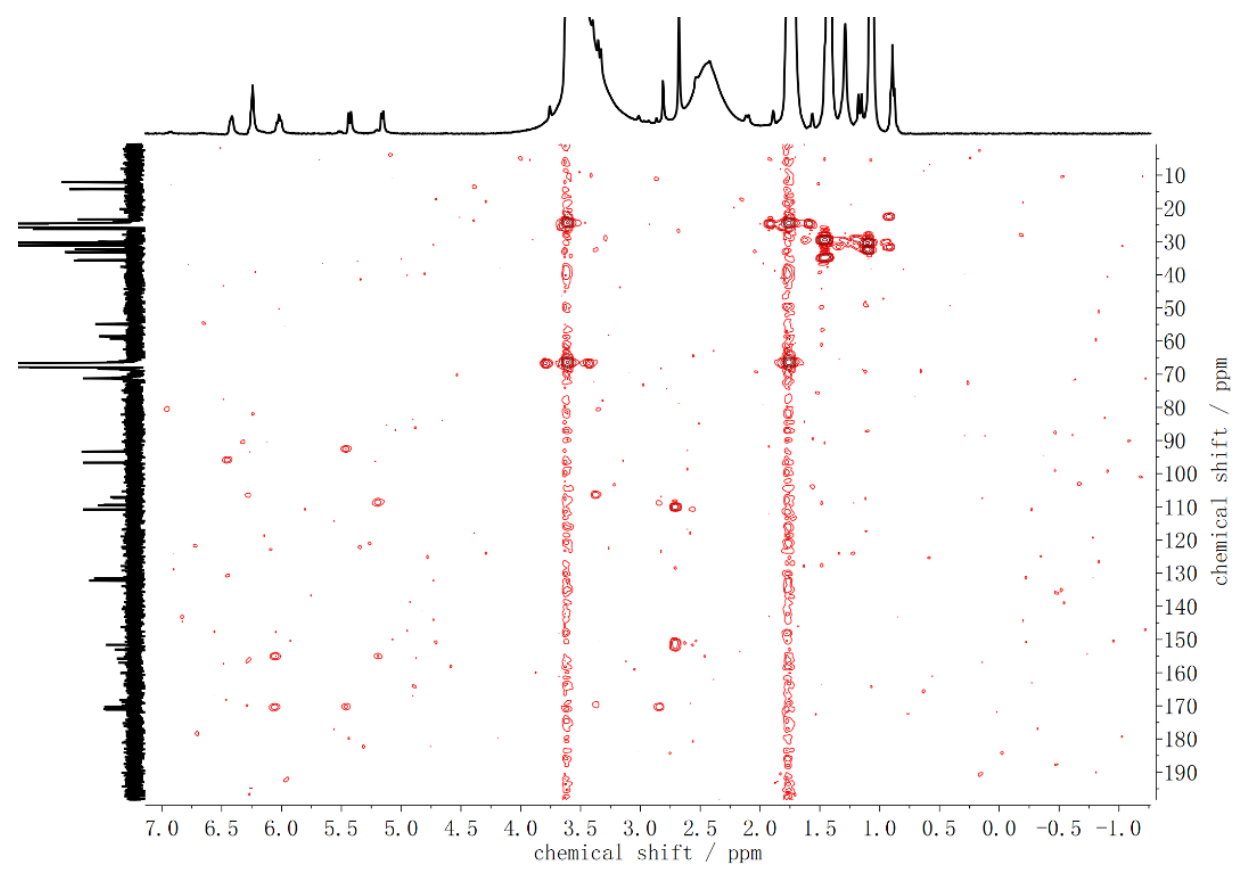

Figure 9.66: ${ }^{1} \mathrm{H}-{ }^{13} \mathrm{C}$ HMBC spectrum of complex 12 in $\mathrm{THF}-\mathrm{d}_{8}$. 


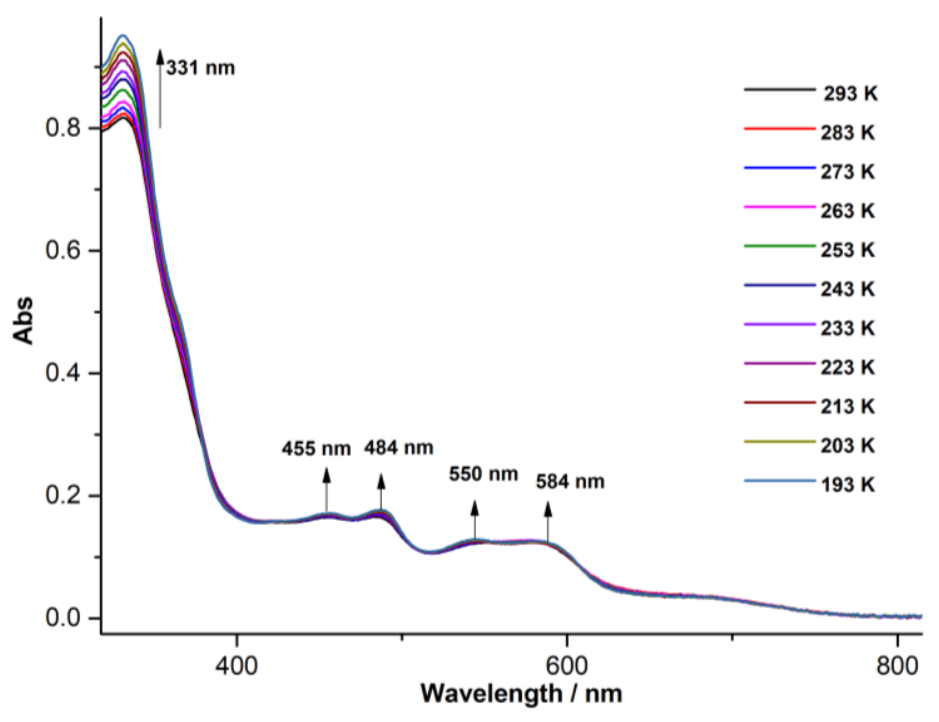

Figure 9.67: Variable temperature UV-vis spectrum of complex 12 in THF.

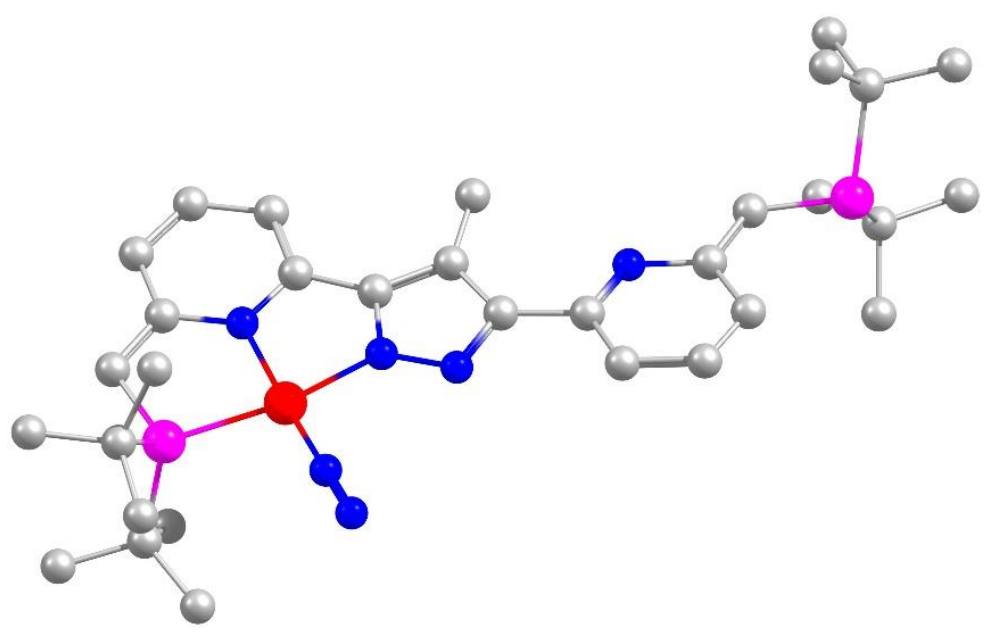

Figure 9.68: DFT optimized molecular structure of complex $12(\mathrm{Co}=\mathrm{red}, \mathrm{N}=$ blue, $\mathrm{P}=$ violet, $\mathrm{C}=$ grey). Spin restricted DFT calculations with ORCA 3.0.3, BP86 functional, def2-svp basis set, RI approximation using the auxiliary def2-svp/J basis set, D3 dispersion correction with Becke-Johnson damping, tight convergence and optimization criteria). 


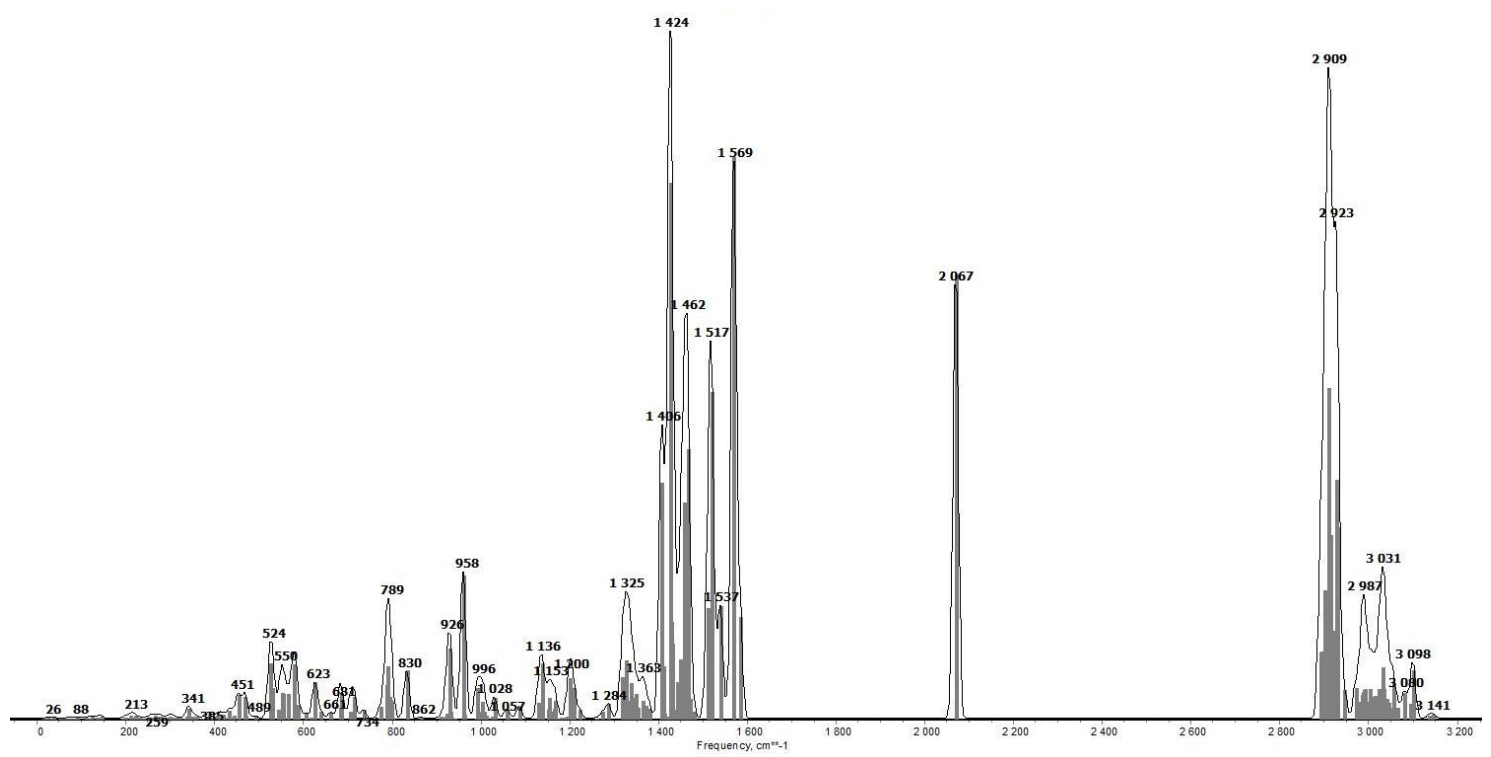

Figure 9.69: Calculated IR spectrum of 12. Predicted $\mathrm{N}_{2}$ stretching: $2067 \mathrm{~cm}^{-1}$. The spectrum was convoluted using a Gaussian line shape function with a half-width of $15 \mathrm{~cm}^{-1}$.

Table 9.4: Comparison of experimental and DFT calculated metric parameters of 12; selected distances $[\AA]$ and angles $\left[{ }^{\circ}\right]$.

\begin{tabular}{ccc}
\hline & $\mathbf{1 2}(\mathbf{e x p})$ & $\mathbf{1 2}$ (calculated) \\
\hline Co-N $-\mathrm{N}^{\mathrm{pz}}$ & $1.901(3)$ & 1.900 \\
$\mathrm{Co}-\mathrm{N}^{\mathrm{py}}$ & $1.911(3)$ & 1.928 \\
$\mathrm{Co}-\mathrm{N}_{2}$ & $1.727(4)$ & 1.724 \\
$\mathrm{Co}-\mathrm{P}$ & $2.1942(11)$ & 2.170 \\
$\mathrm{~N}-\mathrm{N}$ & 1.116 & 1.136 \\
$\mathrm{Co}-\mathrm{N}-\mathrm{N}$ & $176.457(384)$ & 178.072 \\
\hline
\end{tabular}




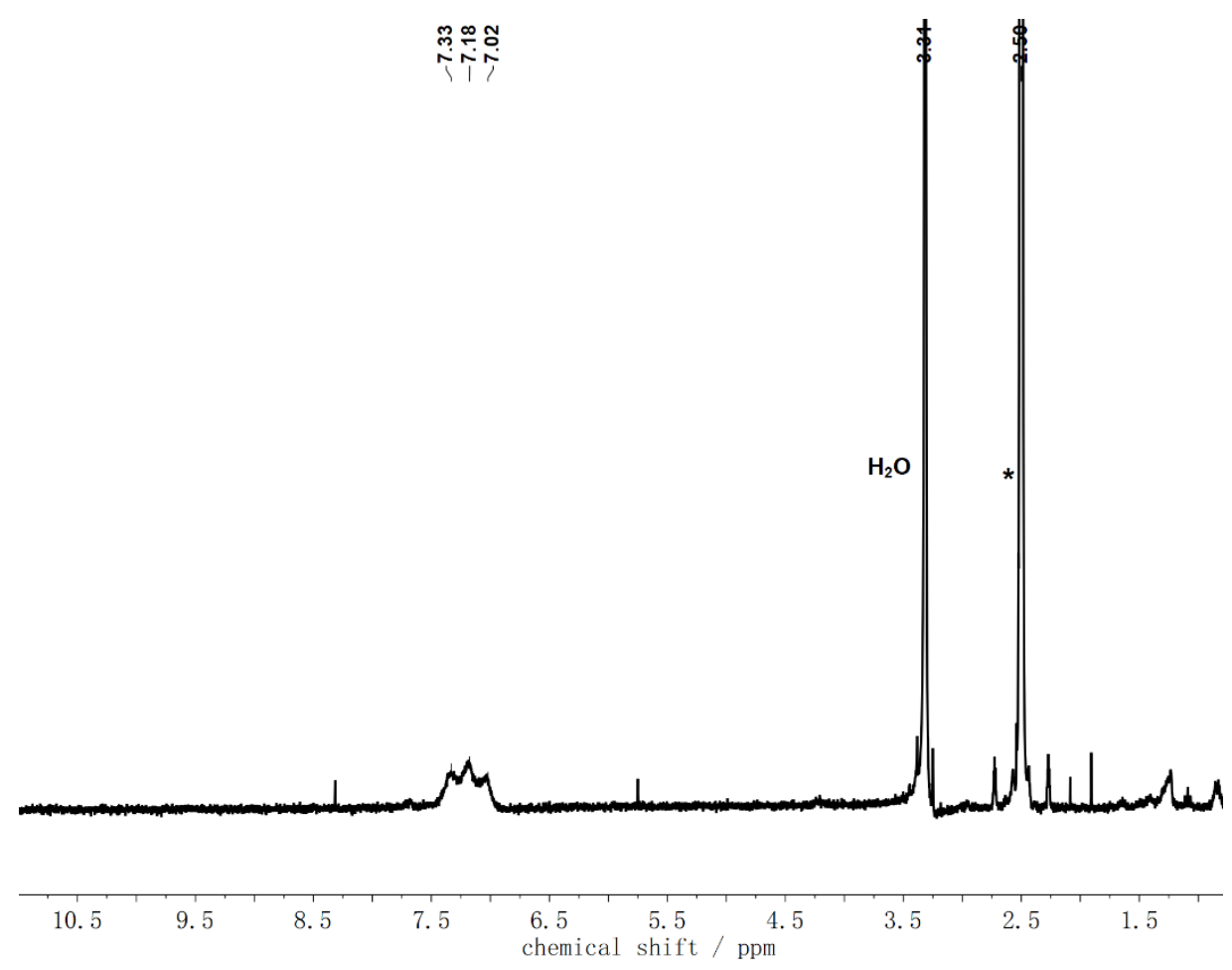

Figure 9.70: ${ }^{1} \mathrm{H}-\mathrm{NMR}$ spectrum $(300 \mathrm{MHz})$ of ammonia chloride $\left(\mathrm{NH}_{4} \mathrm{Cl}\right)$ in $\mathrm{DMSO}-\mathrm{d}_{6}$ solution. Solvent signals are marked with an asterisk (*).

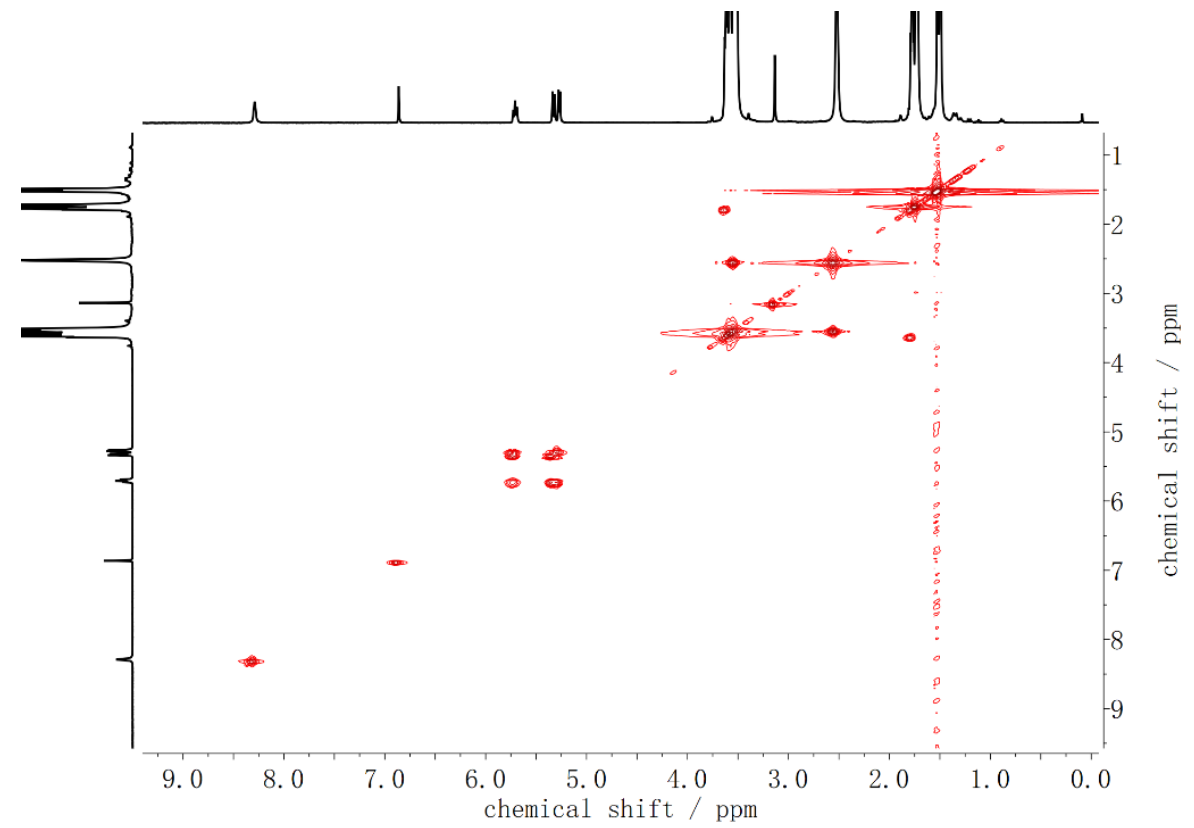

Figure 9.71: ${ }^{1} \mathrm{H}-{ }^{1} \mathrm{H}$ COSY (400 MHz) of complex 13 in THF-d 8. 


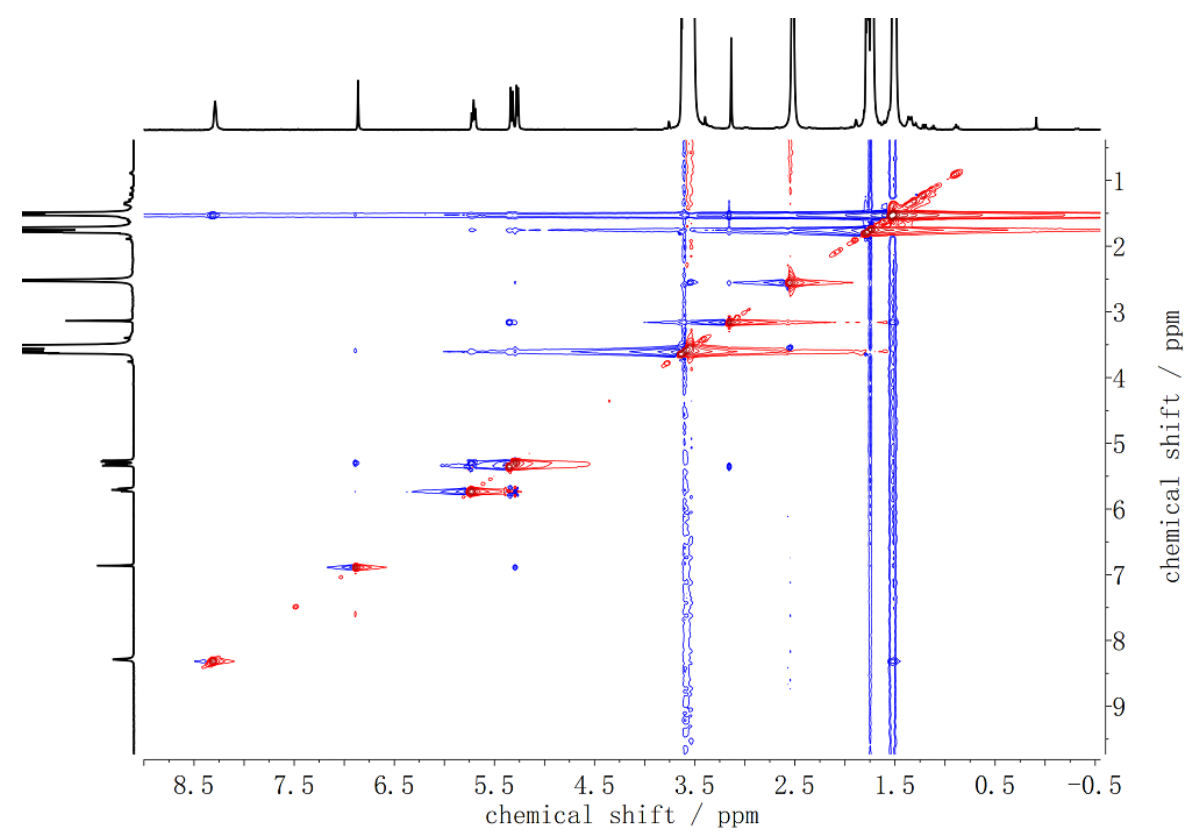

Figure 9.72: ${ }^{1} \mathrm{H}-{ }^{1} \mathrm{H}$ NOESY $(400 \mathrm{MHz})$ of complex 13 in THF-d8.

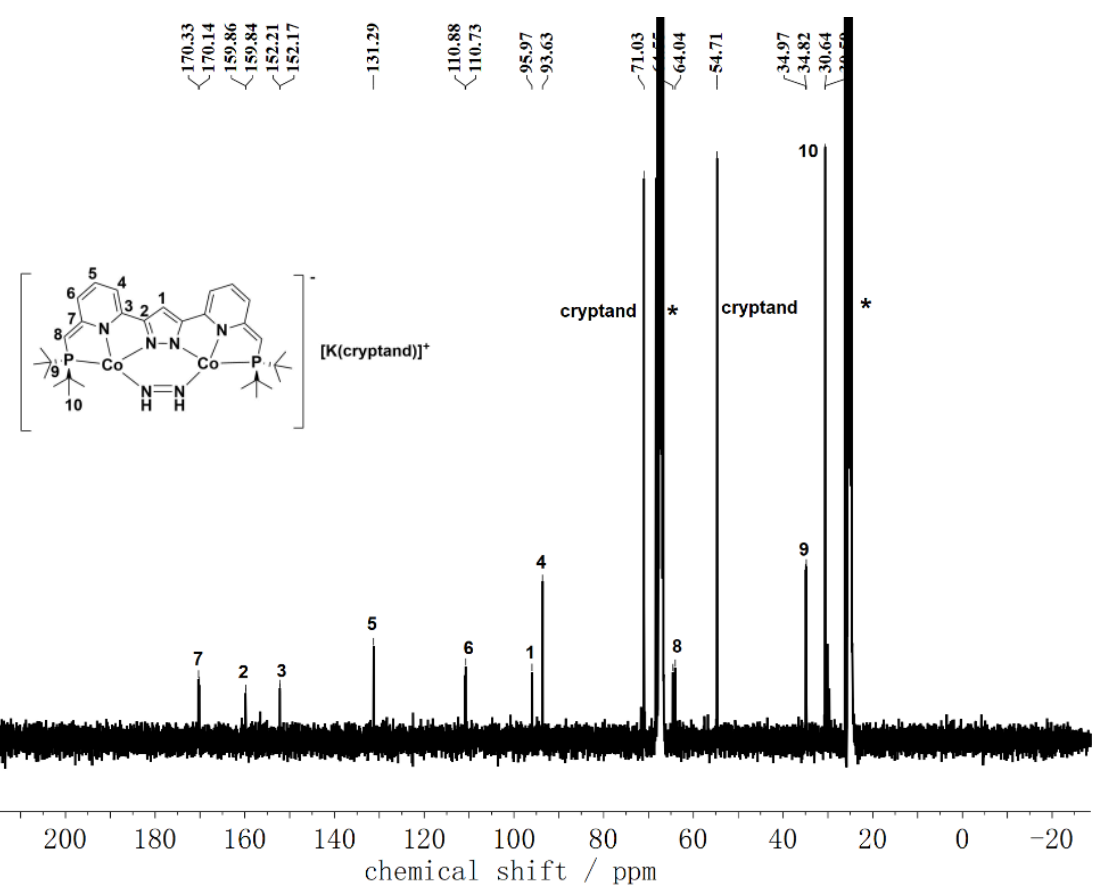

Figure 9.73: ${ }^{13} \mathrm{C}-\mathrm{NMR}$ spectrum of complex 13 in THF-d $\mathrm{d}_{8}$. Solvent signals are marked with an asterisk $(*)$. 


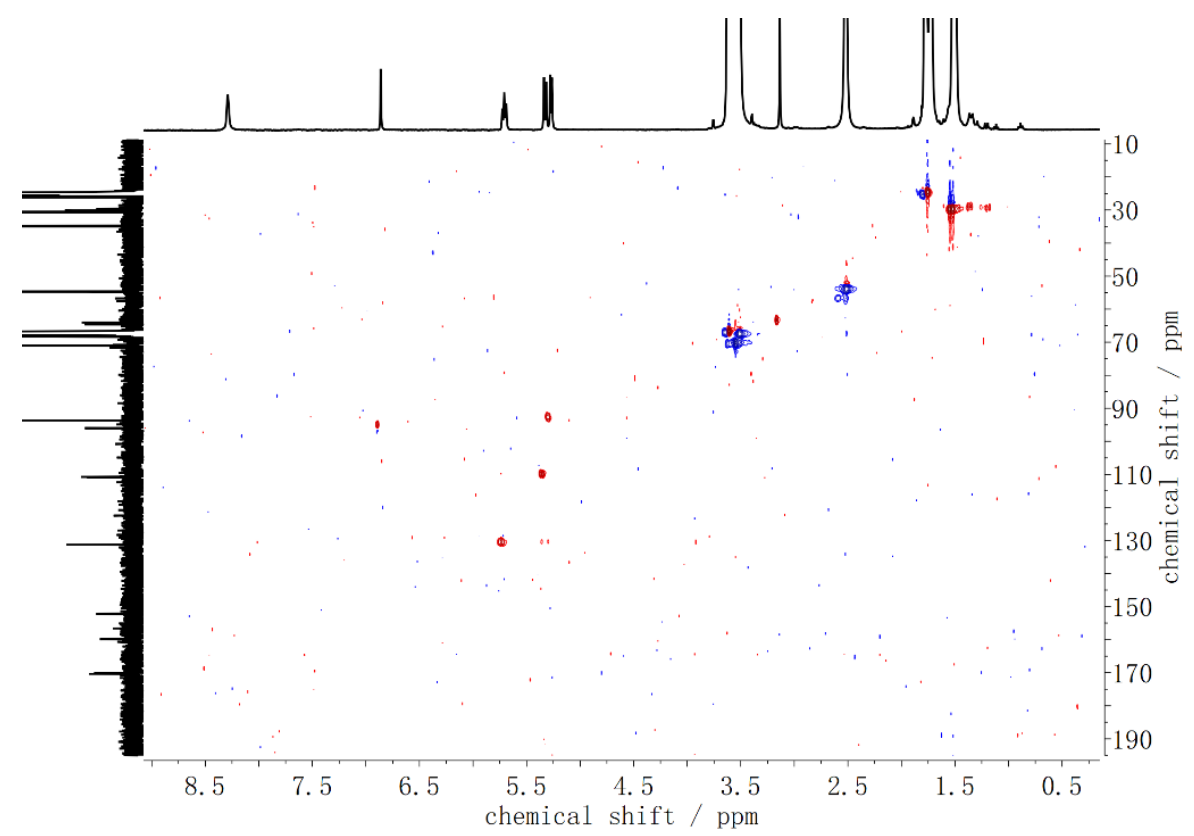

Figure 9.74: ${ }^{1} \mathrm{H}^{-13} \mathrm{C}$ HSQC (400 MHz) of complex 13 in THF-d8.

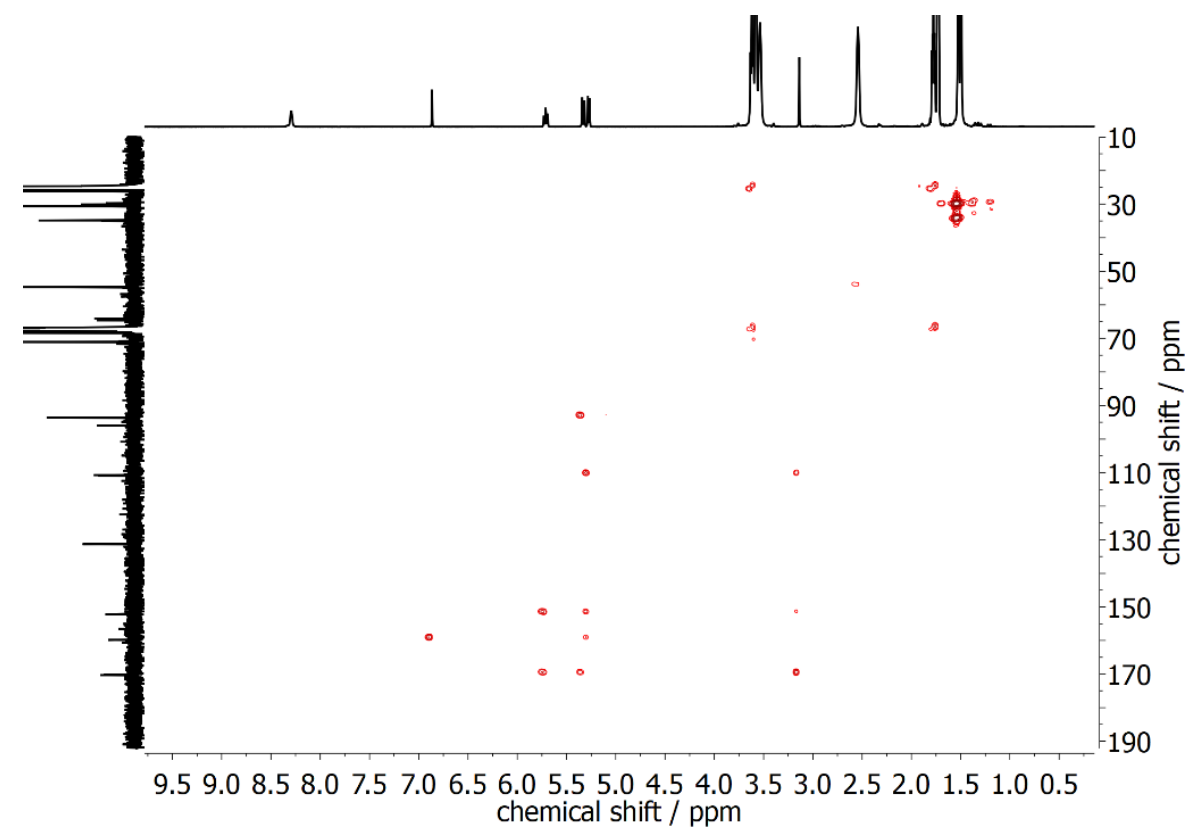

Figure 9.75: ${ }^{1} \mathrm{H}_{-}{ }^{13} \mathrm{C} \mathrm{HMBC}(400 \mathrm{MHz})$ of complex 13 in THF-d8. 


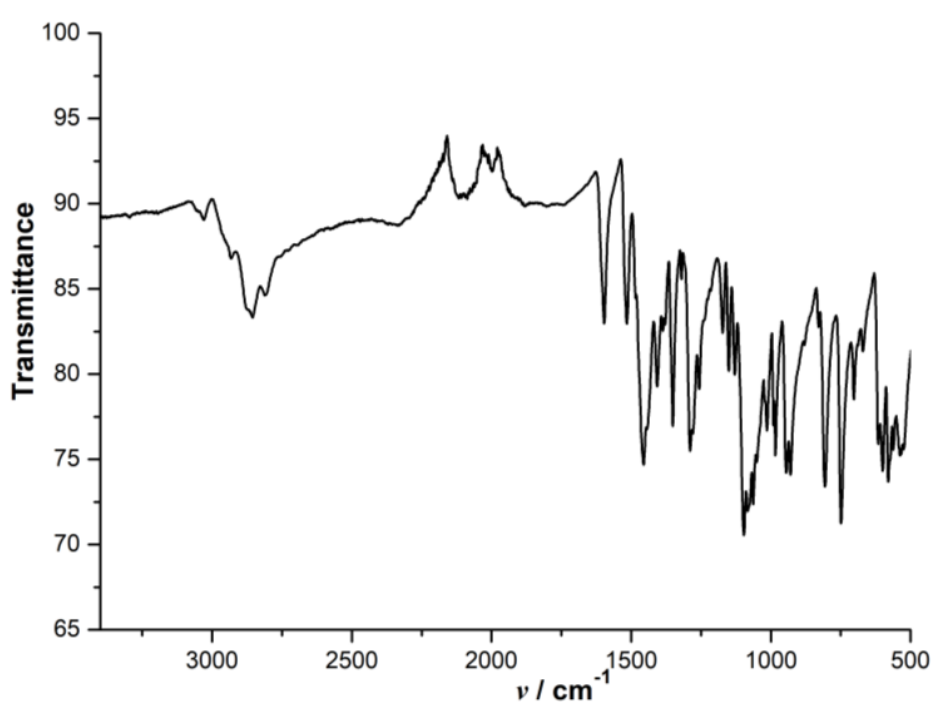

Figure 9.76: IR spectrum of complex 13 in solid state.

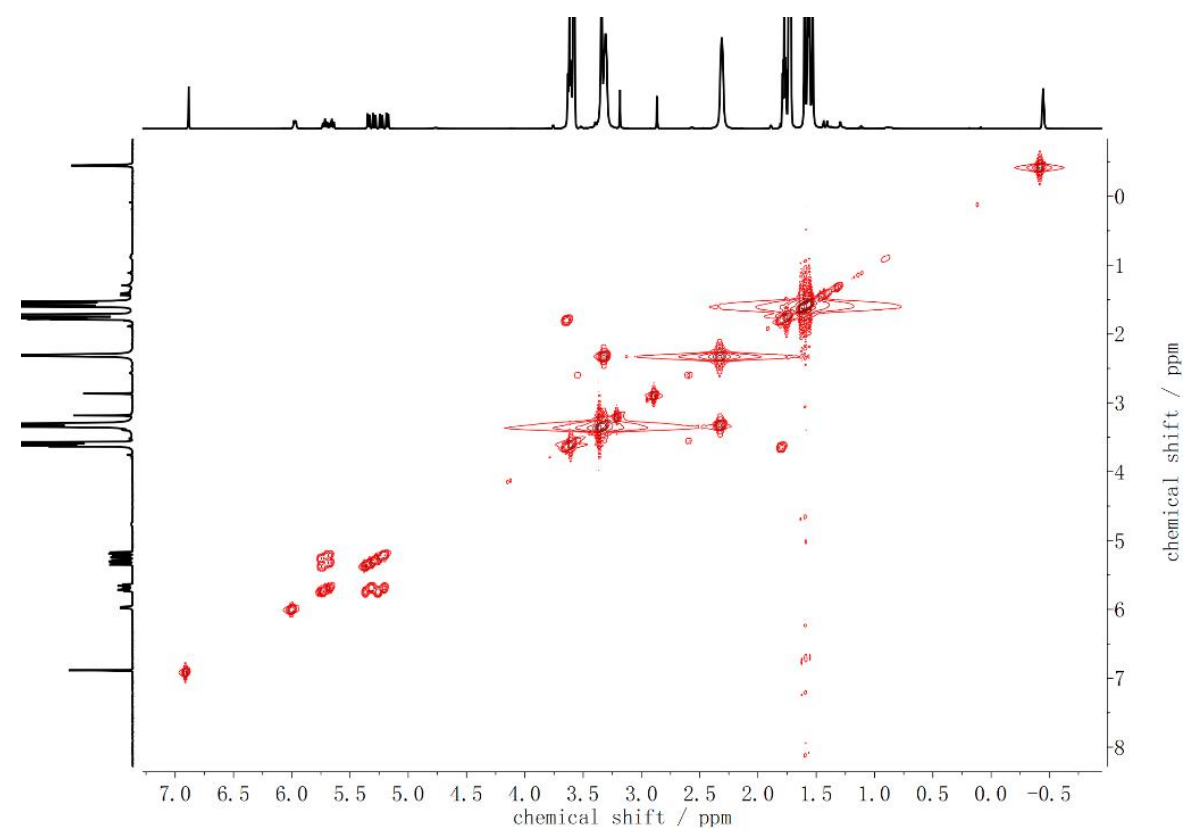

Figure 9.77: ${ }^{1} \mathrm{H}-{ }^{1} \mathrm{H}$ COSY $(400 \mathrm{MHz})$ of complex 14 in THF-d8. 


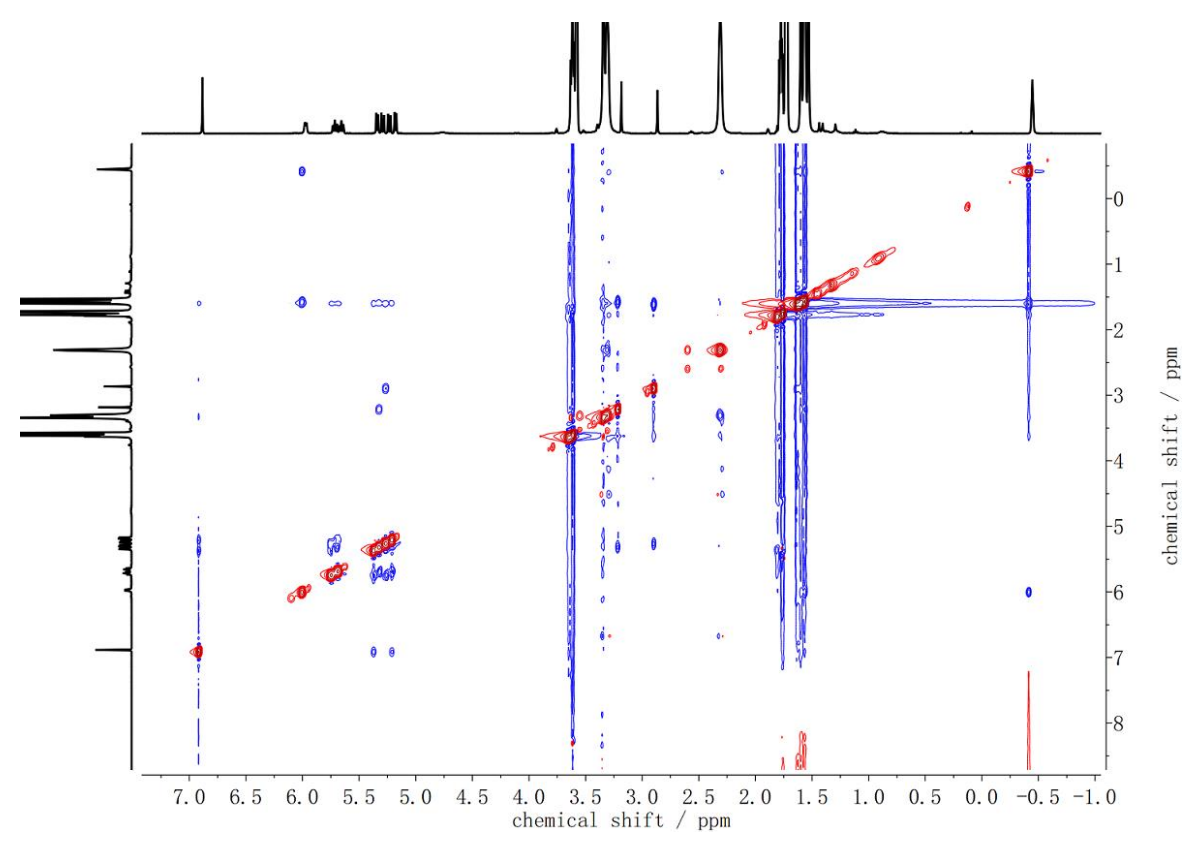

Figure 9.78: ${ }^{1} \mathrm{H}-{ }^{1} \mathrm{H}$ NOESY $(400 \mathrm{MHz})$ of complex 14 in THF-d 8 .

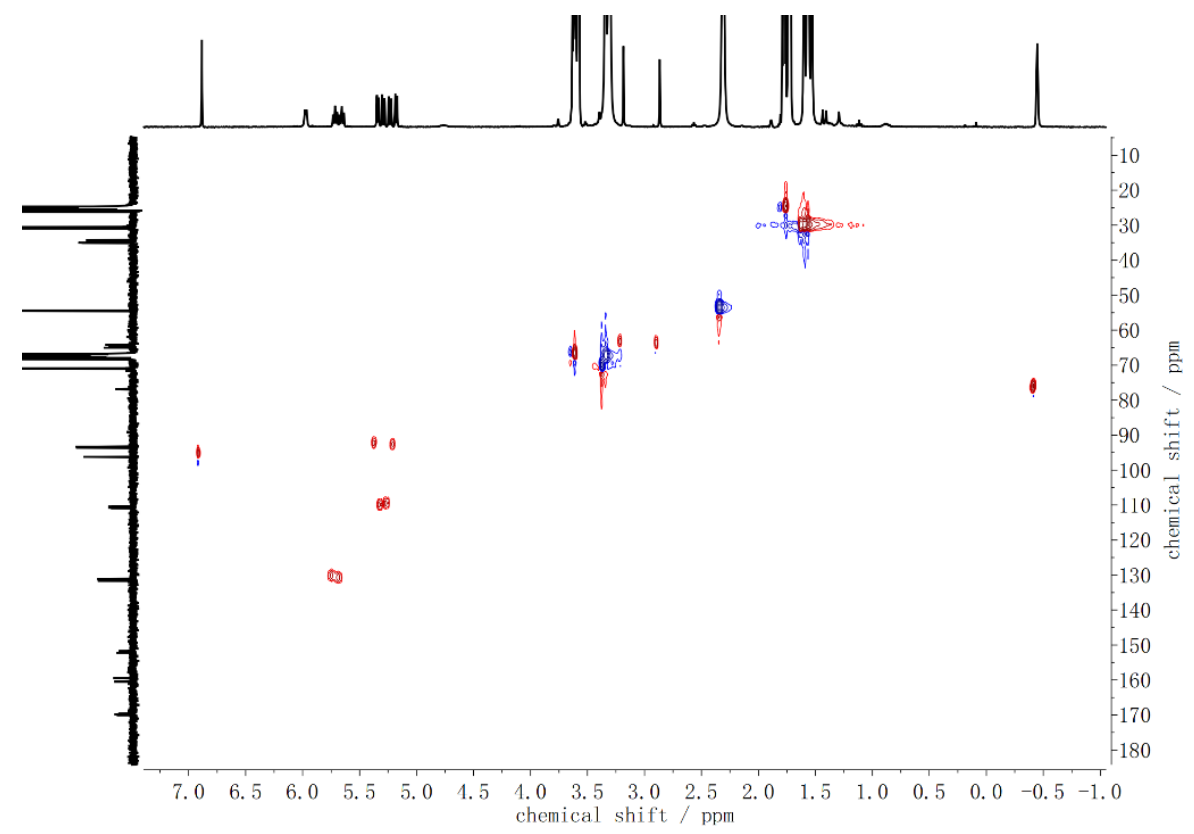

Figure 9.79: ${ }^{1} \mathrm{H}^{-13} \mathrm{C}$ HSQC (400 MHz) of complex 14 in THF-d 8. 


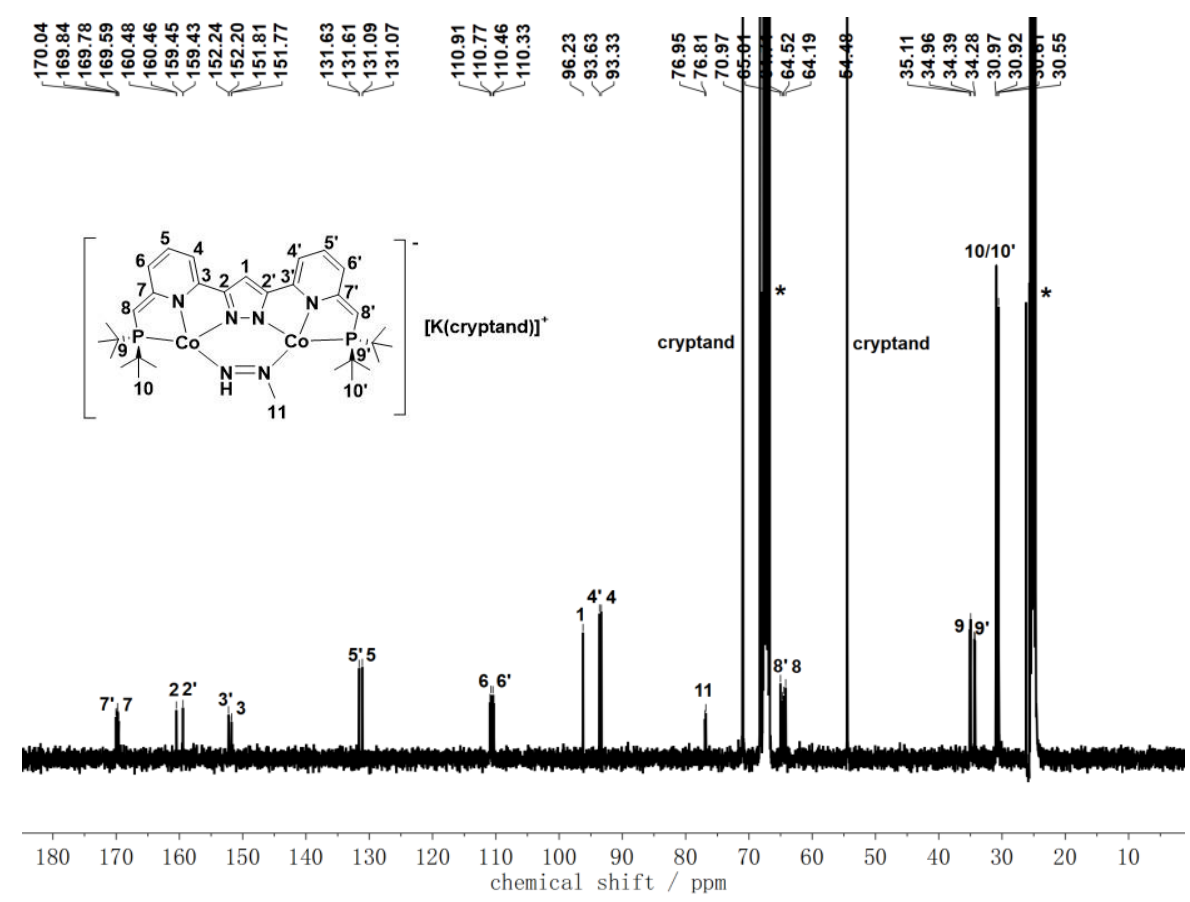

Figure 9.80: ${ }^{13} \mathrm{C}-\mathrm{NMR}$ spectrum $(400 \mathrm{MHz})$ of complex 14 in THF-d 8 . Solvent signals are marked with an asterisk (*).

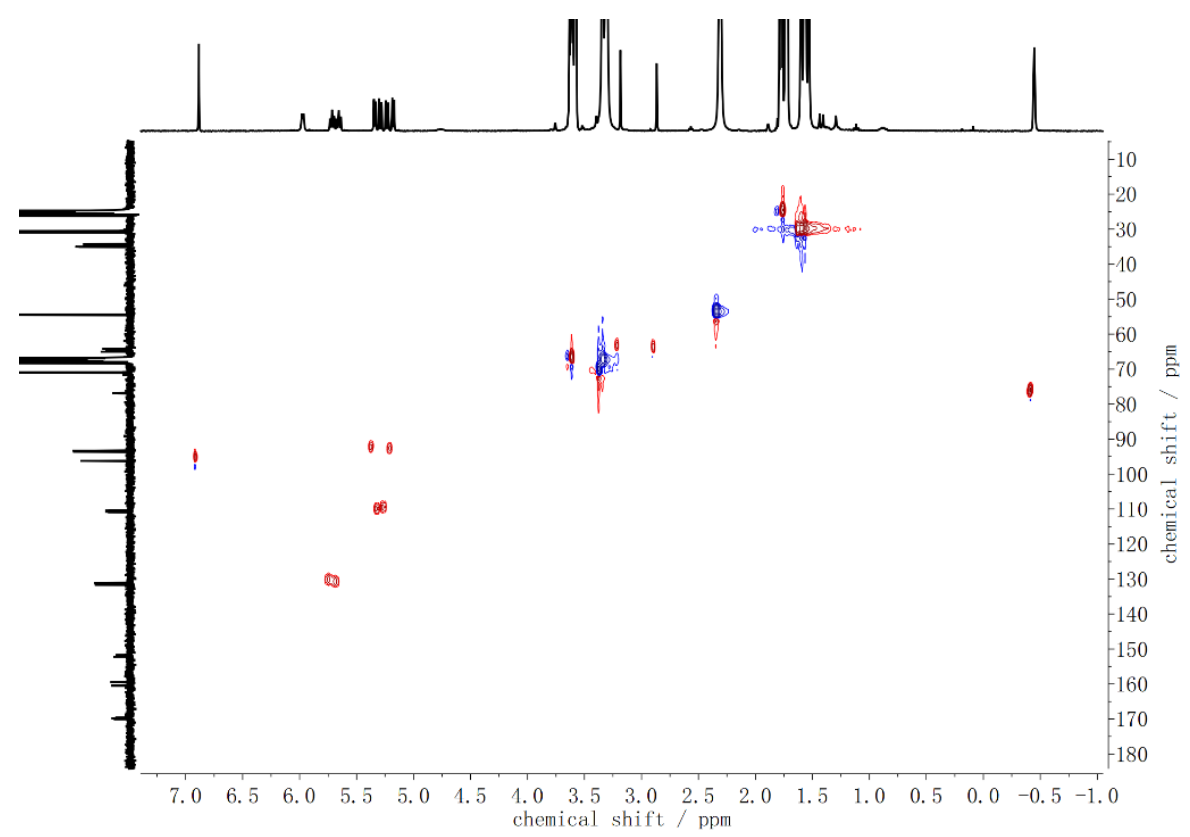

Figure 9.81: ${ }^{1} \mathrm{H}^{-13} \mathrm{C}$ HSQC (400 MHz) of complex 14 in THF-d 8. 


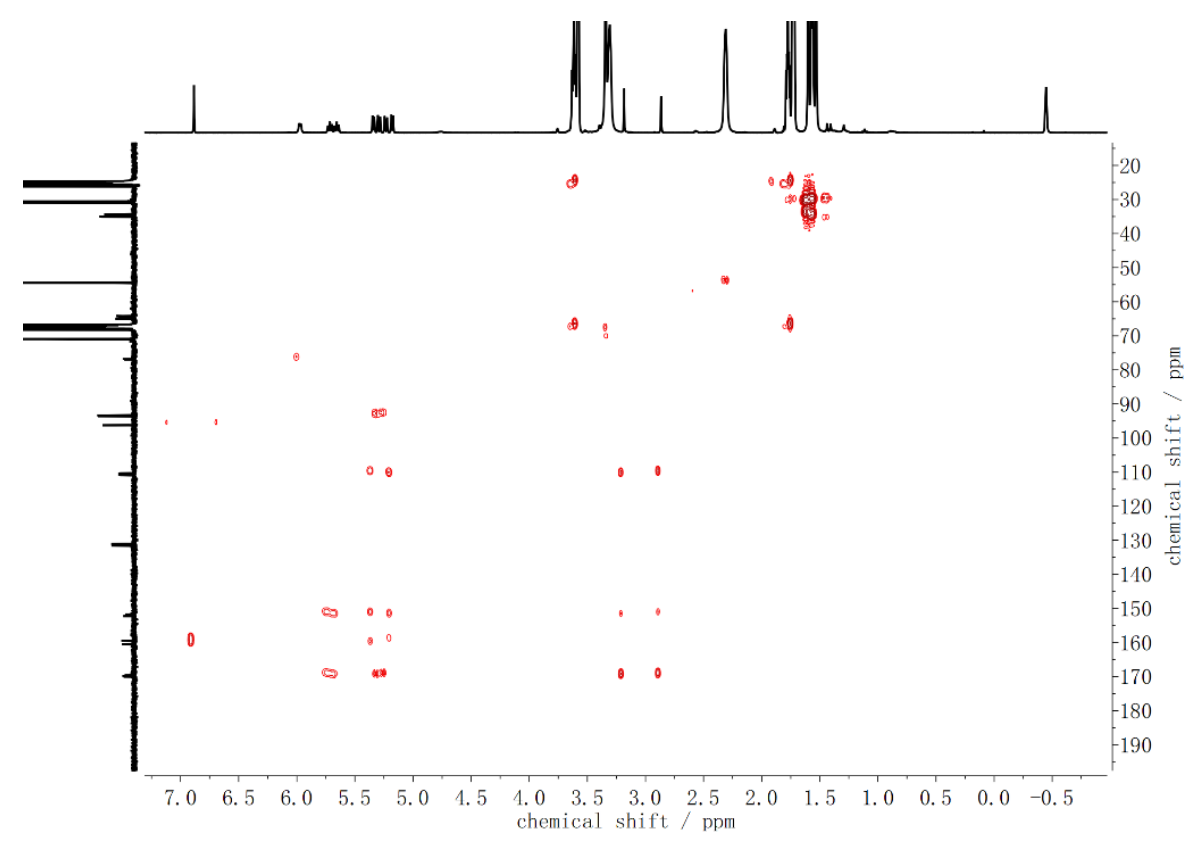

Figure 9.82: ${ }^{1} \mathrm{H}^{13}{ }^{13} \mathrm{HMBC}(400 \mathrm{MHz})$ of complex 14 in $\mathrm{THF}-\mathrm{d}_{8}$.

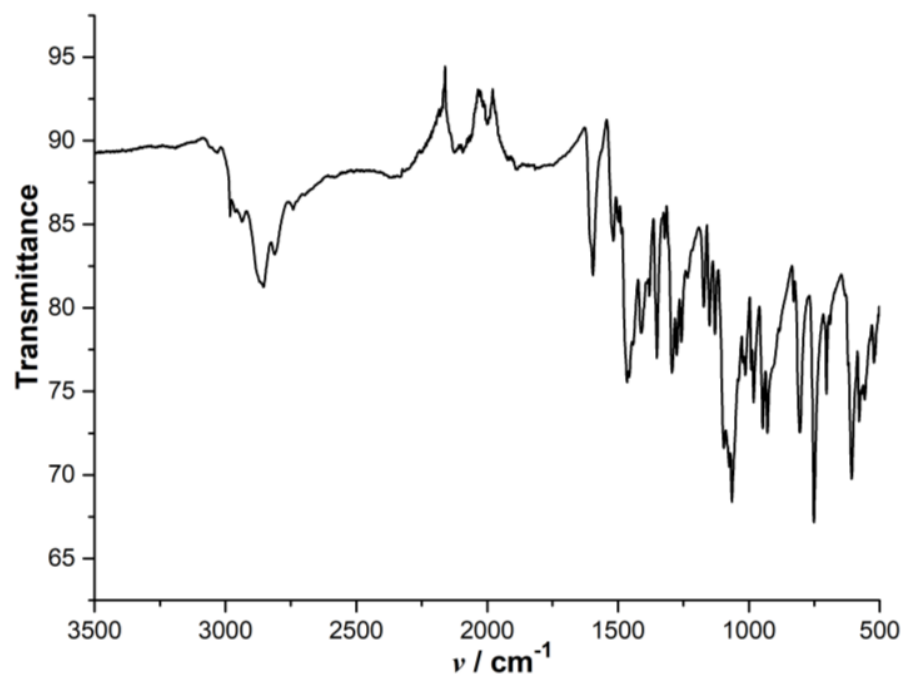

Figure 9.83: IR spectrum of complex 14 in solid state. 


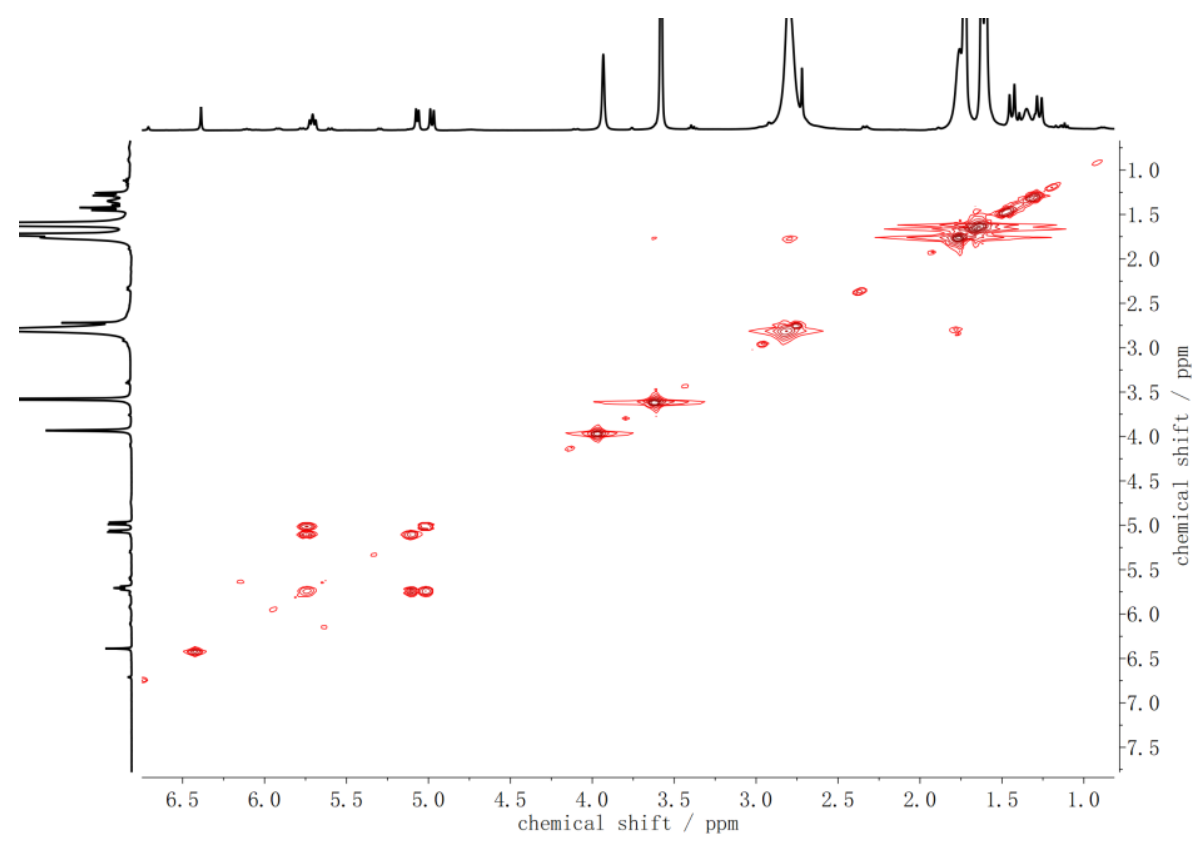

Figure 9.84: ${ }^{1} \mathrm{H}-{ }^{1} \mathrm{H}$ COSY $(400 \mathrm{MHz})$ of complex 15 in THF-d 8.

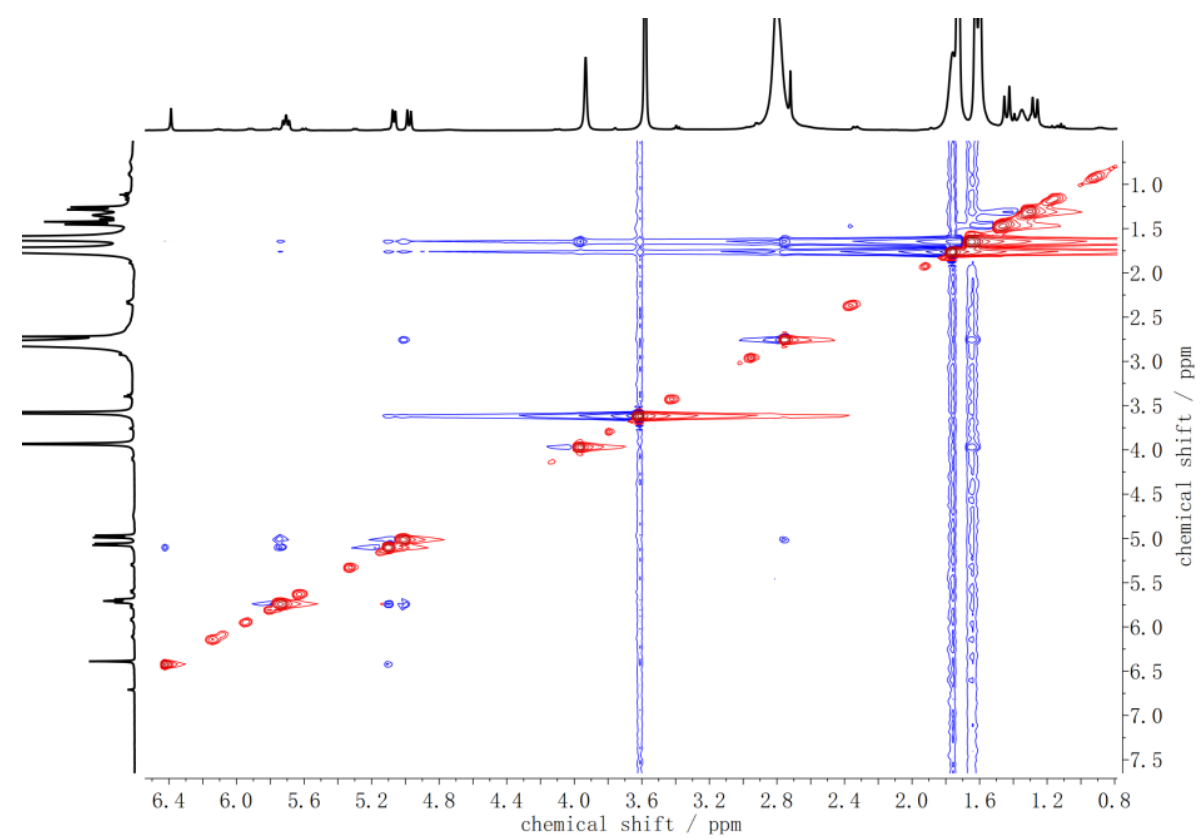

Figure 9.85: ${ }^{1} \mathrm{H}-{ }^{1} \mathrm{H}$ NOESY (400 MHz) of complex 15 in THF-d 8 . 

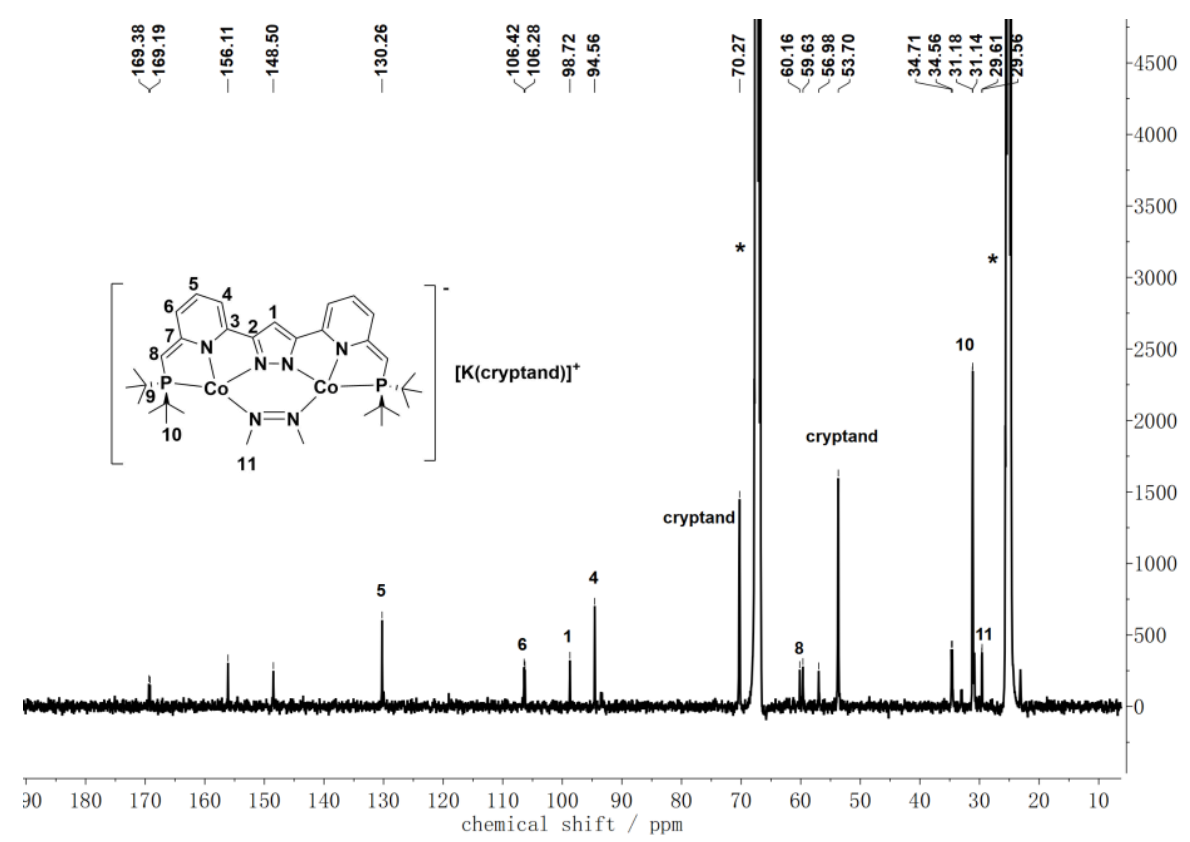

Figure 9.86: ${ }^{13} \mathrm{C}-\mathrm{NMR}$ spectrum $(400 \mathrm{MHz})$ of complex 15 in THF-d 8 . Solvent signals are marked with an asterisk $(*)$.

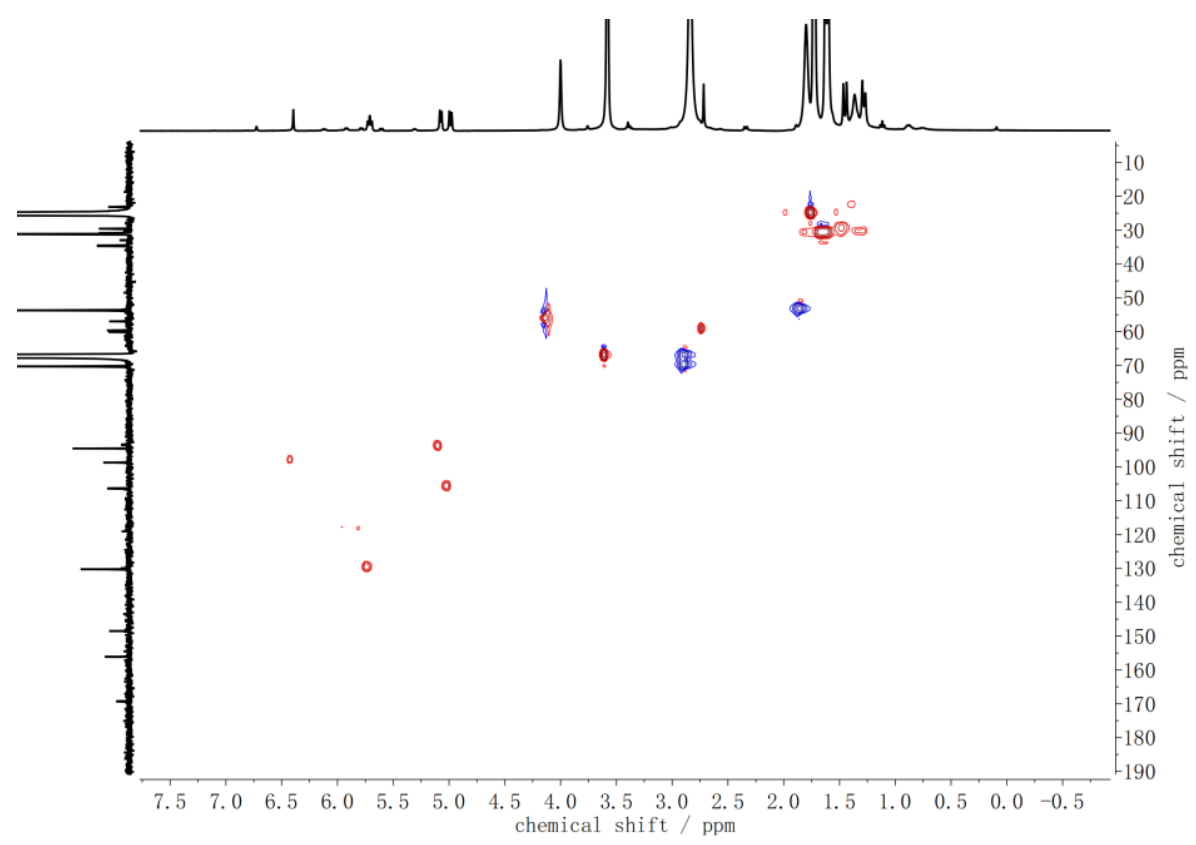

Figure 9.87: ${ }^{1} \mathrm{H}^{-13} \mathrm{C}$ HSQC (400 MHz) of complex 15 in THF-d 8. 


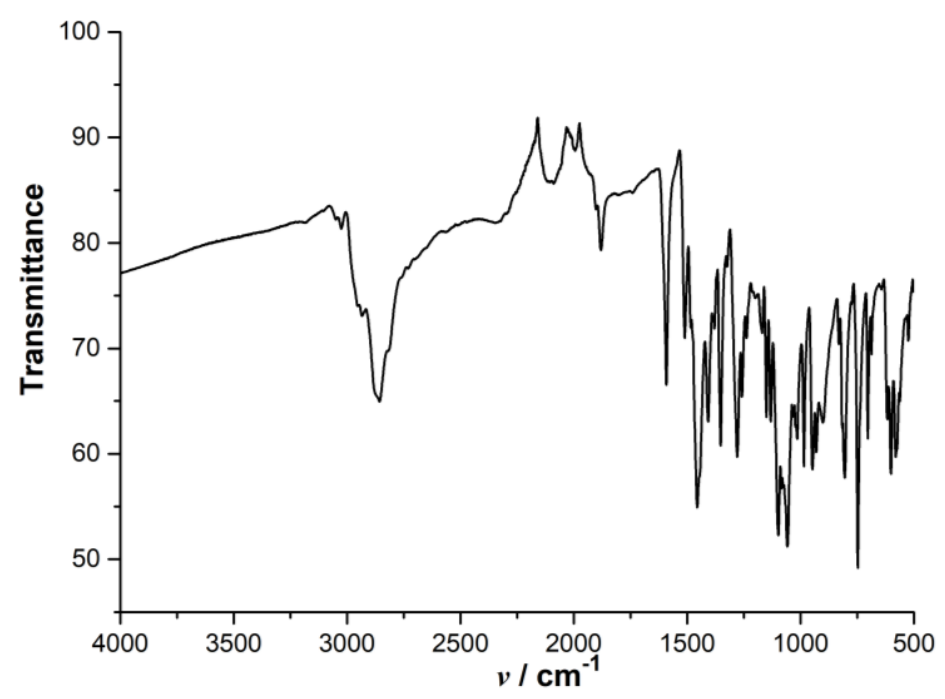

Figure 9.88: IR spectrum of complex 15 in solid state.

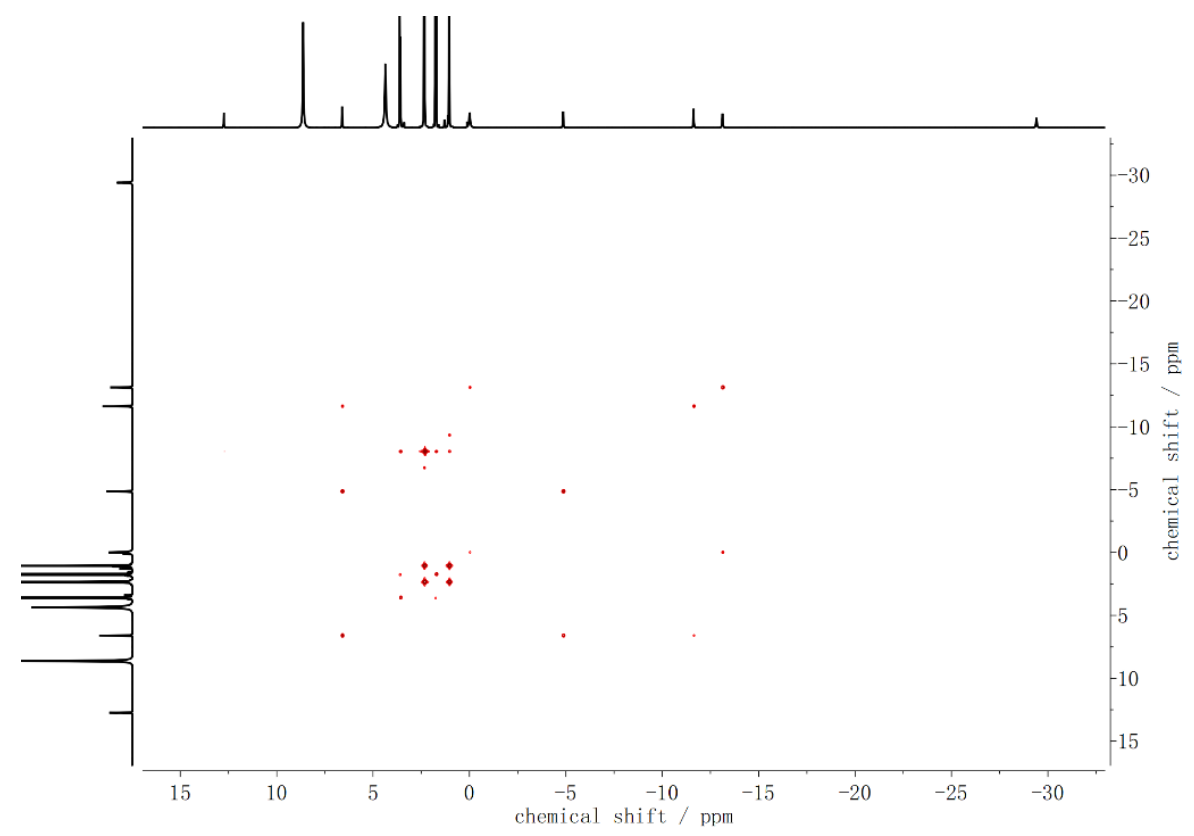

Figure 9.89: COSY spectrum of complex 16 in THF-d 8 . 


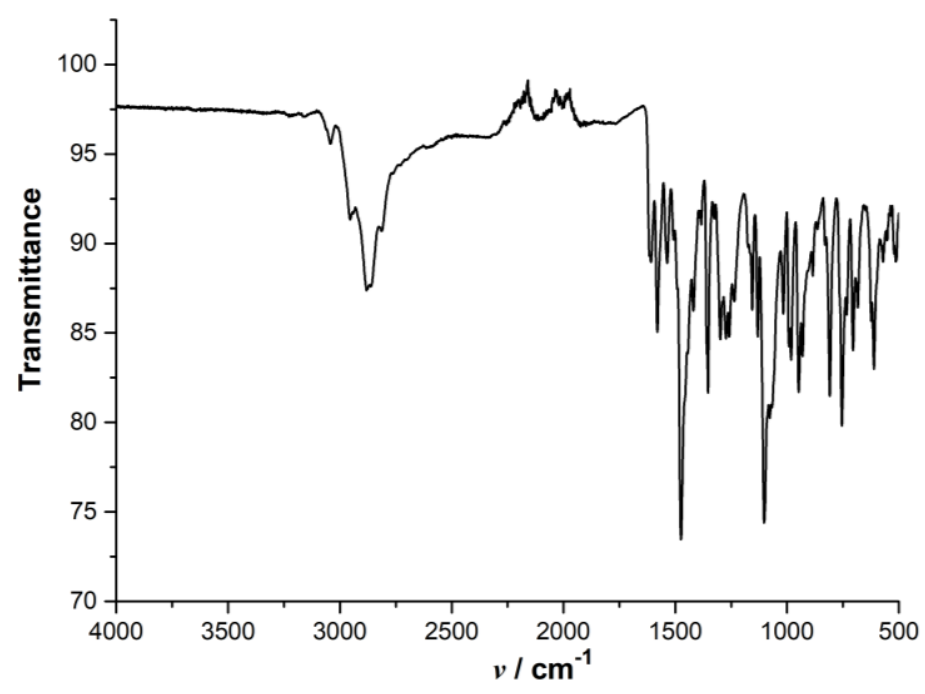

Figure 9.90: IR spectrum of complex 16 in solid state.

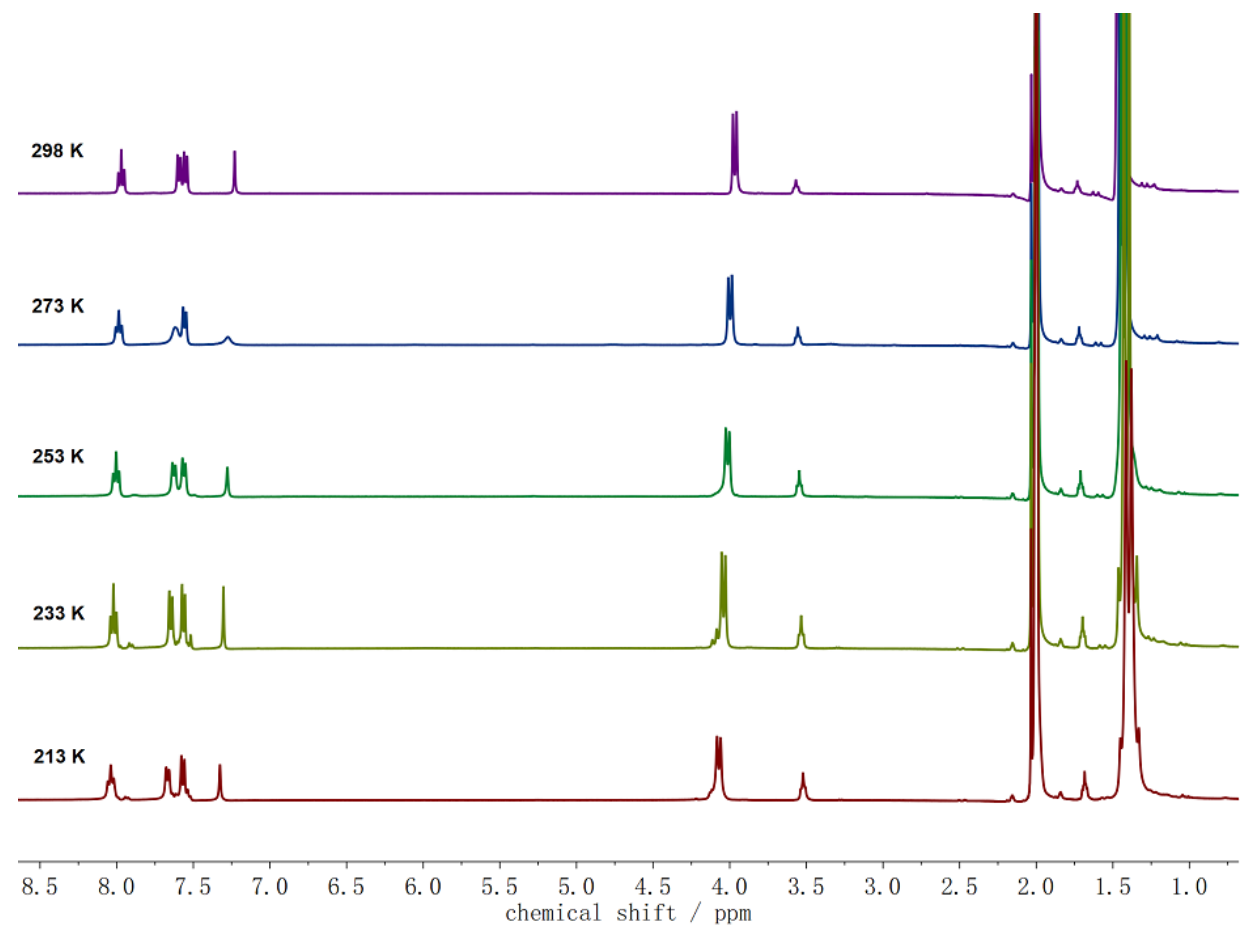

Figure 9.91: Variable temperature ${ }^{1} \mathrm{H}-\mathrm{NMR}$ spectra of complex 18 in acetone-d $\mathrm{d}_{6}$. 


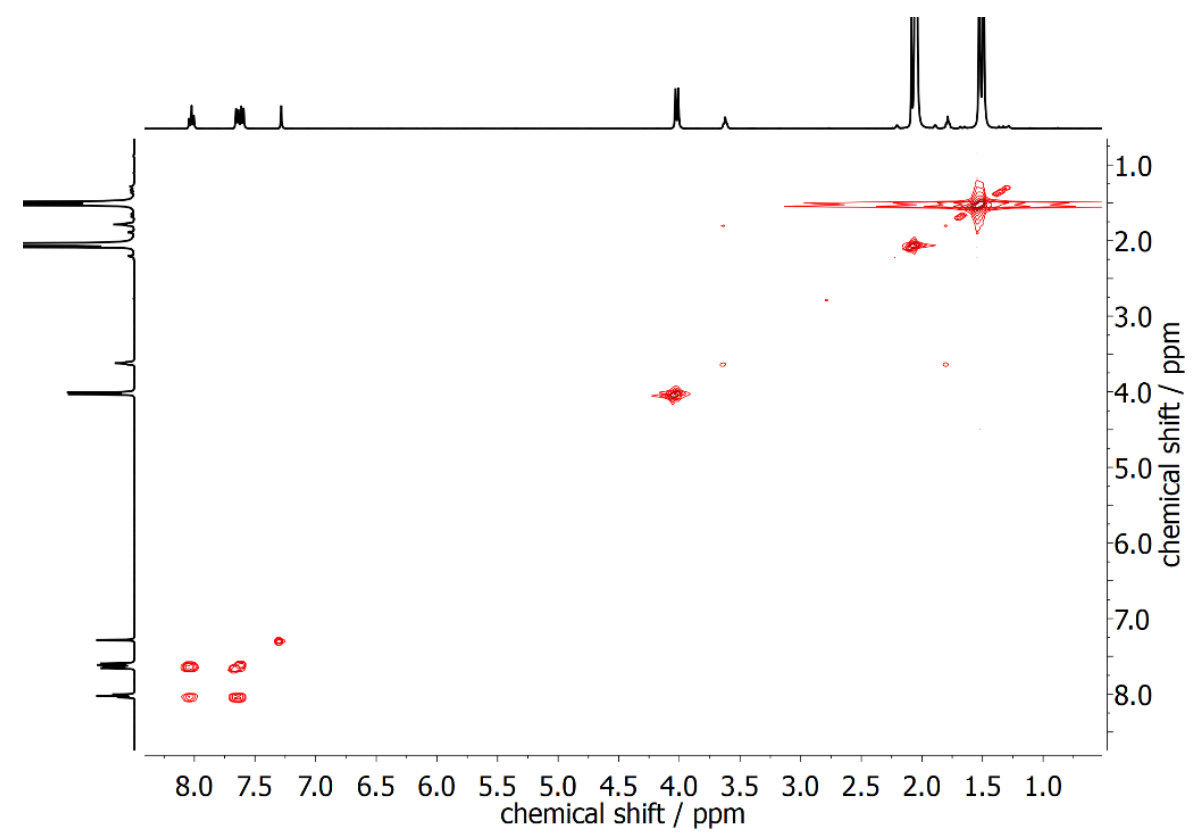

Figure 9.92: ${ }^{1} \mathrm{H}-{ }^{1} \mathrm{H}$ COSY $(400 \mathrm{MHz})$ of complex 18 in acetone- $\mathrm{d}_{6}$ at room temperature.

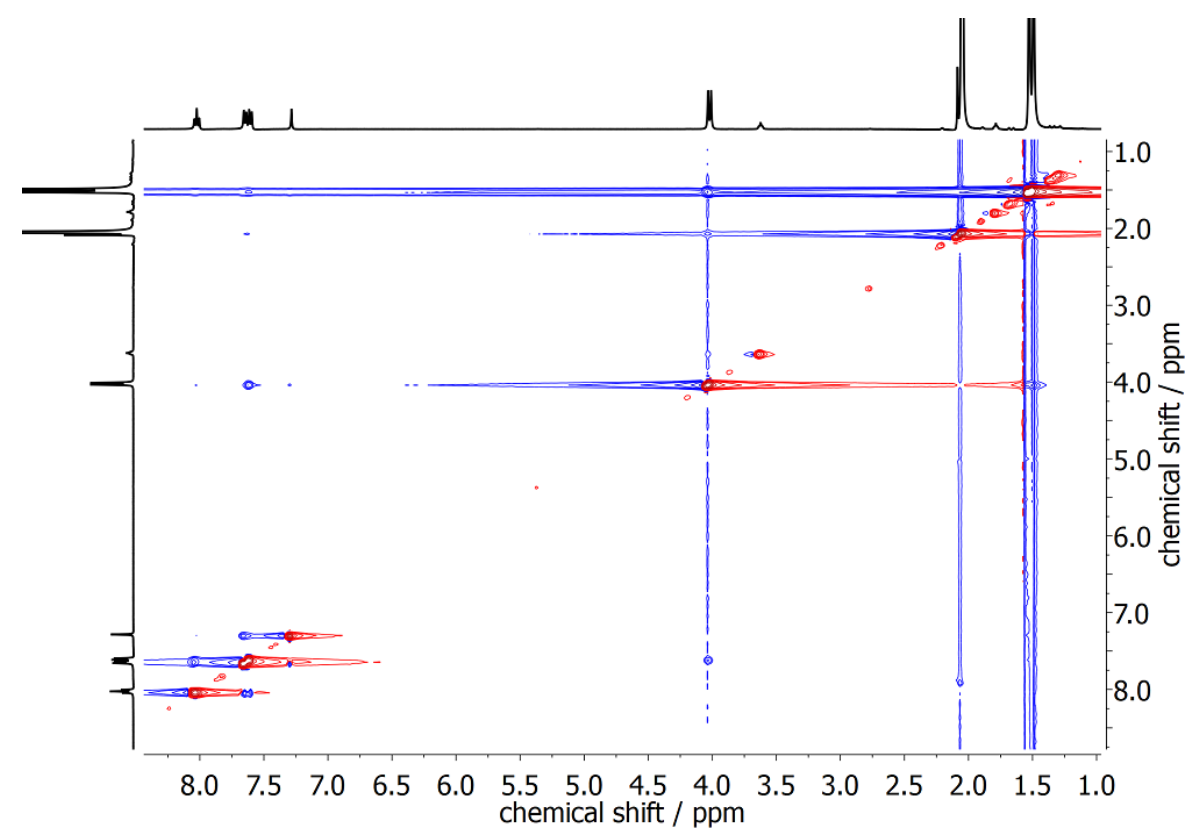

Figure 9.93: ${ }^{1} \mathrm{H}-{ }^{1} \mathrm{H}$ NOESY (400 MHz) of complex 18 in acetone- $\mathrm{d}_{6}$ at room temperature. 


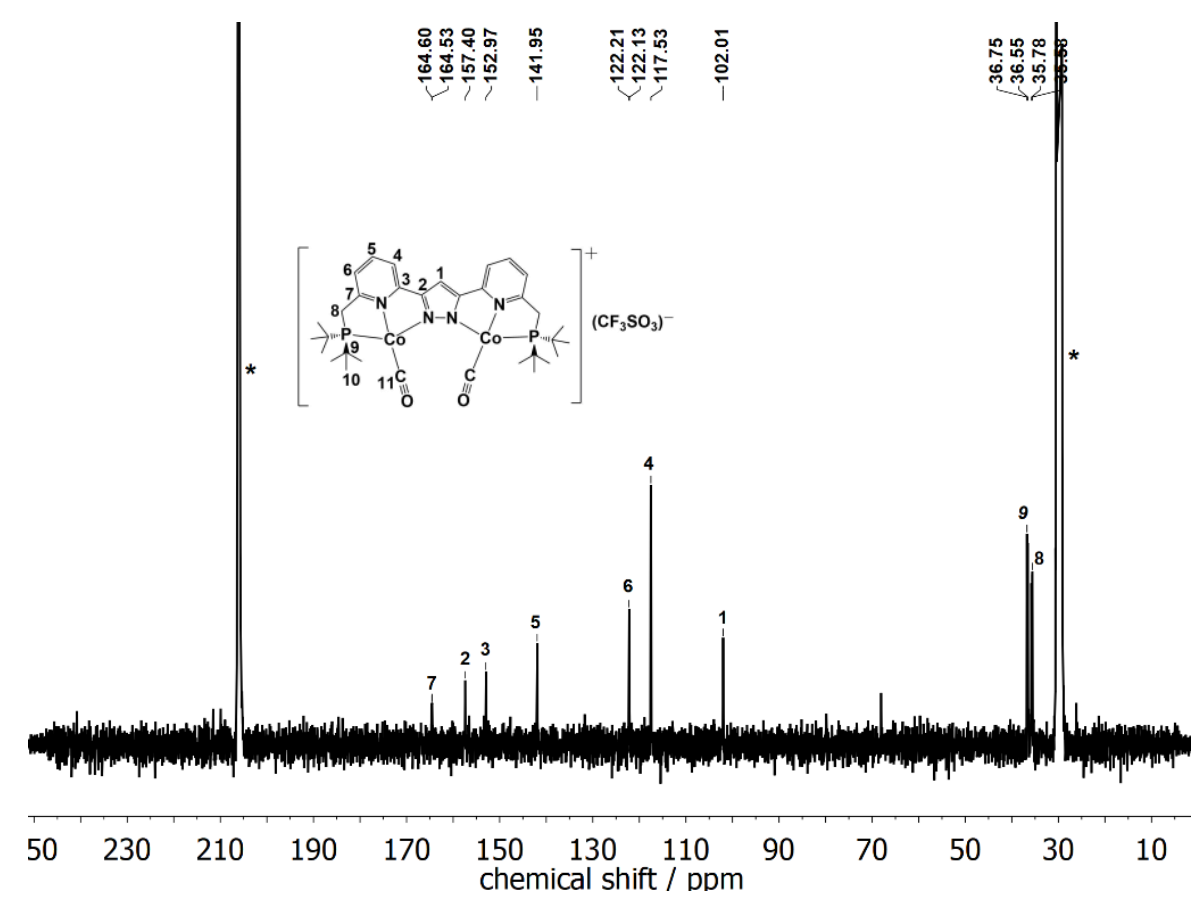

Figure 9.94: ${ }^{13} \mathrm{C}-\mathrm{NMR}$ spectrum of complex 18 in acetone- $\mathrm{d}_{6}$ at room temperature. Solvent signals are marked with an asterisk $(*)$.

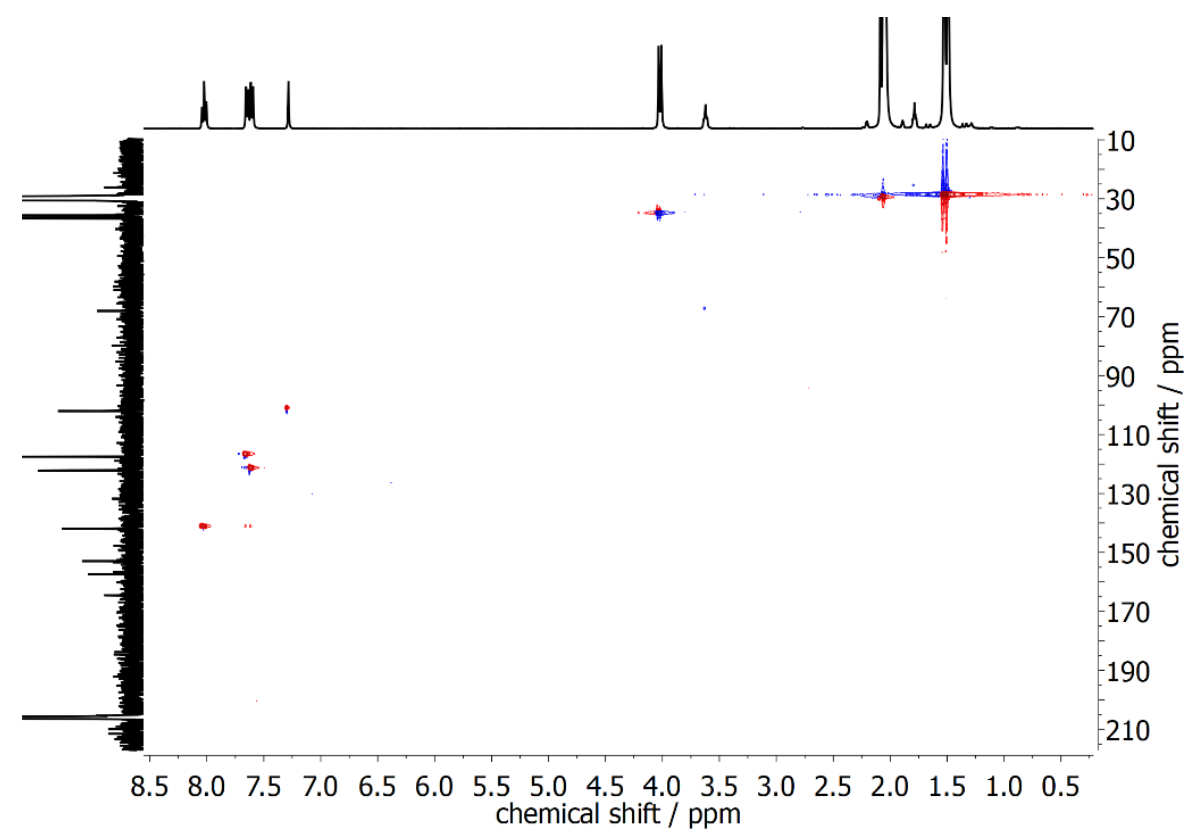

Figure 9.95: ${ }^{1} \mathrm{H}^{13} \mathrm{C}$ HSQC of complex 18 acetone- $\mathrm{d}_{6}$ at room temperature. 


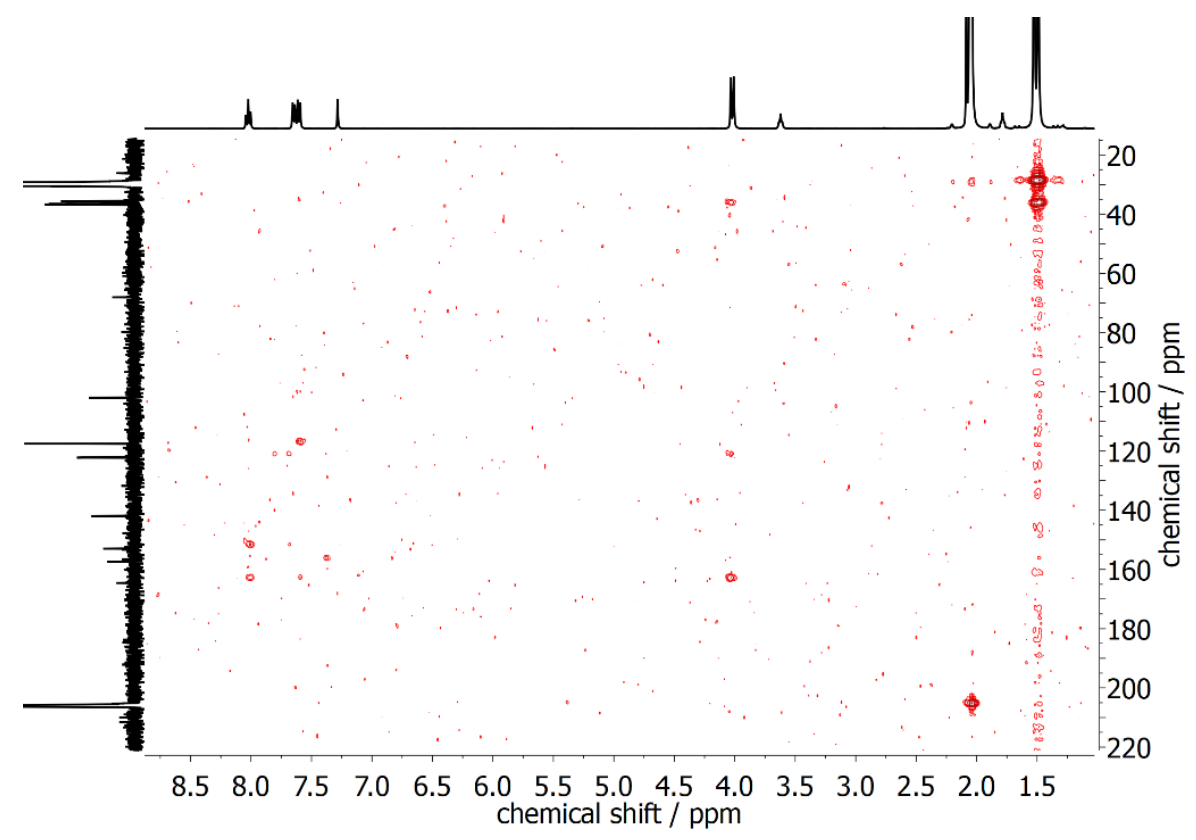

Figure 9.96: ${ }^{1} \mathrm{H}_{-}{ }^{13} \mathrm{C} \mathrm{HMBC}$ of complex 18 in acetone- $\mathrm{d}_{6}$ at room temperature.

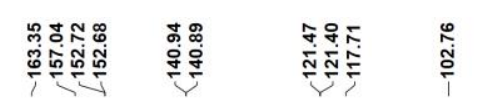
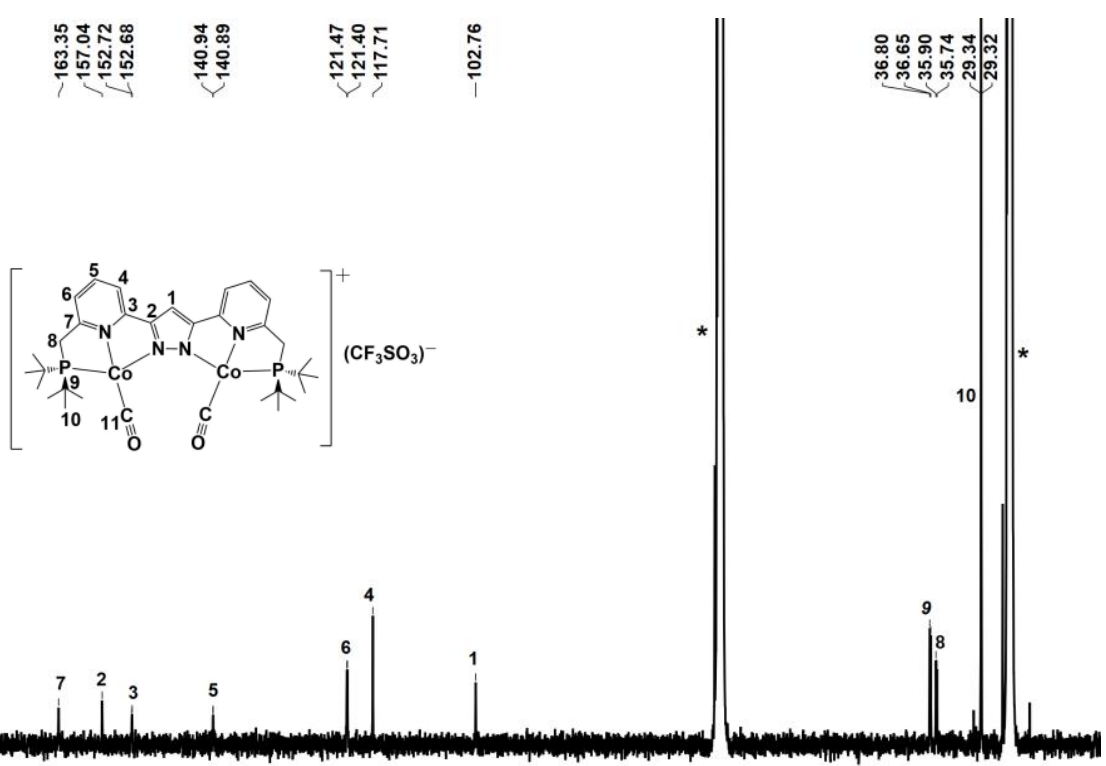

$\begin{array}{lllllllllllllllll}80 & 170 & 160 & 150 & 140 & 130 & 120 & 110 & 100 & 90 & 80 & 70 & 60 & 50 & 40 & 30 & 20\end{array}$ chemical shift / ppm

Figure 9.97: ${ }^{13} \mathrm{C}-\mathrm{NMR}$ spectrum $(500 \mathrm{MHz})$ of complex 18 in $\mathrm{THF}-\mathrm{d}_{8}$ at $40{ }^{\circ} \mathrm{C}$. Solvent signals are marked with an asterisk (*). 


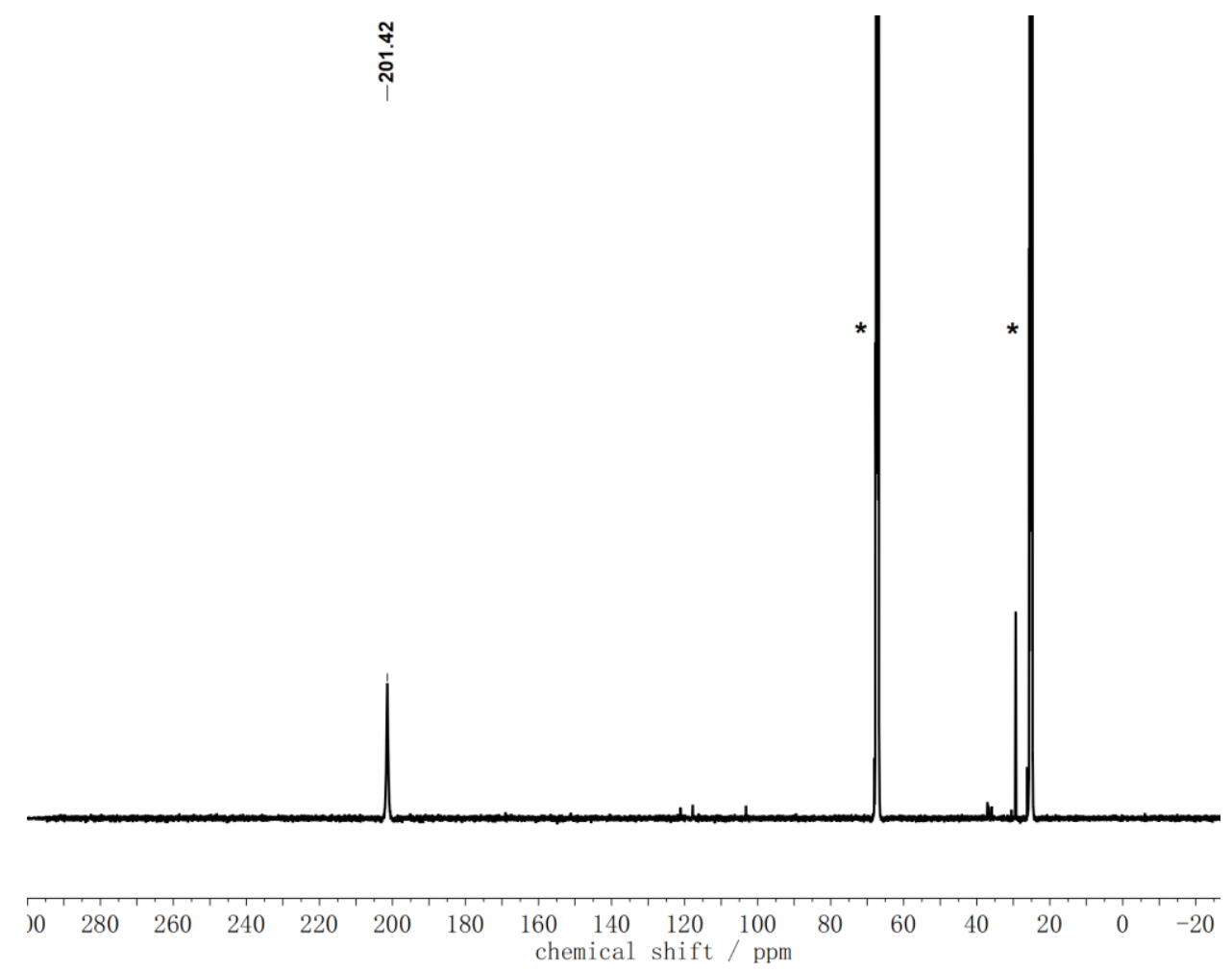

Figure 9.98: ${ }^{13} \mathrm{C}-\mathrm{NMR}$ spectrum $(500 \mathrm{MHz})$ of complex $\mathbf{1 8}-{ }^{\mathbf{1 3}} \mathbf{C O}$ in $\mathrm{THF}-\mathrm{d}_{8}$ at room temperature. Solvent signals are marked with an asterisk (*).

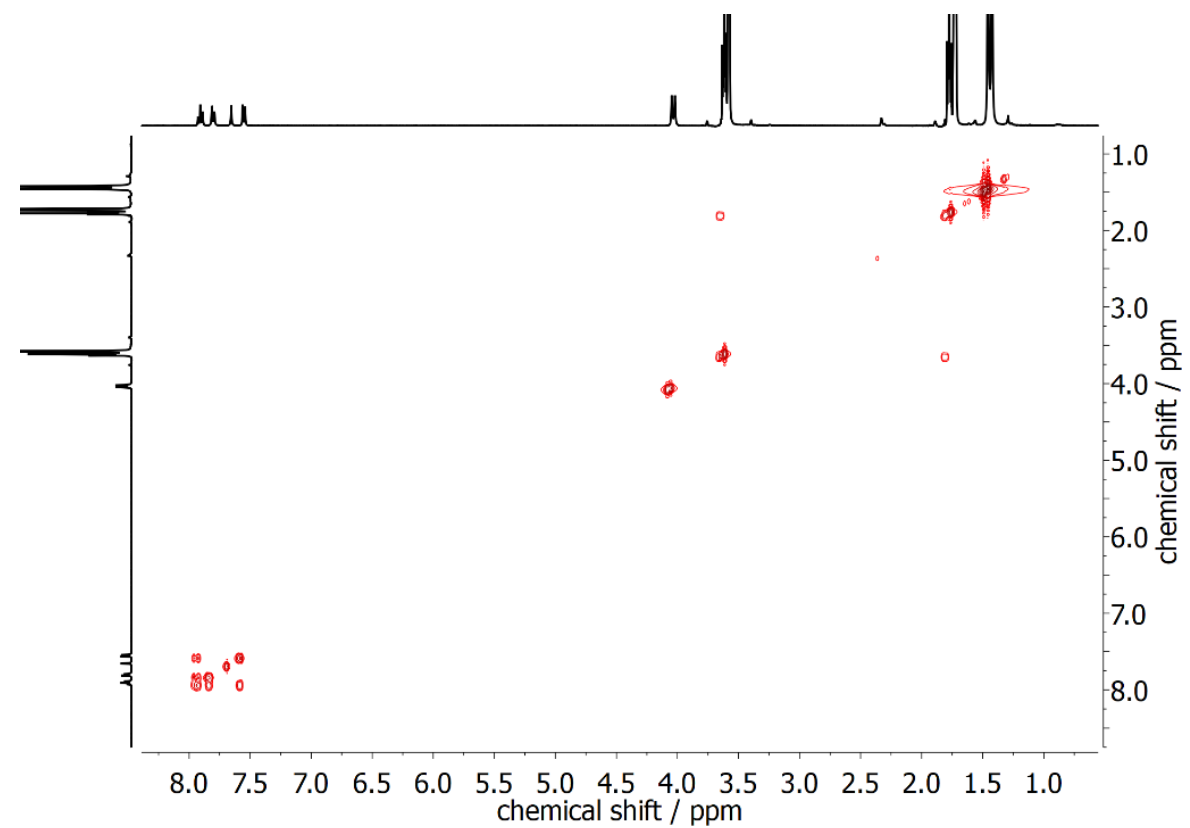

Figure 9.99: ${ }^{1} \mathrm{H}-{ }^{1} \mathrm{H}$ COSY $(400 \mathrm{MHz})$ of complex 19 in THF-d8. 


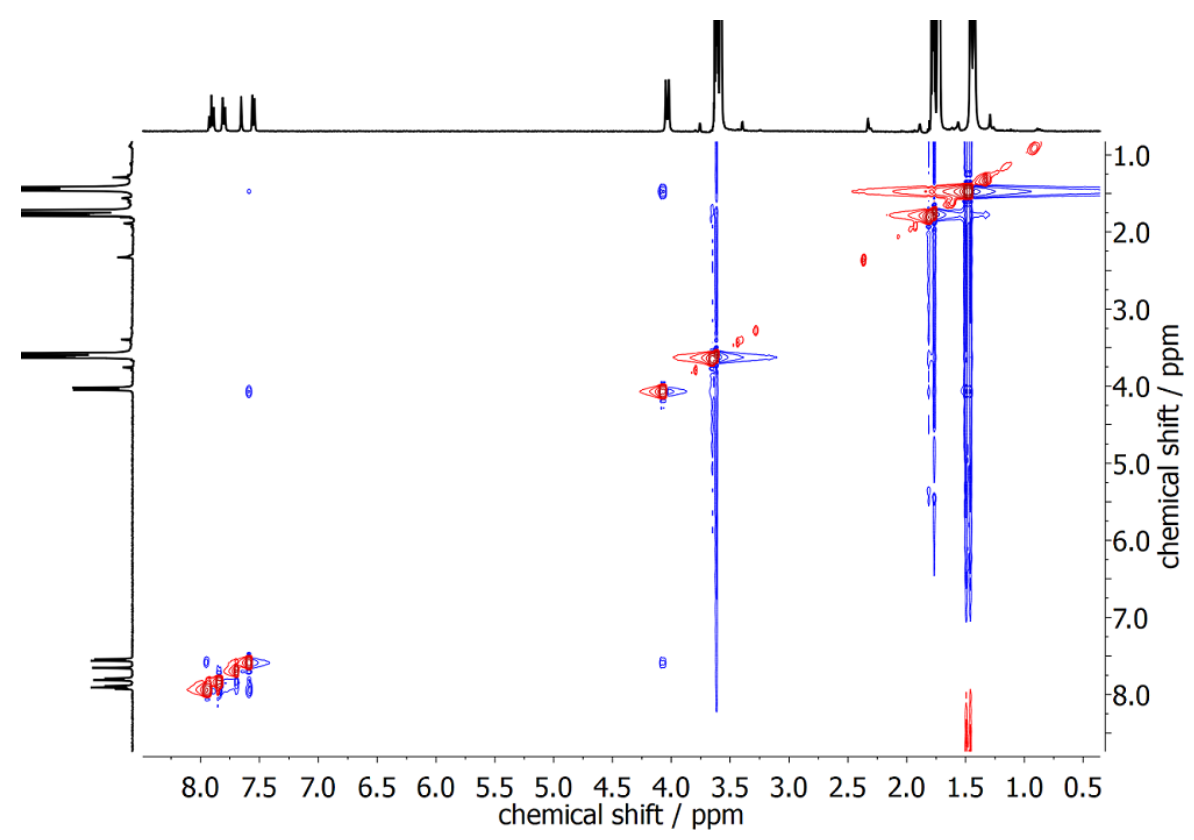

Figure 9.100: ${ }^{1} \mathrm{H}-{ }^{1} \mathrm{H}$ NOESY (400 MHz) of complex 19 in THF-d 8 .

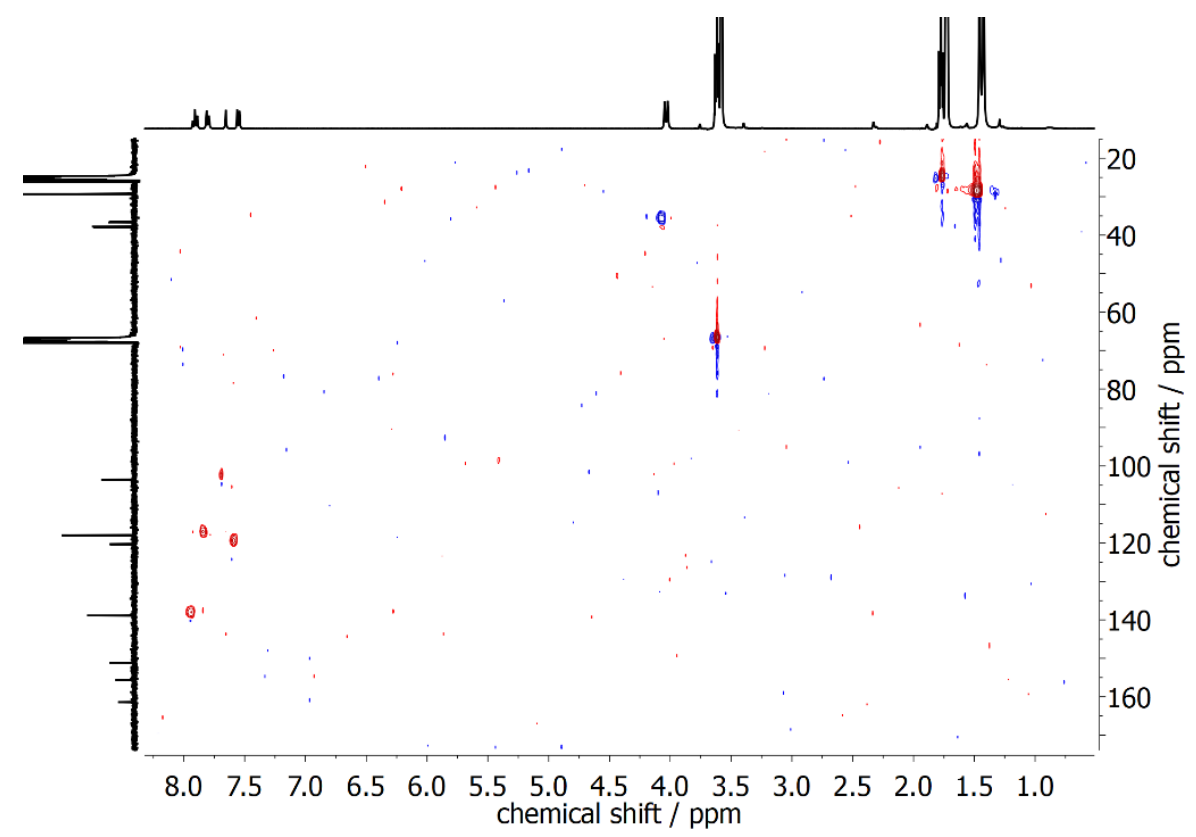

Figure 9.101: ${ }^{1} \mathrm{H}^{13} \mathrm{C}$ HSQC (400 MHz) of complex 19 in THF-d 8 . 


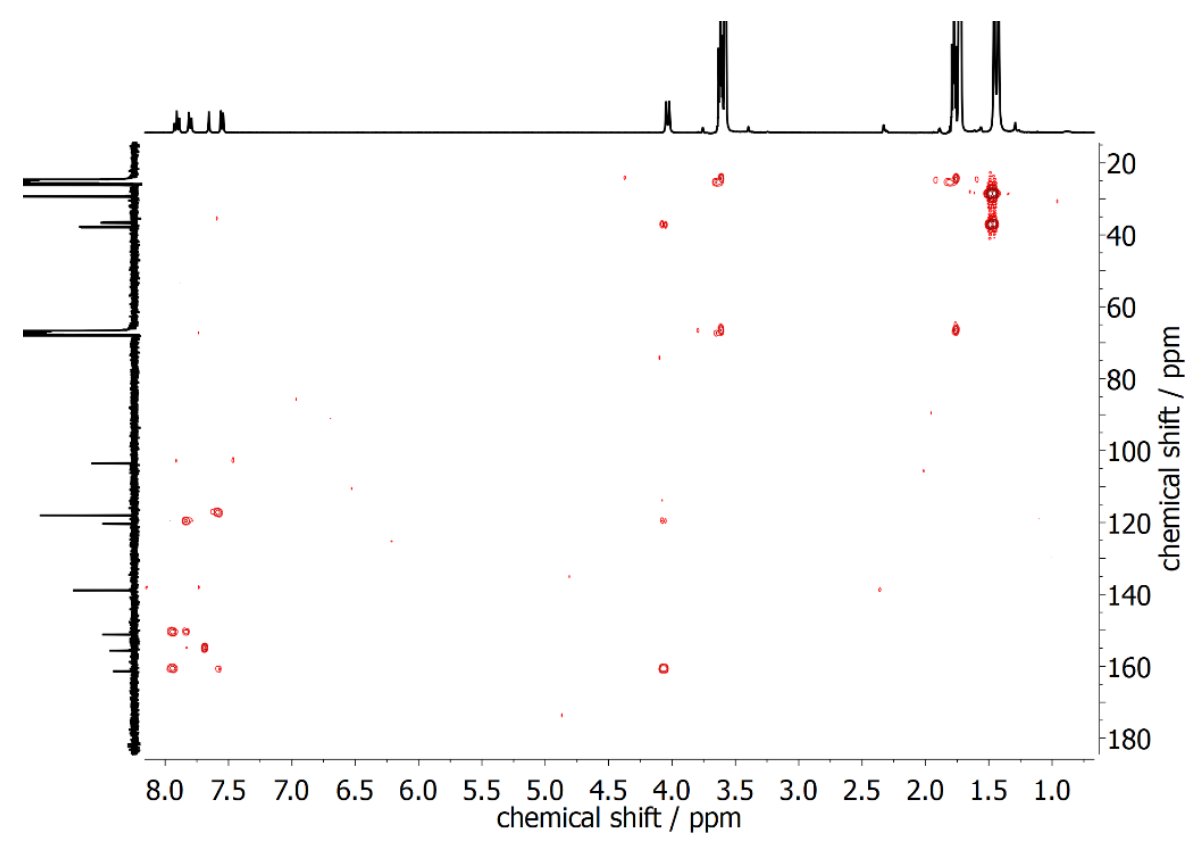

Figure 9.102: ${ }^{1} \mathrm{H}^{-13} \mathrm{C} \mathrm{HMBC}(400 \mathrm{MHz})$ of complex 19 in $\mathrm{THF}-\mathrm{d}_{8}$.

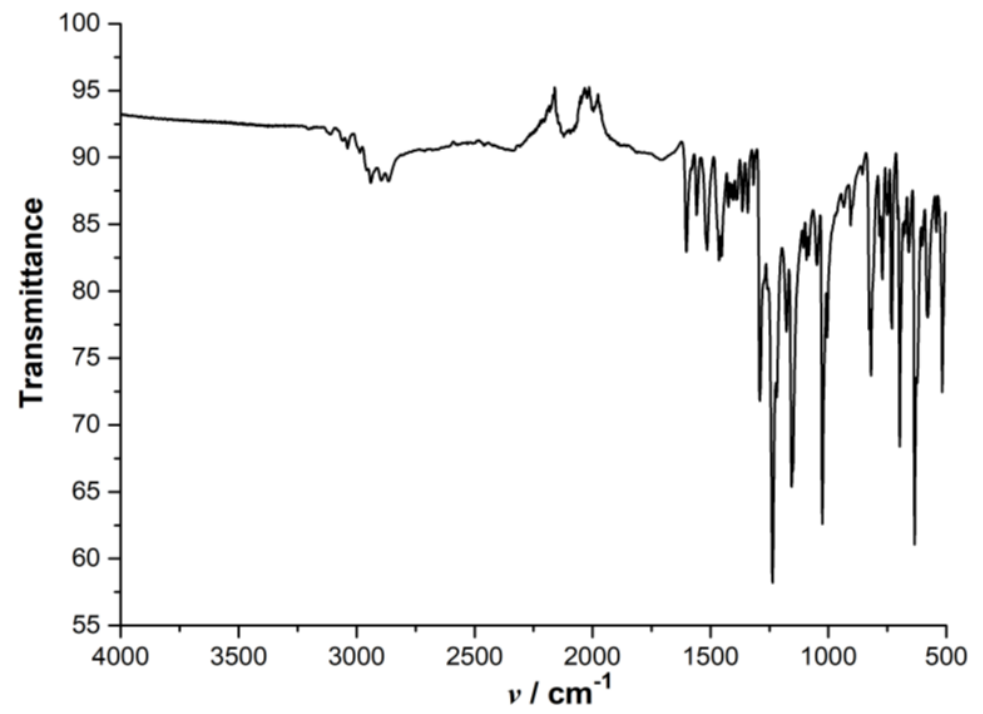

Figure 9.103: IR spectrum of complex 20 in solid state. 


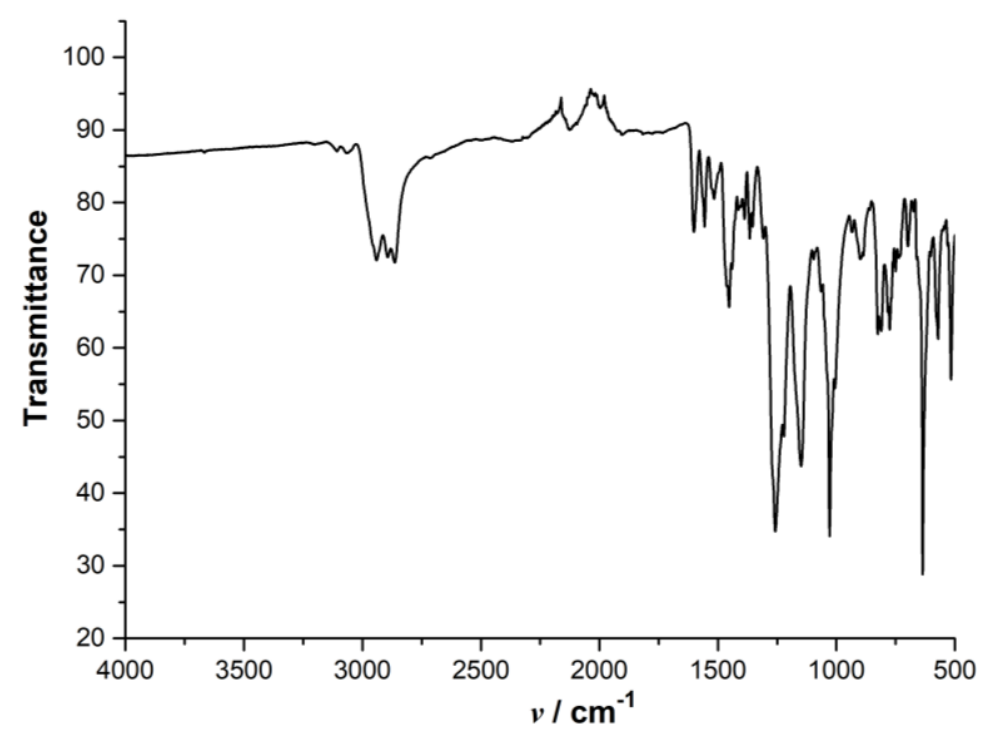

Figure 9.104: IR spectrum of complex 21 in solid state.

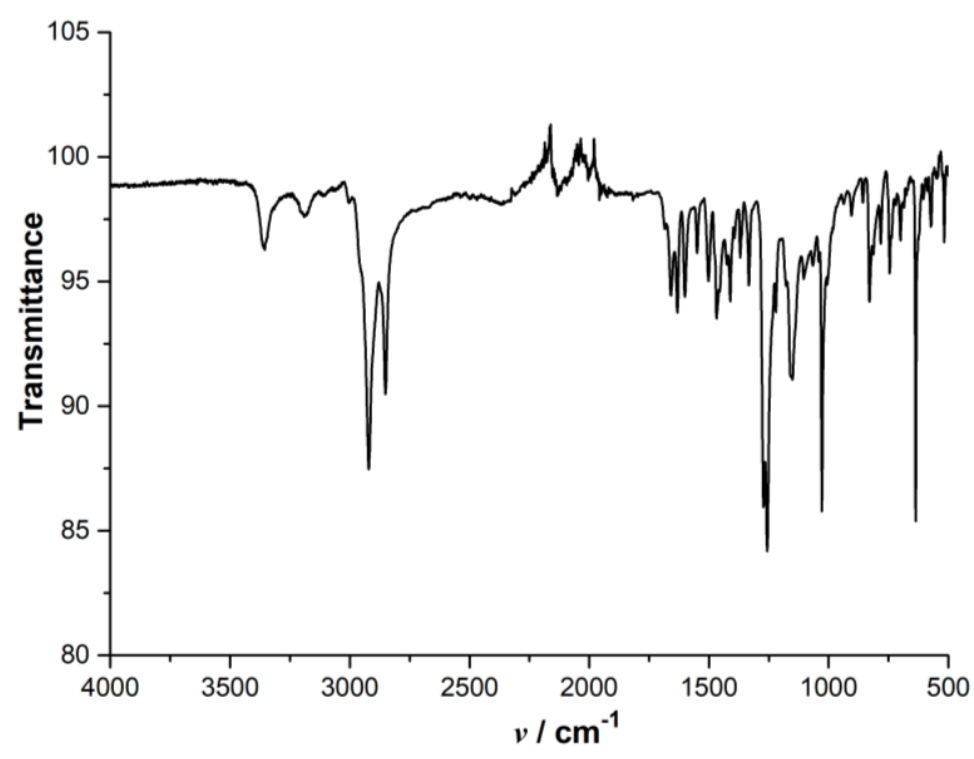

Figure 9.105: IR spectrum of complex 22 in solid state. 


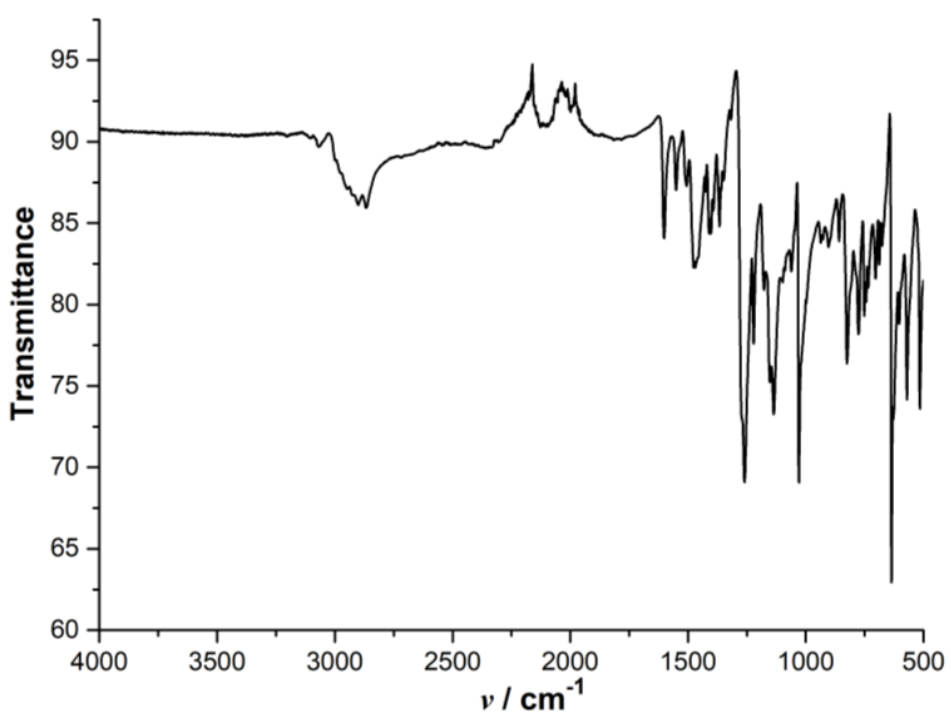

Figure 9.106: IR spectrum of complex 23 in solid state. 



\section{References}

[1] (a) L. Alig, M. Fritz, S. Schneider, Chem. Rev., 2019, 119, 2681-2751; (b) A. Singh, D. Gelman, ACS Catal., 2020, 10, 1246-1255.

[2] (a) E. Poverenov, D. Milstein, Top. Organomet. Chem., 2013, 40, 21-48; (b) A. J. Kosanovich, C. H. Komatsu, N. Bhuvanesh, L. M. Pérez, O. V. Ozerov, Chem. Eur. J., 2018, 24, 13754-13757.

[3] (a) C. Gunanathan, D. Milstein, Chem. Rev., 2014, 114, 12024-12087; (b) D. Gelman, S. Musa, ACS Catal., 2012, 2, 12, 2456-2466.

[4] (a) D. G. McCollum, L. Hall, C. White, R. Ostrander, A. L. Rheingold, J. Whelan, B. Bosnich, Inorg. Chem., 1999, 38, 2554-2562; (b) J. Klingele, S. Dechert, F. Meyer Coord. Chem. Rev., 2009, 253, 2698-2741; (c) F. Yu, V. M. Cangelosi, M. L. Zastrow, M. Tegoni, J. S. Plegaria, A. G. Tebo, C. S. Mocny, L. Ruckthong, H. Qayyum, V. L. Pecoraro, Chem. Rev., 2014, 114, 3495-3578.

[5] S. Samanta, S. Demesko, S. Dechert, F. Meyer, Angew. Chem., 2015, 127, 593-597; Angew. Chem. Int. Ed., 2015, 54, 583-587.

[6] A. Gers-Barlag, Doctoral Thesis, Two-in-one Pincer Type Ligands and Their Metal Complexes for Catalysis, University of Göttingen, 2016.

[7] P. Goursot, Doctoral Thesis, Dinickel Complexes of the "Two-In-One" Pincer Scaffold, University of Göttingen, 2019.

[8] (a) P. Warneck, J. Williams, The Atmospheric Chemist's Companion: Numerical Data for Use in the Atmospheric Sciences. Dordrecht: Springer, 2012; (b) S.V. Vassilev, D. Baxter, L.K. Andersen, C.G. An Overview of the Chemical Composition of Biomass, 2010, Fuel 89, 913-933.

[9] (a) D. E. Canfield, A. N. Glazer, P. G. Falkowski, Science, 2010, 330, 192-196; (b) Q. Cheng, J. Integr. Plant Biol., 2008, 50, 786-798; (c) B. Thamdrup, Annu. Rev. Ecol. Evol. Syst.. 2012, 43, 407-428.

[10] (a) B. M. Hoffman, D. Lukoyanov, Z. Yang, D. Dean, L. C. Seefeldt, Chem. Rev., 2014, 114, 4041-4062; (b) M.W. Ribbe, Nitrogen Fixation: Methods and Protocols, Methods in Molecular Biology, 2011, 766. New York: Humana Press; (c) Y. Nishibayashi, Transition Metal-Dinitrogen Complexes: Preparation and Reactivity, 2019, Wiley-VCH, 1-77.

[11] (a) M. M. Georgiadis, H. Komiya, P. Chakrabarti, D. Woo, J. J. Kornuc, D. C. Rees, Science, 1992, 257, 1653-1659; (b) T. Spatzal, M. Aksoyoglu, L. Zhang, S. L. a. Andrade, E. Schleicher, S.

Weber, D. C. Rees, O. Einsle, Science, 2011, 334, 940-940; (c) K. M. Lancaster, M. Roemelt, P. Ettenhuber, Y. Hu, M. W. Ribbe, F. Neese, U. Bergmann, S. DeBeer, Science, 2011, 334, 974-977. [12] (a) S. Kuriyama, K. Arashiba, K. Nakajima, Y. Matsuo, H. Tanaka, K. Ishii, K. Yoshizawa, Y. Nishibayashi, Nature Communications, 2016, 7, 12181; (b) Y. Sekiguchi, S. Kuriyama, A. Eizawa, K. Arashiba, K. Nakajima, and Y. Nishibayashi, Chem. Commun., 2017, 53, 12040-12043.

[13] N. Khoenkhoen, B.de Bruin, J. N. H. Reek, W. I. Dzik, Eur. J. Inorg. Chem., 2015, 567-598.

[14] M.W. Chase, NIST-JANAF, 1998, Thermochemical Tables, 4e, Gaithersburg, MD: American Chemical Society and American Institute of Physics.

[15] H. Jia, E. A. Quadrelli, Chem. Soc. Rev., 2014, 43, 547-564.

[16] A.D. Allen, C.V. Senoff, Chem. Commun., 1965, 1, 621-622.

[17] (a) A. Yamamoto, S. Kitazume, L.S. Pu, S. Ikeda, Chem. Commun., 1967, 3, 79-80; (b) A. Yamamoto, L.S. Pu, S. Kitazume, S. Ikeda, J. Am. Chem. Soc., 1967, 89, 3071-3073. 
[18] (a) J. P. Collman, J. E. Hutchison, M. A. Lopez, R. Guilard, J. Am. Chem. Soc., 1992, 114, 21, 8066-8073; (b) S. Demir, S. E. Lorenz, M. Fang, F. Furche, G. Meyer, J. W. Ziller, W. J. Evans, J. Am. Chem. Soc., 2010, 132, 32, 11151-11158; (c) E. Gutierrez, A. Monge, M. C. Nicasio, M. L. Poveda, E. Carmona, J. Am. Chem. Soc., 1994, 116, 2, 791-792; (d) D. J. Knobloch, D. Benito-Garagorri, W. H. Bernskoetter, I. Keresztes, E. Lobkovsky, H. Toomey, P. J. Chirik, J. Am. Chem. Soc., 2009, 131, 41, 14903-14912.

[19] (a) R. Hoffmann, M.M.-L Chen, D.L. Thorn, Inorg. Chem., 1977, 16, 503-511; (b) S. Sakai, K. Morokuma, K. Ohkubo, J. Am. Chem. Soc., 1985, 107, 2686-2693; (c) C. Esterhuysen, G. Frenking, Chem. Eur. J., 2003, 9, 3518-3529.

[20] (a) B. Peigné, G. Aullón, Acta Crystallogr., Sect. B: Struct. Sci. Cryst. Eng. Mater., 2015, 71, 369-386; (b) D. Pun, E. Lobkovsky, P.J. Chirik, J. Am. Chem. Soc., 2008, 130, 6047-6054; (c) L. J. Murray, W. W. Weare, J. Shearer, A. D. Mitchell, K. A. Abboud, J. Am. Chem. Soc., 2014, 136, 13502-13505; (d) R. Ferguson, E. Solari, C. Floriani, Angew. Chem. Int. Ed. Engl., 1993, 32, 396-397; Angew. Chem., 1993, 105, 453-455; (e) J.M. Smith, R.J. Lachicotte, K.A. Pittard, J. Am. Chem. Soc., 2001, 123, 9222-9223.

[21] (a) K. Ding, A. W. Pierpont, W. W. Brennessel, G. Lukat-Rodgers, K. R. Rodgers, T. R. Cundari, E. Bill, P. L. Holland, J. Am. Chem. Soc., 2009, 131, 9471-9472; (b) J. Scott, S. Gambarotta, I. Korobkov, Can. J. Chem., 2005, 83, 279-285; (c) A. C. Bowman, C. Milsmann, C. C. H. Atienza, E. Lobkovsky, K. Wieghardt, P. J. Chirik, J. Am. Chem. Soc., 2010, 132, 1676-1684; (d) T. J. D. Castillo, N. B. Thompson, D. L. M. Suess, G. Ung, J. C. Peters, Inorg. Chem., 2015, 54, 9256-9262; (e) D. L. M. Suess, C. Tsay, J. C. Peters, J. Am. Chem. Soc., 2012, 134, 14158-14164; (f) M. T. Whited, N. P. Mankad, Y. Lee, P. F. Oblad, J. C. Peters, Inorg. Chem., 2009, 48, 2507-2517; (g) R. B. Siedschlag, V. Bernales, K. D. Vogiatzis, N. Planas, L. J. Clouston, E. Bill, L. Gagliardi, C. C. Lu, J. Am. Chem. Soc., 2015, 137, 4638-4641; (h) Y. Gao, G. Li, L. Deng, J. Am. Chem. Soc., 2018, 140, 2239-2250; (i) T. Suzuki, K. Fujimoto, Y. Takemoto, Y. Wasada-Tsutsui, T. Ozawa, T. Inomata, M. D. Fryzuk, H. Masuda, ACS Catal., 2018, 8, 3011-3015.

[22] (a) A. R Fout, F. Basuli, H. Fan, J. Tomaszewski, J. C Huffman, M. Baik, D. J Mindiola, Angew. Chem. Int. Ed., 2006, 45, 3291-3295; (b) S. S. Rozenel, R. Padilla, J. Arnold, Inorg. Chem., 2013, 52, 11544-11550; (c) S. P. Semproni, C. Milsmann, P. J. Chirik, J. Am. Chem. Soc., 2014, 136, 9211-9224; (d) S. Kuriyama, K. Arashiba, H. Tanaka, Y. Matsuo, K. Nakajima, K. Yoshizawa, Y. Nishibayashi, Angew. Chem. Int. Ed., 2016, 55, 14291-14295.

[23] (a) K. Arashiba, Y. Miyake, Y. Nishibayashi, Nat. Chem. 2011, 3, 120-125; (b) D. V. Yandulov, R. R. Schrock, Science 2003, 301, 76-78; (c) P. J. Hill, L. R. Doyle, A. D. Crawford, W. K. Myers, A. E. Ashley, J. Am. Chem. Soc. 2016, 138, 13521-13524; (d) S. Kuriyama, K. Arashiba, H. Tanaka, Y. Matsuo, K. Nakajima, K. Yoshizawa, Y. Nishibayashi, Angew. Chem., Int. Ed. 2016, 55, 14291-14295; (e) A. J. Kendall, S. I. Johnson, R. M. Bullock, M. T. Mock J. Am. Chem. Soc. 2018, 140, 2528-2536; (f) L. R. Doyle, A. J. Wooles, L. C. Jenkins, F. Tuna, E. J. L. McInnes, S. T. Liddle Angew. Chem. Int. Ed. 2018, 57, 6314-6318.

[24] (a) M. J. Chalkley, T. J. Del Castillo, B. D. Matson, J. P. Roddy, J. C. Peters, ACS Cent. Sci. 2017, 3, 217-223. (b) T. J. Del Castillo, N. B. Thompson, J. C. Peters, J. Am. Chem. Soc. 2016, 138, 5341-5350.

[25] (a) A. D. Piascik, R. Li, H. J. Wilkinson, J. C. Green, A. E. Ashley, J. Am. Chem. Soc. 2018, 140, 10691-10694; (b) H. Tanaka, A. Sasada, T. Kouno, M. Yuki, Y. Miyake, H. Nakanishi, Y. Nishibayashi, K. Yoshizawa J. Am. Chem. Soc. 2011, 133, 3498-3506; (c) Q. Liao, N. 
Saffon-Merceron, N. Mézailles, Angew. Chem., Int. Ed., 2014, 53, 14206-14210; (d) M. Yuki, H. Tanaka, K. Sasaki, Y. Miyake, K. Yoshizawa, Y. Nishibayashi, Nat. Commun. 2012, 3, 1254.

[26] S. Liu, A. Motta, A. R. Mouat, M. Delferro, T. J. Marks, J. Am. Chem. Soc., 2014, 136, 29, 10460-10469.

[27] (a) J. L. Detrich, R. Konecny, W. M. Vetter, D. Doren, A. L. Rheingold, K. H. Theopold, J. Am. Chem. Soc. 1996, 118, 1703-1712; (b) P. Fernández, A. Sousa-Pedrares, J. Romero, M. L. Durán, A. Sousa, P. Pérez-Lourido, J. A. García-Vázquez, Eur. J. Inorg. Chem. 2010, 814-823.

[28] D. J. Metz, A. Clines, Density, Viscosity, and Dielectric Constant of Tetrahydrofuran between -78 and $30^{\circ}$, J. Phys. Chem., 1967.

[29] A. Einstein, Ann. Phys., 1905, 17, 132.

[30] (a) L. D. Field, H. L. Li, S. J. Dalgarno, Inorg. Chem., 2010, 49, 6214-6221; (b) S. S. Rozenel, J. Arnold, Inorg. Chem., 2012, 51, 9730-9739; (c) L. D. Field, H. L. Li, S. J. Dalgarno, P. Jensen, R. D. McIntosh, Inorg. Chem., 2011, 50, 5468-5476; (d) S. Vogel, A. Barth, G. Huttner, T. Klein, L. Zsolnai, R. Kremer, Angew. Chem. Inf. Ed. Engl., 1991, 30, 303-304.

[31] D. Sellmann, A. Hennige, Angew. Chem. Inf. Ed. Engl., 1997, 36, 276-278.

[32] (a) C. T. Saouma, C. E. Moore, A. L. Rheingold, J. C. Peters, Inorg. Chem., 2011, 50, 11285-11287; (b) L. D. Field, H. L. Li, S. J. Dalgarnob, P. Turnerc, Chem. Commun., 2008, 1680-1682; (c) C. T. Saouma, R. A. Kinney, B. M. Hoffman, J. C. Peters, Angew. Chem. Int. Ed., 2011, 50, 3446-3449.

[33] (a) J. L. Crossland, C. G. Balesdent, D. R. Tyler, Inorg. Chem., 2012, 51, 439-445; (b) J. L. Crossland, D. R. Tyler, Coord. Chem. Rev., 2010, 254, 1883-1894.

[34] (a) C. Köthe, R. Metzinger, C. Herwig, C. Limberg, Inorg. Chem., 2012, 51, 9740-9747; (b) L. D. Field, H. L. Li, S. J. Dalgarno, R. D. McIntosh, Inorg. Chem., 2012, 51, 3733-3742; (c) T. M. Powers, T. A. Betley, J. Am. Chem. Soc., 2013, 135, 12289-12296; (d) S.M. Bellows, N. A. Arnet, P. M. Gurubasavaraj, W. W. Brennessel, E. Bill, T. R. Cundari, P. L. Holland, J. Am. Chem. Soc., 2016, 138, 12112-12123.

[35] L. D. Field, H. L. Li, S. J. Dalgarno, R. D. McIntosh, Inorg. Chem., 2013, 52, 1570-1583.

[36] (a) J. Chatt, B. A. L. Crichton, J. R. Dilworth, P. Dahlstrom, R.Gutkoska, J. Zubieta, Inorg. Chem., 1982, 21, 2383-2391; (b) R. R. Schrock, T. E. Classman, M. G. Vale, J. Am. Chem. Soc., 1991, 113, 725-726; (c) R. R. Schrock, T. E. Classman, M. G. Vale, M. Kol, J. Am. Chem. Soc., 1993, 115, 1760-1772; (d) J. L. Crossland, L. N. Zakharov, D. R. Tyler, Inorg. Chem., 2007, 46, 10476-10478; (e) Y. Lee, N. P. Mankad, J. C. Peters, Nat Chem., 2010, 2, 558-565; (f) C. T. Saouma, C. C. Lu, J. C. Peters, Inorg. Chem., 2012, 51, 10043-10054, (g) K. Umehara, S. Kuwata, T. Ikariya, J. Am. Chem. Soc., 2013, 135, 6754-6757, (h) Z. Huang, J. Zhou, J. F. Hartwig, J. Am. Chem. Soc., 2010, 132, 11458-11460.

[37] (a) S. Vogel, A. Barth, G. Huttner, T. Klein, L. Zsolnai, R. Kremer, Angew. Chem. Int. Ed. Engl., 1991, 30, 303-304; (b) V. Korner, G. Huttner, S. Vogel, A. Barth, L. Zsolnai, Chew. Ber:/Recueil, 1997, 130, 489-492.

[38] C. Köthe, R. Metzinger, C. Herwig, C. Limberg, Inorg. Chem., 2012, 51, 9740-9747.

[39] (a) L. D. Field, H. L. Li, S. J. Dalgarno, P. Turner, Chem. Commun., 2008, 1680-1682; (b) L. D. Field, H. L. Li, S. J. Dalgarno, R. D. McIntosh, Inorg. Chem., 2012, 51, 3733-3742; (c) L. D. Field, H. L. Li, S. J. Dalgarno, R. D. McIntosh, Inorg. Chem., 2013, 52, 1570-1583.

[40] (a) L. Blum, I. D. Williams, R. R. Schrock, J. Am. Chem. Soc., 1984, 106, 8317-8319, (b) M. Fang, D, S. Lee, J. W. Ziller, R. J. Doedens, J. E. Bates, F. Furche, W. J. Evans, J. Am. Chem. Soc., 
2011, 133, 3784-3787; (c) S. S. Rozenel, J. Arnold, Inorg. Chem., 2012, 51, 9730-9739, (d) S. Kuwata, Y. Mizobe, M. Hidai, Inorg. Chem., 1994, 33, 3619-3620; (e) Y. Chen, Y. Zhou, P. Chen, Y. Tao, Y. Li, J. Qu, J. Am. Chem. Soc., 2008, 130, 15250-15251; (f) M. Yuki, Y. Miyake, Y. Nishibayashi, Organometallics, 2012, 31, 2953-2956; (g) J. Vela, S. Stoian, C. J. Flaschenriem, E. Münck, P. L. Holland, J. Am. Chem. Soc., 2004, 126, 4522-4523.

[41] C. T. Saouma, P. Müller, J. C. Peters, J. Am. Chem. Soc., 2009, 131, 10358-10359.

[42] Y. Li, Y. Li, B. Wang, Y. Luo, D. Yang, P. Tong, J. Zhao, L. Luo, Y. Zhou, S. Chen, F. Cheng, J. Qu, Nature Chem., 2013, 5, 320-326.

[43] (a) N. S. Lewis, D. G. Nocera, Powering the Planet: Chemical Challenges in Solar Energy Utilization. Proc. Natl. Acad. Sci. U. S. A., 2006, 103, 15729-15735; (b) M. Aresta, A. Dibenedetto, Dalton Trans., 2007, 2975-2992.

[44] (a) A. M. Appel, J. E. Bercaw, A. B. Bocarsly, H. Dobbek, D. L. DuBois, M. Dupuis, J. G. Ferry, etc, Chem. Rev., 2013, 113, 8, 6621-6658, (b) M. Aresta, A. Dibenedetto, A. Angelini,. Chem. Rev., 2014, 114, 1709-1742.

[45] (a) P. Wang, M. Bruschi, L. D. Gioia, J. Blumberger, J. Am. Chem. Soc., 2013, 135, 25, 9493-9502; (b) M. Can, F. A. Armstrong, S. W. Ragsdale, Chem. Rev., 2014, 114, 4149-4174.

[46] (a) Q. Liu, L. Wu, R. Jackstell, M. Beller, Nat. Commun., 2015, 6, 5933; (b) C. Federsel, R. Jackstell, M. Beller, Angew. Chem. Int. Ed., 2010, 49; 6254-6257; (c) P. G. Jessop, T. Ikariya, R. Noyori, Chem. Rev., 1995, 95, 259-272.

[47] R. Francke, B. Schille, M. Roemelt, Chem. Rev., 2018, 118, 4631-4701.

[48] Activation of Small Molecules: Organometallic and Bioinorganic Perspectives, William Tolman, 2006, Wiley-VCH.

[49] I. Castro-Rodriguez, H. Nakai, L. Zakharov, A.L. Rheingold, K. Meyer, Science, 2004, 305, 1757-1759.

[50] (a) B. Horn, C. Limberg, C. Herwig, B. Braun, Chem. Commun., 2013, 49, 10923-10925; (b) L. Roy, M. H. Al-Afyouni, D. E. DeRosha, B. Mondal, I. M. DiMucci, K. M. Lancaster, J. Shearer, E. Bill, W. W. Brennessel, F. Neese, S. Ye, P. L. Holland, Chem. Sci., 2019, 10, 918-929; (c) A. R. Sadique, W. W. Brennessel, P. L. Holland, Inorg. Chem., 2008, 47, 784-786.

[51] (a) J. P. Krogman, B. M. Foxman, C. M. Thomas, J. Am. Chem. Soc., 2011, 133, 14582-14585; (b) C. C. Lu, C. T. Saouma, M. W. Day, J. C. Peters, J. Am. Chem. Soc., 2007, 129, 4-5; (c) R. Angamuthu, P. Byers, M. Lutz, A. L. Spek, E. Bouwman, Science, 2010, 327, 313-315.

[52] F. Schneck, J. Ahrens, M. Finger, A. C. Stückl, C. Würtele, D. Schwarzer, S. Schneider, Nat. Commun., 2018 9, 1161.

[53] D. Sahoo, C. Yoo, Y. Lee, J. Am. Chem. Soc., 2018, 140, 2179-2185

[54] (a) J. C. Calabrese, T. Herskovitz, J. B. Kinney, J Am Chem Soc., 1983, 105, 5914-5915; (b) J.-C. Tsai, M. Khan, K.M. Nicholas, Organometallics, 1989, 8, 2967-2970; (c) J. Wu, P.E. Fanwick, C. P. Kubiak, Organometallics, 1987, 6, 1805-1807.

[55] A. Gers-Barlag, P. Goursot, M. Li, S. Dechert, F. Meyer, Eur. J. Inorg. Chem., 2019, 3329-3334.

[56] M. J. Ingleson, M. Pink, H. Fan, K. G. Caulton, Inorg. Chem., 2007, 46, 10321-10334.

[57] S. Murugesan, B. Stöger, M. D. Carvalho, L. P. Ferreira, E. Pittenauer, G. Allmaier, L. F. Veiros, K. Kirchner, Organometallics, 2014, 33, 6132-6140.

[58] L. M. Guard, T. J. Hebden, D. E. Linn, Jr., D. M. Heinekey, Organometallics, 2017, 36, 3104-3109. 
[59] (a) F. Gauvin, J. F. Harrod, H. G. Woo, Adv. Organomet. Chem., 1998, 42, 363-405; (b) J. Y. Corey, Adv. Organomet. Chem., 2004, 51, 1-52; (c) J. F. Hartwig, Acc. Chem. Res., 2011, 45, 864-873; (d) A. K. Roy, Adv. Organomet. Chem., 2008, 55, 1-59; (e) D. Troegel, J. Stohrer, Coord. Chem. Rev., 2011, 255, 1440-1459; (f) R. Waterman, Chem. Soc. Rev., 2013, 42, 5629-5641.

[60] (a) D. Seyferth, Organometallics, 2001, 20, 4978-4992; (b) V. Schmidt, J. V. Wittemann, S. Senz, U. Gösele, Adv. Mater., 2009, 21, 2681-2702.

[61] (a) X.-L. Luo, G. J. Kubas, C. J. Burns, J. C. Bryan, C. J. Unkefer, J. Am. Chem. Soc., 1995, 117, 1159-1160; (b) J. L. Vincent, S. Luo, B. L. Scott, R. Butcher, C. J. Unkefer, C. J. Burns, G. J. Kubas, A. Lledós, F. Maseras, J. Tomàs, Organometallics, 2003, 22, 5307-5323; (c) X.-L. Luo, G. J. Kubas, J. C. Bryan, C. J. Burns, C. J. Unkefer, J. Am. Chem. Soc., 1994, 116, 10312-10313.

[62] J. Y. Corey, Chem. Rev., 2016, 116, 11291-11435.

[63] J. Y. Corey, Chem. Rev., 2011, 111, 863-1071.

[64] J. P. Collman, L. S. Hegedus, J. R. Norton, R. G. Finke, Principles and Applications of Organotransition Metal Chemistry, University Science Books: Mill Valley, CA, 1987; Chapter 5.

[65] J. Y. Corey, J. Braddock-Wilking, Chem. Rev., 1999, 99, 175-292.

[66] M. J. Ingleson, M. Pink, H. Fan, K. G. Caulton, J. Am. Chem. Soc., 2008, 130, 4262-4276.

[67] J. Choi, Y. Lee, Angew. Chem. Int. Ed., 2019, 58, 6938-6942.

[68] (a) R. B. Said, K. Hussein, J. Barthelat, I. Atheaux, S. Sabo-Etienne, M. Grellier, B. Donnadieu, B. Chaudret, Dalton Trans., 2003, 4139-4146; (b) N. S. Radu, F. J. Hollander, T. D. Tilley, A. L. Rheingold, Chem. Commun., 1996, 10 (21), 2459-2460; (c) I. Castillo, T. D. Tilley, Organometallics, 2000, 19, 4733-4739; (d) A. A. Zuzek, G. Parkin, J. Am. Chem. Soc., 2014, 136, 8177-8180.

[69] (a) S. Park, B. G. Kim, I. Göttker-Schnetmann, M. Brookhart, ACS Catal., 2012, 2, 307-316; (b) K. Tamao, G.-R. Sun, A. Kawachi, J. Am. Chem. Soc., 1995, 117, 8043-8044; (c) P. Sangtrirutnugul, T. D. Tilley, Organometallics, 2007, 26, 5557-5568.

[70] (a) K. Rahimian and J. F. Harrod, Inorg. Chim. Acta, 1998, 270, 330.

[71] M. Tian, J. Zhang, H. Yang, C. Cui, J. Am. Chem. Soc., 2020, 142, 9, 4131-4135.

[72] (a) R. C. Fischer, P. P. Power, Chem. Rev., 2010, 110, 3877-3923. (b) A. Baceiredo, T. Kato, Multiple Bonds to Silicon (Recent Advances in the Chemistry of Silicon Containing Multiple Bonds). In Organosilicon Compounds From Theory to Synthesis to Applications; Lee, V. Y., Ed.; Elsevier: London, 2017.

[73] A. Sekiguchi, R. Kinjo, M. Ichinohe, Science, 2004, 305, 1755-1757

[74] N. Wiberg, S. K. Vasisht, G. Fischer, P. Mayer, Z. Anorg. Allg. Chem., 2004, 630, 1823-1828.

[75] D. Scheschkewitz, Angew. Chem. Int. Ed., 2004, 43, 2965-2967.

[76] R. Kinjo, M. Ichinohe, A. Sekiguchi, J. Am. Chem. Soc., 2007, 129, 26-27.

[77] (a) M. Ichinohe, K. Sanuki, S. Inoue, A. Sekiguchi, Organometallics, 2004, 23, 3088-3090; (b) K. Abersfelder, D. Güclü, D. Scheschkewitz, Angew. Chem., Int. Ed., 2006, 45, 1643-1645; (c) D. Pinchuk, J. Mathew, A. Kaushansky, D. Bravo-Zhivotovskii, Y. Apeloig, Angew. Chem., Int. Ed., 2016, 55, 10258-10262.

[78] (a) J. Sun, Y. Gao, L. Deng, Inorg. Chem., 2017, 56, 10775-10784; (b) Y. Ishizaka, Y. Nakajima, Organometallics, 2019, 38, 4, 888-893.

[79] (a) C. Präsang, D. Scheschkewitz, Silyl Anions. In Functional Molecular Silicon Compounds II; Scheschkewitz, D., Ed.; Springer: Weinheim, Germany, 2014; (b) Y. Li, J. Li, J. Zhang, H. Song, C. Cui, J. Am. Chem. Soc. 2018, 140, 1219-1222.

[80] A. Kostenko, M. Driess, J. Am. Chem. Soc., 2018, 140, 16962-16966. 
[81] J. P, Shupp, A. R. Rosea, M. J. Rose, Dalton Transactions, 2017, 46, 9163-9171.

[82] A. Kumar, A. K. Pandiakumar, A.G. Samuelson, Tetrahedron 2014, 70, 3185-3190.

[83] O, Kahn, Molecular Magnetism; VCH Publishers Inc.: New York, 1993. 


\section{List of Abbreviations}

\begin{tabular}{|l|l|}
\hline$\AA$ & Angstrom (s) $10^{-10} \mathrm{~m}$ \\
\hline COSY & Correlation spectroscopy \\
\hline $\mathrm{d}$ & Doublet (NMR) \\
\hline DCM & Dichloromethane \\
\hline DFT & density functional theory \\
\hline DMSO & Dimethyl Sulfoxide \\
\hline DOSY & Diffusion ordered spectroscopy \\
\hline EA & Elemental analysis \\
\hline EPR & Electron Paramagnetic Resonance \\
\hline eq. & equivalent(s) \\
\hline ESI & Electrospray Ionization \\
\hline$g$ & landé $g$ - factor \\
\hline GC & Gas chromatography \\
\hline HMBC & Heteronuclear Multiple Bond Correlation \\
\hline HOMO & Highest occupied molecular orbital \\
\hline HSQC & Heteronuclear Single Quantum Coherence \\
\hline${ }^{i}$ pr & iso-propyl \\
\hline$J$ & coupling constant \\
\hline MLCT & Metal to ligand charge transfer \\
\hline $\mathrm{m}$ & medium (IR), multiplet (NMR) \\
\hline m/z & mass per charge (MS) \\
\hline Me & Methyl \\
\hline MeCN & acetonitrile \\
\hline MS & Mass Spectrometry \\
\hline NHC & N-heterocylic carbene \\
\hline NIR & near infrared \\
\hline NMR & Nuclear Magnetic resonance \\
\hline NOESY & Nuclear Overhauser Effect Spectroscopy \\
\hline OTf & Trifluoromethanesulfonate \\
\hline Ph & phenyl \\
\hline$P I$ & Paramagnetic impurity \\
\hline ppm & parts per million \\
\hline & \\
\hline
\end{tabular}




\begin{tabular}{|l|l|}
\hline py & pyridine \\
\hline $\mathrm{Pz}$ & pyrazole \\
\hline $\mathrm{r}$ & molecular radius \\
\hline $\mathrm{RT}$ & Room temperature $\left(25^{\circ} \mathrm{C}\right)$ \\
\hline $\mathrm{s}$ & singlet (NMR), Strong (IR) \\
\hline $\mathrm{SQUID}$ & Superconducting quantum interference device \\
\hline${ }^{t} \mathrm{Bu}$ & Tert-buthyl \\
\hline${ }^{t} \mathrm{BuOK}$ & Potassium tert-butoxide \\
\hline${ }_{\mathrm{THF}}$ & Tetrahydrofuran \\
\hline TON & turnover number \\
\hline $\mathrm{UV}$-vis & Ultraviolet-visible spectroscopy \\
\hline$V$ & volume \\
\hline VT & Variable temperature \\
\hline $\mathrm{w}$ & weak(IR) \\
\hline
\end{tabular}




\section{Formula Overview}

\section{Ligand Precursors}

$\overbrace{N}^{1}$<smiles>Cc1cccc(-c2cc(-c3cccc(CP(C(C)(C)C)C(C)(C)C)n3)n[nH]2)n1</smiles>

VI<smiles>COC(=O)c1cccc(C)n1</smiles>

III

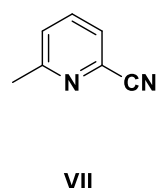

VII
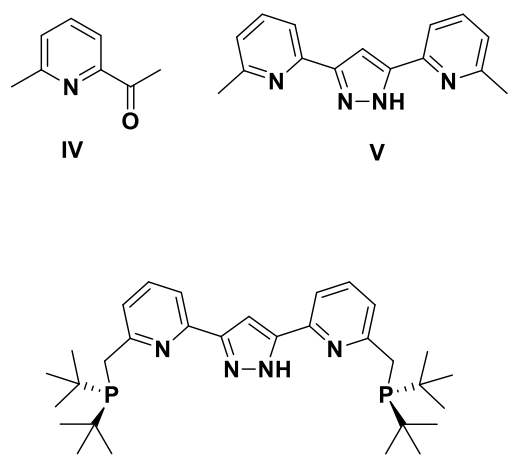

HL
VIII

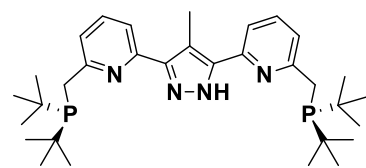

$H^{M e}$ 


\section{Complexes}
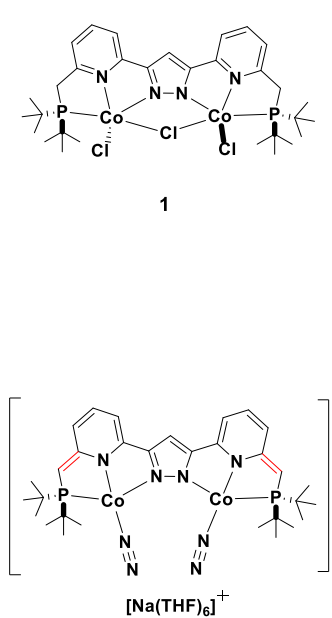

5

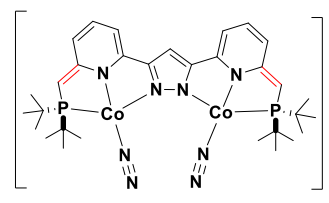

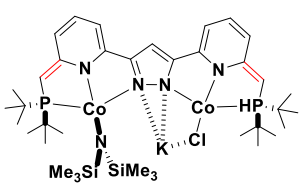

3
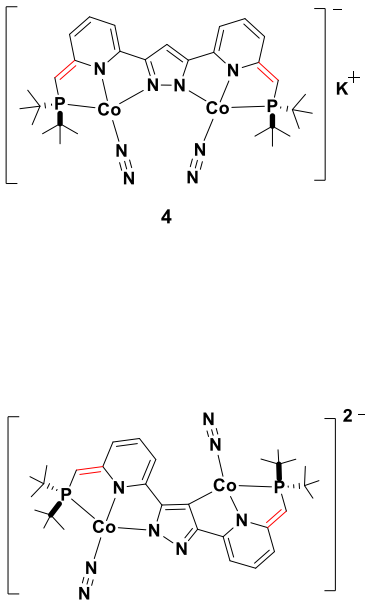

[ K (cryptand) ] ${ }^{+}$[ K (cryptand) (THF)]

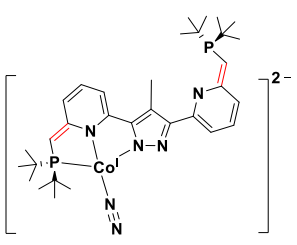

12

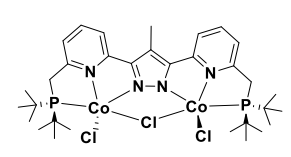

9

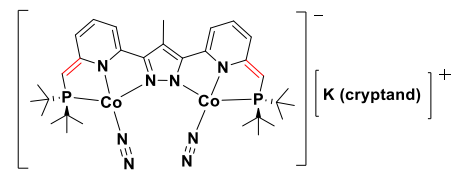

10

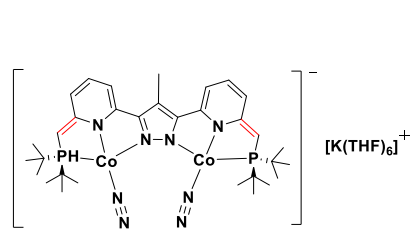

11

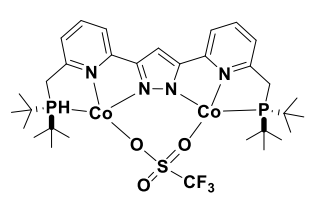

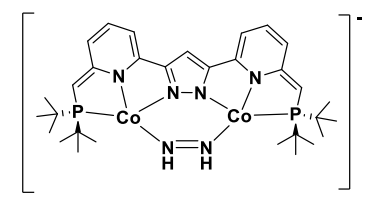

13

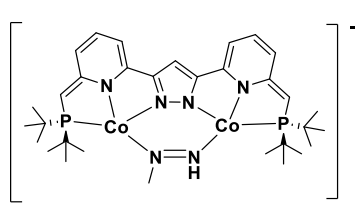

14

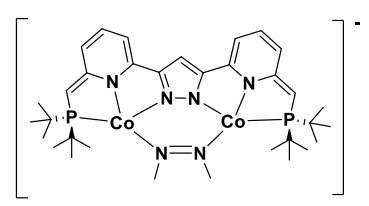

15

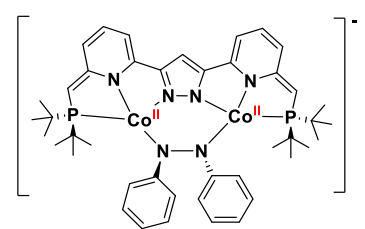

16

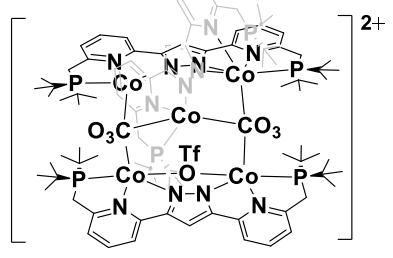

17

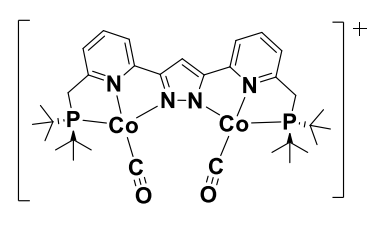

18

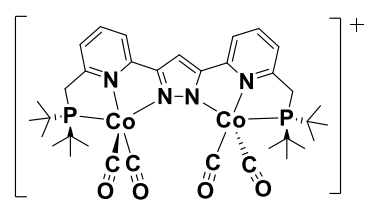

19 


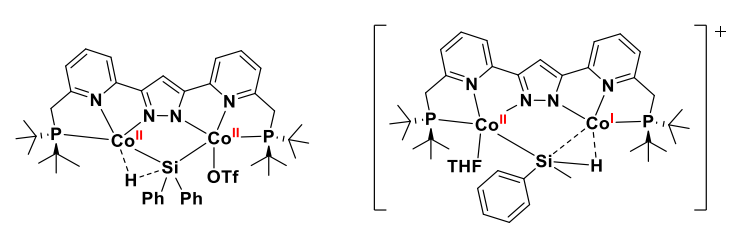

20

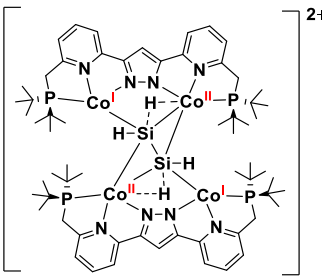

22

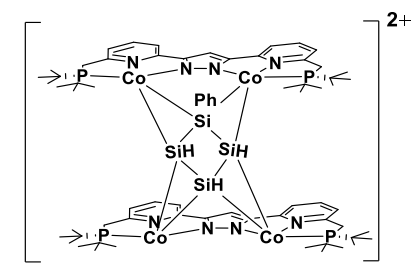

23 



\section{Acknowledgments}

It is a great time to do my $\mathrm{PhD}$ in Goettingen. I would like to thank many people, my teachers, my colleagues, my friends and my family. This thesis would not have been possible without all your supports.

First of all, I am grateful to my mentor, Prof. Dr. Franc Meyer, for offering me the opportunity to work in his group. Many thanks to his optimism, expertise, and the excellent laboratory equipment. I would also like to offer my thanks to my second supervisor, Prof. Dr. Sven Schneider for his constructive comments on my project. The other members of my thesis committee and examination board are gratefully acknowledged for spending their precious time on my thesis project.

I would also like to acknowledge all my colleagues and external collaborators who contributed to this thesis work: Dr. Sebastian Dechert, Anna Kölpin and Jana Lücken for X-ray diffraction measurements and refinement of the obtained molecular structures, Dr. Sebastian Dechert for Raman measurement and DFT calculations, Dr. Serhiy Demeshko, Dr. Sandeep Gupta and Dr. Jianfeng Wu for magnetic measurements, Dr. Michael John and Ralf Schöne for NMR measurement and the assistance for analyzing NMR spectroscopy, Andreas Schwarz and Jörg Teichgräber for the distribution of chemicals and laboratory materials, the Analytics Department for the EA measurements, Dr. Claudia Stückl for the EPR measurements, Dr. Holm Frauendorf for the GC-MS measurements, Britta Müller and Dr. Claudia Stückl for the handling of administrative issues.

I would like to particularly thank Dr. Allyssa Ann Massie and Guillermo Duran-Solares for the thesis corrections. Many thanks to Dr. Pengcheng Duan and Dr. Yang Liu for very helpful discussions and suggestions. For the great working atmosphere and a lot of fun in the lab I want to thank Dr. Pengcheng Duan, Dr. Pierre Goursot, Dr. Jin Tong, Dr. Yang Liu, Dr. Joanne Wong, Dr. Jianfeng Wu, Anna Kölpin, Lanxia Hu, Guillermo Duran-Solares, Andreas Schwarz, Dr. Sandeep Gupta, Dr. Shao-An Hua, Massimiliano Morganti, Ting-Yi Chen, Jana Lücken, Yue Ma and Sara Ida Mozzi.

I am particularly grateful for the financial support from the Chinese Scholarship Council. Finally, last but not least, I am deeply thankful to my family, my friends and my boyfriend, Dr. Xiaolong Du for their unconditional support and endless love! 